\title{
Reinforcing the Legitimacy of the State following a Conflict: Assessing the Institution-building - Legitimacy Paradox
}

by

\author{
Ruby Dagher
}

A dissertation submitted to the Faculty of Graduate Studies and Postdoctoral Affairs in partial fulfillment of the requirements for the degree of

\author{
Doctor of Philosophy \\ in \\ Public Policy: Development \\ Carleton University \\ Ottawa, Ontario
}

(C)2017

Ruby Dagher 


\section{Table of Contents}

Section I: Introduction

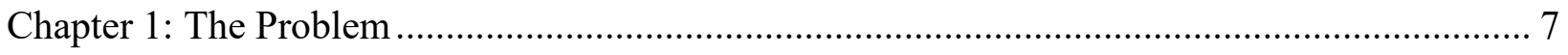

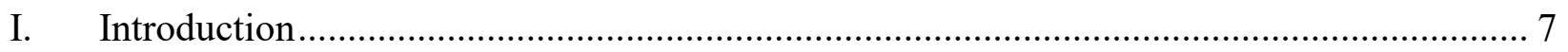

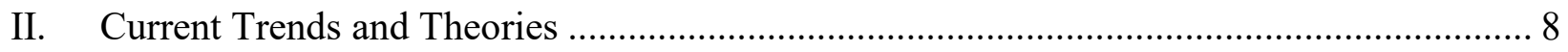

III. The Role of Performance Legitimacy.................................................................. 10

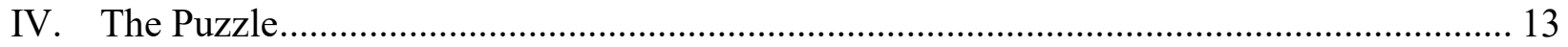

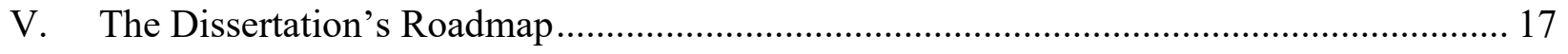

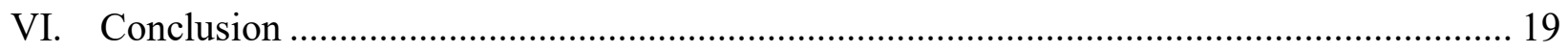

Section II: The Theoretical Frameworks..........................................20

Chapter 2: Post-conflict Legitimacy: The Role of Performance Legitimacy ............................ 21

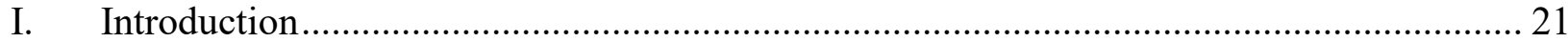

II. Legitimacy and Post-Conflict Development............................................................ 22

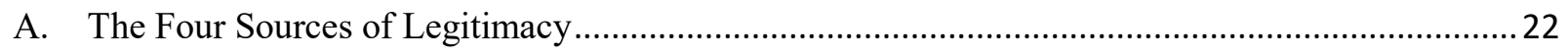

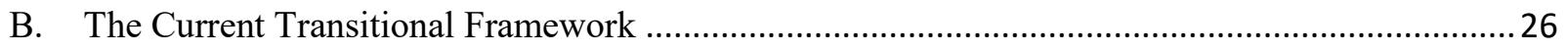

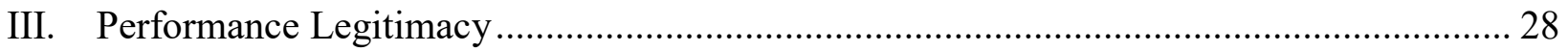

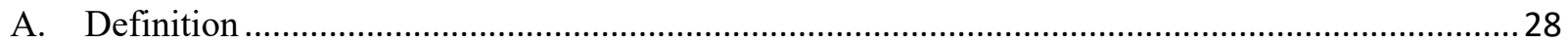

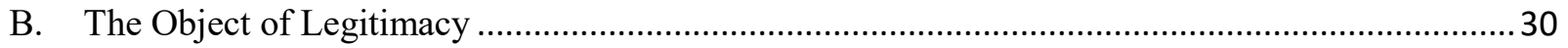

IV. Performance Legitimacy and Post-Conflict Development ........................................ 31

V. Challenges to Increasing a State's Performance Legitimacy........................................ 36

A. Performance Legitimacy and Institution building................................................................. 36

B. Performance Legitimacy and the Dynamics of Institutional Changes ........................................37

VI. Towards a New Theoretical Framework................................................................... 38

VII. Potential Criticisms of the Performance Legitimacy Theory of Transition Framework ..... 42

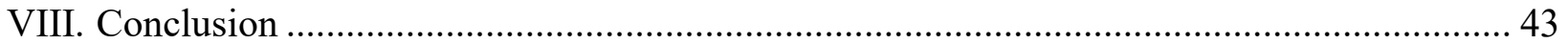

Chapter 3: The Need for New Legitimacy Measures ......................................................... 44

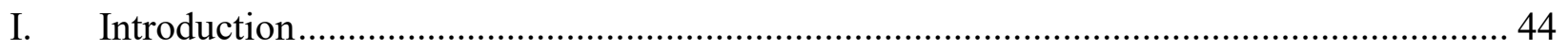

II. The Case for Measuring Performance Legitimacy .................................................... 45

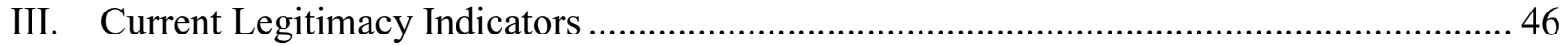

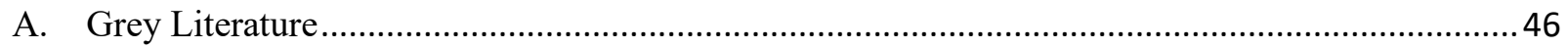

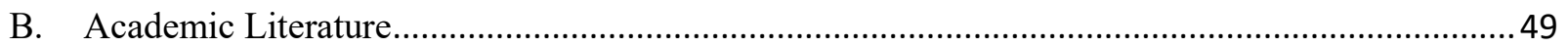

C. Performance Legitimacy Indicators ................................................................................ 54 


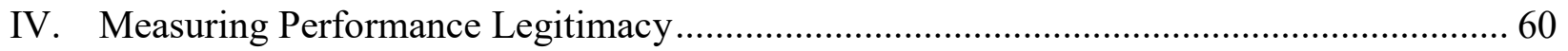

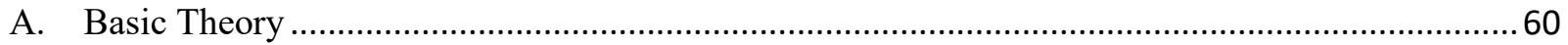

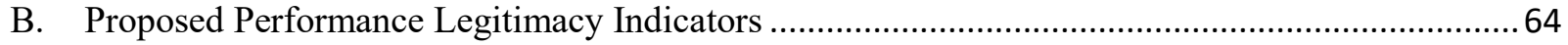

C. Challenges Related to the Proposed Indicators........................................................................... 69

V. Research Eliminating Possible Indicators................................................................ 70

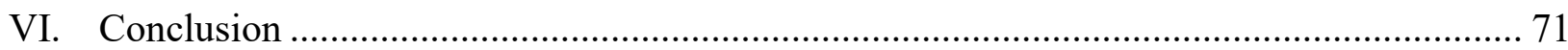

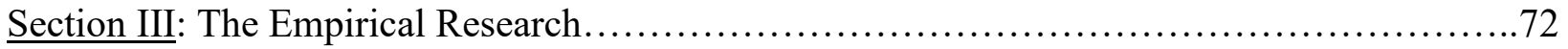

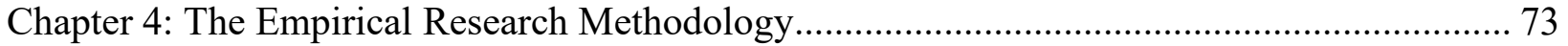

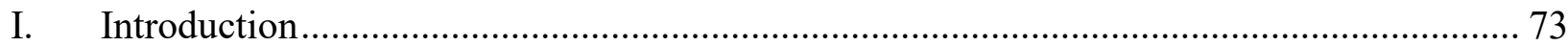

II. Methodological Approach ........................................................................................ 73

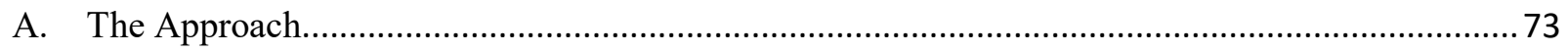

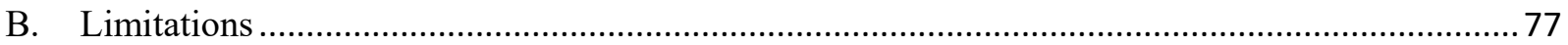

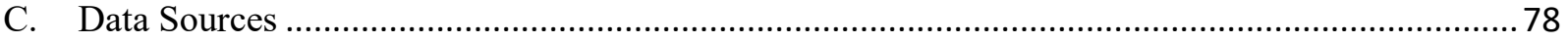

III. Characteristics Identified by Conflict, Peacebuilding and Post-Conflict Theories ............. 79

A. Important Characteristics of Conflict.....................................................................................79

B. Other Major Factors Influencing the Success of Conflict Cessation ...............................................8 80

C. Mainstream Requirements to Achieve Post-Conflict Development ...............................................81

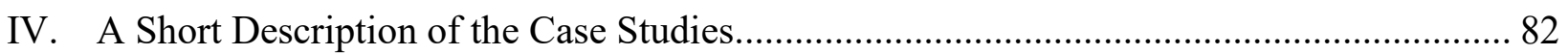

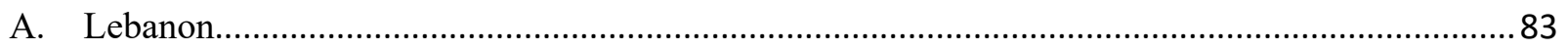

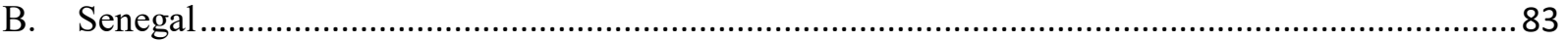

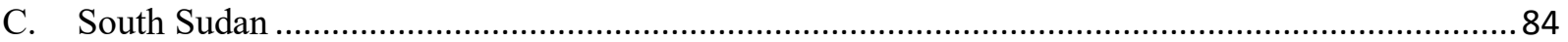

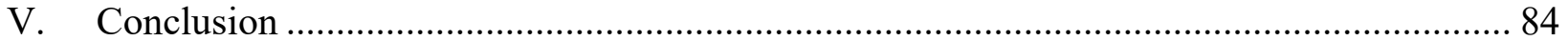

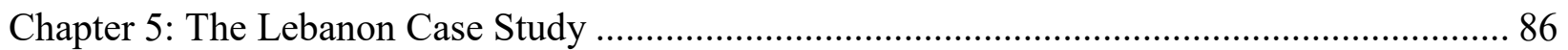

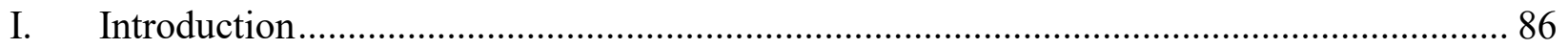

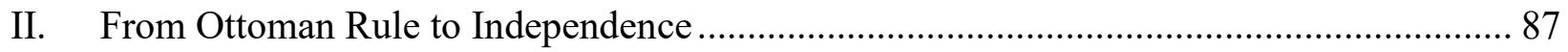

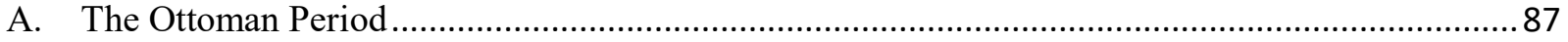

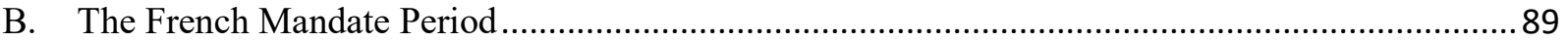

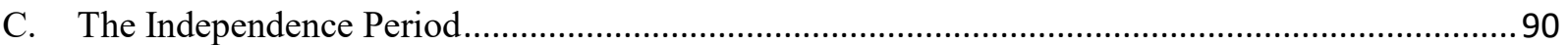

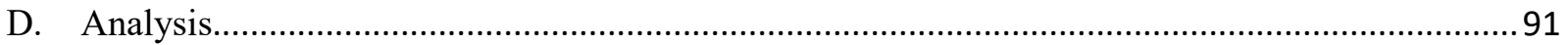

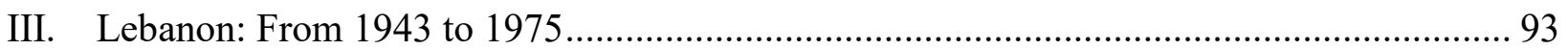

A. Post Independence Lebanon.............................................................................................. 93

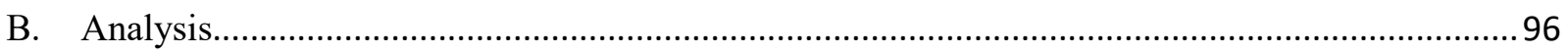




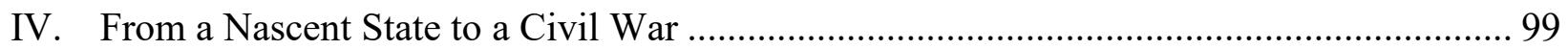

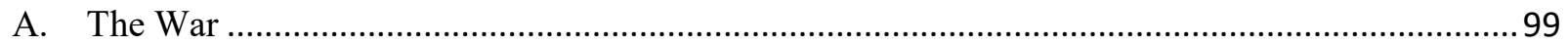

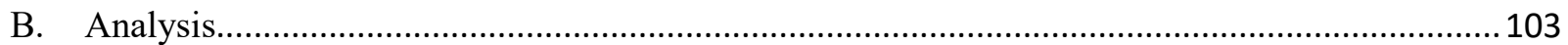

V. Lebanon's Post-Conflict Era I: Syrian Tutelage (1990-April 2005) ................................ 103

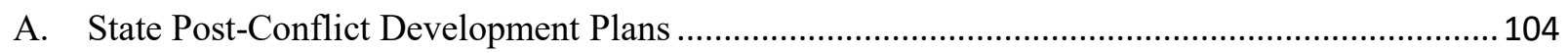

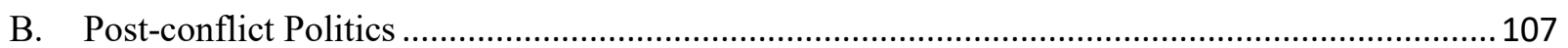

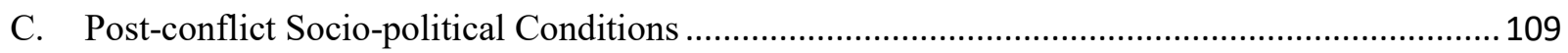

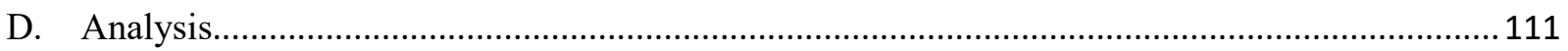

VI. Lebanon Post-Conflict Era II: Following the Withdrawal of Syria …….......................... 112

VII. The Implications on the State-Society Relationship ....................................................... 115

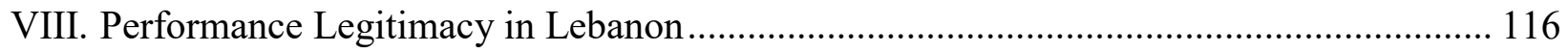

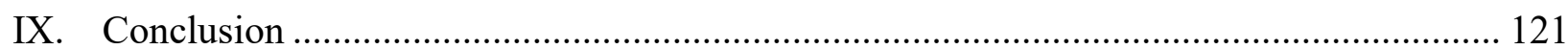

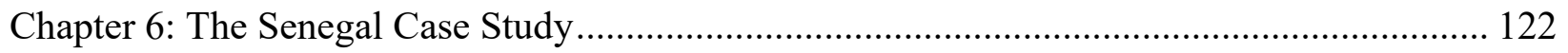

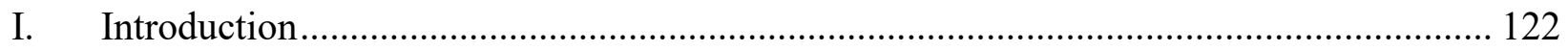

II. From Pre-colonial Times to Colonialism to Independence ……..................................... 124

A. Pre-French Colonial Senegal ……………………………………………………………...124

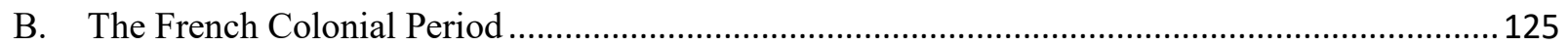

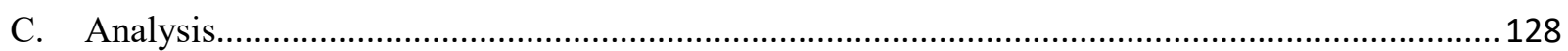

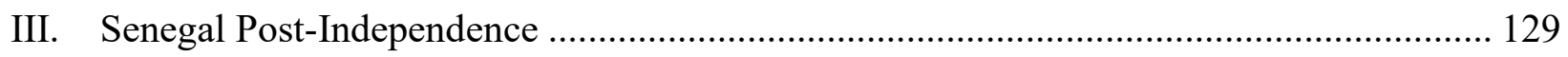

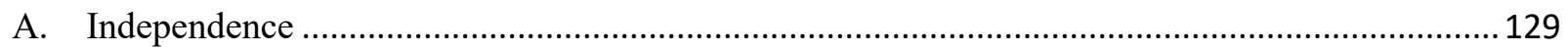

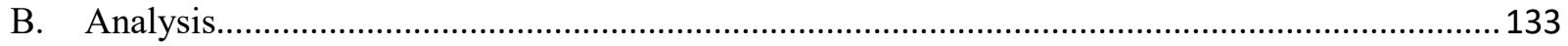

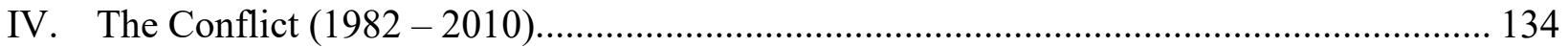

A. Consequences of the Conflict ……………………….......................................................143

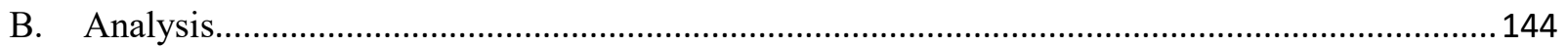

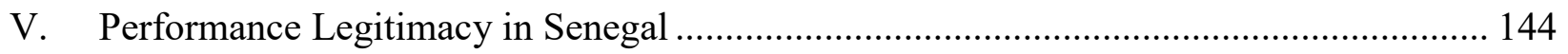

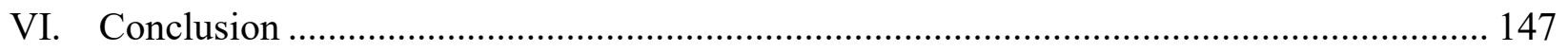

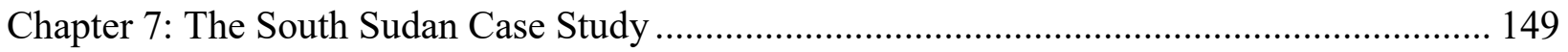

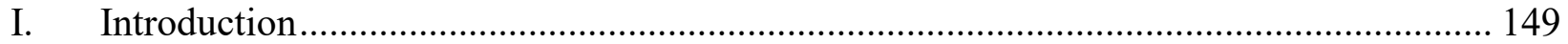

II. From Pre-colonial Times to the Independence of the Republic of the Sudan ................... 150

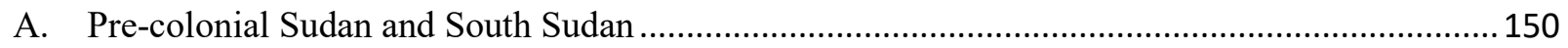

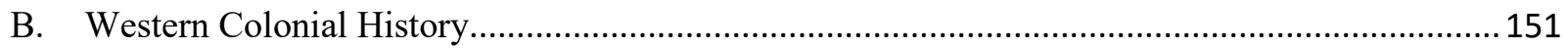

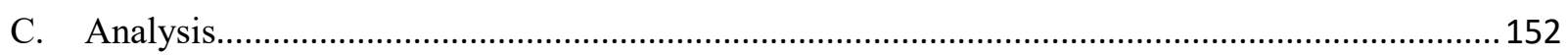


III. From the Independence of the Republic of the Sudan to the Independence of the Republic of South Sudan.

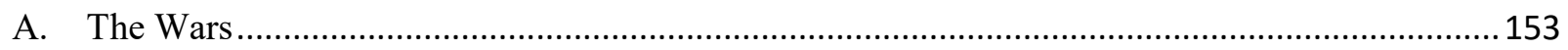

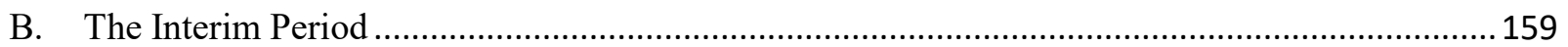

C. The Role of the Delivery of Relief and Basic Services ......................................................... 160

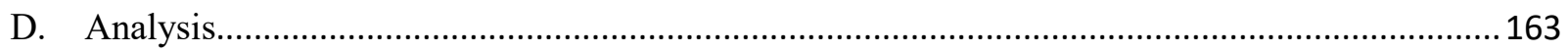

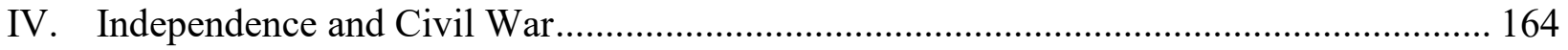

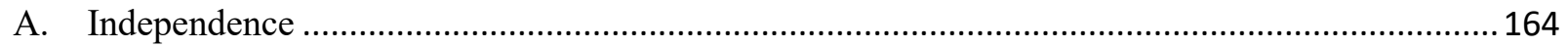

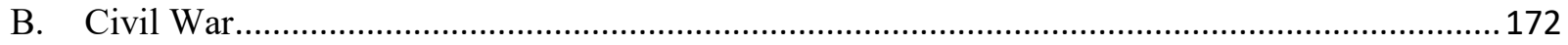

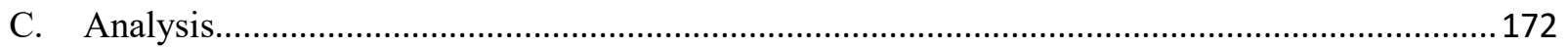

V. Performance Legitimacy and the State-Society Relationship in South Sudan ................ 173

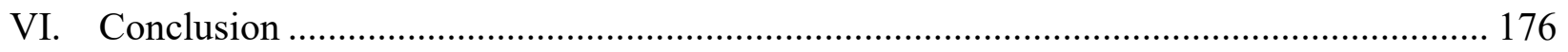

Section IV: The Findings...................................................... 177

Chapter 8: Performance Legitimacy and the Impact of Contextual Factors ........................... 178

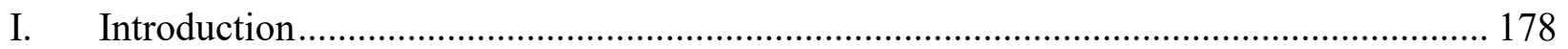

II. Existing Approaches and the Space for Performance Legitimacy................................ 179

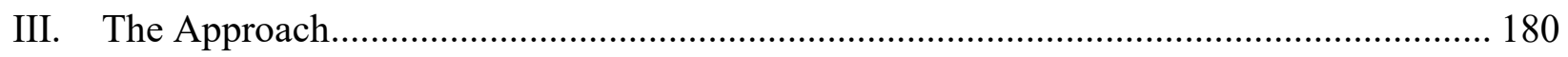

IV. Characteristics Identified by Conflict, Peacebuilding and Post-Conflict Theories .......... 181

A. An Assessment of the Applicability of the Key Characteristics ................................................. 181

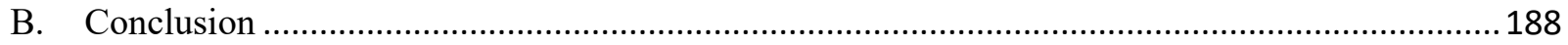

V. Case Study Findings Related to Performance Legitimacy ......................................... 189

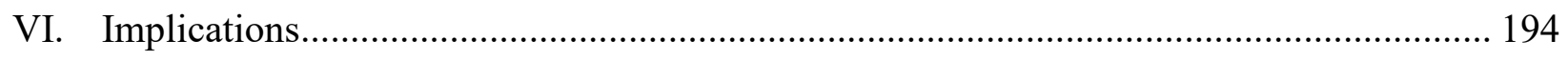

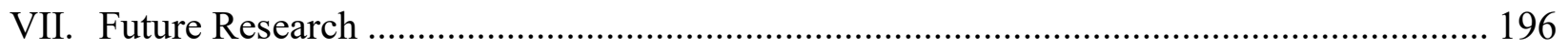

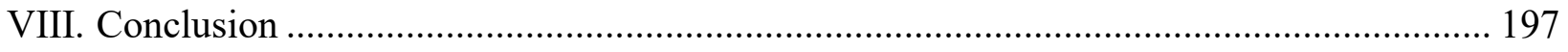

Section V: References............................................................ 198

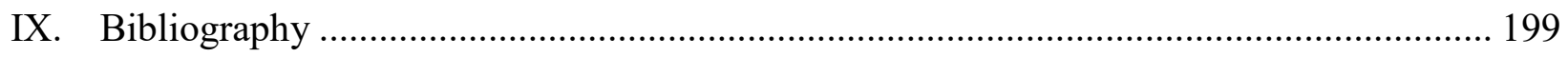




\section{Section I Introduction}




\section{Chapter 1: The Problem}

\section{Introduction}

The end of conflict is thought to usher in a new phase in a country's history. It is often thought of as a critical juncture when new and better processes and systems can be introduced thus allowing the country to embark on a new and more fruitful development path. Establishing or improving the state's legitimacy is central to post-conflict development and as such, donors, practitioners and scholars often consider the building of state institutions as the main means through which the state can gain legitimacy. In effect, the suggested post-conflict development process mirrors the following causal pathway: Improving state institutions leads to improved governance, which in turn leads to improved legitimacy and thus development.

However, as the research in this dissertation demonstrates, the state institution-building process introduces complications to this presumed causal pathway. Not only does performance legitimacy, the legitimacy earned through the delivery of basic goods and services, lie at the heart of these complications, but it also affects the strategic decisions of various actors. Because the population values performance legitimacy and because this type of legitimacy is not exclusively held by the state, the competition for performance legitimacy can fundamentally derail the state institution-building - legitimacy process.

This dissertation argues that the current most dominant post-conflict development theory is focused on improving the post-conflict state's process legitimacy. In doing so, it misses the importance of the state's performance in the lives of citizens following a conflict and thus undermines the key role of performance legitimacy in post-conflict states where shared beliefs and previous experience with democratic systems and processes are limited.

As such, the dissertation contributes to current research by (a) adding or re-introducing performance legitimacy into the current discourse and practice of post-conflict development and (b) extending the existing research on performance legitimacy to account for the fact that states as well as leaders can earn performance legitimacy and they use state institution-building processes to do so. Doing so allows us to not only account for the powerful role that performance legitimacy plays in these cases, but to also better understand how the state can gain and protect its performance legitimacy from the actions of leaders. It also allows us to reflect on the significant implications associated with the sequencing of post-conflict institution-building and state legitimacy actions.

In order to accomplish these tasks, I needed to develop two main frameworks: (a) an analytical theoretical framework that helps us understand the processes that lead to either the state or the leaders earning performance legitimacy and (b) a measurement framework that guides the analysis of the empirical data on performance legitimacy. 
These frameworks allowed me to undertake an empirical analysis of three cases - Lebanon, Senegal ${ }^{1}$ and South Sudan. The analysis of empirical data resulted in the discovery of the following two main variables that had a significant impact on the legitimacy trajectory of the state and leaders: the strength of the state-society relationship and the limited manoeuvring space that is available to the leaders.

While these key points are presented and argued throughout this dissertation, this introductory chapter outlines the main contributions of this research. It starts with a brief analysis of the current trends and theories related to post-conflict development. This is followed by a brief description of the importance of performance legitimacy and the role that it plays in conflict and post-conflict conditions. Once the main ideas are presented, the analysis then turns to a brief introduction of the puzzle that has guided the research. This is then followed by some definitions of key concepts. The discussion then turns to a brief account of the findings. The chapter closes with a description of the dissertation's roadmap.

\section{Current Trends and Theories}

For the purposes of this dissertation, post-conflict has a specific meaning. Countries are understood to be in a post-conflict phase when the following five conditions hold. First, the bulk of the fighting has ceased. Violence may linger, but it does not reach a high enough level for conflict-study experts to categorize the country as back in civil war. Second, any lingering violence does not overwhelm the state. Third, actions are being taken to rebuild a state and its legitimacy. Fourth, an agreement exists amongst the majority of the leaders to lay down arms, to become involved in the government and the state structure, and to attempt to build a future through the political system. Fifth, and finally, the use of the term conflict is meant to encapsulate civil wars, genocides, and the decimation of state institutions following the violent expression of grievances.

Considerable work that examines countries in this post-conflict phase - and seeks to prescribe a state-building process - focus on only one type of legitimacy: process or input legitimacy. As is demonstrated in Chapter 3, under the current theoretical framework, this type of legitimacy is intimately associated with definitions of democracy and democratic systems. Put simply, the logic of this theory is premised on the idea that processes associated with democracies such as competitive elections are a key foundation for building state legitimacy in states emerging from conflict. As such, the theory promotes the establishment of liberal democracy. This is viewed as a means to ensure the building of process legitimacy and the formation of democratic systems, economic liberalisation as a means to improve economic activity and thus stability, securitysector reform as a means to ensure peace, and the reformation of the rule of law to ensure equitability and the respect for human rights.

\footnotetext{
${ }^{1}$ The applicability of Senegal as a case study given the circumstances of the conflict might initially seem at odds with the research. However, as explained in Chapter 4, the Senegalese case shares a lot of commonalities with the other two cases, Lebanon and South Sudan, and provides interesting explanations regarding performance legitimacy indicators and the indicators of the current post-conflict theories when an internal comparison between regions are undertaken.
} 
This theory, however, has two key shortcomings. First, it overlooks the fact that a country has access to four different types of legitimacy that are not necessarily always interdependent: process legitimacy, performance legitimacy, shared beliefs, and international recognition. Stable democratic countries tend to have all four types of legitimacy while non-democratic countries, like China, tend to be missing process legitimacy, as it is currently defined (refer to Chapter 3 ).

Second, as the analysis in this dissertation clarifies, when dealing with countries where there are low levels of shared beliefs and limited or non-existent experiences with process legitimacy, the current framework is not likely to be very helpful (refer to Chapters 2, 3, and 4). According to the current framework, the legitimacy of the state is significantly derived from democratic processes. While performance legitimacy and shared beliefs are considered to be significantly shaped by democratic processes, there is only limited recognition of the fact that these types of legitimacy, which are built following the establishment of process legitimacy, can in turn reinforce levels of process legitimacy. In essence, process legitimacy is considered to be the base onto which performance legitimacy and shared beliefs are built (Figure 1.1). This emphasis on process legitimacy and the belief that it supersedes other sources, or is necessary to facilitate the acquisition of the other sources of legitimacy, overlook many factors that can derail the supposed manner in which the legitimacy-building process is expected to unfold in these countries

\section{Figure 1.1: The Current Perception of Internal Post-Conflict Legitimacy}

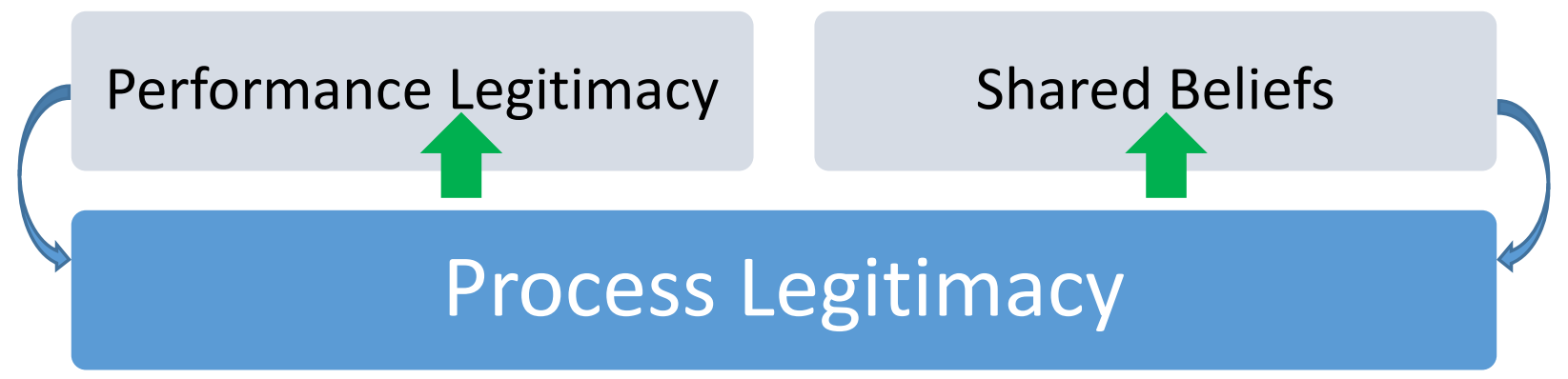

To precise arguments made in fuller detail in chapters 2 and 3, there are at least five key weaknesses to the assumptions that underlie the emphasis on process legitimacy. First, the assumption that legitimacy is exclusive to the state leads to a very partial view of the actual situation on the ground and thus discounts the manner in which other actors use legitimacy to achieve their goals. Second, and relatedly, the assumption that countries transitioning from war have little to no legitimacy overlooks the fact that many of these countries and their various leaders had legitimacy during the conflict and continued to do so after the conflict ended. Third, it is also problematic to assume that leaders, a concept that I define below, are going to be willing to part with their hard-earned legitimacy only because they can now lead parts of the state is also debatable. It underestimates the power of these leaders and their desire to continue to access the benefits of the legitimacy that they have earned.

Fourth, the assumption that the establishment of public financial management and other anticorruption laws and the empowerment of civil society to ask for transparency and effective use 
of resources is based on an incomplete assessment of the local conditions in the type of postconflict countries that are covered by this dissertation. Essentially, the following requirements that are necessary for the fulfillment of the assumption are incompatible with situations in many post-conflict countries: (a) the idea that such events or processes would not be abused by leaders, (b) that the society or a certain percentage of the population would be willing to overlook the benefits that it has received from these leaders, even in a culture that expects leaders to take care of their own, and (c) that the population would use the resources available to them to hold the leaders to account.

Finally, the assumption that citizens wish to bestow process legitimacy unto the state guides a significant focus on actions that are intended to lead to increased process legitimacy. This comes at the cost of little investment in the state's performance legitimacy, the type of legitimacy that means more to the locals, and increased opportunities for leaders to increase their legitimacy at the state's expense.

Not only do these five weaknesses challenge the applicability of the assumptions of the current theories and their post-conflict development frameworks, but they also point to more important complications. First, current theories suffer from a problem of endogeneity which is manifested in reverse causality and thus the omission of certain variables that, in actuality, play an important role in post-conflict development. ${ }^{2}$ This problem of endogeneity is also guided by the idea that anything short of a democratic system is likely to be harmful and oppressive and thus should not be allowed to unfold. In essence, the ideological focus of these theories and the underlying assumptions that are applicable in specific kinds of societies tend to lead to the omission of performance legitimacy, a partial understanding of the existing state-society relationship, and the undermining of the importance of the leaders' manoeuvring space when state institution-building is being undertaken.

As is demonstrated in Chapter 8, the current theories often miss other important factors that play a significant role in explaining why some states are successful in gaining the type of legitimacy that matters most to the majority of citizens while others are not. These theories also do not account for the impact that performance legitimacy has on the actions taken to establish process legitimacy and shared beliefs.

\section{The Role of Performance Legitimacy}

Countries and societies cannot be completely void of legitimacy. Even when the state has completely collapsed and social cohesion and shared beliefs have been severely affected, forms of legitimacy will persist. These societies are often led by leaders who have earned performance legitimacy and who use this legitimacy to rule over their territory, even when the state has either limited or no legitimacy.

Before further explaining the role of performance legitimacy, let me define three key concepts that are a foundation for my analysis: performance legitimacy, the state, and leaders

\footnotetext{
${ }^{2}$ Refer to Chapters 2 and 3 for further information.
} 
Performance legitimacy is the type of legitimacy that is earned when meeting the basic needs of the population. This type of legitimacy is heavily impacted by the situation at hand and by the perception of the population. While every person requires the most basic goods and services, the exact definition of basic needs is also influenced by political elites as well as by communities and their leaders. As such, the definition of basic needs is exogenous and endogenous to the actions of political leaders and is also influenced by the legacy of what existed in the past.

This dissertation focuses on the most basic of needs, needs that are shared across societies, and assumes that successful leaders work to both actively shape the definition of basic needs and respond to citizen-led definitions. In doing so, the dissertation allows for the inclusion of situational factors while maintaining the argument that by responding to basic needs, the state and/or the leaders succeed in earning performance legitimacy.

The state - the second concept - is central to the thesis of this dissertation. The analysis focuses on the structures and responsibilities of the state and the impact that the state-institution-building process has on the actions, goals or objectives that are established for the various parts of the state. As such, I define the state as a set of formal institutions that forms a collectivity with established functions and structures. In an attempt to assess the real owners of performance legitimacy, understand the actions of the leaders, and identify who citizens associate the benefits with, the political chambers or the government - the President, Prime Minister, House of Commons or the Parliament - and the politicians who work in these chambers are not included in my working definition of the state.

Overall, this definition is inspired by the work of Grzymala-Busse who defines a state as a "set of formal institutions that administers citizen obligations (e.g., taxes, military service), enforces legal sanctions, and regulates public provisions (e.g., infrastructure, rule of law, welfare, defense, etc.). It comprises both public finances and the channels of their distribution" $(2008,640)$. It also includes the public and non-political apparatus, or the institutions that form the country's public service, that are the backbone of the country's governance. ${ }^{3}$

Mitchell (1991) criticizes this definition for being too elusive, too narrow, and too artificial. He argues that the definition of the state should also include a reference to the "set of structural effects" that also define state actions and outcomes $(1991,94)$. The approach of this dissertation and the argument that leaders abuse state resources for their own purposes and that their supporters expect them to do so in order to receive the benefits allows the dissertation to focus on the functions and structures of the state as well as on the structural effects that dictate many of the state's actions

When referring to the term leader - the final central concept - I mean individuals who have developed enough power and influence over a percentage of the population and on whom the population has bestowed trust and/or accepted their power to represent them at the highest level, even if it is in a non-democratic form. This is inline with the research that Beck (2008) conducted on clientelism and her argument that the political autonomy of local brokers combined

\footnotetext{
${ }^{3}$ This also includes all levels of the state system - central, regional and local - and different types of decentralized
} structures. 
with their social authority dictates the level of influence that local brokers have as it relates to clientelism.

As such, the term leader does not exclusively focus on those who are inside the state structure. However, this dissertation tends to emphasize the actions of those who work within the state structure, especially those leaders who continue to act as private actors within the public sphere. Given that the logistics under which they operate are different than ones under which those outside the state operate, I am very interested in understanding how leaders within the state actively work on differentiating themselves from the state through their discourse related to the provision of basic goods and services.

This definition does not exclude actors outside the public sphere who have amassed support from the population. As the empirical evidence demonstrates, these actors provide support for other leaders who operate within the state structure and often help shape the approaches taken by these leaders. Yet, as the empirical evidence also demonstrates, the power of the leaders, whether inside or outside the state structure, is also heavily impacted by their perceived role in the delivery of basic goods and services and the amount of legitimacy and power that they have been able to amass given their actions or interventions.

At the same time, leaders cannot operate in a vacuum. While I recognize that leaders can influence the type of need that citizens' deem to be basic, they must still be able to respond to the needs that have been identified by the population and by certain community or religious leaders. ${ }^{4}$ This often leads them to work with other representatives of the population who have also amassed influence over their followers (Migdal 2001, 64). Subsequently and as the evidence in this dissertation indicates, these leaders must ensure that the powerful representatives also bestow upon them a certain level of legitimacy by responding to certain demands or requests that have been put forward by these representatives. As such, leaders do not always behave as dictated by the utilitarian vision (amassing great power and abusing their position to the detriment of the population) given that they require the support of at least a certain percentage of the population (P. B. Evans 1989). Moreover, as the empirical evidence within this dissertation has shown, leaders need to maintain an open mutually reinforcing relationship between them, the population, and certain community representatives.

With these definitions in mind, in post-conflict states a leader's ability and willingness to take care of his/her supporters' basic needs allows that leader to gain a level of legitimacy that can then be used to either reinforce the leader's legitimacy or undermine that of the state and other members of society. This legitimacy does not disappear once the country transitions into peace and it does not automatically transfer to the state by virtue of including legitimate leaders in the state structure. Moreover, post-conflict conditions and investments in state capacity via the construction of state institutions introduce a level of competition for legitimacy between the leaders and the state. Given that leaders are often included in the state as part of a reconciliatory government and as a means to maintain peace, these leaders often limit this level of competition

\footnotetext{
${ }^{4}$ This argument is similar to the work that has been done by Evans (1989) where he demonstrates the need to go beyond neoutilitarian assessments of the state as a predatory state and begin thinking about the potential benefits that a state provides, even when neopatromonial behaviour is present.
} 
by abusing state resources and capturing the resulting performance legitimacy. This process is often facilitated by the power that these leaders have, the resources that are available to them, and the level of legitimacy that they already possess.

In these cases, performance legitimacy is the base onto which the other two internal sources of legitimacy (process legitimacy and shared beliefs) are eventually earned. One does not really see the amplitude of performance legitimacy and, as the three case studies and the literature review on performance legitimacy and post-conflict development indicate, much of what is built is significantly influenced by how performance legitimacy was earned. Essentially, this process is reflected in the iceberg analogy where the biggest or most important parts are not visible and are part of the past. The existing levels of performance legitimacy, what is under the sea level in the iceberg analogy, influences greatly what is built following the end of the conflict, the part that is above the sea level, by influencing the incentives that leaders face.

The incentives facing the leaders and the state and the resulting competition for performance legitimacy lead to the following paradox. Building state institutions with the hopes of increasing state legitimacy is likely to increase leaders' legitimacy and actually decrease the legitimacy of the state. This paradox is captured in the Performance Legitimacy Theory of Transition framework that is presented in Chapter 2. This framework recognizes the non-exclusivity of legitimacy, a conflict's lasting effects on the level of legitimacy garnered by various actors, and the perception or values of the local population. In doing so, it avoids perceiving internal postconflict legitimacy as it is currently perceived (Figure 1.1), avoids the 'best practices' approach by identifying unique local constraints, ${ }^{5}$ and establishes a continuum with two extreme points/cycles: a vicious cycle and a virtuous cycle (Figure 2.3). These cycles represent the outcomes of cases where leaders were able to abuse state resources and usurp performance legitimacy (the vicious cycle) and cases where the state was able to protect its resources and earn performance legitimacy (the virtuous cycle).

\section{The Puzzle}

The idea of performance legitimacy is not new. However, its role in post-conflict settings is under appreciated. In particular, the argument that various actors can earn performance legitimacy and that one needs to assess whether this legitimacy belongs to the actors within the state structure or to the state itself sheds important light on critical dynamics in countries emerging from conflict.

My research has indicated that there is an overriding emphasis on process legitimacy in the current main theories of and approaches to post-conflict development. Yet, my research has also proven that performance legitimacy is a key factor in post-conflict development and in the state's legitimacy-building process. It has significantly affected the success of democracy-related transparency and corruption-control measures and has played a significant role in the leaders' decision to increase their legitimacy by abusing state resources and institutions. As a result, and given that leaders can abuse state resources and usurp performance legitimacy from the state and

${ }^{5}$ Larson et al (Larson, Ajak, \& Pritchett, 2013) in quoting Levy and Fukuyama (2010) consider this process to be paramount. 
the current measures have proven incapable of limiting such an abuse, what is it that can explain why counties fall on different parts of the continuum, including on the virtuous cycle and vicious cycle trajectories?

In order to answer this overarching question, I needed to first start by answering the following questions: (1) Given the importance of performance legitimacy, what are the possible outcomes of state institution-building in post-conflict states? and (2) How can I measure the level of or identify the holders of performance legitimacy in post conflict states? Answering these two questions allows me to answer my overall research question: What explains the variation in outcomes (the state earning performance legitimacy versus the leaders earning performance legitimacy)? Put differently, why in the post-conflict phase do we see some countries ending up on the vicious cycle where leaders capture performance legitimacy while other countries end up on the virtuous cycle with the state gains performance legitimacy?

To answer these questions, I (a) develop a theoretical framework, the Performance Legitimacy Theory of Transition framework, that conceptualizes performance legitimacy and highlights the extreme cycles (virtuous and vicious) that result from the various trajectories (Chapter 2), (b) develop indicators ${ }^{6}$ for identifying where countries are situated within this framework (Chapter 3), and (c) use empirical evidence to substantiate the framework and identify possible variables that can explain the variation in the outcomes within the Performance Legitimacy Theory of Transition framework (Chapters 4, 5, 6, 7 and 8).

The empirical exercise began with an initial stock taking of all conflicts since World War II. The assessment yielded three cases, with two, Lebanon and South Sudan, on the vicious end of the continuum and one, Senegal, on the virtuous end. As detailed in Chapter 4, the research used process tracing within these three cases to examine the long history leading up to the conflict and the post-conflict period. The research also assessed variables identified in the existing theories and undertook a comparative analysis between the three cases. Variables that were identified through the initial process that yielded the theoretical framework in Chapter 2 were also assessed. This helped to identify whether any of these new variables could provide answers to my central research question.

It is important to note though that the use of a mixed methods approach was challenging. While I recognized that historical institutionalism and comparative analysis approaches were helpful in understanding the outcomes and identifying important variables on their own, I found it more appropriate to combine these different approaches in order to adequately challenge the mechanics of the conceptual and measurement frameworks and improve the validity of the results. Essentially, my aim was to draw on the advantages of each of the approaches so as to reach an acceptable level of validity in the results while recognizing and accounting for the weaknesses associated with each approach.

My contribution is based on the use of both inductive and deductive research. The development of the theoretical framework and the measurement indicators are largely guided by an inductive

${ }^{6}$ This is based on a theoretical approach that is grounded in the empirical research of other scholars. In essence, by developing these indicators, I am making a methodological theoretical contribution. 
approach. However, this process was significantly informed by a review of empirical data that was gathered by scholars. The two variables that were considered to shed light on the variation in outcomes were based on a deductive research approach. Figure 1.2 helps provide some clarity regarding the main arguments and approaches that motivate this research.

As a final note, I am not questioning the importance or value of democracy. Rather, I am suggesting that one needs to carefully consider the sequencing of steps that are to occur as a country transitions out of conflict. Indeed, success in the early post-conflict stage is expected to allow for the more effective implementation of systems and structures, including those associated with democracies, if so desired by the population.

\section{Figure 1.2: Main Contribution Roadmap}

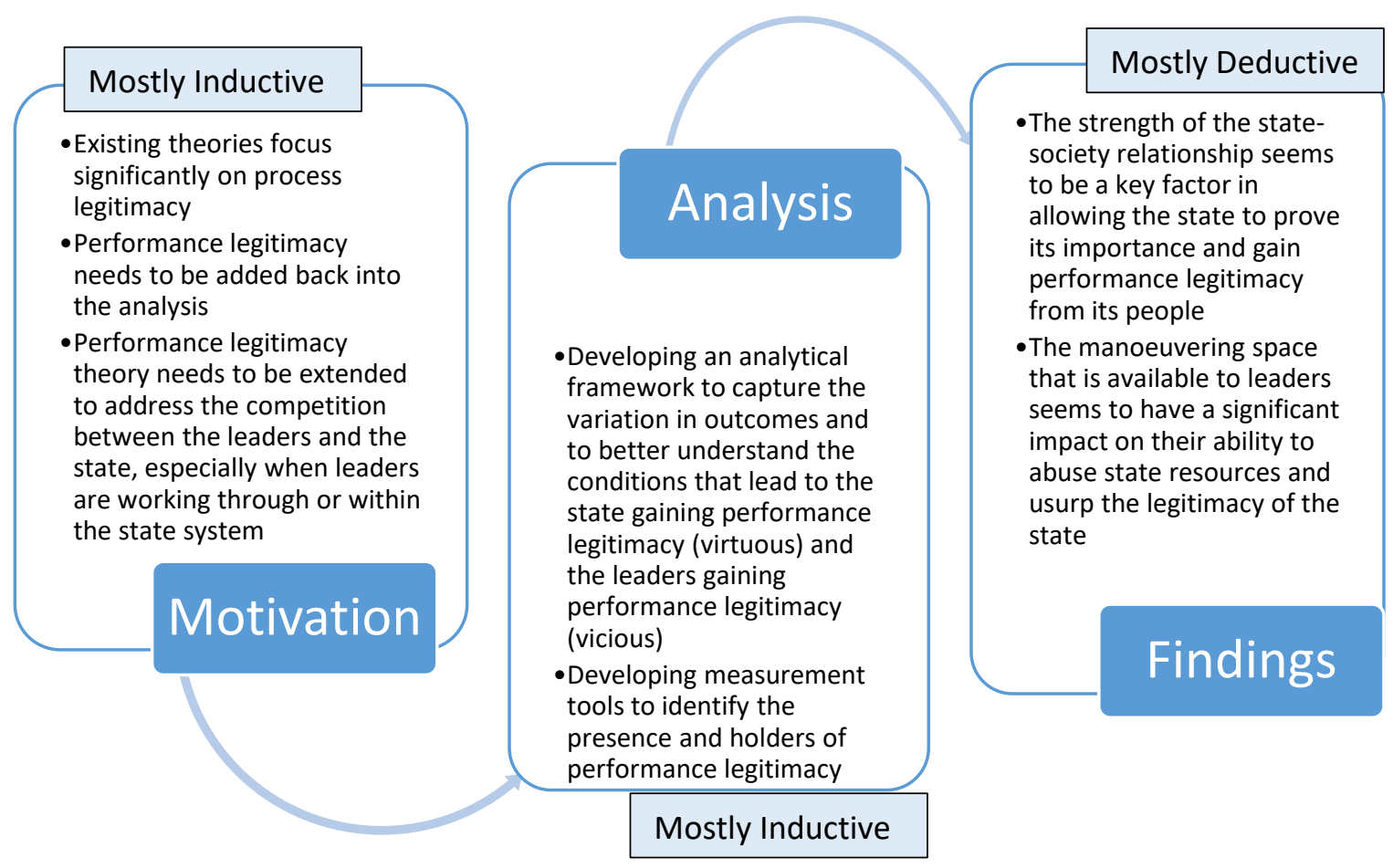

\section{Main Findings}

The central finding of this dissertation centers on explaining the paths countries travel once they have emerged from conflict. Performance legitimacy, and whether the state or leaders are seen by the population to hold it, is central to understanding these paths. In addition, the empirical evidence from the three examined case studies pointed to two variables that push countries towards one or the other end of the virtuous and vicious cycles: the strength of the relationship between the state and the society and the manoeuvring space available to leaders.

The state-society relationship is a key determinant that influences how the population perceives the state and its role in their lives. The more indirect the relationship is between the state and the population where leaders play a brokerage role between the state and the population, the easier it 
is for the leaders to usurp performance legitimacy by ensuring that the benefits are associated with their individual actions and not with those of the state. The more direct the relationship is between the state and the population, the more likely it is for the population to associate benefits with the state.

The results of the research also demonstrate that the type of state-society relationship, while influenced by path dependency, can be changed, especially when the leaders' political manoeuvering space is restrained. The manoeuvering space that is available to leaders has a significant impact on the leaders' ability to abuse state resources. The more space that leaders have in abusing the state with no or limited successful controls, the more likely it is that the leaders can abuse state resources and claim responsibility for the delivery of the basic goods and services. The results of the research indicate that a reconciliatory liberal democratic political system where leaders have more or less equal political power incentivizes leaders to abuse state resources and develop a cooperative dependency relationship which tends to hinder successful anti-corruption or anti-abuse measures. In such cases, leaders are unlikely to legitimize the state; rather, they are likely to amplify their legitimacy in the eyes of their supporters by adjusting the institution-building process of the post-conflict state in order to benefit them and meet their needs.

I am not arguing that these are the only variables that matter. Other important variables such as religion, ethnicity, international interference, geographic location, and the like also play an important role in the conflict and post-conflict stages. However, for these to have been influential, they had to be accepted and promoted by the leaders. The research has indicated that this can only work when the leaders are considered to be legitimate by their followers and the population that they represent. Moreover, as the research into the three case studies shows, leaders often became successful after fending off challenges from others within their religious or ethnic groups. They were able to do so and become the stronger representatives when they had adequate performance legitimacy.

Beyond these central finding, the research has several other implications for research on postconflict countries. It has, primarily, made the case for the reintroduction of performance legitimacy as a serious consideration in scholarship on countries that are trying to build state institutions after periods of violence. Performance legitimacy matters over process legitimacy because people care about their basic needs more than about the political system in place or the idea or values that the country should be espousing. By serving these basic needs, the state, a group, a leader, or other actors earns trust and gains authority over those being served. This source of legitimacy thus is not unique to states; rather, various actors can also earn it.

Conceptually, this dissertation has also pushed current theoretical perspectives on post-conflict countries and state development to clarify and disentangle the relationships between process legitimacy and democratic systems. This has important empirical implications for future research because the focus on process legitimacy and democratic indicators is influenced by the availability of indicators that are easier to measure and assess through established methodologies. Yet, the existing indicators are ill suited for capturing local legitimacy and thus 
increase the chances of developing inappropriate post-conflict development policies and programs.

This narrow operationalization of legitimacy and the ensuing systems and structures that are suggested as solutions ignore the institution-building - legitimacy paradox I have detailed above. This paradox arises when the state institution-building process is undertaken in an environment where the culture and the values of society differ from those that are required for the liberal democratic system to function, leaders use their performance legitimacy to fuel religious and ethnic sensitivities and thus establish reasons for their abuse of the state, and the relationship between the state and the society is limited or brokered by these leaders. Under these conditions, the process of building state institutions offers leaders the chance to de-legitimize the state. This process is described as the vicious cycle: leaders earn more performance legitimacy, they use this legitimacy to further abuse the state, this in turn decreases the performance legitimacy of the state and increases the distance between the state and the population, which in turn affords the leaders more legitimacy and so forth. However, there are cases where the state is capable of earning performance legitimacy due to the institution-building process and thus improving the relationship between it and the population, which in turn leads the state to earn further legitimacy and increases its protection from the abuse of leaders, and so on. This is referred to as the virtuous cycle.

From a policy perspective, my work also points to a different approach to post-conflict development. By being aware of performance legitimacy and working on allowing the state to earn it and protect it from the abuse of leaders, the environment is then likely to be better suited for the establishment and institutionalization of a more successful democratic system, if so chosen. With the passage of time and the empowerment of the state, the enhancement of the relationship between the state and the society, and limits placed on leaders as far as their actions are concerned, there is an increased possibility of having the leaders' incentive structures change, improving the engagement of the society with the state, and having the environment becoming more conducive to the application of systems and structures that require a more direct engagement between the public and the state.

To further refine our understandings of these processes, a next research step would be to focus on understanding the conditions that make these cycles more or less 'sticky'. In other words, how or what can occur for these cycles to be reversed therefore causing a shift along the continuum. We need further work investigating whether a state earning performance legitimacy and moving along the continuum towards the virtuous end can insulate the country from further conflict.

\section{The Dissertation's Roadmap}

The remainder of the dissertation is divided into three sections. Part one is made up of two chapters that establish the theoretical and conceptual underpinnings. Chapter 2 establishes the importance of performance legitimacy and offers a new conceptual model that helps account for the existing discrepancies between the current post-conflict development model and the reality on the ground. To accomplish this, the chapter documents the current conflation of legitimacy and democracy in the most prominent post-conflict development theories. The assessment is then 
put into perspective when the analysis turns to the other sources of legitimacy and the preexisting conditions in post-conflict countries. This is followed by the introduction of a more suitable framework that accounts for performance legitimacy and the state institution-building legitimacy paradox. The chapter closes with a discussion on the limitations of the Performance Legitimacy Theory of Transition framework.

Chapter 3 builds on the previous chapter and introduces the idea that issues related to measurement and methodological challenges should not restrict the development of theoretical and conceptual frameworks that are more representative of the reality in post-conflict countries. The chapter begins with an analysis that highlights the need to measure performance legitimacy. This is followed by an overview of the current legitimacy indicators in both the grey and academic literature and those specifically related to performance legitimacy. The chapter then turns to the assessment of the validity and strength of the current measures of legitimacy. After the case is made for the need to measure performance legitimacy and after the current measurements are shown to suffer from significant weaknesses, the analysis then considers alternative measures for performance legitimacy. This is done using Bollen and Lennox's (1991) innovative approach for measuring latent variables. The measurements are developed with the objective of capturing performance legitimacy and identifying the object of this legitimacy. Given the fact that these indicators are lacking a strong precedence, the chapter closes with a discussion of a few challenges that impact the success of the measurement process and the difficulties encountered in identifying other potential performance legitimacy indicators.

Part two of the dissertation presents the results of the empirical research. Chapter 4 opens up this section with a description of the empirical methodological approach that was taken during the research phase and the resulting choice of case studies. The chapter ends with a short summary of the three chosen case studies.

The three case-study chapters follow: Chapter 5 for Lebanon, Chapter 6 for Senegal and Chapter 7 for South Sudan. Each chapter traces the history of the country from pre-colonial times to the present. For each period, the analysis looks at the relationship between the state and society, the political situation, the socio-economic conditions, external interferences, and the role of the delivery of basic goods and social services. The chapter ends with an assessment of performance legitimacy in the case-study country. The assessments are guided by the sample indicators that were developed in Chapter 3 and that had enough data that I could use to be able to judge the results.

The last part of the dissertation focuses on the results and implications of the research. Chapter 8 begins with a quick review of the main theoretical findings and the justification for a new approach. The discussion then turns to a quick review of the possible trajectories that countries can take when performance legitimacy is factored into the analysis. The chapter then turns to a summary of the case-specific findings for Lebanon, Senegal and South Sudan as they relate to the relevant factors or variables that are identified in the dominant conflict, peacebuilding and post-conflict literature. The analysis then turns to the assessment of the performance of additional variables that were inspired by the findings in the theoretical section of the dissertation by using the three case studies. This is then followed by a summary of the main similarities and 
differences among the three case studies and their implications. After reminding the reader of what had been established in the previous sections of the dissertation and of the justification for a new approach, the analysis turns to the assessment of the results of the empirical evidence and the trends that were identified amongst the three case studies, especially the two main variables that seemed to be the most vital as per the results of the comparative analysis exercise. The chapter ends with a discussion of potential general implications and possible future research opportunities.

\section{Conclusion}

This dissertation was inspired by a question. This question in turn was inspired by experiences that I had gone through while living and working in conflict and post-conflict countries. The realization that the current theoretical and conceptual frameworks seem to be unsuitable for certain post-conflict countries inspired an in-depth search for answers.

This search led to the advancement of the importance of performance legitimacy, its reintroduction into the discourse, and the identification of the competition for performance legitimacy between leaders and the state. This required the development of what is hoped to be a more appropriate theoretical framework that is informed by the theory of performance legitimacy and new measurement indicators that can help measure performance legitimacy and make future research on performance legitimacy easier to undertake. The empirical findings and conclusions have also identified some possible variables that play an important role in the legitimacy-related trajectory of the state.

In doing so, the research herein pushes the theory of performance legitimacy into a new domain. As such, it is clear that this work provides a solid ground for much-needed additional research. 


\section{Section II \\ The Theoretical Frameworks}




\section{Chapter 2: Post-conflict Legitimacy: The Role of Performance Legitimacy}

\section{Introduction}

Few argue against the importance of building state legitimacy, especially in post-conflict cases. The legitimacy of the state is considered central to stabilization, continued peace, and development.

Yet, the focus is typically on a particular form of and paths to legitimacy, which are rooted in the experience of Western countries and the tenets of the liberal democratic theory. Put simply, the framework is premised on the idea that processes associated with democracies, such as competitive elections, are a key foundation for building state legitimacy in countries emerging from conflict. However, as this dissertation demonstrates, this framework is not necessarily applicable to all cases where post-conflict development occurs. This is especially true where there are low levels of shared beliefs and limited or non-existent experiences with process legitimacy - the type of legitimacy that is earned through democratic processes such as elections. By focusing on process legitimacy, this framework also tends to minimize the complicated relationship between the state and its citizens as well as the citizens' perceptions of the state's relevance in their lives.

There are several consequences associated with these shortcomings. The first is neglect for legitimacy that is garnered by meeting the basic needs of the population (performance legitimacy). This form of legitimacy is arguably the main source of legitimacy for actors during the conflict and in the early post-conflict stage. ${ }^{7} \mathrm{~A}$ second is the problem of overlooking the possibility that leaders will pursue performance legitimacy and hence negatively impinge the process of post-conflict development and state legitimization. In other words, focusing on process legitimacy overlooks the state's competition with other internal actors for performance legitimacy and the multitude of actors that are likely to work against the state's efforts at building its performance legitimacy, whether inside or outside of its institutions.

Unfortunately, this mismatch between the ideals of the international community and the reality facing post-conflict countries is significant and ignores the impact that institution-building has on the performance legitimacy of the state and that of the leaders, especially those found leading these institutions. Therefore, in summary, by concentrating on democratic structures and systems, the current framework ignores the resulting paradox between institution-building and decreased legitimacy of state institutions in the early post-conflict stage.

The neglect or minimization of the importance of the multiple non-democratic sources of performance legitimacy represents significant challenges in countries where: (a) experience with process legitimacy is weak; (b) the level of shared beliefs is low; and (c) the performance

\footnotetext{
${ }^{7}$ States of countries where conflict is isolated to specific areas and where the rest of the country continues to function normally (e.g. Sri Lanka) will likely continue enjoying process legitimacy in non-conflict affected areas. However, performance legitimacy will likely be the main source in areas of conflict where restrictions on processes necessary for gaining process legitimacy are numerous and impactful.
} 
legitimacy of the state is weak and/or the state is competing with other internal actors for legitimacy. These challenges are further amplified in cases where weak states that are emerging from conflict and that lack capacity and resources to significantly impact the lives of their citizens end up competing with actors who have the capacity to provide goods and services to their supporters.

Such post-conflict cases do not represent clean slates from which successful development can be launched. The weakness of the institutions, existing social cleavages, the distrust of the 'other' on the part of the leaders, the impact of the war economy, the desire to control institutions and their services as a means for survival, and the unwillingness of the factional leaders to fade from the limelight or loose prestige or power, all contribute to a volatile context for development.

With this in mind, this chapter begins by detailing the current trend of blending legitimacy with democracy. This is followed by a description of the existing theoretical framework that most academics and practitioners use when assessing and planning the development of the legitimacy of a post-conflict state. The analysis then explores the theory behind performance legitimacy and its impact on the relationship between the citizen and the state. Next, the chapter turns to a discussion of post-conflict conditions and the potential competing owners of performance legitimacy. With the argument made for paying closer attention to the performance legitimacy of both the state and the leaders, the analysis turns to the assessment of the challenges facing states in improving their performance legitimacy. The chapter ends by laying out a new Performance Legitimacy Theory of Transition framework for building the state's legitimacy following the end of a conflict and some of the criticisms that this framework might invite.

\section{Legitimacy and Post-Conflict Development}

A. The Four Sources of Legitimacy

The legitimacy of states is vital. Even though globalization has decreased the importance of some state functions, legitimacy remains critical for states (Van der Vossen 2012). Legitimacy gives a state the right to manage society as an agent that mobilizes collective interests and makes decisions, checked or unchecked, on behalf of the society (Khadiagala 1995). Legitimacy allows the state to exercise authority over all of its territory and limit or eliminate all actions for autonomous control within its borders. It also facilitates a state's efforts to establish a social contract with the populace, making it possible to establish trust with its citizens, create rules and have them honoured, use force, and minimize the impact of actors looking to destabilize the state (R. I. Rotberg 2004). As Skocpol (1979) convincingly argues, states that are deemed to be legitimate by the politically powerful and mobilized groups have increased chances of avoiding revolutions and collapse.

Legitimacy, according to most political scientists, is acquired through a multifaceted process between a 'legitimizer' (citizen) and a 'legitimizee' (one receiving the legitimacy status). The field of political science has identified four main sources of legitimacy (Beetham and Lord 1998; Fraser 1974; Gilley 2006a, 2006b; Kanol 2011; Levi and Sacks 2009; Lipset 1983; Treier and Jackman 2008; Weil 1989): process (input) legitimacy; performance (output) legitimacy; shared beliefs (feelings of citizenship or community); and international recognition of the sovereignty 
and legitimacy of the state. These sources are not mutually exclusive and each source can reinforce or undermine the other.

Figure 2.1 reflects this idea of multiplicity of sources and allows one to recognize that legitimacy can be earned using either all or some of these sources. Most Western countries have all four sources thus falling into the area common to all sources. Other countries, like China, have performance legitimacy, shared beliefs and international recognition, thus falling into the area shared by these three sources. Still other 'countries' like Somaliland have process legitimacy, performance legitimacy and shared beliefs (Kaplan 2008), but lack international recognition and thus fall into the area shared by these three sources. If a 'country' lacks all four sources of legitimacy and still exists, then it lacks legitimacy at all levels and is found in the white area. Such cases are arguably rare. This analysis does not ignore the role of predominant statesponsored violence and oppression. However, violence and control are a means to an unstable end and de-legitimization; they thus do not represent long-lasting true sources of legitimacy.

While this figure refrains from weighting these four sources for valid reasons ${ }^{8}$, it does provide one with a clearer idea as to the multitude of paths a country can embark on in the quest of building the legitimacy of its state.

When academics write about internal state legitimacy, or practitioners work to improve it, process legitimacy is often championed, sometimes implicitly, as the primary factor affecting a state's internal legitimacy. According to this view, process legitimacy is earned by holding frequent elections, increasing accountability and transparency of the public administration, wiping out corruption, establishing and maintaining good governance, establishing rule of law, upholding human rights ${ }^{9}$, establishing a constitution that ensures freedoms (including political freedoms) and civil liberties, as well as establishing and supporting a multi-party system (Brinkerhoff, 2007; Dahl, 1971; Eaton \& Schroeder, 2010; Englebert, 2000; Ghani \& Lockhart, 2008; Gilley, 2006; Goldsmith, 2007; Lipset, 1983; Sisk, 2013; Weil, 1989; the World Bank; Political Risk Services Group; Transparency International; Freedom House).

\footnotetext{
${ }^{8}$ The analysis in this chapter clearly identifies a dichotomy between most non-locals and local citizens regarding the weight of these four sources. Moreover, according to the analysis presented herein and in Chapter 3, it would be inadvisable to weight these sources according to a theory that is based on a moral ideal that, in all likelihood, is not close or identical to the moral ideals shaping the local citizens' decisions, ideas and expectations.

${ }^{9}$ While the substantive aspects of the laws refer to the system or structure (rules and laws), the procedural aspects refer to the manner in which the system or structure is implemented. However, at its most basic level, the procedural aspects deal with the performance of the state and thus has an impact on its performance legitimacy. However, this distinction is not made in the current literature and as such, the upholding of human rights (process legitimacy) is seen as a means to allow the state to use its process legitimacy to earn performance legitimacy. As such, the idea is that the substantive aspects have to exist and be developed properly (from a democratic perspective) so that the procedural aspects are properly implemented.
} 


\section{Figure 2.1: The Four Sources of Legitimacy}

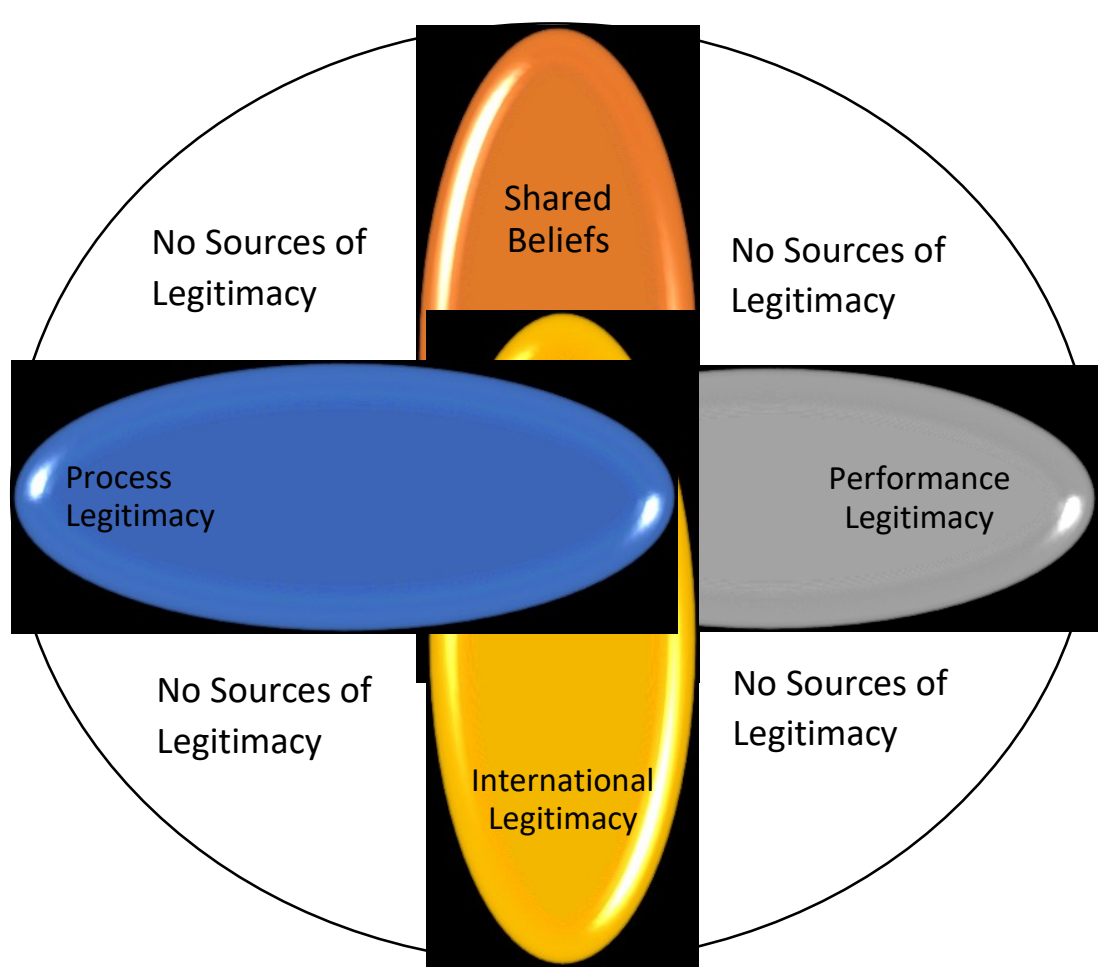

Unfortunately, this theory and the associated necessary steps to build state legitimacy conflates the definition of process legitimacy with democratic practices and structures and is influenced by a particular development path experienced by western states. ${ }^{10}$ It is the normative belief in democratic systems, more specifically liberal democratic systems, that has led to this constrained assessment of legitimacy. More importantly, if process legitimacy is described and measured in terms of the level of democracy and democratic practices, this has a strong implication for conflict and post-conflict countries, or areas of these countries that have experienced or continue to experience conflict, where the features associated with process legitimacy are either minimal or non-existent. Additionally, the near exclusive emphasis on process legitimacy ignores the contested performance legitimacy terrain, the state's performance legitimacy, the non-state actors' levels of performance legitimacy, and the likely consequences on the state's achievement of performance legitimacy. ${ }^{11}$ As a result, most analyses of legitimacy have led to assessments of legitimacy that are biased and inaccurate. Moreover, as the analysis below will demonstrate,

\footnotetext{
${ }^{10}$ In an exceptional report that was written by the Organisation for Economic Development and Cooperation (OECD), a report that contradicts the previous work that the OECD has done and continues to do, the authors assessed the schism between the underpinning assumptions or prerequisites of the existing theories. In doing so, they have raised questions regarding the following factors: (a) the non-presence of a Western idea of statehood, (b) the lack of separation between the public and the private areas, and (c) the undertaking of economic and political interactions that, more often than not, take place informally and outside official rules (OECD 2010). Chapter 3 provides a fuller discussion and analysis of the underpinning assumptions.

${ }^{11}$ The analysis presented herein does not negate the merits or benefits of democratic systems. It does however question the tendency to ignore the pre-existing conditions on the ground and the other factors that play a significant role in the state-society relationship, relationships that might cause significant damage to the democratic agenda.
} 
these assessments prescribe problematic interventions for countries seeking to transition out of conflict.

Nevertheless, the majority of practitioners, donors and international financial institutions (including the World Bank, the United States Agency for International Development, and the Canadian International Development Agency), and scholars (among them Diamond \& Plattner, 2006; Lyons, 2005) have placed considerable emphasis on individuals' voting right and democratic processes as a means to enhance state legitimacy. This emphasis has led to the de facto development of a hierarchy of legitimacy with process legitimacy claiming the top prize and performance legitimacy and shared beliefs playing a less important supportive role. This hierarchy was clearly evident in the arguments presented by Inbal and Lerner (2007) who, while noting the cooperative relationship between performance and process legitimacy, argue that the success of performance legitimacy is based on the achievement of process legitimacy and its effective governance system. Their argument is based on the premise that effective governance cannot be achieved without a system that has democratic values and structures. Given that this system represents the foundation of process legitimacy, Inbal and Lerner (2007) clearly attach a bias towards democratic values in their assessment of a state's overall legitimacy. Moreover, while the link between increased process legitimacy and the performance legitimacy of the state is important, this link ignores the performance legitimacy of leaders, whether working through the state apparatus or otherwise, and their desire to maintain their performance legitimacy through any means, including by undermining the state's process legitimacy or by abusing the system and state resources.

As noted earlier, performance legitimacy and shared beliefs are often valued for the support that they provide in the course of achieving process legitimacy. This supportive role reflects a healthy understanding of the fact that democratic processes and the enhancement of process legitimacy are likely to fail if a society lacks shared beliefs. It is also understood that without improvements in security, the monopoly over violence, and the rule of law, the state's overall legitimacy, and more importantly, the state's democratic processes are likely to suffer. Therefore, because of their importance in solidifying the state's process legitimacy, the two other sources of legitimacy are often narrowly defined or considered in limited terms. As the following analysis demonstrates, these definitions tend to tease out the aspects of these sources that play a supporting role in the task of developing a state's legitimacy through democratic processes. They also tend to either represent performance legitimacy as being exclusive to the state, overlook the levels of performance legitimacy of the non-state actors and the subsequent impact on the state's achievement of performance legitimacy, or both.

As such, this theory tends to associate legitimacy with the supply capabilities of the state (the managerial or functional capacity of the state related to the state's monopoly on the exercise of violence, bureaucratic control, sustainable public finances, and core infrastructure investment, good governance), democratic practices and structures (formal procedural mechanisms of democracy - e.g. competitive elections, good governance, sustainable public finances based on 
good public administration practices), and market incentives (Barbara 2008; Busumtwi-Sam 2004; Diamond and Plattner 2006; Fukuyama 2006; Lyons 2005). ${ }^{12}$

More specifically, under this liberal ideology, elections are considered to be the leading legitimizing force for the government and the state. According to Lyons $(2005,269)$, "[e]lections are one of the very few mechanisms available to provide internal and external legitimacy to a new government ... Elections represent a critical mechanism to legitimize new leaders and institutions following state failure and civil war. Such elections can serve as important opportunities for institution building and therefore contribute to state reconstruction by advancing conflict resolution and democratization." This emphasis on elections also reflects the needs and preferences of the international community: the preference to be engaged for short time periods when dealing with large financial costs, the requirement to hold elections prior to the disbursement of funds ${ }^{13}$, the programming risks involved in delivering aid ${ }^{14}$, the donors' need to be accountable and responsive to their tax-paying citizens, as well as the international community's need for a clear 'exit strategy'.

\section{B. The Current Transitional Framework}

This predominant liberal post-conflict theory is premised on an idea that one needs to move postconflict countries from an ill-fated non-democratic government and system to a democratic regime that is inherently considered to be more stable, secure, and prosperous. As such, the first phase of legitimacy building under the current transitional framework, especially following a conflict, requires the building of the foundations of democratic legitimacy (Diamond and Plattner 2006; Lyons 2005). This includes the establishment of security, the building of state institutions with an emphasis on the key sectors that support process legitimacy (security, finance, rule of law, the constitution, and public institutions that are charged with the economy), an improvement in economic conditions and activity by working on the regulatory environment, and supplementation of the weakened state with non-governmental organisations (NGOs) as a means to deliver much-needed basic services. It also includes the establishment of a transitional government for differing lengths of time (as in Afghanistan and Bosnia and Herzegovina) until elections can be successfully held. It is important to note that leaders who were active in the war are often included in transitional governments not only as a means to maintain peace, but also with the hope that they will transfer their legitimacy onto the state. ${ }^{15}$

The second stage is composed of actions that are meant to further improve the necessary foundations of democratic systems and ultimately process legitimacy (Paris 2005). Movement into the second stage can happen in a staggered format where the achievement of a milestone

\footnotetext{
12 These make up the post-conflict international development programming agenda, which itself is based on the international community's experience with the 20th century reconstruction and democratic re-legitimization of West Germany and Japan. However, what is often missed when these experiences are used as a benchmark and guiding principle for current post-conflict environments is that both of these countries had a history with strong state institutions and democratic institutional cultures prior to the conflict (Dinnen 2007).

${ }^{13}$ Examples abound, but the most relevant examples are the World Bank and the International Monetary Fund.

${ }^{14}$ Given that elections represent the desire or choice of the people, there is an assumption that free and fair elections processes will inherently lead to a more stable government and thus a decreased risk for donors.

${ }^{15}$ The evidence presented will demonstrate that this transfer does not often occur. It is more likely that the legitimacy remains attached to the person and thus transfer with him or her once s/he leaves the government.
} 
would automatically lead to the next milestone that is drawn from phase two. The second phase includes the development of the electoral system, improvement in security, improvement in the capacity of all or most state institutions (especially those related to the electoral process), improvement in the economy and economic activity, improvement in the rule of law, a transfer of most of the basic services to the state, decentralization of state structures as a means to get closer to the people and to increase efficiency, and assistance to civil society groups and local NGOs in the areas of democratic development.

In establishing this type of democratic transition, the predominant transitional framework overlooks the fact that in non-Western states, "state-society relations are more likely to be based on personal ties of kin and community; public goods are provided to one's own social reference group or supporters rather than on the basis of universal rights; and access to resources depends on exclusive personal ties, not on open economic and political competition. Distinctions between public and private spheres are blurred" (OECD 2010, 7-8). ${ }^{16}$ Moreover, given this fact and, as noted earlier, given that this framework is based on Western democratic values, there seems to be a certain level of incompatibility between the values and actions that are identified within this framework and the values of the local citizens (Gilley 2006b). This raises important concerns in cases where democratic norms and practices are not prevalent and where the establishment of such systems may provoke underlying grievances (Dinnen 2008; Mac Ginty 2010).

Essentially, this framework overlooks the critical factors that impact people's value systems, the citizens' trust in the system that is fostered through government capacity (Hutchison and Johnson 2011), decision-making processes, and behaviour. More crucially and as will be demonstrated below, this liberal-democratic model either overlooks or discounts certain important factors and actors that have the power and capacity to delegitimize the state even when democratic processes exist or establishes systems that are incompatible with the local culture and situation.

Interestingly, the power and success of these actors or spoilers is even more potent when they participate in democratic processes, gain positions of power, and have access to state institutions to use as means to enhance their own legitimacy.

As such, with definitions and processes being based on the recent conditions and structures of Western, liberal and democratic countries, a theoretical framework that entails a hierarchy of importance with process legitimacy representing the all important significant base onto which the other sources are built, and a need to focus in on aspects of performance legitimacy that support democratic systems, the definition of a legitimate state has effectively become conflated with that of a democratic state. ${ }^{17}$

\footnotetext{
16 This assessment by the OECD is unique and does not seem to have influenced the current agenda or policies of the OECD. Subsequent documents that have been analysed make no reference to this report and do not present similar ideas or points.

${ }^{17}$ This becomes exceptionally clear when one assesses the indicators that are used to measure legitimacy. The following chapter has a more in-depth analysis of this point.
} 


\section{Performance Legitimacy}

\section{A. Definition}

As noted earlier, performance legitimacy is a bi-product of delivered outputs. Performance legitimacy is earned by the object that provides for the welfare of citizens or a specific group of people (subjects). Many outputs can serve as the basis for the performance legitimacy but they typically are goods and services that impact the daily lives of citizens. Some of the most visible and common outputs include health, water, sanitation, electricity, education, traffic, roads, security, and justice. In essence, the more the object responds to the basic needs of people, the higher the likelihood that these people will find the object legitimate.

The key analytic point is that an entity - a state or a leader - can earn performance legitimacy by offering outputs that someone deems very relevant in their daily life. For that to occur though, three factors must exist: knowing the interest of the subjects, meeting their expectations, and having the capacity necessary to provide the services. I review these three factors and then discuss how different entities may meet these factors and hence obtain performance legitimacy.

\section{Knowing the Subject's Interests}

First, the object of legitimacy (state or other actor) needs to know the interests of the subjects (citizens) so that the subjects' needs and expectations are met. Once that is accomplished, the subject is likely to reciprocate by imparting legitimacy upon the object. However, inevitably, one might wonder whether the object of legitimacy is capable of knowing what the subject needs and wants. Questions regarding the likelihood of acquiring this knowledge are understandable in cases where the targeted needs and desires are complex and non-basic. However, such questions are less pertinent in cases of post-conflict development where the emphasis is more on basic needs and the minimum requirements for survival. Furthermore, there is a level of commonality of needs across all of humanity ${ }^{18}$ and meeting these basic needs leads to a minimum level of performance legitimacy. As such, when dealing with the provision of primary basic social services, especially in international development, there is enough information regarding the preferences of the subject (citizens), or the desired minimum requirements, in order to develop and implement policies that will help enhance performance legitimacy.

When such minimum requirements are met, the state will then likely begin finding it more difficult to assess the more complex needs and desires of its citizens and the citizens' prioritization of these needs and desires. At that moment, the state would have likely gathered enough legitimacy to afford such a challenge and the subsequent mistakes inherent in trying to 'get it right'. This analysis also applies to leaders who have the resources to provide such services to citizens, especially to their own supporters.

\section{Meeting the Expectations of the Subjects}

The object of legitimacy (state or leader) must meet the expectations of the subjects (citizens). Once the object of legitimacy is aware of the needs and expectations of the subject and can meet

\footnotetext{
${ }^{18}$ One can refer to the work done by Maslow and other researchers whose work has been used to develop the basic principles related to food security, the Millennium Development Goals, and humanitarian assistance.
} 
them, then the subject is likely to reciprocate. There are questions related to whether the object of legitimacy is capable of meeting the subject's expectation, especially in cases of collective action problems (see Beetham \& Lord, 1998).

The issue of collective action is an important challenge to the provision of basic social services (e.g. water, health, education). ${ }^{19}$ When the subjects are discriminated against, one can infer that the level of performance legitimacy they impart onto the object as a result of the delivery of the good will be minimal at best. Furthermore, this unequal access is likely to provide other actors with an opportunity to become objects of performance legitimacy. Thus, the size and identity of the group being excluded and the extent of the exclusion are all important factors in assessing the deficiencies in the performance legitimacy of the object in question and the potential increase in the performance legitimacy of other potential objects that fill the void. In essence, the size and identity of the group being excluded and the extent of the exclusion are all important factors in assessing the deficiencies in an object's performance legitimacy and the potential increase in the performance legitimacy of other potential objects. Thus, rather than negate the presence and impact of performance legitimacy, collective action problems seem to highlight its importance.

\section{Having Capacity}

Knowledge of the citizens' needs and desires requires a certain level of capacity (Scharpf 2003), one that involves the ability to establish and implement intelligent policies to help deliver basic services. Hence, performance legitimacy is critically impacted by the capacity of the object of legitimacy. When a state is attempting to increase its performance legitimacy, it is likely to face a complex situation that requires complicated policies and systems.

The situation of post conflict states makes the need to build capacity even more pernicious. Indeed, the state is likely to be weak and have limited capacity in developing policies and delivering services. Given that the important measure in performance legitimacy is whether the citizen is receiving basic services, it is likely that the starting point for the state's performance legitimacy would be low. Complicating the situation further, citizens, especially in post-conflict settings, are unlikely to distinguish between capacity, willingness and expertise and are likely to be expecting immediate and unrealistic improvements in their lives as a result of the peace dividend (Von Kaltenborn-Stachau 2008).

In summary, the more needed benefits the state provides, the higher the likelihood that the receivers of these benefits will find it legitimate. As Inbal and Lerner $(2007,46)$ note: "To the degree that governments provided needed or desired services to the people - be they social, economic or health-related services or security - the people are likely to support the government's right to govern ... and comply with the rule of law and to submit voluntarily to the government's authority" (emphasis added).

\footnotetext{
${ }^{19}$ International commitments to the principles of international development, including the Millennium Development Goals, attempt to ensure equal access to the most basic services for all citizens. However, capacity plays a major role in achieving this outcome.
} 


\section{B. The Object of Legitimacy}

The state may not be the only object able to realize these three factors. Indeed, other actors (civil society groups, militias, leaders or groups) who are inside or outside the state as well as all levels of a state who are believed to be implicated in the delivery of these basic goods and services also have the ability to earn performance legitimacy. This lack of exclusivity presents states with a significant challenge. First, while states are likely to find it hard to meet the basic needs of the entire population, other actors are unlikely to face the same challenges. ${ }^{20}$ That is, when it comes to specific actors (leaders), there is generally an understanding amongst the population that these leaders are not expected to deliver basic services to the entire population. Quite the contrary, they are expected to initially focus on meeting the basic needs of citizens that make up their support base. The delivery of goods and services to a portion of the population requires fewer resources and less capacity than would delivery to the entire population or large parts of it. As such, post-conflict states are at a stage where they require capacity-building activities to allow them to compete while leaders are often capable of meeting these lower expectations.

In addition to having lower expectations imparted on them, leaders, especially those working or leading service-delivery state institutions, have the opportunity to own the delivery of these services and brand them either as their own or as resulting from their personal intervention (Mayall 2005). Examples include cases in Sierra Leone, Lebanon, Afghanistan, the Solomon Islands, Colombia, and Iraq. The use of these institutions in these environments is, more often than not, extensive and thus leads to a sort of clientelistic abuse between the institution and the leader (Armstrong and Rubin 2005). Since perception is of the utmost importance when it comes to performance legitimacy, the actual originating point of the service or good is less important than the receiver's perception of the 'true' owner of the delivery of the service or good.

These are important points to consider as the current tendency among many practitioners (examples include USAID, World Bank, OECD ${ }^{21}$, European Commission) and scholars (examples include Angeles \& Magno, 2004; Brinkerhoff, 2005; Dodge, 2011; Eaton \& Schroeder, 2010; Ghani \& Lockhart, 2008; Hartzell, 2006; Keefer, Narayan, \& Vishwanath, 2006; Mukhopadhyay, 2009) is to advocate for the decentralization or devolution of the state to the local level as a means to deal with inefficiencies, capacity challenges, and legitimacy crises. With the non-exclusive nature of performance legitimacy, the risks associated with decentralization and devolution (the strengthening of the divisions between the various groups in society and the tendency to bring local leaders closer to their constituency and furthering them away from the state (Bardhan and Mookherjee 2006; Blair 2007; Dinnen 2008)), as well as the disillusionment of the citizens towards their state (Ducci 2004; Oxhorn 2004; Selee and Tulchin 2004), such policies are likely to lead to the de-legitimization of the state and the legitimization of local leaders.

\footnotetext{
${ }^{20}$ This argument is further elaborated in the next two sections.

${ }^{21}$ As noted earlier, the OECD report that questions the underlining assumptions behind the general approach is an exception. The OECD continues to write reports that are in alignment with the current tendency of focusing on process legitimacy and democratic transitions and does not seem to have changed its approach following the publication of its 2010 report that questions this approach.
} 
Still, some authors (Levi and Sacks 2009; Mcloughlin 2014) have questioned the direct relationship between performance legitimacy and meeting basic needs on grounds of morality, shifting expectations, the ideological position of citizens, impartiality, and attribution. As it relates to moral values, meeting absolute basic needs is a moral act in its own right - it is an internationally recognized basic human right and highly likely to be part of a country's moral and social contract (shared beliefs). ${ }^{22}$ Furthermore, there is no denying that the temporal factor is significant. As discussed earlier, there is an increase in the complexity of demands or graduating expectations as lower level demands are being met. This gradation introduces a certain level of complexity into the relationship between performance legitimacy and service delivery, but it also demonstrates that the expectations are present and need to be fulfilled. Finally, ideology, impartiality and attribution highlight the non-exclusive nature of performance legitimacy and raise significant concerns as to the impact of this non-exclusivity. This is especially important in countries and societies where the differentiation between the leaders, parties and governments is non-existent or very limited (Gilley 2006b) and donors are concerned with democratic or process legitimacy.

Clearly, the legitimacy of a state or a leader is derived from their relevance in their subjects' lives. By following this analysis, one can then conclude that the higher the importance or perceived benefit of the state in the daily lives of citizens in developing countries, the higher the support and legitimacy those citizens impart on their states. ${ }^{23}$ This method of analysis is also relevant for assessing the reasons behind what drives people to want to be involved in or abstain from democratic processes in countries with a limited democratic history and culture. ${ }^{24}$ It might also help shed light on the major constraints that place the democratic agenda at risk clientelism, corruption, and the like. If this thread of analysis is followed through, it seems that reciprocal actions by citizens ${ }^{25}$ require a state to meet a certain minimum level of the citizens' expectations through the delivery of basic services and to demonstrate its relevance in and positive contributions to the lives of its citizens (Levi and Sacks 2009).

\section{Performance Legitimacy and Post-Conflict Development}

The current debate regarding the sources of legitimacy is highly relevant to cases where the state has had a very precarious and sometimes minimal, non-existent, and/or controversial role in the lives of its citizens. It is rare to find post-conflict cases where the legitimacy of the state has not been negatively impacted in the eyes of at least a part of the population, and, more generally,

\footnotetext{
${ }^{22}$ The experience of Hizballah, Hamas and other groups who have been able to transcend religious lines has demonstrated that the desire for meeting one's basic human needs is common in most societies and often transcends other values (Harik 1996). This will be elaborated further in the following chapter.

${ }^{23}$ This argument or method of deconstructing the legitimacy of the state is heavily influenced by case studies that attempt to understand the support that militia groups, warlords, and other 'unlawful' groups have received from supporters, even when such support seems illogical or counterproductive. This point will be expanded upon further below.

${ }^{24}$ It is important to note that low voting rates could be a result of apathy rather than a crisis of legitimacy. However, this is much more likely to happen in cases with mature democracies than in developing or post-conflict countries.

${ }^{25}$ These reciprocal actions include trusting the state in its decision-making process, becoming involved in the electoral process (if applicable), being faithful to the state and its processes, and abiding by the rules and laws that are issued by the state even without threats of repercussion (e.g. payment of quasi-voluntary tax).
} 
where the belief in the role of the state has not been shaken or diminished. Moreover, countries that are emerging from conflict have experiences and environments that are vastly different from that of the western liberal democracies whose "formal [state] institutions ... derive their capacity and legitimacy from a long history of interaction between state and society, [something that] cannot be reproduced simply by transferring the same institutional models into different social and political contexts" (OECD 2010, 7).

Current research has demonstrated that even with the holding of elections, post-conflict states and democratically elected governments face a crisis of legitimacy as a result of the state's demise during the years of conflict. During the conflict, the failure of the state does not only manifest itself in the level of destruction of physical infrastructure but also in the delegitimization of political and administrative institutions of the state (Busumtwi-Sam 2004), a process that reduces the range of political action and feasible policies, even for legitimately elected leaders of post-conflict states (Englebert 2000). Equally important though, the conflict leads to the rise in groups ${ }^{26}$ that have taken over the role of the state in the areas under their control or influence, thus offering much-needed support to parts of the population during the difficult times of conflict. These groups tend to continue to enjoy the legitimacy-related benefits associated with their role even in the post-conflict phase, especially when they use state resources as a means to secure or enhance their legitimacy.

These experiences during and following the end of the conflict often lead to competition for relevance, loyalty, and legitimacy between the state, the existing indigenous structures, and these 'support' groups, even when alternative democratically-inspired competitive venues are provided (Busumtwi-Sam 2004; Siegle and O’Mahony 2010).

With the acknowledgment of their presence and the assessment of legitimacy from a performance perspective, it becomes evident, that even with elections and rule of law, alternative centres of authority actively compete with the state for loyalty and legitimacy (Busumtwi-Sam 2004). When these alternative actors are successful, their level of legitimacy allows them to constitute a 'state' within a state (e.g. regional warlords in Afghanistan and Hizballah in Lebanon) (Brinkerhoff 2005). Complicating the situation further, these centres are often led by major players who were/are themselves co-opted into the government as part of the reconciliation process and have subsequently become powerful politicians in the post-conflict government (e.g. Lebanon, South Sudan and Afghanistan). With the ability of these alternative authority centres to foster legitimacy through the delivery of basic goods and services, the chances of the weakened state's success in gaining legitimacy or transferring some of the performance legitimacy onto itself, especially in the 'disputed' areas, are low.

As such, the de-legitimization crises and the ever present competition for legitimacy have led governments and leaders in developing countries to recognize that the state's legitimacy rests more on its ability to provide its citizens with basic goods and services and less on sovereignty and elections (elements of de jure or process legitimacy) (Posner 2004).

\footnotetext{
${ }^{26}$ The term 'support' groups entails groups that catered to the needs of the population during the conflict. As such, the term makes reference to militias, para-military groups, NGOs, and civil society groups.
} 
Afghanistan provides a striking example of this reality. In Afghanistan, the "US [through USAID] and the World Bank had set the overall guidelines for state-building, giving priority to the minimum prerequisites for the creation of a functional, lean and efficient state" (Ministry of Foreign Affairs Denmark 2005, 25). Yet, in 'Nation-Building: Beyond Afghanistan and Iraq', Starr $(2006,110)$ quoted Afghans as highlighting the following important requirements for a legitimate Afghan government:

"First, is the government providing, or likely to provide, their specific region and group with what they see as "governmental" services? These services included securing borders, providing internal policing, freeing roads of bandits, rebuilding and tending the main irrigation channels, and providing basic medical help and education. Second, is the government, as the country's chief employer, distributing jobs and the authority and resources that go with them in a fair and equitable manner - that is one that benefits their specific region and group?"

Thus, as Starr's research demonstrates, legitimacy for many Afghans was not limited to elections and the establishment of a central government. Afghans were ready to bestow legitimacy upon their government if and when their government began to provide them with basic goods and services and not if or when they exercised their right to vote.

In the absence of the government, warlords and other actors have taken on the challenge of meeting the basic needs of the population living within their area of control or influence (Coburn 2011; Lister and Wilder 2005; Paris 2006). This resulted in the preservation of the warlords' social relevance (Mac Ginty 2010), the questioning of the legitimacy of the state (Lister and Wilder 2005), an increase in the legitimacy of the warlords, and a decrease in the legitimacy of the government (Paris 2006). It also manifested itself in the reluctance of many Afghans, especially those living outside Kabul and Kandahar, to cooperate with administrators sent to their areas by $\mathrm{Kabul}^{27}$ and an increase in the support for any local authority who refused to turn over tax revenues to the capital (Starr 2006). As a result, the Karzai government found itself in the middle of a vicious cycle: not only did it lose its performance legitimacy to the alternative centres of authority, it was also unable to raise the money that it required to reengage in the lives of its citizens and fund service delivery. Ultimately, the government's democratically elected status could not allow the state to gain the legitimacy that it needed to govern the entire country (François and Sud 2006).

Consequently, under the performance-legitimacy theory and as the Afghanistan case illustrates, there is an important link between the delivery of services, which indicates willingness on the part of government to respond to the citizens' needs and demands (Brinkerhoff 2005), and the citizens' support for the state and its government. ${ }^{28}$ The Afghan case points to important lessons

\footnotetext{
${ }^{27}$ Undoubtedly, no one can completely rule out reluctance resulting from threats of violence. However, Starr's research has identified such reluctance even in areas where there is no overt threat of violence, thus allowing for such a general statement.

${ }^{28}$ This conclusion is also supported by the experiences of several non-conflict affected states, such as many of the ex-communist European countries, Uganda, Zambia, and Botswana. In the case of Kyrgyzstan, the withdrawal of the
} 
for post-conflict development and the relevance of performance legitimacy in the future longterm stability of the country. Theses experiences also lend credence to the idea that "[s]ervicedelivery and economic development effectiveness relate to legitimacy in that citizens tend to withdraw support from governments that cannot or will not provide basic services and some level of economic opportunity" (Starr 2006, 112).

\section{The Importance of Performance Legitimacy - Concluding Remarks}

The analysis thus far has identified that the most prevalent academic writings on and approaches to post-conflict development are primarily based on process legitimacy. However, this does not correlate with the reality on the ground and with the idea that the society, in general, places a higher emphasis on the delivery of basic goods and services than on items related to process legitimacy. Thus, it seems that the primary source of state legitimization in the early post-conflict stage is through its performance when delivering these desired goods and services.

Central to this conclusion is the reassessment of our understanding and measurement of legitimacy by asking the following: legitimacy in the eyes of whom, who or what is legitimate, and how did it, or how can it, become legitimate?

First, the analysis thus far indicates that, in general, there is a dichotomy between the desires or beliefs of the international community (including most scholars and practitioners) and that of the locals. For the international community, process legitimacy makes up the biggest part of the assistance or analysis. As noted earlier, the other sources seem to be less important with

state from the social sphere as it relates to welfare services played into the rhetoric that led to the conflict in the Freghana Valley and the inability of the state to develop or maintain a social contract with its citizens (Goodhand 2006). In the Ugandan and Zambian cases, satisfaction with the government was directly linked to the performance of the government in the delivery of basic goods and services (Widner 2004)(Widner 2004)(Widner 2004)(Widner 2004)(Widner 2004)(Widner 2004)(Widner 2004)(Widner 2004)(Widner 2004)(Widner 2004)(Widner 2004)(Widner 2004)(Widner 2004)(Widner 2004)(Widner 2004)(Widner 2004)(Widner 2004)(Widner 2004)(Widner 2004)(Widner 2004)(Widner 2004)(Widner 2004)(Widner 2004)(Widner 2004)(Widner 2004)(Widner 2004)(Widner 2004)(Widner 2004)(Widner 2004)(Widner 2004)(Widner 2004)(Widner 2004)(Widner 2004)(Widner 2004)(Widner 2004)(Widner 2004)(Widner 2004)(Widner 2004)(Widner 2004)(Widner 2004)(Widner 2004)(Widner 2004)(Widner 2004)(Widner 2004)(Widner 2004)(Widner 2004)(Widner 2004)(Widner 2004)(Widner 2004)(Widner 2004)(Widner 2004)(Widner 2004)(Widner 2004)(Widner 2004)(Widner 2004)(Widner 2004)(Widner 2004)(Widner 2004)(Widner 2004)(Widner 2004)(Widner 2004)(Widner 2004)(Widner 2004)(Widner 2004)(Widner 2004)(Widner 2004)(Widner 2004)(Widner 2004)(Widner 2004)(Widner 2004)(Widner 2004)(Widner 2004)(Widner 2004)(Widner 2004)(Widner 2004)(Widner 2004)(Widner 2004)(Widner 2004). In the Botswana case however, given that the government's level of performance was relatively better than that of Uganda and Zambia, the satisfaction with the government did not hinge on issues related to the delivery of basic goods and services (Widner 2004). Moreover, given that "[s]tates exist not only because they are successful in generating positive payoffs for a majority of the citizens, but also because a degree of loyalty binds citizens to the state" (Meierhenrich 2004, 153), the state's demonstrated relevance and importance in its citizens lives is likely to increase its legitimacy and contribute to the development of the foundations of this loyalty. This strengthening of the bond between the state and its citizens becomes even more crucial in cases where citizens are distrustful of the state and of certain coalitions or groups represented in the government, especially when alternative centres of authority present a strong competing factor for loyalty. 
emphasis placed on only the aspects of performance legitimacy that support process legitimacy (delivery of security, justice, and, at times, basic infrastructure) and the supportive role of international recognition ${ }^{29}$ and shared beliefs. In the case of the citizens' perspectives, we have seen that there is a higher emphasis that is placed on performance legitimacy early on in the postconflict stage. Shared beliefs are often viewed as relevant but the development of a shared vision for the country is often constrained due to the lack of trust amongst the various warring factions and the anxiety over the natural elimination of certain options when moderating amongst the various groups. Moreover, given the analysis above, it seems that the importance of process legitimacy and international recognition, including whether the international community is happy or unhappy with the level of process legitimacy, factor at the lower end of the spectrum. ${ }^{30}$ As noted earlier, this is partly due to the limited presence of the underlying factors that are necessary for citizens to demand or want democratic process legitimacy.

Second, we have seen that there are multiple objects of legitimacy. Yet, the predominant legitimacy-building processes focus on only one - the state - and overlook the possible other objects of legitimacy. The assumption that states earn legitimacy and leaders earn political support is at odds with the empirical reality of countries emerging from conflict. Securing the legitimacy of the state requires this recognition and specific actions to limit the use of state resources for the benefit of the non-state actors.

Third, there are different means for earning legitimacy. The analysis clearly demonstrates that the international community's focus on process legitimacy might not be the most appropriate method for the state to earn its legitimacy from its own people. The predominant source of state legitimacy and stability in the early phase of post-conflict is often the delivery of basic goods and services, even when democratic processes have already been established.

Considering these points altogether, the central argument I advance is that the state's performance legitimacy is paramount for stability and long-term development. Performance legitimacy, at least in certain post-conflict cases, is the basis onto which other sources of statecentred legitimacy ${ }^{31}$ can be built in post-conflict countries that have limited experiences with democratic culture, a weakened shared belief, and leaders that have demonstrated socially responsive behaviour. One can argue that the presence of performance legitimacy allows the state to deliver basic goods and services, mediate some of the negative impact that groups or leaders have on the stability of the state, and improve the willingness of citizens to accept state decisions and actions even when they do not align with their individual preferences or objectives. Thus, when looking at early-stage interventions to improve the legitimacy of the state through

\footnotetext{
${ }^{29}$ International recognition should be understood only as the actual recognition of rightful leadership and statehood by the United Nations and other multilateral bodies that represent states and their leaders at the international stage. While there is an implicit international recognition when a post-conflict state abides by the process-centric development trajectory, it is not a necessary requirement (e.g. China, Somaliland, West Bank and Gaza). ${ }^{30} \mathrm{It}$ is important to note that not all citizens classify these four types as they have been classified herein. There are citizens who perceive process legitimacy to be more important than perhaps performance legitimacy. The point is that there is a general trend where people in conflict and post-conflict countries value performance legitimacy more than process legitimacy in the early post-conflict stage.

${ }^{31}$ State-centred legitimacy implies the legitimacy of a state that can be gathered by working on the state to improve its institutions.
} 
state-building, the analysis indicates a hierarchy of priority with performance legitimacy at the top followed by the others in the later stages of stabilization and development.

\section{Challenges to Increasing a State's Performance Legitimacy}

Improvements in the performance legitimacy of post-conflict states require the reintegration of public services back into the structure of the government after the initial crisis phase (Caplan 2004; Tony Dodge 2011) and making certain that these services reach the population, especially those most in need. However, with state institutions and structures emerging as weak players following the end of the conflict, success in gaining performance legitimacy is directly linked to building the capacity of state institutions (Busumtwi-Sam 2004; Meierhenrich 2004; Paris 2005, 2006; Posner 2004; R. I. Rotberg 2004; Widner 2004). Hence, building the capacity of servicerelated institutions needs to be central to any theoretical framework that is concerned with enhancing performance legitimacy. Yet, the institution-building process, in itself, presents challenges to the building of the state's performance legitimacy, especially in such volatile and complex environments. That is, the institution-building process presents both a threat and an opportunity for leaders in such uncertain and volatile times.

\section{A. Performance Legitimacy and Institution building}

A first step for increasing the state's performance legitimacy is transferring responsibility for the delivery of basic services over to the state. This is done to ensure that the receivers of these basic services perceive such benefits as resulting from state actions, and, of course, state institutions must exist or be built before such services can be effectively delivered.

When these responsibilities are transferred, three consequences often follow. First, empowering the state to take on new responsibilities is likely to represent a direct challenge to the leaders' own performance legitimacy and power (Barbara 2008; Dinnen 2008; Tony Dodge 2011; Goodhand 2006; Hameiri 2009; Hess 2010; Mukhopadhyay 2009; Ottaway 1995; Sharan 2011). These leaders, on the other hand, may simply use state service-delivery institutions for their own benefit in an attempt to increase their own performance legitimacy and influence (Dinnen 2007; Grzymala-Busse and Jones Luong 2002; Hameiri 2009; Kitschelt and Wilkinson 2007; Marquette and Beswick 2011; Mayall 2005; Zanotti 2008). In doing so, they may negate any efforts to increase the performance legitimacy of the post-conflict state.

Second, despite its technocratic overtone and the international community's overwhelming reliance on technical assistance, ${ }^{32}$ institution building necessarily constitutes a political project with identifiable political and ideological underpinnings that attempts to challenge and transform existing power relations and establish a certain relationship between the rulers and the ruled. Research has underscored the political contest that can ensue over who will control and thus benefit from state-building interventions. Just as with the preceding conflict, there will be winners and losers that flow from any intervention (Dinnen 2007). A state-building intervention will also inevitably affect informal structures and power relations. Such structures and relations "are neither codified nor sanctioned officially, consisting instead of shared understandings rather

\footnotetext{
${ }^{32}$ References can be found on the websites of the World Bank, the International Monetary Fund, and most donors and United Nations agencies.
} 
than formal rules, personal agreements rather than legal contracts, or organizations without necessary legal recognition or legitimate power that can nonetheless serve as the basis for extracting and allocating resources" (Grzymala-Busse and Jones Luong 2002, 534). Thus, building institutional capacity has more of a far reaching transformational effect; it supports and often fuels the emergence of new sets of interests and coalitions within the state and among elites (Hameiri 2009).

Third, given the above two consequences and the need for the government and state institutions to implement change, this process allows leaders who lead state institutions or are major players in these institutions the opportunity to use state service-delivery institutions for their own benefit in an attempt to increase their own performance legitimacy and influence (Dinnen 2007; Grzymala-Busse and Jones Luong 2002; Hameiri 2009; Kitschelt and Wilkinson 2007; Marquette and Beswick 2011; Mayall 2005; Zanotti 2008).

In summary, the institution-building process is likely to a) present leaders with an opportunity to design institutions according to their needs and goals, ones that are likely to contradict that of the state, and b) be directed by power dynamics and struggles associated with building institutions, establishing mandates, writing policies and the like (Dinnen 2007; Ghani and Lockhart 2008; Grzymala-Busse and Jones Luong 2002; Hameiri 2009). These practices have often been referred to in the literature as capture, clientelism and fusion (Ghani and Lockhart 2008; Grzymala-Busse and Jones Luong 2002; Kitschelt and Wilkinson 2007). ${ }^{33}$ In effect, institution building in post-conflict states is a tumultuous process that can lead to undesirable consequences, including the entrenchment of political powers, interests and the legitimacy of specific leaders.

According to the theory of performance legitimacy, it is these undesirable consequences that work against efforts to improve the performance legitimacy of the state and work to contribute to a continuous vicious cycle that involves increases in the legitimacy of leaders and further decreases in the legitimacy of the state. These outcomes, I argue, can be partly offset when institution-building is undertaken with: (a) a recognition of the existing limitations to democratic governance and the role that performance legitimacy plays in the process; and (b) tailored and locally appropriate provisions to deal with these obstacles.

\section{B. Performance Legitimacy and the Dynamics of Institutional Changes}

Institution building also requires a healthy understanding of the relationship between the leaders and the institutions, the factors that shape this relationship, and the manner in which either one influences the other. As such, the dynamics of institutional change are influenced by the interactions between the institutions, the employees and the leaders and the impact that these interactions have on the success of public policies that aim to limit the abuse of state institutions.

State institution-building is a process that is usually undertaken at the end of a conflict. However, as sociological and historical institutionalism both emphasize, any institution-building or adjustment process will likely encounter constraints of varying strengths (March and Olsen 1989;

\footnotetext{
${ }^{33}$ While many authors have invested much time and energy in making a distinction between these terms, they all have a negative impact on the performance legitimacy of the state. As such and for the sake of simplicity, the analysis herein will refer to all these events or situations as clientelism.
} 
Streeck and Thelen 2005). These internal constraints are shaped by the institution's culture, habits and routines (March and Olsen 1989) and by the competition between varying internal and external views, ideas, interests, beliefs, and power sources (Streeck and Thelen 2005). These factors make institutions more regime-like and subject to the outcomes of the continuous interactions between rule-makers and rule-takers, especially when the rule-takers are influenced by leaders who oppose proposed rule changes. These factors contribute to the slow pace of reforms, to new opportunities for leaders to demonstrate the ineffectiveness of the state, and to further opportunities for the diversion of state resources. As such, institution building becomes a complex, uncertain, and option-eliminating process (March and Olsen 1989; Pierson 2004; Streeck and Thelen 2005) with multiple imprecisions that tend to limit the rate of success ${ }^{34}$ of directed changes (Pierson 2004; Streeck and Thelen 2005). This process, with its multiple uncertainties and the sheer level of internal influence that is impacted by the makeup of the public service and the level of control of the various leaders on those working within the institution, also provide leaders with additional opportunities to increase their performance legitimacy, whether they are inside or outside the state.

Moreover, institution building is also significantly influenced by path dependency and historical junctures or option-eliminating moments in time. ${ }^{35}$ Peace processes are often considered to be critical junctures that afford the country and its citizens a new start and the chance to implement changes that are considered crucial for continued peace and development. Yet, this belief contradicts what is often observed. In many post-conflict countries, peace processes and the institution building that follows demonstrate characteristics of path dependency (Pierson 2004). Moreover, conflicts as critical junctures appear to offer leaders the opportunity to entrench their practices, even when their practices fall outside official or formal rules. Making the link between these issues, the abuse of state resources by leaders who are more concerned with building their own performance legitimacy at the expense of that of the state, and the likelihood of success of new public policies that are implemented to limit this abuse helps account for how certain aspects of the institution building process contribute to the de-legitimization of the state and the legitimization of the leaders.

\section{Towards a New Theoretical Framework}

Following the conclusions related to the improvements of performance legitimacy and the importance of recognizing that legitimacy can be earned by the state as well as by other actors who often compete with the state, the case has been made for the development of a new theoretical framework. The Performance Legitimacy Theory of Transition framework is built on the understanding that the working definition of legitimacy needs to be broadened to reflect the factors that lead people who have limited experiences with democratic culture and limited trust in the state to accept the state and abide by its rules.

This framework needs to account for a more granular analysis of the relationship between the state and its citizens and the manner in which state institutions are impacted by the actions of the

\footnotetext{
34 This refers to the rate of success of implementing the directed change as was envisioned (e.g. If X then Y).

35 This refers to the idea that at specific moments in history, decisions had to be made for going forward. These decisions involved the elimination of options that were not ultimately chosen.
} 
leaders. In doing so, the new Performance Legitimacy Theory of Transition framework can then reflect the vicious (continuous de-legitimization of the state), virtuous (continuous legitimization of the state), and less extreme cycles that a post-conflict country can fall into. As a result, the framework is then likely to account for the presence of actors that intend on delegitimizing the state, whether from within or outside the state structure.

Thus, critical to the development of this theoretical framework based on performance legitimacy is the recognition that:

a) The state as well as other actors have the ability to earn performance legitimacy;

b) Initially, the state's legitimacy is weak, if not amongst the entire population, certainly amongst a significant ${ }^{36}$ portion of the population;

c) The enhancement of the performance legitimacy of the state requires the building of state institutions; and

d) Actors have access to state resources and are willing to use their distribution as a means to increase their own legitimacy.

These four factors, and the recognition that a model based on the development of a Western state is not necessarily applicable to post-conflict situations, allows one to assess whether state institution-building meant to build the legitimacy of the state actually delegitimizes the state and reinforces the legitimacy of competing actors (vicious cycle), especially those working through state institutions, increases the performance legitimacy of the state at the expense of that of the leaders (virtuous cycle), or has elements of both.

The framework begins with a recognition of the weakened position of the state vis-à-vis the leaders and an understanding of the need to build the institutional capacity of the state to deliver basic goods and services. By incorporating the likely reactions of the leaders and the existing dynamics on the ground between the leaders and their supporters, as noted in the discussion on institutional change, the framework incorporates the perceived ownership of the delivery of the service or good and the implications of such a perception.

There are two possible extreme paths identified by the framework (Figure 2.2). These two paths form the extreme ends of a continuum of performance legitimacy where performance legitimacy is contested between leaders and the state and where the country's position on the continuum is dependent on how much performance legitimacy both the state and the leaders are able to gain. The first extreme path leads to performance legitimacy for leaders. If institution-building leads to the delivery of services and they are either owned - or perceived by the recipients to be owned by the leader, then the recipients of these benefits are likely to impart the leaders with performance legitimacy. This will either maintain or increase the recipients' ambivalence towards the state. With this increased ambivalence and legitimacy of the leaders, it is likely that

\footnotetext{
${ }^{36}$ The use of the term significant implies the size and/or the level of importance of segments of the population. The existence of an alienated section of the population is significant in the sense that it signifies a potential threat to the legitimacy of the state, and perhaps long-term stability and control, when combined with leaders who are actively competing to undermine the state and its legitimacy.
} 
the state would be unable to reverse the trend of its own de-legitimization, thus the vicious nature of the cycle. This vicious cycle puts into question stability and compliance with state rules.

The second extreme path, by contrast, leads to performance legitimacy for the state. If the state is capable of owning the benefit from the delivery of goods and services, as the analysis has demonstrated, the state is likely to benefit from an improvement in its image, increased performance legitimacy, increased compliance with state rules, and increased likelihood of stability. Achievements in each of these areas will help reinforce further achievements in the other, hence the reference to a virtuous cycle.

It is important to note however that, in reality, the two cycles can occur concurrently in different levels of government or in different service-delivery institutions. In essence, there could be limited abuse of certain institutions and full abuse of others. In this case, the result is both the increased performance legitimacy of certain leaders and that of the state. This competition between the two objects of legitimacy is likely to lead to power struggles, including the leaders' active search for further opportunities to use state services.

As can be seen from the diagram below, this new model is capable of accounting for the legitimization, de-legitimization, or continued struggle for state legitimacy as the country transitions from the peace process to long-term development. It also allows for an analysis of the impact of the presence of leaders inside state institutions and the possibility of the leaders' use of these institutions as a means to increase their performance legitimacy. In doing so, the framework does not assume that the mere presence of a legitimate leader in the state leads to the transfer of this legitimacy unto the state. It also does not assume that the implementation of good governance and policies related to the functioning of the public service, both political in nature and open to influence, will eliminate the abuse by the leaders and their cadres within state institutions. 


\section{Figure 2.2: Theoretical Framework - Performance Legitimacy}

\section{Theory of Transition}
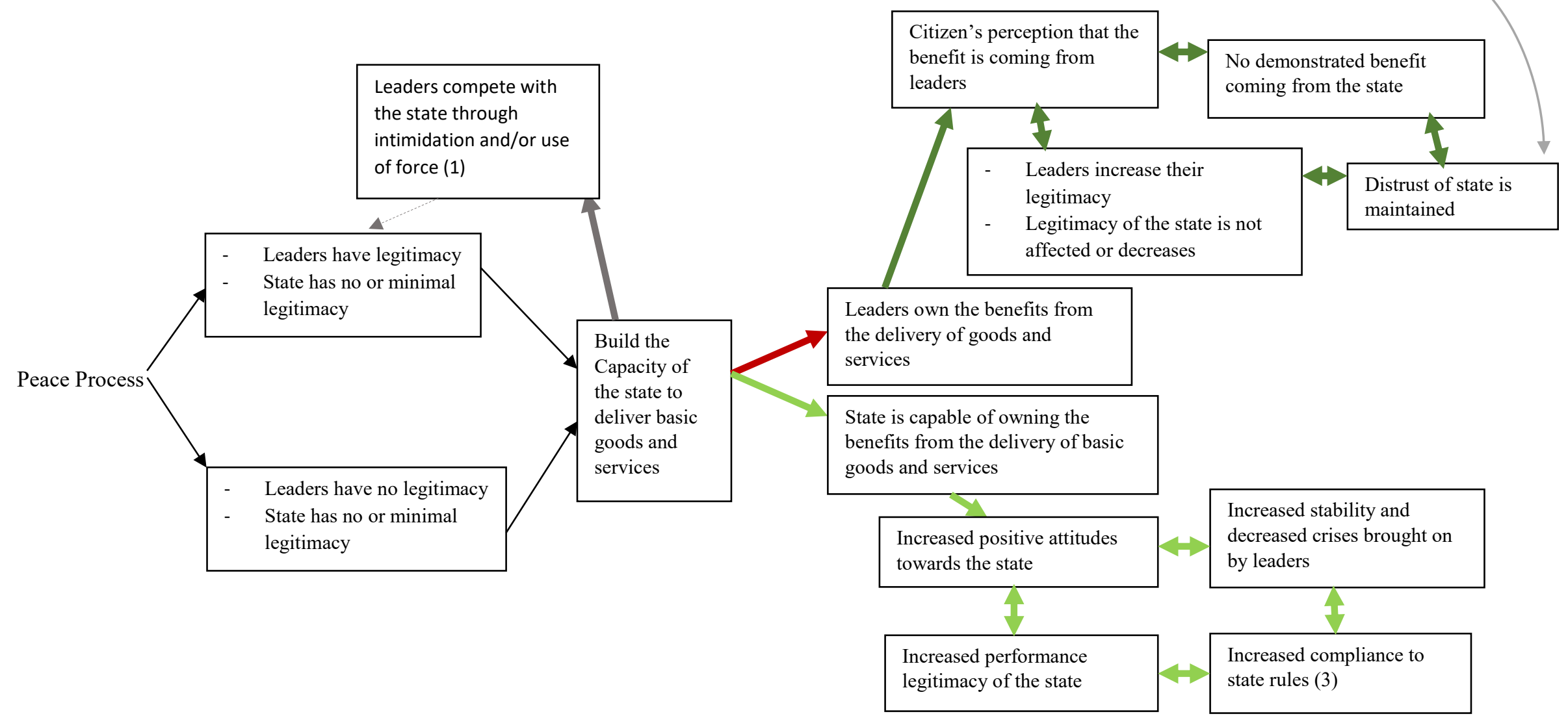

(1) Intimidation and use of force will lead to temporary, incomplete and/or unsustainable performance legitimacy. It needs to be supported by the provision of basic goods and services for it to remain successful and be a sustained factor.

(2) The source of this negative information could be political leaders (including warlords or those involved in the conflict), the media, and religious leaders.

(3) Increase in compliance will occur regardless of which leader is in the state and in the absence of violence forcing citizens to comply. 


\section{Potential Criticisms of the Performance Legitimacy Theory of Transition Framework}

The introduction of any new theoretical framework is bound to be associated with high levels of criticism. Eliminating the criticism will either require adjusting or abandoning the Performance Legitimacy Theory of Transition framework. The following are three criticisms identified in advance.

First, performance legitimacy is hard to measure. Currently, acceptable legitimacy indicators measure aspects of process legitimacy and are deemed to be easily comparable across different countries ${ }^{37}$ Accordingly, it is assumed that any measurement of performance legitimacy is likely to lack statistical rigour and be unfit for comparability purposes. Measurement challenges do not, however, justify the discounting of a theory. They do not refute the potential importance of performance legitimacy in post-conflict conditions or the need to distinguish between the legitimacy of leaders and the legitimacy of the state. As such, in the chapters to come, I provide an initial attempt at measuring performance legitimacy while maintaining a certain level of statistical rigour.

Second, the fact that this framework allows for the inclusion of many aspects of complicated relationships between the society and the leaders, the society and the state, as well as the leaders and the state makes it difficult to develop conclusive arguments and prescriptions. While this point is important, the development of frameworks that ignore complex relationships, especially in complex and high stakes settings, serve to lead to further confusion, the likelihood of failure, the alienation of a society, and further complications that are likely to lead to irreversible damage. As such, the case has already been made for the development of a new framework that I argue better reflects reality and that might have a better chance at succeeding. It is also likely to develop the understanding of certain aspects that seem to hinder the potential benefits that come from process legitimacy (e.g. clientelism).

Third, the Performance Legitimacy Theory of Transition framework suggests that the development of a state's legitimacy is particularly challenging in post-conflict environments. It also expects that failure may become path dependent and thus solidify the development of regimes and systems that are not beneficial for the citizens. As such, some might suggest that given these odds, there is a rather high potential benefit for pushing for the establishment of democratic regimes from the onset. This is a valid point to make. Perhaps by shedding light on the possible trajectories that countries can embark on, this framework may indirectly support the arguments for the promotion of democratic values. However, further research needs to be done in order to be able to compare the costs and benefits of waiting or quickly embarking on the promotion of democracy. Nevertheless, the current evidence demonstrates a lack-luster performance for post-conflict democratic development. Failure or limitations can occur in both frameworks. However, if, as it is argued herein, stability and long-term development is

\footnotetext{
${ }^{37}$ The following chapter will provide an interesting contradiction whereby the analysis raises important questions and concerns regarding such claims.
} 
contingent on the state earning performance legitimacy, then there is compelling evidence to move forward with the testing of this framework.

\section{Conclusion}

Conflating, on the one hand, legitimacy and democracy and, on the other, the desires of the international community and those of a country's citizens have proven to be counterproductive to many post-conflict situations. In many cases, the underlying assumptions related to the existing framework are inappropriate for the local context and ignore several factors that often derail the framework.

The understanding of the meaning of the state and the leaders in the lives of citizens, whether supporters or not, is critical knowledge for successful and stable development in post-conflict situations. Performance legitimacy is central to the relationship between the state and citizens and between leaders and their constituencies. It also affects the relationship between leaders and the state, particularly via a leader's intentions and motivations vis-à-vis state institutions.

Recognizing these dynamics means state building needs to control the abuse of state institutions by leaders who want to retain their legitimacy and power.

A focus on process legitimacy does not properly account for these fundamental issues. As such, this chapter presented an alternative framework that provides the initial steps needed for a solid foundation unto which a strong and stable state system may be built. By designing a legitimacybuilding process that is linked to the desires and requirements of the citizens and seeks to transfer legitimacy from leaders to the state, one can sidestep the discussions related to which of the four sources of legitimacy comes first and concentrate on working with the actual variables on the ground.

The utility of this framework, however, can only be assessed with indicators that focus on the delivery of goods and services and the perception of citizens about who or what institutions are responsible for their delivery. As such, the following chapter will be dedicated to the assessment of current indicators and the exploration of potential indicators associated with performance legitimacy and this framework. 


\section{Chapter 3: The Need for New Legitimacy Measures}

\section{Introduction}

Chapter 2 established the need to understand which political object (the leader or the state) holds performance legitimacy. The identification of this object is an important step in establishing structures and mechanisms that can help improve the legitimacy of a post-conflict state. From a purely research perspective, the identification of the level and object of legitimacy makes the assessment of the empirical evidence possible and allows for a more focused case study selection process. This identification process in turn requires the measurement of the levels of performance legitimacy of each object. As is noted below, with existing measures of legitimacy being inappropriate for the measurement of performance legitimacy and with the nonexistence of indicators that measure performance legitimacy, there is no real means to assess how different countries fair regarding performance legitimacy.

Any measurement of performance legitimacy needs to focus on the perceptions of citizens towards the state and the leaders (Suchman 1995). Arguably, placing citizens at the heart of the measurement is not without precedence. Even academics examining process legitimacy call for the measurement of legitimacy through the assessment of the belief and expectations of citizens as they relate to the system (e.g. Fraser 1974; Gilley 2006b). What is new though is the attempt to (a) move away from measuring indicators of process legitimacy to those of performance legitimacy and (b) design these indicators to help distinguish between the levels of performance legitimacy that are held by the various political objects.

Normative views of democracy (mostly liberal democracy), morality, and the maturity of political systems have fostered a strong focus on measuring process legitimacy through indicators of democratic values and systems. This focus has occurred in the overwhelming majority of academic and grey literature and is often accompanied by discussions that dismiss other measures due to their perceived lack of focus on morality, weaknesses as they relate to cross-national comparisons, and the conceptual failure of overlooking the distinction between political support and legitimacy.

This chapter shows that these 'limitations' are not universally applicable. When a clear analysis of the existing relationships between the objects (state and leaders) and the citizens is undertaken, it becomes evident that most of these limitations are inappropriate in post-conflict settings. Several issues point to this conclusion, including questions regarding the quality of the more conventional indicators, their conceptual validity, and their fit with societies that have little experience with democratic values and systems. Given the weaknesses of 'conventional' indicators, the chapter raises concern about their hegemonic use and lends conceptual strength to a citizen-centred process of measuring performance legitimacy.

The approach adopted herein is also a major improvement on the current methodology used to measure process legitimacy. While both approaches define legitimacy as a latent variable or a variable that cannot be measured directly, the 'conventional' method measures legitimacy by only using effect indicators, indicators that change depending on the levels of legitimacy, and 
ignores the variables that are responsible for the fluctuations in the levels of legitimacy. I develop an approach that focuses on indicators that are responsible for the fluctuations in performance legitimacy (causal indicators) and uses a few indicators that fluctuate with changes in the levels of performance legitimacy (effect indicators). In essence, my new measurement approach places a higher emphasis on causal indicators but also recognizes the importance of understanding the outcomes of performance legitimacy.

Finally, the analysis adds another interesting and often overlooked component of legitimacy the identification of the object of legitimacy. Existing indicators are unable to differentiate between the legitimacy of various objects. The ability to differentiate between the holders of legitimacy is central to identifying whether post-conflict institution-building leads to the legitimization of the state or the leaders and thus the virtuous or vicious cycles identified in the Performance Legitimacy Theory of Transition framework in the previous chapter.

This chapter proceeds in four sections. First, it begins by making the case for measuring performance legitimacy. Second, the discussion turns to an overview of the current legitimacy indicators in both the grey and academic literature and those specifically related to performance legitimacy. The overview includes an assessment of the validity and strength of the current measures of legitimacy. Third, given the identified weaknesses with the current measures of legitimacy, the analysis turns to the measurement of performance legitimacy by first elaborating on the measurement of latent variables and the implications of using the Bollen and Lennox's (1991) approach to measuring latent variables, then by reviewing possible indicators that not only attempt to measure performance legitimacy but also help to identify the object of this legitimacy, and finally by identifying a few challenges that impact the success of the measurement process. The chapter concludes with a discussion on the reasons for the early-stage removal of certain potential performance legitimacy indicators that had originally seemed theoretically appropriate.

\section{The Case for Measuring Performance Legitimacy}

Performance legitimacy is earned by meeting the basic needs of the population. It can be earned by state institutions and/or leaders including those leading state institutions. Capacity to deliver goods and services is a prerequisite for this form of legitimacy. Thus, state-like institutions are necessary. However, building state institutions can increase the performance legitimacy of the state at the expense of the performance legitimacy of the leaders or vice versa. These dynamics are central to the Performance Legitimacy Theory of Transition theoretical framework I developed to capture the complex relationship between these various actors in post-conflict countries.

This new framework identifies a continuum with two extreme paths that can be taken following the building of state institutions. The first is a virtuous path where the state owns (or is perceived to own) the delivery of basic goods and services. As such, the state continuously earns performance legitimacy. The second is a vicious path where leaders own (or are perceived to own) the delivery of goods and services, which can work to further de-legitimize the state. Each path leads to a different outcome along the continuum; it is these outcomes that will help determine the prospects of the post-conflict state's long-term development. 
There are also multiple paths that occupy the grey area between the extremes of the vicious and virtuous paths. In some instances, the state will be able to own the delivery of certain goods and services, while it may lose out to leaders on the delivery of other services. In such cases, it is important to assess the resulting level of competition between the leaders and the state. Knowing which of the two paths the country has embarked on and the level of competition between the leaders and the state is important to understanding the outcomes and the options available for the state in its post-conflict development journey.

Furthermore, the Performance Legitimacy Theory of Transition framework allows for the differentiation between the performance legitimacy of the leaders who are found within the state structure and the state itself. This differentiation is important for capturing the true picture of where legitimacy lays and understanding the implications of this on the likelihood of continued or increased abuse of state institutions, the list of available policies, and thus the overall stability of the state.

This discussion and the outcomes rest on comparisons between the various levels of performance legitimacy and the impact of policies on these levels. These in turn rest on the identification of the level of performance legitimacy imparted or owned by the various objects (state and leaders). As such, the measurement of performance legitimacy is a core characteristic of this framework and future state-building interventions. Overall, the framework takes the normative position that development interventions ought to lead states towards the virtuous path and away from the vicious one.

\section{Current Legitimacy Indicators}

Three characteristics are common to existing work on legitimacy. Legitimacy is narrowly defined to centre on the adoption of democratic norms and procedures. Indicators for legitimacy are often effect indicators. Finally, many of these indicators or measurements are based on subjective analyses, a process that usually leads to significant error factors that "account for a non-negligible portion of the variance in most measures" (Bollen and Paxton 2000, 78).

In what follows, I review the indicators used in existing work to establish a foundation for the alternative approach that I detail later in the chapter.

\section{A. Grey Literature}

As noted earlier, most grey literature links legitimacy to the political, economic, security, and social conditions in a country. Most practitioners and donors like the World Bank, the United Nations Development Programme (UNDP), the Organization of Economic Cooperation and Development (OECD), and the United States Agency for International Assistance (USAID) measure legitimacy through indicators related to electoral democracy, security, the economy, human rights and freedom. 
Table 3.1: A Sample of Popular Legitimacy Indicators

\begin{tabular}{|c|c|}
\hline Indicator & $\begin{array}{l}\text { Organization } \\
\text { Responsible }^{38}\end{array}$ \\
\hline $\begin{array}{l}\text { Worldwide Governance Indicators } \\
\text { - Voice and Accountability: perception of the extent to which a country's citizens are able to } \\
\text { participate in selecting their government, as well as freedom of expression, freedom of } \\
\text { association, and a free media. } \\
\text { - Political Stability and Absence of Violence: perceptions of the likelihood that the government will } \\
\text { be destabilized or overthrown by unconstitutional or violent means, including politically- } \\
\text { motivated violence and terrorism. } \\
\text { - Government Effectiveness: perceptions of the quality of public services, the quality of the civil } \\
\text { service and the degree of its independence from political pressures, the quality of policy } \\
\text { formulation and implementation, and the credibility of the government's commitment to such } \\
\text { policies. } \\
\text { Regulatory Quality: perceptions of the ability of the government to formulate and implement } \\
\text { sound policies and regulations that permit and promote private sector development. } \\
\text { Rule of Law: the extent to which agents have confidence in and abide by the rules of society, and } \\
\text { in particular the quality of contract enforcement, property rights, the police, and the courts, as well } \\
\text { as the likelihood of crime and violence. } \\
\text { Control of Corruption. }\end{array}$ & $\begin{array}{l}\text { World Bank } \\
\text { Group }\end{array}$ \\
\hline $\begin{array}{l}\text { Bureaucratic Quality Index: strength and expertise to govern without drastic changes in policy or } \\
\text { interruptions in government services, autonomy from political pressure, and established mechanism for } \\
\text { recruitment and training. }\end{array}$ & $\begin{array}{l}\text { Political Risk } \\
\text { Services } \\
\text { Group }\end{array}$ \\
\hline $\begin{array}{l}\text { Executive Recruitment: Openness and competitiveness of the process related to the recruitment of political } \\
\text { executives. }\end{array}$ & Polity IV \\
\hline $\begin{array}{l}\text { Political Rights Indicator: citizens' freedom to participate in the political process, compete for public } \\
\text { office, join political parties, and elect representatives. }\end{array}$ & $\begin{array}{l}\text { Freedom } \\
\text { House }\end{array}$ \\
\hline Corruption Measure & $\begin{array}{l}\text { Transparency } \\
\text { International }\end{array}$ \\
\hline $\begin{array}{l}\text { Civil Liberties: freedoms of expression and belief, associational and organizational rights, rule of law, and } \\
\text { personal autonomy }\end{array}$ & $\begin{array}{l}\text { Freedom } \\
\text { House }\end{array}$ \\
\hline $\begin{array}{l}\text { Index of Economic Freedom: rule of law (property rights, freedom from corruption), limited } \\
\text { government (fiscal freedom, government spending), regulatory efficiency (business freedom, labor } \\
\text { freedom, monetary freedom), and open markets (trade freedom, investment freedom, financial freedom). }\end{array}$ & $\begin{array}{l}\text { Heritage } \\
\text { Foundation }\end{array}$ \\
\hline Political Party Finance, Regulation and Enforcement & $\begin{array}{l}\text { Institute for } \\
\text { Democracy } \\
\text { and Electoral } \\
\text { Assistance }\end{array}$ \\
\hline Human Rights Index & $\begin{array}{l}\text { Cingranelli- } \\
\text { Richards } \\
\text { (CIRI) } \\
\text { Human } \\
\text { Rights Data } \\
\text { Project }\end{array}$ \\
\hline
\end{tabular}

\footnotetext{
${ }^{38}$ Each definition of an indicator is based on information available from the respective institution's website.
} 
These indicators often use data related to accountability, transparency, political stability, good governance, regulatory quality related to the economy (e.g. Ease of Starting a Business), rule of law, economic performance, and control for corruption. ${ }^{39}$ The measurements are based on information gathered through formal surveys administered by governmental and nongovernmental organizations, evaluation of formal rules, and the subjective assessment of think tanks and advocacy groups. All in all, such indicators reflect the state's monopoly of power, the obligation or willingness of citizens to exercise their electoral rights, the independence of the market, rights and freedoms of all actors, and the experience of citizens when they initiate an interaction with the state and the government. The performance of the state is evaluated vis-à-vis its internal dealings, its support for a strong economy, the manner in which it uses the resources available to it from an economic perspective, and its ability to provide services in a nondiscriminatory manner. Thus, the majority of these indicators are an assessment of the manner in which the state handles its internal affairs and the role that the citizens play in expressing and actively working on reflecting their desires in the decision-making process of the state and the government. Interestingly, there is a perfect alignment between these indicators and the definition of process legitimacy, one which, as highlighted in Chapter 2, is linked to elections, accountability and transparency, good governance, rule of law, human rights, political freedoms and civil liberties, and a multi-party system.

Naturally, one would assume that an assessment of the state's ability to provide services is potentially a good measure of performance legitimacy. An initial assessment might highlight the World Bank's Governance Effectiveness indicator as an exception. According to the World Bank, this composite indicator includes several representative and non-representative indicators. The World Bank (Kaufmann, Kraay, and Mastruzzi 2010, 24) defines representative indicators as "indicators that cover a set of countries in which the distribution of governance is likely to be similar to that in the world as a whole." Non-representative indicators are defined as indicators that "cover either specific regions ... or particular income levels" (Kaufmann, Kraay, and Mastruzzi 2010, 24). The sub-indicators cover a range of topics, including the quality of the bureaucracy and public administration, the perception of businesses related to the businessenabling environment, and the satisfaction of the general public with public services. A closer assessment of the methodology used to evaluate these indicators suggests that these indicators, with the exception of the satisfaction of the general public, are better suited for analysis of democracies and are evaluated based on democratic criteria, norms and standards.

It is important to note though that the indicators related to the citizens' perception of the effectiveness of certain government services are of specific interest to the analysis herein. On first glance, they seem to provide promising information related to the performance legitimacy of the state. Unfortunately, a deeper look reveals two major issues that make these indicators inappropriate for the purpose of this research.

The first problem is that the indicators are based on survey questions that do not distinguish between the state and the leaders. The second issue is the general wording of the survey questions. Consider an example: "In city or area where you live, are you satisfied or dissatisfied

${ }^{39}$ The World Bank's Worldwide Governance Indicators is a prime example (see Table 1). 
with the educational system or the schools?"40 This question presumes a link between the state and the experience of the people with the educational system or the schools. In doing so, it conflates the state with the other actors (aid agencies, United Nations organizations, international non-governmental organizations, religious organizations, etc.) that provide such services, thus leading to measurement error. As such, these general questions make drawing clear conclusions about the perceived performance legitimacy of the state challenging.

\section{B. Academic Literature}

The academic research that is focused on measuring legitimacy parallels the shortcomings of the grey literature. Studies frequently use indicators that are either developed or championed by the World Bank, the International Monetary Fund, and various think tanks (e.g. Freedom House, Fraser Institute, Transparency International, Political Risk Services Group).

The following is a list of concepts of legitimacy and associated indicators common to academic work. ${ }^{41}$ The list provides a picture of the existing measures that are mostly used to assess the legitimacy of states, including post-conflict states.

The types of legitimacy indicators cover ${ }^{42}$ :

1. The Political System:

a. Freeness and Fairness of Elections: At all levels including at the national as well as the sub-national levels (e.g., Index of Political Freedom).

b. Electoral Rules: Level of separation of elections for executive and representative offices, level of plurality rules, size of districts, concurrence between national and sub-national elections, quality and structure of ballots, and access to independent judicial mechanisms to resolve election-related disputes.

c. Political Parties: Level of control of one party over the others (nationally or subnationally), number of legal political parties, level of system fractionalization, and level of system polarization.

d. Government Stability: Level of duration of the party in power.

2. The Fiscal System:

a. Public Financial Management: Level of contractual obligations (e.g. Bureaucracy Quality Index) and level of budgetary deficit.

b. Capacity to Raise Funds: Rate of payment of semi-voluntary taxes.

3. The Administrative System:

a. Accountability: Level of accountability to the public.

\footnotetext{
${ }^{40}$ Gallup - http://www.gallup.com/strategicconsulting/156926/indexes-questions.aspx.

${ }^{41}$ Examples include (Brinkerhoff 2007; Dahl 1971; Eaton and Schroeder 2010; Englebert 2000; Ghani and Lockhart 2008; Gilley 2006b; Goldsmith 2007; Lipset 1983; Sisk 2013; Weil 1989). Not all of the authors have highlighted all of the indicators presented in the list. It suffices to note that all have developed, referenced, and/or conceptualized some of the indicators in the list.

42 It is important to note that the definitions or sub-measures are meant as examples to illustrate the concept of the indicator. They are not meant to be exhaustive.
} 
b. Corruption: Corruption Perception Index or Transparency International's Corruption Index.

c. Checks and Balances: Level of politicization, competence and professionalism of the public service (e.g. Bureaucratic Quality Index) and number and effectiveness of rules limiting abuse.

d. Citizens' Trust in Institutional Functions: Contract Intensive Money (CIM) indicator.

4. The Economy:

a. Capitalism: Level of capitalism (e.g. Fraser Institute's Index of Economic Freedom).

b. Market Economy: Level of reliance on the market (e.g. Fraser Institute's Index of Economic Freedom).

c. Discriminatory Taxes: Level of discriminatory taxes in the economy (e.g. Fraser Institute's Index of Economic Freedom).

d. Business Enabling Regulations: Number of business-friendly regulations, institutional arrangements and policies (e.g. Fraser Institute's Index of Economic Freedom).

e. International Exchange: Level of freedom to exchange internationally (e.g. Fraser Institute's Index of Economic Freedom).

f. Economic Performance: Level of Gross Domestic Product, rate of growth, and the level of satisfaction of the citizens with the performance of the economy.

5. Rule of Law:

a. Constitution: Level of freedoms and level of control of government power.

b. Equitability of the System: Level of access to and non-discrimination in the legal system (e.g. Index of Political Freedoms).

c. Socio-economic Rights: Level and equality of access to economic opportunities (e.g. Index of Political Freedoms) and level of legal obstacles to holding private property (e.g. Index of Political Freedoms).

d. Civil Liberties: Level of civil liberties (e.g. Gastil Index of Civil Liberties from Freedom House).

6. Security:

a. Security: Perception of security amongst the population and level of effectiveness and fairness of the police.

b. Civil Disorder: Rates of demonstrations, rates of riots, rates of political deaths, and rates of governmental sanctions.

7. Socio-Economic Situation:

a. Income Inequality

b. Misery Index: Average annual rate of employment plus the annual rate of inflation.

8. Civil Society: 
a. Conditions Allowing for Congregation

b. Freedom of Expression: Level of freedom of expression (e.g. Index of Political Freedoms).

c. Freedom of Assembly and Association: Level of freedom to assemble and associate (e.g. Index of Political Freedoms)

d. Impact on Policy-Making: Level of access to decision-makers.

9. Media:

a. Impact of the Media: Control over media, number of media outlets, and level of access of the media to information.

Similar to the grey literature, some of the listed indicators may appear useful to measuring performance legitimacy of the state. The citizens' satisfaction with the performance of the economy, for instance, could reflect performance legitimacy. However, as with the grey literature, these indicators are unable to differentiate between performance legitimacy garnered by the state versus leaders. Moreover, a citizen's satisfaction with the overall economic conditions is not likely to reflect a satisfaction with the performance of a post-conflict state. The association between the performance of the economy and that of the state requires the citizenry to view the state as the leading economic player or source of control over the economy. The question then is whether weak or post-conflict states, states that have not demonstrated their role or importance from an economic standpoint, will be able to capitalize on improved economic conditions. With the lack of state presence in many citizens' lives and the economic and social strategies undertaken by citizens and their leaders in the absence of the state, the link made by the citizens regarding the state's performance and the performance of the economy is likely to be tenuous. Thus, there is no clear indication that for weak states that lack a clear track record as a decision-maker in the economic realm, such an association or link will be expected from the citizenry of post-conflict countries.

The Bureaucracy Quality Index might also be considered as another contender. The organization responsible for this index, the Political Risk Services Group, notes that the index measures the strength of the bureaucracy by looking at the autonomy of the bureaucracy from political pressure and the presence of mechanisms for recruitment and training. These are compared to democratic bureaucratic mechanisms and the new public management standards based on Western democratic bureaucratic models. These measures are again inspired by democratic norms and practices, ones which are neither necessarily present in post-conflict countries nor needed for the delivery of basic services and thus pose some applicability concerns when used for measuring performance legitimacy.

Finally, the Contract Intensive Money (CIM) indicator (measuring the citizens' trust in institutional functions) also seems to measure citizens' perceptions of a state's performance. The indicator is based on contractual laws and law enforcement as a means to protect private property. The idea is that if people trust the judicial institutions, they are likely to use contracts instead of cash. As more and more contracts are used, the index value (the ratio of non-currency money to the total money supply) rises. Thus, a high index implies increased trust. As is the case with the other indicators, the CIM is based on a free-market principle of individual property 
rights and market interactions. It also risks ignoring the views of many citizens who are not in a financial position to take advantage of non-currency contracts. As well, it does not measure the performance of the state in providing basic goods and services, especially as it relates to all citizens regardless of their financial capacity and power. With a slow post-conflict economy and low levels of trust, this indicator is, at least in the early stages of post-conflict, an inadequate measure of performance legitimacy.

A special note should be made regarding the Capacity to Raise Funds indicator. This indicator measures the willingness of the citizens to pay taxes and the capacity of the state to implement a system that allows for this exchange to occur. While, the willingness of citizens to pay taxes is considered to be a direct effect of performance legitimacy, the collection of taxes is also dependent on the capacity of the state to implement a functioning collection system and the financial ability of the citizens. Given that both of these conditions are questionable or lacking in many post-conflict countries, there is a good possibility that this indicator might reflect nonperformance legitimacy factors and thus cause inaccuracies with the resulting findings.

Other authors have stepped back from this overall narrow system-oriented perception and suggested measurements that consider the perspective of the people. One example is Gilley's (2006b) work on legitimacy where he attempts to measure legitimacy by defining it through three concepts: views of legality, views of justification and acts of consent. At the heart of Gilley's concepts is a belief in common interest orientations like equity, fairness and justice. According to Gilley (2006b, 502), "[v]iews of legality refers to the idea that the state has acquired and exercises political power in a way that accords with citizen views about laws, rules and customs." Because the legality does not encompass the evaluation of the state from a moral perspective, Gilley (2006b, 502-3) refers to views of justification as representing the conformity to shared principles, beliefs and values and "the citizen responses to the moral reasons given by the state for the way it holds and exercises its power." By acts of consent, Gilley (2006b, 503) implies the "positive actions that express a citizen's recognition of the state's right to hold political authority and an acceptance, at least in general, to be bound to obey the decisions that result."

For Gilley (2006b), the measurement of the views of legality requires a measurement of citizens' satisfaction with the state's respect for human rights, confidence in the police, and confidence in the civil service. Gilley (2006b) would have also examined the judiciary had data existed across the 72 countries he assessed. The measurement of views of justification is accomplished through the use of (a) surveys that test the citizens' attitudes towards the political system, such as satisfaction with democratic development, evaluation of the current political system, satisfaction with the operation of democracy, and the violence in civil protests, and (b) an indicator that measures the incidence of violence in political protests (Gilley 2006b). As for acts of consent, Gilley's measurements include voter turnout and the level of quasi-voluntary tax payment. Gilley (2006b) had not ventured to rank the importance of these three concepts until 2012 where he placed issues related to morality at the highest point of the hierarchy by claiming the following: "justification is roughly twice as important as legality and consent" (Gilley 2012, 694 emphasis in the original text). 
In stepping back from the issue of morality and in evaluating the current legitimacy measures as they relate to Africa, Hutchison and Johnson (2011) argue for a different measure of legitimacy. They demonstrate that political trust is very relevant to the level of legitimacy earned by African states. According to their research, while the level of tax revenue that a state earns is a close indicator of political trust, it tends to describe the "level of development and structural characteristics of a given economy more than institutional efficiency" (Hutchison and Johnson 2011, 740). This weakness has led them to use the concept of Relative Political Capacity (RPC), or the capacity of the governments to extract resources from society given the available economic resources. This indicator allows them to isolate the measure of the government's efficiency and its ability to implement policies, thus affecting trust.

Their measure is based on individual-level as well as state-level variables. The individual-level variables include attitudinal indicators, political engagement, economic hardship, media exposure, and socio-economic indicators. Their attitudinal indicators are related to the citizens' assessment of the government's performance, their disposition towards government responsibility for individual well-being, as well as their satisfaction with democracy, the economy, and the government. Political engagement indicators comprise political engagement (attendance at a public meetings and demonstrations, raising a public issue, and contacting a member of government) and level of political trust (interest in politics and how they discuss politics). The state-level variables include RPC (tax revenue divided by the predicted tax revenue base), internal violence and prior conflict, democracy/autocracy, prior transition as it relates to democracy/autocracy, economic development (GDP per capita), and politically relevant ethnic diversity (politically relevant ethnic group index). It is important to note that all of these indicators assess the legitimacy of the state and are silent on the legitimacy of leaders.

As can be seen, with the exception of Hutchison and Johnson (2011) and some of Gilley's indicators (2006b), there is a very heavy emphasis on indicators that measure the legitimacy of the state from the perspective of the system and the subsequent behaviour of the citizens following a citizen-led involvement in the system (e.g., elections, administrative efficiency and corruption). I have found limited measures that seek to assess the legitimacy of the state in the eyes of citizens, particularly citizens that do not interact with the state for political or nonpolitical (e.g. interacting with the state in order to acquire an official document or a service) reasons. These indicators often neglect the views of these 'inactive' citizens. Also, as noted earlier, measures of democracy and legitimacy are often conflated. This is especially problematic in post-conflict countries where the level of democracy is often very low and alternative forms of legitimacy are nevertheless present. Finally, existing indicators do not capture different objects of legitimacy especially when leaders are present within, and often lead, state institutions.

This combination of low levels of democracy and the almost exclusive focus on the measurement of legitimacy through democracy-related indicators raises additional concerns. Since democracy measures are particularly error prone where democracy is very limited or extensive (Treier and Jackman 2008), this error will colour measures of legitimacy that rest on the level of democratic indicators in a given state. As Treier and Jackman $(2008,214)$ note, "[f]ailing to properly acknowledge the measurement uncertainty in latent constructs risks inferential errors; scholars 
finding significant impacts of democracy on various dependent variables may well be wrong or (at least) guilty of overstating matters, pretending that they know more about a country's level of democracy than they really do." These inconsistencies, generalizations and inaccuracies represent a severe challenge to understanding the on-the-ground conditions in post-conflict countries, with equally important consequences for choosing the kind of development interventions that are most appropriate.

\section{Performance Legitimacy Indicators}

Performance legitimacy gained particular attention as a result of the European Union's (EU) ongoing legitimacy crisis (Kanol 2011). Without a citizen-centered procedural legitimacy (for example, direct elections by the citizens) and given the lack of shared beliefs across disparate European societies, the EU has turned to other tools to garner legitimacy (Eriksen and Fossum 2004). This has spurred a renewed interest among practitioners and academics in performance legitimacy and its impact on EU policymaking. An emerging finding from this work is how poorly suited indicators of democratic practice are for assessing the EU's legitimacy (Kanol 2011).

Beyond this emerging recognition of the importance of alternative indicators for legitimacy, the practicalities of this measurement agenda remain troubling. For EU scholars, difficulties remain in developing measurement indicators due to issues related to ensuring a common valuation basis and the impact of cooperation over time between the various states (Eriksen and Fossum 2004), the relationship between the various countries and their impact on the performance of the EU (Kanol 2011), and the ability to discern the needs of a varied population with multiple cultures and tastes.

Moreover, even with this renewed attempt, there is very limited academic and grey literature related to the measurement of performance legitimacy, particularly outside the EU. According to the comprehensive research completed for this dissertation, there also seems to be no literature related to the differentiation between the performance legitimacy of the state and that of the individual leaders. This distinction is well recognized by organizational sociologists, like Suchman (1995). When assessing the sources of legitimacy of organizations, Suchman (1995) refers to personal legitimacy as a type of legitimacy that allows an organization to gain overall legitimacy, maintain it, and repair it. Crucially, he defines personal legitimacy as transitory, idiosyncratic, and low in institutionalization. He also points to the importance of looking at the distinction between the varying sources or holders of legitimacy and their impact on an organization's perceived legitimacy and the manner in which it functions.

For scholars assessing the legitimacy of the state, the hesitation to measure performance legitimacy and identify the actual object receiving this legitimacy is partly a result of the need to ensure validity and reliability of indicators, the ability to compare across countries, and the difficulty of carrying out manageable and statistically sound empirical studies that measure other types of mass expression of state legitimacy (Gilley 2006b; Mcloughlin 2014; Sedgwick 2010).

On a conceptual level, this hesitation to establish measurements of performance legitimacy stems from the belief that any measurement would be conflated with the measurement of political 
support. As Gilley (2006b, 502) summarizes, "[a] citizen who supports the regime 'because it is doing well in creating jobs' is expressing views of legitimacy. A citizen who supports the regime 'because I have a job' is not." Key to this statement is the differentiation between personal support and public support. Personal support is often linked to political support to one party or the other, whereas public support implies the satisfaction with the current system. Moreover, implicit in this statement is the separation between political support and the legitimacy of the system. This 'clear' separation between the views of the state and that of politicians, parties, and government is often associated with democratic countries (Muller, Jukam, and Seligson 1982) or more mature political systems. This is not the case in many developing countries where the state has been captured by leaders or where the differentiation between the leaders, parties and governments is non-existent or very limited (Gilley 2006b). Moreover, the new public management reforms have led to a certain level of confusion as to the originator of the service, a personalization of the delivery of the service, and thus the simultaneous minimization of the role of the state in people's lives and the increase in the role of leaders or other organizations.

This emphasis on process legitimacy also reflects the problematic practice of first identifying statistically valid data and then choosing a theory that supports the data (Shapiro 2001). Unfortunately, allowing the availability of data to dictate theoretical frameworks and the mistaken belief in the inherent conflation between performance legitimacy and political support are not the only weaknesses related to the current approach and the existing critique of performance legitimacy. Four others require mention.

First, most existing cross-national data, with their emphasis on Western democratic values and systems, are incompatible with the reality that the majority of the world's population faces (Gilley 2006b), are unreliable in places with weak or non-existent data, and are often misleading in cases where experts are asked to fill in the gaps (von der Mehden and Hill 1980). Second, the value systems underlying these critiques are biased (e.g. the issue of morality) and at times inappropriate to the cases of post-conflict countries. Third, 'conventional' indicators minimize or overlook significant error margins by confounding the variable to be measured with other related concepts (Bollen 1980, 1986, 1990; Bollen and Paxton 2000), including indicators that do not measure the variable intended to be measured (e.g. voter turnout rates, political stability), and minimizing the error factor attributable to the information filtering process and personal bias. Finally, the desire for statistical validity and relevance tends to lead to a neglect of more appropriate statistical models that lead to more appropriate and relevant indicators and misleading conclusions (Bollen and Lennox 1991).

On the issue of margin errors associated with existing 'conventional' indicators, questions have been raised regarding the validity of both non-subjective and subjective indicators. For example, related to the use of voter turnout as a measure of levels of democracy in industrial democracies (and, by extension legitimacy, given the earlier discussion of the confusion between legitimacy and democracy), Jackman (1987) demonstrates that voter turnout rates actually depend on existing institutional arrangements rather than the level of democracy present in the country. This finding means using voter turn out to measure the level of democracy in a country, and in turn legitimacy, is problematic. More specifically, he notes: "the odds that citizens will vote vary with 
the structural incentives that they confront" (Jackman 1987, 419). As such, he concludes that cross-national variations in industrial democracies are greatly impacted by variations in "institutional arrangements" (Jackman 1987, 419) (or procedures) and not democratic levels per se. Bollen $(1986,571)$ also notes that "[a]lthough a low turnout raises doubts as to whether political rights are enjoyed equally, the extent of participation is conceptually distinct from the ability or potential to participate." In an earlier article, Bollen (1980) cautions against the use of voter turnout data since the data reflects an ambiguous meaning - lower rates could be explained by people's satisfaction with government policies, voter apathy, and a pessimism regarding the likely benefits of voting.

Bollen (1986) also cautions against the confounding of democracy with other related concepts, like stability, and the consequent impact on the validity of the indicators. Furthermore, he uses the example of measures of multiparty or competitive political systems to demonstrate the inherent ethnocentric dimension to these measures, one that favours the systems of most Western nations. He also notes the lack of meaningful contribution of these indicators given the many factors that are distinct from the degree of democracy that can impact the stability of the regime and the percentage of votes that each party receives.

Moreover, a central weakness of many indicators of democracy is their reliance on available and accessible information. Borrowing from Bollen (1986), Figure 3.1 helps to demonstrate the increased error margin and bias that is inherent with these types of indicators. No one can dispute the fact that information gathering is hindered by many factors. All information is not recorded and there is much that remains unrecorded, either deliberately or not. Of the recorded information, there is only a subset that is accessible, whether due to censorship or ease of access to the information at hand. Moreover, not all of the accessible information is reported locally. The reporting depends on government censorship, the interests of the reporters, their ability to discover the information, research interests, and publication space to name a few. Only a small subset of this information travels abroad and reaches the Western world or donors. Finally, of this information, scholars and other evaluators choose the information, whether consciously or unconsciously, that mostly aligns with their views or judgments regarding the quality of the information (e.g. reputable sources, selective websites, focus on established indicators, etc.).

\section{Figure 3.1: Information Filtering Process}

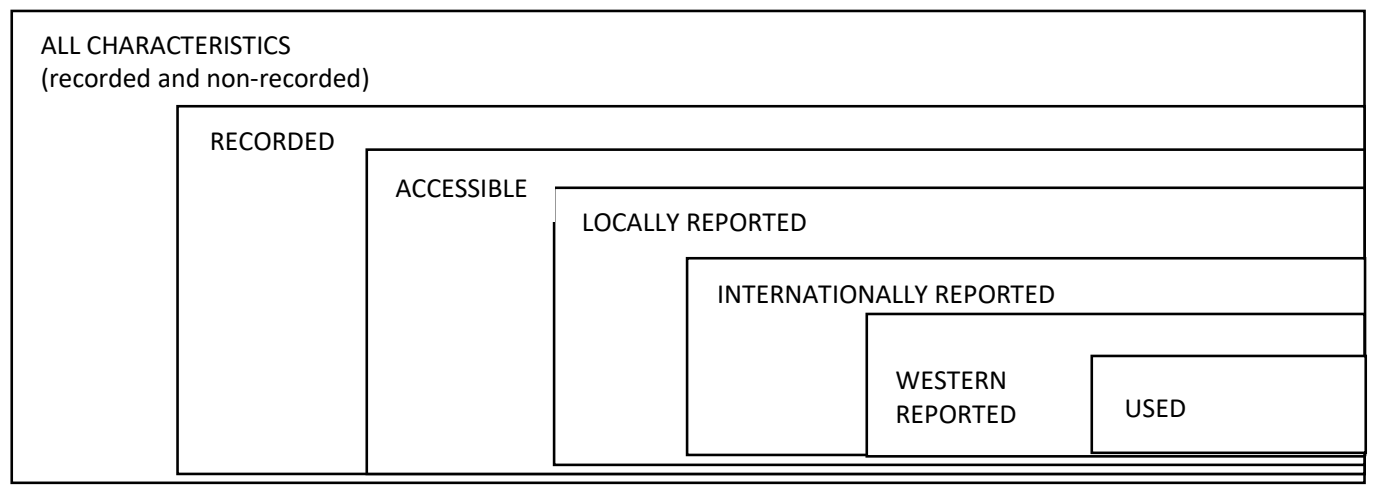


This judgement of data or information is influenced by many factors. Figure 3.2, again borrowing from Bollen (1986), helps to demonstrate this point.

\section{Figure 3.2: Factors Influencing the Judging of Information}

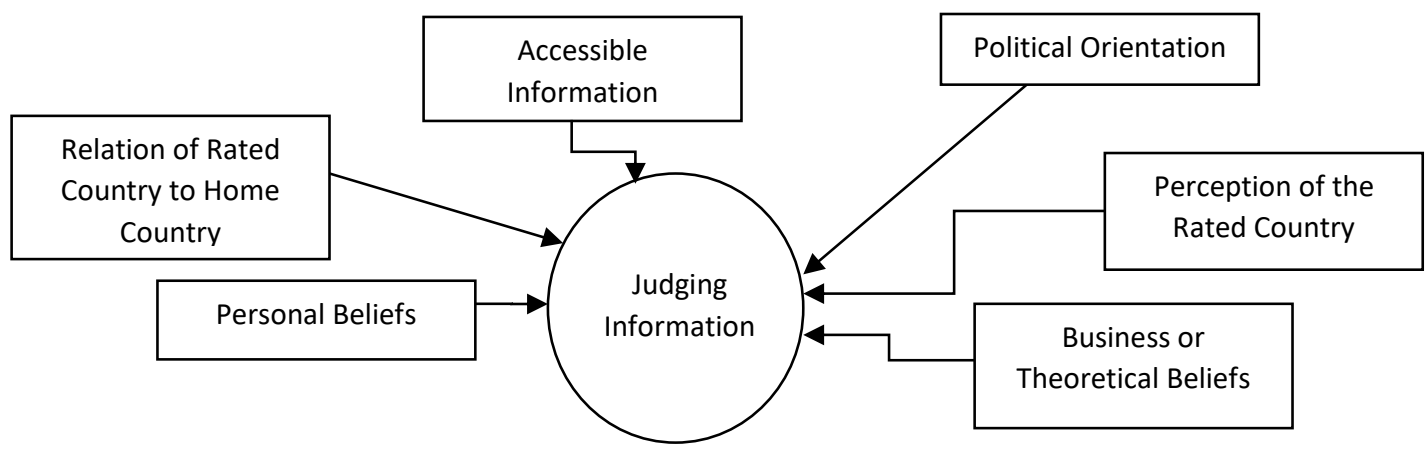

While there has been much work done on enhancing data reporting and measurement, the above two figures still resonate strongly, at least in post-conflict cases. Notwithstanding the lack of capacity on the part of the state and societal groups to accurately and continuously collect data, much of the data that is released is often done so to meet donor requirements. These requirements are often linked to the priorities of the Western donors and as such, provide only a sample of the existing data. Moreover, the dominance of large influential development actors (e.g. World Bank) often leads to a de facto emphasis on the data provided by them without enough scrutiny regarding the quality and rigour of the data. As Bollen $(1990,17)$ has concluded following an analytical and statistical measure of political democracy ${ }^{43}$ indicators, "nonsubjective indicators besides party composition and voter turnout [two of which he refutes the quality of] are rare." As such, these flawed or questionable measures - especially those that confuse two different concepts (confounding democracy with legitimacy) - have potentially serious policy repercussions.

The hypothesis at the centre of this chapter is that the level of differentiation between the leaders and the system is especially weak in many post-conflict situations. In cases where the state has experienced a severe legitimacy crisis and the country has experienced a rise in the number of leaders that have intervened in support of their people, the relationship between the various system players is complicated and thus makes such a separation in the eyes of citizens difficult or unimaginable. Moreover, the inability to draw clear lines between the various players and factors leads to increased difficulty in ensuring statistical rigour. But, this difficulty is not exclusive to measures of performance legitimacy. It is also very much, and perhaps even more so, an issue for 'conventional' measurements that have little applicability in the early stages of post-conflict and that impose an artificial separation based on Western ideologies and experiences.

In addition to the issue of statistical and conceptual rigour, the criticisms regarding the lack of linkages between performance legitimacy and morality need to be addressed. Many writers who

\footnotetext{
${ }^{43}$ Bollen $(1990,9)$ defines "political democracy as the extent to which the political power of the elites is minimized and that of the nonelites is maximized." His measures of political democracy include indictors of political rights and political liberties.
} 
were dissatisfied with what they considered to be Weber's limited definition of legitimacy have linked legitimacy to a moral perspective. This moral perspective is associated with the type of life or ultimate vision for society that guarantees the basic rights or protection of all individuals in society (e.g. Rawls's Veil of Ignorance). This ultimate vision is a long-term goal that a society would have to work at achieving. Thus, for those who look to measure legitimacy from the top down, measuring the legitimacy of the state implies measuring the level that the state systems, structures or processes play in supporting the morals this perspective advances. For those more concerned with a bottom-up approach, or a citizen-centric approach, measuring legitimacy implies measuring the level of satisfaction of the citizens with the state's attempt at meeting the society's moral values. However, there are some authors like Levi et al. (2009) who insist that legitimacy is not necessarily linked to the promotion of the good of society but an implication of the acquiescence of the citizens to governmental power. If one agrees with this argument, then there should not be a severe obstacle to measuring performance legitimacy of either the state or the leaders through the use of indicators related to the acquiescence of citizens.

If the idea of morality is a necessary feature in evaluating legitimacy, then questions should be raised regarding a possible biased and incomplete link between morality and legitimacy. Central to this assessment is the argument that morality changes with time and a level of complexity or hierarchy exists in any definition of morality. The claim that a citizen's gratitude for receiving basic goods and services either from the state or from a leader implies political support ignores the possibility that the citizens have dictated these acts to be a reflection of their basic demands regardless of who is in power or what values the society has chosen. Moreover, it also ignores the fact that any citizen has the right, at least under the United Nation's Universal Declaration of Human Rights, to be guaranteed such goods and services. This guarantee and the identification of such services as basic rights for any citizen imply that their delivery is a moral act. As well, measuring against the longer-term more complex and perhaps comprehensive moral standards ignores the short-term morality of meeting the basic needs of the citizens. The issue of morality versus political support, if warranted, is a valid issue when one attempts to evaluate performance legitimacy based on the delivery of non-basic goods and services, especially in more mature political systems that have identified their ultimate moral goals and are advanced in the process of achieving them.

Finally, certain authors, including McLoughlin (2014), have argued that the 'benefits' of service delivery are very much linked to a state's norms and values and the ideologically-coloured perception of the citizens. Following these claims, McLoughlin (2014) concludes that there cannot be any good measures of a state's performance legitimacy, especially in post-conflict states. McLoughlin (2014) identifies five factors that impact the link between service delivery and performance legitimacy: (a) shifting expectations of what a state should provide, (b) perceptions of impartiality and distributive justice, (c) relational aspects of delivery (the relationship established between the various actors as a result of the delivery of services), (d) attribution, and (e) sector characteristics (essentiality and visibility). As in much of the research related to performance legitimacy (Levi and Sacks 2009; e.g. Levi, Sacks, and Tyler 2009), these identified weaknesses and the resulting conclusions related to the weaknesses of the performance legitimacy argument are based on a narrow understanding of legitimacy. 
These weaknesses and McLoughlin's (2014) last four factors can be explained or accounted for by the non-exclusive nature of performance legitimacy and the likelihood that several statistically-supported conclusions overlook the distinction between the various objects of legitimacy, including those working within or through the state. As it relates to the shifting of expectations and the impact of ideology, it is important to note that there is a desire to have needs met regardless of their level of complexity, needs are not uniform, and they change as one moves from those at the lower end of the spectrum (basic needs - water, health, education, electricity, etc.) to the higher end of the spectrum (more advanced needs - functioning car, advanced high-tech equipment for classrooms, etc.). Thus, while shifting expectations are relevant and introduce another level of complexity, this complexity is likely to occur as one moves along the spectrum with most post-conflict cases being found on the lower end of the spectrum. Still, as needs evolve and expectations shift, the state will need to contend with leaders or non-state objects that are closer to the people, more in tune with people's desires, and capable of meeting people's needs, thus positively impacting their own performance legitimacy.

Moreover, while needs, values and ideology are related, they also do not need to overlap throughout the spectrum. There are cases where entities that have met the basic needs of people have been able to gain performance legitimacy even though their values, ideology and religion are at odds with or not commonly shared by the recipient of these services. ${ }^{44}$ This reconceptualization of these supposed weaknesses provides further evidence of the importance of performance legitimacy and the impact of its non-exclusive nature.

In conclusion, performance legitimacy could be distinguished from political support and passes the test of morality, if warranted. Moreover, as the analysis has demonstrated, removing the statistical bias against non-conventional measures allows for the development of indicators that assess the early-stage legitimacy of the state, especially when democratic norms and practices are not prevalent. By pulling back and understanding that the delivery of basic goods and services is a measure of legitimacy, one can assess performance legitimacy from a top-down (systems) and a bottom-up (citizens) perspective. More importantly, by doing so, it becomes possible to measure the performance legitimacy of leaders, whether within the state or outside, and all of the resulting implications for the stability and success of post-conflict development.

Ultimately, by highlighting the weaknesses of the existing indicators, the analysis has sought to mute the argument that conventional indicators are superior to those that could be designed to capture performance. The analysis also detailed reasons why it is important to choose indicators that do not conflate democracy and democratic practices with legitimacy. Avoiding the focus on normative beliefs, including the assumptions that a specific political system is superior to all others (Hutchison and Johnson 2011) will allow for a more 'realistic' and, thus, a more accurate assessment of the level of legitimacy the state holds. Also, equally important and as argued earlier, it allows for the realization of the non-exclusionary nature of legitimacy.

\footnotetext{
44 The case of Hizballah in the Bekaa Valley and South Lebanon provides a well documented example of this fact (Harik 1996).
} 


\section{Measuring Performance Legitimacy}

\section{A. Basic Theory}

Developing valid indicators involves several key steps. One starts with a theoretical concept. This concept then needs to be defined in terms of how it relates to other variables. Indicators for the concept can then be identified and selected, which are, as a final step, tested to validate whether they match theoretical expectations (Fraser 1974). While simple to state, these steps can be complicated, especially those related to the measurement of concepts. As well, there are situations where a concept, especially a latent one, is considered vital and its use actually mirrors real life, but measuring it is extremely difficult.

As such, any attempt at measuring legitimacy has to overcome a fundamental hurdle: The inherent errors associated with the measurement of a latent concept. Measuring latent concepts involves what Bollen and Lennox (1991) call effect and cause indicators. Effect indicators are those that reflect the latent variable (or what we are aiming to measure) and that shift following a change in the latent variable. Cause indicators are indicators that determine the latent variable. ${ }^{45}$ According to Bollen and Lennox (1991), measurement of the latent variable can be done through a single effect indicator, multiple effect indicators, a single cause indicator, multiple cause indicators, or a combination of cause and effect indicators.

The current tendency is to focus on multiple effect indicators. According to Ozer $(1999,675)$, "[c]lassical test theory regards the items of a measure as effects of a latent, causal variable." As such, "[n]early all treatments of measurement in the social sciences treat observed variables as dependent on the latent variable" (Bollen and Ting 2000, 3). This focus on effect indicators ignores the fact that some variables or indicators should be treated as causes or determinants of the latent variable, rather than an effect of it. The following is an example that will help illustrate this point: Drawing from the field of psychology, academics often use health status, educational attainment level, income, occupational prestige and area of residence as effect indicators of socio-economic status index. In essence, the assumption behind the model is that a person with low socio-economic status is likely to live in poorer neighbourhoods and experience more health problems, lower educational achievements, lower income, and less occupational prestige (see Figure 3.3a). So measuring socio-economic status could be done in a backward fashion by measuring these effect indicators and combining the results to come up with a value for socioeconomic status (the latent variable).

\footnotetext{
${ }^{45}$ It is important to note that, according to Bollen and Lennox (1991), the use of the term 'cause indicators' bears no special significance and is not a judgment as to the real causes of the latent variable. The use of the term is strictly related to the impact that changes within these indicators have on the measurement of the latent variable.
} 
Figure 3.3a: Latent Variable with Effect $\underline{\text { Indicators }}$

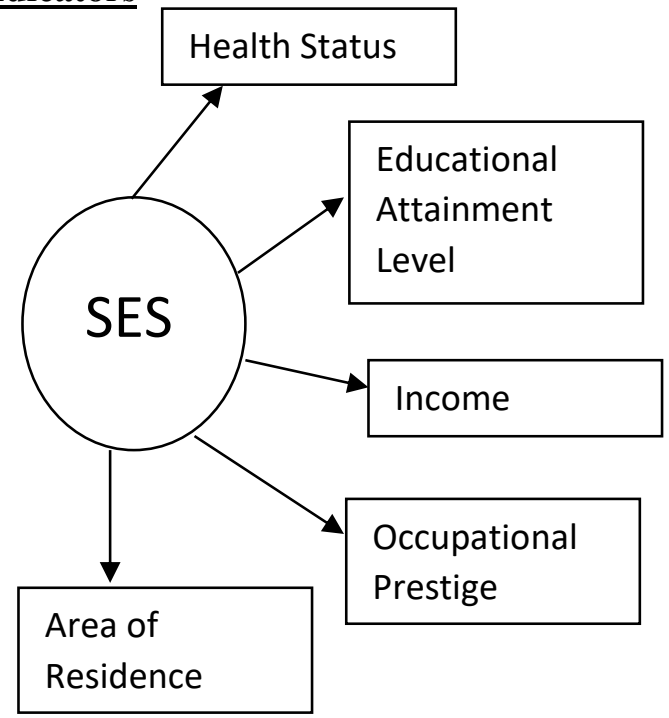

Figure 3.3b: Latent Variable with Causal $\underline{\text { Indicators }}$

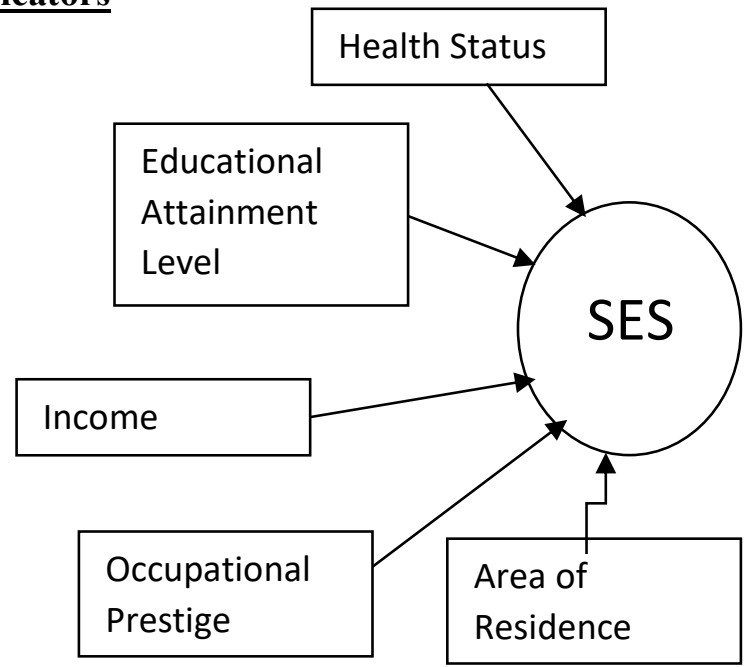

But would it not be true that if one moved up the socio-economic ladder one would probably not experience an improvement in all of these indicators? Moreover, would it also not be true that socio-economic status is more likely impacted by these indicators and not vice versa? In essence, someone receiving higher income and maintaining the same measurement levels on all of the other indicators would probably have a higher socio-economic status than someone experiencing no change in any of the indicators (Netemeyer, Bearden, and Sharma 2003). If one redefines these indicators as causal indicators (see Figure 3.3b) then, conceptually, a shift in one indicator would not necessarily lead to a resulting or comparable shift in another. For example, would a change in income necessarily lead to changes in occupational prestige and educational achievements? One need only think of insurance or used car salesmen who have secured high incomes, perhaps higher than a university professor with a doctorate degree, tend to have lower occupational prestige than people in many other professions and, generally tend to have only attained a minimum school or university-level education (and are not likely to go back to complete a university degree).

What if the relationship extends both ways? As an example, Bollen and Ting (2000) refer to tests related to exposure to stress. They suggest that the loss of a job, a divorce, and birth of a child are indicators of causality rather than effect. However, one can plausibly make the argument that in certain circumstances stress could lead to the loss of job due to increased sick leave and an inability to perform at the expected level. Furthermore, many would suggest that stress in a marriage contributes significantly to whether a couple remains together or not. In essence, while someone might view certain indicators as causal indicators, someone else might view them as effect indicators.

The questions put forth and the examples provided raise important issues related to the construct of one's methodological model. First, the construct should be dictated by the theoretical framework or model that is being tested. It is the framework or model that provides one with the tools to be able to determine whether an indicator is considered an effect or causal indicator. 
Second, the construct of one's methodological model should also be inspired by measurement conventions. Third, the conceptualization and construct of the methodological model is important and allows for a level of transparency and rigour that is required to ensure quality. Fourth, the choice of methodological model will establish the type of requirements that ensure internal consistency. For example, as Bollen and Lennox (1991) clearly demonstrate, the need to maintain internal consistency by arriving at a positive or optimal correlation level between the measurement indicators (or otherwise referred to as an optimal clustering of indicators) applies only to assessments that are based on the conventional effect-variable models. In the effectvariable models, a shift in the latent variable is expected to lead to a simultaneous shift in all of the effect (observed) indicators that have a relevant level of correlation between them (Bollen and Ting 2000). However, going back to the socio-economic status example, when indicators are redefined as causal indicators, such as income, the increase in the value of income implies an increase in the overall value of socio-economic status, but not necessarily an increase in the value of the other indicators. In this case, correlation could not possibly be used as a measure of internal consistency since a change in one indicator (income) is not necessarily matched with a simultaneous change in other indicators (health status, occupational prestige, educational level, and area of residence).

In essence, causal indicators are not and should not be expected to move in similar or correlated (simultaneous) fashion - a change in one causal indicator cannot be expected to occur at the same time as a change in another. Moreover, the value of the latent variable does not have to depend on changes in multiple causal indicators. Thus, this independent behaviour of the various causal indicators makes correlation tests (or the extent to which indicators fluctuate together) "generally irrelevant, if not misleading, for causal indicator measurement models" (Ozer 1999, 676). Correlation in this case may be present, however, its presence is not due to the statistical appropriateness of the indicators (Loehlin 1998). Consequently, according to Bollen and Lennox (1991), any simultaneous fluctuations in causal indicators is explained by factors outside the model and is not linked to the statistical quality or rigour of the outcomes. However, correlation between indicators remains an important measure of internal consistency when dealing with effect indicators.

With the existence of both types of indicators and the resulting implications on both the measurement methodology and the results associated with the latent variable, the proper definition of indicators as cause or effect is vital. Each type of indicator has different measurement properties and the mistaken identification of indicators leads to model specification errors. ${ }^{46}$ It is also important to note that the choice of causal indicators implies a conceptual statement regarding the definition or variables related to the latent concept. This arises from (a) the fact that the use of causal indicators demonstrates a link between the value of the latent

\footnotetext{
${ }^{46}$ As noted earlier, many legitimacy indicators, both academic and in the grey literature, actually use effect-indicator models. However, from a conceptual standpoint, many also seem to misidentify indicators as effect indicators when several are in fact causal indicators. For example, and in putting the subjective bias on hold for now, are free and fair elections a result of a legitimate state or does the act of having free and fair elections lead to a more legitimate state? If the latter is the better answer, then combining this indicator with that of civil disorder (conceivably likely arising from a perception of low or no legitimacy) and treating them both as effect indicators raises some methodological and statistical concerns.
} 
variable and the level of the causal indicator and (b) the lack of measurement of correlation and the level of importance placed on the choice of the most appropriate indicators implies an established hierarchical bias, theoretical framework, or conceptual statements (Gilley 2006b).

Furthermore, given the fact that causal indicators tend to define latent variables, care has to be taken in order to avoid omitting a key causal indicator and thus a misalignment with the intended meaning of the latent variable (Ozer 1999). To that effect, Bollen $(2011,362)$ notes: "Decisions on whether to eliminate [or add] indicators must be made taking account of the theoretical appropriateness of the indicator and its empirical performance in the researcher's and the studies of others." He further notes that the validity or exclusion/inclusion question can be mitigated, at least somewhat, with the use of effect indicators within the same model. The effect indicators provide one with the opportunity to validate the results obtained from the causal indicators.

However, even the use of the objective rightness tests, as a means to provide a holistic measure of a latent variable and to move away from the controversy surrounding conceptual statements, heavily relies on the availability of enough effect indicators that have very low levels of bias ${ }^{47}$ and that reflect the breadth of the latent variable. But as noted earlier, the existence of such indicators in post-conflict countries is very limited. For example, using statistically sound ${ }^{48}$ effect indicators that measure the voting rate or the number of political parties to measure the democratic level (and hence the legitimacy) of a post-conflict state is very likely to lead to inaccurate or biased results given that these indictors (a) measure levels of democracy, (b) are based on the limited availability of good data outside city centres or government stronghold zones, (c) include significant inherent errors due to the fact that they are both affected by a significant number of factors that are not linked to legitimacy, and (d) reflect a significant difference between the value that is allocated to them by the researchers and by people in postconflict states. ${ }^{49}$ Even if the statistical error coefficient turns out to be low following certain statistical calculations, these four errors remain significant and have a significant impact on the true value of democracy and process legitimacy. As such, several scholars (Bollen and Lennox 1991; Gilley 2006a, 2006b; Ozer 1999) have raised concern regarding the dismissal of an important latent concept when there is a tendency to bias the results by choosing effect indicators that suffer from inherent conceptual and empirical limitations.

It is thus clear that the use of either type of indicator provides answers and raises concerns regarding some of the inherent weaknesses associated with their usage. Consequently, it is likely more appropriate to use a multidimensional construct (the combination of effect and causal indicators) rather than a unidimensional construct (the act of addressing either effect or causal indicators in exclusivity of the other) when measuring latent constructs. This combination of effect and causal indicators tends to increase the appropriateness of measuring latent variables

\footnotetext{
47 The inaccuracies or biased conclusions related to the level of appropriateness of indicators arise from lack of adequate data or the choice of inappropriate indicators.

48 This implies that the indicators meet the internal consistency test.

${ }^{49}$ One example is the manner in which Afghan elections were interpreted by the international community as being a sign of increased legitimacy and acceptance of democratic values when, in effect, elections for a significant percentage of Afghans were used as a means to demonstrate allegiance to certain leaders and to get access to state resources (Coburn 2011).
} 
(Bollen and Lennox 1991). Ultimately, increased rigour can be ensured by (a) developing a strong theoretical framework, one which is not hijacked by a specific ideology (e.g. neoliberlaism, liberal democracy), and (b) defining the latent concept, causal indicators, and effect indicators.

\section{B. Proposed Performance Legitimacy Indicators}

The previous section on the theoretical merits and qualities of indicators and the different approaches for measuring latent variables serves as the basis for the following proposed indicators of performance legitimacy. These indicators are an initial attempt and should be validated through an empirical process, a process that makes for interesting future research.

The following is the testable hypothesis: An object's (state/leader) performance legitimacy increases the more it is responsive to the basic needs of the subjects (citizens). Implicitly and as discussed earlier, any measurement of this latent variable (performance legitimacy) is dependent on the actual record of the object (state/leaders) in delivering basic services. Second, the statement places a significant emphasis on the observations of the subjects' (citizens) attitudes and behaviours related to the laws and policies or rules (formal or informal) that are established by the object. Third, this statement clearly identifies two objects - the state and the leader. Hence, the working assumption is that there is a means to differentiate or to assign legitimacy to a specific object. Finally, the statement has clearly identified performance legitimacy as the variable that is dependent on changes in the value of the causal indicators - the accomplishments of the objects and the perceptions of the subjects. Building from the previous section, effect indicators - the subject's behaviour - have also been added to increase rigour.

As such, the chosen indicators are meant to reflect actual performance, attitudes, and the citizen's behaviour. The actual performance indicators are ones that assess the actual performance of the object (state/leader) in meeting the basic needs of the subjects (citizens). Both the attitudinal and behavioural indicators draw on Gilley's (2006) classification of cause variables as views of legality, views of justification, and acts of consent. Herein, the views of legality $^{50}$ variable is meant to assess the level of importance that citizens afford the object (state/leader) and their views on the relevance of this object (state/leader) in their lives. The views of justification variable is meant to represent the reasons why citizens would consent to the laws, rules, and regulations of the object - ones that develop from the perceived benefits received from the object. The acts of consent variable is meant to measure the translation of these attitudes into actions. In that sense, these acts of consent could be considered the effect variables.

In summary, the following indicators assess (a) the actual performance of the object (state/leader) as it/they relate to the delivery of basic social goods and services, (b) the attitudes of citizens regarding the legality and justification of the object, and (c) the citizens' consensual behaviour as it relates to the laws and formal/informal policies or rules. Given the importance associated with identifying the object of legitimacy, additional subcategories have been added as

\footnotetext{
${ }^{50}$ The use of the term legality does not necessarily imply an assessment of the actual laws on the books. It is meant to imply the position of the citizen regarding the need to perceive the object's laws, rules and regulations as the necessary 'law of the land'.
} 
a means to tease out the differences in the performance of the two objects and the subject's attitudes and behaviour towards the two objects.

A. Indicators that assess the Actual Performance of the object may include:

- The number ${ }^{51}$ of basic social goods and services provided by the:
- State
- Leader

- The quality of basic social goods and services provided by the:
- State
- Leader

- Ease of access to basic services delivered by the:

- State

- Leader

B. Attitudinal indicators of the citizens regarding the legality and justification of the object may include:

- Legality:

- Perception of the reach of the law and its applicability to all citizens, including their leader

O Perception of the importance of state institutions

- Confidence in the security provided by the:

- Police/state

- Leaders

- Confidence in the civil service

- Justification:

- Level of satisfaction with the level of basic needs being met by the:

- State

- Leader

- Perception of the willingness of the:

- State to support its citizens

- Leader to support his/her citizens

○ Degree to which citizens turn to the following for help:

- State

- Leader

C. Indicators related to the citizens' Acts of Consent may include:

- Level of compliance with rules and regulations sanctioned by the:

○ State

○ Leader

\footnotetext{
${ }^{51}$ The list of basic goods and services will be determined by field research. A basic list could be developed, but the actual list will depend on local conditions. Generalizations can be made once the field research identifies the commonality between the lists established by the citizens of the cases studied.
} 
- Level of compliance with health state-sanctioned rules and regulations during an epidemic

- Level of compliance with health state-sanctioned rules and regulations during an epidemic that are not supported by leader

- Level of compliance with laws and regulations enforced by the:

○ Police

○ Leader's security or armed team

It is important to note that the measurement of some of these indicators is already occurring through Afrobarometer, Latinobarometro and Asiabarometer questionnaires. These organizations implement surveys in several countries asking citizens for their feedback related to several topics. There are a few questions related to the citizens' perception of or trust in the police, paying or avoiding taxes, obeying the government no matter who one voted for, level of trust, satisfaction with government services, and ease of access to government services. Unfortunately, most of these questionnaires have few questions that categorize answers according to the object of these perceptions (state or leader).

Following the earlier discussion on cause and effect indicators and the need to develop a methodology that combines both, the indicators related to the actual performance of the object (A) and those related to the attitudes of the citizens regarding the legality and justification of the object (B) are defined as causal indicators. The indicators related to the citizens' consensual behaviour $(\mathrm{C})$ have been defined as effect indicators.

Figures 3.4a and 3.4b illustrate this measurement model. Given the presence of two objects of legitimacy, the state or the leader(s), two sub-models are required. The state is represented in figure 3.4a and the leader(s) is represented in figure 3.4b. The separation of the two sets of objects minimizes or avoids decisions related to the weighting of the performance legitimacy of the two objects when using one model and the errors that might subsequently arise. In essence, it avoids the need to attribute positive points to the state and negative points to the leaders.

Separating the two also allows for a clearer and less convoluted model and the measurement of performance legitimacy as a continuous concept, or one that is reflected on a continuum with higher or lower degrees of performance legitimacy, rather than a dichotomous concept (present or non-present).

It is important to note that the relationship between the causal and effect indicators is selfreinforcing. The lack of arrows flowing back to the causal indicators is not meant to reflect a one-way relationship. As was illustrated in Chapter 2, the result of the performance of the object of legitimacy leads to either an increased or decreased level of consent. This is likely to be reciprocated by either object, ${ }^{52}$ which then leads to further variations in the level of consent.

\footnotetext{
${ }^{52}$ If the state is not doing its part, then the leaders will step in and take over. If the state is doing its part, then it is likely to continue as a means to maintain its control or advantage.
} 


\section{Figure 3.4a: Cause and Effect Indicators of the State's Performance Legitimacy (Latent Variable)}

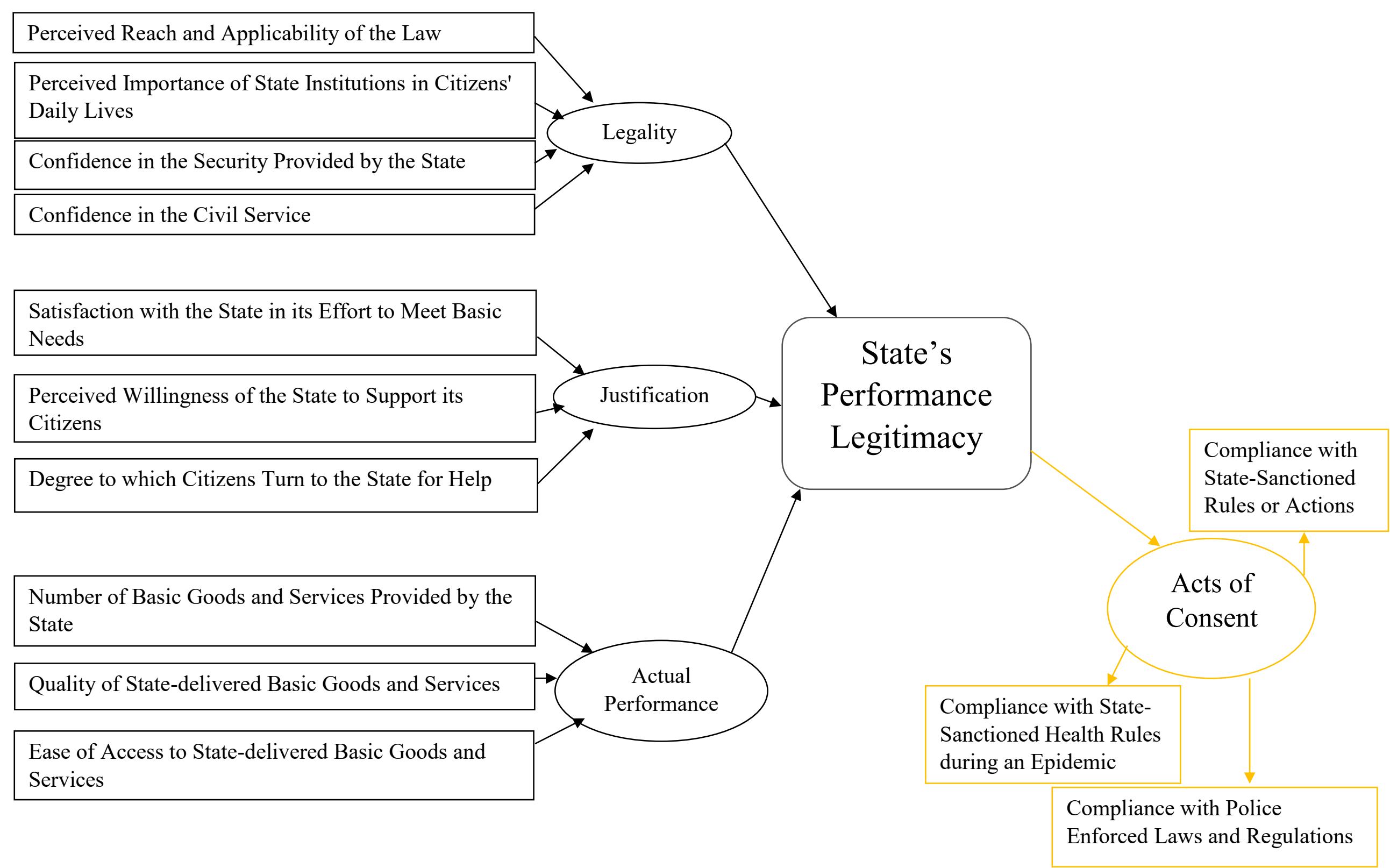




\section{Figure 3.4b: Cause and Effect Indicators of the Leader's Performance Legitimacy (Latent Variable)}

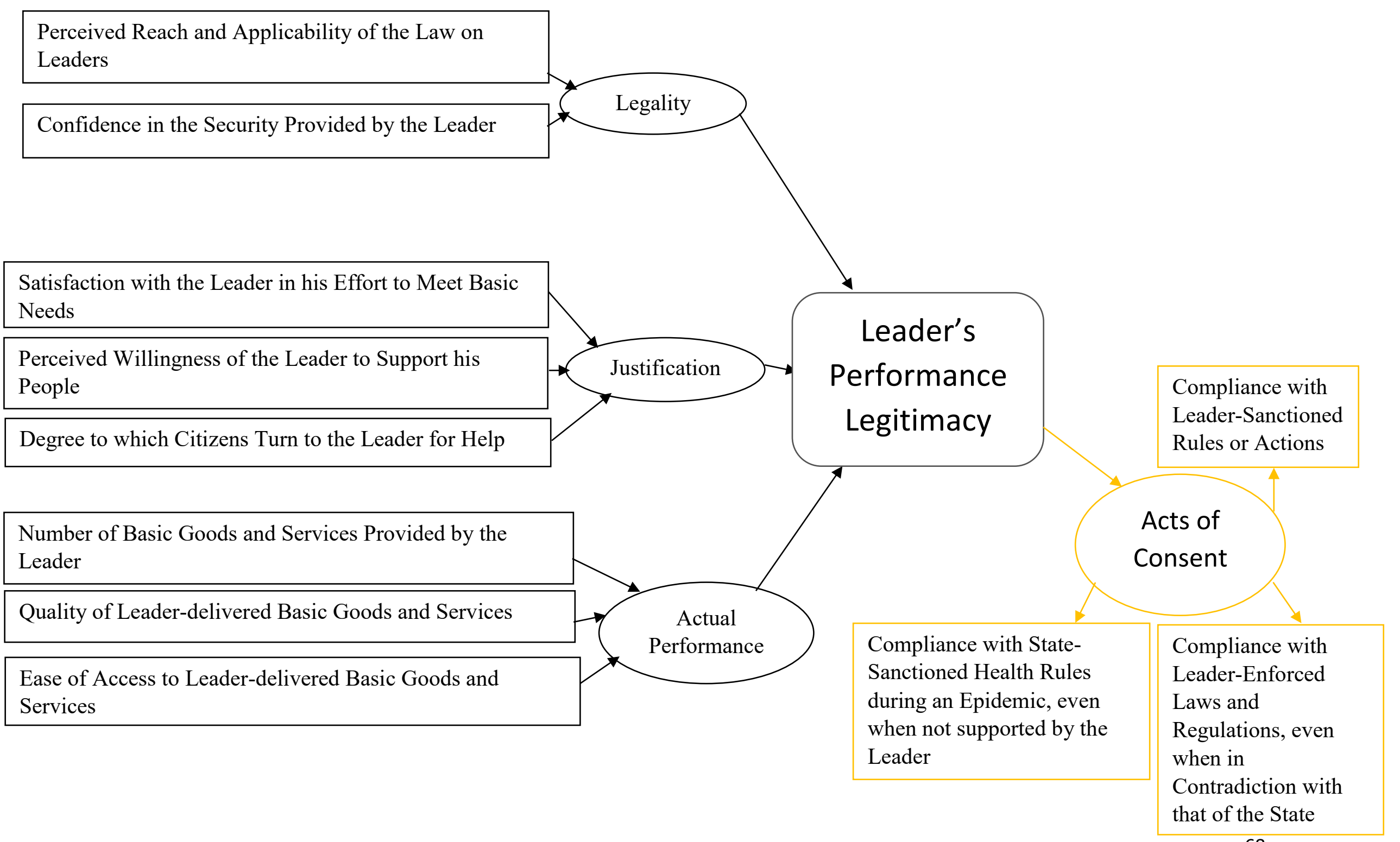


Therefore, the cause and effect indicators form integral parts of the vicious and virtuous cycles that were described in Chapter 2. Ultimately, this multidimensional approach provides a more complete picture of the situation, an assessment from the top-down (object) and bottom-up (subject), and increased accuracy in the measurement of performance legitimacy (Bollen and Lennox 1991).

\section{Challenges Related to the Proposed Indicators}

Measuring the performance legitimacy of the state is a complicated feat that is bound to face a few challenges. First, there is an issue of finances given the lack of readily available data and the subsequent need to test the indicators in a few post-conflict countries. In essence, measuring the perception of people requires significant boots on the ground, time, people willing to voice their concern (because of the lack of fear or retribution), and expertise in putting the data together. Measuring economic, electoral, and, to a certain extent, rule of law indicators is an easier process given that the indicators are usually measured by the state in question and are based on some available raw data that can be compiled by local or international experts. The financial cost could be slightly remedied by the integration of such indicators into the process of improvement or building of state institutions in post-conflict states ${ }^{53}$ and by the use of Afrobarometer, Latinobarometro and Asiabarometer results.

Second, with the various indicators for each one of the three main variables (views of justification, views of legality and views of consent), questions are quickly raised about the weighting of both the indicators and the variables when calculating the values of performance legitimacy. This challenge should be addressed in future research after the indicators are tested in the field and more information is available on the feasibility and applicability of the proposed indicators. Given the importance of local views and perceptions of legitimacy and the reflection of local values, it would be inappropriate to launch into a theoretical process to identify a weighting scheme this early on in the process. Furthermore, the potential error arising from the aggregation of data related to various indicators is not exclusive to the use of performance legitimacy indicators. As Treier and Jackman (2008) demonstrate, the measurement of democracy faces similar increased error margins when the various sub-indicators are combined to form one overall measure of legitimacy. This and other issues related to measurement and interpretive errors allow the authors to conclude that "a country's level of democracy is the product of an imperfect measurement process, and hence uncertain and error-prone. Like so many concepts in social science, a country's level of democracy is a fiction of sorts, a manufactured construct, an abstraction rendered in a form amenable for data analysis" (Treier and Jackman 2008, 214).

Third, by using indicators based on perceptions and on the most micro-level measure of the relationship between the citizen and their state, the level of correlation between the various effect indicators might be higher than the statistically-acceptable value and thus might constitute aspects of the same over-arching construct. Moreover, posing the same qualitative question but with a slight difference in the object of legitimacy (state versus leader) might introduce some confusion in the variables given the inter-linkages that might make the distinction difficult to make. For example, asking about the satisfaction with the services delivered by the state and following that with a

\footnotetext{
53 This would not be revolutionary since the practice of ensuring measurement within state institutions is currently being integrated into most development programming and state-building efforts.
} 
question about the satisfaction with the services delivered by the leader might cause some confusion in countries where the state and the leaders are considered as one entity. In essence, a distinction between the performance legitimacy of the two objects is reliant on the perception of the citizen. This perception might be inaccurate and thus might introduce inaccuracy in the analysis of the effect indicators (did they really follow the rules because the state is perceived as legitimate or because the leader is considered legitimate?). While this might be true, the amplitude of this challenge will only be truly understood once the indicators are tested. As it relates to correlation, having a higher level of correlation between effect indicators is not an indication of weaknesses in the design of the measurements and is not a relevant factor (Bollen and Lennox 1991).

Fourth, acts of consent are behavioural indicators that are seen to reflect the performance legitimacy of the state or the leader. However, there are various causes of certain behaviours and thus these causes might skew the results. While behaviours are complex and tend to be a result of multiple variables, the fact that several indicators are included and that they represent various aspects of citizens' lives while ensuring the distinction between state and leader, the likelihood of misleading results is hopefully minimized to an acceptable level.

\section{Research Eliminating Possible Indicators}

When assessing possible indicators of consent, the research led to the possibility of using an indicator related to the following: adoption and use of state-sanctioned history books in postconflict environments. History books are a contentious issue in many developing countries, especially in post-conflict cases. Objections tend to be related to the reflection of certain versions of history or the use of certain statements that tend to delegitimize one group or draw it in unflattering terms. As such, the idea was based on the perceived notion that if the state is not perceived to be legitimate, then the leaders' or various school systems will refuse to adopt the state-sanctioned history textbook. This can be clearly seen in Lebanon. A version of this can be seen in Bosnia where each canton has its own history book with divergent views and facts related to the history of the area (Cole and Barsalou 2006; Low-beer 2001). Unfortunately, there is a fundamental flaw in this potential indicator. The flaw comes from the work of the international community and its role in enforcing the use of the state-sanctioned or tribunal-sanctioned history textbook. As such, if used, this indicator will measure the success of the international community in enforcing the use of these textbooks and not the performance legitimacy of the state measured through the acceptance of state-sanctioned processes and documents.

As noted earlier, the research has also eliminated the Bureaucratic Quality Index that is put together by the Political Risk Service (PRS) Group. Underlying the Index's methodology is a methodology that awards high points "to countries with strong bureaucracies that have the strength and expertise to govern without drastic changes in policy or interruptions in government services ... [and where] the bureaucracy tends to be somewhat autonomous from political pressure and to have an established mechanism for recruitment and training." (PRS website) The indicators included within this index are measures of the manner in which the state functions (strength and expertise to govern, autonomy from political pressures, established mechanisms for recruitment and training) and are measured using scales reflecting levels of democracy. Given the subjectivity in evaluating the 
bureaucratic quality, one that is based on the definition of democratic norms and principles, this index seems unlikely to help measure performance legitimacy.

Finally, there was a desire to use indicators related to the number of children attending schools or the rate of death from sickness. After further research, it became clear that these figures do not necessarily represent the work or impact of the state and thus its performance legitimacy. More accurately, they tend to represent the impact of all actors working on these two particular areas. These actors include non-governmental organizations, private individual actors, companies, philanthropists, philanthropy foundations, and civil society organizations. Even if one was to look at the number of students enrolled in state-schools or public schools, this would not solve the problem. Questions are raised regarding the perception of the originator of the service and the involvement of the state in running these schools, hospitals or clinics. These questions are being raised more often as a result of the public-private partnerships that are currently becoming the new fad in development.

\section{Conclusion}

The assessment of the existing indicators, whether in the academic or grey literature, has identified a direct casual link between the choice of the indicator and the inherent belief in the superiority of democratic systems. It has also identified an inherent bias related to the maturity of the political system, the values related to morality, and the perceptions related to the independence of the various actors or players within the system. Finally, the research and the analysis identified other significant error factors that are present in the 'conventional' measures - errors related to subjectivity, applicability, validity and access to information. As a result, the case was made for the development of indicators that capture performance legitimacy from a non-democratic perspective and help to identify the objects of this legitimacy.

The proposed indicators deal with the actual performance of the objects, the attitudes of the citizens towards these actors from a 'legal' and justification point of view, and finally, the behaviour of citizens or their acts of consent towards the objects. These indicators were segregated as a means to appropriately identify the objects. However, these indicators are not without their weaknesses. These weaknesses range from the financial costs associated with measuring them to issues related to correlation and the distinction between the objects, the weights associated with the various indicators, and the various reasons or causes of behaviour. Ideas were put forward as a means to deal with these challenges. Finally, the chapter ended with a quick overview of the potential indicators that were rejected and the reasons for their rejection.

The indicators of performance legitimacy that were developed in this chapter informed the process of choosing empirical case studies and the analysis of in-case empirical evidence. While there is no historical precedence for these indicators, I was able to use them as a guide to assess the performance-legitimacy evidence in each country and to thus assess the position of the case studies on the performance legitimacy continuum that is delimited by the vicious and virtuous cycles. The following chapter expands on the methodological approach that was undertaken to choose the empirical case studies and the manner in which the insights that were advanced in this chapter helped inform the selection. 
Section III

The Empirical Research 


\section{Chapter 4: The Empirical Research Methodology}

\section{Introduction}

As noted in previous chapters, development in the post-conflict stage is considered to be a critical juncture that allows a country and its society to turn a violent situation into a process of positive long-term development. There are many factors prior to, during, and after the conflict that can facilitate, limit, or impair successful development in the post-conflict stage.

As I argued in Chapter 2, the path that is most prominently identified in the academic and grey literature is informed by a liberal peace-building and post-conflict development model. Yet, this model leaves a lot of unanswered questions and does not account for the presence and importance of performance legitimacy. The resulting Performance Legitimacy Theory of Transition framework that I presented in Chapter 2 (Figure 2.3) reflects the importance of performance legitimacy and the possible outcomes that it can lead to. However, given that current indicators are silent on the issue of performance legitimacy and tend to present incomplete assessments of legitimacy in post-conflict states, I also presented new indicators as a first step to measuring performance legitimacy and potentially validating my theoretical framework. These two frameworks, the theoretical and conceptual frameworks, allowed me to justify a new approach and guided me in the selection of the empirical case studies.

In this second section (Chapters 4, 5, 6, and 7), I introduce the case studies from which the empirical data was drawn, the justification for a new approach, and the role that performance legitimacy has played in all three case studies.

While Chapters 5, 6, and 7 present the findings of each case study, this chapter sets out the research methodology that I used to arrive at the choice of case studies and the general findings of the empirical part of my research. The chapter begins with a description of the empirical methodological approach. This is followed by a quick description of the possible population of cases from which three cases were chosen. In an attempt to ensure further research rigour, the discussion then sets up the analysis in the three case studies by presenting a very brief discussion of factors that the current theories consider to play an important role in conflict and post-conflict conditions. The chapter closes with a short description of the three cases that were ultimately chosen.

\section{Methodological Approach}

\section{A. The Approach}

Many research studies look for what data is available and easily categorized to build or test theories. However, as discussed in Chapter 3, this approach introduces many biases especially in post-conflict cases where good quality data that reflects reality well is limited, of limited quality, and not easily categorized.

My research focused on selecting cases from a total of 54 conflicts that followed the end of the Second World War. I began with cases that had ended in reconciliatory governments with no clear 
victory for any side. I then focused on cases where the society was polarized or divided and where state structures and institutions were weak or non-existent. ${ }^{54}$ Moreover, access to actual data that was more complete than the simple indicators that are commonly in use was a defining variable for the choice of case studies. Finally, I assessed cases by using the indicators that I had developed in Chapter 3. I needed to find enough information in order to determine the entity (state or leaders) that ranked highest on a sufficient number of the performance legitimacy indicators (Legality, Justification, Actual Performance, and Acts of Consent) that I had developed in Chapter 3. In doing so, I was able to choose cases that allowed me to ensure variation on the performance legitimacy variable. As such, I was able to assess the multitude of cases and come up with nine shortlisted cases. These cases are included in Table 4.1.

Table 4.1: List of Potential Cases and their Applicability to this Research

\begin{tabular}{|c|c|c|c|}
\hline Country & $\begin{array}{c}\text { Holder of Performance } \\
\text { Legitimacy }\end{array}$ & $\begin{array}{c}\text { Issues with Access to } \\
\text { Data }\end{array}$ & $\begin{array}{c}\text { Other Important } \\
\text { Qualifiers }\end{array}$ \\
\hline Afghanistan & $\begin{array}{l}\text { Leaders in most of } \\
\text { Afghanistan } \\
\text { The state in North Eastern } \\
\text { Afghanistan }\end{array}$ & $\begin{array}{l}\text { It is difficult to access } \\
\text { region specific data } \\
\text { given the security } \\
\text { situation. }\end{array}$ & \\
\hline $\begin{array}{l}\text { Democratic } \\
\text { Republic of } \\
\text { Congo } \\
\text { (DRC) }\end{array}$ & Leaders & & $\begin{array}{l}\text { Most of the fighting parties } \\
\text { were non-Congolese. }\end{array}$ \\
\hline Iraq & Leaders & & $\begin{array}{l}\text { There is a de facto breakup } \\
\text { of the country. }\end{array}$ \\
\hline Lebanon & Leaders & & $\begin{array}{l}\text { Lebanon is politically } \\
\text { paralyzed but has not yet } \\
\text { reverted back to conflict. }\end{array}$ \\
\hline Nepal & $\begin{array}{l}\text { Other groups. } \\
\text { Both the leaders and the } \\
\text { government have failed in } \\
\text { this regard. }\end{array}$ & & \\
\hline Senegal & $\begin{array}{l}\text { Leaders (early on) } \\
\text { The government (in the later } \\
\text { stages of the conflict) }\end{array}$ & & \\
\hline $\begin{array}{l}\text { Solomon } \\
\text { Islands }\end{array}$ & Leaders & & \\
\hline Somalia & Leaders & & $\begin{array}{l}\text { There are no serious state } \\
\text { institution-building efforts }\end{array}$ \\
\hline South Sudan & Leaders & & $\begin{array}{l}\text { The country is moving } \\
\text { back into conflict. }\end{array}$ \\
\hline
\end{tabular}

\footnotetext{
54 These characteristics were identified early on in the dissertation.
} 
I subsequently identified two cases - North Eastern Afghanistan and Senegal - where performance legitimacy seemed to be held by the state, seven other cases - the rest of Afghanistan, the DRC, Iraq, Lebanon, Senegal, Solomon Islands, Somalia, and South Sudan - where performance legitimacy was held by the leaders, and one case - Nepal - where performance legitimacy seemed to be held by other groups, mostly non-governmental organizations. As such, I initially chose Lebanon and South Sudan - the two countries that were best suited to the research given that institution-building was being undertaken, the fighting parties were of local origin, and the countries were not being broken apart (with claims of independence) by the actions of a group that spanned multiple countries. I also chose the only two other cases - Senegal and North Eastern Afghanistan - where the state seemed to be able to garner performance legitimacy.

Given the difficulties associated with access to information that is specific to North Eastern Afghanistan, the security situation, and time limitations, I was unable to continue with the research on that region. This left me with three cases - Lebanon (with over 130,000 conflict-related deaths), Senegal (with over 5,000 conflict-related deaths) and South Sudan (with over 2 million conflictrelated deaths). Senegal represented the virtuous end of the performance legitimacy continuum, whereas Lebanon and South Sudan represented the vicious end of the continuum. The choice of these three cases allowed me to ensure variation on the dependent variable - the owner of performance legitimacy - and to examine factors that are identified in the mainstream or current theories. ${ }^{55}$

In all three cases, I assessed performance legitimacy early on through the indicators that I had developed in Chapter 3. This allowed me to assume that performance legitimacy had played an important role in the trajectory that these three countries took. This assumption likely introduced some selection bias. However, this bias was minimized as much as possible by undertaking a 'comparative-historical' method that encompasses both synchronic (various cases) and diachronic (temporal variation within case) approaches (Gerry 2007). In essence, the research approach was based on a small $\mathrm{n}$ sample within a large T sample (Geddes 1990). This allowed the introduction of periods when performance legitimacy might not have been a significant factor in the actions of one or several groups that were active in the conflicts.

To ensure a high level of 'probative value' (Bennett and Elman 2006), the research was guided by a temporal assessment of the three cases, an assessment that covered historical events during the colonial period, period of independence, the period prior to the conflict, the period during the conflict, and the period after the conflict ended. This temporal-based analysis helped identify and control for issues related to a) path dependency, or the impact of history, culture and institutional dynamics on the trajectory of institution building, b) historical junctures or important events that might have shaken the 'normal' path of institution building, and c) the impact of the environment on the actions of the leaders. Finally, in addition to assessing the items identified by the main theories, the case-study analysis also assessed the impact the type of political system had on the

\footnotetext{
${ }^{55}$ While the state in South Sudan is considered to be young and while this might represent difficulties in assessing longterm effects of performance legitimacy, it speaks to the timeframe that this dissertation is concentrated on. Moreover, the process tracing technique that was used to study South Sudan provides a longer-term examination of the outcomes.
} 
opportunities for abuse and on the possible interruption of the two cycles that were identified in Chapter 2.

Hence, instead of assuming indicators that would explain success (Geddes 1990), the research went through the long history of these cases and identified commonalities and differences. This allowed me to discover other variables that could explain the performance legitimacy path taken in each case. Once that was completed, the research then identified the clear distinction between the performance legitimacy outcomes. Assessing the results according to several criteria helped guard as much as possible against confirmation bias, weaknesses from clear alternative explanations, and alternative explanations or factors on the results (Bennett and Elman 2006; Geddes 1990). By assessing the political, economic, security, and social context of the country and the environment within which the leaders operate, the analysis avoided pitfalls associated with leader specific assessments, including the difficulties in assessing, quantifying or comparing charisma traits (Mac Ginty 2010). Finally, due to the lack of existing indicators that measure performance legitimacy, the difficulty in measuring a latent variable (refer to Chapter 3), and the multitude of independent variables with many being hard to quantify, the research was not well suited to a larger $\mathrm{n}$ analysis using statistical methods. This decision was informed by the feasibility and practicality of the research as well as the difficulties associated with accessing the necessary information.

More specific to the case of Senegal, initial concerns regarding selection bias based on questions regarding the type and characteristic of the conflict: (a) the conflict's low level of intensity, (b) the focus of the conflict on one part of the country, the Casamance, and (c) the stability of the political system since independence. However, the country was actually excellent as an illustrative probe for the Performance Legitimacy Theory of Transition framework given the particularities of the case that became apparent during the research.

The Casamancais, the residents of the Casamance region in the extreme southern part of Senegal, began to perceive the Senegalese state as legitimate and as an entity that represents their region even though they had a long history of fighting for independence and of being excluded or ignored by the central state. ${ }^{56}$ During the conflict the Casamancais leaders who were active outside the state won and then lost their performance legitimacy, and the Casamancais leaders who were part of the state system were unable to earn performance legitimacy by abusing state resources. As well, other non-political leaders of the Sunnis who had relocated to the Casamance region throughout the region's modern history did not abuse state resources and earn performance legitimacy. The population in the rest of Senegal, while not feeling the effect of the conflict, bestowed performance legitimacy onto the state and not onto their religious leaders or their politicians, even when these actors facilitated the population's access to basic goods and services. Finally, the factors that are deemed to have caused the conflict in the Casamance were not exclusive to the Casamance and yet such factors did not lead to conflicts in the other parts of the country, thus leading us to further assess the underlying environment. As such, the experience of Senegal as a whole, and not just that of the Casamance region, provides invaluable information that can help provide a more general but

\footnotetext{
${ }^{56}$ This is an important qualifier since people living in Southern Sudan prior to independence were also fighting for independence, were mostly ignored by the central state in Khartoum, and had little affiliation with the central state. However, the outcome was quite different from that of Senegal.
} 
also regionally and culturally appropriate understanding of the underlying dynamics that shaped Senegal's performance legitimacy outcomes.

\section{B. Limitations}

There is an acute recognition that the conditions faced by post-conflict states are tremendously complicated and multifaceted. While many journal articles and significant sections of books have been written on and dedicated to the role of regional spoilers or players and their impact on the success of post-conflict development (Armstrong and Rubin 2005; Haldén 2010), this research neither focused on nor attempted to provide recommendations related to this aspect of development. Furthermore, for the sake of manageability, the research did not tackle issues related to the recognition of the necessity to work with the population itself to help build a culture of nationhood, civic education and national identity in tandem with the work being done inside government institutions and with the various leaders (Allen 2010; Von Einsiedel 2005; Mayall 2005). However, the role of regional players and the culture of the society were both assessed in order to understand the environmental factors that could shape the results.

From a methodological approach, the combination of various methods is a difficult task, especially given that different research traditions have different ways to assess evidence. As such, there are varying ideas of understanding the world. One might question the applicability of using historical analysis to tabulate or give values to recently developed indicators. In recognition of these tensions, I also developed indicators that were based on people's actions resulting from changes in performance legitimacy as a means to minimize judgement-related errors associated with allocating a value or an outcome to perception-based indicators for historical periods. This decreased the error value associated with applying perceptual and situational indicators to historical events and helped me to corral the Performance Legitimacy Theory of Transition framework.

There are also methodological weaknesses related to the use of case studies. These include:

A. The bias related to the choice of cases could be based on backwards inductive reasoning in an attempt to pre-empt the result of the research.

B. The existence of too many variables and sub-variables that impact the achievement of the dependent variable complicate the assessment of causal effects, especially when looking at a small number of cases.

In response, the research triangulated multiple sources of evidence and limited the number of applicable variables to those determined to be important variables in existing theories and studies related to legitimacy, institutional change, and institution building. Finally, given the limitations to claiming causality, I do not try to prove causality. Rather, the research seeks to identify plausible causal variables by focusing on eliminating common variables between differing outcomes and by assessing the remaining variables that varied between the case studies. I also am careful not to generalize the results (Geddes 1990).

On a more personal note, the process of analysis related to the Lebanese case study might have included some personal biases. Even though my Lebanese culture and experience during the civil war helped clarify information, there was also a risk of selection bias when it came to choosing 
data. However, as in the other cases, this risk was minimized by using triangulation techniques and by presenting several angles to the story.

\section{Data Sources}

The research used the following qualitative data:

- Academic and peer-reviewed work

- Academic and non-peer-reviewed work

- Policy papers and reports from think tanks and development organizations

- Civil society reports

- Newspaper articles and sources

Quantitative information that was used was drawn from:

- The official data portal of the Organization for Economic Development and Cooperation

- The World Bank's data portal

- The International Monetary Fund's data portal

- International Monetary Fund Reports

- Civil Society Reports

- National statistics offices of each of the countries

I also drew on the surveys performed by Afrobarometer and Arabbarometer in Senegal and Lebanon respectively. Survey data that was used for South Sudan was taken from the South Sudan National Bureau of Statistics.

These secondary sources were complemented by several interviews. Interviewed individuals had experiences in the state administration, with the war, with political parties, or with life as it transpired in the country during or after the war. For the case of Lebanon, I interviewed an academic who is an expert on the conflict in Lebanon and the manner in which leaders behaved inside state institutions, a current member of parliament, an ex-combatant who fought during the civil war, and an important Christian figure who has significant influence on one of the Christian political parties. In the case of Senegal, I interviewed an academic based at the University of Dakar who is an expert on the conflict in Senegal, a citizen living in Dakar who was active in providing aid to the Senegalese in various parts of the country, and a citizen who was living in Casamance during the conflict and had direct access to leaders within the party that had started the conflict. Unfortunately, I was unable to secure any interviews for the case of South Sudan. All interviews were undertaken through Skype and were completed between April and September 2016.

Much of the quantitative data, other than that related to economic performance, was only available for a single time period. There were very few indicators where one could trace the evolution of what the indicator measured over a specific period of time. One notable example is poverty and income inequality. Moreover, other than the case of South Sudan, there was not much transparency related to government expenditure or expenditures by militias and other non-governmental groups. This, along with the lack of indicators that can help differentiate between the owners of performance legitimacy, made the ability to run quantitative statistical analyses very challenging. 
As such, these data weaknesses were avoided by relying on a combination of approaches that provided more substance.

\section{Characteristics Identified by Conflict, Peacebuilding and Post-Conflict Theories}

Part of the process that I had used to improve the level of rigour in my research was the identification of potential explanations for the outcomes that were observed in the case studies. As such, I undertook a literature review that identified the factors at various intervals - the conflict, the end to the conflict, and the post-conflict period - that have a significant effect on conflict and postconflict development.

The purpose is not to test the relative strength of the current theories' existing variables. The following very brief description of the factors or variables and their performance using the empirical data that was gathered from the three case studies (Chapters 5 to 7) is meant to help the reader understand the role of these variables in understanding the trajectories or events in the three case countries.

\section{A. Important Characteristics of Conflict}

The resolution of conflict and the transition into a long-term peaceful phase has been the subject of much research. Many researchers have identified key characteristics of conflict that are linked to the difficulties or challenges associated with the institutionalization of peace. The following are the five key conflict characteristics that are often mentioned in the literature.

Duration of conflict: The length of a conflict is seen to matter for several reasons. Many scholars focused on peacebuilding propose a 'war-weariness' argument. This argument presents a negative relationship between the length of a conflict and its resumption following a peace agreement. This claim is based on the idea that the longer the conflict, the more war weary the population becomes and thus, the lower the likelihood of a resumption of violence after a peace agreement is concluded (C. Hartzell, Hoddie, and Rothchild 2001; D. T. Mason et al. 2011). However, there are other authors, including Doyle and Sambanis (2000) and Walter (2004), who argue that the correlation between the length of conflict and its resumption after a peace agreement is very weak when crosscorrelation with other independent variables are taken into consideration.

Influence of external actors: The influence of external actors has been assessed through multiple meta- and case-specific studies. Some researchers have demonstrated that the direct or indirect involvement of external state and non-state actors (including the United Nations) in the internal affairs of the country has a strong potential to increase the length of conflicts (Bellamy 2007; Regan 2002) as well as the difficulties associated with peace-treaty negotiations. However, there are other authors who have contradicted this finding by demonstrating the ability of some external actors, especially the United Nations, to speed up conflict cessation, enhance peace prospects, and thus increase stability (Doyle and Sambanis 2006).

Levels of social fracturing: Levels of violence and atrocities against the various ethnic or religious groups is an important obstacle in achieving peace. The likelihood of a successful transition from civil war into peace is believed to be negatively affected by the level of violence as well as the 
number of factions and atrocities committed during the war (Doyle and Sambanis 2006). Moreover, the successful transition to peace is more likely to happen when social fracturing is translated into divisions along geographical lines where each group controls a geographic space (Doyle and Sambanis 2006).

Impact on capacity: State capacity has been directly linked to the outbreak of civil wars (Sobek 2010). The link is premised on the idea that the inability of the state to deal with the grievances of certain groups (whether economic, political or otherwise) offers these groups an excuse to explore violence as a means to solve their grievances. Some authors, including Thies (2010), have questioned the link between lack of state capacity and the outbreak of conflict. Yet, there is an acknowledgement that the onset of conflict and its duration have a negative impact on state capacity.

Geography of conflict: Countries that are considered to exist in difficult neighbourhoods are expected to face significant difficulties in establishing and maintaining peace (Sambanis 2001). Issues related to refugees, the harbouring of a military active group, the geopolitical power balance, the interference of neighbouring country governments in the internal affairs of the conflict ridden country, and conflicts in neighbouring countries are expected to play a significant and mostly negative role in conflict cessation.

B. Other Major Factors Influencing the Success of Conflict Cessation In addition to the characteristics of conflict, there are also certain social and economic factors that can limit its successful cessation. The following are the major factors that are most often identified in the literature.

Level of poverty: The link between poverty and the outbreak of conflict is controversial. Certain authors, like Blomberg, Hess and Thacker (2006), have argued that low economic growth contributes to the outbreak of conflict. Others, like Collier and Hoeffler (1998), view poor people as more susceptible to being recruited into the conflict given the low opportunity cost that they face. Moreover, some have identified a link between low income and a longer duration of the conflict in cases where contraband is available or where there is conflict over land (Fearon 2004).

Presence of natural resources: In cases where countries depend on natural resources, for economic development or for fueling the war, they are more likely to face obstacles in establishing long-term peace (Doyle and Sambanis 2006). Natural resources, including contraband materials (cocaine, opium, hashish, etc.) offer warring factions the financial means to continue fighting and peace implies losing control over these resources and thus significant power (Fearon 2004).

The foundation of 'stateness': The perception of the importance of a state, the experience of the society with a state that is present in many aspects of their lives, perhaps even their daily lives, and the acceptance and belief in what the state has to offer play an integral role in the relationship between the society and the state. The acceptance of the role of the state by the population or a "congruence or compatibility between political boundaries and national identifications" (Miller 2015,533 ) is important in allowing the state to maintain peace. However, this peaceful transition also hinges on the willingness and capacity of the state to govern its population and provide benefits in the form of security, economic growth, and basic social services (Miller 2015). In essence, 
stateness depends on the "recognition of the state as a significant factor in political and social life" (Nettl 1968, 566) and not merely as a structural entity. This in turn depends on the presence or absence of (a) a historical tradition for the existence of the state, (b) societal ideas that incorporate or exclude the state and that define its role, and (c) cultural values that define the importance and role of the state (Gurowitz 1999).

Diaspora's financial support of rebels: The larger the financial benefit that the rebels receive from the diaspora, the higher their chances of success, the higher their willingness to go to war, and thus the higher the likelihood of war (Collier and Hoeffler 2004). In essence, the costs of war are lowered since the opportunity cost of giving up work or income is drowned out by the financial benefits transferred in by the diaspora and earned through the control of more resources as the fighters are better prepared for war and thus are likely to succeed in battle.

Ethnically or religiously diverse population: The more fractionalized a society the longer the war (Fearon 2004), the longer it takes to achieve a cessation of violence, and the lower the likelihood of a durable peace (Zürcher et al. 2013). Moreover, the fractionalization of society increases the risk of peace failure (D. T. Mason et al. 2011). However, according to Collier and Hoeffler (2004), the more diverse a society is the less likely that it will experience civil war. Sambanis $(2001,280)$ reevaluates the findings of Collier and Hoeffler (2004) and following a differentiation between ethnic and non-ethnic conflicts finds that increased ethnic heterogeneity "is significantly and positively correlated with the onset of ethnic war."

Prior history of conflict: War increases tensions between members of the population and therefore is thought to provoke less trust, increased apprehensiveness, and in the absence of strong rule of law, further violence in a bid to avenge previous acts of violence (Wood 2008). Also, since conflict often leads to a cycle of environmental destruction, human destruction, societal breakdowns, and economic destruction, it is also argued that these in turn instigate further violence (Gleditsch 1996).

The manner in which the war has ended: According to Mason et al (2011), the length of peaceful transition is impacted by the manner in which the war ended - rebel victory, government victory, and negotiated settlement. For example, a military victory by one group is thought to improve the chances of peace (Zürcher et al. 2013). As for a negotiated settlement through power sharing, the evidence points to mixed outcomes (Zürcher et al. 2013).

\section{Mainstream Requirements to Achieve Post-Conflict Development}

As was elaborated on in Chapter 2, the main post-conflict development theory, that being the liberal peacebuilding theory, identifies governments of reconciliation in divided societies with no clear winner, democratic development, rule of law, and market economies as the means for successful post-conflict peacebuilding and development (Toby Dodge 2013).

Establishing a government of reconciliation: Negotiated settlements are considered to provide for a more durable peace in the long run than if there was a clear victory for rebels or the government (D. T. Mason et al. 2011). The negotiated settlements include the inception of a government of reconciliation as a means to entice the various warring factions to lay down their arms and battle it out peacefully in the political domain. 
Building democratic regimes: Sambanis $(2001,276)$ notes that democracy and its ability to usher in more egalitarian economic development "are two good ways to manage ethnic conflict in most societies." Moreover, Doyle and Sambanis (2006) as well as Mason et al (2011) establish a link between strong democratic regimes and peace following the end of a civil war. However, Mason et al. (2011) caution against premature democratization given that the presence of partial democracies as measured by the POLITY score $(-5$ to +5$)$ are likely to fail in sustaining peace. It is also interesting to note that strong authoritarian regimes are also considered to be another means to ensuring peace (Doyle and Sambanis 2006; D. T. Mason et al. 2011). Given the preference for democratic development, Doyle and Sambanis (2006, 314-15) suggest the need for the United Nations to provide security and develop institutions that are protected from the abuse of spoilers. All in all, the evidence points to a focus on building "liberal democratic state[s] organized around markets, the rule of law, and democracy" (Zürcher et al. 2013, 20). As such, post-conflict development agendas include the following items, all of which were previously discussed in Chapter 2:
a. Elections
b. Rule of Law
c. Institution-Building
d. Constitution
e. Public Financial Management (including the rooting out of corruption)
f. Economic stability
g. Decentralization (Brinkerhoff and Johnson 2009)
h. Security
i. Delivering social services

Significant levels of aid over the long-term: The argument for significant level of aid over the longterm is based on the idea that states emerging out of conflict have limited capacity, resources, economic activity, and expertise to be able to chart and implement a long-term peaceful development strategy. Hence, the idea is that a significant amount of aid is needed to allow these post-conflict countries to face the tremendous burdens - both those emanating from the conflict and others that will place the country on the proper development path. Collier (2002) also argues that given post-conflict countries experience a temporary growth spurt in the early post-conflict stage, while controlling for policies and aid flows, it is paramount that aid gradually rises in the first four years after conflict has ended and returns to normal levels by the end of the decade. However, given the recognition of the absorptive capacity of the country in question and the crowding out effect of aid on economic development, it is recommended that aid be spread out over many years.

\section{A Short Description of the Case Studies}

Based on the factors identified above, there seem to be many similarities amongst the three cases. These include influences of external actors, ethnic or religious diversity, level of atrocities, the impact of the neighbouring countries' instabilities, corruption, and the geographical division of society along ethnic or religious lines among several others. There also seem to be several differences: poverty rates, the geographic location of the conflict, the political systems that are in place, and capacity among several others. As is highlighted throughout the three case study chapters 
and in Chapter 8, the evidence from the Lebanese, Senegalese and South Sudanese cases identifies gaps that are not appropriately dealt with in the existing research. The evidence indicates that performance legitimacy adds significant explanatory power, especially when the desire to gain performance legitimacy interacts with the strength of the state-society relationship and the manoeuvring space that is available to the leaders.

The evidence indicates that the combination of performance legitimacy, strength of the state-society relationship, and the level of manoeuvering space that is available to leaders provides a more convincing explanation for where countries fall on the performance legitimacy continuum. It is important to note that this does not debunk or negate the importance of existing theories; it is meant to help the reader understand the role of performance legitimacy and its impact on post-conflict development.

The following short descriptions of the three cases previews the analysis that will follow in chapters 5,6 , and 7. I offer comparative conclusions in Chapter 8.

\section{A. Lebanon}

Lebanon's civil war lasted from 1975 until 1990 and engulfed most of the country at one point or another. The war caused tremendous damage to the infrastructure, the economy, the state, and the population. The conflict came at a time when the Lebanese political system was considered to be democratic, albeit with several weaknesses. As is demonstrated in Chapter 5, most researchers have linked the religious makeup of the society, the geopolitical importance of Lebanon within the region and abroad, and the dysfunctional democratic political system as the key variables that have stopped the country from advancing beyond fragility towards development.

However, the Lebanese case is interesting in that the role of performance legitimacy is very evident in the calculations and behaviours of both the leaders and the population at large. These calculations have also had a significant impact on the manner in which the people treat their leaders and the population's expectations from their leaders, the manner in which the state has been treated by the population and its leaders, and the manner in which the leaders have reacted to any state institutionbuilding initiative that has been attempted. As the empirical evidence in Chapter 5 demonstrates, the long history of the interaction between the Lebanese population and its leaders and the weak relationship that the people had with their state have had a significant impact on the manner in which the roles of the state and the leaders are defined. Moreover, the case study also identifies the manoeuvring space that the leaders have as a strong contributing factor that has pushed Lebanon onto the vicious cycle of the performance legitimacy continuum.

\section{B. Senegal}

The Senegalese civil war began as an independence movement in 1982 and began to die down in the late 2000s. Sporadic clashes between rebels and the Senegalese army continue to this day. The civil war was mostly concentrated in the Casamance region (in the southern most part of the country) and most of the victims of the conflict came from that region.

The Casamancais conflict occurred at a time when the Senegalese political system was an authoritarian one-party system. The government initially fought the rebels militarily and attempted to scare and intimidate rebel supporters. The government's actions initially coincided with actions 
by the rebels that were aimed at helping the affected population. This initially led the local population to impart legitimacy unto the rebel leaders. However, this soon changed when the rebels, due to the lack of funds and external support, turned against their people and when the government began investing in the delivery of state social goods and services. At the same time, the nonCasamancais valued their relationship with their state and believed in its role as the entity that was responsible for providing basic goods and services. This along with the control that the president had on the politicians and the president's reliance on the politicians' ability to garner votes limited the leaders' manoeuvring space. This is despite the fact that the problem of corruption continues to be significant in Senegal.

Following investments in the state's infrastructure and institutions, the Senegalese state was able to deliver much needed goods and services to the Casamancais, a process that won it performance legitimacy and led many Casamancais to change their allegiances regarding the quest for independence.

\section{South Sudan}

People in South Sudan have experienced a series of protracted wars. These wars were very much part of the South Sudanese population's existence even when South Sudan was part of the Republic of the Sudan. The South Sudanese have also had a history of being neglected by the central state and of having to fend for themselves for survival, even after independence in 2011. As such, the South Sudanese have not developed a strong state-society relationship. They have also been led by leaders who have continued to use any resources at their disposal to maintain power and influence.

The leaders' actions have gone as far as diverting humanitarian aid and creating humanitarian crises so that they could earn the support of the same people that they were causing suffering to. Access to resources and the legitimacy that is earned by the leaders when some or all of these resources are diverted to their supporters continues to play a significant role in the manner in which leaders maintain their power. Leaders have pulled out of governments or caused political and security crises so as to maintain their hold on resources, power, and performance legitimacy. Moreover, the South Sudanese political system and the manner in which the population is linked to its leaders affords leaders with significant maneuvering space that they can then use to paralyze and delegitimize the state. Unlike Lebanon, South Sudan has been pushed back into conflict by its leaders in a bid for further power and legitimacy.

\section{Conclusion}

Undertaking proper case study research is almost inevitably accompanied by a significant amount of care that is taken to decrease the impact of the associated limitations. I attempted to limit the impact of selection bias by (a) beginning the research process through an initial assessment of the population of cases and then narrowing the cases down to ones that can help provide a variation along the dependent variable, (b) undertaking process tracing techniques in order to arrive at a sample with a large $\mathrm{T}$, and (c) continuing to use current theoretical arguments to assess whether variables that have already been tested by many academics could explain the findings. This methodological approach led to the choice of the three case studies - Lebanon, Senegal and South Sudan - that provide the bulk of the empirical findings in this dissertation. 
While the results of the assessment of the three case studies against the factors that were identified by the existing theories and the Performance Legitimacy Theory of Transition framework (Chapter 2) will be presented in the final chapter, each of the three chapters that follow are dedicated to a study of each of the cases. As noted earlier, the analysis is informed by the arguments presented in Chapters 2 and 3. 


\section{Chapter 5: The Lebanon Case Study}

\section{Introduction}

Lebanon is a small mountainous country that is at the intersection between East and West. It has a long history of civilization with a multitude of foreign conquests and the implantation of groups by foreign powers in an effort to control the Lebanese population. All throughout, Lebanon's mountainous terrain and its deep valleys have served as a refuge for many minorities in times of massacres and upheavals.

Lebanon is a Parliamentary democracy. Lebanon's electoral system is based on a majority system. Citizens vote for Parliamentary Representatives through a block vote system. In this system, a voter votes for an electoral list that contains the names of parliamentary candidates. These lists are negotiated between leaders who form various pacts. The President is elected by Parliament and not directly by the people. Following an unwritten 1943 National Pact between the various leaders, the Lebanese President is always expected to be a Maronite Christian, the Prime Minister a Sunni Muslim and the Speaker of Parliament a Shia Muslim. According to the current Constitution, the Chamber of Deputies (or the legislative authority) has to have an equal number of Christian and Muslim Deputies. The Council of Ministers, which holds the executive authority, is supposed to reflect the

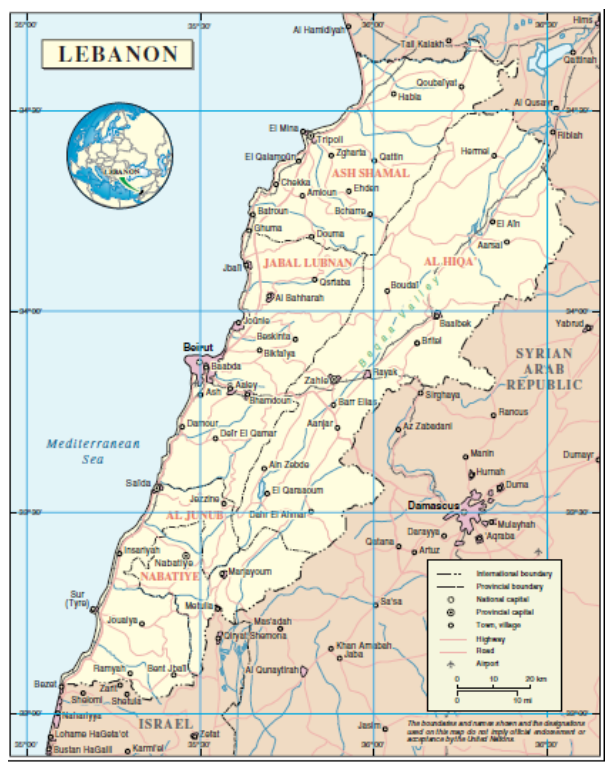

Source: United Nations,

http://www.un.org/Depts/Cartographic/map/prof ile/lebanon.pdf. religious makeup of the Parliament. The National Pact also established an unwritten rule that required the representation of the major sects in the Council of Ministers. Without such a representation, the Council of Ministers (or the government) is considered to be illegitimate in the eyes of the leaders and the population.

The various sects within the Lebanese population have had a special relationship with their representatives since the early $1500 \mathrm{~s}$. This relationship has moulded the manner in which the state is perceived and the ability of the state to earn legitimacy. This chapter shows that the fight over performance legitimacy between the various actors and the use of this legitimacy to amass significant support have led to the acquiescence of the population and thus the ability of the leaders to use religion and external interferences to further solidify their hold over the population.

The remainder of the chapter traces the history of Lebanon from the Ottoman rule until the present. For each period, the analysis looks at the relationship between the state and society, the political situation, the socio-economic conditions, external interferences, the state of the public administration, and the role of the delivery of basic goods and social services. The chapter ends with an assessment of performance legitimacy in Lebanon. 
The following is a simple timeline graphic that allows one to visualize the outcomes of the following process tracing analysis.

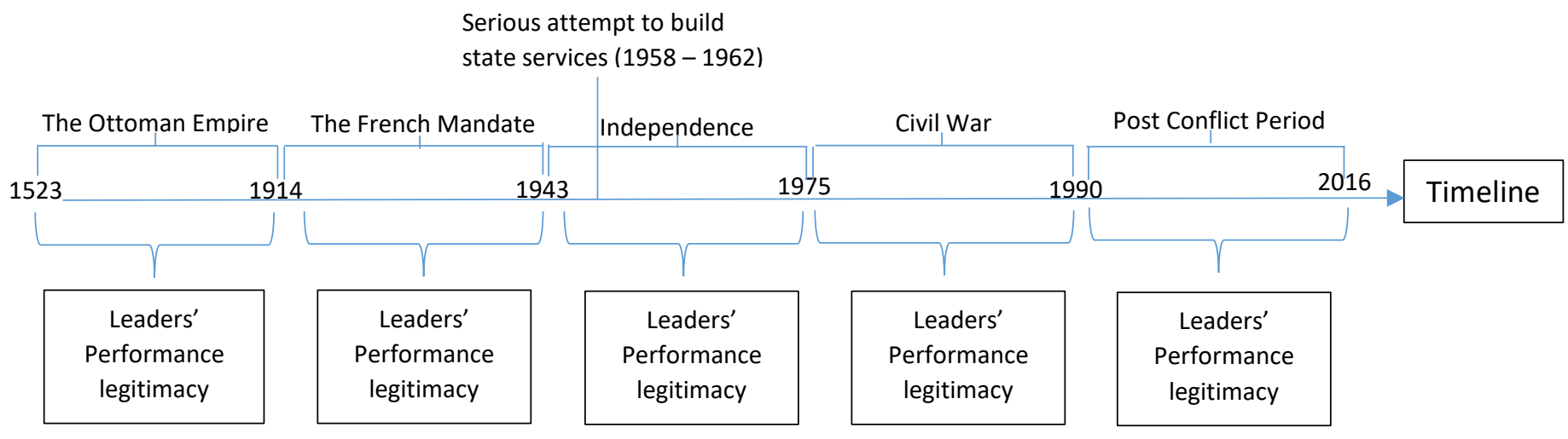

\section{From Ottoman Rule to Independence}

\section{A. The Ottoman Period}

The first form of a Lebanese state was established in 1523 following the formation of the Emirate of Mount Lebanon under the auspices of the Ottoman Empire (Traboulsi 2007). Life within the Emirate was ruled by a two-tier hierarchal system that gave the Muslims the upper hand and made the 'People of the Book' (Christians and Jews) second class citizens (Traboulsi 2007). The 'People of the Book' had to pay a protection tax (jizya) which gave them the right to live in peace and practice their religious rites. This division between Muslims and 'People of the Book' also dictated the type of profession that one could undertake. Under this system, military and government administrative positions were reserved for Muslims, while the excluded Christians and Jews resorted to commerce, finance and handicrafts (Traboulsi 2007). This societal division significantly reinforced sectarian silos and offered religious leaders and their non-religious elite supporters significant amount of power and performance legitimacy. It also offered these leaders the space and opportunity to directly influence the lives of their followers and contribute to the breakout of several conflicts and many bloody massacres between the various religious groups (Salamy 2014).

Life within the Emirate was also defined by economic and social inequalities. The level of inequality was strengthened by a division between leaders and commoners with leaders extracting resources from their respective commoners (Salamy 2014; Traboulsi 2007). Throughout the later stages of the Ottoman rule, Maronite and Druze peasants fought against their respective feudal bosses (Salamy 2014). The main demands of the commoners were related to a life based on equality between the commoners and their sheikhs (leaders) and the establishment of a representative political system that included electoral representation (Traboulsi 2007).

The Emirate of Mount Lebanon witnessed three stages: the feudal (Amir) stage from 1523 until 1842 (319 years), the Muqata'ji stage from 1842-1861 (19 years), and the Mutasarrifiya stage from 1861 until the breakout of World War I (43 years). The initial feudal system allowed the Ottoman Empire to remain the powerful force in the Emirate of Lebanon by providing the local feudal lords, the Amirs, ultimate power in return for tax payments to the Ottoman Sultan (Iskandar 1964). The 
later stages of the feudal phase (from the mid-1700s to the mid-1800s) saw decreased economic activity and much more difficult living conditions (Iskandar 1964).

The mid-1800s also ushered in more severe conflicts along both vertical and horizontal lines with many Christians paying the heaviest price. The conflicts and the Ottoman Sultan's dissatisfaction with the Amir Baasheer Ash Shehabi led to the unravelling of the feudal (Amir) system and the establishment of the Muqata'ji system, which divided Mount Lebanon into two administrative regions. The division was designed to provide the Christians control of their own area in the North with their Maronite Christian leader or Qaimaqam and the Druze with their own region in the South controlled by a Druze leader or Qaimaqam. In doing so, the Ottoman Empire, with the support of the British, officially establish the first sectarian geopolitical division in Lebanon partitioning Mount Lebanon into two jurisdictions and reinforcing the role and power of the respective religious leaders (Iskandar 1964; Salamy 2014; Salloukh, Barakat, and Al-Habbal 2015). The establishment of the Muqata'ji system also weakened the feudal control over the population and ushered in the beginning stages of popular participation in political bodies (Iskandar 1964). Unfortunately, this geopolitical division allowed for a retrenchment of sectarian divisions and did not provide a direct solution to societal inequalities. Moreover, bloody sectarian conflicts and conflicts between commoners and the politically and economically powerful Qaimaqam occurred constantly during this period (Traboulsi 2007).

The 1860 massacre of thousands of Christians by Druze citizens ushered in a more ambitious intervention by European powers (beyond France and England) to assist in the protection of the Lebanese and the resolution of the problems plaguing Mount Lebanon. The international intervention took the form of an international commission made up of representatives from England, France, Austria, Russia, Prussia, and Turkey that was tasked with finding a more suitable governing system (Iskandar 1964).

The subsequent 1860 protocol effectively ended the Muqata'ji era and ushered in the Mutasarrifiya (autonomous provinces) era. This third stage lasted until 1915 and provided Mount Lebanon with relative peace and stability during its 54 years of existence (Salamy 2014). This new system installed a Christian Ottoman administrator for Mount Lebanon, effectively allowing the region a higher but still limited form of political autonomy from the Ottoman Empire (Traboulsi 2007). This revised political system divided Mount Lebanon into seven districts (cazas) with each district being ruled according to the desires of the majority group (Traboulsi 2007) through indirect popular elections (Iskandar 1964). It also led to the division of the Maronite region into two areas. This division and the economic crises that ensued at a time when there were significant social and economic divisions led to the immigration of 120,000 Christians (representing 25 percent of the population) and thousands of Druze peasants and commoners. As a result, Mount Lebanon lost nearly one third of its population (Traboulsi 2007).

When referring back to the Justification and Actual Performance indicators that were presented in Chapter 3 - satisfaction with the leader in his effort to meet basic needs; perceived willingness of the leader to support his people; degree to which citizens turn to the leader for help; number of basic goods and services provided by the leader; and ease of access to leader-delivered basic goods 
and services - the research demonstrates that the Lebanese leaders were successful in harvesting and protecting their performance legitimacy.

In essence, according to Hottinger $(1966,91)$, while the Ottoman empire abolished feudal power, Lebanon's "feudal relationship had developed into an organic institution whose utility was not exhausted when the military function of the za'im [or feudal leader] became obsolete." This natural progression or reconfiguration placed Lebanon on the vicious end of the performance legitimacy continuum by allowing the leaders to maintain their performance legitimacy and continue to fulfill their social and political responsibilities through their role as the spokesmen for their people and as intermediaries between the state and their people, all under the guidance of religious leaders (Hottinger 1966). The role of the non-religious leaders was made easier by the performance legitimacy that each leader had earned from his people owing to his access to state resources following his inclusion in the state administration. Moreover, for his people, the leader was often, and continues to be until today, viewed as the only viable means of communication with the administration that was either perceived as alien, hostile, or indifferent to them (Hottinger 1966). Access to the leader was also considered to be the only means to receive state services or other favours (Hottinger 1966).

This system of $z a^{\prime}$ im-ship prospered following the abolishment of feudalism and allowed new $z u^{\prime}$ 'ama or leaders to emerge. Unlike political leaders in Western cultures, the $z u$ 'ama mobilized and gathered their performance legitimacy from their local supporters with little or no intention to mobilize and gather power from across the population at large (Hottinger 1966). In essence, Lebanon's Ottoman period was characterized by circumstances that rendered the state illegitimate and the leaders legitimate in the eyes of the population - hence a period that had Lebanon in the vicious cycle that was identified in Chapter 2.

\section{B. The French Mandate Period}

The beginning of World War One marked the collapse of the Ottoman Empire and the transfer of responsibility of or control over Lebanon and Syria to the French. The French mandate saw an expansion of the Lebanese territory through the annexation of Tripoli, Sidon, Tyre, and Beirut, provinces that were predominantly inhabited by Sunni Muslims. According to Traboulsi (2007), the creation of Greater Lebanon through the annexation of these additional provinces was a calculated move by the French to divide and control Syria and not a means to bow to either the Christians, who had ambitions for territorial expansion and separation from Syria under French protection or guarantee, or the Muslims, who had an ambition to remain as part of Greater Syria. As such, the Greater Lebanon that came to be under the French Mandate did not correspond to either Christian or Muslim ambitions (Traboulsi 2007). Finally, this enlargement process significantly changed the demographic structure of Lebanon, moving from a predominantly Christian one to one where no single religious group maintains a strong or large majority (Iskandar 1964). The outcome was a shift in the existing conflict demarcation lines from Maronite-Druze to Maronite-Sunni (Salamy 2014) and new opportunities for leaders to maintain their performance legitimacy by maintaining the distance between their supporters and the state and by using their legitimacy to promote rhetoric that redefined economic, social and political grievances along religious lines. This also allowed them to maintain their position as the brokers between the state and their own supporters and as the 
political representatives of their religious leaders. In essence, the French Mandate period did not provide the impetus for the Lebanese state to earn performance legitimacy and thus move Lebanon, even slightly, towards the virtuous cycle end of the spectrum.

The annexation of territory led to the establishment of the State of Greater Lebanon in September 1920. With the work of the French, the leaders created a Lebanese constitution and a democratic system with equal treatment of all citizens (Salamy 2014). They also established a highly centralized bureaucratic administration (Iskandar 1964), one which continues until this day. Overall, from a political and administrative point of view, France was instrumental in developing or reconfiguring Lebanon's political and administrative structure and procedure to mimic that of the French (Crow and Iskandar 1961).

It was also under the French Mandate that Lebanon experienced its first free election. Even though the anti-French nationalists won the elections, they were still allowed to form a government (Iskandar 1964). It was only when President Bechara al-Khoury and Prime Minister Riyad as-Sulh amended the Constitution and ended the French Mandate over the country that France reacted by violently arresting the President, the Prime Minister, and most of the Cabinet members (Iskandar 1964). Lebanon was allowed its independence only after Britain, the United States, and other Arab countries interfered and France retreated (Iskandar 1964).

C. The Independence Period

Lebanon declared independence on November 26, 1941 but was only accepted by France following the release of the President, Prime Minister, and Cabinet Members on November 22, 1943. Independent Lebanon faced significant challenges. Sectarian conflicts and tensions manifested themselves in the formation of the identity of Muslims and the identity of Christians. With the majority of Muslims identifying as Arabs and the majority of Christians identifying not with Muslim but with Western or non-Muslim cultures, social cohesion and internal unity were practically lacking. Many had doubted the viability of an independent Lebanon given its religious groups' vastly divergent views regarding the position of Lebanon - its continuous independence or its annexation by Syria/another Arab country (Iskandar 1964).

A first effort to address these issues was a power-sharing formula known as the 1943 National Pact. The National Pact, an unwritten gentlemen's agreement between the Maronite President Bishara alKhouri and the Sunni Prime Minister Riyad as-Solh, reserved the presidency to the Maronites, the Prime Ministerial position to the Sunnis and the Head of Parliament to the Shia (Salloukh, Barakat, and Al-Habbal 2015). The Pact also distributed executive, legislative, and judicial powers on confessional terms based on the 1932 population census. With these assurances, the Muslims promised to abandon their plans for the annexation of Lebanon by an Arab neighbour and the Christians promised to limit the interference of Western players, mainly France, in the domestic affairs of the Lebanese (Iskandar 1964). According to Iskandar (1964), soon after independence, sharp differences resurfaced. The unity that was used to fight the French collapsed once the French left (Iskandar 1964).

The power-sharing formula and the democratic political system did not do much to change the relationship that the population had with the state since (a) it allowed the same leaders to maintain 
their power and (b) it did not impact the performance legitimacy of these leaders and their use of this legitimacy to continue abusing the state and maintaining a deep gulf between the state and its population. Yet again, the Lebanese state was not able to earn performance legitimacy and help Lebanon move towards the virtuous end of the performance legitimacy spectrum.

During these same tumultuous times, newly independent Lebanon was faced with several external challenges, including the complete evacuation of the French military, the formation of the Arab League (with a more Arab identity), the economic problems with Syria, the formation of the State of Israel and the influx of Palestinian refugees who were mostly Sunni Muslims (Iskandar 1964), and the influence of Egypt in the efforts to 'Arabize' Lebanon.

From a state administrative perspective, the initial years were plagued with capacity problems, staffing issues, the multiplication of responsibilities emanating from the French withdrawal, the expansion of the Lebanese economy, and persistent social and economic disparities. The state struggled to deal with these issues. It focused on other significant internal matters like national unity and managing external political pressures from its neighbours and previous colonial powers. At the same time, bureaucratic inefficiencies and corruption rose increasing widespread dissatisfaction of the population with what the state had to offer (Iskandar 1964). This dissatisfaction and perceived unwillingness of the state to support its citizens translated into limited state performance legitimacy as measured by the following two Justification indicators that were presented in Chapter 3: Satisfaction with the state in its effort to meet basic needs and perceived willingness of the state to support its citizens. Yet, the dissatisfaction with the state did not translate into the dissatisfaction with one's own leader since each leader maintained his delivery of basic goods and services and thus a certain level of performance legitimacy (as measured by the Justification and Actual Performance indicators). It is also important to note that the leaders were able to use their performance legitimacy to stoke religious fears and ensure people's compliance with their sanctioned rules or actions. Moreover, the weaknesses of the state also meant that the state was unable to step into the realm of the religious leaders' domain, one that was protected by the political leaders, and thus allowed the religious leaders to maintain their control over the Lebanese population (El Zein 2003).

\section{Analysis}

Overall, one can draw four conclusions from the history of the Emirate of Mount Lebanon and Lebanon under the French Mandate. First, from the days of the Emirate of Mount Lebanon to its independence, Lebanon has been dominated by sectoral strife and economic and social inequalities. While members of all religious sects have suffered from these conflicts, the Maronites of Mount Lebanon have carried the brunt of the burden. From the time of the Turkish Ottoman Empire, authorities have attempted to decrease the power of the Maronite and improve their hold on the area by installing Sunni Turks in key positions and areas within Mount Lebanon (interview with Christian key figure). This demographic reconfiguration along with the massacres of Maronites, their relegation to secondary status, and the economic crises within their regions have all helped drive the exodus of hundreds of thousands of Maronites. Moreover, following the independence of Lebanon, the constant rhetoric from the Muslim (mostly Sunni) community regarding their desire to either reconfigure Lebanon based on Islamic terms or replace the secular state with an Islamic one 
(El-Khazen 2000), did not help to ease the fears of Christians. One such example is the opinion piece that Hussein al-Quwatli, director of the office of Sunni Mufti Hassan Khalid, penned in Al Safir, a Beirut daily newspaper, on August 19, 1975 (El-Khazen 2000) in which he offers Christians an ultimatum of either giving up the presidency and submitting to the power of the Sunnis or living under an Islamic state (El-Khazen 2000).

Moreover, the forced overtaking of the Sunni-dominated areas that had once belonged to Syria and their reconfiguration as Lebanese territories increased the distrust between the Sunnis and the Christians and subsequently caused nationality and identity crises. Hence, the ensuing distrust manifested itself in the challenges related to the formation of the political system in Lebanon. While the Maronite control of the presidency of Lebanon was a "a vulnerable defensive shield" (ElKhazen 2000, 379) or a means for the Maronite to protect their vulnerable status (Gemayel 1992) in a region where their Christian brethren had been directly or indirectly forced to leave, the Sunni Muslims perceived this control as a means of domination and of the subjugation of their religion and identity.

Second, the Lebanese have had a long history of demanding political representation by locally elected officials (Traboulsi 2007). As El-Khazen $(2000,389)$ notes, the democratic outcome of Lebanon is a "reflection of the country's political culture. It is the outcome of a long process of historical communal development." Yet, it is important not to simply assume that increased political representation implies trust in the state or a reinforcement of the relationship between the state and the population. Increased political representation was a way to ensure that the leadership of the various sects had a means to guarantee their rights and their protection from the other actors, even those found in the state administrative and political systems. It did not necessarily imply a belief in the role of the state in the lives of the Lebanese.

Third, resolving sectarian divisions and diffusing sectarian conflict has consistently led external players to intervene (the Turks, Western states, and Arab leaders). The conflicts between the Maronites and the Druze followed by increased conflicts between the Maronites and the Sunnis invited several external players who had their own political agenda for Lebanon and the region. As the development of the 1943 National Pact demonstrates, external players have played a critical role in shaping the political arena in Lebanon.

Fourth, while the emphasis was placed on resolving sectarian conflict, little if anything was done on the issue of deep inequalities that had significantly impacted the lives of the Lebanese. With most Lebanese being controlled by the upper class, either the feudal lords, the religious leaders, or the new representatives of economic powerhouses, intra-sectarian conflicts became a part of life. However, little was done by the Lebanese and their proxies to resolve the massive inequalities that existed between the commoners and their leaders.

Fifth, the Ottoman, French Mandate, and early independence periods were not known for adequate state-building measures. During these periods, the state was used as a central repository system that allowed the leaders to control their subjects and abuse the resources that they had amassed for their benefit (Messarra 1998). Moreover, the centralized state allowed the director generals, ministers, and the Council of Ministers the power they needed to run the country (Ghossain 1988). Thus, with 
the predominant laissez-faire ideology becoming the foundation of Lebanon's economy (Baaklini 1976) and the increased power of individual leaders, the state was not able to implement the necessary actions that would allow it to provide services for the Lebanese, that is despite the fact that the majority of the Lebanese expected it to do so (Crow and Iskandar 1961).

\section{Lebanon: From 1943 to 1975}

\section{A. Post Independence Lebanon}

The first post-independence regime of Bishara al-Khouri faced tremendous challenges. The economy was faltering, corruption was increasing, state administrative inefficiencies were high, the state was inactive in developing actual public policies that were meant to move Lebanon forward, and the popularity of the government began to decline in the later stages of al-Khouri's reign (Crow and Iskandar 1961; El-Khazen 2000; Iskandar 1996; Maroun Kisirwani 1997a). Apart from ushering in an independent Lebanon, al-Khouri was also a president known for politicizing the civil service by filling civil service positions with supporters and electors (El Zein 2003). This process allowed al-Khouri to abuse state resources and maintain his performance legitimacy ${ }^{57}$ at a time when he already had the highest form of political legitimacy. Interestingly, instead of helping the country move towards the virtuous end of the spectrum, this critical juncture reinforced Lebanon's vicious cycle of state de-legitimization and leader legitimization.

Al-Khouri was ousted from power in 1952 by a peaceful revolution dubbed the Rose-Water revolution. He was replaced by Camille Chamoun who immediately sought to reform the state administration (El Zein 2003). The Chamoun period coincided with a period of economic prosperity for Lebanon with a five percent average annual growth in gross national product (Hakim 1966). However, it also coincided with increased social and regional disparities and tensions (Traboulsi 2007).

Nevertheless and owing to the inefficiencies in the system, President Chamoun introduced many public service reforms, including "a new organizational structure for ministries, a new personnel law which laid the foundations of a merit system, a new auditing and accounting system, a revised local government law, and a new State Inspection Commission" (Iskandar 1996, 25). However, despite these reforms, favouritism and corruption remained prevalent in the Lebanese administration and President Chamoun, as in the case of his predecessors, maintained his performance legitimacy by appointing supporters to key administrative positions (El Zein 2003). According to Crow and Iskandar (1961), the public sector reforms did not alter the Lebanese public administration and did not solve the fundamental problems within the Lebanese administration. Again, when assessing the situation through the Legality indicators (perceived importance of the state and confidence in the civil service), Justification indicators (satisfaction with the state's/leaders' effort to meet basic needs of citizens and perceived willingness of the state/leaders to support its citizens), and Actual Performance indicators (number of goods and services provided by the state/leaders and ease of access to these services), the results seem to point to the bestowment of performance legitimacy onto the leaders and not the state. Moreover, the state

\footnotetext{
${ }^{57}$ As measured by the following indicators: the satisfaction of people with the state's delivery of basic goods and services, the people's lack of confidence in the civil service, and the above-mentioned leaders' continued attention to the needs of citizens.
} 
continued to avoid moving in on religious leaders' territory by ensuring a non-interventionist policy that allowed leaders to continue working through a shadow system of administration that used state institutions and resources and that did not include or require the state to pass public policies or laws.

The late 1950s was also a tumultuous time for the region. The rise of Nasserism or Arab nationalism had disrupted the status quo in many Arab countries. In Lebanon, the charisma of Egypt's Jamal Abdel Nasser reinvigorated the Arab-Lebanon identity crisis. With the Sunnis increasingly identifying with Nasser and his Arab vision, there were increased calls for the unification of Lebanon with Syria and Egypt and the formation of the United Arab Republic (ElKhazen 2000). Chamoun's decision to align Lebanon with the United States rather than with the Soviet Union (and Nasser) led Lebanon to be alienated from the majority of its Arab neighbours and undermined Lebanon's neutralist policies (Traboulsi 2007). Consequently, Chamoun alienated Muslims, divided Christians, allowed external interferences to thrive (Traboulsi 2007), and brought a near collapse of the political and administrative systems (Iskandar 1964).

External interferences along with internal power struggles led to the outbreak of the 1958 conflict. At this point, external players began to play a more important and deeper role in the politics of Lebanon. Syria allowed for the flow of arms from its territory. Egypt played a direct role in developing 'solutions' for Lebanon. And the United States worked as broker (Traboulsi 2007), The conflict ended with the United States sending in its marines to stabilize the country, overseeing peaceful parliamentary elections, and ensuring that General Fouad Chehab was elected by parliamentarians as the next president. The resulting environment was one of mistrust and weakened national unity (El Zein 2003).

The Chehab era lasted from 1958 until 1964. It was the era that heralded the only true expansion of the state in the lives of much of the alienated population, with Chehab strongly believing that national unity and stability could be rebuilt through a strong public administration (El Zein 2003). The Lebanon that Chehab inherited had a society suffering from high rates of poverty, which reached 50 percent in the 1960 (Fawaz and Peillen 2003). Moreover, the unbalanced development within Lebanon was a major concern for Chehab, something that he tried to tackle by making the state administration more efficient, expanding state services, extending them to many underprivileged rural areas (Cammett 2014; El-Khazen 2000), and by-passing the intermediary role of the zu'ama (Hottinger 1966). In doing so, he established the National Social Security Fund as well as government-run pharmacies and hospitals in rural areas, and extended government schools, roads, basic social goods and services to the entire country (Cammett 2014). According to Gaspard (2004), this period was the only developmental period in the history of Modern Lebanon. It was also a period of rapid advancements in economic and social development (Hakim 1966).

The expansion of the Chehabi state into areas that were considered to be exclusively controlled by the leaders was perceived by the leaders to have been a direct attack on them and an indirect means to disempower them, decrease their legitimacy, and limit their role. These leaders were often able to use religious rhetoric to (a) paint Chehab as a threat to their religious group by either painting him as a Maronite Christian who wanted to dominate the other religious groups or as someone who was working with the Muslims against the Christians, (b) maintain support at the grassroots level, and 
(c) subsequently turn their supporters against Chehab. ${ }^{58}$ Thus, actions that Chehab took were viciously opposed by most communal leaders who had earned performance legitimacy from their supporters, felt increasingly threatened by his actions, were able to count on their grassroots support to block reform efforts, and were able to block certain administrative reforms within state institutions that they either had control over or had enough support from those within (El-Khazen 2000; Salloukh, Barakat, and Al-Habbal 2015; Traboulsi 2007). In the end, his efforts were not enough to lead to the establishment of a broad social protection system (Cammett 2013), allow the state to earn significant performance legitimacy and thus move Lebanon towards the virtuous end of the performance legitimacy spectrum. As Salloukh et al $(2015,20)$ note, Chehab's "objective of undermining the confessional elite's political power and creating an alternative trans-sectarian national Lebanese identity anchored on state-sponsored integrative socio-economic policies ultimately proved elusive."

In 1964 Chehab refused to extend his mandate and stepped aside to allow for the election of a new President. Charles Helou, a Chehabi-inspired Maronite, led the country from 1964 until 1970 at a time when Lebanon was considered the Switzerland of the Middle East with the highest scores in the region on indicators of modernization and human development (El-Khazen 2000). At the time, the World Bank classified Lebanon as a country comparable to a lower-income European country with a strong financial performance (Gaspard 2004). The Helou period was also known for its unforgiving war on corruption that had led to the dismissal of hundreds of civil servants without due process and the subsequent popular and political dissatisfaction (El Zein 2003). Despite the economic success, Lebanon was increasingly pulled in different directions as a main player in the proxy war between Egypt and Saudi Arabia, the United States and the Soviet Union, and Israel and the Arab world (Traboulsi 2007). It also began to feel the impact of the Palestinian Liberation Organization's anti-Israeli military actions from within Lebanon (Traboulsi 2007). With (a) Israel retaliating militarily and causing severe damage and (b) the drafting of the Egyptian Cairo Accord allowing the Palestinian Liberation Organization (PLO) the right to fight against Israel from within Lebanon, carry arms inside Lebanon and acquire Lebanese land that would fall under their control, Christians began to feel more insecure and sectarian tensions between the various groups increased (Traboulsi 2007).

The early 1970s witnessed continued struggles between Christian Lebanese groups and the PLO (Traboulsi 2007) and increased radicalization resulting from the 1967 Arab-Israeli war and the defeat of Egypt (El-Khazen 2000). The presence of the Palestinians increased distrust between the Muslims and the Christians with both camps accusing the other of playing the sectarian card. In the meantime, social inequalities were rising and the economic conditions were becoming harder for the poor and the disadvantaged (Traboulsi 2007).

Helou was replaced by President Suleiman Franjieh who led Lebanon from 1970 until 1976. Franjieh's election was a result of the anti-Chehabist coalition made up of political leaders whose

\footnotetext{
${ }^{58}$ Although this strategy worked in the majority of cases, there were still some exceptions. The few leaders who saw a long-term benefit from Chehab's actions did not undermine him. Moreover, there were people who did not accept the arguments of their leaders and switched their support to the state due to Chehab's efforts and the subsequent performance legitimacy that the state was able to earn.
} 
performance legitimacy was either threatened by the Chehabist actions or by the actions of both Chehab and Helou (El Zein 2003). This era was best known for its re-politicization of the civil service, the reversing of many Chehabi reforms, including the retrenchment of the state towards a strategy of non-intervention (Iskandar 1996), increased socio-economic problems, increased sectarian tensions, increased Christian-Palestinian tensions, and Israeli warfare in Lebanon targeting civilians and Palestinian guerrillas in response to Palestinian attacks (El-Khazen 2000). These actions continued to limit the ability of the state to earn performance legitimacy, as measured by the indicators presented in Chapter 3.

Lebanon also became the battle in the war between Jordan and Fatah (the biggest Palestinian militia headed by Yasser Arafat) with attacks on Christian churches and businesses (El-Khazen 2000). This proxy war ended when the Palestinians lost the war against the monarchy in Jordan and moved their military and political headquarters to Lebanon (El-Khazen 2000). This move invited further retaliation by Israel through commando raids in Beirut and the South of Lebanon and through allout bombardments and incursions (El-Khazen 2000). The raids by Israel increased tensions between the Lebanese Christian and Muslim populations. They also increased political tensions between the various sectarian politicians and led to many confrontations between the PLO and the Lebanese Army (El-Khazen 2000). The fighting between the Lebanese Army and the Palestinian guerrillas throughout the first half of the 1970s increased Arab dissatisfaction with the Lebanese government leading to various Arab governments imposing sanctions on Lebanon (El-Khazen 2000). By then, Syria's Hafez al-Assad regime became a major power broker in Lebanon and gradually imposed its interests (El-Khazen 2000).

Finally, the various leaders established militias as a means to protect their sectarian interests and the security of their followers at a time when the Lebanese army was perceived to be failing at its job (El-Khazen 2000). The militias offered leaders additional opportunities to gain performance legitimacy by offering physical, economic and social protection for their supporters and presented a critical obstacle for any initiatives that would have helped the state earn performance legitimacy. By 1974, all local and foreign parties acquired weapons and began engaging in military practice and military-like attacks (El-Khazen 2000). The differences in visions for Lebanon by the Muslims and Christians (Salloukh, Barakat, and Al-Habbal 2015), the militia mindset within the government (Messarra 1998), the establishment of the PLO in Lebanon after their expulsion from Jordan in 1971, increased radicalism and intolerance, as well as the retaliation of Israel on Lebanese soil for the attacks committed by the PLO all strained relations between Muslims and Christians and contributed to internal unrest (Salamy 2014). In response, the government resigned thus throwing Lebanon into a major political crisis.

\section{B. Analysis}

Lebanon's experience between independence and the outbreak of the civil war is one dominated by six major tendencies. First, external interference in Lebanon's affairs was very high and it allowed Lebanese leaders to gain support for their actions. The openness of the Lebanese society allowed external players to intervene in the country's domestic affairs (Salloukh, Barakat, and Al-Habbal 2015). From the 1950s to the 1970s, Arab states "used Lebanon as an arena to advance their competing regional agendas" and coopted domestic actors as their protégés (Salloukh, Barakat, and 
Al-Habbal 2015, 17). Second, Lebanon continued to witness internal sectarian challenges that were not adequately dealt with or diffused. Third, socio-economic differences were prevalent in Lebanon throughout this period. Fourth, the national unity of the Lebanese society and the development of a common Lebanese identity proved to be elusive. As Gemayel $(1992,11)$ notes, "[t]he new political culture had not had time to create the Lebanese citizenry capable of countering antagonism from outside with the solidarity that results from political faith in state values and institutions." Fifth, attempts at limiting the politicization of the state administration were unsuccessful and faced significant opposition by most leaders. Sixth, pre-war state policies were not intended to deprive certain religious communities for the benefit of others, even though the Shia community continued to be the most excluded (El-Khazen, 2000).

As it relates to the state, this period did not represent significant increases in the state's performance legitimacy, as measured by the indicators presented in Chapter 3. First, the state never succeeded in being the unification tool for all Lebanese. It was also not able to be a national integration tool since the reforms needed to achieve this goal threatened the performance legitimacy of the political, religious and social elite, many of whom were in control of the state and its decision-making apparatus. Second, sectarianism was integrated in every action that the government took thus allowing for a significant entrenchment of sectarianism within the state's administration (Crow and Iskandar 1961). The state was weakened by the actions of the leaders and the communalconfessional system which was in direct competition with the state (El-Khazen 2000) and the overwhelming majority of the needs of the population continued to be met through the communalconfessional system (Kingston and Zahar 2004).

Third, the state was never able to overcome the subordination of its loyalty to that of family, clan, village or religious community (Crow and Iskandar 1961). As Crow and Iskandar $(1961,294)$ note, "[i]t is axiomatic that when any Lebanese citizen finds it necessary to approach the government, he first seeks out « some one he knows » or " some one who knows some one he knows », that is, some one with whom he shares at least one of the above relationships" (Crow and Iskandar 1961, 294). These unofficial channels were preferred to the slower, $\operatorname{costlier}^{59}$, and more impersonal official channels. Working through the parallel unofficial system caused informal personal and political interventions which in turn interrupted the official system and caused further inefficiencies (Crow and Iskandar 1961; Salem 1973). It also decreased the confidence in and satisfaction with the state and the civil service while increasing the confidence in and satisfaction with the leaders' performance. This limited the state's ability to earn performance legitimacy and increased the performance legitimacy of those who were inside the informal system and had the decision-making power. As Crow and Iskandar $(1961,307)$ note, "[most] of the fundamental principles of administration and administrative regulations were frequently violated by political figures making effective administrative procedures erratic if not impossible, and making exceedingly difficult the occasional feeble effort to improve the system. The Ministers and Deputies intervened with immunity, and the resulting administrative irregularities were accepted as normal and went unheeded." Moreover, as Iskandar (1964) notes, an important legacy of the Ottomans and the

\footnotetext{
${ }^{59}$ If people did not know someone working in the relevant state institution, that person would have had to pay a significant bribe to get the services that this person needed.
} 
French was the subordination of the civil servants to their political masters and their servitude to the masters rather than to the people. This allowed the leaders to work with the existing internal administrative culture, abuse state institutions, and improve their performance legitimacy.

Fourth, this parallel unofficial system and the resulting inadequacy in the official system also allowed for the persistence of religious charities and political/militia groups. These groups seized on the inefficiencies of the state and its absence in many areas to start, continue or expand their social welfare services, thus ultimately replacing the state and further entrenching sectarian loyalty at the expense of national loyalty (Cammett 2014). Essentially, the performance legitimacy of the leaders' as measured by the Justification and Actual Performance indicators (Chapter 3) was significantly high while the performance legitimacy of the state as measured by the Legality, Justification, and Actual Performance indicators was limited.

Fifth, the state system was built to be administratively centralized. Unfortunately with the centralization of the state, the tendency of the society to be more aligned along communal lines and thus to identify more with specific leaders, the politicization of the bureaucracy, and the entrenchment of the sectarian leaders in the lives of their constituents, abuse of state institutions and patronage became more and more entrenched (El-Khazen 2000). Maintaining the abuse of the state and limiting it to specific areas allowed the bourgeoisie to use the state as a means to allow for the dominance of the private sector and the Zuama (leaders) to maintain their patronage system (Najem 2000) and maintain or increase their performance legitimacy (as measured by the Justification and Actual Performance indicators that were presented in Chapter 3). It also helped ease concerns associated with a strong government that could be led by one group and that could then dominate the others (Crow and Iskandar 1961). All in all, the political and economic bourgeoisie colluded to keep the Lebanese state weak, limit the state's social control or its ability to penetrate society and regulate various aspects of people's lives, and protect their respective performance legitimacy. In essence, the state was restricted to a narrow scope of activities that relegated it to secondary importance behind the political leaders, economic powerhouses, and the religious authorities (Crow and Iskandar 1961). According to El-Khazen (2000), this combination of actions and factors have led the state to be accepted by the population for its non-interventionist policy and become neutralized politically and militarily, which led it to relinquish its monopoly over authority and the populations.

Sixth, the post-independence period entrenched a vision of financial trusteeship for the state ${ }^{60}$ rather than one of social programming and development (Kerr 1966). The state left the development process to the market and other private endeavours (Salem 1973), became the effective funder for leaders' performance legitimacy ambitions, and settled into a function that allowed the leaders to meet the basic needs of their followers and thus increase their performance legitimacy.

As can be concluded from the evidence thus far, Lebanon's independence and the 32 years that followed the independence critical juncture reinforced the country's position on the vicious end of the spectrum. The power of the leaders and their desire to protect their performance legitimacy

\footnotetext{
${ }^{60}$ The state became solely responsible for the managing its properties and the public purse and leaders became responsible for all other major aspects that we associate with modern day states.
} 
overwhelmed any democratic and non-democratic attempt at building the state's legitimacy and limiting the power of the leaders.

\section{From a Nascent State to a Civil War}

\section{A. The War}

The period leading up to the outbreak of the civil war was one of conflict along both horizontal and vertical lines (Najem 2000). Yet, sectarian fears and tensions had a bigger impact on society and the subsequent sectarian clashes divided the society along religious lines with the capital, Beirut, being divided into Muslims and Christians cleansed sectors (Salamy 2014).

Eventually, the tensions exploded into a full-fledged war on April 13, 1975 when Palestinian fighters shot at a congregation of Maronite Kataeb party partisans which then led to the retaliatory killing of 21 Palestinians travelling by bus through a Maronite stronghold (Traboulsi 2007). The titfor-tat actions, along with the existing differences between Muslims and Christians regarding the Palestinian file, led to the outbreak of street battles between the partisans of the Kataeb party and partisans of Palestinian armed groups and their local Lebanese allies. Several attempts at a ceasefire were unsuccessful in resolving the problem. The army eventually split and the fighting turned into a full-fledged civil war along sectarian lines (El-Khazen 2000) and the people's own communities became their primary source of security (Gemayel 1992). Syria was asked by the Maronites to intervene to control the PLO and limit their violence within Lebanon (Traboulsi 2007). Syria took advantage to extend its political control, undertook an all-out invasion under the auspices of an invitation from the Lebanese, and thus became another partisan involved in the fighting against Christians and Shias (interview with Christian ex-combatant).

From a sectarian perspective, Christians felt that they had no choice but to go to war given their perception that the West and the East (Arabs) were against them (interview with a Christian key figure). Discussions with Christians regarding their feelings of being left to their own defenses revolve around two examples: first, the invitation by the United States to open its borders to Christians as a means to offer a geographic area to resolve the Palestinian issue while keeping Israel intact; and second the inability of the Christian militias to buy or procure weapons from the Arabs and the West during the early years of the war (interview with a Christian leader). This actual or perceived exclusion or rejection led some Christian factions to turn to Israel for military support (interview with a Christian ex-militia fighter who fought in the early civil war years and was a member of the contingent that went to Israel for negotiations). According to the person interviewed, Israel acknowledged the precarious situation of Christians and their rejection by the West. The visit to Israel ushered in an era of indirect Israeli involvement in Lebanese affairs.

More generally, the civil war was fought along all fronts with all factions fighting each other at several points in time: Sunni fighting Shia, Shia fighting Palestinians, Druze fighting Christians, Druze fighting Shia, Maronites fighting Armenians, Maronites fighting Sunni, Maronites fighting Shia, Maronites fighting Palestinians, Shia fighting each other, Christians fighting each other, etc. (Traboulsi 2007). Acts of ethnic cleansing were committed by all parties involved in the fighting (Ghosn and Khoury 2011). Moreover, along with the internal dynamics, fighting also occurred between Syrian forces and most of the militias in Lebanon across the sectarian divide as well as 
between Israel and various Muslim, and later Christian, groups. While Israel was active in bombarding Lebanon and in offering short-lived assistance to some Christian forces, Syria's more active military and political divide-and-rule strategy fuelled the war for 15 years with many militias (the PLO, Lebanese Forces, Hizballah, etc.) establishing states within the state of Lebanon (Traboulsi 2007), and thus continuing the earlier practice of state delegitimization.

Even with all of the military fighting that pitted leaders against each other, the political system, with the same leaders participating in it, continued to function from 1975 until 1988. Two new presidents were elected and the Lebanese bureaucracy maintained many of its functions with its public servants continuing to get paid and being allowed to cross the green line to receive their paycheck (Najem 2000). Even though their actions might have indicated otherwise, the leaders allowed the state to continue functioning since it was not in the leaders' benefit to call for the destruction of the state that continued to offer them many benefits (Najem 2000). As such, even with the continued undertaking of some democratic practices, the performance legitimacy of the state continued to suffer and thus the state continued to be perceived as illegitimate in the eyes of many Lebanese.

The war led the state to become hopelessly powerless and ineffective, even as it related to the most basic daily matters in people's lives (Ghossain 1988). It also led to displacements and movements within the country and the homogenization of areas within Lebanon (Ghossain 1988). In response and with the feeling of being surrounded and left to their own defenses, Christians in the Christian canton set up a para-state system and rallied to support each other. The Kataeb party concentrated on offering much needed social goods and services, including medical clinics and medical care, mobile clinics, sanitation, public infrastructure, road repair, food distribution, and price controls (Cammett 2014). The Lebanese Forces had a much better welfare system offering health, education, food rations, heating oil, security, road repair, garbage collection, infrastructure development (bridges and roads), public awareness campaign on health and the environment, price monitoring and educational scholarships (Cammett 2014; Kingston and Zahar 2004). In the later stages and as the Kataeb militia was losing steam, the Lebanese Forces militia developed state-like apparatus with a public transportation system, a police force, a public service department, a tax-collection department, and a foreign affairs department with representatives in important capitals (Najem 2000). As Kingston and Zahar (2004) note, the Christian militias increased their penetration into society.

On the Shia front, after several years of neglect, Hizballah, in the early 1980s, took the initiative to support the Shia of south Beirut who were displaced from the south of Lebanon and who faced catastrophic living conditions (Harik 1996). With the increasing neglect of the Shia, even by representatives of the Shia Amal party, Hizballah worked hard to assist them in their needs, establish possibilities for upward mobility, and improve their status from the oppressed poor people of Lebanon to the holders of strength and power (Harik 1996). Hizballah's services spanned the basic needs spectrum and included assistance for food, housing, health, and education. As for the Sunni and Druze communities, their leaders developed more humble para-state service systems (Cammett 2014). 
From a state-society perspective, the war destroyed public social programs and replaced them with those of non-state actors (Cammett 2014). The militias filled the vacuum left by the state, established 'societal order' (Picard 1993), and used social services as a means to encourage the people to stay in their areas and maintain a hold on the land (Cammett 2014). These services were offered to fighters and residents within the militia's sphere of influence (Cammett 2014). This helped increase the performance legitimacy of the leaders of the militias as it is reflected in the Legality, Justification and Actual Performance indicators.

From a state-administration perspective, the war significantly decreased the level of supervision of public servants and had a negative impact on coordination between various units within the public administration (Maroun Kisirwani and Parle 1987). The war also led to direct interferences by political and militia leaders in the appointment of public servants. Demand for and the offering of bribes increased too, as did a fear-ridden acquiescence of the public servants to the threats and desires of the militias (Maroun Kisirwani 1997b; Maroun Kisirwani and Parle 1987). Hence, according to Kisirwani and Parle (1987), the civil war reduced the professionalism of the public service, increased tension between civil servants, increased sectarian prominence within the bureaucracy, weakened the attachment of the civil servants to the state, and significantly decreased the ability of the state to function on a national basis.

The replacement of public basic services by militia basic services and the continued abuse of state resources allowed leaders to (a) either replace the state or divert state resources, (b) gain tremendous levels of performance legitimacy, and (c) thus maintain the country's position on the vicious end of the performance legitimacy spectrum.

From an economic perspective, despite the breakout of the civil war, Lebanon witnessed economic prosperity from 1975 until 1982 with a stagnant or increasing standard of living. According to Najem (2000), the economic achievements were due to three main factors: (1) remittances received from expatriates in Gulf countries, (2) the economic activity and monetary influx created by the presence of the PLO that had a budget that was bigger than that of the state, and (3) the money received by the various militias from their foreign backers. Unfortunately, this prosperity was replaced by an economic decline from 1984 until 1992. The economic crises in the Gulf, the decreasing exchange rate, the expulsion of the PLO, decreasing state revenues due to lower taxation, increasing state military spending, and ballooning public sector wages led to increased inflation, the exodus of the middle income class, increased inequality, and increased poverty (Najem 2000).

This period also coincided with the Israeli invasion of south Lebanon in 1982 and the ushering in of an unstable security situation with increased kidnapping of Westerners, increased intervention and control by Syria and Iran, and decreased patience by the Western world, especially after Hizballah's attack on the American military base in Lebanon (Najem 2000). The result was Western acquiescence to Syria's increased control as well as an increased desire by many Lebanese, especially Christians, for the removal of militia rule and the existence of a more controlling state that was independent of external interference (Najem 2000). By then, many of the militias had lost much of their performance legitimacy by degenerating into mafia-style organizations prying on their own people to subsidize their work (Salamy 2014). The various militias were involved in bank 
robberies, drug smuggling, extortion, kidnapping for ransom, smuggling of arms and stolen goods, and battles to control ports or economic hubs (Salamy 2014). However, the state did not have the capacity or the willingness to do what was required for it to take advantage of the resulting performance legitimacy vacuum.

The civil war continued the tradition of external interference in local politics and in society. As noted earlier, Syria and Israel were directly involved in the war through their presence on Lebanese soil and their control of parts of Lebanon (Salamy 2014). In addition, the two countries, along with Saudi Arabia, Egypt, Iran and other Western powers, were also involved in arming and subsidizing various militias. According to Kisirwani (1997b), every militia group was supported financially, militarily and politically by a foreign country. In the later stages of the war, this influence trickled down into the daily lives of the population through certain militias' offering of non-Lebanese funded social goods and services.

In 1988, Lebanon was facing an impasse in electing a new president with a presidential vacuum looming. In reaction, the outgoing president, Amin Gemayel, appointed General Michel Aoun as prime minister under special circumstances allowed for in the constitution. With this post reserved for Sunni Muslims and the unwillingness of the Sunni Prime Minister to work under Aoun, Lebanon inherited two cabinets, one headed by Prime Minister Salim el-Hoss and considered legitimate in the majority of the non-Christian areas and another headed by Michel Aoun and only considered legitimate amongst Christians (Salamy 2014). With his inability to force the el-Hoss government to acquiesce, Aoun launched the futile 1989 War of Liberation. The short-lived war led to massive Christian immigration and increased militia rule (Salamy 2014). In 1989, the various factions, with the exclusion of Aoun and his supporters, were invited to Ta'if in Saudi Arabia to produce an agreement to end the war. The Ta'if Accord, also known as the Document of National Reconciliation, rewrote the constitution by (a) decreasing the power of the Maronite president and increasing the powers of the Sunni prime minister and the Shia speaker of parliament (Salloukh, Barakat, and Al-Habbal 2015), and (b) instituting a 50/50 rule for the public service with the equal division of posts between Christians and Muslims. It also legitimized the control of Syria, not as an invader, but as the broker of peace in Lebanon and allowed for the election of a new president. The Accord was signed on October 22, 1989 (Salamy 2014). However, the Accord only became a reality when Iraq invaded Kuwait in 1990 and the United States was actively working on getting Syria to join its anti-Saddam coalition (Salloukh, Barakat, and Al-Habbal 2015). Aoun refused the Ta'if Accord and launched another war in 1990 to halt its implementation. The war led to Syria's invasion of the whole of Lebanon, the imposition of the Ta'if Accord over the entire territory (Salamy 2014), and Aoun's exodus to France on October 13, 1990.

According to the Ta'if Accord, the de-secularization of the state was to be undertaken on an undefined future date that was established by the leaders themselves (Salloukh, Barakat, and AlHabbal 2015). Without a defined date or process and with the reliance on leaders to implement policies that would limit a significant factor in the legitimacy of their power, the Ta'if Accord made leaders the king makers and the guardians of their own future and that of their state. In essence, the recycling and updating of the sectarian political system was an undeclared outcome of the Ta'if Accord (Salloukh, Barakat, and Al-Habbal 2015). 
The war finally ended in 1990 when Syria invaded all of Lebanon and the new government was able to extend its control thus turning Lebanon into "a country under tutelage" (Gemayel 1992, 3). The new government was perceived by many, with the exception of the majority of Christians, as a welcomed imperfect step towards a stable representative government (Hudson 1999).

\section{B. Analysis}

Lebanon's civil war involved sectarian overtones, external players, external provocation, proxy agendas, economic consequences, the destruction of state institutions, and the further entrenchment of sectarian loyalties. The war also imposed a significant human cost with over 130,000 civilian deaths, about one million injured (representing about one quarter of the Lebanese population), 900,000 displaced people, and the immigration of hundreds of thousands of people (Salamy 2014). From an infrastructural perspective, the civil war led to a destruction of physical capital that is estimated to be in excess of US $\$ 15$ billion (Saidi 1994). The war also significantly weakened the Maronite position in the country (Salloukh, Barakat, and Al-Habbal 2015).

Unfortunately, the war experience increased the alienation of the people from the Lebanese state, caused a transfer or a retrenchment of their loyalty, and perhaps their submission, to the militias and their leaders (Picard 1993). It also re-entrenched the importance of sectarianism in the society (ElKhazen 2000). Finally, while there were changes in the leadership of certain groups, the $z u$ 'ama system continued in a new less obvious form.

Yet again, the conflict critical juncture did not usher in a change in the performance legitimacy landscape since leaders were able to maintain their hold on the delivery of basic goods and services. The eventual peace - another potential critical juncture - also failed to usher in a process that allowed the state to earn performance legitimacy. The result was a reinforcement of the vicious cycle and the retrenchment of the performance legitimacy of the leaders, a process that the analysis now turns to examine.

\section{Lebanon's Post-Conflict Era I: Syrian Tutelage (1990-April 2005)}

By 1992, Lebanon had witnessed significant economic and social destruction. The destruction of infrastructure totalled in the billions of US dollars, less than 50 percent of telephone lines were working, electricity was available for only a few hours a day, 80 percent of potable water was polluted, all sewage treatment plants were not functioning, most roads were badly damaged, and the international airport and ports needed significant repair (Najem 2000). Moreover, 55 percent of the population suffered from overcrowding, 21 percent did not have access to water supply connections, 48 percent were housed in illegal and overcrowded dwellings, the minimum wage dropped from $\$ 135$ in 1975 to $\$ 50$ in October 1992, unemployment rate was at 35 percent, and real per capita Gross National Product was at one third of where it was in 1975 (Najem 2000).

From a public administration point of view, the war disrupted state social services and weakened state authority; it also transferred royalties, fostered new cultural norms, and generated states within states with their authority being based on political and military strength and their access to state resources (El-Zein and Sims 2004). According to El-Zein and Sims (2004), following the end of the civil war, 60 percent of the administrative posts were vacant, there were no recruitments of new civil servants to fill the vacant positions, and training initiatives targeting public servants were non- 
existent. The outcome was an older public service population that lacked capacity and expertise and a public administration that was incapable of undertaking the tasks needed to reconstruct and rehabilitate Lebanon. If we refer back to the Legality, Justification and Actual Performance indicators that were advanced in Chapter 3 - the confidence in the civil service, people's perceived importance of state institutions, confidence in the security provided by the state, perceived reach and applicability of the law, satisfaction with the state's effort to meet the basic needs of the population, perceived willingness of the state to support its citizens, degree to which the citizens turns to the state for help, number of basic goods and services provided by the state, quality of statedelivered basic goods and services, and ease of access to state-delivered basic goods and services it becomes clear that the state was not provided with the means to earn performance legitimacy.

\section{A. State Post-Conflict Development Plans}

The solution to the administrative limitations involved (a) turning to private actors, businesses as well as non-governmental organizations and (b) working on improving the capacity of the state through the National Administrative Rehabilitation Program (NARP), a program that was implemented by the Office of the Minister of State for Administrative Reform (El-Zein and Sims 2004). The objectives of the NARP were to restore state analytical capacity, state physical/infrastructural capacity, state data gathering capacity, responsiveness of the public administration to the needs of the population, improvement of fiscal management, and improvement in governance through increased accountability and management for results (El-Zein and Sims 2004). The plan was supported by the United Nations Development Programme, the World Bank, the Arab Fund for Social and Economic Development, the European Union, France, Canada, and Kuwait (El-Zein and Sims 2004). The plan achieved very limited success with the body responsible for its implementation being paralyzed by structural issues, corruption, political interference, cumbersome procedures and lack of accountability (El-Zein and Sims 2004).

Yet, the experience of the NARP perfectly demonstrates the political nature of reform. Reform within Lebanon's public administration ran up against socio-political realities and thus the preferences of the political leaders. Given the history of the politicization of the administration, the master-worker relationship between leaders and public servants, and the transfer of loyalty of public servants to their leaders, reforms, which required the leaders' approval and implementation of decrees often became acts on paper or words in thin air (interview with El-Khazen). Given that the leaders had a long history of earning performance legitimacy by abusing as well as replacing the state, the post-conflict process clearly demonstrates the process identified in the discussion related to the vicious cycle of the theoretical framework that was advanced in Chapter 2. Not only did the state lack capacity to earn performance legitimacy, but also all the reforms that were intended to help the state build capacity were derailed by leaders who worked on diverting state resources in their bid to maintain or gain performance legitimacy.

Serious post-conflict reconstruction only began when Rafik Hariri, the new Sunni Prime Minister and billionaire tycoon, developed Horizon 2000, the ten-year neoliberal economic plan for Lebanon. The plan was to cover the period from 1992 until 2002 and had an estimated cost of US $\$ 11.7$ billion. Horizon 2000 had two main goals. First, it was to improve economic activity by improving the investment environment through the building of physical infrastructure, social 
infrastructure by working on housing and resettlement, public health, social services, education, sports, and culture, and establishing macroeconomic stability. Second, it aimed to reconstruct public confidence in the state and the future of the country through public sector reform (Najem 2000). More than 56 percent of the expenditure within the plan was on physical infrastructure (Najem 2000) while most of the non-infrastructure-related projects were given secondary attention.

The plan was to be funded through grants, loans, and money from investors. However, the plan was massively underfunded and experienced significant delays in implementation due to the precarious situation in the Middle East, the risks associated with the presence of Syria in Lebanon, institutional capacity problems, and internal political gridlock with most leaders wanting to benefit from the program (Najem 2000). Clearly, the desires of leaders to maintain or earn further performance legitimacy had a significant effect on the design and development of the project and on the

Figure 5.1: Mashreq Region: Real

GDP Growth, 1995-2005

(Annual percentage change)

(International Monetary Fund 2006, 38)

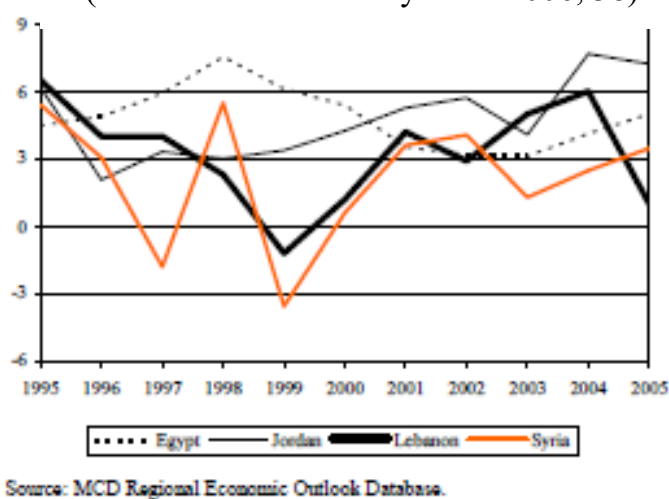

subsequent changes that were made. As a result, Hariri's government moved to cut expenses with social infrastructure projects becoming the first to be cut (Najem 2000). In effect, Horizon 2000 turned out to be a more geographically restricted plan that aimed to restore downtown Beirut to its glory times and renew its role as a regional and international financial and commercial hub. ${ }^{61}$ With all funding focused on infrastructure, the weakened agricultural and industrial sectors as well as the emancipated state social services sector received little to no attention (Jawad 2002). If the level of performance legitimacy is captured through indicators that measure the success of the state in meeting the needs of the population and the perceived importance and confidence

in the state, then one can argue that Horizon 2000 again limited the ability of the state to earn performance legitimacy.

Lebanon's debt-to-Gross Domestic Product (GDP) ratio increased steadily from 58 percent in 1992 (Saleh and Harvie 2005) to 146 percent in 2000 (Jad 2011). During this same period and as the Figure 5.1 demonstrates, GDP growth rate went from just over six percent in 1995 to just over one percent in 2000 with continuous decreases from 1995 until 1999 when the GDP growth rate reached -1.2 percent before it rose again in 2000 (International Monetary Fund 2006).

The Hariri government managed the post-war reconstruction as an enterprise that was led in a nontransparent and non-competitive manner by an alliance of political and business partners (Salloukh, Barakat, and Al-Habbal 2015). He established a parallel administration to the state for his own business goals and to allow him control over the state administration (interview with El-Khazen academic and a current MP). Hariri's actions established a system of double bureaucracy that significantly improved his popularity (interview with El-Khazen academic and a current MP) and

\footnotetext{
${ }^{61}$ As a side note, Lebanon's reconstruction provided external companies with significant revenues since more than US $\$ 3$ billion were awarded in contracts to non-Lebanese organizations, private businesses, and agencies based in the donor countries (Najem 2000).
} 
his performance legitimacy while limiting that of the state (as perceived through the Legality and Justification indicators that were identified in Chapter 3). Moreover, in using the cumbersomeness and limited capacity of the public administration as weapons to implement his neoliberal plan, Hariri allowed leaders to minimize the state and rely on sectarian organizations to fill in the vacuum (El-Mufti 2011; Jawad 2002; Salloukh, Barakat, and Al-Habbal 2015). Furthermore, for many of the services that were officially provided by the state, the Hariri government contracted out these services through private actors and local non-governmental organizations (El-Mufti 2011; Jawad 2002) that were, more often than not, linked to one or several leaders with positions in the government. As such, the state became more and more distant from its population and the leaders worked in tandem to abuse state resources, earn performance legitimacy and limit that of the state. If the state's and the leaders' performance legitimacy are measured by the willingness (Justification indicators) and capacity (Actual Performance indicators) of the state and leaders to deliver basic goods and services and thus the relevance of the state and leaders in people's lives (Legality indicators), then one can conclude that the vicious cycle was well oiled and continued unabated even with the rise in power of new leaders.

Figure 5.2: Debt-to-GDP Ratio (Jad 2011, 3)

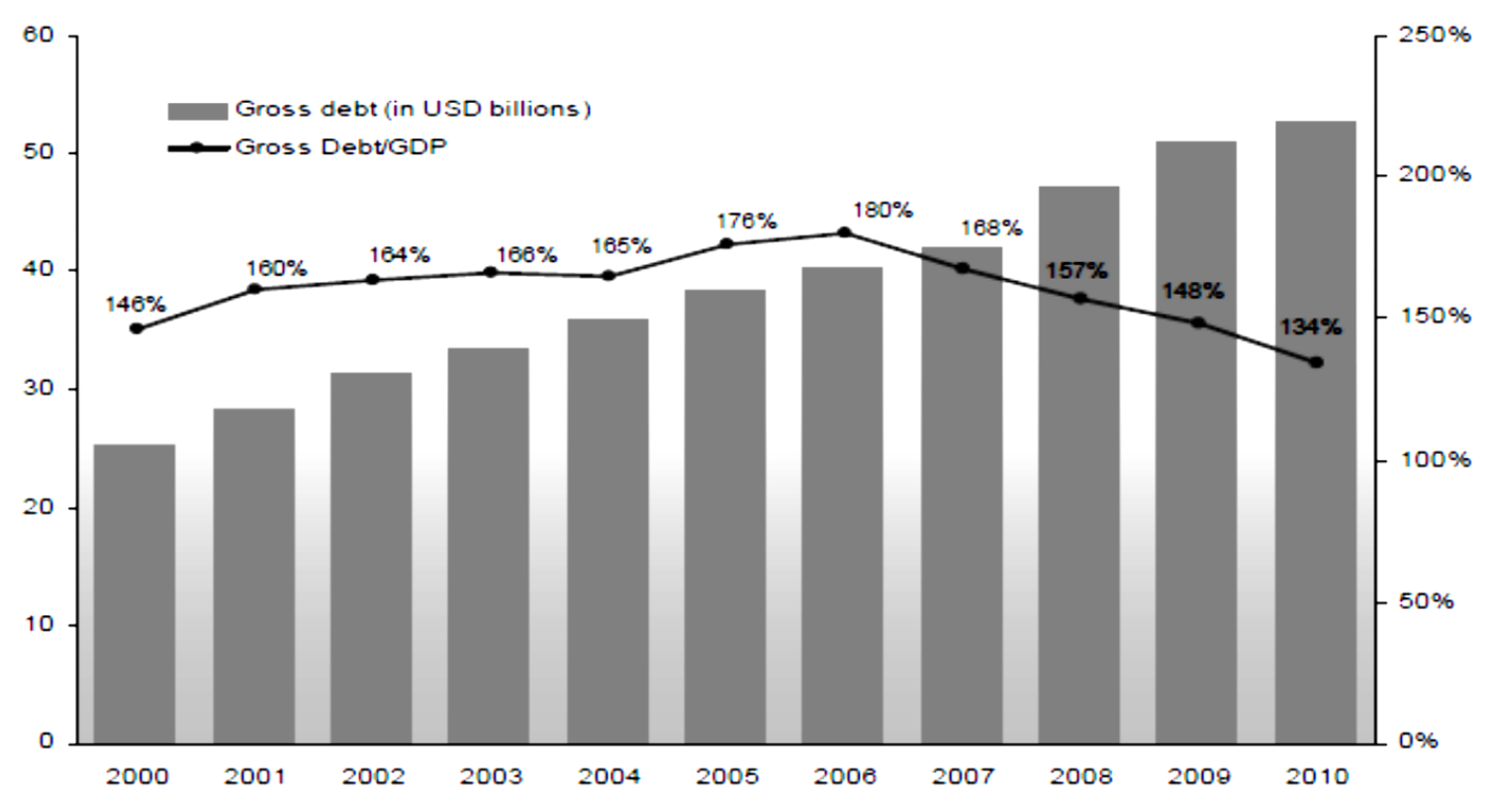

The Hariri era (1992 - 2004) witnessed a significant climb in the debt-to-GDP ratio that was assessed at 58 percent in 1992 (Saleh and Harvie 2005) and 176 percent in 2005 (Jad 2011). However, the transition into the Hariri era did contribute to the economy by helping to decrease inflation from 131 percent in 1992 to 12 percent in 1994 and reinvigorating the GDP (Najem 2000). Hariri was able to use his business skills to advance the economy and the reconstruction of some parts of Lebanon. Hariri was also able to secure 500 million euros worth of development funding from France in February 2001 and a pledge of US\$4.4 billion worth of development funding from the international community, with only $\$ 2.5$ billion entering the country (Schenker 2007). This was 
a significant increase as compared to the US\$2.5 billion that Lebanon received in total official development aid in the first 11 post-conflict years (Figure 5.3).

However, even with remittances growing by 202 percent between 1990 and $2007^{62}$ (Salloukh, Barakat, and Al-Habbal 2015), the Hariri years were economically tumultuous with two recessions occurring in 1997 and 1998 (Najem 2000), a near economic collapse in 2001, and another economic downturn following his assassination in 2005 (Dibeh 2005). The Hariri era also signalled the return and reinvigoration of collusion between big business and politicians, something that did not exist prior to the war (interview with El-Khazen), and the abuse of the state's fiscal policies for the leaders' own interests (Salloukh, Barakat, and Al-Habbal 2015). It also excluded most Lebanese from accessing the spoils of peace (Baroudi 1998) and led to increased taxation on the poor, decreased taxation on the rich, increased inequality, and the disappearance of what was left of the middle class (Hudson 1999). In effect, the Hariri era led to a ramping up of the vicious performance legitimacy cycle and a new process whereby all leaders used their performance legitimacy to divide the country further by blaming 'the other' for the social and economic impasses that caused havoc in most Lebanese people's lives.

Figure 5.3: Official Development Aid (USD Millions)

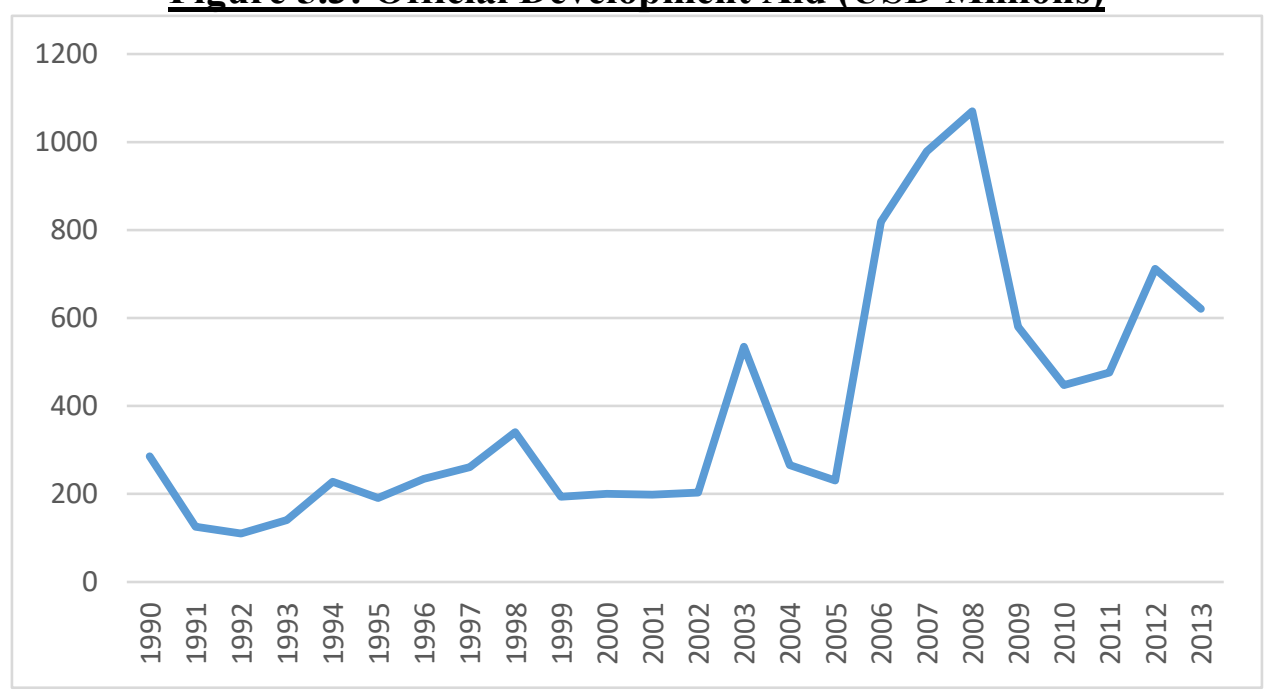

Source: The Organization for Economic Development and Cooperation ${ }^{63}$

\section{B. Post-conflict Politics}

The post-conflict era was rife with political assassinations. It began with the assassination of René Mouawad, a Maronite and the first president elected following the signing of the Ta'if Accord. He was assassinated on the $22^{\text {nd }}$ of November 1989, 17 days after taking office. Less than a year later, Dany Chamoun, the leader of the National Liberal Party representing Christians, was assassinated along with his entire family. In 2002, Christians lost another political leader when Elie Hobeika, the leader of the Lebanese Forces Political Party, was assassinated. The period of assassination under Syria's tutelage ended with the assassination of Prime Minister Rafik Hariri and Minister Bassel

\footnotetext{
${ }^{62}$ Remittances represented 20 percent of GDP in 2006 and 2007. In 2013, remittances were valued at US\$7.6 billion and their share of GDP fell slightly to 17.4 percent (Salloukh, Barakat, and Al-Habbal 2015).

${ }^{63}$ https://stats.oecd.org/qwids/.
} 
Fleihan in February 2005. This last assassination caused an uproar amongst the Sunni populace, who were supported by the majority of Christians in their condemnation of Syria and their demand for its withdrawal. The uprising was dubbed the Cedar Revolution and led to the withdrawal of Syria in May 2005. However, Syria still maintained its significant influence through its Lebanese allies, which included many Shiite groups, among them Hizballah, and other non-religiously aligned parties.

The main beneficiaries of the post-conflict era were warlords and other political leaders. While their economic interests were being expanded, they worked politically to ensure their political dominance and became responsible for several important state portfolios which they used for patronage purposes (Cammett 2014; Salloukh, Barakat, and Al-Habbal 2015). This patronage system ensured that leaders increased their power through higher votes in elections and muchneeded support on the street which they then used to incite violence (Cammett 2014). This process is captured by the effect indicator that measures the leaders' performance legitimacy by capturing the fact that supporters follow the leaders' rules or actions as a result of these leaders' perceived performance legitimacy.

In effect, the peace process and the initial post-conflict years led to the division of state resources and all of the benefits associated with post-conflict development initiatives amongst the leaders (Leenders 2012). It also led to the reorganization of the leaders' areas of influence (Leenders 2012) and accelerated efforts to erase whatever was left of the state's legitimacy. As such, the state was very important to leaders and played a critical role in their calculations of self-enrichment and the outmanoeuvring of rivals. Furthermore, the prospects of continued or additional power and control emanating from state institution-building pushed many leaders to influence the institution-building process and guide it in the direction that was most beneficial to them (Kingston and Zahar 2004). In general, significant political underpinnings guided state institution-building initiatives and processes resulting in increased power for leaders (Leenders 2012) and a ramping up of the vicious performance legitimacy cycle.

Post conflict elections did not do much to 'fix' the problem. According to Salloukh (2006), postconflict elections allowed for the consolidation of an existing confessional and clientelistic system. The elections and the Ta'if Accord, both of which were part of the democratic governance agenda, allowed for the reconciliation of leaders and the abuse by new and old leaders in order to have access to the spoils of war and peace (Ghosn and Khoury 2011). Electoral processes also did not allow for the development of an accountability system at the populace level given that reconciliation never occurred between the various communities in Lebanon (Ghosn and Khoury 2011), thus allowing the leaders to use sectarian divisions and the delivery of social services to continue their historical role as defenders of their communities. As such, process legitimacy became secondary to performance legitimacy and democratic reforms became captured by leaders who had the legitimacy to do so.

From a demographic and socio-political perspective, the civil war caused a major transformation in the socio-economic and political landscape (Interview with El-Khazen). The disadvantaged Shia community experienced a major social, economic and political transformation allowing them to shed their disadvantaged status. The Sunni community also enhanced its political and economic 
power owing to the Ta'if Accord and the collusion between big business and the state (interview with El-Khazen academic and a current MP). Moreover, while all Christian militias and non-Syrian allies were being demobilized as per the stipulations of the Ta'if Accord, Syria undertook other political and social actions, including the jailing of the Christian Lebanese Forces leader Samir Geagae, to break apart all organized actual and potential opposition to its control (Salloukh, Barakat, and Al-Habbal 2015). It also did so to allow its proxy, Hizballah, to maintain military hegemony as a bargaining chip over Israel (Salloukh, Barakat, and Al-Habbal 2015). Hizballah was also given the power to exclude other Lebanese factions from fighting for the withdrawal of Israel from the South (Salloukh, Barakat, and Al-Habbal 2015) and was supported by the state, which, with the insistence of Syria, decided not to reclaim the South by sending military troops to secure the area following Israel's withdrawal in 2000 (Saouli 2003). Hizballah was also allowed to exclude the Lebanese state from its strategic areas of control, including southern Beirut, the Bekaa Valley, and parts of South Lebanon (Salloukh, Barakat, and Al-Habbal 2015).

In post-war Lebanon, Syria continued to play the divide-and-rule game, one that it had played since before the outbreak of the civil war (Norton 2000). Syria also penetrated and pulverized civil society groups, the media, and the judicial system (Salloukh, Barakat, and Al-Habbal 2015). Syria's overwhelming political, military, and secret service hegemony over Lebanon is one of the biggest distinct features of the early post-conflict period (interview with Fouad El-Khazen, an academic and a member of parliament with Aoun's Free Patriotic Movement party). From 1989 until 2005, Syria was the kingmaker and the ultimate arbitrator of all issues in Lebanon (Salloukh et al., 2015). It chose the Lebanese leadership (President, Prime Minister, and Speaker of Parliament) and ensured that the policies that were implemented were politically and economically beneficial for Syrian leadership (Salloukh, 2006).

With the Christian community representing the largest opposition to Syria's actions in Lebanon and given the history of Christian opposition to Syrian invasion and rule in Lebanon, the community became Syria's primary target (Salloukh 2006). Syria neutralized the Christians politically by: (a) jailing some of its leaders, (b) exiling many others, (c) penetrating Christian political and social organizations with Syrian-chosen supporters, (d) assassinating Christian leaders that had the potential to cause trouble, and (e) having Christian Members of Parliament being chosen by Muslims through the addition of Christian parliamentary seats representing areas with Muslim majorities (Salloukh 2006). Moreover, Syria and its allies in Lebanon also worked on limiting the future power of Christians by placing significant hurdles for many Christian immigrants who wanted to maintain their citizenships and register their offspring (interview with Christian key figure). In conclusion, Syria's actions along with that of its allies reconfigured the political, social and religious fabric of Lebanon.

\section{Post-conflict Socio-political Conditions}

By 1996, the Maronites were marginalized, the Shia and Druze militias remained intact, old Sunni and Shia traditional politicians were replaced with new oligarchs and religious figures, civil society, as defined by western liberal development theory, was devastated, the state was controlled by the oligarchy of the very rich (El-Mufti 2011; Hudson 1999), and Lebanon was part of a very strong and vicious performance legitimacy cycle. This resulted in the continuation of state non- 
responsiveness to the basic needs of the population that was transitioning out of a devastating civil war. By 1995, 34 percent of the population was considered deprived of whom seven percent were considered to have very low living conditions (Ministry of Social Affairs and United Nations Development Programme 2007). This along with the state's lack of administrative capacity to meet these needs, and the leaders' unwillingness to transfer this major source of legitimacy to the state, allowed the various non-Christian militias, political parties, and non-state actors associated with these parties to fill the vacuum and entrench themselves in people's lives.

For its part, Hizballah continued to take advantage of the precarious conditions of the Shia population in southern Beirut, the Bekaa Valley, and the south of Lebanon (Harik 1996) to increase and entrench its performance legitimacy. Owing to the suffering of the Shia during the war and the early post-war period and to the desire for Hizballah to earn legitimacy, the militia and party developed a highly sophisticated catering system with a very extensive network of services that improved the lives of thousands of deprived Shia and infused the party in every aspect of their beneficiaries' lives (M. Harb and Leenders 2005). While the services were offered mostly to Shia, Hizballah also extended its assistance to needy Christians, Druze and Sunnis in its areas of control. The goods and services they offered were in the areas of health, water, education, material assistance, agricultural extensions, infrastructure and construction, microcredit, sports and youth clubs, media outlets, and religion (Cammett 2014). In addition to the three hospitals and over 17 medical centers, Hizballah also currently runs a network of commercial actors ranging from supermarkets to petrol stations to department stores and construction companies (Hamzeh 2000). Hizballah's system of service delivery continues to this day and covers a diversity of policy sectors, is perceived to be more reliable and of higher quality standards than that of the state and cheaper than that of private providers (M. Harb and Leenders 2005). This has made Hizballah a highly respected party in the eyes of many Lebanese, including the non-Shia (Hamzeh 2000), and has entrenched its performance legitimacy and power. The militia and party has used its services to build electoral support and to maintain the continued support of its core base made up of fighters and their families (Cammett 2014). Hizballah has used its performance legitimacy to earn process legitimacy through the electoral process (Hamzeh 2000) and it has been very successful at gaining support amongst Shia and non-Shia beneficiaries who have been supported by Hizballah after being ignored by the state and their own community actors (Harik 1996). Moreover, Hizballah has used its performance legitimacy apparatus to "disseminate codes, norms and values that produce what has been described by the party as the "Resistance society" (M. Harb and Leenders 2005, 188). This has allowed Hizballah to develop parallel administrations to the state and infuse a Shia identity that is interlinked with Hizballah's identity (M. Harb and Leenders 2005).

Amal, the other Shia party, has also offered services to its supporters in the post-conflict phase. It currently offers education, health and social assistance programs. Yet, given its limited resources and the need to compete with Hizballah, Amal has found the need to use state institutions and state resources to maintain performance legitimacy (e.g. loyalty and support), something that party officials have openly acknowledged (Cammett 2014). One glaring example is its use of the position of Minister of Public Health, which it has controlled for several years, to offer health services to its supporters (Cammett 2014). 
The Sunnis were supported by Hariri who used various charitable organizations to offer educational grants, health services, food parcels, and housing. The Druze have also benefitted through access to state resources as a means to offer assistance to their supporters. One obvious example is the control over the file of the displaced that Jumblatt has used to assist the Druze and limit the return of the Christians in the Chouf mountains (Cammett 2014). As for the Christians, the social programs of the Kataeb party and the Lebanese Forces unraveled under Syria's tutelage and, owing to Syrian pressures, these militias were unable to regain their social services arm (Cammett 2014) and their performance legitimacy.

The practice of replacing the state by offering social services became so widespread that many party officials recognized the important role that social services played in maintaining their relevance (Cammett 2014; Leenders 2012) and their performance legitimacy. The chance of being rendered useless and of losing supporters due to the lack of social service support (Cammett 2014) led the parties to use whatever means necessary to maintain the loyalty of their supporters and regain those that they had lost.

The delivery of social services resulted in improvements in the lives of many deprived people in Lebanon. According to the report by the Ministry of Social Affairs (2007), the percentage of deprived people dropped from 31 percent in 1995 to 25 percent in 2004. The authors of the Ministry's report note

"that the biggest improvements occurred in the fields of housing and education, where the percentage of the deprived households declined by $9 \%$ for each, followed by the water and sewerage field (at a decrease of 3\%). The field of income-related indicators, however, witnessed an increase in deprivation by 9 percentage points (from approximately $43 \%$ to $52 \%$ of the total households in Lebanon). Whereas the indicators related to housing and education improved, as have water and sewerage, the income-related indicators have declined" (Ministry of Social Affairs and United Nations Development Programme 2007, 22).

This trend was consistent even when the data was broken down by muhafaza or province.

The resulting outcome of these leaders' actions - performance legitimacy - is captured by the indicators that measure the actual performance of the leaders of the various groups, the perceived willingness and success of these leaders to help their supporters, and the confidence that the supporters have in the security and services provided by these leaders. These indicators also demonstrate the state's limited level of performance legitimacy.

\section{Analysis}

The early post-conflict period witnessed economic turmoil, the withdrawal of Israel from Lebanese land, continued Israeli incursions into Lebanese territory and airspace, Syrian hegemony over politics and many aspects of people's lives, political crises, political assassinations, socio-economic and political reconfiguration of the Lebanese society, a reconstruction of Beirut's financial hub, increased inequality, political decision-making paralysis, an unruly political maze (Maroun Kisirwani 1997b; Salloukh, Barakat, and Al-Habbal 2015), and increased competition between 
leaders who saw it fit to jockey for their positions without undermining the system and causing a return to war.

Moreover, as the data from the Ministry of Social Affairs indicates, the various social service interventions of these leaders, whether through the state apparatus or outside of it, have had a positive impact on the living conditions of the population. Yet, this impact has come at a price: the transformation of the relationship between people and militias from one of support to one based on clientelism (Nassif 1998) and performance legitimacy and the reinforcement of the leaders as brokers between the 'untrustworthy' state and the population. In essence, the peace process and the early post-conflict years introduced a higher level of viciousness to the cycle that Lebanon was already familiar with since the years of the Ottoman Empire. The Ta'if Accord, the Syrian control of the state, the militias' use of state resources, and the competition for state resources between the various leaders led the state to become a tool for militias whose objective was to abuse the state by increasing the level of sectarianism and clientelism within the state apparatus (Salloukh, Barakat, and Al-Habbal 2015). The research has also demonstrated that performance legitimacy was more important to leaders and their population than process legitimacy. Moreover, the research also demonstrated the impact of performance legitimacy on the level of process legitimacy. Overall, based on the measurement indicators that are found in Chapter 3, the result is one of increased performance legitimacy for leaders and the maintenance of a weak state-society relationship that exhibits little or no performance legitimacy, a situation that is reflected in the vicious cycle of the theoretical framework that was represented in Chapter 2.

\section{Lebanon Post-Conflict Era II: Following the Withdrawal of Syria}

Many of the exiled Christian leaders returned to Lebanon following Syria's withdrawal in 2005. Michel Aoun and former President Amine Gemayel returned from Europe and began to reclaim their influence over the Christian political scene. Aoun formed the Free Patriotic Movement Party while the Gemayel family began to reinvigorate the Kataeb party. Samir Geagae was released from prison and worked on regaining power or influence through his Lebanese Forces party. In 2007, the Hariri family established the Future Movement party as a means to merge Sunni representation under one party.

Political assassinations continued with an uptick during the first few months following Syria's withdrawal. Samir Kassir, a university professor, journalist and historian, was the first to be assassinated during this period, less than four months following Hariri's assassination. The former secretary of the Lebanese Communist Party was also assassinated in June 2005. Gebran Tueni, a Christian and a staunch anti-Syrian newspaper editor, was assassinated in December 2005, eight months after he became a member of parliament. Less than a year later, the son of Amine Gemayel, Minister Pierre Gemayel, a member of the Kataeb movement and critic of Hizballah and Syria, was also assassinated. In June 2007, a Sunni member of parliament, Walid Eido, was also assassinated. Three months later, a Christian member of parliament, Antoine Ghanem, was assassinated. Following an undercover investigation into the role of Hizballah in the assassination of Hariri, François al-Hajj, Brigadier General of the Lebanese Army, was assassinated in December 2007. The leader of the Lebanese Democratic Party and a member of the Druze community was also 
assassinated in September 2008. Mohamad Chatah, a former Minister of Finance representing the Sunni community, was assassinated in December 2013.

Meanwhile, external players maintained their influence and control. Syria maintained its presence indirectly through its influence on politicians, militia leaders and other private citizens. Iran maintained its influence through Hizballah. Saudi Arabia increased its interference through the Sunni community. Israel continued its air raids into Lebanon and invaded Lebanon in July/August 2006 following Hizballah's kidnapping of two Israeli soldiers. ${ }^{64}$ In the spring of 2007, Lebanon faced another external threat from certain Palestinian factions in the Northern Refugee Camp of Nahr al-Bared culminating in a severe conflict and the subsequent destruction of the camp. In 2008, following street fighting between Sunnis and Shias, Qatar increased its involvement in Lebanon by brokering a new agreement to decrease tensions between the leaders of the two sects. Essentially, as of 2009, all leaders within Lebanon had foreign patrons or sponsors who exerted influence on events in Lebanon (Hajjar 2009).

The Lebanese Government has faced many instances of paralysis since the withdrawal of Syria. With two presidential vacuums ${ }^{65}$ and the resignation of several members of parliament, including most of the Shia politicians, the state has been in a state of paralysis. It is important to note though that these actions have been accepted if not promoted by many of the supporters of these leaders. For example, Hizballah has used its performance legitimacy to mobilize its beneficiaries whenever a demonstration of their support is needed (M. Harb and Leenders 2005). The 2006 Hizballah-led sit-in saw the participation of hundreds of thousands of people (Chassay 2006) with the majority belonging to the Shia population. The threat to Hizballah's arms led the party to withdraw its ministers from government and use its supporters, who deemed the state to be illegitimate, and its performance and process legitimacy to paralyze the country (Hajjar 2009). With not much changing politically, the opposition, led by Hizballah called for a general strike that soon deteriorated into violence between Hizballah, with the support of Amal, and Sunnis, with the support of the Druze (Haddad 2009). At the same time, hostilities were running high between the government and the opposition, with the pro-Sunni Lebanese government challenging Hizballah's right to run a telephone network outside the control of the state or the existing system (Atzili 2010; Hajjar 2009). Hizballah's response was a military-style offensive on Sunni areas within Beirut and on Druze areas in the Chouf Mountains. The clashes ended with Hizballah claiming military victory, maintaining its telephone lines, and enforcing de-facto military control over many parts of Lebanon (Atzili 2010). Yet again, the legitimization of Hizballah and the de-legitimization of the state (or the vicious cycle) allowed Hizballah leaders to undermine the security of the country and push Lebanon

\footnotetext{
${ }^{64}$ Israel continued to launch attacks on Lebanon in retaliation for attacks committed by Hizballah. Three major attacks took place in 1993 (Operation Accountability resulting in more than 100 civilian deaths), 1996 (Operation Grapes of Wrath with over 150 civilians killed (Hudson 1999)), and 2006 (Lebanon War with over 1,100 civilian deaths (International Crisis Group 2006)). Each of these attacks led to major destruction of infrastructure. The 2006 attack took place following Israel's withdrawal from Lebanon in 2000. The withdrawal of Israel was seen as a significant victory for Hizballah, the self-proclaimed liberation and resistance movement.

${ }^{65}$ A presidential vacuum imparts additional power onto the Sunni community since the constitution allows the Sunni Prime Minister to become acting President. This has raised the fury of the Lebanese Christian community (interview with El-Khazen, interview with Christian leader).
} 
to the brink of another civil war - actions that are reflected in the Acts of Consent, more specifically, the 'compliance with leader-sanctioned rules or actions' effect indicator in Chapter 3.

The impasse led to the intervention of external regional players, including Qatar, Saudi Arabia, Iran, Turkey, Syria, and the Arab League (Hajjar 2009). Their intervention led to the signing of the Doha Agreement by all Lebanese political players. The new deal ushered in a new head of state, changed the power structure within cabinet, removed the deadlock in the Lebanese parliament, and gave signs of a commitment to maintain economic stability (Haddad 2009). The resulting new power structure within cabinet currently requires only 11 ministers to block any government decision, a situation that allows for perpetual paralysis. Yet again, while efforts were made to adjust the political processes, no effort was spent on strengthening the state and protecting it from the abuse of leaders. More recently, external factors related to the spillover of the Syrian civil war into Lebanon have led to acts of violence against Sunnis, Shia, and Alawites within Lebanon.

On the economic front, a significant amount of new money entered the economy between 2005 and 2008 as a result of foreign governments' commitments to help Lebanon improve its economy and reinvigorate its development. As is evident in Figure 5.3, Lebanon received more than US\$5.9 billion from 2005 to 2013. The disbursements were linked to the 2006 war between Hizballah and Israel, the socio-economic crises, the influx of refugees from the Iraq war, and the crisis associated with the spill-over of the Syrian civil war.

In the midst of all of this, all leaders continued to strengthen their hold on the population through the use of their party's or group's service delivery arm. Hizballah's services continued to reach the Shia population and many non-Shia living in Shia-dominated areas under their control. ${ }^{66}$ There is evidence of cross-sectoral support with many Christians and Sunnis imparting performance legitimacy onto Hizballah owing to its assistance (Cammett 2014). Saad Hariri, son of assassinated Rafik Hariri, officially established the Future Movement Party in 2007. The party continued the legacy of Rafik Hariri by offering assistance with housing, food, education, health, disabled children, and poverty alleviation to Sunnis and non-Sunnis alike (Cammett 2014). The party has used these services as a means to gain mass appeal and allow Hariri to have the desired impact on the socio-economic and political front (Cammett 2014). As for the Christian parties, the withdrawal of Syria allowed for the Lebanese Forces party and the Kataeb party to restart their social welfare programs (Cammett 2014). The Lebanese Forces currently offers services in health, assistance to the poor and food aid and uses its connections to negotiate better university fees and scholarships (Cammett 2014). The Kataeb party has a limited social services arm since it refuses to acquiesce to external pressures that accompany such financial support (interview with a Kataeb political party official) and thus uses private donations to offer basic assistance. The Free Patriotic Movement led by Aoun launched its social programs following its official 2006 alliance with Hizballah and the subsequent transfer of funds (Cammett 2014). As such, even the Christian parties have

\footnotetext{
${ }^{66}$ It is very difficult to estimate an actual number that can represent the percentage of the population that has received Hizballah services. Lebanon has not undertaken an official census since the late 1960s. However, Shias are assumed to make up more than 30 per cent of the Lebanese population and Hizballah receives the overwhelming Shia support.
} 
reinvigorated their service delivery and have contributed to the undermining of the state's performance legitimacy. ${ }^{67}$

According to Cammett (2014), there is an open acknowledgement by the various players of the need to reward their supporters. Offering services has allowed these actors to lock-in their control over their supporters, both on the political and the social front (Cammett 2014; Salloukh, Barakat, and Al-Habbal 2015). The delivery of basic goods and services has also built the actors' political power and, when provided across religious lines, it has played an important role in the mobilization of wide-ranging support outside of the core constituency (Cammett 2014) and in ensuring acts of consent on the part of the population. For leaders with limited financial resources, providing basic social goods and services requires them to draw on state resources, hence the importance of working inside the state and abusing state resources.

In summary, warlords and militia men dominate the current system, continuously manipulating it (Salamy 2014) and using it as a means to defend and promote their power and their group's interest "at the expense of an entire nation" (Picard 1993, 50). Because of this, the legacy of the war, and foreign interventions, the state continues to face manipulation by militia and elite politics. The desire to control the state when it offers benefits to the leaders and undermine it when it offers no or very limited benefit, is an indication of the subordination of the state to the overriding legitimacy of the leaders (Salamy 2014). Moreover, the state has been a tool for legitimate sectarian elites to use their legitimacy and reproduce sectarian identities, increase division, eliminate alternative nonsectarian based identities, allow external players room to manoeuvre, facilitate geopolitical power plays, and maintain the crisis (Salloukh, Barakat, and Al-Habbal 2015). These actions have resulted in an increase in the distance between the people and their state, thus impacting the value of the state's Legality, Justification, and Actual Performance indicators (Chapter 3). Consequently, the attachment that the Lebanese have towards their state has either remained low or decreased further and the focus of the leaders on their supporters has prevented the emergence of a trans-sectarian citizenship (Cammett 2014; Salloukh, Barakat, and Al-Habbal 2015).

\section{The Implications on the State-Society Relationship}

Throughout Lebanon's modern history, the Lebanese have been more loyal and committed to their religion and their leaders than to their country (El-Solh 994). In essence, the Lebanese society was built around religion and the leaders have always been elected to represent their religion rather than the general population (Al Sayegh 1998). Since the first set of elections in 1920, Lebanese people have viewed their elected officials as legitimate holders of power and as mediators between them and the state (Picard 1993), failing to do so could spell political suicide for leaders (Al Sayegh 1998). With parties representing venues for citizen expression, social interactions, and achievement of personal as well as religious goals and not just places for ideological or political goals (Messarra

\footnotetext{
${ }^{67}$ The Lebanese tend to conflate leaders with their groups. As such, when one refers to Hizballah, then one implies the group's leader, Sayyed Hassan Nasrallah. When references are made about the Kataeb, then one is usually making references to its leader Amin Gemayel. The same is true about Amal (Nabih Berri), the Free Patriotic Movement (Michel Aoun), the Lebanese Forces (Samir Geagae), the Future Movement Party (Saad Hariri), the Progressive Socialist Party (Walid Jumblat), and so forth. Therefore, when references are made to the groups, the reader should be able to see the link with the leaders.
} 
1998; Nassif 1998), sectarian fears have been a good tool for leaders of these groups who hold performance legitimacy to maintain control over their followers and instil continued paralysis (Messarra 1998; Salamy 2014). The goal for the Lebanese political parties is not to compete on political platforms but to use politics as a means to get their leaders in important political positions, including the head of the government (El-Khazen 1998). Yet, it is not any kind of person that has been successful in leading a group of people based on religion or history. The leaders that have emerged or survived have been the ones that have done their utmost to take care of their constituents' basic needs and then used their performance legitimacy to raise sectarian fears, institute sectarianism, and solidify their control.

This need to remain relevant and to maintain one's own performance legitimacy has also had implications for the functioning of the public administration. Public sector positions are filled only with the approval of the political or sectarian elite. This level of interference has allowed the leaders to maintain their control over significant aspects of the state system to "lubricate their clientelistic networks" (Salloukh, Barakat, and Al-Habbal 2015, 45), grant "favorable treatment ... on the basis of political loyalty, family influence, class or sect" (M. Kisirwani and Parle 1987, 1-2), and charge a fee for doing so. Moreover, the implementation of public policy has offered these leaders key opportunities to solidify their patronage systems and, consequently, their control over their supporters (Salloukh, Barakat, and Al-Habbal 2015). This has increased the distance between the population and the state and has reinvigorated the vicious performance legitimacy cycle.

This institutionalization of sectarianism and abuse of state resources by leaders have led to situations where public servants act as clients of sectarian leaders (Salloukh, Barakat, and AlHabbal 2015). Yet, even with all of the rhetoric and with several attempts at fixing the problem by working on establishing transparency, accountability and a functioning legal system (interview with El-Khazen academic and a current MP), unruly public officials have not been successfully tamed (Crow and Iskandar 1961; El-Khazen 2000; Iskandar 1996; Maroun Kisirwani 1997a). As Iskandar (1996) notes, leaders have continuously protected civil servants from disciplinary actions as a means to maintain their ability to abuse state resources and earn or maintain their performance legitimacy. Therefore, kinship, friendship and patron-client relations are three informal structures that have controlled the formal structure and limited successful reforms in spite of the fact that most Lebanese view these practices as corrupt and undesirable (Maroun Kisirwani 1997a). Thus, the lack of successful reforms has come as a result of the interplay between cultural, sectarian, political and professional considerations (Maroun Kisirwani 1997a) and the desire for increased performance legitimacy at the expense of that of the state. The outcome is a type of politics that is not linked to the structure of the political system but to personal relationships and favours, even when it is against the rules (B. Harb 1998), as well as a low degree of legitimacy for the state (Atzili 2010; Haddad 2009).

\section{Performance Legitimacy in Lebanon}

Lebanon is a very interesting case. There are challenges related to a strong history of conflict, high religious diversity, high external interferences, severe socio-economic inequalities, endemic corruption and clientelism, high regional instability, high social fracturing, severe state capacity problems and high level of remittances. The Lebanese also have an interesting relationship with 
their state. As noted earlier, while they recognize the importance of the state, they see it as a terrain where they can secure their right to exist, contain the power of the other groups, and use it to ensure survival in the long run. The state, while important, is limited to a space for power jockeying between the various groups where a major mistake could lead to severe socio-political consequences for the population that the leader represents. With the type of political system in place, the unwritten pacts regarding the religious ratio of political positions, the 'selling' of ministerial positions to tame or reward certain leaders or parties, and the lack of a controlling factor within the government and the state institutions, Lebanese leaders had significant manoeuvering space. Essentially, the manner in which the electoral and the legislative were institutionalized had a significant impact on the ability of leaders to use their considerable manoeuvering space, abuse state resources and/or undermine the state, and subsequently build and/or protect their performance legitimacy.

Given all of these challenges, Lebanon has been of great interest to many scholars and practitioners. The country has been studied from many angles and nearly each study includes a set of prescriptions. Many of these have to do with improving Lebanon's democracy by either changing the electoral system, improving transparency and accountability, decentralizing the state, separating religion from the state, building civil society that can transcend religious lines and demand change, excluding external interferences, resolving the Palestinian issue, and implementing a federal system with each religious group receiving a province where they are the majority and being governed by representatives of the dominant religion.

However, all of these actions require policy changes that are approved by the leaders and their external backers. They also require that a majority of the Lebanese population demand, accept or, at the very least not oppose, such changes. As Lebanon's history has demonstrated and as the Chehab and Hizballah examples have indicates, these two conditions have been proven to be unrealistic when leaders can use their performance legitimacy to reframe the discussion and divert responsibility. The policy changes related to all aspects of government - elections, rule of law, state institution-building, public financial management, decentralization, economic stability, security, and social services - have indicated a major challenge owing to the state's weak administrative system, the aspirations of leaders, especially as it relates to their performance legitimacy, external interference, and the obedience of the population. On the issue of state weakness, any improvement in the administrative system has to be approved by the leaders within the government and such changes are often perceived as threats to either the leader responsible for the portfolio in question or to the other leaders that cannot share in the spoils of this reform. As it relates to the aspiration of leaders, while many Lebanese are tired of the corruption (El-Khazen 2000), they tend to demand changes from the other leaders and excuse the action of their leader as a coping mechanism in this do-or-die system (interview with El-Khazen), one that is captured by the Legality indicator in Chapter 3. On external interference, the ability of the external players to have an impact on the Lebanese system is owing to the power that these players have on the leaders within Lebanon. Much of this power is gathered through financial bribes and support, donation of military equipment, or political and security manoeuvrings within the region. Yet, given that each group within society, with the potential exception of the Kataeb (more recently), benefits from these 
interferences, each group perceives them as part of a set of a necessary evil that they would need to survive.

This leaves one wondering about the obedience of the population. Why have not enough Lebanese fought for the revamping of the system if they perceive it to be broken? How and why did they allow for all of the issues highlighted above to occur? One answer that is often postulated has to do with religion. Given that religion plays an important role in people's lives in general, and more specifically in Lebanon, using religion to play the fear card and demonstrate supremacy allows the leaders to amass power and continue their divide and concur strategies. However, as the Lebanon case has demonstrated, these religious divides can be overcome and allegiances can change. This can occur if a leader from another religious group offers much-needed social, security, and financial support to non-group members (as is the case with Hizballah) and the leader avoids implementing policies that are perceived as an attack on the non-group members' faith or religion.

In essence, religion could be trumped by basic needs when one wants to go beyond the zealous minority and look at mass support. The competition for the delivery of basic goods and services among all of the groups in Lebanon is a clear indication of the impact that such actions have on the overall legitimacy of these groups and their leaders. The power of performance legitimacy is demonstrated in the fact that (a) the relationship between the population and the state has consistently been undermined since the 1500 s and (b) there is a continuous struggle between the state and the leaders regarding the meeting of the people's basic needs, even with the roll-over in the ranks of the zu'ama in the 1800s, leaders in the 1950s, 60s and 70s, during the civil war, in the period of Syrian tutelage and thereafter. These leaders have realized the importance of performance legitimacy and what it can offer them in the pursuit of their agendas. History has taught us that it was only after leaders demonstrated their relevance to their people by meeting their basic needs that the majority of the targeted population acquiesced and allowed the space for further religious or sectarian elements to emerge. ${ }^{68}$ Moreover, the fact that the people turned against their militias when the militias began abusing them, even though they had no other sectarian representatives, demonstrates that religion or sectarianism was secondary to basic goods and services. As such, leaders have worked hard and expensed a lot of money to develop their own performance legitimacy and limit that of the state. In the process, their actions have tainted the population's view of the role of the state as a means to gain more power and access more resources rather than for its full potential. It has also solidified the performance legitimacy vicious cycle that Lebanon cannot seem to get itself out of.

The infighting between the Christian groups as well as the infighting between the two Shia groups demonstrates that while religion is important and can be used to allow external interference and inflammatory rhetoric, it cannot succeed if the people have not benefitted from these groups. In essence, external interference, religious divisions and tensions, state abuses, and conflicts occurred not because of the divisions in society per se, but because of the performance legitimacy of the

\footnotetext{
${ }^{68}$ The infighting between the more moderate Amal and the more religiously zealous Hizballah is a perfect example. It was not because Hizballah leadership was more religious than their Amal counterpart but because Hizballah recognized and met the needs of the majority of the Shia population who were ignored by Amal. At that time, the Shia population was not radicalized or extremely religious.
} 
leaders that has allowed them to take these actions with the support of their followers. Even with all of the leaked information about corruption, the abuses of the state systems, and the influence of external players, few Lebanese have turned their backs on their leaders.

By extension, the performance legitimacy of the leaders has precluded the development of a truly democratic culture that is based on a strong relationship between the people and the state and has allowed for the continuation of a fragile system that can be pushed into crises by the actions of specific leaders without the active consent of the population and democratic oversight by the population.

The presence and owners of performance legitimacy, as measured by the indicators in Chapter 3, at the various critical junctures in Lebanon's history are summarized in the following table. 
Table 5.1: The Entity that Ranked Highest in the Performance Legitimacy Indictors (Chapter 3) during Lebanon's Critical Junctures

\begin{tabular}{|c|c|c|c|c|c|c|c|}
\hline \multirow[t]{2}{*}{ Indicators } & \multicolumn{7}{|c|}{ Critical Junctures } \\
\hline & $\begin{array}{l}1523-1914 \\
\text { Ottoman Empire }\end{array}$ & $\begin{array}{l}1914-1943 \\
\text { French Mandate }\end{array}$ & $\begin{array}{l}1943-1958 \\
\text { Independence }\end{array}$ & $\begin{array}{l}1958-1962 \\
\text { Development Period }\end{array}$ & $\begin{array}{l}1962-1975 \\
\text { Pre-Civil war }\end{array}$ & $\begin{array}{l}1975-1990 \\
\text { Civil War }\end{array}$ & $\begin{array}{l}1990-2016 \\
\text { Post-conflict }\end{array}$ \\
\hline \multicolumn{8}{|l|}{ A. Legality } \\
\hline $\begin{array}{l}\text { 1. Perceived Reach and } \\
\text { Applicability of the Law }\end{array}$ & None & None & None & None & None & None & State \\
\hline $\begin{array}{l}\text { 2. Perceived Importance of } \\
\text { State Institutions in } \\
\text { Citizens' Daily Lives }\end{array}$ & None & None & None & $\begin{array}{l}\text { None - but state's } \\
\text { level was improving }\end{array}$ & None & None & None \\
\hline $\begin{array}{l}\text { 3. Confidence in the } \\
\text { Security Provided by the } \\
\text { Actor }\end{array}$ & Leaders & Leaders & Leaders & Leaders & Leaders & Leaders & $\begin{array}{l}\text { Leaders more } \\
\text { than the state }\end{array}$ \\
\hline $\begin{array}{l}\text { 4. Confidence in the Civil } \\
\text { Service }\end{array}$ & None & None & None & None & None & None & None \\
\hline \multicolumn{8}{|l|}{ B. Justification } \\
\hline $\begin{array}{l}\text { 1. Satisfaction with the } \\
\text { Actor in its Effort to Meet } \\
\text { Basic Needs }\end{array}$ & Leaders & Leaders & Leaders & $\begin{array}{l}\text { Leaders - but state's } \\
\text { level was improving }\end{array}$ & Leaders & Leaders & Leaders \\
\hline $\begin{array}{l}\text { 2. Perceived Willingness of } \\
\text { the Actor to Support } \\
\text { Citizens/Followers }\end{array}$ & Leaders & Leaders & Leaders & $\begin{array}{l}\text { Leaders - but state's } \\
\text { level was improving }\end{array}$ & Leaders & Leaders & Leaders \\
\hline $\begin{array}{l}\text { 3. Degree to which Citizens } \\
\text { Turn to the Actor for } \\
\text { Help }\end{array}$ & Leaders & Leaders & Leaders & $\begin{array}{l}\text { Leaders - but state's } \\
\text { level was improving }\end{array}$ & Leaders & Leaders & Leaders \\
\hline \multicolumn{8}{|l|}{ C. Actual Performance } \\
\hline $\begin{array}{l}\text { 1. Number of Basic Goods } \\
\text { and Services Provided by } \\
\text { the Actor }\end{array}$ & $\begin{array}{l}\text { Leaders - with a } \\
\text { slight edge }\end{array}$ & $\begin{array}{l}\text { Leaders - with a } \\
\text { slight edge }\end{array}$ & $\begin{array}{l}\text { Leaders - } \\
\text { with a slight } \\
\text { edge }\end{array}$ & $\begin{array}{l}\text { Leaders- with a } \\
\text { decreased edge }\end{array}$ & $\begin{array}{l}\text { Leaders - } \\
\text { with a slight } \\
\text { edge }\end{array}$ & Leaders & Leaders \\
\hline $\begin{array}{l}\text { 2. Quality of Actor- } \\
\text { delivered Basic Goods } \\
\text { and Services Provided } \\
\end{array}$ & No Data & No Data & $\begin{array}{l}\text { Leaders - } \\
\text { with slight } \\
\text { edge }\end{array}$ & $\begin{array}{l}\text { Leaders- with a } \\
\text { decreased edge }\end{array}$ & $\begin{array}{l}\text { Leaders - } \\
\text { with a slight } \\
\text { edge }\end{array}$ & Leaders & Leaders \\
\hline $\begin{array}{l}\text { 3. Ease of Access to Actor- } \\
\text { delivered Basic Goods } \\
\text { and Services }\end{array}$ & $\begin{array}{l}\text { Leaders - with a } \\
\text { slight edge }\end{array}$ & $\begin{array}{l}\text { Leaders- with a } \\
\text { slight edge }\end{array}$ & $\begin{array}{l}\text { Leaders- with } \\
\text { a slight edge }\end{array}$ & $\begin{array}{l}\text { Leaders- with a } \\
\text { decreased edge }\end{array}$ & Leaders & Leaders & Leaders \\
\hline \multicolumn{8}{|l|}{ D. Acts of Consent } \\
\hline \multicolumn{8}{|l|}{ State } \\
\hline $\begin{array}{l}\text { 1. Compliance with State- } \\
\text { Sanctioned Health Rules } \\
\text { during an Epidemic }\end{array}$ & No Data & No Data & No Data & No Data & No Data & No Data & No Data \\
\hline $\begin{array}{l}\text { 2. Compliance with State- } \\
\text { Sanctioned Rules or } \\
\text { Actions } \\
\end{array}$ & No Data & No Data & No Data & State & None & None & State \\
\hline $\begin{array}{l}\text { 3. Compliance with Police } \\
\text { Enforced Laws and } \\
\text { Regulations }\end{array}$ & No Data & No Data & No Data & None & None & None & State \\
\hline \multicolumn{8}{|l|}{ Leader } \\
\hline $\begin{array}{l}\text { 1. Compliance with Leader- } \\
\text { Sanctioned Rules or } \\
\text { Actions }\end{array}$ & No Data & No Data & No Data & No Data & No Data & No Data & No Data \\
\hline $\begin{array}{l}\text { 2. Compliance with State- } \\
\text { Sanctioned Health Rules } \\
\text { during an Epidemic, even } \\
\text { when not supported by } \\
\text { the Leader }\end{array}$ & No Data & No Data & No Data & No Data & No Data & No Data & No Data \\
\hline $\begin{array}{l}\text { 3. Compliance with Leader- } \\
\text { Enforced Laws and } \\
\text { Regulations, even when } \\
\text { in Contradiction with that } \\
\text { of the state }\end{array}$ & No Data & No Data & No Data & No Data & No Data & Leaders & Leaders \\
\hline
\end{tabular}

Note: The variables that are included in Table 5.1 are based on qualitative data that was gathered through the research. The valuation of the results is also based on my judgment, which was influenced and guided by the results of the research. The indicators were not tested in the field. As such, the values attached to these variables are preliminary and, as a next step, require both further research and rigorous testing. 


\section{Conclusion}

The history of Lebanon is significantly influenced by leaders working on gaining performance legitimacy by separating the people from their state, replacing the state in the daily lives of the population, and using state resources to ensure their performance legitimacy and their subsequent hold on power. These actions have significantly contributed to the weakening of the state, increased fragmentation within the Lebanese welfare system, and an unequal development process across all levels of the Lebanese society.

The triggers and structural deformations that have been monopolizing the discourse on Lebanon, while important, cannot happen if the population does not acquiesce. The evidence points to a clear understanding of this fact by the leaders and their subsequent actions to win over their supporters through basic social services. The successful leaders have been the ones that have also recognized the limitation of relying on religion and the power of performance legitimacy in allowing them to undertake their agenda with more abundant support.

Lebanon has a long history of trying to resolve sectarian divisions and crises through adjustments in the political system and the public administration. Lebanon also has a long history of solving vertical tensions (rich versus poor) by ignoring structural changes and transferring the responsibility of offering much-needed social services to leaders and non-state groups. This has resulted in a state that has no or little performance legitimacy, leaders that have high performance legitimacy, leaders that use their legitimacy to increase sectarian tensions, a state that keeps getting weaker and weaker, and a vicious performance legitimacy cycle that does not seem to be sensitive to changes. 


\section{Chapter 6: The Senegal Case Study}

\section{Introduction}

Senegal is situated in North-Western Africa with the majority of its topology dominated by somewhat dry and arid land. In contrast, the Casamance region, found in the southern part of Senegal, has vibrant and abundant vegetation. The geographical make-up of Senegal is also unique. It has a long coast along the Atlantic Ocean and has borders with five countries - Mauritania, Mali, Guinea, Guinea-Bissau, and The Gambia. The Gambia intrudes eastwards and inwards through a narrow stretch from the Atlantic Ocean to more than half of the width of Senegal, nearly cutting off the region referred to as the Casamance and its population (the Casamancais) from the rest of Senegal and the capital Dakar. The inhabitants of the Casamance are referred to as the Casamancais.

Senegal is a presidential republic. The President is directly elected by the people and is appointed based on an absolute majority popular vote. The President

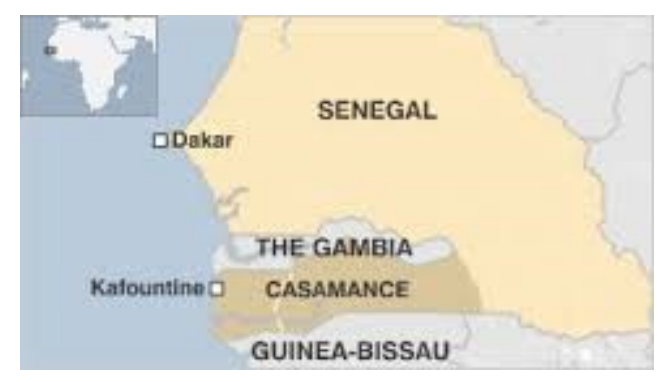
appoints the Prime Minister and the members of the Cabinet (or the Council of Ministers). Members of the National Assembly (Legislative branch) are directly elected by voters. Out of the 150 seats, 90 seats are filled through simple majority vote and 60 are filled through proportional representation vote.

Senegal has been marred by the longest running civil war in West Africa. The civil war, which is confined to the Casamance region, started in 1982, was halted for six years, and was reignited in 2010. One of the key demands or objectives of the rebel movement was for the Casamance to gain independence from Senegal. The desire for independence seemed to emanate from the seemingly different historical, social, economic, and religious trajectories of the region. Yet, as the analysis herein demonstrates, the desire for independence was also directly linked to the lack of benefits that the Casamance was receiving from the Senegalese state and thus the lack of performance legitimacy that the state had in the region.

Senegal has a special colonial history and a history of internal conquests and transformations. It has also served as a bridge between Africa and the Arab World, Africa and the West, as well as the Arab World and the West. The ethnic and religious makeup of Senegal has played an important role in Senegal's development. Ethnicity and religion were used as rallying calls by the Casamancais separatists during Senegal's long civil war.

Senegal has 17 official ethnic groups (Ndegwa and Levy 2003). According to the CIA World Factbook, as of 2010, the Wolof was the largest ethnic group representing 38.7 percent of the total Senegalese population. ${ }^{69}$ The Wolof are followed by the Pular at 26.5 percent, the Serer at 15 percent, the Mandinka at 4.2 percent, the Diola (or Jola) at 4 percent, the Soninke at 2.3 percent, and others, including Europeans and people of Lebanese descent, at 9.3 percent. ${ }^{70}$ The Diola are the

${ }^{69}$ CIA Factbook, https://www.cia.gov/library/publications/the-world-factbook/geos/sg.html.

${ }^{70}$ Ibid. 
main ethnic group in the Casamance region, representing over 60 percent of the Casamancais population (Diallo 2009). The religious make-up of the Diola is diverse. Islam, Christianity and animism are present in the Casamance region. Christians only represent about four percent of the total Senegalese population ${ }^{71}$ and the majority of them are found in the Casamance region with the Lower Casamance being the least Islamized (Diallo 2009).

Overall, the Senegalese case provides an interesting look at how colonial rule, religion, ethnicity, and geography worked together to shape the trajectory of a country and its society. More so, the Senegalese case highlights: (a) the importance of the interaction between performance legitimacy, political structures, and the relationship between the state and the population, and (b) the success of the state in gaining performance legitimacy.

This chapter traces the history of Senegal from the pre-colonial era to the present. For each period, the analysis looks at the relationship between the state and the population, the political situation, the socio-economic conditions, external interferences, and the role of the delivery of basic goods and social services. The chapter ends with an assessment of performance legitimacy in Senegal.

The following is a simple timeline graphic that allows one to visualize the outcomes of the following process tracing analysis.

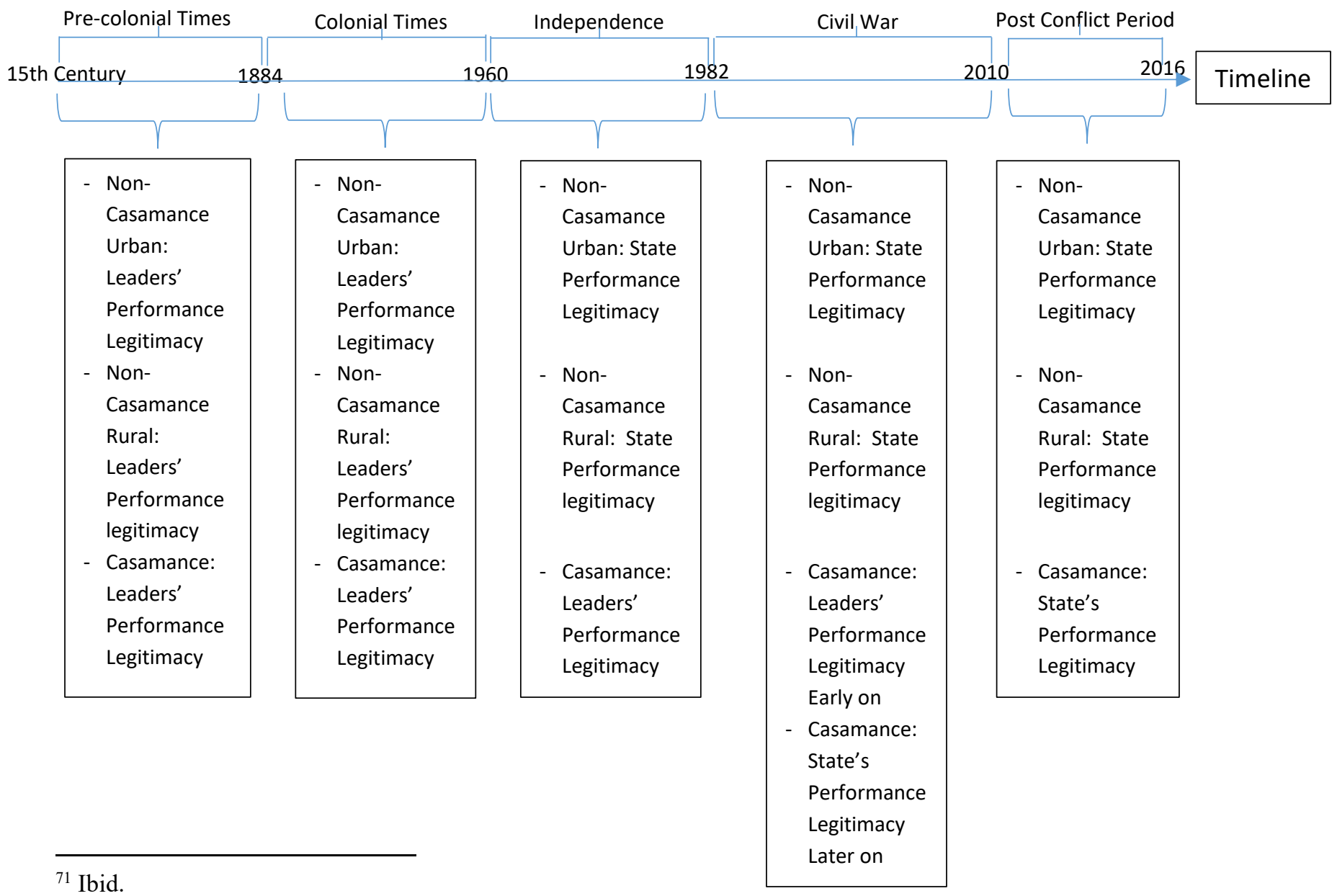




\section{From Pre-colonial Times to Colonialism to Independence}

\section{A. Pre-French Colonial Senegal}

During the $15^{\text {th }}$ century, rulers in the region that we now know as Senegal were faced with tremendous natural barriers. The abundance of land and the disbursed nature of the population allowed the rulers to rule their lands without much conquest. It also did not require them to have a direct and ongoing relationship with the population that inhabited their land. As such, they ruled by extracting tribute from the people living within their area of control rather than by ensuring full political sovereignty over their land (Gellar 1995). These tributes included taxation income, a supply of men for military services and public works, and the acceptance of the authority of the rulers (Gellar 1995). Local leaders received rewards from the rulers in return for their tributes. These rewards included access to royal land, trade, as well as other economic resources and opportunities (Gellar 1995). In essence, the rulers ruled through clientelistic networks with material benefits bestowed upon those ruled in return for their obedience and their acceptance of the local political autonomy of their rulers (Gellar 1995). ${ }^{72}$ According to the performance legitimacy causal and effect indicators that were advanced in Chapter 3 , the perceived behaviour of the leaders (causal indicators) and the resulting action of their supporters (effect indicators) indicate that these clientelistic networks increased the rulers' performance legitimacy at a time when process legitimacy was absent.

Most of the society ${ }^{73}$ living in the region now known as Senegal was divided along the following lines: Royalty and the royal lineage, nobility (those related to the royal lineage), commoners (free men and women that made up most of the peasant population), and slaves. By the end of the $16^{\text {th }}$ century, Senegal had a stable state structure (Gellar 1995) with the Wolof ethnic group, the largest within the region, having established a system of rule controlled by the noble class where rulers were elected and were expected to lead in war and bring prosperity to the people (Gamble 1957).

The royalty and nobility classes of society were actively engaged in trading slaves with the British, French, Portuguese, and the Dutch. The slave trade reinforced the power and domination of the Wolof ethnic group since most of those involved in the slave trade were Wolof and most of those captured as slaves belonged to ethnic groups that were found in the interior areas of Senegal, including the Diola from the Casamance region. Following several years of brutality, the slave trade led to famine, misery, and a marabout uprising (or an uprising of Sunni Muslim religious leaders). The uprising lasted from 1673 until 1677 when the marabouts and their followers were defeated by the aristocrats with the support of the French (Gellar 1995). One hundred years later, the marabouts succeeded in overthrowing the rulers and established a Sunni Islamic theocratic oligarchy (Gellar 1995). What followed were several decades of the Islamization of the Wolof ethnic group. The theocratic oligarchy was eventually dismantled by the French in the mid 1850s (Gellar 1995).

The defeat of the leading Wolof figures, the dismemberment of their political and economic support system, and the resulting social upheaval ushered in another era of influence for local religious leaders (Gellar 1995, 2005). With the upheaval and the resulting inability to influence the political

\footnotetext{
${ }^{72}$ There were a few instances where land changed hands and where certain rulers had to face a certain number of revolts and changes in alliances.

${ }^{73}$ The Diola of the Casamance were an exception. They had a flat society with no stratification.
} 
leadership, people began turning to their religious leaders for advice and support. The religious leaders' influence on the society continues until today, especially in the rural areas where people turn to their religious leaders for religious, social, economic and political support and advice (Gellar 1995, 2005).

However, these social dynamics unfolded differently in the Casamance region. For the Diola and the other non-Wolof ethnic groups in the Casamance, the marabouts' power was limited. The Casamance region was well known for its non-hierarchical and communal societal structures and its self-sustaining presence (Beck 2008). Moreover, the Diola in the Lower Casamance were known to staunchly defend their territory against whom they considered to be Muslim colonizers who were looking to incorporate them into the Islamic State (Gellar 2005). Their unwillingness to be 'colonized' by anyone else was also apparent in their staunch defence against any external powers. Before the Casamancais were even colonized by the French, they were occupied by the Portuguese and the British (Diallo 2009), both having a very difficult time 'taming' the Casamancais and eliminating their violent attacks (Diallo 2009, 26). The opposition to external colonizers began in 1645 against the Portuguese and continued after the Portuguese handed the region over to the French in 1886 (Diallo 2009). In essence, one could conclude that the Casamancais were led by their own leaders who also earned performance legitimacy by being responsible for the protection of the populations and the organization of the societal and economic benefits.

\section{B. The French Colonial Period}

The boundaries of Senegal were established during the 1884-1885 Berlin Congress where the French, British and Portuguese drew the boundaries of the various African colonies (Gellar 2005). It was during this process that the steps were established to integrate the Casamance region with the rest of the French colony of Senegal.

During Senegal's colonial period, French authorities implemented an assimilation approach that led to the establishment of a Senegalese administrative and political system, including the establishment of a territorial assembly (Conseil Général), municipal councils, and an office to support the representative of Senegal in the French Chamber of Deputies in Paris (Gellar 1995). However, these administrative structures were concentrated in urban communes (Dakar, Gorée, Rufisque and Saint Louis), did not extend to the rural areas, and were used for clientelistic favours (Gellar 1995). According to the indicators that were presented in Chapter 3, with the population identifying the leaders as the entities responsible for the delivery of basic goods and services (Gellar 1995), the leaders were able to increase their performance legitimacy while that of the state continued to be limited. While these communes experienced democratic practices early on (especially with electoral practices), the rural areas where controlled autocratically by the colonial administrators through 15 administrative districts or cercles (Gellar 1995). Each cercle had several cantons and each canton was controlled by a French-chosen Senegalese canton chief who was responsible for collecting taxes and recruiting men for labour. The French administrative system did not allow locals to make decisions outside the urban communes (Gellar 2005) thus allowing some canton chiefs to take advantage of their powerful position to extort money from the residents of the canton (Gellar 1995). 
The canton system was disliked by most of the rural population (Gellar 1995). There was increasing discontent with the manner in which the rural population was ruled and an unwillingness to allow the colonizers further power. As such, the rural population worked together to solve problems and meet their needs (Gellar 2005), all the while being guided by the marabouts. With several colonial decades behind them, the marabouts became the social and religious anchors for the population living in the cantons with a significant Sufi majority (Gellar 2005). Given their perceived importance and the absence of the state, the Justification indicators (satisfaction with the leader in his effort to meet basic needs, perceived willingness of the leader to support his people, and degree to which citizens turn to the leader for help) and Actual Performance indicators (ease of access to leader-delivered basic goods and services) indicate that the marabouts had successfully earned performance legitimacy from their supporters. They were able to use their legitimacy to guarantee the population's support for a politician in Dakar (the capital of Senegal) in exchange for favours for their followers, which in turn reinforced their performance legitimacy (as measured by the Acts of Consent indicator - compliance with leader-sanctioned rules or actions). Such favours included jobs for their followers, subsidies to build and expand mosque and koranic schools, expanded access to water, the building of roads, and access to agricultural land and inputs (Gellar 1995).

However, the marabouts' performance legitimacy hinged on the transfer of 'benefits' from the politicians in Dakar. This made the marabouts dependent on politicians in Dakar, who in turn were dependent on the marabouts for political support due to the distance between them and the population. This co-dependency limited both groups' ability to abuse state resources for the fear of loosing access to the same resources that had allowed them to continue earning performance legitimacy. As such, this co-dependent relationship did not allow the situation to deteriorate into a vicious cycle defined by an increase in the leaders' performance legitimacy and a decrease in that of the state.

In the end, Senegal was ruled by three different systems: (a) An urban democratic system led by educated Senegalese intellectuals, (b) a rural authoritarian system led by leaders who were mostly chosen by the colonial masters, either through elections or otherwise, and (c) an unofficial sociopolitical structure led by the marabouts.

According to Gellar (Gellar 1995), between 1854 and 1939, the French administered the Casamance region separately from the rest of Senegal and was only integrated near the end of the colonial period. Moreover, the French ruled with violence over the Casamance region by fighting against local groups who refused to submit to their rule, allowing northerners, especially the Wolof, to take Diola youth as slaves, forcing many able-bodied young male Casamancais into the army, and deporting many queens and traditional leaders who opposed their rule (Diallo 2009). The French, with the help of the Senegalese government in Dakar, also confiscated rice from the Casamance without paying remuneration (Diallo 2009). The French also either supported or turned a blind eye to the actions taken by the Northerners against the Casamancais, including raids, killings, and other forms of violence (Diallo 2009). For example, in the 1880s Wolof marabouts, mostly from the north, led several jihads against the Diola and other ethnic groups in the northwestern part of the lower Casamance with the prior knowledge of the French (Beck 2008, 167). One attack on a village chief by the 'northerners' who were part of the French forces because 
the village had not reached its rice, livestock and poultry quota, had significant meaning for the Casamancais and their fight for independence. The attack was witnessed by then five-year old Augustin Diamacoune Senghor, who in his later years became a Catholic priest and one of the most important actors in the rebel movement (Diallo 2009).

Nevertheless, even with the significant amount of bloodshed, the French were not successful in pacifying the Casamancais. Starting in the early 1900s, the French changed their approach and began a process of migration, one that had a significant impact on the ethnic makeup of the Casamance region. In effect, they brought in the more 'docile' northerners to inhabit the land, undermine the opposition of the Casamancais, and increase their support in the region (Diallo 2009).

From an economic standpoint, the French colonial masters were keen on developing the peanut industry. Knowing this and realizing the profits that could be associated with this industry, the marabouts encouraged their supporters to grow and sell peanuts (Gellar 1995). The marabouts were handsomely rewarded by the French with land for distribution to their supporters (Gellar 1995), once again allowing them to maintain, and in some cases increase their performance legitimacy. The French also developed the infrastructure (trains and roads) that was needed to transport peanut to the ports. Unfortunately, the areas that were not represented by the marabouts, including the Casamance region, were overlooked and local leaders were left to find resources for their own people (Gellar 1995) and earn performance legitimacy with no connection to the colonial politicians. As such, Senegal was effectively divided into three economic regions: (1) The modern sector that developed in the four communes where political players had performance legitimacy; (2) the cash-crop economy in the peanut-producing areas where marabouts had performance legitimacy; and (3) the subsistence sector in the peripheral non-peanut producing areas responsible for providing much of the labour used in the peanut zones and towns (Gellar 1995) where local non-marabout leaders had performance legitimacy.

When assessing these events through one Legality indicator (confidence in the security provided by the state), the Justification indicators (satisfaction with the state in its effort to meet basic needs, perceived willingness of the state to support its citizens, and degree to which citizens turn to the state for help), and two Actual Performance indicators (number of basic goods and services provided by the state and ease of access to state-delivered basic goods and services), it seems clear that the state was unable to earn performance legitimacy.

In 1944, French Head of State Charles de Gaulle promised post-World War Two colonial reform (Gellar 1995). The official ruling system became less authoritative when the French extended democratic electoral politics to some rural groups in 1946 and to everyone in 1956 (Beck 2008). However, the unofficial system that saw the rise in power of the marabouts continued unabated (Gellar 1995). In 1958, De Gaulle gave the Senegalese three options: (1) become part of France, (2) receive quasi independence with France retaining power over foreign affairs, defense, financial and monetary matters, and higher education, or (3) immediate independence. According to Gellar (1995), there did not seem to be a strong appetite for independence among the majority of the Senegalese at that time. With their dislike of the idea of assimilation with France and their fears regarding the loss of control to the 'radicals', the marabouts, with the support of Léopold Sédar 
Senghor who was the leader of the Bloc Démocratique Sénégalais, pushed for the implementation of the second option (Beck 2008; Gellar 1995). However, this arrangement did not last long. In April 1959, Senegal merged with French Sudan and formed the Mali Federation. The Mali Federation became independent in June 1960 with Senghor as president and Mamadou Dia as prime minister. Senghor's party, the Union Progressiste Sénégalaise (UPS), won all of the seats in the 1959 elections (Beck 2008).

\section{Analysis}

Clan politics played an important role in the development of the political tradition in Senegal. This tradition significantly influenced how political parties were built and how the various representatives within a party and across parties interacted with each other. According to Gellar (1995), even with a one-party political system, clan politics was an important factor especially for representatives of the same party who competed for control over local and regional party chapters. However, clan politics was also guided by the concept of demokaraasi, a concept that Gellar (2005) borrowed from Schaffer (2000). Demokaraasi, or the local concept of democracy, "places the emphasis on such values as consensus in decision-making, solidarity, and mutual reciprocity in sharing resources and even-handedness in treating everyone [from the same clan] fairly" (Gellar $2005,12)$. These values shaped the manner in which people voted, and continue to do so. The desire for consensus implies that all voters from the same area or social networks had to agree on the official that would get their support (Gellar 2005; interview with a Dakar-based aid worke). The decision was guided by the material benefits that they received and the even-handed distribution of these benefits (Gellar 2005). In essence, the person who won the clan's votes was the one who had already earned performance legitimacy by taking care of the basic needs of the clan and not just a handful of people.

Overall, the Senegalese population has a history of bestowing its leaders with performance legitimacy. It also has a history of working through intermediaries, mostly the marabouts. However, these intermediaries were not able or willing to use their performance legitimacy to threaten the power of the state. The marabouts were as much in need of the resources that were being transferred to them by the state and its central leaders as the state was in need of the marabout's influence on the local population. Hence, even though demokaraasi was influenced by the guidance of local leaders, especially the marabouts and other religious leaders, the belief in demokaraasi, along with the enduring mistrust of leaders, the influence of the marabouts, and the reliance of the marabouts on state resources for their performance legitimacy, placed limits on authoritarianism in Senegal.

Moreover, Senegal's pre-independence history has had an important influence on Senegal's trajectory. This history was marred by occasional ethnic strife outside the main regions surrounding Dakar, exclusions and abuse of various ethnic groups, religious strife, and significant socioeconomic inequalities. It was also marred by a never-ending fight for independence by the 'original' inhabitants of the Casamance region. 


\section{Senegal Post-Independence}

\section{A. Independence}

Two months following the declaration of independence by the Mali Federation, Senegal withdrew from the Federation and declared its full independence on August 20, 1960. Léopold Sédar Senghor was declared Senegal's first president in September 1960. His party, the Senegalese Progressive Union, dominated the newly independent government and, with no other parties legally allowed to be established, Senghor dominated the political scene from 1964-1978.

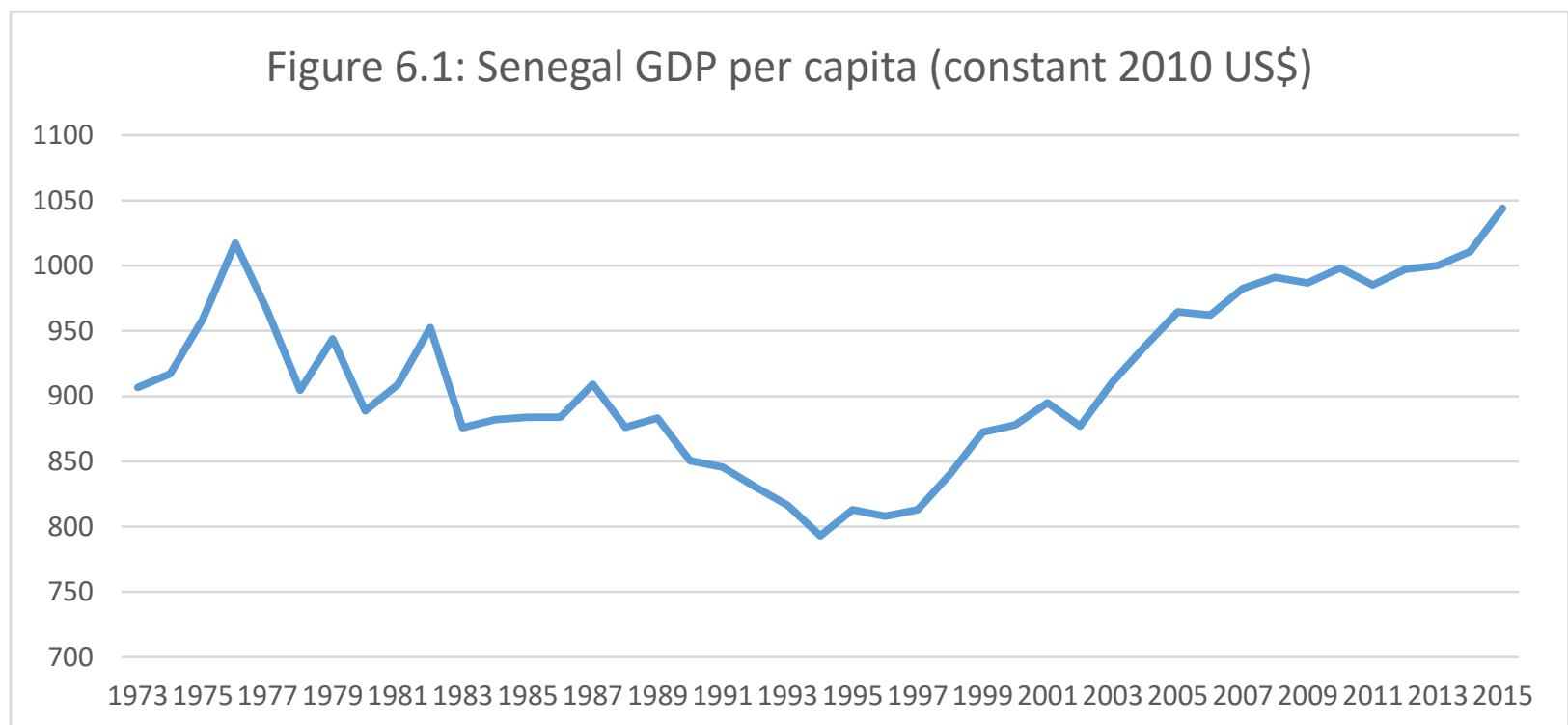

President Senghor was adept at eradicating all formidable challenges. He used three major tactics to maintain power: (1) absorbing all parties into his umbrella party, (2) outlawing parties that refused to succumb to his power from 1966 to 1974, and (3) using state resources to develop a wellorganized and well-oiled system (Gellar 1995; Mendy 2006) that depended on the performance legitimacy of local leaders. The ability to use the first two approaches allowed Senghor to directly control the political machinery. For example, in 1962, Senghor accused his prime minister, Mamadou Dia, of planning to undertake a coup d'état and imprisoned him until 1974 (Beck 2008). During Dia's imprisonment, Senghor changed Senegal's constitution and political system from a parliamentary system to a centralized presidential system (Beck 2008). Senghor was also known for his reversal of the many decentralization actions that were undertaken during the transition period. He increased the control of the central government by (a) depoliticizing local governments and having presidents of rural councils and mayors chosen by the central state, (b) decreasing financial flows to the local governments, and (c) increasing the power of regional governments (Gellar 1995). In the 1970s, Senghor was facing rising discontent and opposition due to a downturn in the price of peanuts (on which Senegal's economy was very dependent), increased urbanization, and increased unemployment (Beck 2008). During the same timeframe, Senegal was facing a significant contraction in its economy as indicated in Figure 6.1. In response, Senghor used cooptation, price controls on food products, subsidies for peanut farmers, and repression tactics as means to undermine the opposition (Beck 2008). On the political level, he eased restrictions in 1974 and allowed for a three-party political system. He also released his one-time prime minister, Mamadou 
Dia, from jail, reinstated the Office of the Prime Minister by appointing Abdou Diouf to the post, and transferred some power to younger technocrats within his party (Gellar 2005). The transfer of power also allowed the technocrats to exercise control over elected mayors and to limit local autonomy. All budgets and expenditures, including on development projects, were controlled by the Senghor-appointed technocrats who, most of the time, were from outside the region (Gellar 2005). Effectively, this control limited the ability of local leaders to directly or indirectly meet the needs of their clients without having to go through Senghor's political machine. This made local leaders' performance legitimacy highly dependent on the actions of the state and Senghor's decisions. It also increased the performance legitimacy of the marabouts (as measured by the Actual Performance indicators (Chapter 3) since external technocrats depended on the marabouts for political support and ensured this support through the transfer of benefits.

The third tactic, developing a patronage system, allowed Senghor the opportunity to maintain his popularity, influence, and, ultimately, his performance legitimacy. The patronage system allowed him to draw on the performance legitimacy of the marabouts, earn performance legitimacy from ordinary Senegalese, and ensure the acquiescence to his rule by most of the other leaders and politicians. As far as the marabouts were concerned, even though they were unhappy with the 1970s economic crisis and the manner in which the state handled the situation, they did not actively support opponents because of fear of loosing their access to state resources (Beck 2008) and thus their performance legitimacy. According to Beck (2008), the marabouts legitimized the Senegalese state and Senghor's leadership and received material benefits in exchange for their support. These economic interests translated into the transfer of peanut seeds and fertilizers to the marabouts' supporters as well as the undertaking of water well and other development projects in the marabouts' area of influence (Beck 2008). Access to patronage networks was of significant importance to the marabouts. Their prestige and ability to attract religious students (as represented by the Acts of Consent indicator in Chapter 3) depended on their ability to provide the students or talib with material benefits such as access to land, access to jobs, and funds to start a business (Gellar 2005).

It is important to note that access to the patronage system was also highly coveted by other leaders and politicians (Gellar 2005). The leaders' desire to gain or increase their performance legitimacy, the necessity of meeting people's needs in order to gain or increase one's own performance legitimacy, and the monopoly of the winning party over state resources combined to provide strong incentive for many hopeful leaders to join the winning party, regardless of what party they ran for and of their political beliefs, ideology or thought (Gellar 2005; Mendy 2006). Yet, access to the patronage system required approval by Senghor and was only granted to those that agreed to play within the rules (Gellar 1995; Mendy 2006). For example, in areas where the marabouts did not exist, the society was ruled by hierarchal system, and local religious leaders did not command as much loyalty and influence as the marabouts (Beck 2008), the state offered aspiring leaders access to state resources that they could then use to earn performance legitimacy, influence, and power. One such example is the Tukulor ethnic group from the Senegal River Valley in North Senegal. According to Beck (2008), the Tukulor politicians had little alternative sources of power or legitimacy and, as such, relied heavily on state resources to either maintain or gain performance legitimacy. As such, even though many Tukulors criticized the state for its lack of investment in the 
area and deemed the state to be too corrupt for it to function in a democratic form, most continued voting for the party in power in the hopes of maintaining the patronage link (Beck 2008). Another example relates to the transfer of allegiance of local politicians from the defeated ruling party for which they had campaigned to the party that had won the elections in 1993 (Beck 2008). This could be considered a transfer in the value of the Acts of Consent indicator to the party that was able to provide the benefits associated with the delivery of basic goods and services.

Senghor was also able to effectively deal with what he considered to be the 'troublemakers'. These individuals, who presented significant threats to Senghor and his party, were removed from the patronage system by Senghor, a process that often decreased their local support (Mendy 2006), performance legitimacy (as measured through the Justification and Actual Performance indicators (Chapter 3), and thus power.

Moreover, even though religious leaders had amassed significant power and influence, they were not successful in bringing down the government. For example, Cheikh Abdoulaye Dièye, a marabout religious leader who established his own party and demanded the establishment of an Islamic state, did not receive significant support from other marabouts and the general population (Gellar 2005). Moustapha Sy, the son of a prominent marabout Cheikh and the founder of a marabout youth movement, also formed his own political party, but withdrew from the political process after his father had asked him to. In these cases, access to resources from the state (or the most likely winners of the electoral process) and the likely loss of this access and thus their own performance legitimacy if they were to support opponents played heavily in the decision-making process of the other marabouts and the subsequent shutting out of these leadership hopefuls.

These patronage-like practices continued with every subsequent political leader. Whatever the political system looked like (a one-party state, a limited political party system, a centralized system, etc.), the wishes of local traditional leaders were respected and traditional leaders aligned themselves with the presidential hopeful that was likely to win the elections (Gellar 2005) and maintain their performance legitimacy.

In December 1980, Senghor was succeeded by Abdou Diouf, his sitting prime minister (Beck 2008). Diouf was the president of Senegal from 1981 to 2000 . He was the first president to invest in administrative functions so as to meet some of the needs of his population, but he also relied heavily on patronage to maintain support (Beck 2008). He worked to reduce the concentration of certain administrative functions by improving local governance, implementing development projects in the neglected regions, improving the delivery of social services, and increasing the Senegalese's access to loans (Gellar 1995). Diouf was also credited for opening up the electoral space for more competition (Gellar 1995).

Beginning in the late 1980s, Senegal was facing economic distress. Diouf claimed a decisive victory in the 1988 elections even though there was significant populace discontent with the ruling party. The Senegalese were growing weary of the ruling party and turned to the street to demonstrate against the official results of the elections. Diouf subsequently extended a peace offering by suggesting the formation of a National Unity Government in 1991 (Beck 2008). Following the opposition parties' refusal, Diouf began adjusting the electoral code so as to establish 
a freer and fairer system (Beck 2008). In 1993, Diouf's party won the elections and formed a consensus government with several smaller parties (Beck 2008).

In 2000, Senegal experienced its first electoral transfer of power since independence when President Diouf lost the elections to Abdoulaye Wade, the head of the Parti démocratique sénégalais (Beck 2008). The death of a prominent marabout and his replacement by another marabout who refused to instruct his people on how to vote, the increased violence in the Casamance region, and a downturn in the economy spelled the end of Diouf's reign. Moreover, these events coincided with a decrease in the influence of the marabouts' political ndigels (fatwa) or religious commands (Beck 2008). According to Beck (2008), the decreased influence of political ndigels could be traced to the increasingly unmet needs of the population and the limited financial and social support that they received from the marabouts. In other terms, the impact of the ndigels was affected by a decrease in the level of the marabouts' performance legitimacy.

All in all, with its control over most of the resources within Senegal, the state was able to ensure a monopoly over several aspects of people's lives. Senegal had effectively been dominated by a oneparty state and all political actors and local leaders became dependent on the presidents' power and patronage (Beck 2008). According to Beck (2008), Senghor and his ruling party used clientelism not for electoral purposes but to maintain authority and implement public policies (something that is reflected in the Acts of Consent indicators in Chapter 3). In essence, the presidents used clientelism to earn performance legitimacy and used performance legitimacy to govern.

However, this seems contradictory in nature. Over the years, the population had grown to be distant from its political leaders. The relationship between the leaders and the population was indirect with the marabouts acting as brokers between the state and the population (interview with a Dakar-based aid worker). As such, requests for help from citizens, at least those who did not have access to leaders, continued to be channelled through the marabouts (interview with a Dakar-based aid worker). Yet, even though the relationship between the people and the state was indirect and reliant on the power and influence of the marabouts, the Senegalese continued nevertheless to believe in and expect a lot from their state (interview with a Casamancais who lived through the conflict and has access to leaders of the MFDC, interview with a Dakar-based aid worker) - something that translated in high scores for the 'perceived importance of state institutions' indicator (Chapter 3).

What is it that allowed the state to remain a powerful variable in this equation? Four major factors appear to matter. First, according to one Senegalese interviewee who was involved in delivering aid resources in Senegal, "even when the marabouts delivered resources, the people knew that it was coming from the state. The state was and continues to always be present, even in religious celebrations. They send in police. They help fund things" (interview with a Dakar-based aid worker). Second, the population did not support the entry of marabouts into the political domain (interview with a Dakar-based aid worker). According to Gellar (2005), the Senegalese did not favour their religious leaders entering the political domain. Moreover, the majority of the marabouts were more comfortable to stay in their role as brokers than to enter the political arena (Beck 2008). As such, religious leaders were limited to the power and legitimacy that they earned (interview with a Dakar-based aid worker). Third, the state had the monopoly over resources and as soon as a marabout moved to defy the state, as in the case of Cheikh Abdoulaye Dièye, resources 
were cut off and other marabouts withdrew their support in a strategic move to safeguard the resources that they were receiving from the state. Fourth, even though corruption and the inefficiencies in the system tainted the Senegalese's perception of the political leaders, the Senegalese seemed to still believe in the state (interview with a Dakar-based aid worker). ${ }^{74}$ This perception had been influenced by the state's monopoly over the delivery of goods and services as well as the general population's perceived powerlessness in the face of much larger issues (interview with a Dakar-based aid worker).

According to Mendy (2006), the control and monopoly of the state over many resources, the use of these resources in elaborate client-patron relationships (up and down the chain of command and between the state and the population), as well as the population's need for goods and services, combined to lead the population to accept the following compromise: the surrender of their political rights for the satisfaction of their economic and social rights. Yet, according to Gellar (2005), given that communities relied on social ties to meet some of their needs, people expected their leaders to distribute state resources based on familial, friendship, and ethnic ties as well as on political support. As such, even though people complained about corruption and the limited willingness of the leaders to listen to them, ${ }^{75}$ many within the Senegalese society still expected their representatives to take care of them. Moreover, these expectations existed while there was a significant commitment on behalf of most political elites to democratic processes, values and traditions (Gellar 1995). Essentially, people favoured performance legitimacy even when there was a commitment to democratic behaviour on the part of leaders and people were fed up with corruption.

As it relates to the public administration, while public servants continued to be engaged in low level corruption, the significant presidential power over the appointment of senior public servants (Mendy 2006) allowed for the development of two systems of corruption - a system of petty corruption that helped increase the income of public servants (like the police) and a system of significant corruption that supported the diversion of large sums of public funds for patronage and performance legitimacy purposes. Yet, the performance legitimacy of the state remained intact.

As it relates to ethnic and religious cleavages, some researchers consider Senegal to be a religiously tolerant society given that President Senghor was a Catholic and President Diouf's wife was also a Catholic (Gellar 2005). However, the perceived dominance of the Sufi Brotherhood over all of the other Muslim brotherhoods, President Wade's nod to the marabouts and open criticisms of the Catholic faith (News 2009), and, as referred to below, the feelings of exclusion by those living in the Casamance region, and the perceived or actual 'forced' Islamization of the Catholics and animists raise some criticisms regarding such generalizations.

\section{B. Analysis}

The post-independence history of Senegal is defined by actions of patronage and control that leaders used to gain or improve their own performance legitimacy. The abuse of resources filtered into the lowest level of Senegal's public administration. Yet, even though the delivery of goods and

\footnotetext{
${ }^{74}$ This confirms the importance of the reflection of the citizens' perception in the performance legitimacy indicators that were advanced in Chapter 3.

${ }^{75}$ Afrobarometer surveys (http://afrobarometer.org/online-data-analysis/analyse-online).
} 
services was inadequate, the use of resources to provide basic goods and services offered the leaders, and the state in general, adequate performance legitimacy, legitimacy that was used to govern and implement policies. These resources were also used at a time when the process legitimacy of the state was in question. In essence, performance legitimacy seemed to have overridden the need for significant process legitimacy: all leaders attempted to pacify their population through the patronage system that was intended to take care of some of the basic needs of the population.

Still, the performance legitimacy that each leader earned did not negate that of the state. Interestingly, the Senegalese population was aware of the source of the funds and understood the important role that the state played. The people also understood the need for the state and its institutions, a need that went beyond just meeting the population's basic needs. Moreover, the inability of the leaders to move Senegal towards the vicious end of the performance legitimacy continuum - abusing state resources and transferring the performance legitimacy onto themselves was due to the existing relationship between the state and the population (which was strongly affected by the belief in the role of the state), the general lack of desire to see religious leaders as politicians, and the costs to the abuser if and when the abuser attempted such actions.

Nevertheless, Senegal did not experience an easy development path. The post-independence period was mired in economic crises and social insecurity. Moreover, there existed disquiet among nonmarabout supporters with the increased power of the marabout and between President Wade (a Sufi Muslim) and the Catholic Church. Finally, conflict in the Casamance region raised concerns. In many respects, religion and ethnicity were at the forefront of social interactions and grievances.

It must be noted though that starting with the actions of President Diouf, Senegal proved its commitment to a certain level of democracy. Moreover, as Marut (2010) reminds us, Senegal has also experienced remarkable political stability, an army obedient to civilian power, no military coups, political pluralism, even though there were limits on the number of parties that were allowed to be registered, and a certain level of freedom of expression.

\section{The Conflict (1982 - 2010)}

As noted earlier, people in the Casamance region had a tumultuous and bloody relationship with their Senegalese brethren. Many Casamancais, including the leaders of the rebel movement, believed that the region had always had a unique Casamancais identity, one which conflicts with the existing Senegalese identity (Marut 2010). While this claim has been questioned by some historians (Marut 2010), it remains an important part of the sense of exclusion and misunderstanding that many Casamancais harbour. Interestingly, this sense of uniqueness and exclusion did not limit the willingness of the Casamancais political party, The Mouvement des Forces Démocratiques de la Casamance, to run in pre-independence elections.

The Mouvement des Forces Démocratiques de la Casamance or the Movement of the Democratic Forces of Casamance (MFDC) was created in March 1947 as a political and social movement. It became part of the UPS in 1950. Ironically, the UPS received the highest percentage of votes (94 percent) in Ziguinchor, the area within the Casamance region where the conflict began (Beck 2008). In recognition of the support that he received from the Casamance region, President Senghor 
appointed one MFDC leader as minister of technical education in his government (Beck 2008). Between 1962 and 1966, a Diola politician and leader within the MFDC also served as minister of health in Senghor's government (Beck 2008). Yet, there was some indication, at least as de Jong (2005a) had discovered, that suggested that the support that Senghor received from the Casamance was based on a promise made by Senghor to afford the Casamance political independence in return for support of the local politicians that he chose. This promise was never realized.

In return for their political support, Senghor did afford these political actors access to the patronage machine that dominated the public administration (Beck 2008). Unfortunately, the amount of patronage was limited, did not benefit the regular Casamancais since there was little investment in state infrastructure and in the economic potential of the region (Beck 2008), and thus limited the Casamancais political leaders' ability to earn performance legitimacy. According to Beck (2008), the inability of the Casamancais politicians to have control (or to exercise their performance legitimacy) over a sizeable portion of the population allowed Senghor to (a) avoid implementing significant investments in the region and (b) cut existing public services as part of state cost-cutting measures. Senghor's bargain seemed to have been based on the analysis of the differences in the benefits that he was likely to receive if he had invested in a marabout-led area instead of in the Casamance region where most politicians had little ability to rally significant support. According to the Legality indicator (perceived importance of state institutions), Justification indicators (satisfaction with the state/state representatives in its effort to meet basic needs, perceived willingness of the state/state representatives to support its people, and degree to which citizens turn to the state/state representatives for help), as well as the Actual Performance indicators (number of basic goods and services provided by the state/state representatives and ease of access to state/state representatives -delivered basic goods and service), the state and its Casamancais representatives had very limited performance legitimacy in the eyes of the Casamancais population.

The desire for power and the realization of the limited ability to make much headway in the Casamance region also led Senghor to invest in appeasing Northern Wolof communities and their leaders. For the Casamancais, this not only translated into less investment in the region but also into the appropriation of what they considered to be sacred land and its 'sale' to Northerners (Diallo 2009). Furthermore, the implementation of the structural adjustment programs and other development and fiscal programs that were led by the World Bank and the International Monetary Fund starting in 1994 led to the implementation of land reforms. These land reforms led to two types of property - private property and state-owned property. Given that the Diola had customary communal land tenure, a type of tenure unrecognized by the state, their land was seized by the state and turned into state property, a practice that was also implemented during the colonial period (Diallo 2009; Fall 2010). The land in the South was eventually bought by rich people of the Wolof ethnic group. Much of this land was turned into tourist infrastructure that was built by non-Diola workers and that restricted the access of local people to beach fronts, orchards, water tablets, etc. (interview with an academic at the University of Dakar). Moreover, the structural adjustment reforms also worsened investment in infrastructure, including transportation, which further isolated the Casamance region (M. Evans 2005). 
The practice of favouritism took on a more expanded form following the 1970 drought. While most of Senegal was experiencing droughts, the Casamance region remained a luscious agricultural area. The economic consequences of the drought brought Northerners to the Casamance region. With Northerners controlling the public administration and the powerful businesses in the region, the Northern migrants were able to get work and fishing permits, export wood, use the Casamancais' communal land for habitation and economic activity, and become the dominant force in the tourism industry (Diallo 2009). Moreover, the influx of Northerners required the construction of residential settlements, ones that led to the further destruction of sacred forests (Gehrold and Neu 2010).

Given that the economy of the Casamance region was based on agriculture, wood, and tourism with the tourism sector representing the region's economic engine, the economic benefits cultivated from the region were overwhelmingly felt by Northerners, mostly by the Wolof ethnic group (Marut 2010). The Diola were repeatedly dispossessed during the process (Diallo 2009). This Northerner influx as well as their economic and political dominance in the region was perceived by the Casamancais as an aggression against them and an attack on their way of life (Diallo 2009). The uneasy relationship between the Northerners and the Casamancais led to the Casamancais' rejection of the Wolof language, or the language of the Northerners as it was referred to in the Casamance region (Diallo 2009). Moreover, there seemed to have been some sort of a clash of societies between the two groups. While the sense of Senegalese national identity was very strong north of the Gambian River (Gellar 1995), the majority of the Casamancais associated this identity with the oppressive actions of the Northerners and thus deemed it to be a threat to their religion, ethnicity, and way of life (Diallo 2009).

As noted earlier, as compared to the rest of Senegal, the Casamance region was dominated by a more egalitarian and fragmented population. The clientelistic and patronage network that was established by the state could not find enough traction in the region: few local leaders or local people with mass support existed and thus could be recruited to help the state ensure power. As such, only few local leaders received access to the state's patronage machine and were thus able to earn performance legitimacy. According to Beck $(2008,156)$, Senghor's "clientelist networks in Ziguinchor were relatively weak in that they were limited to a narrow exchange relationship between patron and client, unembellished or reinforced by hierarchical structures of authority." Senghor was unable to ensure control over the region through the recruitment of leaders or brokers who had significant performance legitimacy that they could exercise to benefit Senghor's party and have their supporters succumb to Senghor's authority. As such, he appointed northern allies, mostly non-Diola Senegalese, in the local public administration and local party structures (Beck 2008).

From the lead up to the conflict until the late 2000s, the Casamancais perceived the Northerners to be more economically and politically privileged than the Southerners, a feeling that was also shared by non-Wolof groups in the rest of Senegal (Beck 2008; interview with a Dakar-based aid worker). This perception was also fueled by the lack of investment in infrastructure, social service and education within the Casamance region and its subsequent underdevelopment (Diallo 2009; Fall 2010). The Casamancais filled the vacuum left by the state by either relying on non-state actors to access basic goods and services or by venturing into Gambian border towns to access Gambian services (interview with a Dakar-based aid worker ). 
However, according to survey data that goes as far back as 2002/2003, many rural areas, especially in northeastern Senegal, also faced limited investment in infrastructure and dire conditions. ${ }^{76}$ Whether resulting from a lack of knowledge of the living conditions in other parts of Senegal or from the feeling of being continuously targeted by the Northerners and the Senegalese state, the Casamancais' feeling of alienation persisted, contributed to the rise in tensions, and became an important rallying call during the conflict.

Interestingly, this rallying call was delivered by activists from the richest, most educated and most developed part of the Casamance (Foucher 2005; Marut 2010). Rebel leaders were amongst the most educated people in Senegal and many held high level positions in the French Army (as in the case of the head of the military wing of MFDC, Sidy Badji), Senegal's pre-independence government, and in schools and colleges. Initially, students represented the heart of the rebellion (Foucher 2005). They were led by several teachers and by Father Diamacoune, a highly educated Catholic priest who, as noted earlier, witnessed Wolof aggression in his own village during his childhood (Marut 2010). The sense of alienation and subjugation drew many Casamancais, even those living and working in the Senegalese capital of Dakar, into demonstrating in opposition to the actions taken by the government.

Violence broke out on January 11, 1980 when a student protest against cuts in the education system turned violent (Diallo 2009; Marut 2010). The government cracked down on student demonstrators in a bid to end the demonstration and disperse the students. Over the next few days, the government targeted the rebels and their supporters (Marut 2010). This repression affected the majority of the Casamancais (Marut 2010). These events galvanized many Casamancais youth and increased the rhetoric of independence. On December 26, 1982, Casamancais youth and key leaders, including Father Diamacoune and several school and university educators, launched the rebellion by marching in the streets with the goal of removing the Casamancais flag from the state building in Ziguinchor and replacing it with their own (Diallo 2009). The police arrested and killed many demonstrators (Marut 2010). Father Diamacoune was also arrested (Marut 2010). In December 1983, those arrested were tried and given mild sentences (Fall 2010; Marut 2010).

However, the rebels continued building their movement through secret meetings and on December 18,1983 , a few days after the sentences were handed down to the instigators of the demonstration and on a day referred to as Red Sunday, demonstrators marched once more to the government houses in Ziguinchor. The demonstrators were met with live bullets. The official death toll of the demonstrators stood at 24, but many believed it to be between 50 and 200 (Fall 2010). Further arrests were made and many demonstrators fled into the forests for protection. The forests became an important symbol for the rebels as they represented the reformation of the MFDC and the subsequent birth place of the separatist movement under the MFDC banner (Diallo 2009; Foucher 2005). In 1991, about 350 of those arrested, including Father Diamacoune, were released and they subsequently returned to their land as heroes (Marut 2010). Father Diamacoune was elected Secretary General of the MFDC during that same year. The arrests, humiliation, and killing of

\footnotetext{
${ }^{76}$ Afrobarometer surveys (http://afrobarometer.org/online-data-analysis/analyse-online).
} 
Casamancais demonstrators and rebels became a rallying cause, one that significantly increased the number of MFDC recruits (Marut 2010).

As the situation morphed into an active conflict, the MFDC increased its legitimacy within the region. Many believed in the cause and others supported the MFDC as an alternative to the Senegalese ruling party (Foucher 2005) especially since the MFDC leaders were attempting their best to provide people with some basic services (interview with a Casamancais who lived through the conflict and has access to leaders of the MFDC ). For those who did not support it directly, they accepted the MFDC's actions as long as the costs of the fighting were tolerable (Foucher 2005). In essence, according to the Justification and Actual Performance indicators (Chapter 3), the MFDC leaders were initially able to earn some level of performance legitimacy and the citizens responded through Acts of Consent. For example, the rural population stopped paying taxes to the Senegalese state after the MFDC asked them to do so (Marut 2010). As such, the MFDC turned to the locals and many Casamancais working in Dakar for donations (Marut 2010). Villages had local committees who were responsible for gathering donations and transferring them to MFDC leaders (Marut 2010).

However, over the years, the MFDC needed to increase its funding and began to turn against the local population. MFDC fighters turned to the production and sale of illicit drugs, the taxation of the local population, the confiscation of humanitarian assistance packages, the sale of confiscated agriculture products, and local banditry (Marut 2010). Starting in the late 1980s, MFDC-affiliated rebels began steeling from local businesses and braking into local homes (Marut 2010). Their prizes included watches, radios, cellphones, clothes, food, motorcycles, cars and the like (Marut 2010). They also took action against non-Diola civilians in Ziguinchor who were either non-sympathetic to the MFDC or who were suspected of collusion with the Senegalese state (Fall 2010; Marut 2010). These actions decreased and practically eliminated the performance legitimacy of the MFDC, decreased local support, decreased local donations, and subsequently increased the incidence of theft (Marut 2010). Thus, following an initial attempt at helping local Casamancais by providing some services, including protection, the MFDC, due to either the lack of money, disinterest, or a reprioritization of their actions, ignored the needs of the local population and subsequently turned against them (interview with a Dakar-based aid worker). However, the MFDC continued to be financially and politically supported by the Casamancais Diaspora community in Europe and the United States (Fall 2010; Marut 2010).

In the 1980s and 1990s, the Senegalese state used violence and repression to eliminate the rebellion (Fall 2010; Jong 2005a; Marut 2010). Apart from attacks on MFDC fighters, the Senegalese army also destroyed local crops, executed people and cleared entire villages (Fall 2010; Marut 2010). At the same time, the Senegalese government did a lot to divide the MFDC. MFDC's military wing (Atika) split into two when the leader of the military wing (Sidy Badji) signed the first cease-fire agreement with President Diouf in 1999 in Bissau (Marut 2010). The peace accord was denounced by Father Diamacoune, the head of MFDC's political wing (Marut 2010). Following the initial split, Atika split again into three factions, one extremist and two non-extremist factions, with the non-extremist factions negotiating a peace agreement with President Wade (Marut 2010). Splits also occurred in the political wing of MFDC when Father Diamacoune signed a peace agreement 
with President Wade in 2004 (Marut 2010, interview with a Casamancais who lived through the conflict and has access to leaders of the MFDC). Finally, the breaking up of the MFDC significantly decreased its power and influence.

However, as the years went by, both groups of antagonists realized that violence was not working well for them. The state understood that it could not vanquish the rebels and the rebels understood that they could not eliminate the state and win independence (interview with a Dakar-based aid worker). However, conflict was still erupting off and on while peace negotiations were underway (Fall 2010; Marut 2010). Starting in 1999, President Diouf adjusted his approach to the Casamance conflict by focusing on reconciliation and engaging peace-related civil society and women's groups from the Casamance (Marut 2010).

One year later the state's approach changed again with the election of President Wade. President Wade had a more direct approach to peace. He stopped working with civil society groups, nongovernmental groups, intermediaries and other diplomats and concentrated on directly negotiating with Father Diamacoune (Fall 2010; Marut 2010). He also decided to implement a new approach in the Casamance region. This approached was focused on winning the hearts and minds of the Casamancais at a time when the majority of the Casamancais were suffering significantly from the actions of both sides (interview with a Dakar-based aid worker). In the later stages of the conflict, near the mid to late $2000 \mathrm{~s}$, the state began to spend on infrastructure and the provision of basic goods and services in the Casamance region. The army was involved in digging wells, helping with the return of the internal refugees, offering medical clinics and consultations, and demining (Marut 2010). The state also invested in fixing roads, fixing schools, improving the main port, and investing in smaller infrastructure projects (Marut 2010; The World Bank 2005, interview with an academic at the University of Dakar). The population viewed the state as the entity responsible for the improvements in their lives (interview with an academic at the University of Dakar). This built the performance legitimacy of the state (as measured through the Actual Performance indicators (Chapter 3) and increased local support for it (interview with an academic at the University of Dakar, interview with a Dakar-based aid worker ). Moreover, President Wade began appointing people from the Casamance to government posts, renamed places and statues using the names of Casamancais heroes, and recognized the Catholic and animist religions in Senegal's history books (Marut 2010).

In October 2003, Father Diamacoune and the factions of the MFDC that supported him declared that the rebellion had been a failure from a military perspective and the fight for independence was called off (Fall 2010). At that point, the MFDC had practically no performance legitimacy. However, their public admission was criticized by many inside and outside the Casamance region given that the MFDC actors received significant amounts of money to support their peaceagreement administrative duties and they were likely to continue to do so as long as they were engaged in peace talks (Marut 2010). People have also criticized the amount of money that was transferred to the MFDC leaders from the Senegalese state and have accused them of orchestrating the rebellion in order to get access to state funds (Fall 2010, 28). According to de Jong (2005b), by 2004, the Casamancais were weary of all of the peace initiatives and had little faith in the capacity 
of Father Diamacoune. Moreover, they had begun to view the rebellion as little more than "a rent seeking activity" (Fall 2010, 28) by an illegitimate force.

The eventual peace agreement that was signed between Father Diamacoune and President Wade ushered in an influx of financial promises and expenditures from the United States, Germany, Spain, France, the European Union, the World Bank and other smaller donors (Marut 2010). The influx of aid is reflected in the sudden jump in official development assistance in 2004 as is demonstrated in Figure 6.3. ${ }^{77}$ The Wade government responded by establishing the Agence nationale pour la relance économique et sociale de la Casamance (National Agency for the Economic and Social Rehabilitation of Casamance) to coordinate the influx of aid and assigned a Casamancais to lead it (Marut 2010). The aid was used to enhance economic activity in Lower Casamance, set up medical dispensaries, rehabilitate medical clinics, rehabilitate schools and universities, open a new campus for the public university in Ziguinchor, and establish technical colleges (Afrique Jet 2014; Mane 2014; Marut 2010; O Senegal 2014; Le Soleil 2012; The World Bank 2005).

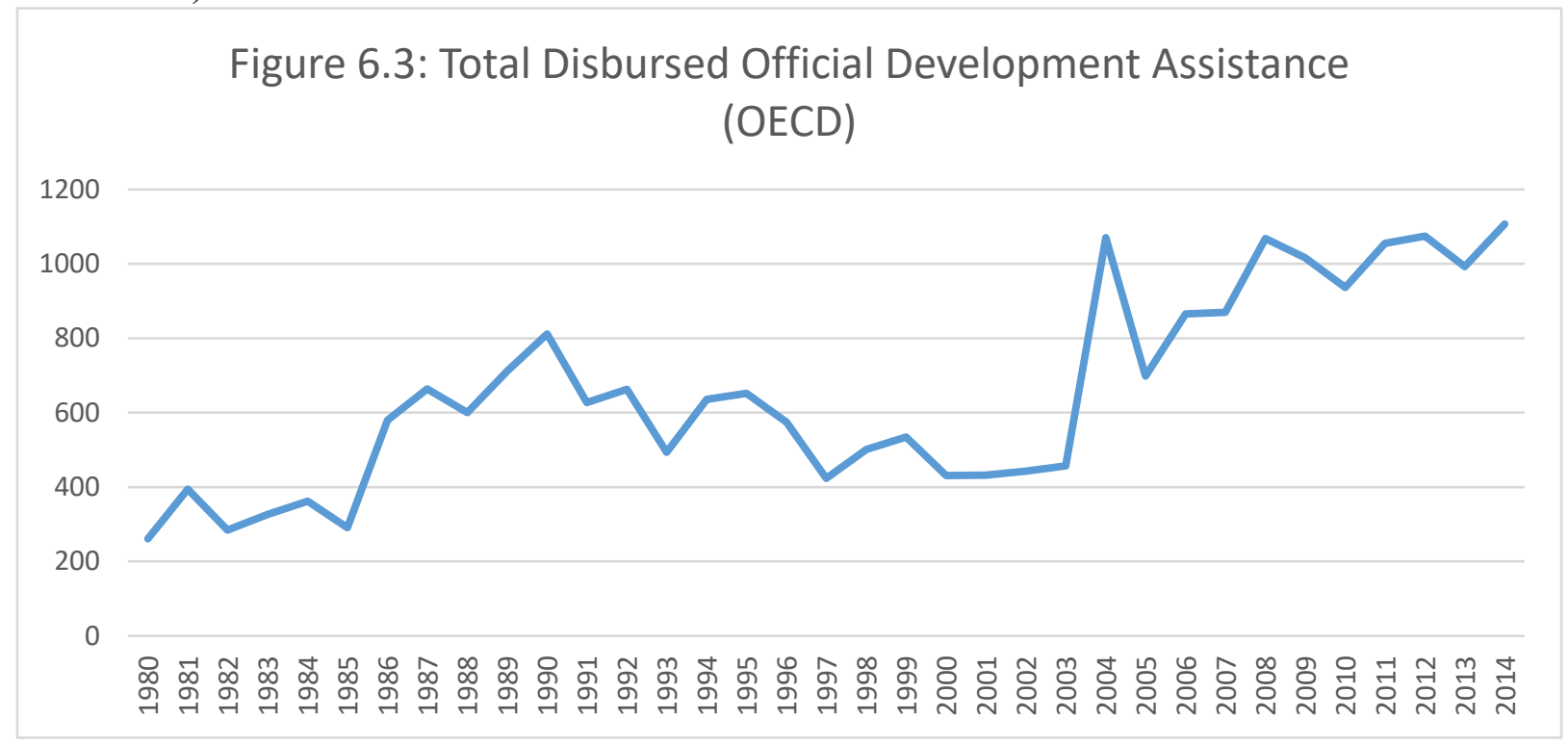

\footnotetext{
${ }^{77}$ All aid-related data was taken from the Query Wizard for International Development Statistics (QWIDS) of the Organization for Economic Development and Cooperation (OECD), https://stats.oecd.org/qwids/.
} 


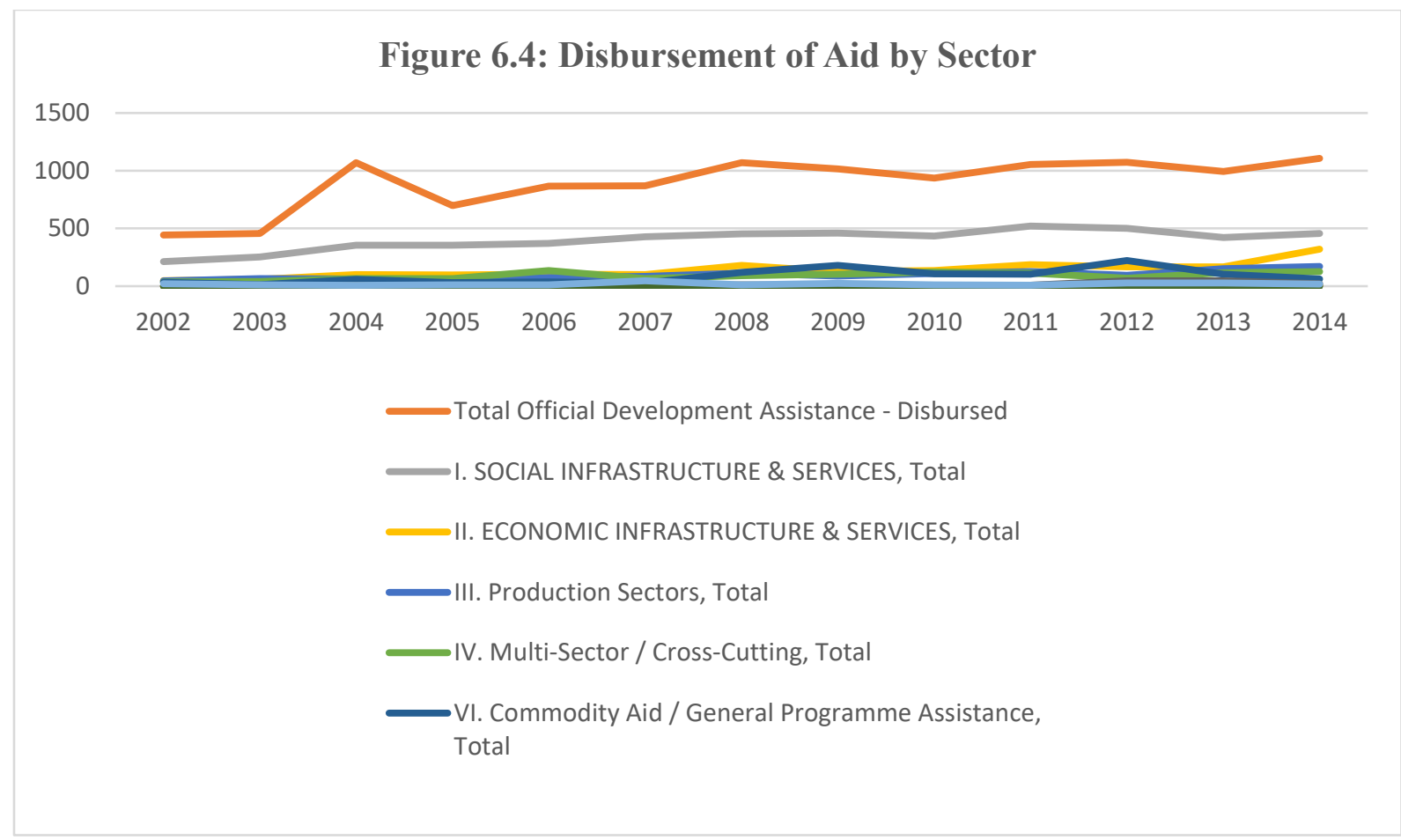

As can be seen in Figures 6.4 and 6.5, the majority of this official development assistance was spent on social infrastructure and services. The majority of the aid targeting social infrastructure and services was spent on education with health, water and sanitation, and government and civil society jockeying for second spot. A significant portion of Senegal's public debt was also forgiven between 2004 and $2006^{78}$, presumably allowing the government to save on interest rates and thus spend on improving the livelihoods of the Senegalese, including those living in the Casamance region.

The investment in basic goods and services increased the Casamancais' loyalty to the state (Marut 2010) as also captured by the Acts of Consent indicators (Chapter 3). As a result, local leaders in the MFDC were forced to recognize their dwindling legitimacy and thus decided to join the government and gain power by accessing the state's patronage system (Marut 2010). Interestingly, the investment in basic services allowed the state to gain performance legitimacy from the Casamancais, something that Senghor deemed too difficult to achieve during his tenure.

${ }^{78}$ This information is based on data from QWIDS, https://stats.oecd.org/qwids/. 
Figure 6.5: Percentage of Expenditure on Social Services

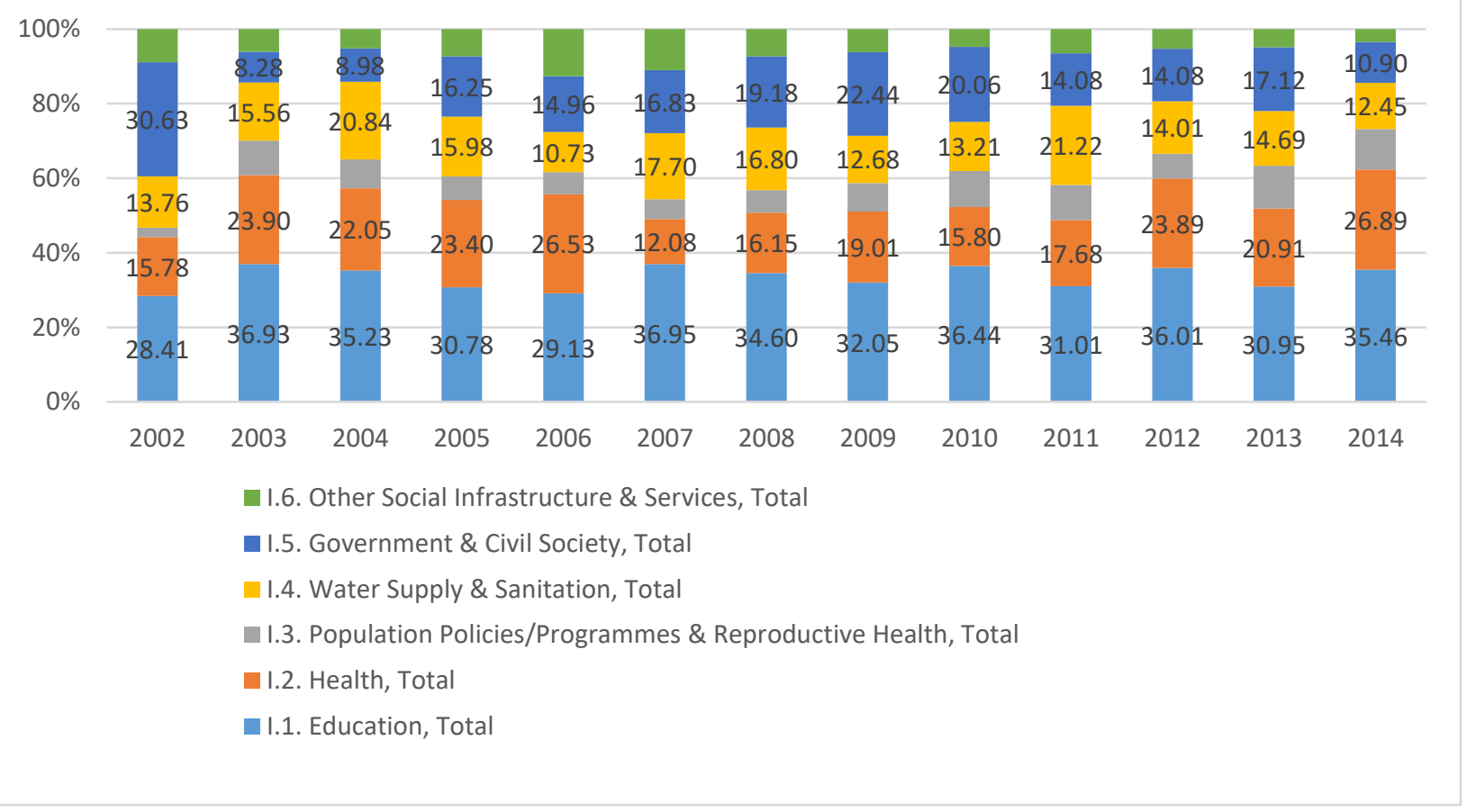

Unfortunately, these social improvements were not able to mitigate the effects of the 2008 economic crisis. Following the onslaught of the crisis, half of the Senegalese population was unemployed, basic goods became very expensive and many services were out of reach for most Senegalese (Marut 2010). While the state announced development projects to assist the population, most of the projects were implemented by foreign agencies and were concentrated in the North, something that once again reinvigorated territorial inequalities (Marut 2010). In 2010, with the poverty rate being the highest in the Casamance region and with a high unemployment rate among ex-MFDC combatants, ex-MFDC combatants rejoined the rebel groups and became involved in local skirmishes (Marut 2010).

As it relates to external interferences, the rebels received little international and non-regional support for their cause (Marut 2010). By the time that the rebellion graduated from a few skirmishes to an actual conflict in 1990, the cold war had ended and the rebels were not able to catalyze on the East-West division (Marut 2010). However, looking for stability in the region and believing that Senegal was an entry way to the non-extremist Arab world and the door to Africa, the international community diplomatically stood behind the Senegalese state (Marut 2010). France, the ex-colonial master, was the only non-regional country to offer military support in the state's fight against the rebels (Marut 2010). With election of Wade as president, his support of free markets, and the strategic importance of Senegal in the war against terrorism, the United States of America, along with France became privileged partners in peace talks (Marut 2010). The United States of America also became one of the largest funders of the peace program for the Casamance region and spent USD \$15 million between 2000 and 2007 on peace-related programs and the delivery of public goods and services in the Casamance region (Marut 2010). As for the MFDC, President Wade had accused Libya, Iraq, Ukraine, Russia and China of supplying arms to various factions 
within the MFDC (Fall 2010, 30). However, apart from the Libyan case, there is little evidence that proves his accusations to be valid.

The conflict was also used by Senegal's neighbours to advance their own agendas (Marut 2010). For example, while Guinea-Bissau was mired in an independence war against the Portuguese, the Casamancais offered Guinea-Bissau fighters help and refuge when the Senegalese state refused to help (Marut 2010). In return, the Casamance rebellion was supported and encouraged by people in Guinea-Bissau (Marut 2010). Moreover, Gambian rebels who were fighting the sitting Gambian president were also supported by the Casamancais (Hameiri 2009; Marut 2010, 131). In return, the new president of The Gambia also supported the Casamance rebellion (Fall 2010; Jong 2005a; Marut 2010) and took military and economic action against the Senegalese state (Marut 2010). It was also reported that the Libyan government had assisted the rebels by training them in Libya (Marut 2010).

Even though the fighting ceased between 2004 and 2010, the conflict, as of the time of the writing of this chapter, has not been resolved. It continues to be characterized as the longest, least intense, and least deadly conflict in Africa (Marut 2010).

\section{A. Consequences of the Conflict}

Given the use of mines and other weaponry, the conflict led to the significant destruction of infrastructure in the Casamance region (Fall 2010; Marut 2010). Moreover, problems with security and the widespread use of mines contributed to significant underinvestment in infrastructure (M. Evans 2005). The problems with transportation, including the insecurity of road travel, the cancellation of air service to the region, and the capsizing of the only fairy between Ziguinchor and Dakar, contributed to a decline in local economic activity, tourism, and the provision of government services (M. Evans 2005; Marut 2010).

Apart from issues related to security, farmers also suffered from distorted prices, access to market information, the lack of inputs, and the lack of availability of marketing opportunities (M. Evans 2005). A war economy developed around timber, cashew, tree crops, cannabis, livestock, and bush meat (Fall 2010, 29). The level of education and accessibility to adequate health services was also severely hampered by the damage done to the infrastructure and the lack of civil servants willing to work in the Casamance owing to the conflict (Fall 2010, 31).

As a consequence of the concentration of fighting in specific areas, the Casamancais economy also became unbalanced between the various regions. While the internal regions of the Casamance saw significant economic decline, those involved in the tourism industry, more specifically the Northerners, saw a lower level of decline in economic activities (Marut 2010).

The conflict also took a significant social toll on the Casamancais society. With some Casamancais youth joining the army for economic as well as for social reasons, some families had kids in both the army and the rebellion, were thus targeted by both groups, and experienced significant emotional turmoil (Marut 2010).

From a human toll perspective, the conflict also led to over 5,000 deaths and over 10,000 people injured. Most of the casualties were from the Casamance region. There was also a significant 
percentage of the population that had to migrate to safer areas. By the end of the 1990s, the number of internal Casamancais migrants was close to 60,000 (Marut 2010).

\section{B. Analysis}

The causes of the war in the Casamance are varied and hard to conclusively claim. Authors have pointed to the stark differences in the ethnic and religious make-up between the North and the South and the impact that this has had on post-independence nation-building project. Part of the issues that are often highlighted are (a) the imposition of the Wolof language, (b) the hierarchical system of governance following the independence of Senegal in 1960, (c) the alienation of the Casamancais, and (d) the lack of a hierarchical structure within the Casamancais society.

In comparison to the many parts of Senegal, the people within the Casamance region had a higher level of education and some had already worked in Wolof-dominated centres like Dakar. Their sense of alienation and injustice was undoubtedly affected by what they witnessed in other parts of Senegal. Moreover, the limited state investment in basic goods and services, likely owing to the non-hierarchical nature of the Casamancais society and thus the inapplicability of the Senegalese political patronage system, had a significant effect on the performance legitimacy of the Senegalese state and the relationship between the Senegalese state and the Casamancais society.

The importance accorded by the Casamancais to meeting basic needs and thus to performance legitimacy was a significant factor in the trajectory of the conflict. In general, the Casamancais supported or bestowed performance legitimacy on the entity that was able to meet their needs. Initially, the support went to the MFDC when the MFDC was taking care of the population. This eventually turned towards the state when the Senegalese state invested in meeting at least some of the basic needs of the Casamancais population.

Religion and ethnicity also played an important role in the conflict. Whether misguided or not, the Casamancais perceived ethnicity as a significant issue in the conflict. The perceived dominance of the Wolof and the specific strand of the Sufi Muslim Brotherhood was a concern to Muslim and non-Muslim Casamancais with both Muslim and non-Muslim Casamancais being actively involved in the rebellion (Marut 2010; interview with a Casamancais who lived through the conflict and has access to leaders of the MFDC). Moreover, the Catholic and animists Casamancais also considered religion to be a major factor in the conflict and used the threat of Islamization as a rallying call (Marut 2010). Interestingly though, the ethnic and religion-based concerns receded from the forefront when the Senegalese state began taking care of some of the basic needs of the Casamancais and the MFDC turned against its population.

Finally, as in the case of other conflicts, the Senegalese conflict saw significant external and regional interferences. The Casamance conflict was used by regional players as part of their geopolitical interests and by Western players as part of their anti-terrorism and free-trade agendas.

\section{Performance Legitimacy in Senegal}

While many have analyzed the level of clientelism and patronage in Senegal and associated these occurrences with weakness in the democratic system, few have assessed the reasons behind the Senegalese population's acceptance of or preference for such a system. As noted in earlier chapters, 
patronage and clientelism are often used as a means to earn performance legitimacy. In the Senegalese case, the presence and use of patronage and clientelism indicates a significant level of importance accorded by leaders and the population at large to performance legitimacy. This was evident in the (a) the marabouts' access to and support of political hopefuls in exchange for the spoils of patronage and thus performance legitimacy, (b) other ethnic leaders' willingness to support whoever had access to state funds in exchange for access to the spoils of patronage and thus performance legitimacy, (c) the Casamancais' willingness to shift allegiances to the state when the state began meeting some of their basic needs despite years of grievances against the Senegalese state and the rest of the Senegalese population, and (d) the willingness of the general population to support, allow or turn a blind eye to the leaders' pursuit of clientelistic networks and systems. In essence, power dynamics were very much connected to the ability of the broker (leaders within the state) to bring the presidents increased votes and influence. This, in return, was very much connected to the benefits that the broker's population received from the presidents and thus the broker's performance legitimacy.

As noted earlier, questions could be raised regarding the power of citizens to request change, the impact of the control of one political party, and the weakness in the democratic system. However, as noted earlier, the population was willing to surrender their political rights for the satisfaction of their economic and social rights (Mendy 2006). In essence, performance legitimacy seemed to take precedence over process legitimacy, even though the Senegalese had a very long history of electoral politics, a history that in some parts of Senegal predated colonialism.

Yet, Senegal did not experience many of the risks associated with performance legitimacy. Performance legitimacy continued to be associated with the state and no actor was able to abuse state resources to the point where the actor was able to undermine the legitimacy of the state. Senegal was successful in avoiding the vicious cycle that was introduced in Chapter 2.

As the analysis demonstrates, there were two major factors that helped in this regard. First, the Senegalese population, even those within the Casamance region, had a significantly clear understanding of the role of the state. They understood the state to be an entity that was responsible for providing them with basic goods and services and for developing policies that help Senegal advance on its developmental path. They placed limits on the aspirations of other actors and established an unwritten code regarding their interference in the political arena. Yet, this strong state-society relationship is surprising given the existence of several hundred years of brokerage between the state and the leaders, religious or otherwise.

Second, Senegal benefitted from a more restrictive political system. There were very few opportunities for hopefuls to abuse state resources and attempt to undermine the performance legitimacy of the state. When the presidents were suspicious of the actions of others and when other leaders attempted to undermine the power of the state and the presidents, the presidents either bought these leaders out by folding them into their parties and giving them access to the patronage machine, adjusted the political system to either exclude or include them, used force to undermine them (as in the case of the Casamance), or removed all of their access to the patronage machine and waited until their influence dwindled or died off. Essentially, the manoeuvering space for the leaders, including the President, and thus the ability to divert performance legitimacy away from the 
state, were limited by the manner in which the political system functioned and the manner in which the electoral system was institutionalized.

As for the conflict in the Casamance region, the delivery of basic goods and services played a significant role in the increased support and legitimacy of the Senegalese state. While the conflict can be characterized by ethnic and religious grievances, a brutal colonial legacy, unfulfilled promises, and differing visions of what defines the society, one needs to recognize that in many ways, the Casamance was not very unique in its situation. The Casamance was not the only region that was neglected by the Senegalese state, had a significantly high poverty rate, and felt dominated by the Wolof. Economic and social inequalities, limited access to economic, social and political opportunities as well as limited ability to choose one's own local administrator, political leader, or third tier government leader were experienced by most of the people living outside the main Northern cities. Most of Senegal experienced social fracturing with tensions between the various ethnic groups. Moreover, many regions along the Senegalese border experienced external interferences (cattle grazing, arms shipment, attacks on the Senegalese and the Senegalese army from the northern Gambian border).

However, while the terrain could have played a role in allowing the rebels protection, more importantly, what was unique to the Casamance was (a) the willingness of the rebels to undermine the state, (b) their ability, at least initially, to provide an alternative to the state when the state was not able to demonstrate its presence as it did in other areas, and (c) the lack of other politically influential leaders in the region that would allow the state to bypass the rebels. Interestingly, when the state decided to invest in meeting the needs of the Casamancais at a time when the rebel movement had lost its performance legitimacy and its morale, the population returned the favour by bestowing it with performance legitimacy. This occurred even though the Casamance region still had not developed the kind of hierarchical societal structure that was amenable to the Senegalese patronage system.

The presence and owners of performance legitimacy, as measured by the indicators in Chapter 3, at the various critical junctures in Senegal's history are summarized in the following table.

Table 6.1: The Entity that Ranked Highest in the Performance Legitimacy Indictors (Chapter 3) during Senegal's Critical Junctures

\begin{tabular}{|l|l|l|l|l|l|}
\hline Indicators & \multicolumn{5}{|c|}{ Critical Junctures } \\
\hline & $\begin{array}{l}15^{\text {th }} \text { Century }- \\
1884\end{array}$ & $\begin{array}{l}1884-1960 \\
\text { Colonial } \\
\text { Pre-Colonialism }\end{array}$ & $\begin{array}{l}1960-1982 \\
\text { Period }\end{array}$ & $\begin{array}{l}1982-2010 \\
\text { Civil War }\end{array}$ & $\begin{array}{l}2010-2016 \\
\text { Post-Conflict }\end{array}$ \\
\hline A. Legality & & U: None & U: None & U: State & U: State \\
\hline 1. Perceived Reach and Applicability of the Law & U: & U: State \\
\hline
\end{tabular}




\begin{tabular}{|c|c|c|c|c|c|}
\hline & $\begin{array}{l}\mathrm{R}: \text { None } \\
\mathrm{C}: \text { None }\end{array}$ & $\begin{array}{l}\mathrm{R}: \text { None } \\
\mathrm{C}: \text { None }\end{array}$ & $\begin{array}{l}\mathrm{R}: \text { None } \\
\mathrm{C}: \text { None }\end{array}$ & $\begin{array}{l}\text { R: State } \\
\text { C: None }\end{array}$ & $\begin{array}{l}\text { R: State } \\
\text { C: State }\end{array}$ \\
\hline $\begin{array}{l}\text { 2. Perceived Importance of State Institutions in Citizens' } \\
\text { Daily Lives }\end{array}$ & $\begin{array}{l}\text { U: None } \\
\text { R: None } \\
\text { C: None }\end{array}$ & $\begin{array}{l}\text { U: State } \\
\text { R: None } \\
\text { C: None }\end{array}$ & $\begin{array}{l}\text { U: State } \\
\text { R: State } \\
\text { C: None }\end{array}$ & $\begin{array}{l}\text { U: State } \\
\text { R: State } \\
\text { C: None }\end{array}$ & $\begin{array}{l}\text { U: State } \\
\text { R: State } \\
\text { C: State }\end{array}$ \\
\hline 3. Confidence in the Security Provided by the Actor & $\begin{array}{l}\text { U: Leaders } \\
\text { R: Leaders } \\
\text { C: Leaders }\end{array}$ & $\begin{array}{l}\text { U: Leaders } \\
\text { R: Leaders } \\
\text { C: Leaders }\end{array}$ & $\begin{array}{l}\text { U: State } \\
\text { R: State } \\
\text { C: Leaders }\end{array}$ & $\begin{array}{l}\text { U: State } \\
\text { R: State } \\
\text { C: Leaders at the beginning, } \\
\text { state in the later stages }\end{array}$ & $\begin{array}{l}\text { U: State } \\
\text { R: State } \\
\text { C: State }\end{array}$ \\
\hline 4. Confidence in the Civil Service & No data & $\begin{array}{l}\text { U: State } \\
\text { R: None } \\
\text { C: None }\end{array}$ & $\begin{array}{l}\text { U: State } \\
\text { R: State } \\
\text { C: None }\end{array}$ & $\begin{array}{l}\text { U: State } \\
\text { R: State } \\
\text { C: None }\end{array}$ & $\begin{array}{l}\text { U: State } \\
\text { R: State } \\
\text { C: State }\end{array}$ \\
\hline \multicolumn{6}{|l|}{ B. Justification } \\
\hline $\begin{array}{l}\text { 1. Satisfaction with the Actor in its Effort to Meet Basic } \\
\text { Needs }\end{array}$ & No Data & $\begin{array}{l}\text { U: Leaders } \\
\text { R: Leaders } \\
\text { C: Leaders }\end{array}$ & $\begin{array}{l}\text { U: State } \\
\text { R: State } \\
\text { C: Leaders }\end{array}$ & $\begin{array}{l}\text { U: State } \\
\text { R: State } \\
\text { C: Leaders at the beginning, } \\
\text { state in the later stage }\end{array}$ & $\begin{array}{l}\text { U: State } \\
\text { R: State } \\
\text { C: State }\end{array}$ \\
\hline $\begin{array}{l}\text { 2. Perceived Willingness of the Actor to Support } \\
\text { Citizens/Followers }\end{array}$ & No Data & $\begin{array}{l}\text { U: State \& } \\
\text { leaders } \\
\text { R: Leaders } \\
\text { C: Leaders }\end{array}$ & $\begin{array}{l}\text { U: State } \\
\text { R: State \& } \\
\text { leaders } \\
\text { C: Leaders }\end{array}$ & $\begin{array}{l}\text { U: State } \\
\text { R: State \& leaders } \\
\text { C: Leaders at the beginning, } \\
\text { state in the later stage }\end{array}$ & $\begin{array}{l}\text { U: State } \\
\text { R: State } \\
\text { C State }\end{array}$ \\
\hline 3. Degree to which Citizens Turn to the Actor for Help & $\begin{array}{l}\text { U: Leaders } \\
\text { R: Leaders } \\
\text { C: Leaders }\end{array}$ & $\begin{array}{l}\text { U: State \& } \\
\text { leaders } \\
\text { R: Leaders } \\
\text { C: Leaders }\end{array}$ & $\begin{array}{l}\text { U: State } \\
\text { R: State \& } \\
\text { leaders } \\
\text { C: Leaders }\end{array}$ & $\begin{array}{l}\text { U: State \& leaders } \\
\text { R: State \& leaders } \\
\text { C: Leaders at the beginning, } \\
\text { state in the later stage }\end{array}$ & $\begin{array}{l}\text { U: State } \\
\text { R: State \& } \\
\text { leaders } \\
\text { C: State }\end{array}$ \\
\hline \multicolumn{6}{|l|}{ C. Actual Performance } \\
\hline $\begin{array}{l}\text { 1. Number of Basic Goods and Services Provided by the } \\
\text { Actor }\end{array}$ & $\begin{array}{l}\text { U: Leaders } \\
\text { R: Leaders } \\
\text { C: Leaders }\end{array}$ & $\begin{array}{l}\text { U: State } \\
\text { R: Leaders } \\
\text { C: Leaders }\end{array}$ & $\begin{array}{l}\text { U: State } \\
\text { R: State \& } \\
\text { Leaders } \\
\text { C: Leaders }\end{array}$ & $\begin{array}{l}\text { U: State } \\
\text { R: State \& Leaders } \\
\text { C: Leaders at the beginning, } \\
\text { state in the later stage }\end{array}$ & $\begin{array}{l}\text { U: State } \\
\text { R: State \& } \\
\text { leaders } \\
\text { C: State }\end{array}$ \\
\hline $\begin{array}{l}\text { 2. Quality of Actor-delivered Basic Goods and Services } \\
\text { Provided }\end{array}$ & No Data & No Data & No Data & $\begin{array}{l}\text { U: State } \\
\text { R: State \& leaders } \\
\text { C: Leaders at the beginning, } \\
\text { state in the later stage }\end{array}$ & $\begin{array}{l}\text { U: State } \\
\text { R: State \& } \\
\text { leaders } \\
\text { C: State }\end{array}$ \\
\hline $\begin{array}{l}\text { 3. Ease of Access to Actor-delivered Basic Goods and } \\
\text { Services }\end{array}$ & No Data & $\begin{array}{l}\text { U: State \& } \\
\text { leaders } \\
\text { R: Leaders } \\
\text { C: Leaders }\end{array}$ & $\begin{array}{l}\text { U: State } \\
\text { R: State \& } \\
\text { leaders } \\
\text { C: Leaders }\end{array}$ & $\begin{array}{l}\text { U: State } \\
\text { R: State \& leaders } \\
\text { C: Leaders at the beginning, } \\
\text { state in the later stage }\end{array}$ & $\begin{array}{l}\text { U: State } \\
\text { R: State \& } \\
\text { leaders } \\
\text { C: State }\end{array}$ \\
\hline \multicolumn{6}{|l|}{ D. Acts of Consent } \\
\hline \multicolumn{6}{|l|}{ State } \\
\hline $\begin{array}{l}\text { 1. Compliance with State-Sanctioned Health Rules during } \\
\text { an Epidemic }\end{array}$ & No Data & No Data & No Data & No Data & No Data \\
\hline 2. Compliance with State-Sanctioned Rules or Actions & $\begin{array}{l}\text { U: None } \\
\text { R: None } \\
\text { C: None }\end{array}$ & $\begin{array}{l}\text { U: State } \\
\text { R: None } \\
\text { C: None }\end{array}$ & No Data & $\begin{array}{l}\text { U: State } \\
\text { R: State } \\
\text { C: None }\end{array}$ & $\begin{array}{l}\text { U: State } \\
\text { R: State } \\
\text { C: State }\end{array}$ \\
\hline $\begin{array}{l}\text { 3. Compliance with Police Enforced Laws and } \\
\text { Regulations }\end{array}$ & No Data & No Data & $\begin{array}{l}\text { U: State } \\
\text { R: None } \\
\text { C: None }\end{array}$ & $\begin{array}{l}\text { U: State } \\
\text { R: State } \\
\text { C: None }\end{array}$ & $\begin{array}{l}\text { U: State } \\
\text { R: State } \\
\text { C: State }\end{array}$ \\
\hline \multicolumn{6}{|l|}{ Leader } \\
\hline 1. Compliance with Leader-Sanctioned Rules or Actions & No Data & No Data & $\begin{array}{l}\text { U: None } \\
\text { R: Leaders } \\
\text { C: Leaders }\end{array}$ & $\begin{array}{l}\text { U: None } \\
\text { R: Leaders } \\
\text { C: Leaders at the beginning }\end{array}$ & $\begin{array}{l}\text { U: None } \\
\text { R: Leaders } \\
\text { C: None }\end{array}$ \\
\hline $\begin{array}{l}\text { 2. Compliance with State-Sanctioned Health Rules } \\
\text { during an Epidemic, even when not supported by the } \\
\text { Leader }\end{array}$ & No Data & No Data & No Data & No Data & No Data \\
\hline $\begin{array}{l}\text { 3. Compliance with Leader-Enforced Laws and } \\
\text { Regulations, even when in Contradiction with that of } \\
\text { the state }\end{array}$ & No Data & No Data & $\begin{array}{l}\text { U: None } \\
\text { R: None } \\
\text { C: Leaders }\end{array}$ & $\begin{array}{l}\text { U: None } \\
\text { R: None } \\
\text { C: Leaders at the beginning }\end{array}$ & $\begin{array}{l}\text { U: None } \\
\text { R: None } \\
\text { C: None }\end{array}$ \\
\hline
\end{tabular}

Legend: U: Urban, R: Rural, C: Casamance

The variables that are included in Table 6.1 are based on qualitative data that was gathered through the research. The valuation of the results is also based on my judgment, which was influenced and guided by the results of the research. The indicators were not tested in the field. As such, the values attached to these variables are preliminary and, as a next step, require both further research and rigorous testing.

\section{Conclusion}

The history of Senegal is one of leaders gaining performance legitimacy by meeting the needs of their population. It is also a history of a belief in a locally-derived form of democracy (demokaraasi), the importance and legitimacy of the state, the use of patronage networks, and a 
limited political manoeuvring space. These factors have worked to ensure the legitimacy of the state, even though Senegal has seen significant periods of undemocratic behaviour.

In conclusion, the Casamance conflict has demonstrated that while many grievances can exist, the ability of an actor, the Senegalese state in this case, to bypass these grievances, at least in the short run, by meeting the needs of the people affords the actor a certain level of performance legitimacy. This performance legitimacy can then be built upon and used to implement further legitimacyenhancing actions. The Casamance conflict has also demonstrated that performance legitimacy does not always go to leaders and can be acquired by the state if two conditions are present: First, a relationship between the state and society exists and is based on the belief in the role of the state, and second, the political manoeuvring space is limited and thus does not allow for the development of the vicious performance legitimacy cycle. 


\section{Chapter 7: The South Sudan Case Study}

\section{Introduction}

The Republic of South Sudan is the youngest country in the world. It achieved independence from the Republic of the Sudan on July 9, 2011. The road to independence was long and bloody and the border between the Republic of the Sudan and the Republic of South Sudan remains contested in the Abyei region (centre-north of the country).

The country shares borders with the Republic of the Sudan, the Central African Republic, the Democratic Republic of the Congo, Uganda, Kenya, and Ethiopia.

South Sudan has a political system that is best defined as a presidential republic. The President is elected by a simple majority vote. The President is both the chief of state and the head of government. The National Council of Ministers is appointed by the President and approved by the National Assembly. Members of the National Assembly are

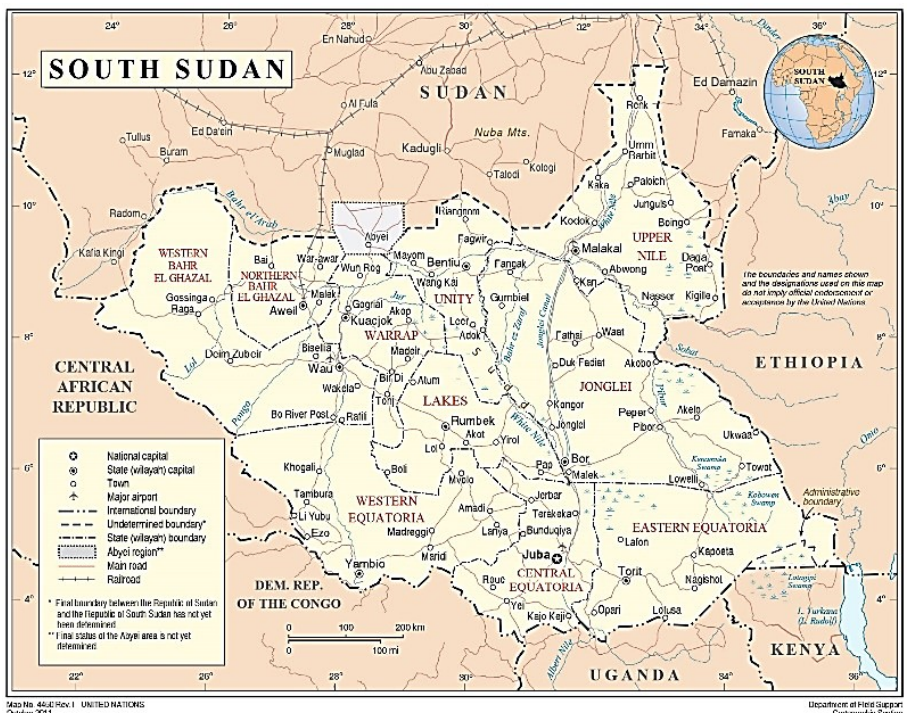

Source: United Nations http://www.un.org/apps/news/infocus/UNdecoded/UNdecoded.asp?NewsID=1337\& elected by the people.

It has a multiethnic, multi-religious and multilingual society made up mostly of a pastorally-based population. Religion and ethnicity were used as a rallying call in the struggle for independence and continue to be used in South Sudan's current civil war. South Sudan is inhabited by more than 65 tribes. It has an overwhelmingly poor society, high levels of inequality, and a highly militarized and divided society.

Throughout their history, the South Sudanese have experienced significant bloodshed. They have been embroiled in two pre-independence civil wars and a more recent civil war that begun in 2013, ended in a peace agreement in 2015 and continues to ignite acts of violence. They have also experienced a very weak relationship with the state and constant brokering for their support by local leaders who were very concerned with their performance legitimacy and thus power.

Overall, the South Sudanese case provides an interesting look at how factors from the past continue to have a significant impact on current events, even when a society has turned a new page. More so, the South Sudanese case highlights (a) the importance of the interaction between performance legitimacy, political structures, and the relationship between the state and the population and (b) the resulting failure in the state's ability to gain performance legitimacy. 
This chapter traces the history of South Sudan from the pre-colonial era to the present. For each period, the analysis looks at the relationship between the state and society, the political situation, the socio-economic conditions, external interferences, and the role of the delivery of basic goods and social services. The chapter ends with an assessment of performance legitimacy in South Sudan.

The following is a simple timeline graphic that allows one to visualize the outcomes of the following process tracing analysis.

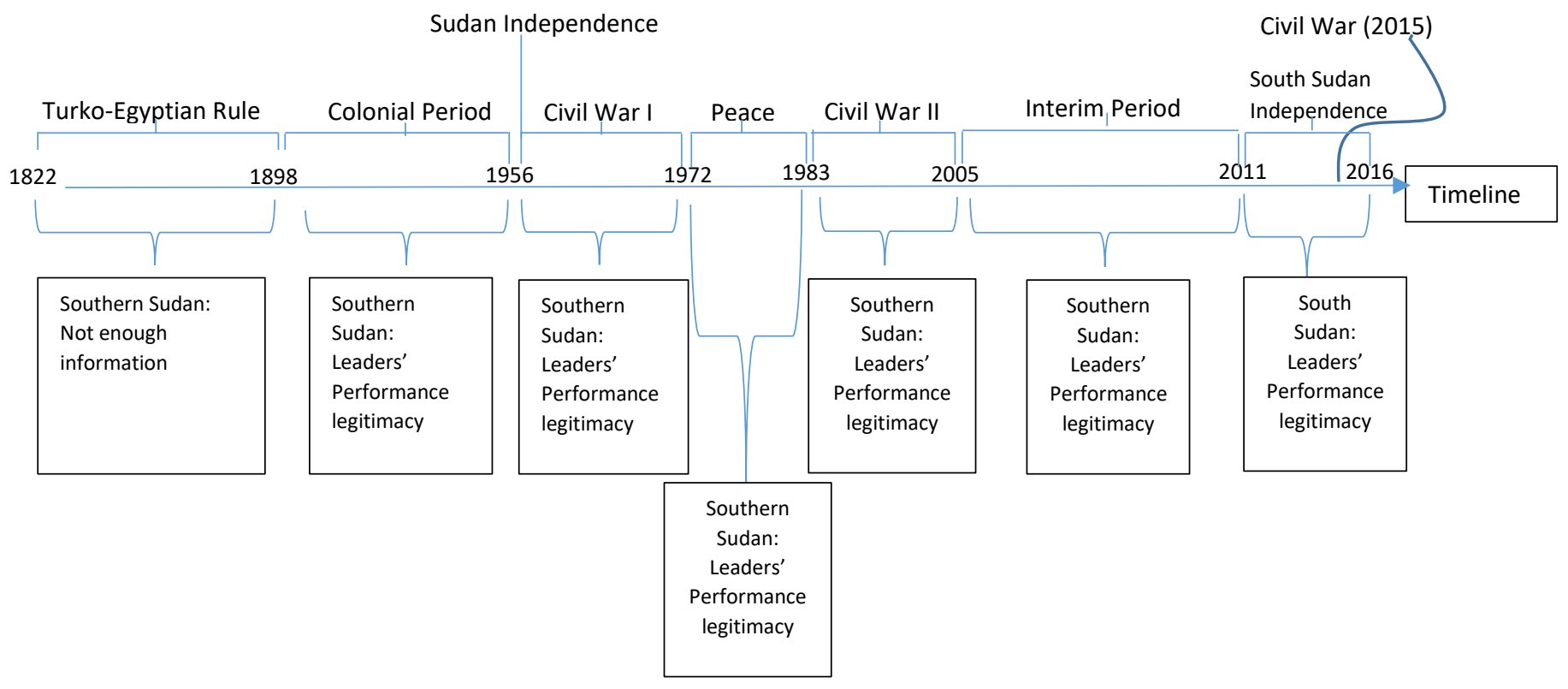

\section{From Pre-colonial Times to the Independence of the Republic of the Sudan}

\section{A. Pre-colonial Sudan and South Sudan}

The Sudans ${ }^{79}$ pre-colonial history was dominated by the Turko-Egyptian rule that lasted from 1822 until 1898 (Kon 2015). During this period, the population in what we now refer to as the Republic of the Sudan was Islamized and Arabized. As for the southern regions and the area that we now refer to as the Republic of South Sudan, people in these regions opposed and fought against the Turko-Egyptian rule. However, the southern population was significantly affected by the slave trade. Turko-Egyptian slave traders undertook incursions into the southern regions and abducted a significant number of Southerners (Jok 2011; LeRiche and Arnold 2012).

Apart from an economic, cultural, and religious interest in the region, there is no evidence that indicates that the Turko-Egyptian era contributed to political or infrastructural advancements. Moreover, unlike Lebanon, there is no indication that the region under the Turko-Egyptian rule experienced the building of a governmental administration or any form of non-tribal and non-local administrative system.

\footnotetext{
${ }^{79}$ The term 'Sudans' is meant to refer to the area covered by the Republic of the Sudan and the Republic of South Sudan.
} 


\section{B. Western Colonial History}

The area that now falls within the borders of both Sudans was jointly colonized by the British and Egyptians in 1898 (Kon 2015). During this time, the territory was administered under two separate bureaucratic arrangements, one for the North and one for the South (Kon 2015), and the majority of British resources were directed towards the Northern parts of Sudan, especially Khartoum ${ }^{80}$ (Larson, Ajak, and Pritchett 2013).

As was the case with the Turko-Egyptian period and unlike the French rule in Lebanon and Senegal, the British-Egyptian period did not see any real building of democratic systems and structures. Outside the emphasis on Khartoum, the people in the Sudans lived according to their traditional practices, practices that were dictated by ethnicity and religion. The Sudanese also lived under an elaborate patronage system that was developed by regional leaders (Grawert 2013) thus making performance legitimacy central to their lives.

There were significant differences in the societal makeup between the North and the South. While the north of Sudan was mostly inhabited by an Arab speaking, lighter skinned, Muslim population, the south was inhabited by a darker-skinned, non-Arabic speaking, Christian and animist population. Moreover, unlike their Northern counterparts, the Southerners were never controlled by an invader or a colonizer (LeRiche and Arnold 2012). The British acknowledged the ethnic and cultural differences between the two areas (Kon 2015) and, according to Larson et al (2013), the British, owing to these differences, initially entertained the idea of separating the South from the North. This was an important consideration at a time when the territory was being divided up into ethnic regions or areas with internal borders (De Simone 2015). ${ }^{81}$

As for the Southern region, the British ensured that it was protected from Arab influences (Kon 2015). The area was also left to develop its own system of tribal rule and tribal authority structures (Larson, Ajak, and Pritchett 2013). However, this protection ended when in 1940, the British and Egyptian leaders acquiesced to the desires and concerns of the Northerners (Kon 2015).

The subjugation of the South to the North and the decision by the British to stop protecting the Southerners reignited desires for official and complete independence from the North. These desires were tempered by the British decision to keep the Sudans as a single entity while working towards the protection of the Southern culture and religion (LeRiche and Arnold 2012). The resulting 1947 Juba Conference was organized by the British and provided the space for debates regarding the future of the two Sudans - whether to remain united, perhaps under a federal-type system, or whether to have two distinct political entities (Kon 2015). With the recognition of the low levels of education and development in the South, the Southern delegation believed that the benefits of being part of a new Sudan under a more representative political system would outweigh the costs and risks associated with establishing a weak and economically non-viable independent South Sudan (LeRiche and Arnold 2012). Thus, the Juba Conference ended in an agreement to constitute one state with a Legislative Assembly that would represent and be represented by politicians from the entire region. However, the Sudanese government that was formed did not abide by the Juba

\footnotetext{
${ }^{80}$ Khartoum is the current capital of the Republic of the Sudan.

${ }^{81}$ This division also strengthened the role of ethnicity in every aspect of society, especially when it came to access to land (De Simone, 2015), something that was significantly important for the agriculturally-based society.
} 
Conference Agreement. The Legislative Assembly that was formed was dominated by Northern elites - out of 900 seats, only eight were filled by Southerners (LeRiche and Arnold 2012). In the end, the British withdrew without making any changes to the Sudanese borders and transferred power to an Arab Norther elite in Khartoum who perceived the Southerners (black Africans) as inferior (Larson, Ajak, and Pritchett 2013).

Violence was reignited in 1955 with a Southerner-led mutiny within the Sudanese army (LeRiche and Arnold 2012). The mutiny came about after Southern military personnel were transferred to Northern regions and replaced by Northern military personnel (LeRiche and Arnold 2012). The mutineers, later dubbed the Anya-Nya rebels, were members of the Equatorial Corps of the Sudan, the only force that Southerners considered legitimate (LeRiche and Arnold 2012). With the possibility of war looming, the Southern Liberal Party (SLP), the main party representing the Southerners in the Legislative Assembly, reiterated the Southerners' demands that were presented during the Juba Conference and proposed a federal system that would rule over the two Sudans (LeRiche and Arnold 2012). Eventually, other smaller parties from the Southern regions joined with the SLP to form the Southern Bloc (LeRiche and Arnold 2012). However, the Southern Bloc was not a united front and was not able to attract all of the groups that were active in the South, especially those that perceived the groups within the Bloc to be working with the non-favoured Northerners (LeRiche and Arnold 2012). This division allowed the North to avoid acquiescing to the Southerners' demands (LeRiche and Arnold 2012).

With no real political solutions forthcoming, the Anya-Nya rebels joined with other independenceseeking fighters and launched Sudan's first civil war.

C. Analysis

Overall, one can draw three conclusions from the history of the two Sudans under foreign rule. First, culture, ethnicity, and religion played an important role in the societies and in the ensuing wars. The society was dictated by ethnic practices and access to benefits depended on ethnic identity.

Second, colonial rule established or reinforced a core-periphery system that led to unequal development between the various regions. Combined with the clear separation between the two societies in the North and in the South, the focus on the core increased the desire for Southern separation.

Third, while the Sudanese did not develop a strong history of stateness and a state administrative system, as in the Lebanese and Senegalese cases, they did develop some form of political ideology. Most of the leaders of the North and the South believed in representation at a national level. The idea of equal representation and unbiased governance was an important part of the discourse. However, performance legitimacy based on patronage and ethnicity was also a very important aspect in people's lives. 


\section{From the Independence of the Republic of the Sudan to the Independence of the Republic of South Sudan}

The greater Sudan achieved its independence on January 1, 1956. At the time, the Sudanese society was already built on a strong patronage-based system and ethnicity played a very important role in people's lives and in the access to resources and land (Grawert 2013). Leaders within one ethnic group often competed against each other and earned performance legitimacy and by using state resources as part of their elaborate patronage system (Grawert 2013).

\section{A. The Wars}

Shortly after independence, it became clear that the Government of the Republic of the Sudan was unlikely to honour its Juba Conference promise to implement a federal system that respected religious and cultural rights (LeRiche and Arnold 2012). Northern cultural hegemony and political and economic marginalization of the South, which had been ongoing for decades, continued unabated (Larson, Ajak, and Pritchett 2013). Moreover, the few development initiatives that were undertaken were focused on the Arab triangle around Khartoum (LeRiche and Arnold 2012). As such, the relationship between the people in the South and the people in the North, as well as the relationship between the people in the South and the Sudanese government was defined by alienation and frustration (LeRiche and Arnold 2012). As measured by the Justification indicators (satisfaction with the state in its effort to meet basic needs, perceived willingness of the state to support its citizens, and degree to which citizens turn to the state for help) and Actual Performance indicators (number of basic goods and services provided by the state and ease of access to statedelivered basic goods and services) in Chapter 3, the state was unable to become a relevant and important actor in the non-Northerners' lives and thus, had limited performance legitimacy in the South . Furthermore, this created a void and allowed for and increased the importance of the role of local leaders in areas outside the North (LeRiche and Arnold 2012) who filled some of the service gap that was left by the state. Based on the Justification and Actual Performance indicators, the leaders were able to earn performance legitimacy by taking care of some of the basic needs of the population under their control.

Even though it is hard to determine the exact causes of the Sudanese civil wars (LeRiche and Arnold 2012), this uneasy relationship between the North and the South contributed significantly to the two civil wars that gripped the Republic of the Sudan. The first civil war began in 1955. The war was mostly fought out in the South between independence-seeking rebels on the one hand and the Sudanese military and government-sanctioned paramilitary forces on the other. The Government of the Republic of Sudan's objective was not only to eliminate all threats to Sudan's unity, but also to continue its historic efforts at Islamizing and Arabizing the South (Grawert 2013).

During the early 1970s, both camps were at a military stalemate and it was only broken in 1972, 16 years after independence, when then Ethiopian Emperor Haile Selassie helped the two camps negotiate the Addis Ababa Agreement. The Agreement established a regional government for Southern Sudan in a bid to grant its people greater autonomy and increased the protection of minorities by creating religious and cultural constitutional provisions (LeRiche and Arnold 2012). As such, the Addis Ababa Agreement gave Southern Sudan a semi-autonomy status with the right to self-rule (Grawert 2013). 
The regional government was to be made up of an elected Regional Assembly, led by a regional president and regional ministers. The Regional Assembly was to be based in Juba, the current capital of the Republic of South Sudan (LeRiche and Arnold 2012). However, the regional government was to have limited authority. For example, while the regional government had the right to raise local taxes, it did not have access to its own budget, relied on financial and nonfinancial resources from the central government in the North, and could not undertake any economic planning or implement any policies that were not approved by the central government (LeRiche and Arnold 2012). The Addis Ababa Agreement also stipulated that the Anya-Nya rebels would become part of the army, be stationed in the South (and represent half of the troops in the South), and report to the army command in Khartoum (LeRiche and Arnold 2012).

The agreement was made official through a new national constitution, one that was completed in 1973 and that included the Southern Sudan Self Government Act (LeRiche and Arnold 2012). In October 1973, Southerners voted to elect members of the Regional Assembly (LeRiche and Arnold 2012). This was the first historic democratic electoral experience that the Southerners had taken an active part in. The elections led to the domination of the regional government by the Dinka ethnic group, the largest group in Southern Sudan (LeRiche and Arnold 2012).

After a few years of being ruled by a Dinka-dominated regional government that did not provide much benefits to the population, other Southern ethnic groups began to be increasingly disenfranchised and to question the legitimacy of the regional government, especially since they still had not received any benefits from the state (LeRiche and Arnold 2012). Their disenfranchisement opened the door to 'unholy' unions with Sudan's governing party; a party that was working to undermine the strength and leadership of the Southern independence movement (LeRiche and Arnold 2012). These unions introduced further complications into the fold since they brought some independence-fighters together with their long-term 'enemy' (Khartoum) to fight against their immediate 'enemy' (Dinka elites). Within the same period, the Government of Sudan divided up the South into three smaller regions, each with its own capital. This division increased tensions among Southerners and between Southerners and the Northern government (LeRiche and Arnold 2012). The tensions undermined Southern unity, allowed the North to have more influence in the South through its divide-and-conquer approach, and significantly increased the number of recruits into the Southern secessionist groups (LeRiche and Arnold 2012; de Waal 2014).

In 1983, with tensions running very high, Sudan facing significant economic turmoil, and the government eliminating basic foods and fuel subsidies (Grawert 2013), Dr. John Garang de Mabior, the leader of the Sudan People's Liberation Army (SPLA) and the SPLA's political wing (the Sudan People's Liberation Movement (SPLM)), took advantage of the weak performance legitimacy of the state and led a rebellion against the North. This rebellion is considered to have been the factor that ignited Sudan's second civil war (LeRiche and Arnold 2012). The rebellion included many actors from different ethnic backgrounds. The Nuer were initially represented by the Anya Nya II. Some Anya Nya II recruits eventually joined the SPLA while others formed their own militia.

The idea of non-representation in the central government or the feeling of exclusion was also shared by many non-Southerners throughout Sudan (in Darfur, the Nuba Mountains, the Blue Nile and 
Eastern Sudan), including those who self-identified as Africans and not Arabs (LeRiche and Arnold 2012). The SPLM/A was able to develop a wider base of support because of the discontent being expressed by neglected groups throughout Sudan and because of the limited or lack of state performance legitimacy. Consequently, the SPLM/A was able to join with other northern militia groups and form the Sudan Alliance Forces. Moreover, the support from some Northerners and the need to gain international acceptance led Garang to change his rhetoric from secession to democracy, equality and pluralism (LeRiche and Arnold 2012).

During the late 1980s and into the 1990s, some Southerners who had worked with the government in the North switched camps and joined the SPLM/A after realizing that the North was using them as a tool to not only undermine the rebels but to also undermine Southern unity and thus the fight for independence (Jok 2011). The Government of Sudan retaliated by attacking civilians in urban areas and undertaking collective punishment by accusing all southerners of being SPLM/A supporters (Jok 2011). The actions of the Khartoum government in the late 1980s and throughout the 1990s led to many gruesome atrocities in the South, especially in villages and SPLA-controlled towns (Jok 2011). Yet, atrocities were also committed by the SPLA who was also responsible for its actions against people in the regions under its control (LeRiche and Arnold 2012).

By 1991, the Government of the Republic of Sudan had won back many of the areas that it had previously lost and halted the SPLA's advances (LeRiche and Arnold 2012). That same year, many high-raking officials within the SPLA were dissatisfied with Garang's rule and left to form the SPLM/A - United. ${ }^{82}$ This movement was led by Riek Machar (a Nuer) and Lam Akol (a Shilluk) and, unlike the SPLM/A's focus on unity with the North, the SPLM/A - United focused its rhetoric and action on Southern independence (Young 2006). It is important to note that the division of the SPLM/A was not done along clear ethnic lines. The division turned leaders from the same ethnic group against each other politically and militarily (LeRiche and Arnold 2012).

Between 1991 and 1996, the SPLM/A lost its ability to bring harmony between its various factions and was no longer able to count on Ethiopia's previously unrelenting support (LeRiche and Arnold 2012). During that time, the only foreign assistance that was coming into the area was in the form of humanitarian assistance and was delivered by international relief organizations. With the economy in shambles and rising food insecurity among the affected population, access to, control, and diversion of the aid was of significant importance to the SPLM/A and other militias in the South. Access to and control of humanitarian assistance allowed militia groups to support their host communities and deny support to opponents (LeRiche and Arnold 2012) thus increasing their own performance legitimacy ${ }^{83}$ and decreasing that of their opponents. The militias also siphoned off aid and sent whatever they could to their combatants (LeRiche and Arnold 2012).

For example, Machar and Akol (leaders of the SPLM/A - United) established the Relief and Rehabilitation Association of South Sudan (RRASS) and worked with the international community to deliver humanitarian relief for the people living in the areas controlled by the SPLM/A - United (LeRiche and Arnold 2012). The relationship between the SPLM/A - United and the international

\footnotetext{
${ }^{82}$ For the sake of clarity, I will continue referring to Garang's party as SPLM/A.

${ }^{83}$ Refer to the Justification and Actual performance indicators in Chapter 3.
} 
community was perceived by the population as a legitimizing force for the SPLM/A - United, a fact that angered Garang and his followers and led to accusations of favouritism being levelled against the United Nations (LeRiche and Arnold 2012). Other militia groups also benefitted from the aid community and thus bolstered their performance legitimacy ${ }^{84}$ and status (LeRiche and Arnold 2012). As such, the SPLM/A was facing significant competition for performance legitimacy and loyalty given that the aid was being funnelled through the SPLM/A - United's RRASS in nonSPLM/A controlled areas, other militia groups were diverting aid to benefit their supporters and fighters, and churches and non-governmental organizations were providing much-needed support to the population in areas under SPLM/A control, (LeRiche and Arnold 2012). With performance legitimacy being held by the various leaders and the state unable to earn performance legitimacy due to the actions of the politicians controlling the central and regional governments, Sudan was unable to move out of the vicious performance legitimacy cycle (Chapter 2).

From Garang's perspective, this competition increased his need to maintain power and eliminate competitors. In response, he used violence and intimidation tactics and his exclusive access to regional players to ensure that all material and military support to rebels went through him first (LeRiche and Arnold 2012). He also controlled the southern economy by cutting off trade, controlling the cattle market, and limiting agricultural production (LeRiche and Arnold 2012). With increased discontent by the local population and the Government of the Republic of the Sudan's increased support of paramilitary groups that opposed the SPLM/A, the SPLM/A turned against the local population in many of these areas by looting villages and committing acts of violence (LeRiche and Arnold 2012). According to LeRiche and Arnold (2012, 72), "[b]oth supporting and opposing tribal groups were treated very harshly; the rebel groups tended to live off of the communities" with food being acquired through battles and raids. This further deteriorated the SPLM/A's performance legitimacy.

In the mid-1990s and in recognition of a need for some sort of overall vision or responsible body that could help govern SPLM/A's territory and earn it legitimacy, the SPLM/A began the process of establishing a civil authority (Branch and Cherian Mampilly 2005). In 1996, the Civil Authority of New Sudan (CANS) was established (Branch and Cherian Mampilly 2005). CANS was formally independent of the SPLM/A and had its own police force, judicial system, and other state-like administrative bodies (Branch and Cherian Mampilly 2005). CANS also represented a means for the SPLM/A to decentralize its service provision (Branch and Cherian Mampilly 2005) and award its local allies more legitimacy and power. CANS was mandated to work on education, health, economic development, communication, and agricultural projects. However, CANS was indirectly controlled by the SPLM/A with all CANS officials being ex-SPLM/A soldiers (Branch and Cherian Mampilly 2005; De Simone 2015) and SPLM/A's high command being in control of important and politically sensitive decisions (Branch and Cherian Mampilly 2005). This helped ensure that the majority of the resulting performance legitimacy ${ }^{85}$ would be bestowed upon the SPLM/A.

The SPLM/A attempted to protect its performance legitimacy and control its territory by dividing the area under its control into counties, payam or districts, and boma or villages and appointed civil

84 Ibid.

85 Ibid. 
administrators throughout all of the levels of government (De Simone 2015). The administration of the boma was split between an SPLM/A-appointed administrator and a traditional chief (Branch and Cherian Mampilly 2005). The traditional chief, in turn, was chosen by a village community and had local elders to advise him (Branch and Cherian Mampilly 2005). However, local administrators deferred to local chiefs, especially when it came to mediating rebels' demands for taxes and recruits and to solving disputes (De Simone 2015). The payam was comprised of four to six bomas. Each payam was led by an SPLM/A-appointed administrator who served as a liaison with the SPLM/A. The county was led by a county commissioner who was drawn from within the SPLM/A ranks (Branch and Cherian Mampilly 2005). The county commissioner was responsible for the administration of taxes, including those on humanitarian relief supplies (Branch and Cherian Mampilly 2005). The commissioner was also responsible of the County Development Committee (CDC) (Branch and Cherian Mampilly 2005).

Garang used this decentralized system to allow his allies to decide on how they would achieve his overall goals (LeRiche and Arnold 2012). Yet, in an un-united patronage-based society that had a difficult experience with centralized authority, relying on a new and nascent system could not occur without the need for actions to control the potential abusers. Consequently, Garang built clientelistic relationships that were beneficial for him, local leaders (both allies and opponents), and the population under his control (LeRiche and Arnold 2012). His new clientelistic strategy, one that needed to be continuously renegotiated, contributed to a reversal in SPLM/A's losses. By 1997, the SPLM/A regained much of the territory that it had lost, reconciled with several Southern militia groups (LeRiche and Arnold 2012), and strengthened its performance legitimacy.

During that same period, the Government of the Republic of the Sudan took advantage of some of the SPLM/A's exclusionary practices and established an umbrella group, the South Sudan Defense Force (SSDF), to consolidate the anti-SPLM/A opposition movement (LeRiche and Arnold 2012). Ironically, the majority of those that formed the SSDF in 1996, including Riek Machar ${ }^{86}$ (the leader of the SPLM/A - United), were independence fighters who saw their 'unholy' cooperation with the Government of the Republic of the Sudan as necessary in order to fight the exclusionary practices of the SPLM/A and the perceived domination of the Dinka ethnic group (LeRiche and Arnold 2012). Even though the SSDF was a project that was established by the Government of the Republic of the Sudan, the SSDF's independence rhetoric and its attraction as a non-Dinka dominated entity won it support among a large part of the non-Dinka independence-seeking southern population who had not benefitted from the SPLM/A's services, especially in the Greater Upper Nile (Unity, Jonglei, and Upper Nile states) and the Equatorias (Central, Western and Eastern Equatoria states) regions (LeRiche and Arnold 2012).

With a military stalemate and rising discontent from the population, the lead protagonists in the conflict ended the second civil war with the signing of the 2005 Comprehensive Peace Agreement (CPA). Libya and Egypt were involved in the negotiation of the CPA and the Agreement was supported by the United States, the United Kingdom and Norway (LeRiche and Arnold 2012), even though the SSDF was not party to the signing of the CPA (Young 2006). The CPA gave Southern

\footnotetext{
${ }^{86}$ Reik Machar became Vice President in the Government of South Sudan after South Sudan's independence. He rejoined the SPLM/A - Mainstream in 2002.
} 
Sudanese the right to have an independence referendum but with the stipulation that such a referendum could only occur six years after the signing of the Agreement (LeRiche and Arnold 2012). In the meantime, Southern Sudan would be (a) ruled by an autonomous regional government, (b) protected by the SPLM/A (the only official defense force), (c) allowed religious and cultural protection, and (d) represented by a Vice President at the national level (LeRiche and Arnold 2012).

In effect, the CPA ushered in the formation of the groundwork for the future Republic of South Sudan through the establishment of a nascent bureaucracy, judicial structures and an official army (LeRiche and Arnold 2012). The Sudan People's Liberation Movement (SPLM) controlled the regional government and was a minority player in the Sudanese national government (LeRiche and Arnold 2012).

All in all, the second civil war lasted from 1983 until 2005 and led to over two million casualties (most of whom died from disease and malnutrition), as well as 800,000 refugees and internally displaced people (LeRiche and Arnold 2012; Maxwell, Gelsdorf, and Santschi 2012). Moreover, both regions, with the exception of Khartoum, were left with little to no viable infrastructure (Larson, Ajak, and Pritchett 2013). The civil wars and the ensuing poverty, trauma and displacement had a negative effect on kinship, community ties, social support mechanisms, and intra-communal collaboration (Maxwell, Gelsdorf, and Santschi 2012). The wars also weakened the power of the non-aligned traditional leaders (Maxwell, Gelsdorf, and Santschi 2012).

The war and the interim period also saw significant regional and international influences and interventions. During the first civil war, Ethiopian emperor Mengistu Haile Mariam was a strong supporter of the SPLA, especially Garang who operated under a version of the Ethiopian experience with Maoist and Marxist militarism, and who used the SPLA as a means to undermine the Government of Sudan's support for the Ethiopian insurgents (LeRiche and Arnold 2012). However, given the close relationship between Garang and the Emperor, the new Ethiopian regime that was led by the successful Ethiopian insurgents retaliated against the SPLA. The regime expelled the SPLA and the South Sudanese refugees from Western Ethiopia and cut off all supply lines going through their territory (LeRiche and Arnold 2012). For its part, Eritrea also supported the SPLA during both civil wars (LeRiche and Arnold 2012). Kenya also played an important role in ensuring the success of the Government of Southern Sudan given its significant economic access to the Southern region during the CPA interim period (LeRiche and Arnold 2012). The SPLA was also receiving assistance from the Ugandan government (LeRiche and Arnold 2012). However, in retaliation, the Lord's Resistance Army in Northern Uganda, worked with the Government of the Republic of the Sudan in its fight against the SPLA (LeRiche and Arnold 2012). For its part, Libya supported the SPLA early on but turned against it in the later stages of the war (LeRiche and Arnold 2012).

From a non-regional perspective, the United States originally supported Sudan and offered it weapons as a means to counter the communist threat in Africa but later switched allegiances when the government in Khartoum started supporting Islamic extremists (LeRiche and Arnold 2012). The Soviet Union also supported the SPLA before the end of the Cold War by providing its fighters with weaponry (Grawert 2013). For its part, China stepped into the fray when oil was discovered in 
Sudan and offered its support to the government in the North in return for access to the newly discovered oil reserves (LeRiche and Arnold 2012). The United Nations was involved in the territory through its humanitarian assistance work and its monitoring of the implementation of the CPA (LeRiche and Arnold 2012).

\section{B. The Interim Period}

The interim period saw a significant shift in the objectives of the SPLM/A. Garang's untimely death in 2005 led to the appointment of Salva Kiir Mayardit as his successor. He became one of two Vice Presidents in the Government of Sudan, as stipulated by the CPA, and the President of the Government of Southern Sudan (LeRiche and Arnold 2012). Kiir reoriented the movement's objectives from democratic reformation of Sudan to the independence of South Sudan (Young 2006). In doing so and following the signing of the 2006 Juba Declaration, Kiir was able to integrate the SSDF into the SPLM and its fighters into the SPLA (LeRiche and Arnold 2012; de Waal 2014; Young 2006). In a bid to eliminate the feelings of alienation that many within the SSDF harboured, Kiir appointed "some 20 people from the SSDF as commissioners, three as members of the regional assembly in Juba, later one as a minister, and ... assign[ing] an unspecified number to state legislatures" (Young 2006, 25).

However, the interim period (2005-2011) also saw the failure of many of the provisions set out in the CPA. Both, the National Congress Party (the ruling Sudanese party) and the SPLM, were responsible for the lackluster performance of the CPA since no group really worked to implement all of the Agreement's stipulations (LeRiche and Arnold 2012). This period also saw some clashes between Southern groups mostly owning to the SPLA/M's efforts at demobilizing militias that were still being supported by the North (LeRiche and Arnold 2012). It was also the period when the Government of Southern Sudan became highly dependent on oil revenue and when the expenditure on the rank and file of the SPLA increased significantly (LeRiche and Arnold 2012).

In 2009, the Government of Southern Sudan passed the Local Government Act as part of the implementation of the CPA (De Simone 2015). The Act established counties as the level of government that was closest to the people. Unfortunately, by 2014, only three towns - Juba, Wau and Malakal - had Urban Local Government Councils (De Simone 2015). With this system, urban areas were to be administered under the Urban Local Government Councils and rural areas were to be administered under traditional local authority (De Simone 2015). In conjunction with this dual administrative system, state administrative functions were further deconcentrated to local chiefs within their jurisdiction (De Simone 2015). Furthermore, chiefdoms were ruled by a decentralized process with chiefs either elected or selected, depending on the traditional practices (De Simone 2015). In rural areas, "officers of statutory institutions seem[ed] to consider themselves in charge of 'protecting' their people's right to land and other entitlements on a communal basis even more than traditional authorities. They manage[ed] to bring claims up to the decision-making levels of the government which the chiefs ... [did] not always have the authority to reach" (De Simone 2015, 68-69). As a result, chiefs and local leaders used state resources to increase their performance legitimacy among their own ethnic groups and ethnicity became an important part of how state resources were being distributed. 
Other than a common identity that was developed around the fight for independence and a history of domination by the North, there was no real common Southern identity (Branch and Cherian Mampilly 2005; Jok 2011; Kon 2015). Moreover, the society in the south was divided along 65 ethno-tribal groups (Kon 2015), with each group placing a stronger emphasis on the benefits for or needs of their tribes than on what the nation as a whole would have benefitted from (Jok 2011). For example, with incursion across the border from northern militias, the influx of returnees, the increased stress on an already insufficient and ineffective state administration (South Sudan Bureau for Community Security and Small Arms Control, South Sudan Peace and Reconciliation Commission, and United Nations Development Programme 2012), people in Warrap state turned to their leaders who had stepped into the vacuum and earned performance legitimacy. The increase in tribal or ethnic allegiance and patronage led people in Warrap to identify more with their tribe than with a more national and broader state cause (South Sudan Bureau for Community Security and Small Arms Control, South Sudan Peace and Reconciliation Commission, and United Nations Development Programme 2012).

As in the Lebanon case, most South Sudanese believed in an independent South Sudan, however, most had a different vision of what the country and the society would look like (Jok 2011). The lack of a common identity that went beyond an opposition to the North, the high level of ethnicization of the government administration, the highly divided and militarized society (Zambakari 2013), the existing patronage culture and the resulting diversion of performance legitimacy away from the state, and the new performance legitimacy opportunities that government positions offered the various players led them to exercise significant patronage and predation (Brosché 2016). As under the tutelage of Garang, the SPLM/A and the Government of Southern Sudan continued to be used as neo-patrimonial entities - entities that were used for factional and personal advantages (de Waal 2014) - by leaders in order to increase their performance legitimacy. These processes reinforced Southern Sudan's position on the vicious cycle end of the performance legitimacy continuum.

The interim period ended on January 1, 2011 when the majority of South Sudanese voted for secession.

\section{The Role of the Delivery of Relief and Basic Services}

As noted earlier, the level of importance associated with meeting people's basic needs played an important role in the rhetoric against the North. As the North continued to exclude Southerners from development-related benefits, Southern leaders used this exclusion to increase the support for independence (LeRiche and Arnold 2012). Moreover, as the civil wars progressed, various leaders gained support by demonstrating their ability to attract aid or by using diverted or stolen aid to benefit their community and supporters (Washburne 2013). As such, people's basic needs became an integral part of the client-patron relationship: the more aid and hence services that their people had access to, the more legitimacy the leaders received (as measured by the Justification and Actual Performance indicators in Chapter 3) and thus the larger the bargaining space that they had with other leaders and protagonists.

Given that the overwhelming majority of basic goods and services, including education, health, infrastructure, and nutritional needs, were delivered by a vast network of foreign NGOs and institutions (Branch and Cherian Mampilly 2005), rebel leaders often controlled the flow of aid to 
these organizations and thus the ultimate beneficiaries of the delivery of goods and services (de Waal 2014). In places where the aid was not as forthcoming, access to the SPLM/A network became highly prized. As de Waal $(2014,352)$ notes, "[ $t]$ he SPLM became a magnet for rent seekers ... [and] corruption had permeated the armed struggle from the earliest days." With time, the SPLM/A became apt by redirecting humanitarian aid to earn performance legitimacy, using natural resources (gold and timber) to finance their operation, and using coercive, corrupt and patrimonial measures to gain power and influence (de Waal 2014).

The CPA opened the door for the influx of billions of dollars of aid and a vigorous post-conflict development effort (Larson, Ajak, and Pritchett 2013). Although there is no complete data source on the aid received by the Government of Southern Sudan between 2006 and 2010, there are indications that the region received over USD \$1 billion each year over the four-year period (Larson, Ajak, and Pritchett 2013). The 'Sudan Troika' were the principal donors with the United States leading the pack, followed by the United Kingdom and Norway (Larson, Ajak, and Pritchett 2013).



The aid that was provided was also very important for the people living in Southern Sudan. For example, according to the Southern Sudan's National Bureau of Statistics ${ }^{87}$ and as is demonstrated in Figure 7.1, the CPA ushered in a significant improvement in the Southern population's access to water. Given that the poverty rate was very high, even near the tail end of the CPA interim period

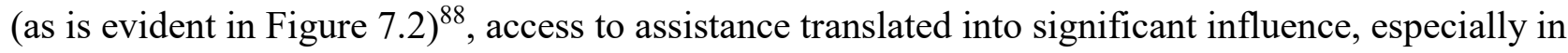
states where the population had a difficult relationship with the SPLM/A: Unity, Jonglei, Upper Nile, Central Equatoria, Eastern Equatoria and Western Equatoria.

\footnotetext{
${ }^{87}$ The data is taken from the South Sudan Data Portal http://southsudan.opendataforafrica.org/tlllek/statisticalyearbook-2011-south-sudan?regionId=SS-UY

${ }^{88}$ The data is also taken from the South Sudan Data Portal http://southsudan.opendataforafrica.org/tlllek/statisticalyearbook-2011-south-sudan?regionId=SS-UY
} 
Figure 7.2: South Sudan Poverty (\%, 2009)

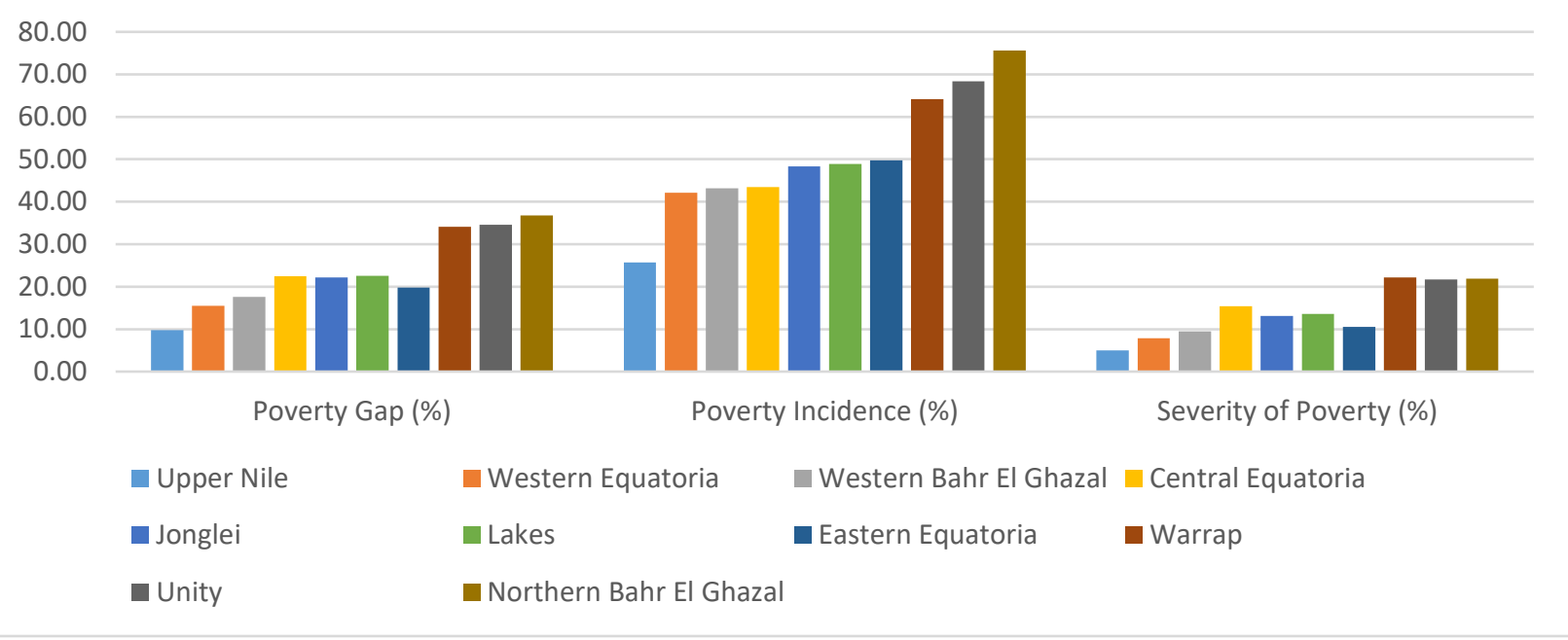

According to Branch and Cherian Mampilly (2005), during the CPA's interim period, nongovernmental organizations became tools of local politicians who were looking to increase their legitimacy and power. CANS and the Government of Southern Sudan, with their control over the aid that was to be distributed in Southern Sudan, became magnets for leaders seeking performance legitimacy. The leaders who were responsible for the development and aid envelops ensured that their ethnic-tribal group received primary access (Branch and Cherian Mampilly 2005). With the aid being delivered to the local level and with limited government representation at the lowest level (e.g. villages), the benefits accrued to the ethnic-tribal leader and to local chiefs. In essence, the leaders were able to use the highly personalized patronage system, the weak government institutions, large manoeuvring space owing to the threat that they could impose on the government if they were to withdraw, and information asymmetry to abuse state resources for their own benefit.

Hence, performance legitimacy remained with the leaders and given the historical uneasiness between the SPLM/A and other groups, this legitimacy was not transferred onto the one-party local government. This maintained South Sudan's position on the vicious end of the performance legitimacy continuum.

Furthermore, the link between the government and the people was broken owing to the use of nongovernmental agencies (Washburne 2013) and the diversion of performance legitimacy. By 2007, people considered the Government of Southern Sudan to have broken its promises, especially in the areas of service delivery and their trust in the government's ability to deliver widespread development had also faded (Cook 2007). More interestingly, by 2007, most of the people in the South considered some people within the Government of Southern Sudan as their representatives while others did not (Cook 2007). This, along with the highly personalized political system, limited the ability of the regional state of Southern Sudan to protect its performance legitimacy and contributed to making the community, and its leader, the centre of the society within Southern Sudan. 
Interestingly, the SPLM/A had vast experience in this process. While it was still a rebel group, the group lost its performance legitimacy once it turned against its people and was no longer offering them this type of assistance. It regained legitimacy when it understood the importance of meeting people's basic needs and worked on bringing aid to their supporters. It lost it again when it became the Government of Southern Sudan and faced competition from various leaders because it was either unable or unwilling to cater to the needs of all groups. For example, the population in Eastern Equatoria credited its local leaders for taking care of their needs, even though the leaders only did so by bringing in the United Nations and the subsequent food and humanitarian aid, and not by delivering the services themselves (Washburne 2013).

\section{Analysis}

The Southerners' experience with the Sudanese state offers many lessons. The following five are very relevant to the thesis of this dissertation.

First, religion and ethnicity have undoubtedly played an important role in the conflicts and in societal relationships. However, each ethnic and religious group has seen its own internal struggle for leadership and influence. These struggles were resolved once one leader earned a significant amount of performance legitimacy or once the leader, like Garang, had access to resources that could be used to 'buy-out', neutralize, or convince other leaders to join the fold. The leaders who were vying for the support of their ethnic kin against another ethnic kin, at least during the later stages of the war, used access to aid and relief assistance to capture performance legitimacy. This legitimacy in turn allowed them to use ethnicity to bolster their fight against another group. For example, the presence of Nuer Sudanese within the SPLM/A and their willingness to fight against Machar the Nuer leader of the SPLM/A - United is testament to the divisibility of ethnicity. The same analysis applies to the Arabs who fought with the SPLM/A (Branch and Cherian Mampilly 2005).

Second, the Southern society had always placed a significant emphasis on access to basic goods and services. Much of the feeling of alienation was linked to the lack of investment in the South by the Government of the Republic of the Sudan. Moreover, the Southerners placed a high value on development initiatives in their region, at least during the interim period.

Third, perhaps owing to the lack of state structures, economic opportunities, peace, or jobs, patronage had become a significantly important part of the Southerners' way of life. The practice was entrenched into the society and had begun to dictate various aspects of the relationship between leaders and their followers.

Fourth, the Southern Sudanese have had limited experience with stateness or with state structures and systems. While they have had a few experiences with elections, the association that they had with the state was very much dependent on the person that represented them. As such, the state became more about the people in its institutions than the institutions themselves. This combined with the emphasis on performance legitimacy and thus patronage allowed the leaders within the state to carry themselves as brokers between the state and the population, thus weakening whatever state-society relationship that had existed and limiting the possibility of the emergence of a new one. 
Fifth, owing to its location and other external agendas, the Southern population was significantly impacted by regional power struggles between various forces. At least six African countries became involved either during the wars or during the negotiation process. Their interference and that of the non-regional players had a significant effect on the lives of the population affected by the war and on the leaders of the various groups that fought in the wars.

\section{Independence and Civil War}

\section{A. Independence}

The Republic of South Sudan was born on January 1, 2011 when 98.83 percent of Southerners voted for independence (LeRiche and Arnold 2012). ${ }^{89}$ South Sudan adopted a parliamentary system with a National Legislative Assembly and the Council of States representing the upper chamber (Radon and Logan 2014). The President is currently elected directly by the people and appoints his Vice President. People are represented by elected members of the National Legislative Assembly with 60 percent of the 400 seats being based on majority cote and 40 percent on proportional representation (Radon and Logan 2014).

South Sudan's independence ushered in a period of significant obstacles. It meant that the Government, led by the SPLM/A, had to begin governing and could no longer rely on the CPA, including funding from the Government of the Republic of the Sudan and aid actors, to do its work. Yet, at independence, South Sudan had one of the lowest densities in Africa with most of the roads being gravel (Attipoe, Choudhary, and Jonga 2014) and an overwhelming majority of the population living in rural areas. ${ }^{90}$ Around one percent of the total population had access to electricity and most of them got it from off-grid private diesel fuelled plants or generators (Attipoe, Choudhary, and Jonga 2014). With a very weak economy and high poverty rates, the government became the country's major employer (Attipoe, Choudhary, and Jonga 2014).

From a public administration perspective, the South Sudanese administrative system was made up of several layers: the central Government of South Sudan, ten state governments, 78 counties, and 19 constitutional commissions (Kameir 2011). As noted earlier, before 2005, the South hadn't really experienced meaningful self-government. The only administration that existed was related to what John Garang had built to administer the regions that he had controlled (Larson, Ajak, and Pritchett 2013). However, the administrative system that the South Sudanese had inherited upon independence was not enough to undertake massive development and state-building initiatives (Larson, Ajak, and Pritchett 2013). The Government of South Sudan (GoSS) faced two major challenges: (a) inexperienced leadership and civil servants and (b) non-existent public institutions (Larson, Ajak, and Pritchett 2013) and capacity (Kameir 2011). Larson et al. $(2013,6)$ aptly compared the building of South Sudan under these challenging conditions to "building a plane while flying it."

\footnotetext{
${ }^{89}$ While the borders had been established by the CPA, the Government of the Republic of the Sudan refused to cede control over Abyei and its oil fields. The area is under a special administrative status and belongs simultaneously to both Sudans. With this dispute ongoing and with violent clashes between Sudan-sponsored militias and the South Sudanese military (the rebranded SPLA), Abyei residents have not experienced the peace dividend.

${ }^{90}$ Data was taken from the 2008 Census housed on the website of the Republic of South Sudan's National Bureau of Statistics (http://www.ssnbs.org/).
} 
With the South Sudanese population having high expectations following independence (Larson, Ajak, and Pritchett 2013) and with increased cynicism amongst the population (Maxwell, Gelsdorf, and Santschi 2012), the state was under significant pressure to deliver benefits and earn the associated credits. As a result, the donor community stepped in and focused its assistance on two main areas - humanitarian assistance and the building of state institutions (Larson, Ajak, and Pritchett 2013,9). Yet, the donor-led institution-building process failed to transfer the skills that were necessary to run a state (Larson, Ajak, and Pritchett 2013). As of 2013, the public service lacked capacity, direction, experienced personnel, accountability, and functional units (Larson, Ajak, and Pritchett 2013). An internal review commissioned by President Kiir and conducted by independent South Sudanese experts found that "GoSS's institutional development [was] still very incomplete; decentralization [was] weak; and the civil service [was] incapable of performing their job responsibilities" (Larson, Ajak, and Pritchett 2013, 8). Moreover, with all of the effort that was placed into building a democratic governance system, the government became beholden to a rigid system of traditional hierarchy that subjugated younger more educated people to their less educated and less-trained bosses and limited the effectiveness of good governance policies (Larson, Ajak, and Pritchett 2013). It also limited the state's performance legitimacy as measured by the Legality (perceived importance of state institutions and confidence in the civil service), Justification and Actual Performance indicators (Chapter 3). In essence, cultural sensitivities and the political economy of GoSS limited the ability of younger more educated public servants to effect real change and place real hurdles that can stop ministers and senior servants from abusing the state institutions (Kameir 2011).

Moreover, certain leaders took advantage of the institution building process and the resulting access to patronage opportunities to enhance their own power (Frahm 2015; Radon and Logan 2014) and performance legitimacy by using "empire building" tactics (Larson, Ajak, and Pritchett 2013, 22). Given that the instability of the client-patron relationships continued to require constant renegotiation and that there was continued significant competition for loyalty, access to the 'empire building' tactics was necessary for the various leaders to remain relevant and protect their power (de Waal 2014) and performance legitimacy. The following description provides an important example:

"One donor official distinguished between the "Real Ministry of Finance" and the "Fake Ministry of Finance." The "Fake Ministry" is the one working with the donors and technical advisors on budget allocations, promoting the outward appearance of high functionality, while the "Real Ministry" is operated through backdoor dealings between South Sudanese officials, concealed from donor view. As the donor official says: "The technical advisors help prepare budget allocations, but then the army generals wheel into the minister's office, and they make the real allocations"' (Larson, Ajak, and Pritchett 2013, 21). ${ }^{91}$

With the abuse of state institutions and the development of a personalized political system, the institution-building process also contributed to the continued significant abuse of state resources

\footnotetext{
${ }^{91}$ Larson et al. (2013) gathered this information from interviews with donor representatives, World Bank
} representatives, government officials and independent consultants. 
and the resulting ethnicization of ministries and their domination by certain groups (Larson, Ajak, and Pritchett 2013). According to Brosché (2016), positions within the government continue to be highly coveted for the prospects of power and status and the ability to safeguard income, influence, and performance legitimacy. This access to state power and resources allowed power-seeking leaders to cement their influence by offering their constituents access to much-needed state resources (Brosché 2016).

Moreover, according to Wassara (2015), there was an institutionalized mistrust given that political leaders had more faith in their own ethnic protégées than in national institutions that were highly divided, ethnicized, militarized, and politicized. As Kameir $(2011,34)$ also notes, bureaucracies were staffed by people from the same ethnic group as the ministers and their senior civil servants. This contradicted state policies (Riak 2013) and yet was still allowed to occur despite the fact that GoSS had an Audit Chamber that reported to the National Assembly and made its reports public, a Public Financial Management Act, a Procurement Law, an Audit Act, a Central Bank Act, Public Expenses and Financial Accountability Assessments, a Financial Management Information System, and an Anti-corruption Commission (Riak 2013).

With the society differentiating between the leaders and the state regarding the delivery of basic goods and services, the institution-building process contributed to or ushered in new opportunities for increased power and patronage (Frahm 2015), a new era of a public sector that is highly politicized, ethnicized, and tribalized (Kon 2015; Riak 2013), and a continued entrenchment of the performance legitimacy of leaders. According to Kameir (2011), as of September 2010, many South Sudanese expressed concern with the link between access to government positions and tribal affiliation and the corruption that this breeds. There also seemed to be a perception that leaders were mostly accountable to their respective ethnic groups rather than towards ensuring that the state was functioning well for all South Sudanese citizens (Kameir 2011).

Adding to the complication was the absence of the state in many parts of South Sudan where, in many localities, the state either had no representation or infrastructure or was represented by a handful of civil servants who had minimal resources and power (Frahm 2015). Local governments often had weak infrastructure and were inadequately staffed and funded (Maxwell, Gelsdorf, and Santschi 2012). This limited the GoSS's ability to extend its authority over all of its territory with (a) Abyei being a contested territory between the Governments of Sudan and South Sudan and (b) tribal militias filling the vacuum left by the state (Frahm 2015).

The state's absence in many rural areas led or helped traditional authority to take on the responsibility of the state (Frahm 2015). The localization of state responsibilities contributed to regional differences in the level of services provided to the population (Maxwell, Gelsdorf, and Santschi 2012). This also increased the role, power and performance legitimacy of local leaders who were either supported by national leaders that had control over some state institutions or by leaders of large militias. With their cooptation by national political or militia leaders, these local leaders contributed to South Sudan's continued inter-communal violence and vicious performance legitimacy cycle. 
Figure 7.3: Official Development Assistance

(USD millions)

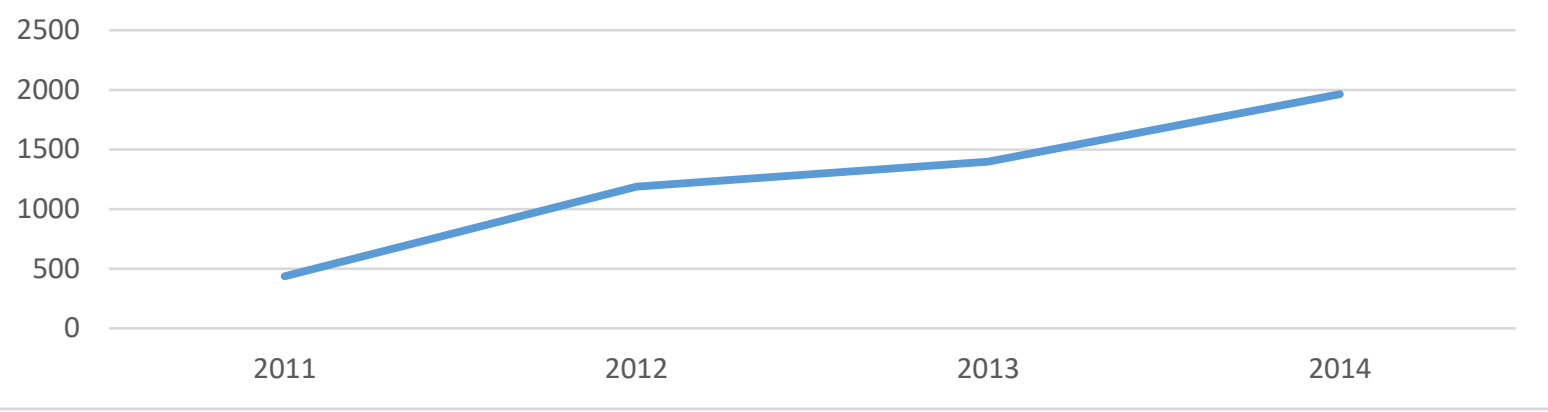

With the state's inability or unwillingness to provide basic goods and services, including security, in most of the country, the new South Sudanese state faced significant legitimacy problems (Washburne 2013). The void that was left by the state allowed leaders to (a) use resources to earn performance legitimacy, (b) use their acquired power to recast the alienation as one based on ethnicity (de Waal 2014), (c) undertake a rebellion or some form of military action, and (d) negotiate peace by requiring inclusion in important government and state positions (de Waal 2014; Wassara 2015). Problems with security also led to the ethnicization of the military and the alignment of various military groups with their ethnic leaders (de Waal 2014).

\section{Figure 7.4: Total Development Aid by Sector}
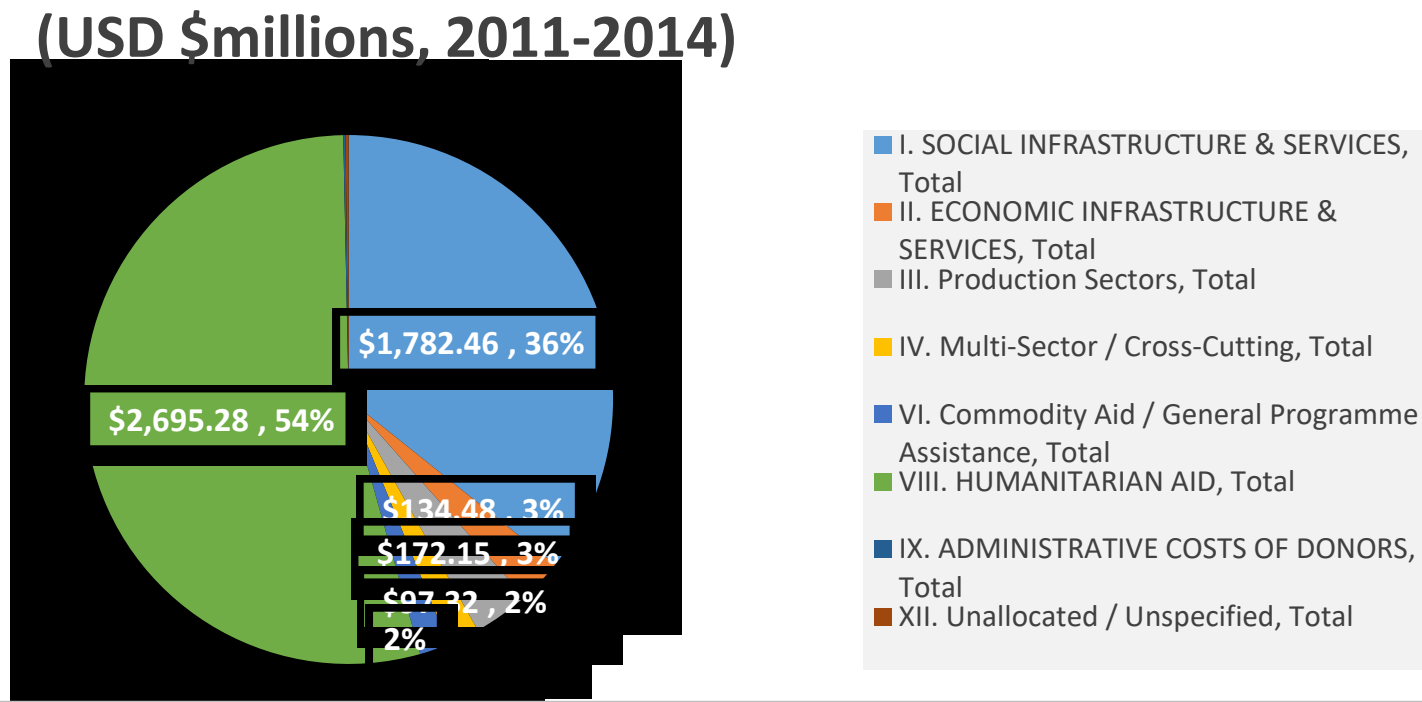

As such, with the lingering violence and threats to stability, the GoSS was forced to mostly focus its budget on security with the donor community providing a significant and increasing amount of funding focused on non-military aspects (Figure 7.3). ${ }^{92}$ From 2011 to 2014, South Sudan received more than USD $\$ 5$ billion in official development aid. As is shown in Figure 7.4, most of the

\footnotetext{
${ }^{92}$ Data was retrieved from the Organisation for Economic Development and Cooperation: https://stats.oecd.org/qwids/.
} 
assistance was directed to deal with the humanitarian crisis and the practically non-existent social infrastructure and services.

\section{Figure 7.5: Total Development Aid Spent on the Social_Sector (USD\$millions, 2011-2014)
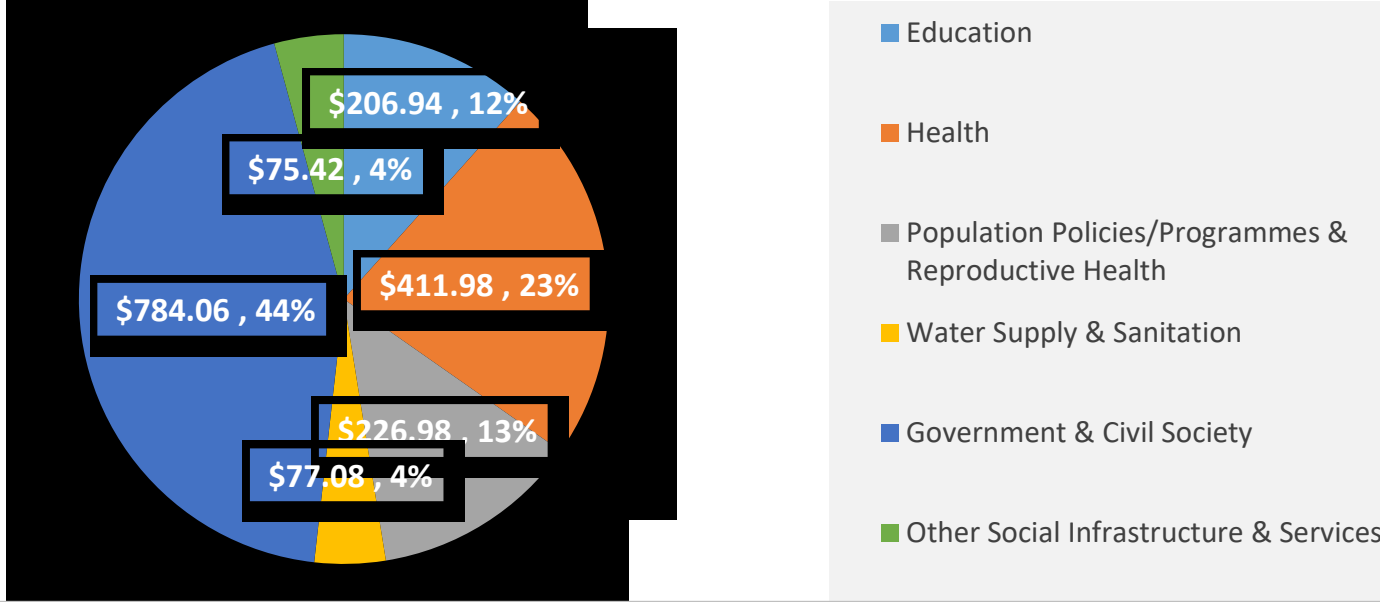

As is also demonstrated in Figure 7.5, most of the funding provided to the social sector was spent on governance-related issues followed by health, population policies and education. From a development perspective, donors were successful in building roads and schools as well as in reducing poverty and mortality rates (Larson, Ajak, and Pritchett 2013).

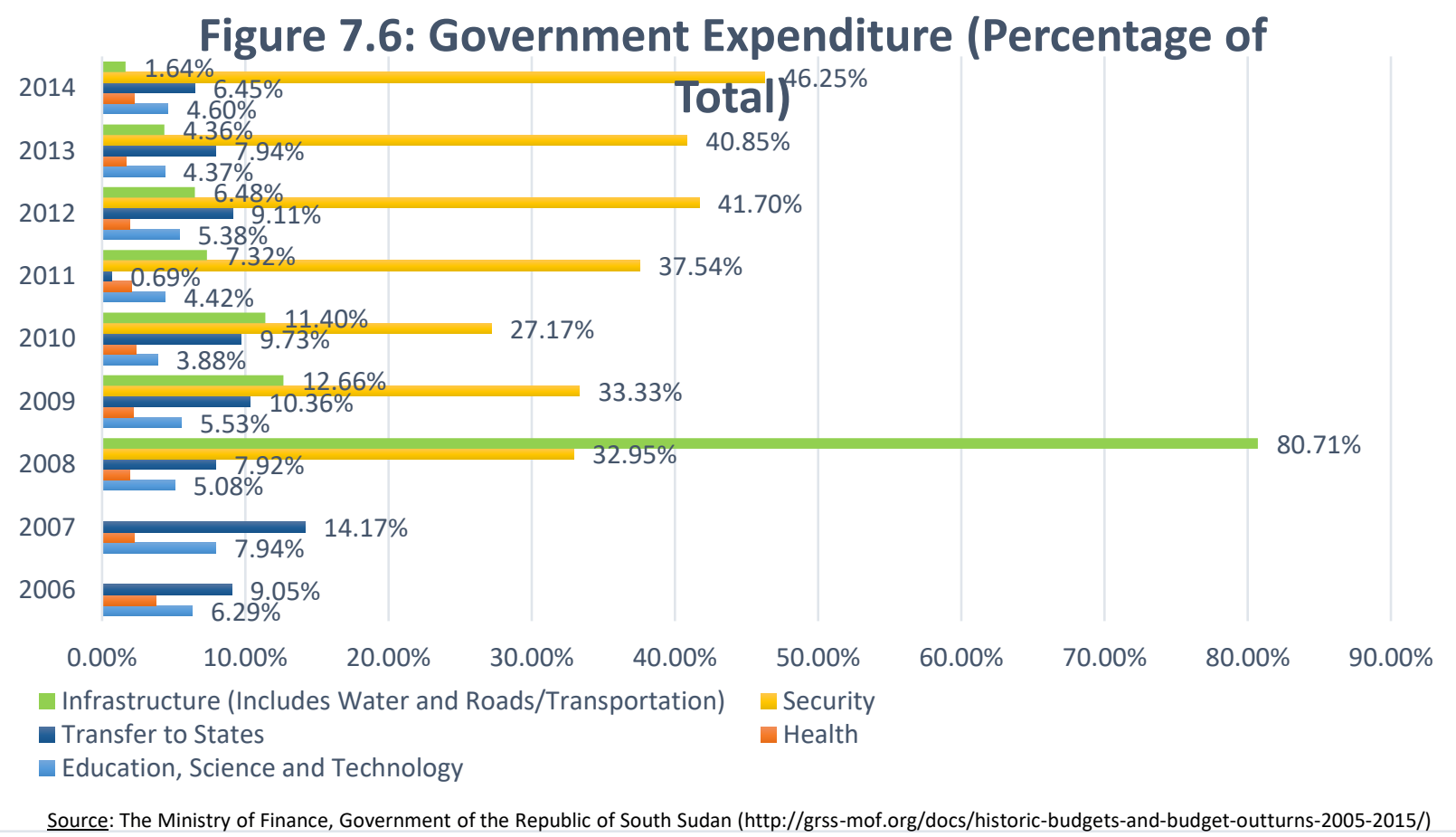


With an unstable security situation and with the need to continuously negotiate alliances, the GoSS has spent over 38 percent of its budget on security since 2011 (Figure 7.6). Most of the securityrelated expenditure went to salaries for militia fighters that had been absorbed into the South Sudanese Army, a result of President Kiir's preference to use financial patronage and positions in the government and in the military to absorb other groups (de Waal 2014). In effect, reconciliation and cooptation took priority over development issues since the SPLA/M preferred to deal with outside threats by subsuming opponents (LeRiche and Arnold 2012; de Waal 2014).

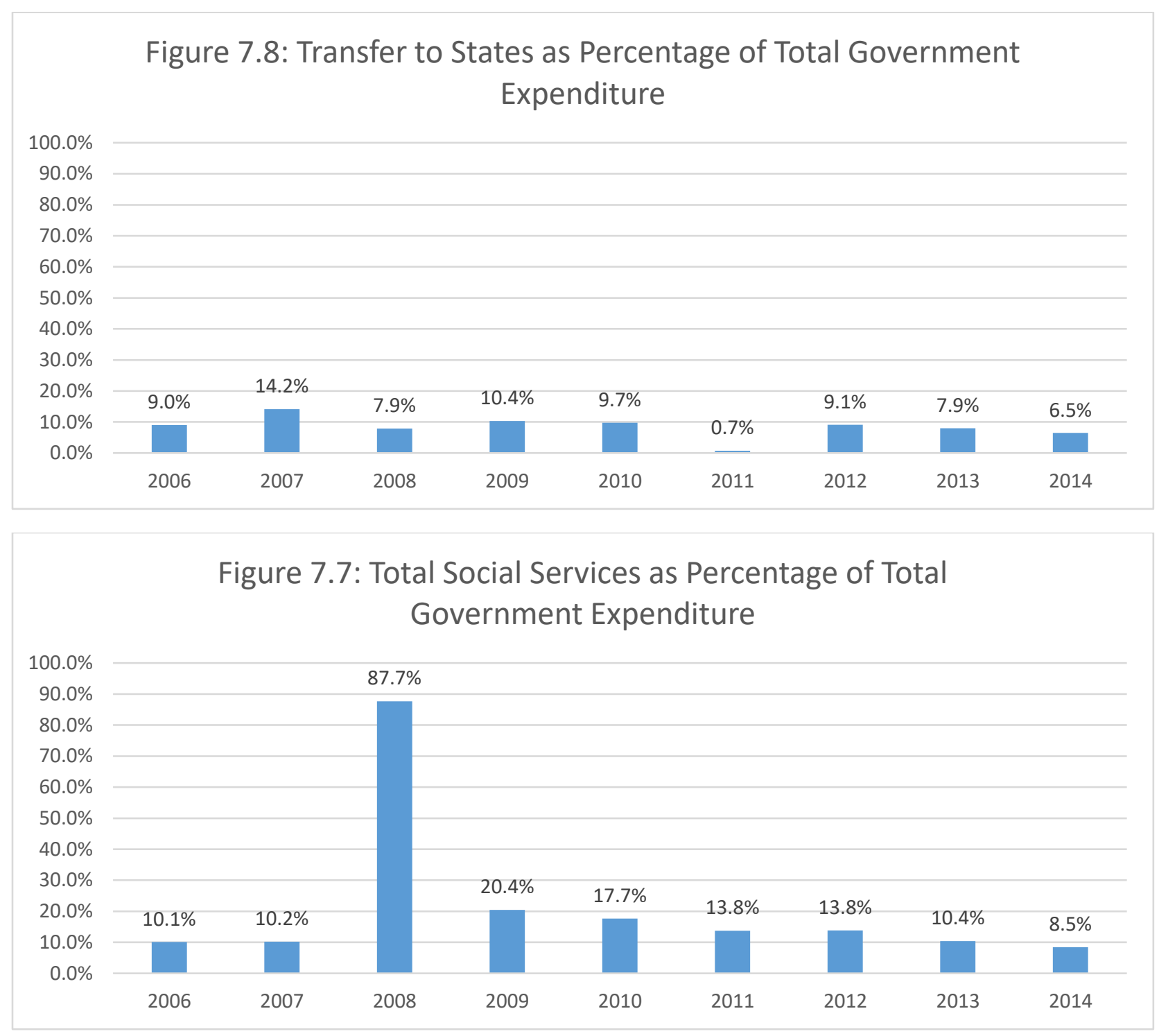

Public expenditures on social services (health, education and infrastructure) remained less than 15 percent of total public expenditures (Figure 7.7). These expenditures were also similar to the amount of transfers that the ten states received (Figure 7.8). Moreover, while total government expenditures increased by 240.93 percent from 2006 to 2014 and by 20.4 percent from 2011 to 2014, public expenditure on social services (infrastructure, health and education) decreased by 28.4 percent from 2011 to 2014. Expenditure in social services was pulled down by a significant drop in expenditure on infrastructure. When expenditure on infrastructure was removed from the 
calculation, government expenditure on social services increased by 23.4 percent from 2011 to 2014.

\begin{tabular}{|c|c|c|}
\hline \multicolumn{2}{|l|}{ Table 7.1: Government Expenditures } & \\
\hline & $\begin{array}{c}\text { Total } \\
\text { Percentage } \\
\text { Change }\end{array}$ & $\begin{array}{c}\text { Average } \\
\text { Annual } \\
\text { Compounded } \\
\text { Percentage } \\
\text { Change } \\
\end{array}$ \\
\hline $\begin{array}{l}\text { Percentage change in total government expenditure (2006- } \\
\text { 2014) }\end{array}$ & $240.93 \%$ & $16.70 \%$ \\
\hline $\begin{array}{l}\text { Percentage change in total government expenditure (2011- } \\
\text { 2014) }\end{array}$ & $20.40 \%$ & $6.40 \%$ \\
\hline Percentage change in expenditure on health from 2006 to 2014 & $94.18 \%$ & $8.65 \%$ \\
\hline Percentage change in expenditure on health from 2011 to 2014 & $28.13 \%$ & $8.61 \%$ \\
\hline $\begin{array}{l}\text { Percentage change in expenditure on education from } 2006 \text { to } \\
2014\end{array}$ & $141.34 \%$ & $11.64 \%$ \\
\hline $\begin{array}{l}\text { Percentage change in expenditure on education from } 2011 \text { to } \\
2014\end{array}$ & $21.18 \%$ & $6.61 \%$ \\
\hline $\begin{array}{l}\text { Percentage change in expenditure on infrastructure from } 2008 \\
\text { to } 2014\end{array}$ & $-63.92 \%$ & $-41.05 \%$ \\
\hline $\begin{array}{l}\text { Percentage change in expenditure on infrastructure from } 2011 \\
\text { to } 2014\end{array}$ & $-73.95 \%$ & $-36.13 \%$ \\
\hline
\end{tabular}

Accordingly, with little institutional capacity and little money that was making its way into state coffers, the services were either contracted out to the aid sector or to some local NGO (Frahm 2015). As of 2011, NGOs and the United Nations provided over 80 percent of basic services in South Sudan (Kameir 2011).

Essentially, where there was no government, there was a network of non-governmental organizations and other entities, including local chiefs and leaders that were catering to the needs of the population. Yet, even though the government was either responsible for some funding or for the initiation of service-delivery projects that were eventually deferred to non-governmental agencies, the state had little visibility and few could relate the delivery of goods and services back to the state (Cook 2007). This is significant since as of 2007, people in the South indicated that development (education, health, infrastructure) and security were the priority for them, much more than the holding of elections (Cook 2007; Maxwell, Gelsdorf, and Santschi 2012; Washburne 2013). Moreover, according to the survey that Cook (2007) undertook, the South Sudanese associated paying taxes with the development of their area, rather than South Sudan in general, and with personal tangible benefits. For a population that had extremely poor access to basic social services (Maxwell, Gelsdorf, and Santschi 2012), securing improved access translated into performance legitimacy (support and loyalty) for the entity deemed responsible. 
Still, corruption was perceived by the population to be a major factor in their non-development (Cook 2007). However, the population also perceived the local government to be the least corrupt and thus more concerned with their situation (Cook 2007). As in the pre-independence era, this perception of local chiefs and leaders played a significant role in the behaviour of national leaders and politicians as well as of those hoping to lead a successful militia campaign. The local leaders' support was important since local leaders tended to advise people on how to vote in elections and where to place their loyalty, with some actually becoming politically involved themselves (Cook 2007).

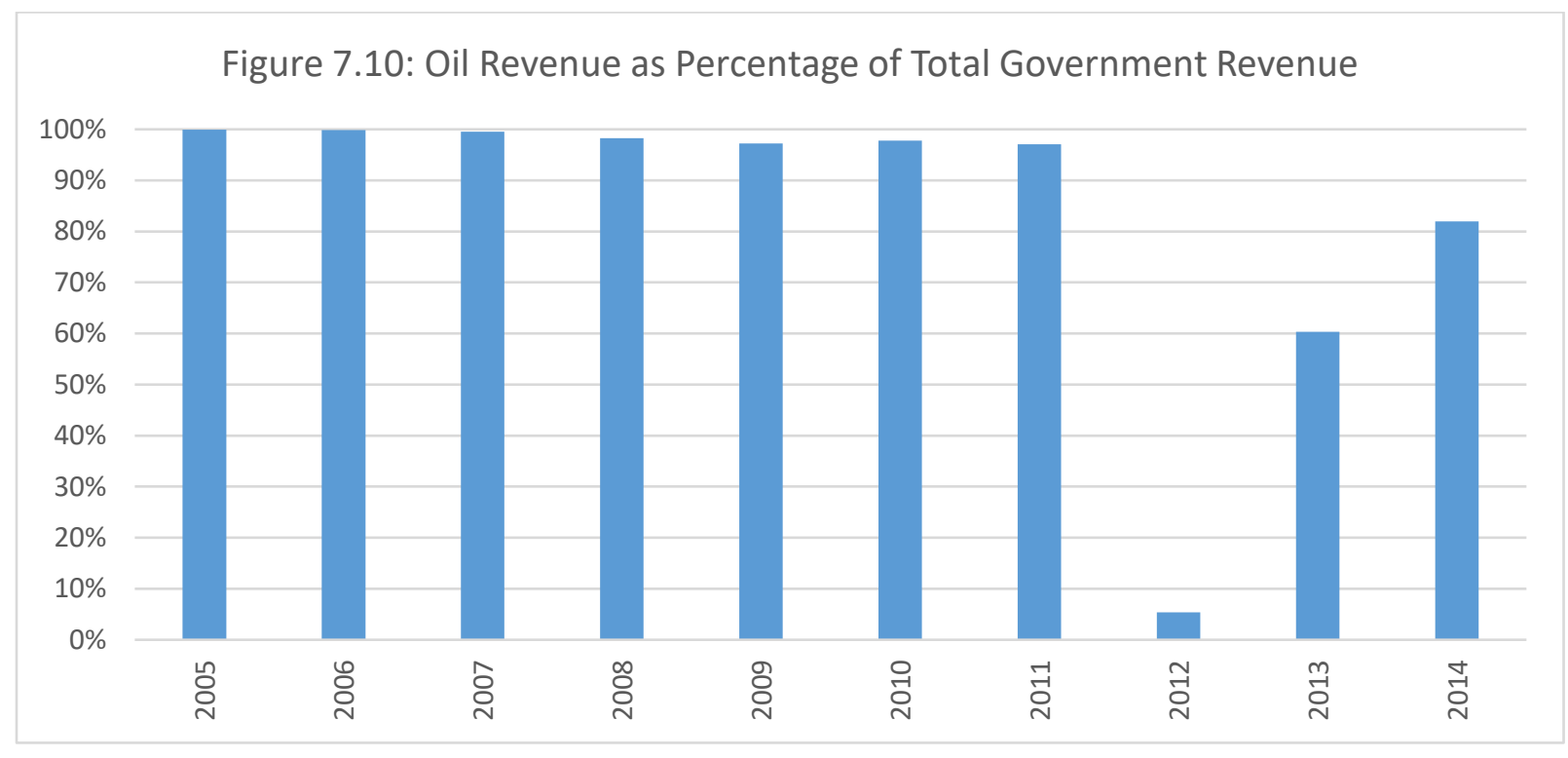

In 2013, the national production of oil was shut down because of a dispute with the Republic of the Sudan. This caused a significant drop in the government's revenue. As is evident in Figure 7.9 and 7.10, the government's revenue was and continues to be significantly dependent on oil revenues. With a collapse in its income, the leaders within the central government were unable to maintain the same level of royalty payments (de Waal 2014).

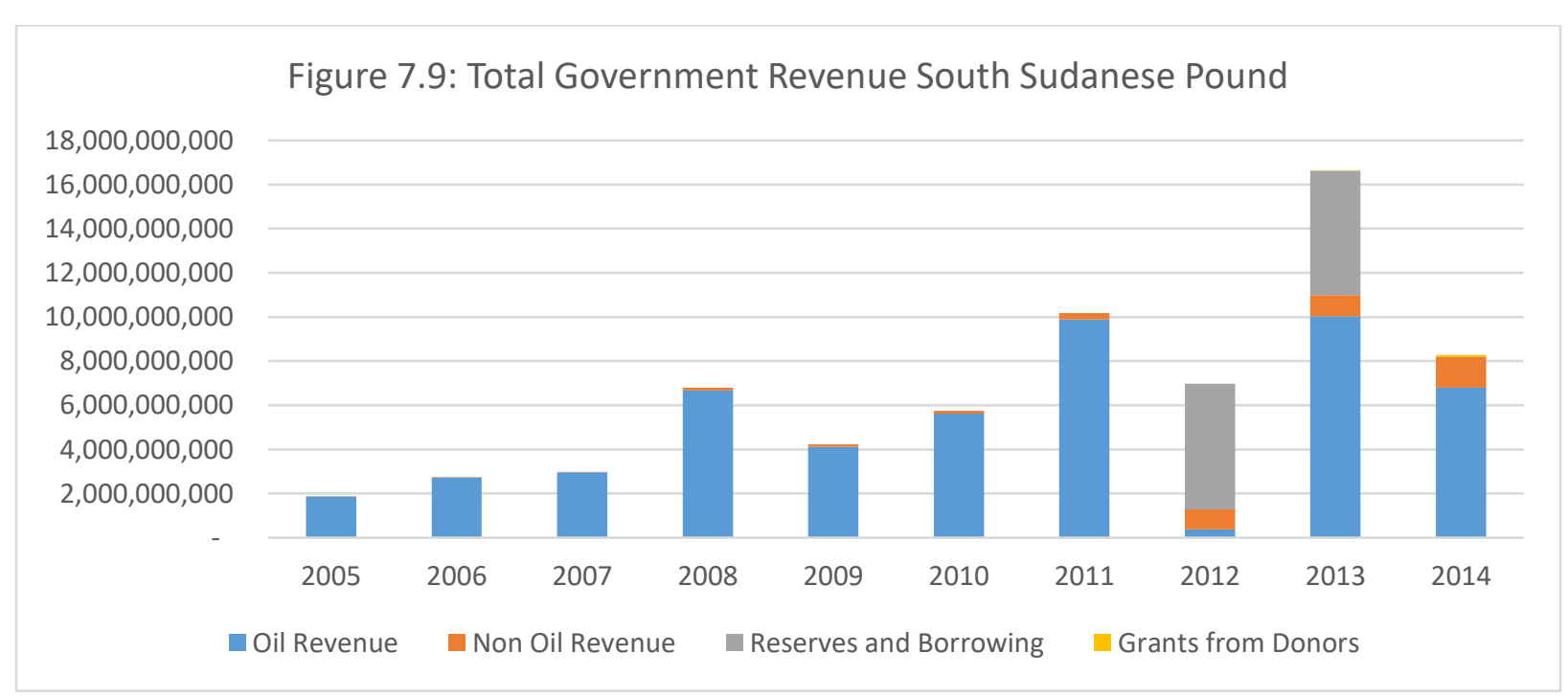




\section{B. Civil War}

In March 2013, Riek Machar, Vice President of South Sudan and the Deputy Chairperson of the SPLM, announced his intention to run for the chairmanship of the SPLM. The chairman at the time, President Kiir, took offense to the threat and dissolved the entire cabinet (Wassara 2015). In doing so, Kiir fragmented the national army along ethnic and regional lines (Wassara 2015). In December 2013, President Kiir accused his Vice President, Riek Machar, of an attempted coup d'état (Radon and Logan 2014), an accusation that led to mass ethnic killings in Juba. By then, South Sudan's first civil war had begun. It ended with a peace agreement between Machar and Kiir in August 2015. Acts of violence have occurred off and on since.

The constant inflow of refugees and internally displaced people also contributed to the exacerbation of tensions within South Sudan (Zambakari 2013).

With a weak national identity (Jok 2011), increased fears of alienation by the non-Dinka community, continued violence, continued use of ethnicity by leaders to promote their power, increased distance between the state and its people, and the need to continuously coopt the opposition, the South Sudanese state ran out of resources to earn performance legitimacy.

\section{Analysis}

The six-year history of the newly independent Republic of South Sudan has been one of violence, state cooptation and state de-legitimization. Four main themes can be discerned from these six years: First, the delivery of basic goods and services continues to be very important for the South Sudanese. The leaders have recognized this fact and have continued to coopt whatever entity that they have access to in order to ensure that they take credit for the delivery of these basic goods and services.

Second, while there has continued to be a high level of violence and leaders have often used ethnicity as a rallying call, these leaders have recognized that their ability to do so is linked to whatever benefits they are able to provide their supporters with. The increased ethnicization of the state is a clear example of the use of a patronage system that offers leaders increased power and performance legitimacy.

Third, the leaders have either directly influenced or contributed to the vacuum that the state has been unable to fill. This has allowed individual players to fill the vacuum, use ethnicity as a means to demonstrate imposed alienation by a dominant group, and present themselves as the only viable brokers between their supporters and the state. ${ }^{93}$ Their role as brokers also allowed these leaders to personalize the state and thus become the defenders of their people from the other 'enemies' that were also working through the state.

Fourth, the relationship between the people and the state is very weak and the leaders' manoeuvering space seems to be significant. The ability to negotiate peace by selling off government positions and access to state resources offers leaders the opportunity to continue threatening the state and the President and returning back for more benefits after they instigate a

\footnotetext{
93 The experience of the Greater Equatorial region, which accommodates 36 different ethnic groups, or 55 percent of South Sudan's total ethnic groups, that have decided to peacefully co-exist and develop their own identity (Kon 2015) demonstrates that ethnicity does not necessarily have to be a negative factor if the leaders make it so.
} 
conflict or a crisis. The manner in which the political system was institutionalized had an impact on the manner in which the leaders treated their manoeuvering space.

Fifth, leaders used and continue to use all resources that are available to them to earn performance legitimacy. In effect, the resource curse (Collier and Hoeffler 2004) associated with having significant natural resources played only a partial role since the leaders used all types of resources, including humanitarian aid, to build their legitimacy. This continued to be the case even after oil was discovered. Moreover, South Sudan never had and continues not to have significant control over the oil production process given that it is in a disputed territory with Sudan.

\section{Performance Legitimacy and the State-Society Relationship in South Sudan}

As a new poverty-ridden nation, South Sudan had to develop its infrastructure, public

administration, and economy. To do so, the South Sudanese had to build state institutions and develop and implement public policies. All of these required the approval of certain leaders within the state apparatus. After several years of war and after understanding the power of performance legitimacy, these leaders saw the institution-building processes and the goal to improve the state's delivery of basic goods and services as a means to safeguard or increase their own performance legitimacy. As such, South Sudan's rebuilding process was influenced by legitimacy-seeking leaders who were unwilling to transfer their legitimacy onto the state.

As has been argued, the South Sudanese placed significant emphasis on access to basic goods and services. The leaders were aware of this fact and used it to increase their own power and legitimacy. The leaders' desire and need for performance legitimacy left an undeniable mark on the life of the South Sudanese. With all leaders having similar goals and using ethnicity as a rallying call, the South Sudanese likely perceived it to be necessary to play within the system so as to be able to safeguard their ethnicity and existence. This could explain why even though the majority of the South Sudanese complained about corruption and blamed its occurrence for their ills, their willingness to support the same leaders that were part of the corrupt system did not really change. In essence, the fear of their ethnic group becoming leaderless in a government that was full of leaders who would only fight for their ethnic group led the South Sudanese to either disengage from the political system or continue supporting a broken system.

Disengagement from the political system implied support to local chiefs and leaders. This increased the bargaining power of the local leaders and made them important actors for the non-local leaders who were looking to gain further support. It also increased the importance of the patronage relationship between the local and non-local leaders and thus the performance legitimacy of each of the leaders, especially when there was competition between leaders from the same ethnic group. Moreover, the disengagement of the population from the political system also fed into the rhetoric of ethnic alienation, a rhetoric that became more powerful once the leaders used their access to state resources and their performance legitimacy to offer an alternative. With infighting between various Nuer leaders (those that remained as the Anya Nya II and those that joined the SPLM/A) and other ethnic groups, including the Dinka, and competition over humanitarian relief and services, even against militias from the same ethnic group, performance legitimacy was deemed to be necessary for the leader's ability to represent his ethnic group. 
Unlike in the Lebanese case, the South Sudanese leaders did not attempt to or were not successful in crossing the ethnic boundaries. At the lower level, much of the performance legitimacy was used to maintain the leaders' power within their respective ethnic group. At the higher political level, that of President and SPLM/A leader, performance legitimacy was used to maintain alliances and support from many leaders across several ethnic and tribal lines.

This desire of leaders to earn performance legitimacy, at any cost (including at the expense of their own supporters), clearly places South Sudan on the vicious performance legitimacy cycle. The leaders successfully diverted what could have been the state's performance legitimacy to themselves by abusing state resources, distancing the state from its population, eliminating all indication of state involvement, rebranding the resources as their own or ensuring that their supporters credited them for the delivery of basic goods and services, and branding all other actors within the state structure as actual enemies or potential threats.

Finally, although the South Sudanese believed in the role of the state, they only recently developed and experience 'stateness'. The absence of the state and the personalization of their representation since pre-colonial times have limited their perception of the role of the state to one that is meant to support them rather than the general population of South Sudan. As such, their experiences and the struggles that they had gone through, including the role of leaders and their tactics to gain performance legitimacy, limited the state-society relationship to minimal levels and eliminated the potential for the development of a strong state-society relationship.

The presence and owners of performance legitimacy, as measured by the indicators in Chapter 3, at the various critical junctures in South Sudan's history are summarized in the following table. 


\section{Table 7.2: The Entity that Ranked Highest in the Performance Legitimacy Indictors (Chapter 3) during South Sudan's Critical Junctures}

\begin{tabular}{|c|c|c|c|c|c|c|c|}
\hline \multirow[t]{2}{*}{ Indicators } & \multicolumn{7}{|c|}{ Critical Junctures $^{94}$} \\
\hline & $\begin{array}{l}1822-1898 \\
\text { Turko-Egyptian } \\
\text { Rule }\end{array}$ & $\begin{array}{l}1898-1956 \\
\text { Colonial Period }\end{array}$ & $\begin{array}{l}1956-1972 \\
\text { Civil War I }\end{array}$ & $\begin{array}{l}1972-1983 \\
\text { Peace }\end{array}$ & $\begin{array}{l}1983-2005 \\
\text { Civil War II }\end{array}$ & $\begin{array}{l}2005-2011 \\
\text { Interim Period }\end{array}$ & $\begin{array}{l}2011-2016 \\
\text { Independence }\end{array}$ \\
\hline \multicolumn{8}{|l|}{ A. Legality } \\
\hline $\begin{array}{l}\text { 1. Perceived Reach and } \\
\text { Applicability of the Law }\end{array}$ & No Data & No Data & No Data & None & None & None & State \\
\hline $\begin{array}{l}\text { 2. Perceived Importance of } \\
\text { State Institutions in } \\
\text { Citizens' Daily Lives }\end{array}$ & No Data & No Data & None & None & None & None & None \\
\hline $\begin{array}{l}\text { 3. Confidence in the } \\
\text { Security Provided by the } \\
\text { Actor }\end{array}$ & No Data & Leaders & Leaders & Leaders & Leaders & Leaders & Leaders \\
\hline $\begin{array}{l}\text { 4. Confidence in the Civil } \\
\text { Service }\end{array}$ & No Data & None & None & None & None & None & None \\
\hline \multicolumn{8}{|l|}{ B. Justification } \\
\hline $\begin{array}{l}\text { 1. Satisfaction with the } \\
\text { Actor in its Effort to Meet } \\
\text { Basic Needs }\end{array}$ & No Data & No Data & Leaders & Leaders & Leaders & Leaders & Leaders \\
\hline $\begin{array}{l}\text { 2. Perceived Willingness of } \\
\text { the Actor to Support } \\
\text { Citizens/Followers }\end{array}$ & No Data & No Data & Leaders & Leaders & Leaders & Leaders & Leaders \\
\hline $\begin{array}{l}\text { 3. Degree to which Citizens } \\
\text { Turn to the Actor for Help }\end{array}$ & No Data & Leaders & Leaders & Leaders & Leaders & Leaders & Leaders \\
\hline \multicolumn{8}{|l|}{ C. Actual Performance } \\
\hline $\begin{array}{l}\text { 1. Number of Basic Goods } \\
\text { and Services Provided by } \\
\text { the Actor }\end{array}$ & No Data & No Data & Leaders & Leaders & Leaders & Leaders & Leaders \\
\hline $\begin{array}{l}\text { 2. Quality of Actor- } \\
\text { delivered Basic Goods } \\
\text { and Services Provided }\end{array}$ & No Data & No Data & No Data & N/A & Leaders & Leaders & Leaders \\
\hline $\begin{array}{l}\text { 3. Ease of Access to Actor- } \\
\text { delivered Basic Goods } \\
\text { and Services }\end{array}$ & No Data & No Data & Leaders & Leaders & Leaders & Leaders & Leaders \\
\hline \multicolumn{8}{|l|}{ D. Acts of Consent } \\
\hline \multicolumn{8}{|l|}{ State } \\
\hline $\begin{array}{l}\text { 1. Compliance with State- } \\
\text { Sanctioned Health Rules } \\
\text { during an Epidemic }\end{array}$ & No Data & No Data & No Data & No Data & No Data & No Data & No Data \\
\hline $\begin{array}{l}\text { 2. Compliance with State- } \\
\text { Sanctioned Rules or } \\
\text { Actions }\end{array}$ & No Data & No Data & No Data & None & None & None & State (weak) \\
\hline $\begin{array}{l}\text { 3. Compliance with Police } \\
\text { Enforced Laws and } \\
\text { Regulations }\end{array}$ & No Data & No Data & No Data & None & None & None & State (weak) \\
\hline \multicolumn{8}{|l|}{ Leader } \\
\hline $\begin{array}{l}\text { 1. Compliance with Leader- } \\
\text { Sanctioned Rules or } \\
\text { Actions }\end{array}$ & No Data & No Data & No Data & No Data & Leaders & Leaders & Leaders \\
\hline $\begin{array}{l}\text { 2. Compliance with State- } \\
\text { Sanctioned Health Rules } \\
\text { during an Epidemic, even } \\
\text { when not supported by } \\
\text { the Leader }\end{array}$ & No Data & No Data & No Data & No Data & No Data & No Data & No Data \\
\hline $\begin{array}{l}\text { 3. Compliance with Leader- } \\
\text { Enforced Laws and } \\
\text { Regulations, even when } \\
\text { in Contradiction with that } \\
\text { of the state }\end{array}$ & No Data & No Data & No Data & No Data & Leaders & Leaders & Leaders \\
\hline
\end{tabular}

${ }^{94}$ These are the critical junctures as it relates to people living in what is now known as South Sudan. As such, the values attributed to the indicators reflect the experiences of the people living in that area. 


\section{Conclusion}

While many considered South Sudan to have had a fresh start when it gained its independence, historical and pre-existing factors played a significant role in the trajectory that this new country has taken. With a limited state-society relationship, leaders acting as brokers, the existence of significant manoeuvring space for leaders, and an aid community that has become an unwilling important contributor in the power battles between the various leaders, the South Sudanese state has had limited success in earning legitimacy and becoming a unifying force.

With the abuse of state resources, the replacement of the state by other actors, and the constant action taken to limit its influence, the South Sudanese state has already experienced tremendous structural deformations and fragmentation. The state has effectively been auctioned off to the highest bidder, a process that has undermined the possibility of equal development for all South Sudanese.

All in all, the South Sudanese state has achieved little performance legitimacy, the type of legitimacy that the South Sudanese population has identified as being the most important and relevant to them. 
Section IV

Findings 


\section{Chapter 8: Performance Legitimacy and the Impact of Contextual Factors}

\section{Introduction}

The international system centres on states. Not belonging to this system, as both Palestine and Somaliland have experienced, creates challenges. In turn, the process of building legitimate states following an internal conflict is of paramount importance.

The academic and grey literature brims with suggestions on how a state could earn its legitimacy and build a more prosperous and advanced society. However, this dissertation has documented that the assumptions underlying mainstream ideas for post-conflict development do not fit the context of many countries emerging from conflict. More specifically, there is a dichotomy between how these theories define post-conflict legitimacy and what, in general, the population associates post-conflict legitimacy with. This dichotomy is based on the differences in what each camp of scholars and practitioners value as the most important function or characteristic of a state and the role of the main actors within it and within society. In this respect, it is about the ends the state ought to be advancing.

Current theories focus on process legitimacy and the democratization of countries and state structures. However, I have shown that, in general, the local population tends to focus more on the performance of the actors vis-à-vis their basic needs. This emphasis on performance legitimacy plays a significant role in the trajectory that a country takes, especially following investments in state-institution building. As argued in Chapter 2, countries can fall on several points along the legitimacy continuum, a continuum identified by two extremes: the vicious cycle and the virtuous cycle.

The analysis and empirics offered earlier underscore that the current theories and their frameworks are inadequate for capturing the impact of performance legitimacy. In the cases of Lebanon, Senegal and South Sudan, these theories seem to omit important variables that can provide explanations for the countries' post-conflict trajectories. The results of the empirical research not only demonstrate the importance of performance legitimacy and the manner in which it is sought and abused, but they also identify two significant factors that ostensibly influence the trajectories of the case study countries: the strength of the state-society relationship and the available manoeuvring space for leaders.

In this final chapter, I restate why a new approach is necessary. This is followed by a quick review of the possible trajectories that countries can take when performance legitimacy is factored into the analysis. The analysis then turns to an assessment of the empirical evidence using the variables identified by the current theories (as noted in Chapter 4) and those inspired by the theoretical framework that was presented in Chapter 2. Finally, the chapter ends with a discussion of the findings' potential general implications and future research opportunities. 


\section{Existing Approaches and the Space for Performance Legitimacy}

As was discussed in Chapters 2, 3 and 4, the existing approaches and mainstream theories related to post-conflict development view process legitimacy as the overriding source of legitimacy in postconflict cases. The emphasis is often placed on two things: First, theories advocate developing liberal democratic systems and processes that are intended to mimic those that are present in developed Western mostly liberal democratic countries. Second, these theories focus on minimizing the role of the inefficient government by relying on non-governmental organizations and the market to assist and bring prosperity to the population.

However, this prescription rests on the following assumptions of post-conflict development conditions.

1) Legitimacy is exclusive to the state and cannot be bestowed upon individuals, especially if they are inside the state structure or system.

2) Process legitimacy is assumed to be the most important source of legitimacy, one that is measured through democracy-related indicators, and it is only when this legitimacy is earned that performance legitimacy and shared beliefs can then be fully attained.

3) While leaders might try to take advantage of their positions in the government, society is ready, willing and capable of using accountability mechanisms associated with liberal democratic systems to limit their leaders' abuse.

4) The incentive of putting down arms to compete peacefully within a democratic system is likely to convince many leaders to avoid further conflict or actions that can lead to conflict.

5) By virtue of leaders working within the government and the state system, the support that the leaders receive from their followers automatically becomes legitimacy for the state.

6) Governments of reconciliation afford the highest chances for peace, and with democratic processes in place, they are the best means to ensure power is transferred from the leaders to the state.

7) Peace processes are perceived as critical junctures that allow for significant changes to be undertaken.

8) Issues related to capacity take time to be solved and thus, non-governmental organizations and private contractors are the most efficient, effective, and appropriate means to deliver goods and services.

These assumptions, however, do not necessarily hold in post-conflict cases. This is particularly true where shared beliefs have been significantly strained among sections of society and where the population lacks experience with and a culture of institutionalized democracy and democratic systems. In these cases, leaders and the state likely compete for legitimacy and much of society will care more about performance than process legitimacy. These two key characteristics significantly influence how leaders behave and how society reacts. As such, the assumptions related to a society using democratic processes to hold leaders to account, the leaders' willingness to pass their power onto the state and its institutions, and the ability of the state to earn legitimacy simply by having leaders work through the state system are inappropriate and are not based on a proper assessment of the local dynamics. 
In addition, the assumptions related to increased capacity due to institution-building are also questionable given that institution-building allows for abuse of state resources by leaders, an abuse that is difficult to control when the society is not fully interacting with the tools that are needed to hold these leaders to account and limit their abuse. Furthermore, the effectiveness and efficiency associated with the deference to non-governmental organizations for the delivery of basic goods and services has a significantly negative effect on the ability of the state to gain legitimacy. Finally, many of these assumptions neglect the experiences in a country before and during the conflict and the relationship that the population has had with the state and their leaders. As such, they overlook possible path dependent processes that make it unlikely a peace process will be sufficient to create a new trajectory for the country.

All told, the current approach does not pay sufficient attention to an important process. Whether states want to achieve performance or process legitimacy, the state requires the capacity and institutions to be able to do so. However, institution building gives leaders access to state resources to pursue their own goals and it gives leaders the chance to increase their performance legitimacy at the state's expense. At the extreme, this leads to a continued de-legitimization of the state and a continued legitimization of the leaders. This can lead to uncertainty and continued insecurity since leaders will use their legitimacy to undertake actions in order to protect, maintain, or further increase their power, actions that would have otherwise been deemed to be unacceptable by the population. This extreme outcome is demonstrated by the vicious cycle in Figure 2.3 in Chapter 2. The other extreme case is identified as the virtuous cycle (Figure 2.3, Chapter 2) where the state is capable of owning the benefits associated with the delivery of basic goods and services and thus continuously building its performance legitimacy. The continuum also includes cases where neither the state nor the leaders have exclusivity over performance legitimacy.

\section{The Approach}

I began my research with a critical analysis of the existing approach to post-conflict development. My analysis led to the realization of an overriding emphasis on process legitimacy in the current theories and approaches, the overlooking of the relevance of performance legitimacy to the leaders and the population, and the unawareness of the divisibility of legitimacy between various actors. This led me to re-introduce performance legitimacy back into the analysis and post-conflict approaches. It also led me to develop means to identify the holders of performance legitimacy and to assess the implications of state institution-building on the level of performance legitimacy of the various actors (vicious versus virtuous cycles). The viability of the results of the inductive theory process and the Performance Legitimacy Theory of Transition framework that I presented in Chapter 2 were verified through an empirical process that included an in-depth analysis of three cases - Lebanon, Senegal and South Sudan. 


\section{Characteristics Identified by Conflict, Peacebuilding and Post-Conflict Theories}

\section{A. An Assessment of the Applicability of the Key Characteristics}

As noted earlier, in order to justify a new approach, one has to identify a problem or a lacuna in the current theories or approaches. As my inductive and deductive research has demonstrated, the existing approach leaves several unanswered questions. This conclusion is based on the assessment of the theories' variables or factors that were presented in Chapter 4 as it relates to each of the three case studies.

Each variable is assessed through the use of an indicator that most closely corresponds to the definition or value of the variable as defined by the existing theories. Moreover, in cases where an indicator already exists, such as Gross Domestic Product, the variable is assessed according to the results of the indicator. In cases where there is no specific indicator that already exists, a proxy indicator was used. The valuation scale of the proxy indicator is kept simple and is often based on a comparative analysis of the three cases. For example, the cut-off line between 'Limited' and 'Average' would depend on the specific case information and on the difference in valuation between a case that would be valued as 'Limited' and the other that might have invested more and thus would be valued as 'Average'. In doing so, the scale can be sensitive to important but yet not so large differences between cases. However, the valuation scale is not likely to be very rigorous and as such, it might introduce a certain level of bias. It is hoped that the bias will be lessened with the use of multiple types of indicators: simple quantitative indicators, complex quantitative indicators that have been used by the proponents of the existing theories and by other internationally recognized actors, complex qualitative indicators with descriptive features, and proxy indicators that I developed based on multiple sources of information. Finally, further information on all of the indicators can be found in the three case study chapters.

For ease of reference, the factors and their valuation are summarized in Table 8.1. The following represents the measurement scale of each of the factors:

1. Duration of Conflict: The unit of measurement is the number of years.

2. Influence of External Actors: The unit of measurement is a value-based three-point scale (-1 through to 1 ), with -1 representing a significantly negative interference and 1 representing a significantly positive interference. The values depend on the level of severity of the interference and the outcome of the interference beyond just achieving peace.

3. Social Fracturing: The overall unit of measurement is based on the Polity IV Magnitude of societal-systemic impact (Mag) indicator with 1 representing the lowest destructive effect and 10 representing the greatest destructive effect that conflict has had on society.

4. Level of Atrocities: The unit of measurement is a value-based three-point scale: None, Some, and Many. The cut off line between the value points is based on what is academically-accepted to be minimal, several but not overwhelming, and an overwhelming number of atrocities.

5. Societal Geographical Division: This indicator is valued as either a Yes or a No with Yes referring to a limited to no assimilation between ethnic/religious groups and No referring to 
high or complete assimilation. The assigned value depends on information provided by academic researchers.

6. Post-war Capacity: This indicator is based on previous analyses of the capacity of the state after conflict. The indicator has the following value scale: No (no real state structures), limited (some state structures exist but there are many human and non-human capacity constraints and the state needs some significant improvements), Average (state structures exist and while the state is functioning, the state needs to undertake some improvements), and High (state structures exist and the state is functioning well with minimally- needed improvements).

7. Geography of Conflict: The indicator has the following value scale: Low (no neighbours experiencing real conflict or little effect from neighbouring conflicts), Medium (half of the border is with a country or several countries experiencing conflict or there is an average effect from neighbouring conflicts), High (more than half of the border shared with a country or countries experiencing conflict or there is a significant effect on the country from neighbouring conflicts (e.g. internal attacks, retaliation across the borders, etc.)).

8. Poverty Rate: This indicator is number-based and is drawn from the United Nations Development Programme reports or from the World Bank Data Bank.

9. Presence of Natural Resources: This indicator is based on descriptive accounts so as to be able to capture the use of natural resources, especially illicit drugs, by rebels. The indicator has a measurement scale of Yes (providing significant financial resources to some or all of the actors), Limited (providing limited financial resources to some or all of the actors), and No (providing no real financial resources to some or all of the actors).

10. Level of Stateness: There is no official indicator of stateness. As such, this indicator is based on descriptive accounts gathered through the literature review. The indicator has the following measurement range: Low (very few state structures in place and very little belief in the need for a state), Medium (some state structures and some belief in the need for a state), High (a lot of state structures and a significant belief in the need and the role of the state).

11. Diaspora Financial Support: Since Diaspora support is extremely difficult to trace, especially since most people in conflict zone send money outside the official financial system and through other people travelling to the area, quantitative information is extremely unreliable. As such, this indicator is based on information gathered from the literature review regarding the assumed values and impact that this funding has had. The indicator is value-based and has a three-point rating scale: Low (very low effect on rebel actions), Medium (some effect on rebel actions) and High (significant effect on rebel actions).

12. Ethnic or Religious Diversity: The unit of measurement is the number of ethnic/religious groups based on UNHCR country profiles.

13. Prior History of Conflict: The unit of measurement is the number of years during which prior conflicts took place.

14. How Conflict Ended: This is a descriptive indicator with the following possibilities: $1=$ One party winning, 2 = Agreement under stalemate, 3 = Agreement under unbalanced power, $4=$ Agreement amongst major parties with smaller parties continuing to fight. 
Table 8.1: Results of the Comparison of the Three Case Studies - Predominant Characteristics

\begin{tabular}{|c|c|c|c|c|c|c|c|c|c|c|c|c|c|c|c|c|c|}
\hline & 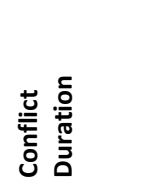 & 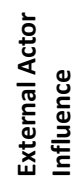 & 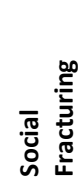 & 范莣 & 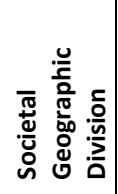 & 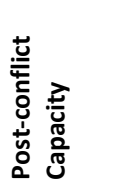 & 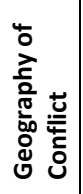 & 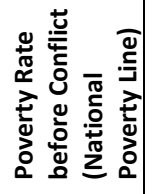 & 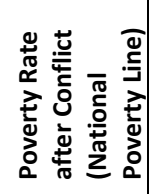 & 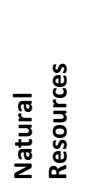 & 苍 & 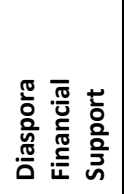 & 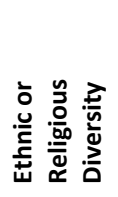 & 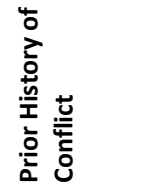 & 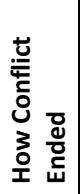 & 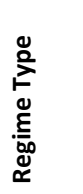 & 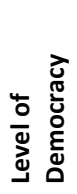 \\
\hline Lebanon & 15 & -1 & $5^{95}$ & Many & Yes & Limited & High & $\begin{array}{c}22.0 \%{ }^{96} \\
(1973- \\
1974)\end{array}$ & $\begin{array}{l}33.7 \%^{97} \\
(1995)\end{array}$ & Limited & $\begin{array}{l}\text { High } \\
\text { (in all } \\
\text { areas) }\end{array}$ & Med & $\begin{array}{c}18 \\
\text { religious } \\
\text { groups }\end{array}$ & $\begin{array}{l}1840- \\
1860 \\
1970- \\
1974\end{array}$ & 2 & $\begin{array}{c}\text { DEM } \\
98\end{array}$ & 7 \\
\hline Senegal & 30 & -1 & 1 & $\begin{array}{l}\text { Many } \\
\text { (in the } \\
\text { conflict } \\
\text { zone) }\end{array}$ & Yes & 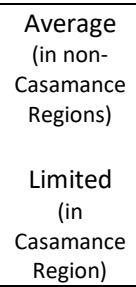 & High & $\begin{array}{c}68 \% \\
(1991)^{99}\end{array}$ & $\begin{array}{c}46.7 \%^{100} \\
(2010)\end{array}$ & Limited & 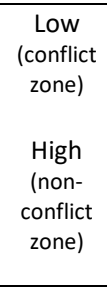 & Low & $\begin{array}{c}17 \\
\text { Ethnic } \\
\text { groups, } \\
3 \\
\text { major } \\
\text { religions }\end{array}$ & $\begin{array}{c}\text { During } \\
\text { many } \\
\text { centuries } \\
\text { of colonial } \\
\text { history } \\
\text { (until } \\
1959 \text { ) }\end{array}$ & 4 & DEM & 2 \\
\hline $\begin{array}{l}\text { South } \\
\text { Sudan }\end{array}$ & $\begin{array}{c}4 \\
\text { (several } \\
\text { decades of } \\
\text { pre- } \\
\text { independen } \\
\text { ce violence) }\end{array}$ & -1 & 1 & Many & Yes & $\begin{array}{l}\text { None to } \\
\text { Limited }\end{array}$ & High & $\begin{array}{c}68.40 \%^{101} \\
(2009)\end{array}$ & $\begin{array}{c}\text { No } \\
\text { significant } \\
\text { change }^{102}\end{array}$ & Yes & $\begin{array}{l}\text { Low } \\
\text { (in all } \\
\text { areas) }\end{array}$ & Low & $\begin{array}{c}65 \\
\text { ethnic } \\
\text { groups, } \\
3 \\
\text { major } \\
\text { religions }\end{array}$ & $\begin{array}{l}1953- \\
1973 \\
1983- \\
2005\end{array}$ & 4 & SF & $\mathrm{N} / \mathrm{A}$ \\
\hline
\end{tabular}

951 is least destructive and 10 is most destructive. (http://www.systemicpeace.org/warlist/warlist.htm)

${ }^{96}$ Kanaan \& Aboul-Hosn (1998)

97 Abla, Karaki, \& Dimachkieh Sweidan (2014)

98 'DEM' implies institutionalized democracy POLITY score of 6-10, 'dem' implies an institutionalized and weak democracy (POLITY score of 1-5), 'SF' implies state failure, http://www.systemicpeace.org/inscr/SFImatrix2014c.pdf.

${ }^{99}$ World Bank Data Bank, http://data.worldbank.org/indicator/SI.POV.DDAY?locations=SN\&name desc=true.

${ }^{100}$ World Bank Data Bank, http://data.worldbank.org/indicator/SI.POV.DDAY?locations=SN\&name_desc=true.

${ }^{101}$ Sudan Statistical Yearbook, http://southsudan.opendataforafrica.org/tlllek/statistical-yearbook-2011-south-sudan?regionId=SS-UY.

102 There is no official data on poverty in South Sudan other than the information in the 2009 census. However, all indication is that poverty has not decreased. Refer to Chapter 7 for more details. 
15. Government of Reconciliation: This indicator is a simply whether the post-conflict government is one of reconciliation (Yes) or not (No).

16. Level of Democracy: The indicator is drawn from the Country Indicator for Foreign Policy's Polity Score: "The POLITY score is computed by subtracting the AUTOC score from the DEMOC score; the resulting unified polity scale ranges from +10 (strongly democratic) to -10 (strongly autocratic)" (Marshall and Jaggers 2002, 15).

According to the analysis, social fracturing, post-conflict capacity, poverty rate prior to and following the conflict, the level of natural resources, the level of stateness, Diaspora financial support, ethnic/religious diversity, the manner in which the conflict ended, regime type, and the level of democracy was not consistent across the three cases. The influence of external actors, the geographic division between the ethnic/religious groups, and the difficult geographic neighbourhood are shared by all three cases. One can also consider that all three cases also share the presence of a prior history of conflict, even though the period between these conflicts and the Casamance conflict could be considered to be significant.

Based on these results, it is difficult to identify a causal or differentiating variable that could explain why Senegal was able to emerge better positioned overall (on most existing and new indicators) than both Lebanon and South Sudan. In essence, it is unable to answer the following questions: Why were the alienated or aggrieved Casamancais willing to submit to the state rather than continue to support the rebels? What was it that the Senegalese state did to win over the Casamancais population? If there were economic, social, and religious grievances, and if the overwhelmingly poor Casamancais population that was geographically divided from the rest of the population and ethnically and religiously distinct was submitted to various atrocities, external influences, several previous conflicts, and external conflict pressures in a weakly democratic country, what was it that convinced them to move forward and accept peace? Why is it that Senegal and Lebanon share nine factors and South Sudan and Senegal share eight factors and yet neither Lebanon nor South Sudan have experienced similar post-conflict relative 'success'?

Finally, the results also do not shed light on why Senegal ended up on the virtuous cycle-end of the performance legitimacy continuum while Lebanon and South Sudan ended up on the vicious cycle-end of the performance legitimacy continuum.

As for the suggested steps to be taken after a conflict has ended, Table 8.2 provides a quick overview of the assessment of how the three countries faired in this regard. The indicators and their measurement scales are:

1. Building Democratic Regimes:

a. Elections: 0 represents no elections after the war ended, 1 represents interrupted elections (elections that are few and far in between), 2 represents consistent elections since the war ended (with minor interruptions), 3 represents consistent and uninterrupted elections.

b. Level of Rule of Law: This is based on the World Bank's Aggregate Rule of Law indicator with data gathered from the World Bank Data Bank. A higher value indicates a better status. The arrow indicates the trend since the time of the rating. 
c. Investment in Rule of Law after Conflict: The scale is represented by the following: None, Minimal, Some, and Significant and the ratings are based on information gathered from descriptive accounts in academic and non-academic literature.

d. Institution-Building: 0 represents no institution-building, 1 represents some investment in building institutions, and 2 represents a serious effort to build state institutions. Again, the ratings are based on information gathered from descriptive accounts in academic and non-academic literature.

e. New Constitution: This is a simple indicator indicating a Yes or a No depending on whether the government passed a new constitution or maintained the one that existed prior to the end of the conflict. This indicator is based on information gathered from the literature review.

f. New Public Financial Management (including the rooting out of corruption): This is based on the investment that donors and the government made in improving their public financial management systems, information that was gathered from aid statistics and the literature review. The value of the indicator is represented by a Yes or a No.

g. Economic stability: This is again based on a review of the literature and data on Gross Domestic Product. The indicator values are based on -2 representing significant economic gyration (a significant drop in purchasing power or Gross Domestic Product), -1 representing some economic gyrations, and 0 representing very minimal or no economic gyrations.

h. Decentralization: This is a simple indicator measured by a value scale of None, Limited (when minimal decentralization is undertaken after a conflict) and Significant (when the government has taken decentralization seriously and implemented several decentralization initiatives after the conflict).

i. Security: This indicator measures whether or not additional investments were made to improve the security situation after the end of conflict. It is informed by the information gathered from the literature review and from information about sectors that the aid community invested in. The value of the indicator is based on the following scale: $0=$ No investment, $1=$ Some investment, and $2=$ A lot of investment.

2. Regime Type: The data is based on a POLITY IV democracy indicator: "The Democracy indicator is an additive eleven-point scale (0-10). The operational indicator of democracy is derived from coding of the competitiveness of political participation (variable 2.6), the openness and competitiveness of executive recruitment (variables 2.3 and 2.2), and constraints on the chief executive (variable 2.4)" (Marshall and Jaggers 2002, 13).

3. Level of Aid: This measures the total aid received within the 10-year period after the end of the conflict or its minimization. In the case of South Sudan, the indicator measures total aid since its independence (2011). This indicator is based on aid data gathered by the Organization for Economic Development and Co-operation.

As in the case of the assessment of the variables that contribute to conflict, the evaluation of the suggested steps to be taken to secure peace and development do not shed much light either. 
While South Sudan has been considered a failure, Lebanon a stalemate, and Senegal a relative success, Lebanon and Senegal have equally faired on seven indicators and Senegal and South Sudan have similar results for three indicators. Interestingly, Senegal faired lower than Lebanon and South Sudan in the following important indicators: Investment in rule of law, establishment of a new constitution, and investment in new public financial management. Finally, as in the assessment of the above factors, these indicators provide little to no information on why Senegal ended up on the virtuous cycle while Lebanon and South Sudan ended up on the vicious cycle.

Table 8.2: Results of the Comparison of the Three Case Studies - Existing Post-Conflict

\section{Recommendations}

\begin{tabular}{|c|c|c|c|c|c|c|c|c|c|c|c|}
\hline & $\frac{\mathscr{a}}{\bar{E}}$ & 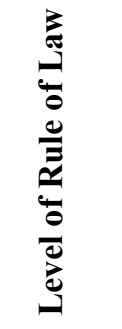 & 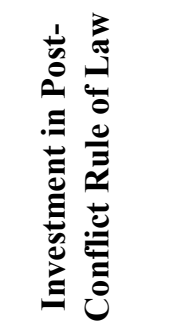 & 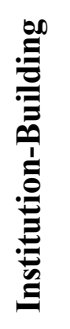 & 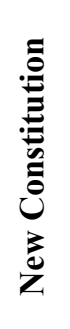 & 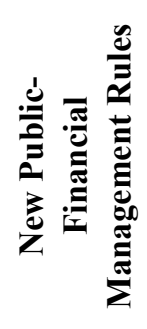 & 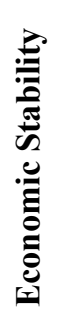 & 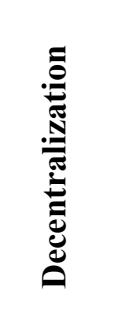 & 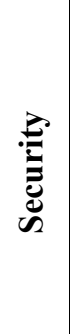 & 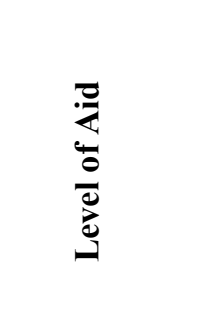 & 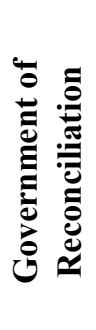 \\
\hline 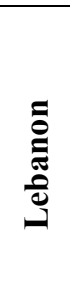 & 2 & $\begin{array}{c}42.6 \\
(1996), \\
\downarrow\end{array}$ & Some & 1 & Yes & Yes & 0 & Limited & 1 & $\begin{array}{l}\text { USD } \$ 2.3 \\
\text { billion } \\
(1990-2000) \\
\text { (or USD } \\
\begin{array}{c}\$ .23 \text { billion } \\
\text { per year) }\end{array}\end{array}$ & Yes \\
\hline 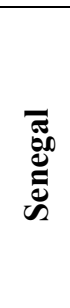 & 2 & $\begin{array}{c}44.5 \\
\text { (1996), } \\
\text { Slight } \\
\uparrow\end{array}$ & Minimal & 1 & No & No & 0 & Limited & 1 & $\begin{array}{l}\text { USD } \$ 10.7 \\
\text { billion } \\
(2004-2014) \\
\text { (Or USD } \\
\begin{array}{c}\text { (Or.07 billion } \\
\text { per year) }\end{array}\end{array}$ & Yes \\
\hline 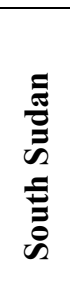 & 1 & $\begin{array}{c}5.6 \\
(2011), \\
\downarrow\end{array}$ & Significant & 2 & Yes & Yes & -2 & None & 1 & $\begin{array}{c}\text { USD \$5 } \\
\text { billion } \\
\text { (2011-2014) } \\
\text { (Or USD } \\
\begin{array}{c}\text { (Or.25 billion } \\
\text { per year) }\end{array}\end{array}$ & Yes \\
\hline
\end{tabular}

In line with the thesis of this dissertation, in accordance with the premise of the performance legitimacy indicators that were identified in Chapter 3, and in line with the results of the identification of the owner of each of these indicators (Legality, Justification, Actual Performance, and Acts of Consent) in each of the cases, the research assessed the state of the delivery of basic goods and service by the actors involved in the conflict, both during and after the conflict. Each overall proxy indicator measures how each group faired and has the following 
values that assess the amount of services that were delivered: None, Limited (some services but very unsophisticated), Average (several services), and Many (a sophisticated system that leaves little unfulfilled basic needs). The two indicators that measure the level of importance of these services have a value scale of Low (not deemed to be vital by the recipient), Medium (services that were considered important and helped meet a few basic needs), and High (services that were deemed to be vital for survival and/or for continued living).

Given the discussion related to the possibility of leaders who work within state structures to capture state services and claim them as their own, the values in Table 8.3 reflect the perception of the population (as was assessed during the research) and not simply the entity that is actually responsible for the funding and delivery of such services.

Table 8.3: Comparison of the Results of the Three Case Studies - Performance Legitimacy

\begin{tabular}{|c|c|c|c|c|c|c|c|c|}
\hline & 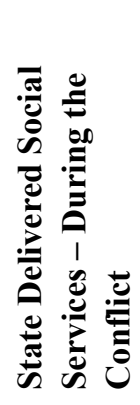 & 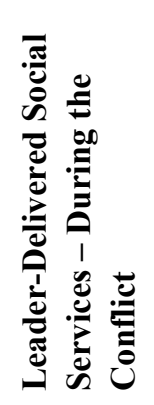 & 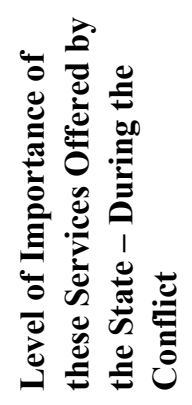 & 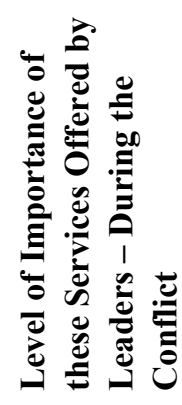 & 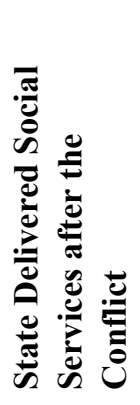 & 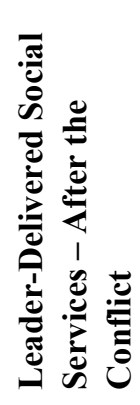 & 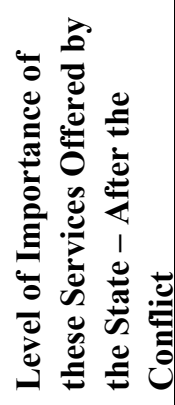 & 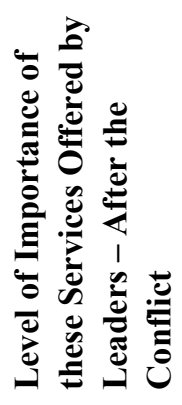 \\
\hline Lebanon & Limited & Many & Low & High & Limited & Many & Low & High \\
\hline Senegal & $\begin{array}{l}\text { Limited } \\
\text { (during } \\
\text { the early } \\
\text { years of } \\
\text { conflict) } \\
\text { Average } \\
\text { (during } \\
\text { the later } \\
\text { years of } \\
\text { the } \\
\text { conflict) }\end{array}$ & $\begin{array}{l}\text { Limited } \\
\text { (during } \\
\text { the early } \\
\text { years of } \\
\text { conflict) } \\
\text { None } \\
\text { (during } \\
\text { the later } \\
\text { years of } \\
\text { the } \\
\text { conflict) }\end{array}$ & $\begin{array}{c}\text { Low } \\
\text { (during the } \\
\text { early years } \\
\text { of conflict) } \\
\text { Medium } \\
\text { (during the } \\
\text { later years } \\
\text { of the } \\
\text { conflict) }\end{array}$ & $\begin{array}{l}\text { Medium } \\
\text { (during the } \\
\text { early years } \\
\text { of conflict) } \\
\text { Low } \\
\text { (during the } \\
\text { later years } \\
\text { of the } \\
\text { conflict) }\end{array}$ & Average & Limited & Medium & Low \\
\hline $\begin{array}{l}\text { South } \\
\text { Sudan }\end{array}$ & Limited & Average & Low & $\begin{array}{c}\text { High } \\
\text { (very vital) }\end{array}$ & Limited & Average & Low & $\begin{array}{c}\text { High } \\
\text { (very vital) }\end{array}$ \\
\hline
\end{tabular}


Table 8.4: Comparison of the Results of the Four Categories of Performance Legitimacy Indicators for the Three Case Studies

\begin{tabular}{|l|l|l|l|l|l|l|l|l|}
\hline & \multicolumn{9}{|c|}{ Pre-Conflict } & \multicolumn{3}{c|}{ After the Conflict* } \\
\hline & Legality & Justification & $\begin{array}{l}\text { Actual } \\
\text { Performance }\end{array}$ & $\begin{array}{l}\text { Acts of } \\
\text { Consent }\end{array}$ & Legality & Justification & $\begin{array}{l}\text { Actual } \\
\text { Performance }\end{array}$ & $\begin{array}{l}\text { Acts of } \\
\text { Consent }\end{array}$ \\
\hline Lebanon & Leaders & Leaders & Leaders & No Data & $\begin{array}{l}\text { State and } \\
\text { Leaders }\end{array}$ & Leaders & $\begin{array}{l}\text { Leaders } \\
\text { State and } \\
\text { Leaders }\end{array}$ \\
\hline Senegal & $\begin{array}{l}\text { NC: State } \\
\text { C: Leaders }\end{array}$ & $\begin{array}{l}\text { NC: State } \\
\text { and Leaders } \\
\text { C: Leaders }\end{array}$ & $\begin{array}{l}\text { NC: State and } \\
\text { Leaders } \\
\text { C: Leaders }\end{array}$ & $\begin{array}{l}\text { NC: State } \\
\text { and } \\
\text { Leaders } \\
\text { C: } \\
\text { Leaders }\end{array}$ & $\begin{array}{l}\text { NC: } \\
\text { State } \\
\text { C: State }\end{array}$ & $\begin{array}{l}\text { NC: State and } \\
\text { Leaders } \\
\text { C: State }\end{array}$ & $\begin{array}{l}\text { NC: State and } \\
\text { Leaders } \\
\text { C: State }\end{array}$ & $\begin{array}{l}\text { NC: State } \\
\text { C: State }\end{array}$ \\
\hline $\begin{array}{l}\text { South } \\
\text { Sudan }\end{array}$ & Leaders & Leaders & Leaders & No Data & $\begin{array}{l}\text { State and } \\
\text { Leaders }\end{array}$ & Leaders & Leaders & Leaders \\
\hline
\end{tabular}

Legend: NC: Non-Casamance, C: Casamance

* In the case of South Sudan, this represents the period following independence.

The results indicate an interesting finding. While in Lebanon and South Sudan, the state was deemed to have not been responsible for meeting people's basic needs either during or after the conflict, the Senegalese state was the only one out of the three that was originally considered irrelevant by the Casamancais and that later was able to become a strong player in their lives. Moreover, the South Sudanese case also provides an interesting assessment: the level of sophistication of social goods and services is trumped by the level of desperation of the population. As such, even though the South Sudanese rebel groups were not able to reach the level of goods and service delivery sophistication that those in Lebanon had reached, the desperation of the people and the acute need for these items allowed them to gain loyalty and support.

Finally, as it relates to the other three sources of legitimacy, all three countries had acquired international recognition and all three countries had a certain level of process legitimacy. It could even be argued that given the stronger level of democracy, Lebanon had a higher level of process legitimacy than the other two countries. ${ }^{103}$ During the conflict, all three countries lacked shared beliefs with each group having a belief or a vision for their society and country, something that was only reversed in Senegal once the state started taking care of its people and earning performance legitimacy while the rebel groups were losing performance legitimacy.

\section{B. Conclusion}

The findings as presented in Tables 8.1 and 8.2 indicate that the current theories leave a void that cannot be explained. They also do not provide a consistent explanation of why Senegal experienced a different path than the other two cases.

While limitations to the methodology, data and measurement have been acknowledged and rectified as much as possible, the results, ones that have been triangulated through a combination of approaches, still represent important findings. They also shed light on a plausible explanation

\footnotetext{
${ }^{103}$ Refer to Chapter 3 for further details on how to measure process legitimacy and its interlinkages with measurements of democracy.
} 
as to why certain countries fall on the virtuous cycle trajectory while others fall on the vicious cycle trajectory.

In conclusion, the results indicate the need for a new approach that can account for the differences in these three countries' trajectories.

\section{Case Study Findings Related to Performance Legitimacy}

Each of the cases studied is unique. Yet, each case also shared many commonalities with the other two cases. Interestingly, the two cases that were identified on the vicious end of the spectrum shared less with each other than with the one case that seemed to have moved into the virtuous end of the spectrum.

\section{Lebanon}

Lebanon's history is very rich and complicated. Lebanon's society is a mosaic of cultures and religions. Different groups within its society experienced history from different perspectives and have developed diverse cultural traits. The Lebanese have had to live through many bloody conflicts, all under the guise of religion. The latest conflict, from 1975 until 1990, saw the destruction of society on many levels. Moreover, owing to Lebanon's geographic location, the country and its population have succumbed to influences from all of its neighbours in political, social, and religious aspects. While it lacks natural resources, it was and continues to be considered the door to the Arab world. The Lebanese population is well-educated with lower levels of poverty than Senegal and South Sudan and many of the other countries experiencing conflicts. Lebanon continues to suffer from a high degree of corruption, one that is fuelled by (a) the high level of social fracturing, (b) the constant use of religion as a cover for the leaders' actions, and (c) a society that is geographically divided along religious lines. It has an institutionalized a weak democratic system.

The 15-year conflict saw the destruction of the state and the replacement of the state by several militia groups and non-governmental organizations. During this time, militia groups had developed complicated systems and structures that were responsible for taking care of the people's basic needs. The conflict ended with an agreement following a stalemate and a period of unofficial foreign occupation by Syria that lasted until 2005. During this time, state institutionbuilding initiatives were undertaken and most of the benefits accrued to the leaders who were in control of the state institutions that delivered basic goods and services. Moreover, the period saw the revival of the leaders' use of non-governmental organizations as fronts for nepotism and as the means to earn and maintain performance legitimacy. The leaders used this legitimacy to take Lebanon back into periods of uncertainty, whether by attacking another country without having a consensus on the matter within Lebanon or by attacking each other on the streets of Tripoli and Beirut. In essence, Lebanon fits well in the vicious cycle scenario that was originally identified in Chapter 2.

While the research identified a high level of importance allocated to performance legitimacy, it also identified the following three major factors that significantly contributed to Lebanon's track towards the vicious cycle: 
1. The relationship between the Lebanese and their state had always been weak. Since the early 1800 s, the Lebanese have dealt with leaders who have acted as brokers between them and the state. This has diminished the role of the state in the eyes of the Lebanese and limited it to one where the religious groups vie for survival and dominance. In essence, the Lebanese had always deferred to their leaders for all of their needs and had supported their leaders' use of, interaction with, and presence in the state as a means to guarantee their existence, rights, and access to resources. The state was devoid of its ability to properly govern and establish public policies that were meant to treat all Lebanese equally.

2. Lebanese leaders had significant manoeuvring space which allowed them to hold the state and the other leaders hostage. There were very few, if any, mechanisms that successfully controlled the leaders' abuse of state resources and power. In essence, the manner in which the political system was established allowed the leaders, and some of their party members, to essentially secure their political future and thus use the resulting manoeuvering space to hold the state hostage if their demands and conditions were not met. Moreover, by earning significant performance legitimacy during the war and in the early post-conflict stages, these leaders had earned enough power to be able to threaten what the government and the other leaders wanted to achieve. Finally, given that most if not all leaders were abusing the state system, a level of collusion had developed between the various leaders thus allowing for continued abuse.

3. Performance legitimacy contributed more to where Lebanon ended up than did religion. When looked at from an overall perspective, religion, combined with the power of external religious and non-religious players who provided support according to religious goals, would seem to have been the key issue that guided Lebanon's trajectory. However, the success of the current leader who allows for external interferences and religious rhetoric is based on his/her ability to out-manoeuvre other leaders from the same sect or religion, something that has been part and parcel of Lebanon's history. Yet, being able to do so is heavily reliant on the ability of the leader to win over supporters. In turn, this ability is heavily reliant on what the leader has been able to contribute to the daily lives of potential and actual supporters. In essence, the ability of the leader to win against another has been directly linked to the leader's ability to earn performance legitimacy. In the case of Lebanon, all potential and successful leaders used religious rhetoric, but the ones that won were the ones that went beyond the rhetoric and assisted their supporters. Moreover, the willingness of leaders to then cross the religious divide and attempt to earn performance legitimacy from people of other religious faiths is also testament to the significant importance of performance legitimacy for the Lebanese and their leaders.

\section{Senegal}

Since its early history, the Senegalese population has struggled with colonialism, the effects of the slave trade, the struggle for independence, several conflicts, corruption, economic crises and a political system that was a reflection of one main party's platform or objectives. The Senegalese have also had to deal with being surrounded by states that had their own struggles and that had projected some of these onto the Senegalese through interference in Senegal's 
internal affairs. This interference, along with a unique geographical make-up and borders, ethnic cleavages, very high levels of poverty, and weak infrastructure contributed to the division of society along two main groups - the Southerners (or the Casamancais) and the Northerners. The alienation of the Southerners led to significant legitimacy issues for the state and the cohesion of the country. There were also significant differences in the societal structures between the Northerners and the Southerners. Senegal's current political system is characterized as an institutionalized democratic system with many inherent weaknesses, but nevertheless a step up from the one-party state system that was in effect from independence until the late 1980s. Still, Senegal continues to suffer from a high degree of corruption.

The conflict that Senegal experienced began as a quest for independence by the Casamancais and lasted for 30 years before it ended in a general view to remain as part of Senegal. The period of conflict also saw several atrocities committed against people in the South. The conflict officially ended with an agreement amongst major players. There continues to be small skirmishes with smaller groups who maintain their arms and their fight against the Senegalese state. The conflict saw the destruction of Southern infrastructure and state capacity in the South. It also led to the destruction of the local economy and increased suffering by the population. This was a significant factor in the ability of the state to earn performance legitimacy. While the rebels initially took care of the population, they quickly turned against the locals when their situation became more difficult. Unlike the rebels, the state initially responded to the Casamance conflict through a military crackdown and judicial powers but later realized the inadequacy of their actions. As such, with the basic needs of the Casamancais being ignored by the rebels, the state invested in its local institutions and began offering social services to the local population. Soon enough, the onetime independence seekers bestowed legitimacy unto the state and thus limited the rebels' chances of success. As such, while religion and ethnicity played a role in the early days of the conflict, they seemed to be secondary in importance to the fulfillment of basic needs. This allowed the state to earn performance legitimacy owing to the institution-building process, thus moving Senegal along the virtuous cycle path.

Yet, if corruption and the access to state services were used as part of a complicated clientelistic network to keep leaders in check or on the side of the President, why was it that the access to state resources did not lead to the de-legitimization of the state? The research has uncovered the following main reasons:

1. Performance legitimacy was deemed by the Senegalese to be more important than process legitimacy. Furthermore, the Senegalese expected and understood that the state was responsible for the benefits that they received. In essence, the state was continuously present in the equation and the population was aware of the role of the state in their daily lives.

2. The state-society relationship was strong. Even though there were several brokers, especially religious leaders, between the state and the population, the population perceived the state as being responsible for taking care of them and of developing and implementing policies that would work to improve their lives. In essence, even though several non-governmental organizations provided the population with basic goods and 
services, the population perceived and expected the state to be the originator of these basic goods and services.

3. The political manoeuvring space for leaders was limited. No specific leader could control or manipulate the situation while disregarding the other leaders. Each leader relied on the ability of the President to provide him with state resources that they could use as part of their clientelistic network. However, once the President perceived a leader to be stepping outside the accepted boundaries, he quickly moved to cut off that leader's source of funding while supporting another leader from the same group and offering him access to state funds for his clientelistic network. Moreover, the President was also limited in his ability to behave selfishly. Given the need to gather wide-ranging support from the various parts of the country, it was necessary for the President to ensure that the leaders were content and able to bring in support.

4. While the Casamancais leaders used ethnicity and religion as a rallying factor at the beginning of and during the conflict, the state, which was perceived to be dominated by Northerners, was able to transcend these issues and win the support of the Casamancais by providing basic goods and services even with little changes to ethnicity and religion and to the manner in which the Casamancais were included in the political and state system. In essence, not only was the divide in societal identities and beliefs transcended by performance legitimacy, but performance legitimacy allowed for shared beliefs between the Northerners and Southerners to begin emerging and for the subsequent minimization of support for cessation.

\section{South Sudan}

Even though South Sudan is the newest country in the world, its history has been long-time in the making. The quest for independence began during colonial times and continued throughout the history of the Republic of the Sudan and into 2011 when the people of South Sudan finally won their fight. The South Sudanese were exposed to multiple conflicts, each having taken a significant toll on the society and its values and structures. As in the case of Lebanon and Senegal, South Sudan had to face many obstacles: significant international intervention, a noncohesive society that is made up of a significant number of ethnicities, significant atrocities, a high degree of societal division along geographical lines, a significantly high level of poverty, and a high level of corruption and clientelism. Moreover, unlike Lebanon and Senegal, South Sudan has had to deal with the effects of being a country that is significantly reliant on natural resources (oil) and one with extremely limited state capacity. Moreover, as in the Lebanese case, the country is populated by a society that has limited shared beliefs, a limited notion of citizenship, and a dysfunctional democratic-style political system that is meant to allow representation for most of the ethnic groups.

The various conflicts and the lack of investment in the Soudanese state structure in the South left little institutional capacity at the time of South Sudan's independence. During the war, the lack of presence of the state was mitigated by the actions of local militias and leaders. The mitigation strategies included the diversion of humanitarian aid, the diversion of economic activity, and the use of financial resources by the militias to purchase much-needed basic goods for their 
population. However, not all militias were successful in taking care of the needs of the locals within the territory that they controlled. Yet, the successful militias that endured and that earned the support of the population were the ones that met some of the basic needs of their supporters. After the end of the second major conflict that resulted in a transition period between the peace process and the referendum for independence, the Sudanese state did not invest in earning performance legitimacy in the South. The sense of alienation and disregard by the North cemented the desire for Southern independence. Post-independence South Sudan saw a significant effort to build state institutions and establish a functioning state. However, as in Senegal and Lebanon, the establishment of a government of reconciliation offered various leaders access to state resources, access that was facilitated by the President in a bid to achieve peace and maintain coalitions. This institutionalized the existing practice of corruption and clientelism. Finally, as in Lebanon, non-governmental organizations were used as fronts for leaders to enhance or maintain their performance legitimacy. Many of the leaders used this legitimacy to re-ignite the conflict that previously existed between the different factions of society. After four relatively peaceful post-independence years, South Sudan was again embroiled in civil war. The results of the research place South Sudan on the vicious cycle with the state being unable to earn performance legitimacy, leaders continuing to use state resources to earn performance legitimacy, and leaders using their legitimacy to undermine the state and other leaders within it.

Overall, performance legitimacy played a central role in the actions of leaders and in the behaviour of the population. Yet, there are four major factors that significantly contributed to South Sudan's vicious cycle:

1. While the society understood the importance of the state, the relationship between the state and the population was very strained and was interrupted by leaders who acted as brokers between the various levels of society and the state. The society seemed to conflate leaders with the state and while the South Sudanese often complained about corruption or inefficiencies, they often did so in regards to other leaders that did not represent them. They seemed to also have what they considered to be valid reasons that explained why their leaders, either at the local, state or national level, were excused in their corrupt or questionable actions.

2. The leaders had very few limits that were placed on them. They were able to use their performance legitimacy to undertake actions that were accepted by their followers and the manner in which the political system was built along with the limited interaction between the state and the society limited the constraints that the leaders had to face and allowed them the luxury of threatening significant damage. These threats were mostly eliminated when leaders received access to further state resources. In cases where the threats were too significant or where additional access was unlikely or impossible, the leaders were capable of taking action to take the country back into conflict.

3. The inability of the state to earn performance legitimacy allowed leaders to continue using their legitimacy to inflate ethnic and religious cleavages and limit the ability of the society to develop shared beliefs and a common view of citizenship. 


\section{Implications}

The three cases that were analysed indicate that the current theories and their variables seem to leave some aspects unaccounted for. As demonstrated above, the analysis related to Lebanon, Senegal and South Sudan yielded interesting findings. When using the factors highlighted by the existing theories, there seemed to be more commonalities between Lebanon and Senegal than between Lebanon and South Sudan. As it relates to post-conflict development, all three countries shared similar contexts, with varying degrees, and implemented institution-building, governments of reconciliation, elections, decentralization, and systems for the delivery of social services. Yet, while there were more commonalities between Lebanon and Senegal than between South Sudan and Lebanon and South Sudan and Senegal, the post-conflict state building trajectory experienced by Lebanon is quite different from Senegal's trajectory.

Overall, Senegal seems to have been the only one out of the three countries that were studied that was relatively successful in moving along the path from conflict to development. While Lebanon has faced significant obstacles and has achieved a more or less dysfunctional status quo, it, at the time of writing, has not been brought back to its knees by constant conflict. Unlike Lebanon, South Sudan has passed the dysfunctional stage and moved into the stage of disarray.

The three cases also highlight the importance of the role of performance legitimacy in postconflict state building. In all three cases, performance legitimacy played a central role in the trajectory of post-conflict development. The delivery of social services, whether through nongovernmental organizations, United Nations organizations, and the state structure itself, was a key aspect in allowing leaders to own their delivery and maintain their power in Lebanon and South Sudan and in allowing the Senegalese state to 'win back' its Casamancais population. As such, while the three cases implemented the key suggestions of the existing framework, albeit to varying degrees, they differed in their trajectories in the Performance Legitimacy Theory of Transition framework. Moreover, the research has demonstrated that some of the key areas in the existing literature (institution-building, governments of reconciliation, decentralization and the delivery of social services) facilitated Lebanon and South Sudan's trajectory onto the vicious cycle.

The findings also point to the impact of the leaders' political manoeuvring space, the historical relationship between the population and the state, and the manner in which the existing framework (institution-building, governments of reconciliation, decentralization, and the delivery of social services) interacts with performance legitimacy to establish the institutionbuilding and legitimacy trajectory onto which the country embarks. In the Senegalese case where the relationship between the state and the population was strong and the political manoeuvring space was limited, the investment that the state made in building its performance legitimacy (through institution-building focused on delivering services in the Casamance region, including rebel leaders in the government, improved decentralization in the Casamance region, and improving the delivery of social services to the Casamancais) bore fruit. Yet, in South Sudan, where the population believes in the importance of the state and its role in their lives, especially when it comes to the delivery of social services, the relationship between the people and their state was not enough to limit the diversion of performance legitimacy through the abuse of the 
state institution-building process, a process that flourished when political manoeuvring was rampant. As for the Lebanese case, the evidence points to the limited state-society relationship and the significant space for political manoeuvring as the key factors that facilitated the abuse of the state institution-building process and the diversion of the state's performance legitimacy.

In conclusion, performance legitimacy and the tracing of the outcomes of state institutionbuilding has allowed for a better understanding of the trajectory of each of these countries. Although the research began with the idea that multiple paths existed along the vicious to virtuous continuum, the case studies provided two unexpected variables that shine a light on the factors that are likely to push countries in either direction of the continuum: the status of the state-society relationship and the manoeuvring space that is available to the leaders. The research into the three case studies seemed to indicate the following plausibility: the better the statesociety relationship and the more limited the manoeuvring space that is available for the leaders, the more likely that the state succeeds in earning performance legitimacy.

This is inline with the research that Beck (2008) conducted on clientelism and her argument that the political autonomy of local brokers combined with their social authority dictates the level of influence that local brokers have as it relates to clientelism. Beck $(2008,17)$, with the use of a graph with political autonomy of local brokers placed on the horizontal axis and social authority of local leaders placed on the vertical axis, notes that brokers with high levels of both variables would tend to become influential brokers, thus requiring them to cater to their supporters but not having them be limited by other players. Those low levels of both variables tend to create limited brokers with limited influence and power. As for those who have low political autonomy and high social authority, they would likely develop a dependent relationship where they would be caught between the higher level decision-makers and their supporters. Finally, for those who have a high political autonomy variable and a low social authority variable, they would likely be autonomous brokers who would not care about the reactions of the locals and who would likely abuse state resources for their own benefit. If I am able to borrow from Beck, then the case of Senegal would be one where both the politicians and the religious leaders (including the marabouts) are likely to belong to the dependent broker category and the South Sudanese and Lebanese politicians are likely to belong to the influential broker category.

The status of the state-society relationship is already somewhat captured by Miller (2015) and Gurowitz (1999) who raise the importance of the role of the state in the population's lives and the cultural traits that influence how the population perceives the state and its role in their lives. However, the impact of the manoeuvering space has not been adequately discussed in the current literature. The discussions often revolve around implementing democratic practices that can limit corruption and the abuse of the media. However, as was demonstrated in the research, the role of leaders in the implementation of these policies and the power that these leaders have owing to their performance legitimacy makes for either the adoption of weakened policies or the disregard of these policies. As such, there is little discussion on how the design of certain political systems and electoral practices allow for an increase in the manoeuvering space that leaders use to jockey for performance legitimacy and thus power. 
Influencing the relationship between the people and their state is a long-term process that requires changes in the perception, culture, and emotions that people hold towards the state. It necessitates the state to take action and become relevant in people's lives, as in the case of the Casamance in Senegal. It could also require an intervention at the community level to help change the community's perception of the state. This could include the insertion of these values in school curriculums, non-governmental organization programs, and community group meetings. As for assistance on limiting the manoeuvering space of leaders, it would require a comprehensive analysis of the institutionalization of various types of political systems so as to identify the impact that it has on the actions of the leaders given their interest in maintaining and gaining performance legitimacy. It would also require the assessment of systems or incentives, both democratic and non-democratic, that can work to limit the manoeuvering space for leaders.

Finally, my research has demonstrated that performance legitimacy is a significantly important variable in post-conflict countries. Unfortunately, not only is performance legitimacy not adequately considered in the current theories and approaches, but the manner in which legitimacy is measured and the data that is gathered regrading post-conflict countries need to be adjusted to account for performance legitimacy and the owners of this legitimacy.

\section{Future Research}

While the theoretical framework and the variables that were identified through the case studies offer an innovative and alternative explanation and new possible means to ensure the building of state legitimacy in the early post-conflict stage, the results of the research were not sufficient to be able to identify the 'stickiness' of the paths that each country took. In essence, the following question remains unanswered: What factors can change the country's current situation by 'unsticking' it from its current path and diverting it towards the more positive or more negative end of the spectrum? The difference between Lebanon and South Sudan are striking in this regard. One can hypothesize that the limited resources that leaders can control in the case of South Sudan increases the stakes for leaders and leads them to take more dangerous actions whereas, in the case of Lebanon, the continuous flow of objects that can be captured by leaders allows for a sort of equilibrium that leads to a high level of dysfunctionality but not collapse or conflict.

Furthermore, one can also wonder what this research can offer in cases where performance legitimacy was not an important factor for any player during the conflict. In the Mozambique case, the various actors had not earned performance legitimacy during the war and yet, Mozambique was able to move along the virtuous path where the state was able to earn performance legitimacy in the early post-conflict stage. Could it be that the leaders had no legitimacy to defend and thus did not see the necessity to abuse the state in order to maintain their power? Could it be that the system also played a role in limiting the leaders' manoeuvring space so that regardless of whether they wanted to have greater power by building their performance legitimacy, the space did not allow them to do so?

Finally, while I have made some suggestions as to how the state-society relationship can be improved and how the manoeuvering space can be limited, further research needs to be undertaken to assess the viability of these suggestions and to develop more appropriate and more 
successful alternatives. Are there any non-public policy actions that can be taken to limit the manoeuvering space for leaders? Should action be taken on limiting the manoeuvering space before there is an attempt by the state to improve its relationship with its population? Essentially, what should the sequencing look like?

These questions raise the need for future research on this topic. The contributions of this dissertation are only the early steps of a longer process that seems to have begun by raising important questions, offering interesting and innovative ideas and analysis, and developing frameworks and tools that can be built on to further and better understand the dynamics in certain post-conflict conditions.

\section{Conclusion}

The current theories tend to associate or conflate the definition of legitimacy with that of democracy and the desires of the international community with that of the locals. This has led to many instances where the desired outcomes have not been achieved and to unintended negative consequences that can only be assessed when one pulls back and looks at the bigger picture and analyses the events from a local perspective. When one does so, one realizes that the underlying assumptions related to the existing framework are inappropriate for the local context and ignore several factors that often derail the framework. With this recognition and knowledge, it would be unhelpful to use the current theoretical framework that overlooks these fundamental issues where there are low levels of shared beliefs and limited or non-existent experiences with process legitimacy.

Performance legitimacy has been proven to be a strong player in the trajectory of post-conflict states. It has an impact on the kind of state-society relationship that develops and on the outcomes of state institution-building processes. It also has a significant impact on the relationship between leaders and the state and on the leaders' intentions and motivations vis-àvis the state's institutions. As such, the research herein has offered an alternative framework that accounts for this previously ignored or underrated variable. Equally as important, the Performance Legitimacy Theory of Transition framework allows for a more accurate reflection of the manner in which the people perceive their leaders and their ability to distinguish between the legitimacy of leaders and that of the state, even when the leaders are working within the state structure. While this further allows for a better reflection of the actual levels of legitimacy that the state and its institutions hold, it also allows one to identify towards which end of the spectrum, vicious or virtuous, the country is positioned.

Finally, the research has identified the following two main variables that have played a significant role in the trajectory of the three cases along the performance legitimacy spectrum: the type of state-society relationship and the manoeuvring space that leaders have access to. In summary, according to the results of the case studies, the stronger the state-society relationship and the more limited the leaders' manoeuvring space, the more likely that the state owns the performance legitimacy that is associated with its investment in meeting people's basic needs.

While the identification of these two variables is based only on three case studies, the research raises important questions and offers important contributions that could then be used to assess a 
larger sample of cases. Overall, perhaps, with the Performance Legitimacy Theory of Transition framework and the questions that it raises, the practice of post-conflict development can be improved to become more effective in establishing systems, including democratic systems, which are more successful and more applicable to local conditions. 


\section{Bibliography}

Abla, Zeina, Amal Karaki, and Nada Dimachkieh Sweidan. 2014. Lebanon Millennium

Development Goals Report 2013-2014. Beirut.

http://www.lb.undp.org/content/lebanon/en/home/library/mdg/lebanon-mdg-report-2013$2014 /$.

Afrique Jet. 2014. "Projet Pôle de Développement de La Casamance." Afrique Jet. http://www.afriquejet.com/afrique-ouest/3654-projet-pole-de-developpement-de-lacasamance.html.

Allen, Daniel. 2010. "New Directions in the Study of Nation-Building: Views through the Lens of Path Dependence." International Studies Review 12(3): 413-29.

Angeles, Leonora C., and Francisco A. Magno. 2004. "The Philippines: Decentralization, Local Governments, and Citizen Action." In Decentralization, Democratic Governance and Civil Society in Comparative Perspectives, eds. Philip Oxhorn and Joseph S. Tulchin.

Washington DC: Woodrow Wilson Centre Press, 211-65.

Armstrong, Andrea, and Barnett Rubin. 2005. "The Great Lakes and South Central Asia." In Making States Work: State Failure and the Crisis of Governance, eds. Simon Chesterman, Michael Ignatieff, and Ramesh Thakur. New York: United Nations University Press, 79101.

Attipoe, Olympio, Biplove Choudhary, and Nicholas Jonga. 2014. An Analysis of Government Budgets in South Sudan from a Human Development Perspective. Juba. http://www.undp.org/content/dam/southsudan/library/Discussion Papers/SS-Discussion paper final.pdf.

Atzili, Boaz. 2010. "State Weakness and 'Vacuum of Power' in Lebanon." Studies in Conflict \& Terrorism 33(8): 757-82.

http://www.tandfonline.com/doi/abs/10.1080/1057610X.2010.494172 (March 7, 2014).

Baaklini, Abdo I. 1976. Legislative and Political Development: Lebanon, 1842-1972. Durnham: Duke University Press.

Barbara, Julien. 2008. "Antipodean Statebuilding: The Regional Assistance Mission to Solomon Islands and Australian Intervention in the South Pacific.” Journal of Intervention and Statebuilding 2(2): 123-49.

Bardhan, Pranab, and Dilip Mookherjee. 2006. "The Rise of Local Governments: An Overview." In Decentralization and Local Governance in Developing Countries: A Comparative Perspective, eds. Pranab Bardhan and Dilip Mookherjee. Cambridge: MIT Press, 1-52. 
Baroudi, Sami E. 1998. "Economic Conflict in Postwar Lebanon: State-Labor Relations Between 1992 and 1997." Middle East Journal 52(4): 531-50.

Beck, Linda J. 2008. Brokering Democracy in Africa: The Rise of Clientelist Democracy in Senegal. New York: Palgrave.

Beetham, David, and Christopher Lord. 1998. Legitimacy and the EU. London: Addison-Wesley Longman.

Bellamy, Paul. 2007. "Introduction.” In Civil Wars of the World: Major Conflicts Since World War II, eds. Karl Jr Derouen and Uk Heo. Santa Barbara, California: ABC-CLIO Inc., 1-26.

Bennett, Andrew, and Colin Elman. 2006. "Qualitative Research: Recent Developments in Case Study Methods." Annual Review of Political Science 9(1): 455-76. http://www.annualreviews.org/doi/abs/10.1146/annurev.polisci.8.082103.104918 (February 21, 2014).

Blair, Harry. 2007. "Rebuilding and Reforming Civil Services in Post-Conflict Societies." In Governance in Post-Conflict Societies: Rebuilding Fragile States, ed. Derick W. Brinkerhoff. London: Routledge, 161-84.

Blomberg, S Brock, Gregory D Hess, and Siddharth Thacker. 2006. "On the Conflict Poverty Nexus." Economics and Politics 18(3): 237-67. http://www.blackwellsynergy.com/doi/abs/10.1111/j.1468-0343.2006.00170.x.

Bollen, Kenneth A. 1980. "Issues in the Comparative Measurement of Political Democracy." American Sociological Review 45(3): 370-90.

_. 1986. "Political Rights and Political Liberties in Nations: An Evaluation of Human Rights Measures, 1950 to 1984.” Human Rights Quarterly 8(4): 567-91.

_. 1990. "Political Democracy: Conceptual and Measurement Traps." Studies In Comparative International Development 25(1): 7-24.

- 2011. "Evaluating Effect, Composite, and Casual Indicators in Structural Equation Models.” MIS Quarterly 35(2): 359-72.

Bollen, Kenneth A, and Richard Lennox. 1991. "Conventional Wisdom on Measurement: A Structural Equation Perspective." Psychological Bulletin 110(2): 305-14.

Bollen, Kenneth A, and Pamela Paxton. 2000. "Subjective Measures of Liberal Democracy." Comparative Political Studies 33(1): 58-86.

Bollen, Kenneth A, and Kwok-fai Ting. 2000. "A Tetrad Test for Causal Indicators." Psychological Methods 5(1): 3-22.

Branch, Adam, and Zachariah Cherian Mampilly. 2005. "Winning the War, but Losing the 
Peace? The Dilemma of SPLM/A Civil Administration and the Tasks Ahead." The Journal of Modern African Studies 43(1): 1-20.

Brinkerhoff, Derick W. 2005. "Rebuilding Governance in Failed States and Post-Conflict Societies: Core Concepts and Cross-Cutting Themes." Public Administration and Development 25(1): 3-14.

_. 2007. "Introduction - Governance Challenges in Fragile States: Re-Establishing Legitimacy, Rebuilding Effectiveness, and Reconstituting Legitimacy.” In Governance in Post-Conflict Societies: Rebuilding Fragile States, ed. Derick W. Brinkerhoff. London: Routledge, 1-21.

Brinkerhoff, Derick W., and Ronald W. Johnson. 2009. "Decentralized Local Governance in Fragile States: Learning from Iraq." International Review of Administrative Sciences 75(4): 585-607.

Brosché, Johan. 2016. "Crisis of Governance in South Sudan : Electoral Politics and Violence in the World's Newest Nation.” Journal of Modern African Studies 54(1): 67-90.

Busumtwi-Sam, James. 2004. "Development and Peacebuilding: Conceptual and Operational Deficits in International Assistance." In Durable Peace: Challenges for Peacebuilding in Africa, eds. Taiser M. Ali and Robert O. Matthews. Toronto: University of Toronto Press, $315-53$.

Cammett, Melanie. 2013. Democracy in Post-Invasion Iraq. http://watson.brown.edu/costsofwar/files/cow/imce/papers/2013/Democracy in PostInvasion Iraq.pdf.

- 2014. Compassionate Communalism: Welfare and Sectarianism in Lebanon. Ithaca: Cornell University Press.

Caplan, Richard. 2004. "Partner or Patron? International Civil Administration and Local Capacity-Building." International Peacekeeping 11(2): 229-47.

Chassay, Clancy. 2006. "Christian Leader Says Lebanese Opposition Ready for Power." The Guardian. http://www.theguardian.com/world/2006/dec/13/syria.lebanon.

Coburn, Noah. 2011. Bazaar Politics: Power \& Pottery in an Afghan Market Town. California: Stanford University Press.

Cole, Elizabeth A., and Judy Barsalou. 2006. Unite or Divide? The Challenges of Teaching History in Societies Emerging from Violent Conflict.

Collier, Paul. 2002. Aid, Policy and Growth in Post-Conflict Countries.

Collier, Paul, and Anke Hoeffler. 1998. "On the Causes of Civil War." Oxford Handbook of the 
Economics of Peace and Conflict 50: 563-73.

—. 2004. "Greed and Grievance in Civil War." Oxford Economic Papers 56(4): 563-95.

Cook, Traci D. 2007. A Place To Call Their Own: Southern Sudanese Comment on the Hard Work Adn Struggles of Self-Governance. Washington DC.

Crow, Ralph E, and Adnan Iskandar. 1961. "Administrative Reform in Lebanon.” International Review of Administrative Sciences 27(3): 293-307.

Dahl, Robert. 1971. Polyarchy: Participation and Opposition. New Haven: Yale University Press.

Diallo, Boucounta. 2009. La Crise Casamançaise: Problématique et Voies de Solutions. Paris: L'Harmattan.

Diamond, Larry, and Marc F. Plattner. 2006. Electoral Systems and Democracy. Baltimore: The Johns Hopkins University Press.

Dibeh, Ghassan. 2005. 44 The Political Economy of Postwar Reconstruction in Lebanon. Helsinki.

Dinnen, Sinclair. 2007. "A Comment on State-Building in Solomon Islands." The Journal of Pacific History 42(2): 255-63.

- 2008. "The Solomon Islands Intervention and the Instabilities of the Post-Colonial State." Global Change, Peace \& Security 20(3): 339-55.

Dodge, Toby. 2013. "Intervention and Dreams of Exogenous Statebuilding: The Application of Liberal Peacebuilding in Afghanistan and Iraq." Review of International Studies 39(5): 1189-1212. http://journals.cambridge.org/article_S0260210513000272.

Dodge, Tony. 2011. "Domestic Politics and State-Building." In Afghanistan: To 2015 and beyond, eds. Toby Dodge and Nicholas Redman. International Institute for Strategic Studies, 69-96.

Doyle, Michael W., and Nicholas Sambanis. 2000. "International Peacebuilding: A Theoretical and Quantitative Analysis.” American Political Science Review 94(4): 779-801. http://www.drworley.org/NSPcommon/Nation Building/2000,12 APSR Doyle Sambanis.pdf.

-2006. Making War and Building Peace. New Jersey: Princeton University Press.

Ducci, María Elena. 2004. "Local Governance and Democracy: The View from the Chilean Border." In Decentralization, Democratic Governance and Civil Society in Comparative Perspectives, eds. Philip Oxhorn, Joseph S. Tulchin, and Andrew D. Selee. Washington DC: Woodrow Wilson Centre Press, 119-39. 
Eaton, Kent, and Larry Schroeder. 2010. "Measuring Decentralization.” In Making Decentralization Work: Democracy, Development, and Security, eds. Ed Connerley, Kent Eaton, and Paul Smoke. Colorado: Lynne Rienner Publishers, 167-90.

Von Einsiedel, Sebastian. 2005. "Policy Responses to State Failure." In Making States Work: State Failure and the Crisis of Governance, eds. Simon Chesterman, Michael Ignatieff, and Ramesh Thakur. New York: United Nations University Press, 13-35.

El-Khazen, Farid. 1998. "Les Alliances et Les Conflits Entre Les Parties Politiques Au Liban." In Parties et Forces Politiques Au Liban: Renouveau et Enagagement, ed. Antoine Messarra. Beirut: Fondation Konrad Adenauer, 133-42.

— 2000. The Breakdown of the State in Lebanon: 1967-1976. Cambridge: Harvard University Press.

El-Mufti, Karim. 2011. Public Policy Initiative The Management of Public Interest in Lebanon, a Broken Concept. Beirut. http://policylebanon.org/topmenu/policyareas/areas/Ressource.html?Id=79\#.

El-Solh, Raghid. 994. "Religious Identity and Citizenship: An Overview of Perspectives." In Peace for Lebanon? From War to Reconstruction1, ed. Deidre Collings. Boulder: Lynne Rienner Publishers, 231-40.

El-Zein, Fares, and Holly Sims. 2004. "Reforming War's Administrative Rubble in Lebanon." Public Administration and Development 24: 279-88.

Englebert, Pierre. 2000. State Legitimacy and Development in Africa. Colorado: Lynne Rienner Publishers.

Eriksen, Erik O., and John E. Fossum. 2004. "Europe in Search of Legitimacy: Strategies of Legitimation Assessed." International Political Science Review 25(4): 435-59.

Evans, Martin. 2005. "Insecurity or Isolation? Natural Resources and Livelihoods in Lower Casamance." Canadian Journal of African Studies 39(2): 284-314.

Evans, Peter B. 1989. "Predatory, Developmental, and Other Apparatuses : A Comparative Political Economy Perspective on the Third World State." Sociological Forum: Special Issue: Comparative National Development: Theory and Facts for the 1990s 4(4): 561-87.

Fall, Aissatou. 2010. Understanding The Casamance Conflict: A Background. Accra. http://www.kaiptc.org/publications/monographs/monographs/monograph-7-aissatou.aspx.

Fawaz, Mona, and Isabelle Peillen. 2003. The Case of Beirut, Lebanon. Beirut. http://www.ucl.ac.uk/dpu-projects/Global_Report/cities/beirut.htm.

Fearon, James D. 2004. “Why Do Some Civil Wars Last So Much Longer than Others?” Journal 
of Peace Research 41(3): 275-301.

Foucher, Vincent. 2005. "La Guerre Des Dieux ? Religions et Séparatisme En Basse Casamance." Canadian Journal of African Studies 39(2): 363-90.

Frahm, Ole. 2015. "Making Borders and Identities in South Sudan." Journal of Contemporary African Studies 33(2): 251-67.

http://www.tandfonline.com/doi/full/10.1080/02589001.2015.1070461.

François, Monika, and Inder Sud. 2006. "Promoting Stability and Development in Fragile and Failed States." Development Policy Review 24(2): 141-60.

Fraser, John. 1974. "Validating a Measure of National Political Legitimacy." American Journal of Political Science 18(1): 117-34.

Fukuyama, Francis. 2006. America at the Crossroads: Democracy, Power, and the Neoconservative Legacy. Connecticut: Yale University Press.

Gamble, David P. 1957. The Wolof of Senegambia. London: International African Institute.

Gaspard, Toufic K. 2004. A Political Economy of Lebanon, 1948-2002: The Limits of LaissezFaire. Leiden: Brill.

Geddes, Barbara. 1990. "How the Cases You Choose Affect the Answers You Get: Selection Bias in Comparative Politics." Political Analysis 2(1): 131-50.

Gehrold, Stefan, and Inga Neu. 2010. Caught Between Two Fronts: In Search of Lasting Peace in the Casamance Region. Berlin.

Gellar, Sheldon. 1995. Senegal: An Africam Nation between Islam and the West. Second edi. Boulder: Westview Press.

- 2005. Democracy in Senegal: Tocquevillian Analytics in Africa. New York: Palgrave.

Gemayel, Amine. 1992. Rebuilding Lebanon. Lanham: University Press of America.

Gerry, John. 2007. Case Study Research: Principles and Practices. New York: Cambridge University Press.

Ghani, Ashraf, and Clare Lockhart. 2008. Fixing Failed States: A Framework for Rebuilding a Fractured World. New York: Oxford University Press.

Ghosn, Faten, and Amal Khoury. 2011. "Lebanon after the Civil War: Peace or the Illusion of Peace?” Middle East Journal 65(3): 381-97.

Ghossain, Antoine. 1988. "Confessional Communities, Space and Political Reform in Lebanon." Social Compass 1 35(4): 563-83.

Gilley, Bruce. 2006a. "The Determinants of State Legitimacy: Results for 72 Countries." 
International Political Science Review 27(1): 47-71.

. 2006b. "The Meaning and Measure of State Legitimacy: Results for 72 Countries." European Journal of Political Research 45(3): 499-525.

_ 2012. "State Legitimacy: An Updated Dataset for 52 Countries." European Journal of Political Research 51(5): 693-99. http://doi.wiley.com/10.1111/j.1475-

6765.2012.02059.x\%5Cnhttps://sremote.pitt.edu/doi/10.1111/j.1475-

6765.2012.02059.x/,DanaInfo=onlinelibrary.wiley.com+pdf (January 26, 2014).

Mac Ginty, Roger. 2010. "Warlords and the Liberal Peace: State-Building in Afghanistan." Conflict, Security \& Development 10(4): 577-98.

Gleditsch, Nils Petter. 1996. "Environmental Change, Security, and Conflict." In Turbulent Peace: The Challenges of Managing International Conflict1, eds. Chester A. Crocker, Osler Hampson, and Pamela Aall. Washington DC: United States Institute of Peace, 53-68.

Goldsmith, Arthur A. 2007. "Does Nation-Building Work? Reviewing the Record." In Governance in Post-Conflict Societies: Rebuilding Fragile States, London: Routledge, 2544.

Goodhand, Jonathan. 2006. Aiding Peace: The Role of NGOs in Armed Conflict. Colorado: Lynne Rienner Publishers.

Grawert, Elke. 2013. "Introduction.” In Forging Two Nations: Insights on Sudan and South Sudan, ed. Elke Grawert. Addis Ababa: Organisation for Social Science Research in Eastern and Southern Africa, 15-51.

Grzymala-Busse, Anna. 2008. "Beyond Clientelism: Incumbent State Capture and State Formation." Comparative Political Studies 41(4/5): 638-73.

Grzymala-Busse, Anna, and Pauline Jones Luong. 2002. "Reconceptualizing the State: Lessons from Post-Communism." Politics \& Society 30(4): 529-54.

Gurowitz, Amy. 1999. "Mobilizing International Norms: Domestic Actors, Immigrants, and the Japanese State." World Politics 51(3): 413-45. http://www.journals.cambridge.org/abstract_S0043887100009138.

Haddad, Simon. 2009. "Lebanon: From Consociationalism to Conciliation." Nationalism and Ethnic Politics 15(3-4): 398-416. http://www.tandfonline.com/doi/abs/10.1080/13537110903346684 (March 4, 2014).

Hajjar, Sami G. 2009. "The Convoluted and Diminished Lebanese Democracy." Democracy and Security 5(3): 261-76. http://www.tandfonline.com/doi/abs/10.1080/17419160903304864 (March 10, 2014). 
Hakim, Georges. 1966. "The Economic Basis of Lebanese Polity.” In Politics in Lebanon, ed. Leonard Binder. New York: John Wiley \& Sons, Inc, 57-69.

Haldén, Peter. 2010. "Systems-Building Before State-Building: On the Systemic Preconditions of State-Building." Conflict, Security \& Development 10(4): 519-45. http://www.tandfonline.com/doi/abs/10.1080/14678802.2010.500540.

Hameiri, Shahar. 2009. “Capacity and Its Fallacies: International State Building as State Transformation.” Millennium - Journal of International Studies 38(1): 55-81.

Hamzeh, A Nizar. 2000. “Lebanon's Islamists and Local Politics: A New Reality.” Third World Quarterly 21(5): 739-59.

Harb, Boutros. 1998. “Le Relancement D’une Vie Politique.” In Parties et Forces Politiques Au Liban: Renouveau et Enagagement, ed. Antoine Messarra. Beirut: Fondation Konrad Adenauer, 53-56.

Harb, Mona, and Reinoud Leenders. 2005. 'Know Thy Enemy: Hizbullah, 'terrorism' and the Politics of Perception." Third World Quarterly 26(1): 173-97.

Harik, Judith. 1996. "Between Islam and the System: Sources and Implications of Popular Support for Lebanon's Hizballah.” Journal of Conflict Resolution 40(1): 41-67.

Hartzell, Caroline A. 2006. "Structuring the Peace: Negotiated Settlements and the Construction of Conflict Management Institutions." In Conflict Prevention and Peacebuilding in PostWar Societies: Sustaining the Peace, eds. T. David Mason and James D. Meernik. Oxon: Routledge, 31-52.

Hartzell, Caroline, Matthew Hoddie, and Donald Rothchild. 2001. "Stabilizing the Peace After Civil War: An Investigation of Some Key Variables.” International Organization 55(1): 183-208.

Hess, Steve. 2010. "Coming to Terms with Neopatrimonialism: Soviet and American NationBuilding Projects in Afghanistan." Central Asian Survey 29(2): 171-87.

Hottinger, Arnold. 1966. “Zu'ama' in Historical Perspective.” In Politics in Lebanon, ed. Leonard Binder. New York: John Wiley \& Sons, Inc, 85-106.

Hudson, Michael C. 1999. "Lebanon after Ta'if: Another Reform Opportunity Lost.” Arab Studies Quarterly 21(1): 27-40.

Hutchison, M. L., and K. Johnson. 2011. "Capacity to Trust? Institutional Capacity, Conflict, and Political Trust in Africa, 2000-2005.” Journal of Peace Research 48(6): 737-52. http://jpr.sagepub.com/cgi/doi/10.1177/0022343311417981 (March 10, 2014).

Inbal, Aliza B., and Hanna Lerner. 2007. "Constitutional Design, Identity and Legitimacy in 
Post-Conflict Reconstruction.” In Governance in Post-Conflict Societies: Rebuilding

Fragile States, ed. Derick W. Brinkerhoff. London: Routledge, 45-63.

International Crisis Group. 2006. Israel/Hizbollah/Lebanon: Avoiding Renewed Conflict.

International Monetary Fund. 2006. Lebanon: Selected Issue. Washington DC.

http://www.imf.org/external/pubs/ft/scr/2006/cr06200.pdf.

Iskandar, Adnan. 1964. Bureaucracy in Lebanon. Beirut: American University of Beirut.

- 1996. Public Service Accountability in Lebanon. Beirut.

http://ddc.aub.edu.lb/projects/pspa/PSAccount/PSAccount-0.html.

Jackman, Robert W. 1987. "Political Institutions and Voter Turnout in the Industrial

Democracies." The American Political Science Review 81(2): 405-24.

Jad, Sana Souaid. 2011. The Balance Sheet Approach and the Public Debt Stock Analysis: The Case of Lebanon. Beirut. http://www.bdl.gov.lb/.

Jawad, Rana. 2002. "A Profile of Social Welfare in Lebanon: Assessing the Implications for Social Development Policy." Global Social Policy 2(3): 319-42.

Jok, Madut Jok. 2011. Diversity, Unity, and Nation Building in South Sudan. Washington DC. http://www.usip.org/sites/default/files/Diversity\%2C Unity\%2C and Nation Building in South Sudan \%28Jok\%29.pdf.

Jong, Ferdinand De. 2005a. “A Joking Nation : Conflict Resolution in Senegal.” Canadian Journal of African Studies 39(2): 391-415.

- 2005b. "Contested Casamance : Introduction." Canadian Journal of African Studies 39(2): 213-29.

Von Kaltenborn-Stachau, Henriette. 2008. The Missing Link-Fostering Positive Citizen-State Relations in Post-Conflict Environments. Washington DC.

http://siteresources.worldbank.org/EXTGOVACC/Resources/CommGAPMissingLinkWeb. pdf.

Kameir, El Wathig. 2011. The Political Economy of South Sudan: A Scoping Analytical Study. Abidjan.

Kanaan, Nimat, and Randa Aboul-Hosn. 1998. "Mapping of Living Conditions in Lebanon." Mapping of Living Conditions in Lebanon (UNDP).

http://www.undp.org.lb/programme/propoor/poverty/povertyinlebanon/molc/setting/A/1975.htm\# (November 2, 2015).

Kanol, Direnç. 2011. "Assessing the Legitimacy of the EU." Interdisciplinary Political Studies 1(0): 49-59. 
Kaplan, Seth. 2008. "The Remarkable Story of Somaliland.” Journal of Democracy 19(3): 14357.

Kaufmann, Daniel, Aart Kraay, and Massimo Mastruzzi. 2010. The Worldwide Governance Indicators Methodology and Analytical Issues. Washington DC.

Keefer, Philip E., Ambar Narayan, and Tara Vishwanath. 2006. "Decentralization in Pakistan: Are Local Governments Likely to Be More Accountable than Central Governments?" In Decentralization and Local Governance in Developing Countries: A Comparative Perspective, eds. Pranab Bardhan and Dilip Mookherjee. Cambridge: MIT Press, 285-304.

Kerr, Malcolm H. 1966. "Political Decision Making in a Confessional Democracy." In Politics in Lebanon, ed. Leonard Binder. New York: John Wiley \& Sons, Inc, 167-86.

Khadiagala, Gilbert M. 1995. "State Collapse and Reconstruction in Uganda." In Collapsed States: The Disintegration and Reconstruction of Legitimate Authority, ed. I. William Zartman. Colorado: Lynne Rienner Publishers, 33-47.

Kingston, Paul, and Marie-Joëlle Zahar. 2004. "Rebuilding A House of Many Mansions: The Rise and Fall of Militia Cantons in Lebanon.” In States Within States, eds. Paul Kingston and Ian S. Speaars. New York: Palgrave, 81-98.

Kisirwani, M., and W. M. Parle. 1987. "Assessing the Impact of the Post Civil War Period on the Lebanese Bureaucracy: A View from Inside." Journal of Asian and African Studies 22(12): 17-29. http://jas.sagepub.com/cgi/doi/10.1177/002190968702200102.

Kisirwani, Maroun. 1997a. "Accountability of Lebanese Civil Servants: An Overview of Disciplinary Mechanisms." In Lebanon Beyond 2000, eds. Amin Saikal and Geoffrey Jukes. Canberra: Centre for Middle Eastern and Central Asian Studies. . 1997b. "The Rehabilitation and Reconstruction of Lebanon." In Remaking the Middle East, eds. Paul J White and William S Logan. Oxford: Berg, 87-104.

Kisirwani, Maroun, and William M. Parle. 1987. "Assessing the Impact of the Post Civil War Period on the Lebanese Bureaucracy: A View from Inside." Journal of Asian and African Studies 22(1-2): 17-29.

Kitschelt, Herbert, and Steven I. Wilkinson. 2007. "Citizen-Politician Linkages: An Introduction." In Patrons, Clients, and Policies: Patterns of Democratic Accountability and Political Competition, eds. Herbert Kitschelt and Steven I. Wilkinson. Cambridge: Cambridge University Press, 1-49.

Kon, Madut. 2015. "Institutional Development, Governance, and Ethnic Politics in South Sudan." Journal of Global Economics 3(2): 1-6. http://www.esciencecentral.org/journals/institutional-development-governance-and-ethnic- 
politics-in-south-sudan-2375-4389-1000147.php?aid=57097.

Larson, Greg, Peter Biar Ajak, and Lant Pritchett. 2013. South Sudan's Capability Trap:

Building a State with Disruptive Innovation. Cambridge. https://www.hks.harvard.edu/content/download/69085/1249150/version/1/file/268_SudanPDIA.pdf.

Leenders, Reinoud. 2012. Spoils of Truth: Corruption and State-Building in Postwar Lebanon. Ithaca: Cornell University Press.

LeRiche, Matthew, and Matthew Arnold. 2012. South Sudan: From Revolution to Independence. London: C. Hurst \& Co (Publishers) Ltd.

Levi, Margaret, and Audrey Sacks. 2009. "Legitimating Beliefs: Sources and Indicators.” Regulation \& Governance 3(4): 311-33.

Levi, Margaret, Audrey Sacks, and Tom Tyler. 2009. "Conceptualizing Legitimacy, Measuring Legitimating Beliefs.” American Behavioral Scientist 53(3): 354-75.

Lipset, Seymour Martin. 1983. Political Man: The Social Bases of Politics. London: Heinemann.

Lister, Sarah, and Andrew Wilder. 2005. "Strengthening Subnational Administration in Afghanistan: Technical Reform or State-Building?" Public Administration and Development 25(1): 39-48.

Loehlin, John C. 1998. Latent Variable Models: An Introduction to Factor, Path, and Structural Analysis. Third. New Jersey: Lawrence Erlbaum Associates.

Low-beer, Ann. 2001. Paradigm Politics, School Textbooks and Cultural Identity: The Struggle in Bosnia and Hercegovina.

Lyons, Terrence. 2005. Demilitarizing Politics: Elections on the Uncertain Road to Peace. Colorado: Lynne Rienner Publishers.

Mane, Bacary Domingo. 2014. "POLE DE DEVELOPPEMENT DE LA CASAMANCE.” Sud Online. http://www.sudonline.sn/au-dela-des-questions-economique-etadministrative_a_17983.html.

March, James G., and Johan P. Olsen. 1989. Institutions: The Organizational Basis of Politics. New York: The Free Press.

Marquette, Heather, and Danielle Beswick. 2011. "State Building, Security and Development: State Building as a New Development Paradigm?" Third World Quarterly 32(10): 1703-14.

Marshall, Monty G, and Keith Jaggers. 2002. Political Regime Characteristics and Transitions, 1800-2002: Dataset User's Manual. Maryland. 
Marut, Jean-Claude. 2010. Le Conflit de Casamance: Ce Qui Disent Les Armes. Paris: Édition Karthala.

Mason, David T., Mehmet Gurses, Patrick T. Brandt, and Jason Michael Quinn. 2011. "When Civil Wars Recur: Conditions for Durable Peace after Civil Wars." International Studies Perspectives 12(2): 171-89.

Maxwell, Daniel, Kirsten Gelsdorf, and Martina Santschi. 2012. Researching Livelihoods and Services Affected by Conflict Livelihoods, Basic Services and Social Protection in South Sudan. London. http://community.eldis.org/.5a0b0243/Livelihoods basic services and social protection in Sri Lanka.pdf.

Mayall, James. 2005. "The Legacy of Colonialism.” In Making States Work: State Failure and the Crisis of Governance, eds. Simon Chesterman, Michael Ignatieff, and Ramesh Thakur. New York: United Nations University Press, 36-58.

Mcloughlin, Claire. 2014. "When Does Service Delivery Improve the Legitimacy of a Fragile or Conflict-Affected State?" Governance: n/a-n/a. http://doi.wiley.com/10.1111/gove.12091 (May 2, 2014).

von der Mehden, Fred R., and Kim Quaile Hill. 1980. “Area Experts' Images of African Nations." Comparative Political Studies 12(4): 497-510.

Meierhenrich, Jens. 2004. "Forming States After Failure.” In When States Fail: Causes and Consequences, ed. Rot. Princeton: Princeton University Press, 153-68.

Mendy, Toumany. 2006. Politique et Puissance de L'argent Au Sénégal: Les Désarrois D'un Peuple Innocent. Paris: L'Harmattan.

Messarra, Antoine. 1998. "L'expérience Libanais Du Parti Dans Le Cadre Arabe." In Partis et Forces Politiques Au Liban: Renouveau et Engagement, ed. Antoine Messarra. Beirut: Fondation Konrad Adenauer, 15-40.

Migdal, Joel S. 2001. State in Society: Studying How States and Societies Transform and Constitute One Another. Cambridge: Cambridge University Press.

Miller, Benjamin. 2015. "Stateness, National Self-Determination and War and Peace in the Twenty-First Century." Ethnopolitics 14(5): 531-39. http://www.tandfonline.com/doi/full/10.1080/17449057.2015.1051818.

Ministry of Foreign Affairs Denmark. 2005. A Joint Evaluation: Humanitarian and Reconstruction Assistance to Afghanistan, 2001-05: From Denmark, Ireland, The Netherlands, Sweden and the United Kingdom.

Ministry of Social Affairs, and United Nations Development Programme. 2007. The effects of brief mindfulness intervention on acute pain experience: An examination of individual 
difference Development of Mapping of Living Conditions in Lebanon, 1995-2004: A Comparison with the Results of "Mapping of Living Conditions in Lebanon, 1998." Beirut.

Mitchell, Timothy. 1991. "The Limits of the State: Beyond Statist Approaches and Their Critics.” The American Political Science Review 85(1): 77-96.

Mukhopadhyay, Dipali. 2009. "Disguised Warlordism and Combatanthood in Balkh: The Persistence of Informal Power in the Formal Afghan State." Conflict, Security \& Development 9(4): 535-64.

Muller, Edward N., Thomas O. Jukam, and Mitchell A. Seligson. 1982. "Diffuse Political Support and Antisystem Political Behavior : A Comparative Analysis." American Journal of Political Science 26(2): 240-64.

Najem, Tom Pierre. 2000. Lebanon's Renaissance: The Political Economy of Reconstruction. Reading: Ithaca Press.

Nassif, Georges. 1998. "Les Parties Libanaises En Crise: Comment Transforment-Elles Politiquement." In Parties et Forces Politiques Au Liban: Renouveau et Enagagement, ed. Antoine Messarra. Beirut: Fondation Konrad Adenauer, 123-29.

Ndegwa, Stephen N, and Brian Levy. 2003. The Politics of Decentralization in Africa: A Comparative Analysis. Washington DC.

http://www1.worldbank.org/publicsector/LearningProgram/Decentralization/Ndegwa.pdf.

Netemeyer, Richard G., William O. Bearden, and Subhash Sharma. 2003. Scaling Procedures: Issues and Applications. California: Sage Publications, Inc.

Nettl, J.P. 1968. “The State as a Conceptual Variable.” World Politics 20(4): 559-92.

News, BBC. 2009. "Senegal Apology for Christ â€ $€^{\mathrm{TM}}$ Slur '." BBC News. http://news.bbc.co.uk/go/pr/fr/-/2/hi/africa/8435805.stm.

Norton, Augustus Richard. 2000. "Hizballah and the Israeli Withdrawal from Southern Lebanon." Journal of Palestine Studies 30(1): 22-35.

O Senegal. 2014. "Une Autoroute Maritime Se Développe Entre Dakar et La Casamance." $O$ Senegal. http://www.osenegal.com/news/transport/autoroute-maritime-se-developpe-dakarcasamance/.

OECD. 2010. The State's Legitimacy in Fragile Situations: Unpacking Complexity. http://www.oecd.org/dac/incaf/44794487.pdf.

Ottaway, Marina. 1995. "Democratization in Collapsed States." In Collapsed States: The Disintegration and Restoration of Legitimate Authority, ed. I. William Zartman. Colorado: Lynne Rienner Publishers, 235-50. 
Oxhorn, Philip. 2004. "Unraveling the Puzzle of Decentralization." In Decentralization, Democratic Governance and Civil Society in Comparative Perspectives, eds. Philip Oxhorn, Joseph S. Tulchin, and Andrew D. Selee. Washington DC: Woodrow Wilson Centre Press, 3-32.

Ozer, Daniel J. 1999. "Four Principles for Personality Assessment." In Handbook of Personality: Theory and Research, eds. Lawrence A. Pervin and Oliver P. John. New York: Guilford.

Paris, Roland. 2005. "Wilson's Ghost: The Faulty Assumptions of Postconflict Peacebuilding." In Turbulent Peace: The Challenges of Managing International Conflict, eds. Chester A. Crocker, Fen Osler Hampson, and Pamela Aall. Washington DC: United States Institute of Peace, $765-84$.

—. 2006. "NATO's Choice in Afghanistan: Go Big or Go Home." Policy Options: 35-43.

Picard, Elizabeth. 1993. The Lebanese Shi'a and Political Violence. Geneva.

Pierson, Paul. 2004. Politics in Time: History, Institutions, and Social Analysis. Princeton: Princeton University Press.

Posner, Daniel. 2004. "Civil Society and the Reconstruction of Failed States." In When States Fail: Causes and Consequences, ed. Robert Rotberg. Princeton: Princeton University Press, $237-55$.

Radon, Jenik, and Sarah Logan. 2014. "South Sudan: Governance Arrangements, War, and Peace." Journal of International Affairs 68(1): 149-67. http://search.ebscohost.com/login.aspx?direct=true \&db=buh\&AN=100052751\&site=ehostlive.

Regan, Patrick M. 2002. "Third-Party Interventions and the Duration of Intrastate Conflicts." The Journal of Conflict Resolution 46(1): 55-73.

Riak, Maker M. 2013. "Reversing the Trend of Corruption in South Sudan: Is Rwanda a Suitable Model?" Journal of Developing Societies 29(4): 487-501. http://jds.sagepub.com/cgi/doi/10.1177/0169796X13504681.

Rotberg, Robert I. 2004. "When States Fail: Causes and Consequences." In When States Fail: Causes and Consequences, ed. Robert I. Rotberg. New Jersey: Princeton University Press, $1-49$.

Saidi, Nasser H. 1994. "The Economic Reconstruction of Lebanon: War, Peace, and Modernization." In Peace for Lebanon? From War to Reconstruction, ed. Deirdre Collings. Boulder: Lynne Rienner Publishers, 195-212.

Salamy, Imad. 2014. The Government and Politics of Lebanon. Oxon: Routledge. 
Saleh, Ali Salman, and Charles Harvie. 2005. "An Analysis of Public Sector Deficits and Debt in Lebanon: 1970-2000.” Middle East Review of International Affairs 9(4): 106-36.

Salem, Elie Adib. 1973. Modernization without Revolution: Lebanon's Experience. London: Indiana University Press.

Salloukh, Bassel F. 2006. "The Limits of Electoral Engineering in Divided Societies: Elections in Postwar Lebanon." Canadian Journal of Political Science 39(3): 635-55.

Salloukh, Bassel F., Rabie Barakat, and Jinan S. Al-Habbal. 2015. Politics of Sectarianism in Postwar Lebanon. London: Pluto Press.

Sambanis, Nicholas. 2001. "Do Ethnic and Nonethnic Civil Wars Have the Same Causes ?: A Theoretical and Empirical Inquiry (Part 1)." The Journal of Conflict Resolution 45(3): 25982.

Saouli, Adham. 2003. "Lebanon's Hizbullah: The Quest for Survival." World Affairs 166(2): 7180.

Al Sayegh, Daoud. 1998. "Organisations Sectaires et Les Forces Politiques: La Recherche Des Limites." In Parties et Forces Politiques Au Liban: Renouveau et Enagagement, ed. Antoine Messarra. Beirut: Fondation Konrad Adenauer, 167-72.

Schaffer, Frederic C. 2000. Democracy in Translation: Understanding Politics in an Unfamiliar Culture. Ithaca: Cornell University Press.

Scharpf, Fritz W. 2003. Problem Solving Effectiveness and Democratic Accountability in the EU.

Schenker, David. 2007. Lebanon Goes to Paris III: High Stakes in France and Beirut. Washington DC. http://www.washingtoninstitute.org/policy-analysis/view/lebanon-goes-toparis-iii-high-stakes-in-france-and-beirut.

Sedgwick, Mark. 2010. "Measuring Egyptian Regime Legitimacy.” Middle East Critique 19(3): 251-67. http://www.tandfonline.com/doi/abs/10.1080/19436149.2010.514474 (March 10, 2014).

Selee, Andrew D., and Joseph S. Tulchin. 2004. "Decentralization and Democratic Governance: Lessons and Challenges." In Decentralization, Democratic Governance and Civil Society in Comparative Perspectives, eds. Philip Oxhorn, Joseph S. Tulchin, and Andrew D. Selee. London: Woodrow Wilson Centre Press, 295-320.

Shapiro, Ian. 2001. "Problems, Methods, and Theories in the Study of Politics, or What's Wrong with Political Science and What to Do about It." Political Theory 30(4): 596-619.

Sharan, Timor. 2011. "The Dynamics of Elite Networks and Patron-Client Relations in Afghanistan.” Europe-Asia Studies 63(6): 1109-27. 
Siegle, Joseph, and Patrick O’Mahony. 2010. "Decentralization and Internal Conflict." In Making Decentralization Work: Democracy, Development, and Security, eds. Ed Connerley, Kent Eaton, and Paul Smoke. Colorado: Lynne Rienner Publishers, 135-66.

De Simone, Sara. 2015. "Building a Fragmented State: Land Governance and Conflict in South Sudan." Journal of Peacebuilding and Development 10(3): 60-73. http://dx.doi.org/10.1080/15423166.2015.1085812.

Sisk, Timothy. 2013. Statebuilding: Consolidating Peace After Conflict. London: Polity Press.

Skocpol, Theda. 1979. States \& Social Revolutions: A Comparative Analysis of France, Russia, \& China. Cambridge: Cambridge University Press.

Sobek, David. 2010. "Masters of Their Domains: The Role of State Capacity in Civil Wars." Journal of Peace Research 47(3): 267-71.

Le Soleil. 2012. "Benoit Sambou Annonce Un Projet de 350 Millions : Les Zones Post-Conflit Vont Relancer L'agriculture En Casamance." Le Soleil. http://www.lesoleil.sn/index.php?option=com_content\&view=article\&id=16706:benoitsambou-annonce-un-projet-de-350-millions-les-zones-post-conflit-vont-relancerlagriculture-en-casamance \&catid=78:a-la-une.

South Sudan Bureau for Community Security and Small Arms Control, South Sudan Peace and Reconciliation Commission, and United Nations Development Programme. 2012. Community Consultation Report: Warrap State, South Sudan. Juba. http://www.undp.org/content/dam/southsudan/library/Documents/CSAC Reports/UNDPSS-Warrap-consult-12.pdf.

South Sudan National Bureau of Statistics. 2011. South Sudan Statistical Yearbook 2011. Juba. http://static1.1.sqspcdn.com/static/f/750842/18935415/1349357346780/South+Sudan+Statis tical+Yearbook+2011+FINAL.pdf?token=xcrh+XTeo9vWw3HAwjYs5YtHA48=.

Starr, S. Frederick. 2006. "Sovereignty and Legitimacy in Afghan Nation-Building." In NationBuilding: Beyond Afghanistan and Iraq, ed. Francis Fukuyama. Baltimore: The Johns Hopkins University Press, 107-24.

Streeck, Wolfgang, and Kathleen Thelen. 2005. "Introduction: Institutional Change in Advanced Political Economies." In Beyond Continuity: Institutional Change in Advanced Economies, eds. Wolfgang Streeck and Kathleen Thelen. Oxford: Oxford University Press, 1-39.

Suchman, Mark C. 1995. "Managing Legitimacy: Strategic and Institutional Approaches." The Academy of Management Review 20(3): 571-610.

The World Bank. 2005. "Senegal Receives 20 Million for Emergency Recovery Project in Casamance." World Bank. 
http://web.worldbank.org/external/default/main?pagePK=64027221\&piPK=64027220\&the SitePK=296303\&menuPK=296336\&Projectid=P069207.

Thies, Cameron G. 2010. "Of Rulers, Rebels, and Revenue: State Capacity, Civil War Onset, and Primary Commodities." Journal of Peace Research 47(3): 321-32.

Traboulsi, Fawwaz. 2007. A History of Modern Lebanon. London: Pluto Press.

Treier, Shawn, and Simon Jackman. 2008. "Democracy as a Latent Variable.” American Journal of Political Science 52(1): 201-17.

Van der Vossen, Bas. 2012. "The Asymmetry of Legitimacy." Law and Philosophy 31(5): 56592.

de Waal, Alex. 2014. "When Kleptocracy Becomes Insolvent: Brute Causes of the Civil War in South Sudan." African Affairs 113(452): 347-69.

Walter, Barbara F. 2004. "Does Conflict Beget Conflict? Explaining Recurring Civil War." Journal of Peace Research 41(3): 371-88.

Washburne, Sarah Lykes. 2013. "Post-War Governance and the Impact of International Aid in South Sudan.” In Forging Two Nations: Insights on Sudan and South Sudan, ed. Elke Grawert. Addis Ababa: Organisation for Social Science Research in Eastern and Southern Africa, 188-200.

Wassara, Samson S. 2015. "South Sudan: State Sovereignty Challenged at Infancy." Journal of Eastern African Studies 9(4): 634-39. http://www.tandfonline.com/doi/full/10.1080/17531055.2015.1105439.

Weil, Frederick D. 1989. "The Sources and Structures of Legitimation in Western Democracies: A Consolidated Model Tested with Time-Series Data in Six Countries since World War II." American Sociological Review 54(5): 682-706.

Widner, Jennifer A. 2004. "Building Effective Trust in the Aftermath of Severe Conflict." In When States Fail: Causes and Consequences, ed. Robert Rotberg. Princeton: Princeton University Press, 222-36.

Wood, Elisabeth Jean. 2008. "The Social Processes of Civil War: The Wartime Transformation of Social Networks." Annual Review of Political Science 11(1): 539-61. http://www.annualreviews.org/doi/abs/10.1146/annurev.polisci.8.082103.104832.

Young, John. 2006. The South Sudan Defence Forces in the Wake of the Juba Declaration. Geneva. http://www.smallarmssurveysudan.org/fileadmin/docs/working-papers/HSBA-WP01-SSDF.pdf.

Zambakari, Christopher. 2013. "Post-Referendum South Sudan: Political Drivers of Violence 
and the Challenge of Democratic Nation-Building." In Forging Two Nations: Insights on Sudan and South Sudan, ed. Elke Grawert. Addis Ababa: Organisation for Social Science Research in Eastern and Southern Africa, 98-111.

Zanotti, L. 2008. "Imagining Democracy, Building Unsustainable Institutions: The UN Peacekeeping Operation in Haiti." Security Dialogue 39(5): 539-61.

El Zein, Fares. 2003. Dissertation Thesis "Politics of Administrative Reform in Post War Lebanon." University at Albany.

Zürcher, Christoph et al. 2013. Costly Democracy: Peacebuilding \& Democratization After War. Stanford, California: Stanford University Press.

Abla, Zeina, Amal Karaki, and Nada Dimachkieh Sweidan. 2014. Lebanon Millennium Development Goals Report 2013-2014. Beirut. http://www.lb.undp.org/content/lebanon/en/home/library/mdg/lebanon-mdg-report-2013$2014 /$.

Afrique Jet. 2014. "Projet Pôle de Développement de La Casamance." Afrique Jet. http://www.afriquejet.com/afrique-ouest/3654-projet-pole-de-developpement-de-lacasamance.html.

Allen, Daniel. 2010. "New Directions in the Study of Nation-Building: Views through the Lens of Path Dependence." International Studies Review 12(3): 413-29.

Angeles, Leonora C., and Francisco A. Magno. 2004. "The Philippines: Decentralization, Local Governments, and Citizen Action." In Decentralization, Democratic Governance and Civil Society in Comparative Perspectives, eds. Philip Oxhorn and Joseph S. Tulchin. Washington DC: Woodrow Wilson Centre Press, 211-65.

Armstrong, Andrea, and Barnett Rubin. 2005. "The Great Lakes and South Central Asia." In Making States Work: State Failure and the Crisis of Governance, eds. Simon Chesterman, Michael Ignatieff, and Ramesh Thakur. New York: United Nations University Press, 79101.

Attipoe, Olympio, Biplove Choudhary, and Nicholas Jonga. 2014. An Analysis of Government Budgets in South Sudan from a Human Development Perspective. Juba. http://www.undp.org/content/dam/southsudan/library/Discussion Papers/SS-Discussion paper final.pdf.

Atzili, Boaz. 2010. "State Weakness and 'Vacuum of Power' in Lebanon." Studies in Conflict \& Terrorism 33(8): 757-82.

http://www.tandfonline.com/doi/abs/10.1080/1057610X.2010.494172 (March 7, 2014). 
Baaklini, Abdo I. 1976. Legislative and Political Development: Lebanon, 1842-1972. Durnham: Duke University Press.

Barbara, Julien. 2008. "Antipodean Statebuilding: The Regional Assistance Mission to Solomon Islands and Australian Intervention in the South Pacific." Journal of Intervention and Statebuilding 2(2): 123-49.

Bardhan, Pranab, and Dilip Mookherjee. 2006. "The Rise of Local Governments: An Overview." In Decentralization and Local Governance in Developing Countries: A Comparative Perspective, eds. Pranab Bardhan and Dilip Mookherjee. Cambridge: MIT Press, 1-52.

Baroudi, Sami E. 1998. "Economic Conflict in Postwar Lebanon: State-Labor Relations Between 1992 and 1997." Middle East Journal 52(4): 531-50.

Beck, Linda J. 2008. Brokering Democracy in Africa: The Rise of Clientelist Democracy in Senegal. New York: Palgrave.

Beetham, David, and Christopher Lord. 1998. Legitimacy and the EU. London: Addison-Wesley Longman.

Bellamy, Paul. 2007. "Introduction." In Civil Wars of the World: Major Conflicts Since World War II, eds. Karl Jr Derouen and Uk Heo. Santa Barbara, California: ABC-CLIO Inc., 1-26.

Bennett, Andrew, and Colin Elman. 2006. "Qualitative Research: Recent Developments in Case Study Methods." Annual Review of Political Science 9(1): 455-76. http://www.annualreviews.org/doi/abs/10.1146/annurev.polisci.8.082103.104918 (February 21, 2014).

Blair, Harry. 2007. "Rebuilding and Reforming Civil Services in Post-Conflict Societies." In Governance in Post-Conflict Societies: Rebuilding Fragile States, ed. Derick W. Brinkerhoff. London: Routledge, 161-84.

Blomberg, S Brock, Gregory D Hess, and Siddharth Thacker. 2006. "On the Conflict Poverty Nexus." Economics and Politics 18(3): 237-67. http://www.blackwellsynergy.com/doi/abs/10.1111/j.1468-0343.2006.00170.x.

Bollen, Kenneth A. 1980. "Issues in the Comparative Measurement of Political Democracy." American Sociological Review 45(3): 370-90.

_ 1986. "Political Rights and Political Liberties in Nations: An Evaluation of Human Rights Measures, 1950 to 1984.” Human Rights Quarterly 8(4): 567-91.

_. 1990. "Political Democracy: Conceptual and Measurement Traps." Studies In Comparative International Development 25(1): 7-24.

—. 2011. "Evaluating Effect, Composite, and Casual Indicators in Structural Equation 
Models." MIS Quarterly 35(2): 359-72.

Bollen, Kenneth A, and Richard Lennox. 1991. "Conventional Wisdom on Measurement: A Structural Equation Perspective.” Psychological Bulletin 110(2): 305-14.

Bollen, Kenneth A, and Pamela Paxton. 2000. "Subjective Measures of Liberal Democracy." Comparative Political Studies 33(1): 58-86.

Bollen, Kenneth A, and Kwok-fai Ting. 2000. "A Tetrad Test for Causal Indicators." Psychological Methods 5(1): 3-22.

Branch, Adam, and Zachariah Cherian Mampilly. 2005. "Winning the War, but Losing the Peace? The Dilemma of SPLM/A Civil Administration and the Tasks Ahead." The Journal of Modern African Studies 43(1): 1-20.

Brinkerhoff, Derick W. 2005. "Rebuilding Governance in Failed States and Post-Conflict Societies: Core Concepts and Cross-Cutting Themes." Public Administration and Development 25(1): 3-14.

_ 2007. "Introduction - Governance Challenges in Fragile States: Re-Establishing Legitimacy, Rebuilding Effectiveness, and Reconstituting Legitimacy." In Governance in Post-Conflict Societies: Rebuilding Fragile States, ed. Derick W. Brinkerhoff. London: Routledge, 1-21.

Brinkerhoff, Derick W., and Ronald W. Johnson. 2009. "Decentralized Local Governance in Fragile States: Learning from Iraq." International Review of Administrative Sciences 75(4): 585-607.

Brosché, Johan. 2016. "Crisis of Governance in South Sudan : Electoral Politics and Violence in the World's Newest Nation.” Journal of Modern African Studies 54(1): 67-90.

Busumtwi-Sam, James. 2004. "Development and Peacebuilding: Conceptual and Operational Deficits in International Assistance." In Durable Peace: Challenges for Peacebuilding in Africa, eds. Taiser M. Ali and Robert O. Matthews. Toronto: University of Toronto Press, $315-53$.

Cammett, Melanie. 2013. Democracy in Post-Invasion Iraq. http://watson.brown.edu/costsofwar/files/cow/imce/papers/2013/Democracy in PostInvasion Iraq.pdf.

- 2014. Compassionate Communalism: Welfare and Sectarianism in Lebanon. Ithaca: Cornell University Press.

Caplan, Richard. 2004. "Partner or Patron? International Civil Administration and Local Capacity-Building." International Peacekeeping 11(2): 229-47. 
Chassay, Clancy. 2006. "Christian Leader Says Lebanese Opposition Ready for Power.” The Guardian. http://www.theguardian.com/world/2006/dec/13/syria.lebanon.

Coburn, Noah. 2011. Bazaar Politics: Power \& Pottery in an Afghan Market Town. California: Stanford University Press.

Cole, Elizabeth A., and Judy Barsalou. 2006. Unite or Divide? The Challenges of Teaching History in Societies Emerging from Violent Conflict.

Collier, Paul. 2002. Aid, Policy and Growth in Post-Conflict Countries.

Collier, Paul, and Anke Hoeffler. 1998. "On the Causes of Civil War." Oxford Handbook of the Economics of Peace and Conflict 50: 563-73.

—. 2004. "Greed and Grievance in Civil War." Oxford Economic Papers 56(4): 563-95.

Cook, Traci D. 2007. A Place To Call Their Own: Southern Sudanese Comment on the Hard Work Adn Struggles of Self-Governance. Washington DC.

Crow, Ralph E, and Adnan Iskandar. 1961. “Administrative Reform in Lebanon.” International Review of Administrative Sciences 27(3): 293-307.

Dahl, Robert. 1971. Polyarchy: Participation and Opposition. New Haven: Yale University Press.

Diallo, Boucounta. 2009. La Crise Casamançaise: Problématique et Voies de Solutions. Paris: L'Harmattan.

Diamond, Larry, and Marc F. Plattner. 2006. Electoral Systems and Democracy. Baltimore: The Johns Hopkins University Press.

Dibeh, Ghassan. 2005. 44 The Political Economy of Postwar Reconstruction in Lebanon. Helsinki.

Dinnen, Sinclair. 2007. "A Comment on State-Building in Solomon Islands." The Journal of Pacific History 42(2): 255-63.

- 2008. "The Solomon Islands Intervention and the Instabilities of the Post-Colonial State." Global Change, Peace \& Security 20(3): 339-55.

Dodge, Toby. 2013. "Intervention and Dreams of Exogenous Statebuilding: The Application of Liberal Peacebuilding in Afghanistan and Iraq." Review of International Studies 39(5): 1189-1212. http://journals.cambridge.org/article_S0260210513000272.

Dodge, Tony. 2011. "Domestic Politics and State-Building." In Afghanistan: To 2015 and beyond, eds. Toby Dodge and Nicholas Redman. International Institute for Strategic Studies, 69-96. 
Doyle, Michael W., and Nicholas Sambanis. 2000. "International Peacebuilding: A Theoretical and Quantitative Analysis." American Political Science Review 94(4): 779-801. http://www.drworley.org/NSPcommon/Nation Building/2000,12 APSR Doyle Sambanis.pdf.

. 2006. Making War and Building Peace. New Jersey: Princeton University Press.

Ducci, María Elena. 2004. "Local Governance and Democracy: The View from the Chilean Border." In Decentralization, Democratic Governance and Civil Society in Comparative Perspectives, eds. Philip Oxhorn, Joseph S. Tulchin, and Andrew D. Selee. Washington DC: Woodrow Wilson Centre Press, 119-39.

Eaton, Kent, and Larry Schroeder. 2010. "Measuring Decentralization.” In Making Decentralization Work: Democracy, Development, and Security, eds. Ed Connerley, Kent Eaton, and Paul Smoke. Colorado: Lynne Rienner Publishers, 167-90.

Von Einsiedel, Sebastian. 2005. "Policy Responses to State Failure." In Making States Work: State Failure and the Crisis of Governance, eds. Simon Chesterman, Michael Ignatieff, and Ramesh Thakur. New York: United Nations University Press, 13-35.

El-Khazen, Farid. 1998. "Les Alliances et Les Conflits Entre Les Parties Politiques Au Liban." In Parties et Forces Politiques Au Liban: Renouveau et Enagagement, ed. Antoine Messarra. Beirut: Fondation Konrad Adenauer, 133-42.

. 2000. The Breakdown of the State in Lebanon: 1967-1976. Cambridge: Harvard University Press.

El-Mufti, Karim. 2011. Public Policy Initiative The Management of Public Interest in Lebanon, a Broken Concept. Beirut. http://policylebanon.org/topmenu/policyareas/areas/Ressource.html?Id=79\#.

El-Solh, Raghid. 994. "Religious Identity and Citizenship: An Overview of Perspectives.” In Peace for Lebanon? From War to Reconstruction1, ed. Deidre Collings. Boulder: Lynne Rienner Publishers, 231-40.

El-Zein, Fares, and Holly Sims. 2004. "Reforming War's Administrative Rubble in Lebanon." Public Administration and Development 24: 279-88.

Englebert, Pierre. 2000. State Legitimacy and Development in Africa. Colorado: Lynne Rienner Publishers.

Eriksen, Erik O., and John E. Fossum. 2004. "Europe in Search of Legitimacy: Strategies of Legitimation Assessed.” International Political Science Review 25(4): 435-59.

Evans, Martin. 2005. "Insecurity or Isolation? Natural Resources and Livelihoods in Lower Casamance.” Canadian Journal of African Studies 39(2): 284-314. 
Evans, Peter B. 1989. "Predatory, Developmental, and Other Apparatuses : A Comparative Political Economy Perspective on the Third World State." Sociological Forum: Special Issue : Comparative National Development: Theory and Facts for the 1990s 4(4): 561-87.

Fall, Aissatou. 2010. Understanding The Casamance Conflict: A Background. Accra. http://www.kaiptc.org/publications/monographs/monographs/monograph-7-aissatou.aspx.

Fawaz, Mona, and Isabelle Peillen. 2003. The Case of Beirut, Lebanon. Beirut. http://www.ucl.ac.uk/dpu-projects/Global_Report/cities/beirut.htm.

Fearon, James D. 2004. "Why Do Some Civil Wars Last So Much Longer than Others?" Journal of Peace Research 41(3): 275-301.

Foucher, Vincent. 2005. "La Guerre Des Dieux ? Religions et Séparatisme En Basse Casamance." Canadian Journal of African Studies 39(2): 363-90.

Frahm, Ole. 2015. "Making Borders and Identities in South Sudan." Journal of Contemporary African Studies 33(2): 251-67. http://www.tandfonline.com/doi/full/10.1080/02589001.2015.1070461.

François, Monika, and Inder Sud. 2006. "Promoting Stability and Development in Fragile and Failed States." Development Policy Review 24(2): 141-60.

Fraser, John. 1974. "Validating a Measure of National Political Legitimacy." American Journal of Political Science 18(1): 117-34.

Fukuyama, Francis. 2006. America at the Crossroads: Democracy, Power, and the Neoconservative Legacy. Connecticut: Yale University Press.

Gamble, David P. 1957. The Wolof of Senegambia. London: International African Institute.

Gaspard, Toufic K. 2004. A Political Economy of Lebanon, 1948-2002: The Limits of LaissezFaire. Leiden: Brill.

Geddes, Barbara. 1990. "How the Cases You Choose Affect the Answers You Get: Selection Bias in Comparative Politics." Political Analysis 2(1): 131-50.

Gehrold, Stefan, and Inga Neu. 2010. Caught Between Two Fronts: In Search of Lasting Peace in the Casamance Region. Berlin.

Gellar, Sheldon. 1995. Senegal: An Africam Nation between Islam and the West. Second edi. Boulder: Westview Press.

- 2005. Democracy in Senegal: Tocquevillian Analytics in Africa. New York: Palgrave.

Gemayel, Amine. 1992. Rebuilding Lebanon. Lanham: University Press of America.

Gerry, John. 2007. Case Study Research: Principles and Practices. New York: Cambridge 
University Press.

Ghani, Ashraf, and Clare Lockhart. 2008. Fixing Failed States: A Framework for Rebuilding a Fractured World. New York: Oxford University Press.

Ghosn, Faten, and Amal Khoury. 2011. "Lebanon after the Civil War: Peace or the Illusion of Peace?” Middle East Journal 65(3): 381-97.

Ghossain, Antoine. 1988. "Confessional Communities, Space and Political Reform in Lebanon." Social Compass 1 35(4): 563-83.

Gilley, Bruce. 2006a. "The Determinants of State Legitimacy: Results for 72 Countries." International Political Science Review 27(1): 47-71.

_ 2006b. "The Meaning and Measure of State Legitimacy: Results for 72 Countries." European Journal of Political Research 45(3): 499-525.

_ 2012. "State Legitimacy: An Updated Dataset for 52 Countries." European Journal of Political Research 51(5): 693-99. http://doi.wiley.com/10.1111/j.14756765.2012.02059.x\%5Cnhttps://sremote.pitt.edu/doi/10.1111/j.14756765.2012.02059.x/,DanaInfo=onlinelibrary.wiley.com+pdf (January 26, 2014).

Mac Ginty, Roger. 2010. "Warlords and the Liberal Peace: State-Building in Afghanistan." Conflict, Security \& Development 10(4): 577-98.

Gleditsch, Nils Petter. 1996. "Environmental Change, Security, and Conflict." In Turbulent Peace: The Challenges of Managing International Conflict1, eds. Chester A. Crocker, Osler Hampson, and Pamela Aall. Washington DC: United States Institute of Peace, 53-68.

Goldsmith, Arthur A. 2007. "Does Nation-Building Work? Reviewing the Record." In Governance in Post-Conflict Societies: Rebuilding Fragile States, London: Routledge, 2544.

Goodhand, Jonathan. 2006. Aiding Peace: The Role of NGOs in Armed Conflict. Colorado: Lynne Rienner Publishers.

Grawert, Elke. 2013. "Introduction.” In Forging Two Nations: Insights on Sudan and South Sudan, ed. Elke Grawert. Addis Ababa: Organisation for Social Science Research in Eastern and Southern Africa, 15-51.

Grzymala-Busse, Anna. 2008. "Beyond Clientelism: Incumbent State Capture and State Formation." Comparative Political Studies 41(4/5): 638-73.

Grzymala-Busse, Anna, and Pauline Jones Luong. 2002. "Reconceptualizing the State: Lessons from Post-Communism.” Politics \& Society 30(4): 529-54.

Gurowitz, Amy. 1999. "Mobilizing International Norms: Domestic Actors, Immigrants, and the 
Japanese State." World Politics 51(3): 413-45.

http://www.journals.cambridge.org/abstract_S0043887100009138.

Haddad, Simon. 2009. "Lebanon: From Consociationalism to Conciliation." Nationalism and Ethnic Politics 15(3-4): 398-416.

http://www.tandfonline.com/doi/abs/10.1080/13537110903346684 (March 4, 2014).

Hajjar, Sami G. 2009. "The Convoluted and Diminished Lebanese Democracy." Democracy and Security 5(3): 261-76. http://www.tandfonline.com/doi/abs/10.1080/17419160903304864 (March 10, 2014).

Hakim, Georges. 1966. "The Economic Basis of Lebanese Polity." In Politics in Lebanon, ed. Leonard Binder. New York: John Wiley \& Sons, Inc, 57-69.

Haldén, Peter. 2010. "Systems-Building Before State-Building: On the Systemic Preconditions of State-Building." Conflict, Security \& Development 10(4): 519-45. http://www.tandfonline.com/doi/abs/10.1080/14678802.2010.500540.

Hameiri, Shahar. 2009. "Capacity and Its Fallacies: International State Building as State Transformation.” Millennium - Journal of International Studies 38(1): 55-81.

Hamzeh, A Nizar. 2000. "Lebanon's Islamists and Local Politics: A New Reality." Third World Quarterly 21(5): 739-59.

Harb, Boutros. 1998. “Le Relancement D’une Vie Politique." In Parties et Forces Politiques Au Liban: Renouveau et Enagagement, ed. Antoine Messarra. Beirut: Fondation Konrad Adenauer, 53-56.

Harb, Mona, and Reinoud Leenders. 2005. 'Know Thy Enemy: Hizbullah, 'terrorism' and the Politics of Perception." Third World Quarterly 26(1): 173-97.

Harik, Judith. 1996. "Between Islam and the System: Sources and Implications of Popular Support for Lebanon's Hizballah.” Journal of Conflict Resolution 40(1): 41-67.

Hartzell, Caroline A. 2006. "Structuring the Peace: Negotiated Settlements and the Construction of Conflict Management Institutions." In Conflict Prevention and Peacebuilding in PostWar Societies: Sustaining the Peace, eds. T. David Mason and James D. Meernik. Oxon: Routledge, 31-52.

Hartzell, Caroline, Matthew Hoddie, and Donald Rothchild. 2001. "Stabilizing the Peace After Civil War: An Investigation of Some Key Variables.” International Organization 55(1): 183-208.

Hess, Steve. 2010. "Coming to Terms with Neopatrimonialism: Soviet and American NationBuilding Projects in Afghanistan.” Central Asian Survey 29(2): 171-87. 
Hottinger, Arnold. 1966. “Zu'ama' in Historical Perspective.” In Politics in Lebanon, ed. Leonard Binder. New York: John Wiley \& Sons, Inc, 85-106.

Hudson, Michael C. 1999. “Lebanon after Ta’if: Another Reform Opportunity Lost.” Arab Studies Quarterly 21(1): 27-40.

Hutchison, M. L., and K. Johnson. 2011. "Capacity to Trust? Institutional Capacity, Conflict, and Political Trust in Africa, 2000-2005." Journal of Peace Research 48(6): 737-52. http://jpr.sagepub.com/cgi/doi/10.1177/0022343311417981 (March 10, 2014).

Inbal, Aliza B., and Hanna Lerner. 2007. "Constitutional Design, Identity and Legitimacy in Post-Conflict Reconstruction." In Governance in Post-Conflict Societies: Rebuilding Fragile States, ed. Derick W. Brinkerhoff. London: Routledge, 45-63.

International Crisis Group. 2006. Israel/Hizbollah/Lebanon: Avoiding Renewed Conflict.

International Monetary Fund. 2006. Lebanon: Selected Issue. Washington DC. http://www.imf.org/external/pubs/ft/scr/2006/cr06200.pdf.

Iskandar, Adnan. 1964. Bureaucracy in Lebanon. Beirut: American University of Beirut. . 1996. Public Service Accountability in Lebanon. Beirut. http://ddc.aub.edu.lb/projects/pspa/PSAccount/PSAccount-0.html.

Jackman, Robert W. 1987. "Political Institutions and Voter Turnout in the Industrial Democracies." The American Political Science Review 81(2): 405-24.

Jad, Sana Souaid. 2011. The Balance Sheet Approach and the Public Debt Stock Analysis: The Case of Lebanon. Beirut. http://www.bdl.gov.lb/.

Jawad, Rana. 2002. "A Profile of Social Welfare in Lebanon: Assessing the Implications for Social Development Policy." Global Social Policy 2(3): 319-42.

Jok, Madut Jok. 2011. Diversity, Unity, and Nation Building in South Sudan. Washington DC. http://www.usip.org/sites/default/files/Diversity\%2C Unity\%2C and Nation Building in South Sudan \%28Jok\%29.pdf.

Jong, Ferdinand De. 2005a. “A Joking Nation : Conflict Resolution in Senegal." Canadian Journal of African Studies 39(2): 391-415.

- 2005b. "Contested Casamance : Introduction." Canadian Journal of African Studies 39(2): 213-29.

Von Kaltenborn-Stachau, Henriette. 2008. The Missing Link-Fostering Positive Citizen-State Relations in Post-Conflict Environments. Washington DC. http://siteresources.worldbank.org/EXTGOVACC/Resources/CommGAPMissingLinkWeb. pdf. 
Kameir, El Wathig. 2011. The Political Economy of South Sudan: A Scoping Analytical Study. Abidjan.

Kanaan, Nimat, and Randa Aboul-Hosn. 1998. "Mapping of Living Conditions in Lebanon." Mapping of Living Conditions in Lebanon (UNDP).

http://www.undp.org.lb/programme/pro-

poor/poverty/povertyinlebanon/molc/setting/A/1975.htm\# (November 2, 2015).

Kanol, Direnç. 2011. “Assessing the Legitimacy of the EU.” Interdisciplinary Political Studies 1(0): 49-59.

Kaplan, Seth. 2008. “The Remarkable Story of Somaliland.” Journal of Democracy 19(3): 14357.

Kaufmann, Daniel, Aart Kraay, and Massimo Mastruzzi. 2010. The Worldwide Governance Indicators Methodology and Analytical Issues. Washington DC.

Keefer, Philip E., Ambar Narayan, and Tara Vishwanath. 2006. "Decentralization in Pakistan: Are Local Governments Likely to Be More Accountable than Central Governments?" In Decentralization and Local Governance in Developing Countries: A Comparative Perspective, eds. Pranab Bardhan and Dilip Mookherjee. Cambridge: MIT Press, 285-304.

Kerr, Malcolm H. 1966. "Political Decision Making in a Confessional Democracy." In Politics in Lebanon, ed. Leonard Binder. New York: John Wiley \& Sons, Inc, 167-86.

Khadiagala, Gilbert M. 1995. "State Collapse and Reconstruction in Uganda." In Collapsed States: The Disintegration and Reconstruction of Legitimate Authority, ed. I. William Zartman. Colorado: Lynne Rienner Publishers, 33-47.

Kingston, Paul, and Marie-Joëlle Zahar. 2004. "Rebuilding A House of Many Mansions: The Rise and Fall of Militia Cantons in Lebanon.” In States Within States, eds. Paul Kingston and Ian S. Speaars. New York: Palgrave, 81-98.

Kisirwani, M., and W. M. Parle. 1987. "Assessing the Impact of the Post Civil War Period on the Lebanese Bureaucracy: A View from Inside." Journal of Asian and African Studies 22(12): 17-29. http://jas.sagepub.com/cgi/doi/10.1177/002190968702200102.

Kisirwani, Maroun. 1997a. "Accountability of Lebanese Civil Servants: An Overview of Disciplinary Mechanisms." In Lebanon Beyond 2000, eds. Amin Saikal and Geoffrey Jukes. Canberra: Centre for Middle Eastern and Central Asian Studies.

_ 1997b. "The Rehabilitation and Reconstruction of Lebanon." In Remaking the Middle East, eds. Paul J White and William S Logan. Oxford: Berg, 87-104.

Kisirwani, Maroun, and William M. Parle. 1987. "Assessing the Impact of the Post Civil War Period on the Lebanese Bureaucracy: A View from Inside." Journal of Asian and African 
Studies 22(1-2): 17-29.

Kitschelt, Herbert, and Steven I. Wilkinson. 2007. "Citizen-Politician Linkages: An

Introduction." In Patrons, Clients, and Policies: Patterns of Democratic Accountability and Political Competition, eds. Herbert Kitschelt and Steven I. Wilkinson. Cambridge:

Cambridge University Press, 1-49.

Kon, Madut. 2015. "Institutional Development, Governance, and Ethnic Politics in South Sudan." Journal of Global Economics 3(2): 1-6.

http://www.esciencecentral.org/journals/institutional-development-governance-and-ethnicpolitics-in-south-sudan-2375-4389-1000147.php?aid=57097.

Larson, Greg, Peter Biar Ajak, and Lant Pritchett. 2013. South Sudan's Capability Trap: Building a State with Disruptive Innovation. Cambridge. https://www.hks.harvard.edu/content/download/69085/1249150/version/1/file/268_SudanPDIA.pdf.

Leenders, Reinoud. 2012. Spoils of Truth: Corruption and State-Building in Postwar Lebanon. Ithaca: Cornell University Press.

LeRiche, Matthew, and Matthew Arnold. 2012. South Sudan: From Revolution to Independence. London: C. Hurst \& Co (Publishers) Ltd.

Levi, Margaret, and Audrey Sacks. 2009. "Legitimating Beliefs: Sources and Indicators." Regulation \& Governance 3(4): 311-33.

Levi, Margaret, Audrey Sacks, and Tom Tyler. 2009. "Conceptualizing Legitimacy, Measuring Legitimating Beliefs.” American Behavioral Scientist 53(3): 354-75.

Lipset, Seymour Martin. 1983. Political Man: The Social Bases of Politics. London: Heinemann.

Lister, Sarah, and Andrew Wilder. 2005. "Strengthening Subnational Administration in Afghanistan: Technical Reform or State-Building?" Public Administration and Development 25(1): 39-48.

Loehlin, John C. 1998. Latent Variable Models: An Introduction to Factor, Path, and Structural Analysis. Third. New Jersey: Lawrence Erlbaum Associates.

Low-beer, Ann. 2001. Paradigm Politics, School Textbooks and Cultural Identity: The Struggle in Bosnia and Hercegovina.

Lyons, Terrence. 2005. Demilitarizing Politics: Elections on the Uncertain Road to Peace. Colorado: Lynne Rienner Publishers.

Mane, Bacary Domingo. 2014. "POLE DE DEVELOPPEMENT DE LA CASAMANCE." Sud Online. http://www.sudonline.sn/au-dela-des-questions-economique-et- 
administrative_a_17983.html.

March, James G., and Johan P. Olsen. 1989. Institutions: The Organizational Basis of Politics. New York: The Free Press.

Marquette, Heather, and Danielle Beswick. 2011. "State Building, Security and Development: State Building as a New Development Paradigm?” Third World Quarterly 32(10): 1703-14.

Marshall, Monty G, and Keith Jaggers. 2002. Political Regime Characteristics and Transitions, 1800-2002: Dataset User's Manual. Maryland.

Marut, Jean-Claude. 2010. Le Conflit de Casamance: Ce Qui Disent Les Armes. Paris: Édition Karthala.

Mason, David T., Mehmet Gurses, Patrick T. Brandt, and Jason Michael Quinn. 2011. "When Civil Wars Recur: Conditions for Durable Peace after Civil Wars." International Studies Perspectives 12(2): 171-89.

Maxwell, Daniel, Kirsten Gelsdorf, and Martina Santschi. 2012. Researching Livelihoods and Services Affected by Conflict Livelihoods, Basic Services and Social Protection in South Sudan. London. http://community.eldis.org/.5a0b0243/Livelihoods basic services and social protection in Sri Lanka.pdf.

Mayall, James. 2005. "The Legacy of Colonialism.” In Making States Work: State Failure and the Crisis of Governance, eds. Simon Chesterman, Michael Ignatieff, and Ramesh Thakur. New York: United Nations University Press, 36-58.

Mcloughlin, Claire. 2014. "When Does Service Delivery Improve the Legitimacy of a Fragile or Conflict-Affected State?" Governance: n/a-n/a. http://doi.wiley.com/10.1111/gove.12091 (May 2, 2014).

von der Mehden, Fred R., and Kim Quaile Hill. 1980. “Area Experts' Images of African Nations.” Comparative Political Studies 12(4): 497-510.

Meierhenrich, Jens. 2004. “Forming States After Failure.” In When States Fail: Causes and Consequences, ed. Rot. Princeton: Princeton University Press, 153-68.

Mendy, Toumany. 2006. Politique et Puissance de L'argent Au Sénégal: Les Désarrois D'un Peuple Innocent. Paris: L'Harmattan.

Messarra, Antoine. 1998. "L'expérience Libanais Du Parti Dans Le Cadre Arabe." In Partis et Forces Politiques Au Liban: Renouveau et Engagement, ed. Antoine Messarra. Beirut: Fondation Konrad Adenauer, 15-40.

Migdal, Joel S. 2001. State in Society: Studying How States and Societies Transform and Constitute One Another. Cambridge: Cambridge University Press. 
Miller, Benjamin. 2015. "Stateness, National Self-Determination and War and Peace in the Twenty-First Century." Ethnopolitics 14(5): 531-39. http://www.tandfonline.com/doi/full/10.1080/17449057.2015.1051818.

Ministry of Foreign Affairs Denmark. 2005. A Joint Evaluation: Humanitarian and Reconstruction Assistance to Afghanistan, 2001-05: From Denmark, Ireland, The Netherlands, Sweden and the United Kingdom.

Ministry of Social Affairs, and United Nations Development Programme. 2007. The effects of brief mindfulness intervention on acute pain experience: An examination of individual difference Development of Mapping of Living Conditions in Lebanon, 1995-2004: A Comparison with the Results of "Mapping of Living Conditions in Lebanon, 1998." Beirut.

Mitchell, Timothy. 1991. "The Limits of the State: Beyond Statist Approaches and Their Critics." The American Political Science Review 85(1): 77-96.

Mukhopadhyay, Dipali. 2009. "Disguised Warlordism and Combatanthood in Balkh: The Persistence of Informal Power in the Formal Afghan State." Conflict, Security \& Development 9(4): 535-64.

Muller, Edward N., Thomas O. Jukam, and Mitchell A. Seligson. 1982. "Diffuse Political Support and Antisystem Political Behavior : A Comparative Analysis." American Journal of Political Science 26(2): 240-64.

Najem, Tom Pierre. 2000. Lebanon's Renaissance: The Political Economy of Reconstruction. Reading: Ithaca Press.

Nassif, Georges. 1998. "Les Parties Libanaises En Crise: Comment Transforment-Elles Politiquement." In Parties et Forces Politiques Au Liban: Renouveau et Enagagement, ed. Antoine Messarra. Beirut: Fondation Konrad Adenauer, 123-29.

Ndegwa, Stephen N, and Brian Levy. 2003. The Politics of Decentralization in Africa: A Comparative Analysis. Washington DC. http://www1.worldbank.org/publicsector/LearningProgram/Decentralization/Ndegwa.pdf.

Netemeyer, Richard G., William O. Bearden, and Subhash Sharma. 2003. Scaling Procedures: Issues and Applications. California: Sage Publications, Inc.

Nettl, J.P. 1968. “The State as a Conceptual Variable.” World Politics 20(4): 559-92.

News, BBC. 2009. "Senegal Apology for Christ â€ ${ }^{\mathrm{TM}}$ Slur'.” BBC News. http://news.bbc.co.uk/go/pr/fr/-/2/hi/africa/8435805.stm.

Norton, Augustus Richard. 2000. "Hizballah and the Israeli Withdrawal from Southern Lebanon." Journal of Palestine Studies 30(1): 22-35. 
O Senegal. 2014. "Une Autoroute Maritime Se Développe Entre Dakar et La Casamance.” $O$ Senegal. http://www.osenegal.com/news/transport/autoroute-maritime-se-developpe-dakarcasamance/.

OECD. 2010. The State's Legitimacy in Fragile Situations: Unpacking Complexity. http://www.oecd.org/dac/incaf/44794487.pdf.

Ottaway, Marina. 1995. "Democratization in Collapsed States.” In Collapsed States: The Disintegration and Restoration of Legitimate Authority, ed. I. William Zartman. Colorado: Lynne Rienner Publishers, 235-50.

Oxhorn, Philip. 2004. "Unraveling the Puzzle of Decentralization.” In Decentralization, Democratic Governance and Civil Society in Comparative Perspectives, eds. Philip Oxhorn, Joseph S. Tulchin, and Andrew D. Selee. Washington DC: Woodrow Wilson Centre Press, 3-32.

Ozer, Daniel J. 1999. "Four Principles for Personality Assessment.” In Handbook of Personality: Theory and Research, eds. Lawrence A. Pervin and Oliver P. John. New York: Guilford.

Paris, Roland. 2005. "Wilson's Ghost: The Faulty Assumptions of Postconflict Peacebuilding." In Turbulent Peace: The Challenges of Managing International Conflict, eds. Chester A. Crocker, Fen Osler Hampson, and Pamela Aall. Washington DC: United States Institute of Peace, 765-84.

—. 2006. "NATO’s Choice in Afghanistan: Go Big or Go Home.” Policy Options: 35-43.

Picard, Elizabeth. 1993. The Lebanese Shi' $a$ and Political Violence. Geneva.

Pierson, Paul. 2004. Politics in Time: History, Institutions, and Social Analysis. Princeton: Princeton University Press.

Posner, Daniel. 2004. "Civil Society and the Reconstruction of Failed States." In When States Fail: Causes and Consequences, ed. Robert Rotberg. Princeton: Princeton University Press, 237-55.

Radon, Jenik, and Sarah Logan. 2014. "South Sudan: Governance Arrangements, War, and Peace." Journal of International Affairs 68(1): 149-67.

http://search.ebscohost.com/login.aspx?direct=true\&db=buh\&AN=100052751\&site=ehostlive.

Regan, Patrick M. 2002. "Third-Party Interventions and the Duration of Intrastate Conflicts." The Journal of Conflict Resolution 46(1): 55-73.

Riak, Maker M. 2013. "Reversing the Trend of Corruption in South Sudan: Is Rwanda a Suitable Model?" Journal of Developing Societies 29(4): 487-501. http://jds.sagepub.com/cgi/doi/10.1177/0169796X13504681. 
Rotberg, Robert I. 2004. "When States Fail: Causes and Consequences." In When States Fail: Causes and Consequences, ed. Robert I. Rotberg. New Jersey: Princeton University Press, $1-49$.

Saidi, Nasser H. 1994. "The Economic Reconstruction of Lebanon: War, Peace, and Modernization." In Peace for Lebanon? From War to Reconstruction, ed. Deirdre Collings. Boulder: Lynne Rienner Publishers, 195-212.

Salamy, Imad. 2014. The Government and Politics of Lebanon. Oxon: Routledge.

Saleh, Ali Salman, and Charles Harvie. 2005. "An Analysis of Public Sector Deficits and Debt in Lebanon: 1970-2000.” Middle East Review of International Affairs 9(4): 106-36.

Salem, Elie Adib. 1973. Modernization without Revolution: Lebanon's Experience. London: Indiana University Press.

Salloukh, Bassel F. 2006. "The Limits of Electoral Engineering in Divided Societies: Elections in Postwar Lebanon.” Canadian Journal of Political Science 39(3): 635-55.

Salloukh, Bassel F., Rabie Barakat, and Jinan S. Al-Habbal. 2015. Politics of Sectarianism in Postwar Lebanon. London: Pluto Press.

Sambanis, Nicholas. 2001. "Do Ethnic and Nonethnic Civil Wars Have the Same Causes ?: A Theoretical and Empirical Inquiry (Part 1)." The Journal of Conflict Resolution 45(3): 25982.

Saouli, Adham. 2003. “Lebanon's Hizbullah: The Quest for Survival.” World Affairs 166(2): 7180.

Al Sayegh, Daoud. 1998. "Organisations Sectaires et Les Forces Politiques: La Recherche Des Limites." In Parties et Forces Politiques Au Liban: Renouveau et Enagagement, ed. Antoine Messarra. Beirut: Fondation Konrad Adenauer, 167-72.

Schaffer, Frederic C. 2000. Democracy in Translation: Understanding Politics in an Unfamiliar Culture. Ithaca: Cornell University Press.

Scharpf, Fritz W. 2003. Problem Solving Effectiveness and Democratic Accountability in the EU.

Schenker, David. 2007. Lebanon Goes to Paris III: High Stakes in France and Beirut. Washington DC. http://www.washingtoninstitute.org/policy-analysis/view/lebanon-goes-toparis-iii-high-stakes-in-france-and-beirut.

Sedgwick, Mark. 2010. "Measuring Egyptian Regime Legitimacy." Middle East Critique 19(3): 251-67. http://www.tandfonline.com/doi/abs/10.1080/19436149.2010.514474 (March 10, 2014).

Selee, Andrew D., and Joseph S. Tulchin. 2004. "Decentralization and Democratic Governance: 
Lessons and Challenges." In Decentralization, Democratic Governance and Civil Society in Comparative Perspectives, eds. Philip Oxhorn, Joseph S. Tulchin, and Andrew D. Selee. London: Woodrow Wilson Centre Press, 295-320.

Shapiro, Ian. 2001. "Problems, Methods, and Theories in the Study of Politics, or What's Wrong with Political Science and What to Do about It." Political Theory 30(4): 596-619.

Sharan, Timor. 2011. "The Dynamics of Elite Networks and Patron-Client Relations in Afghanistan." Europe-Asia Studies 63(6): 1109-27.

Siegle, Joseph, and Patrick O'Mahony. 2010. "Decentralization and Internal Conflict.” In Making Decentralization Work: Democracy, Development, and Security, eds. Ed Connerley, Kent Eaton, and Paul Smoke. Colorado: Lynne Rienner Publishers, 135-66.

De Simone, Sara. 2015. "Building a Fragmented State: Land Governance and Conflict in South Sudan." Journal of Peacebuilding and Development 10(3): 60-73. http://dx.doi.org/10.1080/15423166.2015.1085812.

Sisk, Timothy. 2013. Statebuilding: Consolidating Peace After Conflict. London: Polity Press.

Skocpol, Theda. 1979. States \& Social Revolutions: A Comparative Analysis of France, Russia, $\&$ China. Cambridge: Cambridge University Press.

Sobek, David. 2010. "Masters of Their Domains: The Role of State Capacity in Civil Wars." Journal of Peace Research 47(3): 267-71.

Le Soleil. 2012. "Benoit Sambou Annonce Un Projet de 350 Millions : Les Zones Post-Conflit Vont Relancer L'agriculture En Casamance.” Le Soleil. http://www.lesoleil.sn/index.php?option=com_content\&view=article\&id=16706:benoitsambou-annonce-un-projet-de-350-millions-les-zones-post-conflit-vont-relancerlagriculture-en-casamance\&catid=78:a-la-une.

South Sudan Bureau for Community Security and Small Arms Control, South Sudan Peace and Reconciliation Commission, and United Nations Development Programme. 2012. Community Consultation Report: Warrap State, South Sudan. Juba. http://www.undp.org/content/dam/southsudan/library/Documents/CSAC Reports/UNDPSS-Warrap-consult-12.pdf.

South Sudan National Bureau of Statistics. 2011. South Sudan Statistical Yearbook 2011. Juba. http://static1.1.sqspcdn.com/static/f/750842/18935415/1349357346780/South+Sudan+Statis tical+Yearbook $+2011+$ FINAL.pdf?token $=x c r h+X T e o 9 v W w 3 H A w j Y s 5 Y t H A 48=$.

Starr, S. Frederick. 2006. "Sovereignty and Legitimacy in Afghan Nation-Building." In NationBuilding: Beyond Afghanistan and Iraq, ed. Francis Fukuyama. Baltimore: The Johns Hopkins University Press, 107-24. 
Streeck, Wolfgang, and Kathleen Thelen. 2005. "Introduction: Institutional Change in Advanced Political Economies." In Beyond Continuity: Institutional Change in Advanced Economies, eds. Wolfgang Streeck and Kathleen Thelen. Oxford: Oxford University Press, 1-39.

Suchman, Mark C. 1995. "Managing Legitimacy: Strategic and Institutional Approaches." The Academy of Management Review 20(3): 571-610.

The World Bank. 2005. "Senegal Receives 20 Million for Emergency Recovery Project in Casamance." World Bank.

http://web.worldbank.org/external/default/main?pagePK=64027221\&piPK=64027220\&the SitePK=296303\&menuPK=296336\&Projectid=P069207.

Thies, Cameron G. 2010. "Of Rulers, Rebels, and Revenue: State Capacity, Civil War Onset, and Primary Commodities." Journal of Peace Research 47(3): 321-32.

Traboulsi, Fawwaz. 2007. A History of Modern Lebanon. London: Pluto Press.

Treier, Shawn, and Simon Jackman. 2008. "Democracy as a Latent Variable." American Journal of Political Science 52(1): 201-17.

Van der Vossen, Bas. 2012. "The Asymmetry of Legitimacy." Law and Philosophy 31(5): 56592.

de Waal, Alex. 2014. "When Kleptocracy Becomes Insolvent: Brute Causes of the Civil War in South Sudan." African Affairs 113(452): 347-69.

Walter, Barbara F. 2004. "Does Conflict Beget Conflict? Explaining Recurring Civil War." Journal of Peace Research 41(3): 371-88.

Washburne, Sarah Lykes. 2013. "Post-War Governance and the Impact of International Aid in South Sudan.” In Forging Two Nations: Insights on Sudan and South Sudan, ed. Elke Grawert. Addis Ababa: Organisation for Social Science Research in Eastern and Southern Africa, 188-200.

Wassara, Samson S. 2015. "South Sudan: State Sovereignty Challenged at Infancy." Journal of Eastern African Studies 9(4): 634-39. http://www.tandfonline.com/doi/full/10.1080/17531055.2015.1105439.

Weil, Frederick D. 1989. "The Sources and Structures of Legitimation in Western Democracies: A Consolidated Model Tested with Time-Series Data in Six Countries since World War II." American Sociological Review 54(5): 682-706.

Widner, Jennifer A. 2004. "Building Effective Trust in the Aftermath of Severe Conflict." In When States Fail: Causes and Consequences, ed. Robert Rotberg. Princeton: Princeton University Press, 222-36. 
Wood, Elisabeth Jean. 2008. "The Social Processes of Civil War: The Wartime Transformation of Social Networks." Annual Review of Political Science 11(1): 539-61. http://www.annualreviews.org/doi/abs/10.1146/annurev.polisci.8.082103.104832.

Young, John. 2006. The South Sudan Defence Forces in the Wake of the Juba Declaration. Geneva. http://www.smallarmssurveysudan.org/fileadmin/docs/working-papers/HSBA-WP01-SSDF.pdf.

Zambakari, Christopher. 2013. "Post-Referendum South Sudan: Political Drivers of Violence and the Challenge of Democratic Nation-Building." In Forging Two Nations: Insights on Sudan and South Sudan, ed. Elke Grawert. Addis Ababa: Organisation for Social Science Research in Eastern and Southern Africa, 98-111.

Zanotti, L. 2008. "Imagining Democracy, Building Unsustainable Institutions: The UN Peacekeeping Operation in Haiti.” Security Dialogue 39(5): 539-61.

El Zein, Fares. 2003. Dissertation Thesis "Politics of Administrative Reform in Post War Lebanon." University at Albany.

Zürcher, Christoph et al. 2013. Costly Democracy: Peacebuilding \& Democratization After War. Stanford, California: Stanford University Press.

Abla, Zeina, Amal Karaki, and Nada Dimachkieh Sweidan. 2014. Lebanon Millennium Development Goals Report 2013-2014. Beirut. http://www.lb.undp.org/content/lebanon/en/home/library/mdg/lebanon-mdg-report-2013$2014 /$.

Afrique Jet. 2014. "Projet Pôle de Développement de La Casamance." Afrique Jet. http://www.afriquejet.com/afrique-ouest/3654-projet-pole-de-developpement-de-lacasamance.html.

Allen, Daniel. 2010. "New Directions in the Study of Nation-Building: Views through the Lens of Path Dependence." International Studies Review 12(3): 413-29.

Angeles, Leonora C., and Francisco A. Magno. 2004. "The Philippines: Decentralization, Local Governments, and Citizen Action." In Decentralization, Democratic Governance and Civil Society in Comparative Perspectives, eds. Philip Oxhorn and Joseph S. Tulchin. Washington DC: Woodrow Wilson Centre Press, 211-65.

Armstrong, Andrea, and Barnett Rubin. 2005. "The Great Lakes and South Central Asia." In Making States Work: State Failure and the Crisis of Governance, eds. Simon Chesterman, Michael Ignatieff, and Ramesh Thakur. New York: United Nations University Press, 79101. 
Attipoe, Olympio, Biplove Choudhary, and Nicholas Jonga. 2014. An Analysis of Government Budgets in South Sudan from a Human Development Perspective. Juba. http://www.undp.org/content/dam/southsudan/library/Discussion Papers/SS-Discussion paper final.pdf.

Atzili, Boaz. 2010. "State Weakness and 'Vacuum of Power' in Lebanon.” Studies in Conflict \& Terrorism 33(8): 757-82. http://www.tandfonline.com/doi/abs/10.1080/1057610X.2010.494172 (March 7, 2014).

Baaklini, Abdo I. 1976. Legislative and Political Development: Lebanon, 1842-1972. Durnham: Duke University Press.

Barbara, Julien. 2008. "Antipodean Statebuilding: The Regional Assistance Mission to Solomon Islands and Australian Intervention in the South Pacific." Journal of Intervention and Statebuilding 2(2): 123-49.

Bardhan, Pranab, and Dilip Mookherjee. 2006. "The Rise of Local Governments: An Overview." In Decentralization and Local Governance in Developing Countries: A Comparative Perspective, eds. Pranab Bardhan and Dilip Mookherjee. Cambridge: MIT Press, 1-52.

Baroudi, Sami E. 1998. "Economic Conflict in Postwar Lebanon: State-Labor Relations Between 1992 and 1997." Middle East Journal 52(4): 531-50.

Beck, Linda J. 2008. Brokering Democracy in Africa: The Rise of Clientelist Democracy in Senegal. New York: Palgrave.

Beetham, David, and Christopher Lord. 1998. Legitimacy and the EU. London: Addison-Wesley Longman.

Bellamy, Paul. 2007. "Introduction.” In Civil Wars of the World: Major Conflicts Since World War II, eds. Karl Jr Derouen and Uk Heo. Santa Barbara, California: ABC-CLIO Inc., 1-26.

Bennett, Andrew, and Colin Elman. 2006. "Qualitative Research: Recent Developments in Case Study Methods.” Annual Review of Political Science 9(1): 455-76. http://www.annualreviews.org/doi/abs/10.1146/annurev.polisci.8.082103.104918 (February $21,2014)$.

Blair, Harry. 2007. "Rebuilding and Reforming Civil Services in Post-Conflict Societies." In Governance in Post-Conflict Societies: Rebuilding Fragile States, ed. Derick W. Brinkerhoff. London: Routledge, 161-84.

Blomberg, S Brock, Gregory D Hess, and Siddharth Thacker. 2006. "On the Conflict Poverty Nexus." Economics and Politics 18(3): 237-67. http://www.blackwellsynergy.com/doi/abs/10.1111/j.1468-0343.2006.00170.x.

Bollen, Kenneth A. 1980. "Issues in the Comparative Measurement of Political Democracy." 
American Sociological Review 45(3): 370-90.

. 1986. "Political Rights and Political Liberties in Nations: An Evaluation of Human Rights Measures, 1950 to 1984." Human Rights Quarterly 8(4): 567-91.

_ 1990. "Political Democracy: Conceptual and Measurement Traps." Studies In Comparative International Development 25(1): 7-24.

_. 2011. "Evaluating Effect, Composite, and Casual Indicators in Structural Equation Models." MIS Quarterly 35(2): 359-72.

Bollen, Kenneth A, and Richard Lennox. 1991. "Conventional Wisdom on Measurement: A Structural Equation Perspective.” Psychological Bulletin 110(2): 305-14.

Bollen, Kenneth A, and Pamela Paxton. 2000. "Subjective Measures of Liberal Democracy." Comparative Political Studies 33(1): 58-86.

Bollen, Kenneth A, and Kwok-fai Ting. 2000. "A Tetrad Test for Causal Indicators." Psychological Methods 5(1): 3-22.

Branch, Adam, and Zachariah Cherian Mampilly. 2005. "Winning the War, but Losing the Peace? The Dilemma of SPLM/A Civil Administration and the Tasks Ahead." The Journal of Modern African Studies 43(1): 1-20.

Brinkerhoff, Derick W. 2005. "Rebuilding Governance in Failed States and Post-Conflict Societies: Core Concepts and Cross-Cutting Themes." Public Administration and Development 25(1): 3-14.

_ 2007. "Introduction - Governance Challenges in Fragile States: Re-Establishing Legitimacy, Rebuilding Effectiveness, and Reconstituting Legitimacy.” In Governance in Post-Conflict Societies: Rebuilding Fragile States, ed. Derick W. Brinkerhoff. London: Routledge, 1-21.

Brinkerhoff, Derick W., and Ronald W. Johnson. 2009. "Decentralized Local Governance in Fragile States: Learning from Iraq." International Review of Administrative Sciences 75(4): 585-607.

Brosché, Johan. 2016. "Crisis of Governance in South Sudan : Electoral Politics and Violence in the World's Newest Nation." Journal of Modern African Studies 54(1): 67-90.

Busumtwi-Sam, James. 2004. "Development and Peacebuilding: Conceptual and Operational Deficits in International Assistance." In Durable Peace: Challenges for Peacebuilding in Africa, eds. Taiser M. Ali and Robert O. Matthews. Toronto: University of Toronto Press, $315-53$.

Cammett, Melanie. 2013. Democracy in Post-Invasion Iraq. 
http://watson.brown.edu/costsofwar/files/cow/imce/papers/2013/Democracy in PostInvasion Iraq.pdf.

- 2014. Compassionate Communalism: Welfare and Sectarianism in Lebanon. Ithaca: Cornell University Press.

Caplan, Richard. 2004. "Partner or Patron? International Civil Administration and Local Capacity-Building." International Peacekeeping 11(2): 229-47.

Chassay, Clancy. 2006. "Christian Leader Says Lebanese Opposition Ready for Power." The Guardian. http://www.theguardian.com/world/2006/dec/13/syria.lebanon.

Coburn, Noah. 2011. Bazaar Politics: Power \& Pottery in an Afghan Market Town. California: Stanford University Press.

Cole, Elizabeth A., and Judy Barsalou. 2006. Unite or Divide? The Challenges of Teaching History in Societies Emerging from Violent Conflict.

Collier, Paul. 2002. Aid, Policy and Growth in Post-Conflict Countries.

Collier, Paul, and Anke Hoeffler. 1998. "On the Causes of Civil War." Oxford Handbook of the Economics of Peace and Conflict 50: 563-73.

—. 2004. "Greed and Grievance in Civil War." Oxford Economic Papers 56(4): 563-95.

Cook, Traci D. 2007. A Place To Call Their Own: Southern Sudanese Comment on the Hard Work Adn Struggles of Self-Governance. Washington DC.

Crow, Ralph E, and Adnan Iskandar. 1961. "Administrative Reform in Lebanon.” International Review of Administrative Sciences 27(3): 293-307.

Dahl, Robert. 1971. Polyarchy: Participation and Opposition. New Haven: Yale University Press.

Diallo, Boucounta. 2009. La Crise Casamançaise: Problématique et Voies de Solutions. Paris: L'Harmattan.

Diamond, Larry, and Marc F. Plattner. 2006. Electoral Systems and Democracy. Baltimore: The Johns Hopkins University Press.

Dibeh, Ghassan. 2005. 44 The Political Economy of Postwar Reconstruction in Lebanon. Helsinki.

Dinnen, Sinclair. 2007. "A Comment on State-Building in Solomon Islands." The Journal of Pacific History 42(2): 255-63.

- 2008. "The Solomon Islands Intervention and the Instabilities of the Post-Colonial State." Global Change, Peace \& Security 20(3): 339-55. 
Dodge, Toby. 2013. "Intervention and Dreams of Exogenous Statebuilding: The Application of Liberal Peacebuilding in Afghanistan and Iraq." Review of International Studies 39(5): 1189-1212. http://journals.cambridge.org/article_S0260210513000272.

Dodge, Tony. 2011. "Domestic Politics and State-Building." In Afghanistan: To 2015 and beyond, eds. Toby Dodge and Nicholas Redman. International Institute for Strategic Studies, 69-96.

Doyle, Michael W., and Nicholas Sambanis. 2000. "International Peacebuilding: A Theoretical and Quantitative Analysis.” American Political Science Review 94(4): 779-801. http://www.drworley.org/NSPcommon/Nation Building/2000,12 APSR Doyle Sambanis.pdf.

- 2006. Making War and Building Peace. New Jersey: Princeton University Press.

Ducci, María Elena. 2004. "Local Governance and Democracy: The View from the Chilean Border." In Decentralization, Democratic Governance and Civil Society in Comparative Perspectives, eds. Philip Oxhorn, Joseph S. Tulchin, and Andrew D. Selee. Washington DC: Woodrow Wilson Centre Press, 119-39.

Eaton, Kent, and Larry Schroeder. 2010. “Measuring Decentralization.” In Making Decentralization Work: Democracy, Development, and Security, eds. Ed Connerley, Kent Eaton, and Paul Smoke. Colorado: Lynne Rienner Publishers, 167-90.

Von Einsiedel, Sebastian. 2005. "Policy Responses to State Failure." In Making States Work: State Failure and the Crisis of Governance, eds. Simon Chesterman, Michael Ignatieff, and Ramesh Thakur. New York: United Nations University Press, 13-35.

El-Khazen, Farid. 1998. "Les Alliances et Les Conflits Entre Les Parties Politiques Au Liban." In Parties et Forces Politiques Au Liban: Renouveau et Enagagement, ed. Antoine Messarra. Beirut: Fondation Konrad Adenauer, 133-42.

- 2000. The Breakdown of the State in Lebanon: 1967-1976. Cambridge: Harvard University Press.

El-Mufti, Karim. 2011. Public Policy Initiative The Management of Public Interest in Lebanon, a Broken Concept. Beirut.

http://policylebanon.org/topmenu/policyareas/areas/Ressource.html?Id=79\#.

El-Solh, Raghid. 994. "Religious Identity and Citizenship: An Overview of Perspectives." In Peace for Lebanon? From War to Reconstruction 1, ed. Deidre Collings. Boulder: Lynne Rienner Publishers, 231-40.

El-Zein, Fares, and Holly Sims. 2004. "Reforming War's Administrative Rubble in Lebanon." Public Administration and Development 24: 279-88. 
Englebert, Pierre. 2000. State Legitimacy and Development in Africa. Colorado: Lynne Rienner Publishers.

Eriksen, Erik O., and John E. Fossum. 2004. "Europe in Search of Legitimacy: Strategies of Legitimation Assessed." International Political Science Review 25(4): 435-59.

Evans, Martin. 2005. "Insecurity or Isolation? Natural Resources and Livelihoods in Lower Casamance." Canadian Journal of African Studies 39(2): 284-314.

Evans, Peter B. 1989. "Predatory, Developmental, and Other Apparatuses : A Comparative Political Economy Perspective on the Third World State." Sociological Forum: Special Issue: Comparative National Development: Theory and Facts for the 1990s 4(4): 561-87.

Fall, Aissatou. 2010. Understanding The Casamance Conflict: A Background. Accra. http://www.kaiptc.org/publications/monographs/monographs/monograph-7-aissatou.aspx.

Fawaz, Mona, and Isabelle Peillen. 2003. The Case of Beirut, Lebanon. Beirut. http://www.ucl.ac.uk/dpu-projects/Global_Report/cities/beirut.htm.

Fearon, James D. 2004. “Why Do Some Civil Wars Last So Much Longer than Others?” Journal of Peace Research 41(3): 275-301.

Foucher, Vincent. 2005. "La Guerre Des Dieux ? Religions et Séparatisme En Basse Casamance." Canadian Journal of African Studies 39(2): 363-90.

Frahm, Ole. 2015. "Making Borders and Identities in South Sudan." Journal of Contemporary African Studies 33(2): 251-67. http://www.tandfonline.com/doi/full/10.1080/02589001.2015.1070461.

François, Monika, and Inder Sud. 2006. "Promoting Stability and Development in Fragile and Failed States." Development Policy Review 24(2): 141-60.

Fraser, John. 1974. "Validating a Measure of National Political Legitimacy." American Journal of Political Science 18(1): 117-34.

Fukuyama, Francis. 2006. America at the Crossroads: Democracy, Power, and the Neoconservative Legacy. Connecticut: Yale University Press.

Gamble, David P. 1957. The Wolof of Senegambia. London: International African Institute.

Gaspard, Toufic K. 2004. A Political Economy of Lebanon, 1948-2002: The Limits of LaissezFaire. Leiden: Brill.

Geddes, Barbara. 1990. "How the Cases You Choose Affect the Answers You Get: Selection Bias in Comparative Politics." Political Analysis 2(1): 131-50.

Gehrold, Stefan, and Inga Neu. 2010. Caught Between Two Fronts: In Search of Lasting Peace 
in the Casamance Region. Berlin.

Gellar, Sheldon. 1995. Senegal: An Africam Nation between Islam and the West. Second edi. Boulder: Westview Press.

- 2005. Democracy in Senegal: Tocquevillian Analytics in Africa. New York: Palgrave.

Gemayel, Amine. 1992. Rebuilding Lebanon. Lanham: University Press of America.

Gerry, John. 2007. Case Study Research: Principles and Practices. New York: Cambridge University Press.

Ghani, Ashraf, and Clare Lockhart. 2008. Fixing Failed States: A Framework for Rebuilding a Fractured World. New York: Oxford University Press.

Ghosn, Faten, and Amal Khoury. 2011. "Lebanon after the Civil War: Peace or the Illusion of Peace?” Middle East Journal 65(3): 381-97.

Ghossain, Antoine. 1988. "Confessional Communities, Space and Political Reform in Lebanon." Social Compass 1 35(4): 563-83.

Gilley, Bruce. 2006a. "The Determinants of State Legitimacy: Results for 72 Countries." International Political Science Review 27(1): 47-71. - 2006b. "The Meaning and Measure of State Legitimacy: Results for 72 Countries." European Journal of Political Research 45(3): 499-525.

_ 2012. "State Legitimacy: An Updated Dataset for 52 Countries." European Journal of Political Research 51(5): 693-99. http://doi.wiley.com/10.1111/j.14756765.2012.02059.x\%5Cnhttps://sremote.pitt.edu/doi/10.1111/j.14756765.2012.02059.x/,DanaInfo=onlinelibrary.wiley.com+pdf (January 26, 2014).

Mac Ginty, Roger. 2010. "Warlords and the Liberal Peace: State-Building in Afghanistan." Conflict, Security \& Development 10(4): 577-98.

Gleditsch, Nils Petter. 1996. "Environmental Change, Security, and Conflict." In Turbulent Peace: The Challenges of Managing International Conflict1, eds. Chester A. Crocker, Osler Hampson, and Pamela Aall. Washington DC: United States Institute of Peace, 53-68.

Goldsmith, Arthur A. 2007. "Does Nation-Building Work? Reviewing the Record." In Governance in Post-Conflict Societies: Rebuilding Fragile States, London: Routledge, 2544.

Goodhand, Jonathan. 2006. Aiding Peace: The Role of NGOs in Armed Conflict. Colorado: Lynne Rienner Publishers.

Grawert, Elke. 2013. "Introduction." In Forging Two Nations: Insights on Sudan and South 
Sudan, ed. Elke Grawert. Addis Ababa: Organisation for Social Science Research in Eastern and Southern Africa, 15-51.

Grzymala-Busse, Anna. 2008. "Beyond Clientelism: Incumbent State Capture and State Formation.” Comparative Political Studies 41(4/5): 638-73.

Grzymala-Busse, Anna, and Pauline Jones Luong. 2002. "Reconceptualizing the State: Lessons from Post-Communism.” Politics \& Society 30(4): 529-54.

Gurowitz, Amy. 1999. "Mobilizing International Norms: Domestic Actors, Immigrants, and the Japanese State." World Politics 51(3): 413-45.

http://www.journals.cambridge.org/abstract_S0043887100009138.

Haddad, Simon. 2009. "Lebanon: From Consociationalism to Conciliation." Nationalism and Ethnic Politics 15(3-4): 398-416.

http://www.tandfonline.com/doi/abs/10.1080/13537110903346684 (March 4, 2014).

Hajjar, Sami G. 2009. "The Convoluted and Diminished Lebanese Democracy." Democracy and Security 5(3): 261-76. http://www.tandfonline.com/doi/abs/10.1080/17419160903304864 (March 10, 2014).

Hakim, Georges. 1966. "The Economic Basis of Lebanese Polity.” In Politics in Lebanon, ed. Leonard Binder. New York: John Wiley \& Sons, Inc, 57-69.

Haldén, Peter. 2010. "Systems-Building Before State-Building: On the Systemic Preconditions of State-Building." Conflict, Security \& Development 10(4): 519-45. http://www.tandfonline.com/doi/abs/10.1080/14678802.2010.500540.

Hameiri, Shahar. 2009. "Capacity and Its Fallacies: International State Building as State Transformation.” Millennium - Journal of International Studies 38(1): 55-81.

Hamzeh, A Nizar. 2000. "Lebanon's Islamists and Local Politics: A New Reality.” Third World Quarterly 21(5): 739-59.

Harb, Boutros. 1998. “Le Relancement D’une Vie Politique.” In Parties et Forces Politiques Au Liban: Renouveau et Enagagement, ed. Antoine Messarra. Beirut: Fondation Konrad Adenauer, 53-56.

Harb, Mona, and Reinoud Leenders. 2005. 'Know Thy Enemy: Hizbullah, 'terrorism' and the Politics of Perception.” Third World Quarterly 26(1): 173-97.

Harik, Judith. 1996. "Between Islam and the System: Sources and Implications of Popular Support for Lebanon's Hizballah.” Journal of Conflict Resolution 40(1): 41-67.

Hartzell, Caroline A. 2006. "Structuring the Peace: Negotiated Settlements and the Construction of Conflict Management Institutions." In Conflict Prevention and Peacebuilding in Post- 
War Societies: Sustaining the Peace, eds. T. David Mason and James D. Meernik. Oxon: Routledge, 31-52.

Hartzell, Caroline, Matthew Hoddie, and Donald Rothchild. 2001. "Stabilizing the Peace After Civil War: An Investigation of Some Key Variables.” International Organization 55(1): 183-208.

Hess, Steve. 2010. "Coming to Terms with Neopatrimonialism: Soviet and American NationBuilding Projects in Afghanistan." Central Asian Survey 29(2): 171-87.

Hottinger, Arnold. 1966. “Zu'ama' in Historical Perspective.” In Politics in Lebanon, ed. Leonard Binder. New York: John Wiley \& Sons, Inc, 85-106.

Hudson, Michael C. 1999. "Lebanon after Ta'if: Another Reform Opportunity Lost.” Arab Studies Quarterly 21(1): 27-40.

Hutchison, M. L., and K. Johnson. 2011. "Capacity to Trust? Institutional Capacity, Conflict, and Political Trust in Africa, 2000-2005." Journal of Peace Research 48(6): 737-52. http://jpr.sagepub.com/cgi/doi/10.1177/0022343311417981 (March 10, 2014).

Inbal, Aliza B., and Hanna Lerner. 2007. "Constitutional Design, Identity and Legitimacy in Post-Conflict Reconstruction." In Governance in Post-Conflict Societies: Rebuilding Fragile States, ed. Derick W. Brinkerhoff. London: Routledge, 45-63.

International Crisis Group. 2006. Israel/Hizbollah/Lebanon: Avoiding Renewed Conflict.

International Monetary Fund. 2006. Lebanon: Selected Issue. Washington DC. http://www.imf.org/external/pubs/ft/scr/2006/cr06200.pdf.

Iskandar, Adnan. 1964. Bureaucracy in Lebanon. Beirut: American University of Beirut. . 1996. Public Service Accountability in Lebanon. Beirut. http://ddc.aub.edu.lb/projects/pspa/PSAccount/PSAccount-0.html.

Jackman, Robert W. 1987. "Political Institutions and Voter Turnout in the Industrial Democracies." The American Political Science Review 81(2): 405-24.

Jad, Sana Souaid. 2011. The Balance Sheet Approach and the Public Debt Stock Analysis: The Case of Lebanon. Beirut. http://www.bdl.gov.lb/.

Jawad, Rana. 2002. "A Profile of Social Welfare in Lebanon: Assessing the Implications for Social Development Policy." Global Social Policy 2(3): 319-42.

Jok, Madut Jok. 2011. Diversity, Unity, and Nation Building in South Sudan. Washington DC. http://www.usip.org/sites/default/files/Diversity\%2C Unity\%2C and Nation Building in South Sudan \%28Jok\%29.pdf. 
Jong, Ferdinand De. 2005a. "A Joking Nation : Conflict Resolution in Senegal." Canadian Journal of African Studies 39(2): 391-415.

. 2005b. "Contested Casamance : Introduction." Canadian Journal of African Studies 39(2): 213-29.

Von Kaltenborn-Stachau, Henriette. 2008. The Missing Link-Fostering Positive Citizen-State Relations in Post-Conflict Environments. Washington DC. http://siteresources.worldbank.org/EXTGOVACC/Resources/CommGAPMissingLinkWeb. pdf.

Kameir, El Wathig. 2011. The Political Economy of South Sudan: A Scoping Analytical Study. Abidjan.

Kanaan, Nimat, and Randa Aboul-Hosn. 1998. "Mapping of Living Conditions in Lebanon." Mapping of Living Conditions in Lebanon (UNDP). http://www.undp.org.lb/programme/propoor/poverty/povertyinlebanon/molc/setting/A/1975.htm\# (November 2, 2015).

Kanol, Direnç. 2011. "Assessing the Legitimacy of the EU." Interdisciplinary Political Studies 1(0): 49-59.

Kaplan, Seth. 2008. “The Remarkable Story of Somaliland.” Journal of Democracy 19(3): 14357.

Kaufmann, Daniel, Aart Kraay, and Massimo Mastruzzi. 2010. The Worldwide Governance Indicators Methodology and Analytical Issues. Washington DC.

Keefer, Philip E., Ambar Narayan, and Tara Vishwanath. 2006. "Decentralization in Pakistan: Are Local Governments Likely to Be More Accountable than Central Governments?" In Decentralization and Local Governance in Developing Countries: A Comparative Perspective, eds. Pranab Bardhan and Dilip Mookherjee. Cambridge: MIT Press, 285-304.

Kerr, Malcolm H. 1966. "Political Decision Making in a Confessional Democracy." In Politics in Lebanon, ed. Leonard Binder. New York: John Wiley \& Sons, Inc, 167-86.

Khadiagala, Gilbert M. 1995. "State Collapse and Reconstruction in Uganda." In Collapsed States: The Disintegration and Reconstruction of Legitimate Authority, ed. I. William Zartman. Colorado: Lynne Rienner Publishers, 33-47.

Kingston, Paul, and Marie-Joëlle Zahar. 2004. "Rebuilding A House of Many Mansions: The Rise and Fall of Militia Cantons in Lebanon." In States Within States, eds. Paul Kingston and Ian S. Speaars. New York: Palgrave, 81-98.

Kisirwani, M., and W. M. Parle. 1987. "Assessing the Impact of the Post Civil War Period on the Lebanese Bureaucracy: A View from Inside.” Journal of Asian and African Studies 22(1- 
2): 17-29. http://jas.sagepub.com/cgi/doi/10.1177/002190968702200102.

Kisirwani, Maroun. 1997a. "Accountability of Lebanese Civil Servants: An Overview of Disciplinary Mechanisms.” In Lebanon Beyond 2000, eds. Amin Saikal and Geoffrey Jukes. Canberra: Centre for Middle Eastern and Central Asian Studies. - 1997b. "The Rehabilitation and Reconstruction of Lebanon." In Remaking the Middle East, eds. Paul J White and William S Logan. Oxford: Berg, 87-104.

Kisirwani, Maroun, and William M. Parle. 1987. "Assessing the Impact of the Post Civil War Period on the Lebanese Bureaucracy: A View from Inside." Journal of Asian and African Studies 22(1-2): 17-29.

Kitschelt, Herbert, and Steven I. Wilkinson. 2007. "Citizen-Politician Linkages: An Introduction." In Patrons, Clients, and Policies: Patterns of Democratic Accountability and Political Competition, eds. Herbert Kitschelt and Steven I. Wilkinson. Cambridge: Cambridge University Press, 1-49.

Kon, Madut. 2015. "Institutional Development, Governance, and Ethnic Politics in South Sudan.” Journal of Global Economics 3(2): 1-6. http://www.esciencecentral.org/journals/institutional-development-governance-and-ethnicpolitics-in-south-sudan-2375-4389-1000147.php?aid=57097.

Larson, Greg, Peter Biar Ajak, and Lant Pritchett. 2013. South Sudan's Capability Trap: Building a State with Disruptive Innovation. Cambridge. https://www.hks.harvard.edu/content/download/69085/1249150/version/1/file/268_SudanPDIA.pdf.

Leenders, Reinoud. 2012. Spoils of Truth: Corruption and State-Building in Postwar Lebanon. Ithaca: Cornell University Press.

LeRiche, Matthew, and Matthew Arnold. 2012. South Sudan: From Revolution to Independence. London: C. Hurst \& Co (Publishers) Ltd.

Levi, Margaret, and Audrey Sacks. 2009. "Legitimating Beliefs: Sources and Indicators." Regulation \& Governance 3(4): 311-33.

Levi, Margaret, Audrey Sacks, and Tom Tyler. 2009. "Conceptualizing Legitimacy, Measuring Legitimating Beliefs.” American Behavioral Scientist 53(3): 354-75.

Lipset, Seymour Martin. 1983. Political Man: The Social Bases of Politics. London: Heinemann. Lister, Sarah, and Andrew Wilder. 2005. "Strengthening Subnational Administration in Afghanistan: Technical Reform or State-Building?" Public Administration and Development 25(1): 39-48. 
Loehlin, John C. 1998. Latent Variable Models: An Introduction to Factor, Path, and Structural Analysis. Third. New Jersey: Lawrence Erlbaum Associates.

Low-beer, Ann. 2001. Paradigm Politics, School Textbooks and Cultural Identity: The Struggle in Bosnia and Hercegovina.

Lyons, Terrence. 2005. Demilitarizing Politics: Elections on the Uncertain Road to Peace. Colorado: Lynne Rienner Publishers.

Mane, Bacary Domingo. 2014. "POLE DE DEVELOPPEMENT DE LA CASAMANCE." Sud Online. http://www.sudonline.sn/au-dela-des-questions-economique-etadministrative_a_17983.html.

March, James G., and Johan P. Olsen. 1989. Institutions: The Organizational Basis of Politics. New York: The Free Press.

Marquette, Heather, and Danielle Beswick. 2011. "State Building, Security and Development: State Building as a New Development Paradigm?” Third World Quarterly 32(10): 1703-14.

Marshall, Monty G, and Keith Jaggers. 2002. Political Regime Characteristics and Transitions, 1800-2002: Dataset User's Manual. Maryland.

Marut, Jean-Claude. 2010. Le Conflit de Casamance: Ce Qui Disent Les Armes. Paris: Édition Karthala.

Mason, David T., Mehmet Gurses, Patrick T. Brandt, and Jason Michael Quinn. 2011. "When Civil Wars Recur: Conditions for Durable Peace after Civil Wars." International Studies Perspectives 12(2): 171-89.

Maxwell, Daniel, Kirsten Gelsdorf, and Martina Santschi. 2012. Researching Livelihoods and Services Affected by Conflict Livelihoods, Basic Services and Social Protection in South Sudan. London. http://community.eldis.org/.5a0b0243/Livelihoods basic services and social protection in Sri Lanka.pdf.

Mayall, James. 2005. "The Legacy of Colonialism." In Making States Work: State Failure and the Crisis of Governance, eds. Simon Chesterman, Michael Ignatieff, and Ramesh Thakur. New York: United Nations University Press, 36-58.

Mcloughlin, Claire. 2014. "When Does Service Delivery Improve the Legitimacy of a Fragile or Conflict-Affected State?" Governance: n/a-n/a. http://doi.wiley.com/10.1111/gove.12091 (May 2, 2014).

von der Mehden, Fred R., and Kim Quaile Hill. 1980. "Area Experts' Images of African Nations.” Comparative Political Studies 12(4): 497-510.

Meierhenrich, Jens. 2004. "Forming States After Failure.” In When States Fail: Causes and 
Consequences, ed. Rot. Princeton: Princeton University Press, 153-68.

Mendy, Toumany. 2006. Politique et Puissance de L'argent Au Sénégal: Les Désarrois D'un Peuple Innocent. Paris: L'Harmattan.

Messarra, Antoine. 1998. "L'expérience Libanais Du Parti Dans Le Cadre Arabe.” In Partis et Forces Politiques Au Liban: Renouveau et Engagement, ed. Antoine Messarra. Beirut: Fondation Konrad Adenauer, 15-40.

Migdal, Joel S. 2001. State in Society: Studying How States and Societies Transform and Constitute One Another. Cambridge: Cambridge University Press.

Miller, Benjamin. 2015. "Stateness, National Self-Determination and War and Peace in the Twenty-First Century." Ethnopolitics 14(5): 531-39. http://www.tandfonline.com/doi/full/10.1080/17449057.2015.1051818.

Ministry of Foreign Affairs Denmark. 2005. A Joint Evaluation: Humanitarian and Reconstruction Assistance to Afghanistan, 2001-05: From Denmark, Ireland, The Netherlands, Sweden and the United Kingdom.

Ministry of Social Affairs, and United Nations Development Programme. 2007. The effects of brief mindfulness intervention on acute pain experience: An examination of individual difference Development of Mapping of Living Conditions in Lebanon, 1995-2004: A Comparison with the Results of "Mapping of Living Conditions in Lebanon, 1998." Beirut.

Mitchell, Timothy. 1991. "The Limits of the State: Beyond Statist Approaches and Their Critics." The American Political Science Review 85(1): 77-96.

Mukhopadhyay, Dipali. 2009. "Disguised Warlordism and Combatanthood in Balkh: The Persistence of Informal Power in the Formal Afghan State." Conflict, Security \& Development 9(4): 535-64.

Muller, Edward N., Thomas O. Jukam, and Mitchell A. Seligson. 1982. "Diffuse Political Support and Antisystem Political Behavior : A Comparative Analysis." American Journal of Political Science 26(2): 240-64.

Najem, Tom Pierre. 2000. Lebanon's Renaissance: The Political Economy of Reconstruction. Reading: Ithaca Press.

Nassif, Georges. 1998. "Les Parties Libanaises En Crise: Comment Transforment-Elles Politiquement." In Parties et Forces Politiques Au Liban: Renouveau et Enagagement, ed. Antoine Messarra. Beirut: Fondation Konrad Adenauer, 123-29.

Ndegwa, Stephen N, and Brian Levy. 2003. The Politics of Decentralization in Africa: A Comparative Analysis. Washington DC. http://www1.worldbank.org/publicsector/LearningProgram/Decentralization/Ndegwa.pdf. 
Netemeyer, Richard G., William O. Bearden, and Subhash Sharma. 2003. Scaling Procedures: Issues and Applications. California: Sage Publications, Inc.

Nettl, J.P. 1968. "The State as a Conceptual Variable.” World Politics 20(4): 559-92.

News, BBC. 2009. "Senegal Apology for Christ â€ $\mathrm{TM}^{\mathrm{TM}}$ Slur '." BBC News. http://news.bbc.co.uk/go/pr/fr/-/2/hi/africa/8435805.stm.

Norton, Augustus Richard. 2000. "Hizballah and the Israeli Withdrawal from Southern Lebanon." Journal of Palestine Studies 30(1): 22-35.

O Senegal. 2014. "Une Autoroute Maritime Se Développe Entre Dakar et La Casamance." $O$ Senegal. http://www.osenegal.com/news/transport/autoroute-maritime-se-developpe-dakarcasamance/.

OECD. 2010. The State's Legitimacy in Fragile Situations: Unpacking Complexity. http://www.oecd.org/dac/incaf/44794487.pdf.

Ottaway, Marina. 1995. "Democratization in Collapsed States." In Collapsed States: The Disintegration and Restoration of Legitimate Authority, ed. I. William Zartman. Colorado: Lynne Rienner Publishers, 235-50.

Oxhorn, Philip. 2004. "Unraveling the Puzzle of Decentralization." In Decentralization, Democratic Governance and Civil Society in Comparative Perspectives, eds. Philip Oxhorn, Joseph S. Tulchin, and Andrew D. Selee. Washington DC: Woodrow Wilson Centre Press, 3-32.

Ozer, Daniel J. 1999. "Four Principles for Personality Assessment." In Handbook of Personality: Theory and Research, eds. Lawrence A. Pervin and Oliver P. John. New York: Guilford.

Paris, Roland. 2005. "Wilson's Ghost: The Faulty Assumptions of Postconflict Peacebuilding." In Turbulent Peace: The Challenges of Managing International Conflict, eds. Chester A. Crocker, Fen Osler Hampson, and Pamela Aall. Washington DC: United States Institute of Peace, $765-84$.

- 2006. "NATO’s Choice in Afghanistan: Go Big or Go Home." Policy Options: 35-43.

Picard, Elizabeth. 1993. The Lebanese Shi'a and Political Violence. Geneva.

Pierson, Paul. 2004. Politics in Time: History, Institutions, and Social Analysis. Princeton: Princeton University Press.

Posner, Daniel. 2004. "Civil Society and the Reconstruction of Failed States." In When States Fail: Causes and Consequences, ed. Robert Rotberg. Princeton: Princeton University Press, $237-55$.

Radon, Jenik, and Sarah Logan. 2014. "South Sudan: Governance Arrangements, War, and 
Peace." Journal of International Affairs 68(1): 149-67.

http://search.ebscohost.com/login.aspx?direct=true\&db=buh\&AN=100052751\&site=ehostlive.

Regan, Patrick M. 2002. "Third-Party Interventions and the Duration of Intrastate Conflicts." The Journal of Conflict Resolution 46(1): 55-73.

Riak, Maker M. 2013. "Reversing the Trend of Corruption in South Sudan: Is Rwanda a Suitable Model?" Journal of Developing Societies 29(4): 487-501.

http://jds.sagepub.com/cgi/doi/10.1177/0169796X13504681.

Rotberg, Robert I. 2004. "When States Fail: Causes and Consequences." In When States Fail: Causes and Consequences, ed. Robert I. Rotberg. New Jersey: Princeton University Press, $1-49$.

Saidi, Nasser H. 1994. "The Economic Reconstruction of Lebanon: War, Peace, and Modernization.” In Peace for Lebanon? From War to Reconstruction, ed. Deirdre Collings. Boulder: Lynne Rienner Publishers, 195-212.

Salamy, Imad. 2014. The Government and Politics of Lebanon. Oxon: Routledge.

Saleh, Ali Salman, and Charles Harvie. 2005. "An Analysis of Public Sector Deficits and Debt in Lebanon: 1970-2000.” Middle East Review of International Affairs 9(4): 106-36.

Salem, Elie Adib. 1973. Modernization without Revolution: Lebanon's Experience. London: Indiana University Press.

Salloukh, Bassel F. 2006. "The Limits of Electoral Engineering in Divided Societies: Elections in Postwar Lebanon." Canadian Journal of Political Science 39(3): 635-55.

Salloukh, Bassel F., Rabie Barakat, and Jinan S. Al-Habbal. 2015. Politics of Sectarianism in Postwar Lebanon. London: Pluto Press.

Sambanis, Nicholas. 2001. "Do Ethnic and Nonethnic Civil Wars Have the Same Causes ?: A Theoretical and Empirical Inquiry (Part 1)." The Journal of Conflict Resolution 45(3): 25982.

Saouli, Adham. 2003. "Lebanon's Hizbullah: The Quest for Survival.” World Affairs 166(2): 7180.

Al Sayegh, Daoud. 1998. "Organisations Sectaires et Les Forces Politiques: La Recherche Des Limites." In Parties et Forces Politiques Au Liban: Renouveau et Enagagement, ed. Antoine Messarra. Beirut: Fondation Konrad Adenauer, 167-72.

Schaffer, Frederic C. 2000. Democracy in Translation: Understanding Politics in an Unfamiliar Culture. Ithaca: Cornell University Press. 
Scharpf, Fritz W. 2003. Problem Solving Effectiveness and Democratic Accountability in the EU.

Schenker, David. 2007. Lebanon Goes to Paris III: High Stakes in France and Beirut.

Washington DC. http://www.washingtoninstitute.org/policy-analysis/view/lebanon-goes-toparis-iii-high-stakes-in-france-and-beirut.

Sedgwick, Mark. 2010. "Measuring Egyptian Regime Legitimacy.” Middle East Critique 19(3): 251-67. http://www.tandfonline.com/doi/abs/10.1080/19436149.2010.514474 (March 10, 2014).

Selee, Andrew D., and Joseph S. Tulchin. 2004. "Decentralization and Democratic Governance: Lessons and Challenges." In Decentralization, Democratic Governance and Civil Society in Comparative Perspectives, eds. Philip Oxhorn, Joseph S. Tulchin, and Andrew D. Selee. London: Woodrow Wilson Centre Press, 295-320.

Shapiro, Ian. 2001. "Problems, Methods, and Theories in the Study of Politics, or What's Wrong with Political Science and What to Do about It." Political Theory 30(4): 596-619.

Sharan, Timor. 2011. "The Dynamics of Elite Networks and Patron-Client Relations in Afghanistan.” Europe-Asia Studies 63(6): 1109-27.

Siegle, Joseph, and Patrick O’Mahony. 2010. "Decentralization and Internal Conflict.” In Making Decentralization Work: Democracy, Development, and Security, eds. Ed Connerley, Kent Eaton, and Paul Smoke. Colorado: Lynne Rienner Publishers, 135-66.

De Simone, Sara. 2015. "Building a Fragmented State: Land Governance and Conflict in South Sudan.” Journal of Peacebuilding and Development 10(3): 60-73. http://dx.doi.org/10.1080/15423166.2015.1085812.

Sisk, Timothy. 2013. Statebuilding: Consolidating Peace After Conflict. London: Polity Press.

Skocpol, Theda. 1979. States \& Social Revolutions: A Comparative Analysis of France, Russia, \& China. Cambridge: Cambridge University Press.

Sobek, David. 2010. "Masters of Their Domains: The Role of State Capacity in Civil Wars." Journal of Peace Research 47(3): 267-71.

Le Soleil. 2012. "Benoit Sambou Annonce Un Projet de 350 Millions : Les Zones Post-Conflit Vont Relancer L'agriculture En Casamance.” Le Soleil.

http://www.lesoleil.sn/index.php?option=com_content\&view=article\&id=16706:benoitsambou-annonce-un-projet-de-350-millions-les-zones-post-conflit-vont-relancerlagriculture-en-casamance\&catid=78:a-la-une.

South Sudan Bureau for Community Security and Small Arms Control, South Sudan Peace and Reconciliation Commission, and United Nations Development Programme. 2012. Community Consultation Report: Warrap State, South Sudan. Juba. 
http://www.undp.org/content/dam/southsudan/library/Documents/CSAC Reports/UNDPSS-Warrap-consult-12.pdf.

South Sudan National Bureau of Statistics. 2011. South Sudan Statistical Yearbook 2011. Juba. http://static1.1.sqspedn.com/static/f/750842/18935415/1349357346780/South+Sudan+Statis tical + Yearbook $+2011+$ FINAL.pdf?token $=x c r h+X T e o 9 v W w 3 H A w j Y s 5 Y t H A 48=$.

Starr, S. Frederick. 2006. "Sovereignty and Legitimacy in Afghan Nation-Building." In NationBuilding: Beyond Afghanistan and Iraq, ed. Francis Fukuyama. Baltimore: The Johns Hopkins University Press, 107-24.

Streeck, Wolfgang, and Kathleen Thelen. 2005. "Introduction: Institutional Change in Advanced Political Economies." In Beyond Continuity: Institutional Change in Advanced Economies, eds. Wolfgang Streeck and Kathleen Thelen. Oxford: Oxford University Press, 1-39.

Suchman, Mark C. 1995. "Managing Legitimacy: Strategic and Institutional Approaches." The Academy of Management Review 20(3): 571-610.

The World Bank. 2005. "Senegal Receives 20 Million for Emergency Recovery Project in Casamance." World Bank.

http://web.worldbank.org/external/default/main?pagePK=64027221\&piPK=64027220\&the SitePK=296303\&menuPK=296336\&Projectid=P069207.

Thies, Cameron G. 2010. "Of Rulers, Rebels, and Revenue: State Capacity, Civil War Onset, and Primary Commodities." Journal of Peace Research 47(3): 321-32.

Traboulsi, Fawwaz. 2007. A History of Modern Lebanon. London: Pluto Press.

Treier, Shawn, and Simon Jackman. 2008. "Democracy as a Latent Variable.” American Journal of Political Science 52(1): 201-17.

Van der Vossen, Bas. 2012. "The Asymmetry of Legitimacy." Law and Philosophy 31(5): 56592.

de Waal, Alex. 2014. "When Kleptocracy Becomes Insolvent: Brute Causes of the Civil War in South Sudan." African Affairs 113(452): 347-69.

Walter, Barbara F. 2004. "Does Conflict Beget Conflict? Explaining Recurring Civil War." Journal of Peace Research 41(3): 371-88.

Washburne, Sarah Lykes. 2013. "Post-War Governance and the Impact of International Aid in South Sudan.” In Forging Two Nations: Insights on Sudan and South Sudan, ed. Elke Grawert. Addis Ababa: Organisation for Social Science Research in Eastern and Southern Africa, 188-200.

Wassara, Samson S. 2015. "South Sudan: State Sovereignty Challenged at Infancy." Journal of 
Eastern African Studies 9(4): 634-39.

http://www.tandfonline.com/doi/full/10.1080/17531055.2015.1105439.

Weil, Frederick D. 1989. "The Sources and Structures of Legitimation in Western Democracies: A Consolidated Model Tested with Time-Series Data in Six Countries since World War II." American Sociological Review 54(5): 682-706.

Widner, Jennifer A. 2004. "Building Effective Trust in the Aftermath of Severe Conflict." In When States Fail: Causes and Consequences, ed. Robert Rotberg. Princeton: Princeton University Press, 222-36.

Wood, Elisabeth Jean. 2008. "The Social Processes of Civil War: The Wartime Transformation of Social Networks." Annual Review of Political Science 11(1): 539-61. http://www.annualreviews.org/doi/abs/10.1146/annurev.polisci.8.082103.104832.

Young, John. 2006. The South Sudan Defence Forces in the Wake of the Juba Declaration. Geneva. http://www.smallarmssurveysudan.org/fileadmin/docs/working-papers/HSBA-WP01-SSDF.pdf.

Zambakari, Christopher. 2013. "Post-Referendum South Sudan: Political Drivers of Violence and the Challenge of Democratic Nation-Building." In Forging Two Nations: Insights on Sudan and South Sudan, ed. Elke Grawert. Addis Ababa: Organisation for Social Science Research in Eastern and Southern Africa, 98-111.

Zanotti, L. 2008. "Imagining Democracy, Building Unsustainable Institutions: The UN Peacekeeping Operation in Haiti." Security Dialogue 39(5): 539-61.

El Zein, Fares. 2003. Dissertation Thesis "Politics of Administrative Reform in Post War Lebanon." University at Albany.

Zürcher, Christoph et al. 2013. Costly Democracy: Peacebuilding \& Democratization After War. Stanford, California: Stanford University Press.

Abla, Zeina, Amal Karaki, and Nada Dimachkieh Sweidan. 2014. Lebanon Millennium Development Goals Report 2013-2014. Beirut. http://www.lb.undp.org/content/lebanon/en/home/library/mdg/lebanon-mdg-report-2013$2014 /$.

Afrique Jet. 2014. "Projet Pôle de Développement de La Casamance.” Afrique Jet. http://www.afriquejet.com/afrique-ouest/3654-projet-pole-de-developpement-de-lacasamance.html.

Allen, Daniel. 2010. "New Directions in the Study of Nation-Building: Views through the Lens of Path Dependence.” International Studies Review 12(3): 413-29. 
Angeles, Leonora C., and Francisco A. Magno. 2004. “The Philippines: Decentralization, Local Governments, and Citizen Action." In Decentralization, Democratic Governance and Civil Society in Comparative Perspectives, eds. Philip Oxhorn and Joseph S. Tulchin.

Washington DC: Woodrow Wilson Centre Press, 211-65.

Armstrong, Andrea, and Barnett Rubin. 2005. "The Great Lakes and South Central Asia.” In Making States Work: State Failure and the Crisis of Governance, eds. Simon Chesterman, Michael Ignatieff, and Ramesh Thakur. New York: United Nations University Press, 79101.

Attipoe, Olympio, Biplove Choudhary, and Nicholas Jonga. 2014. An Analysis of Government Budgets in South Sudan from a Human Development Perspective. Juba. http://www.undp.org/content/dam/southsudan/library/Discussion Papers/SS-Discussion paper final.pdf.

Atzili, Boaz. 2010. "State Weakness and 'Vacuum of Power' in Lebanon." Studies in Conflict \& Terrorism 33(8): 757-82.

http://www.tandfonline.com/doi/abs/10.1080/1057610X.2010.494172 (March 7, 2014).

Baaklini, Abdo I. 1976. Legislative and Political Development: Lebanon, 1842-1972. Durnham: Duke University Press.

Barbara, Julien. 2008. "Antipodean Statebuilding: The Regional Assistance Mission to Solomon Islands and Australian Intervention in the South Pacific." Journal of Intervention and Statebuilding 2(2): 123-49.

Bardhan, Pranab, and Dilip Mookherjee. 2006. "The Rise of Local Governments: An Overview." In Decentralization and Local Governance in Developing Countries: A Comparative Perspective, eds. Pranab Bardhan and Dilip Mookherjee. Cambridge: MIT Press, 1-52.

Baroudi, Sami E. 1998. "Economic Conflict in Postwar Lebanon: State-Labor Relations Between 1992 and 1997." Middle East Journal 52(4): 531-50.

Beck, Linda J. 2008. Brokering Democracy in Africa: The Rise of Clientelist Democracy in Senegal. New York: Palgrave.

Beetham, David, and Christopher Lord. 1998. Legitimacy and the EU. London: Addison-Wesley Longman.

Bellamy, Paul. 2007. "Introduction.” In Civil Wars of the World: Major Conflicts Since World War II, eds. Karl Jr Derouen and Uk Heo. Santa Barbara, California: ABC-CLIO Inc., 1-26. Bennett, Andrew, and Colin Elman. 2006. "Qualitative Research: Recent Developments in Case Study Methods." Annual Review of Political Science 9(1): 455-76.

http://www.annualreviews.org/doi/abs/10.1146/annurev.polisci.8.082103.104918 (February 
$21,2014)$.

Blair, Harry. 2007. "Rebuilding and Reforming Civil Services in Post-Conflict Societies." In Governance in Post-Conflict Societies: Rebuilding Fragile States, ed. Derick W.

Brinkerhoff. London: Routledge, 161-84.

Blomberg, S Brock, Gregory D Hess, and Siddharth Thacker. 2006. "On the Conflict Poverty Nexus." Economics and Politics 18(3): 237-67. http://www.blackwellsynergy.com/doi/abs/10.1111/j.1468-0343.2006.00170.x.

Bollen, Kenneth A. 1980. "Issues in the Comparative Measurement of Political Democracy." American Sociological Review 45(3): 370-90. . 1986. "Political Rights and Political Liberties in Nations: An Evaluation of Human Rights Measures, 1950 to 1984." Human Rights Quarterly 8(4): 567-91.

- 1990. "Political Democracy: Conceptual and Measurement Traps." Studies In Comparative International Development 25(1): 7-24.

—. 2011. "Evaluating Effect, Composite, and Casual Indicators in Structural Equation Models." MIS Quarterly 35(2): 359-72.

Bollen, Kenneth A, and Richard Lennox. 1991. "Conventional Wisdom on Measurement: A Structural Equation Perspective.” Psychological Bulletin 110(2): 305-14.

Bollen, Kenneth A, and Pamela Paxton. 2000. "Subjective Measures of Liberal Democracy." Comparative Political Studies 33(1): 58-86.

Bollen, Kenneth A, and Kwok-fai Ting. 2000. "A Tetrad Test for Causal Indicators." Psychological Methods 5(1): 3-22.

Branch, Adam, and Zachariah Cherian Mampilly. 2005. "Winning the War, but Losing the Peace? The Dilemma of SPLM/A Civil Administration and the Tasks Ahead." The Journal of Modern African Studies 43(1): 1-20.

Brinkerhoff, Derick W. 2005. "Rebuilding Governance in Failed States and Post-Conflict Societies: Core Concepts and Cross-Cutting Themes." Public Administration and Development 25(1): 3-14.

_ 2007. "Introduction - Governance Challenges in Fragile States: Re-Establishing Legitimacy, Rebuilding Effectiveness, and Reconstituting Legitimacy." In Governance in Post-Conflict Societies: Rebuilding Fragile States, ed. Derick W. Brinkerhoff. London: Routledge, 1-21.

Brinkerhoff, Derick W., and Ronald W. Johnson. 2009. "Decentralized Local Governance in Fragile States: Learning from Iraq." International Review of Administrative Sciences 75(4): 
$585-607$.

Brosché, Johan. 2016. "Crisis of Governance in South Sudan : Electoral Politics and Violence in the World's Newest Nation.” Journal of Modern African Studies 54(1): 67-90.

Busumtwi-Sam, James. 2004. "Development and Peacebuilding: Conceptual and Operational Deficits in International Assistance." In Durable Peace: Challenges for Peacebuilding in Africa, eds. Taiser M. Ali and Robert O. Matthews. Toronto: University of Toronto Press, 315-53.

Cammett, Melanie. 2013. Democracy in Post-Invasion Iraq.

http://watson.brown.edu/costsofwar/files/cow/imce/papers/2013/Democracy in PostInvasion Iraq.pdf.

- 2014. Compassionate Communalism: Welfare and Sectarianism in Lebanon. Ithaca: Cornell University Press.

Caplan, Richard. 2004. "Partner or Patron? International Civil Administration and Local Capacity-Building.” International Peacekeeping 11(2): 229-47.

Chassay, Clancy. 2006. “Christian Leader Says Lebanese Opposition Ready for Power.” The Guardian. http://www.theguardian.com/world/2006/dec/13/syria.lebanon.

Coburn, Noah. 2011. Bazaar Politics: Power \& Pottery in an Afghan Market Town. California: Stanford University Press.

Cole, Elizabeth A., and Judy Barsalou. 2006. Unite or Divide? The Challenges of Teaching History in Societies Emerging from Violent Conflict.

Collier, Paul. 2002. Aid, Policy and Growth in Post-Conflict Countries.

Collier, Paul, and Anke Hoeffler. 1998. "On the Causes of Civil War." Oxford Handbook of the Economics of Peace and Conflict 50: 563-73.

—. 2004. "Greed and Grievance in Civil War." Oxford Economic Papers 56(4): 563-95.

Cook, Traci D. 2007. A Place To Call Their Own: Southern Sudanese Comment on the Hard Work Adn Struggles of Self-Governance. Washington DC.

Crow, Ralph E, and Adnan Iskandar. 1961. "Administrative Reform in Lebanon.” International Review of Administrative Sciences 27(3): 293-307.

Dahl, Robert. 1971. Polyarchy: Participation and Opposition. New Haven: Yale University Press.

Diallo, Boucounta. 2009. La Crise Casamançaise: Problématique et Voies de Solutions. Paris:

L'Harmattan. 
Diamond, Larry, and Marc F. Plattner. 2006. Electoral Systems and Democracy. Baltimore: The Johns Hopkins University Press.

Dibeh, Ghassan. 2005. 44 The Political Economy of Postwar Reconstruction in Lebanon. Helsinki.

Dinnen, Sinclair. 2007. "A Comment on State-Building in Solomon Islands." The Journal of Pacific History 42(2): 255-63.

- 2008. "The Solomon Islands Intervention and the Instabilities of the Post-Colonial State." Global Change, Peace \& Security 20(3): 339-55.

Dodge, Toby. 2013. "Intervention and Dreams of Exogenous Statebuilding: The Application of Liberal Peacebuilding in Afghanistan and Iraq." Review of International Studies 39(5): 1189-1212. http://journals.cambridge.org/article_S0260210513000272.

Dodge, Tony. 2011. "Domestic Politics and State-Building." In Afghanistan: To 2015 and beyond, eds. Toby Dodge and Nicholas Redman. International Institute for Strategic Studies, 69-96.

Doyle, Michael W., and Nicholas Sambanis. 2000. "International Peacebuilding: A Theoretical and Quantitative Analysis." American Political Science Review 94(4): 779-801. http://www.drworley.org/NSPcommon/Nation Building/2000,12 APSR Doyle Sambanis.pdf.

. 2006. Making War and Building Peace. New Jersey: Princeton University Press.

Ducci, María Elena. 2004. "Local Governance and Democracy: The View from the Chilean Border." In Decentralization, Democratic Governance and Civil Society in Comparative Perspectives, eds. Philip Oxhorn, Joseph S. Tulchin, and Andrew D. Selee. Washington DC: Woodrow Wilson Centre Press, 119-39.

Eaton, Kent, and Larry Schroeder. 2010. "Measuring Decentralization.” In Making Decentralization Work: Democracy, Development, and Security, eds. Ed Connerley, Kent Eaton, and Paul Smoke. Colorado: Lynne Rienner Publishers, 167-90.

Von Einsiedel, Sebastian. 2005. "Policy Responses to State Failure." In Making States Work: State Failure and the Crisis of Governance, eds. Simon Chesterman, Michael Ignatieff, and Ramesh Thakur. New York: United Nations University Press, 13-35.

El-Khazen, Farid. 1998. "Les Alliances et Les Conflits Entre Les Parties Politiques Au Liban." In Parties et Forces Politiques Au Liban: Renouveau et Enagagement, ed. Antoine Messarra. Beirut: Fondation Konrad Adenauer, 133-42.

-2000. The Breakdown of the State in Lebanon: 1967-1976. Cambridge: Harvard University Press. 
El-Mufti, Karim. 2011. Public Policy Initiative The Management of Public Interest in Lebanon, a Broken Concept. Beirut.

http://policylebanon.org/topmenu/policyareas/areas/Ressource.html?Id=79\#.

El-Solh, Raghid. 994. "Religious Identity and Citizenship: An Overview of Perspectives." In Peace for Lebanon? From War to Reconstruction1, ed. Deidre Collings. Boulder: Lynne Rienner Publishers, 231-40.

El-Zein, Fares, and Holly Sims. 2004. "Reforming War's Administrative Rubble in Lebanon." Public Administration and Development 24: 279-88.

Englebert, Pierre. 2000. State Legitimacy and Development in Africa. Colorado: Lynne Rienner Publishers.

Eriksen, Erik O., and John E. Fossum. 2004. "Europe in Search of Legitimacy: Strategies of Legitimation Assessed." International Political Science Review 25(4): 435-59.

Evans, Martin. 2005. "Insecurity or Isolation? Natural Resources and Livelihoods in Lower Casamance." Canadian Journal of African Studies 39(2): 284-314.

Evans, Peter B. 1989. "Predatory, Developmental, and Other Apparatuses : A Comparative Political Economy Perspective on the Third World State." Sociological Forum: Special Issue: Comparative National Development: Theory and Facts for the 1990s 4(4): 561-87.

Fall, Aissatou. 2010. Understanding The Casamance Conflict: A Background. Accra. http://www.kaiptc.org/publications/monographs/monographs/monograph-7-aissatou.aspx.

Fawaz, Mona, and Isabelle Peillen. 2003. The Case of Beirut, Lebanon. Beirut. http://www.ucl.ac.uk/dpu-projects/Global_Report/cities/beirut.htm.

Fearon, James D. 2004. “Why Do Some Civil Wars Last So Much Longer than Others?” Journal of Peace Research 41(3): 275-301.

Foucher, Vincent. 2005. "La Guerre Des Dieux ? Religions et Séparatisme En Basse Casamance." Canadian Journal of African Studies 39(2): 363-90.

Frahm, Ole. 2015. "Making Borders and Identities in South Sudan." Journal of Contemporary African Studies 33(2): 251-67. http://www.tandfonline.com/doi/full/10.1080/02589001.2015.1070461.

François, Monika, and Inder Sud. 2006. "Promoting Stability and Development in Fragile and Failed States.” Development Policy Review 24(2): 141-60.

Fraser, John. 1974. "Validating a Measure of National Political Legitimacy." American Journal of Political Science 18(1): 117-34.

Fukuyama, Francis. 2006. America at the Crossroads: Democracy, Power, and the 
Neoconservative Legacy. Connecticut: Yale University Press.

Gamble, David P. 1957. The Wolof of Senegambia. London: International African Institute.

Gaspard, Toufic K. 2004. A Political Economy of Lebanon, 1948-2002: The Limits of LaissezFaire. Leiden: Brill.

Geddes, Barbara. 1990. "How the Cases You Choose Affect the Answers You Get: Selection Bias in Comparative Politics." Political Analysis 2(1): 131-50.

Gehrold, Stefan, and Inga Neu. 2010. Caught Between Two Fronts: In Search of Lasting Peace in the Casamance Region. Berlin.

Gellar, Sheldon. 1995. Senegal: An Africam Nation between Islam and the West. Second edi. Boulder: Westview Press.

- 2005. Democracy in Senegal: Tocquevillian Analytics in Africa. New York: Palgrave.

Gemayel, Amine. 1992. Rebuilding Lebanon. Lanham: University Press of America.

Gerry, John. 2007. Case Study Research: Principles and Practices. New York: Cambridge University Press.

Ghani, Ashraf, and Clare Lockhart. 2008. Fixing Failed States: A Framework for Rebuilding a Fractured World. New York: Oxford University Press.

Ghosn, Faten, and Amal Khoury. 2011. "Lebanon after the Civil War: Peace or the Illusion of Peace?” Middle East Journal 65(3): 381-97.

Ghossain, Antoine. 1988. "Confessional Communities, Space and Political Reform in Lebanon." Social Compass1 35(4): 563-83.

Gilley, Bruce. 2006a. "The Determinants of State Legitimacy: Results for 72 Countries." International Political Science Review 27(1): 47-71.

_ 2006b. "The Meaning and Measure of State Legitimacy: Results for 72 Countries." European Journal of Political Research 45(3): 499-525.

_ 2012. "State Legitimacy: An Updated Dataset for 52 Countries." European Journal of Political Research 51(5): 693-99. http://doi.wiley.com/10.1111/j.14756765.2012.02059.x\%5Cnhttps://sremote.pitt.edu/doi/10.1111/j.14756765.2012.02059.x/,DanaInfo=onlinelibrary.wiley.com+pdf (January 26, 2014).

Mac Ginty, Roger. 2010. "Warlords and the Liberal Peace: State-Building in Afghanistan." Conflict, Security \& Development 10(4): 577-98.

Gleditsch, Nils Petter. 1996. "Environmental Change, Security, and Conflict." In Turbulent Peace: The Challenges of Managing International Conflict1, eds. Chester A. Crocker, Osler 
Hampson, and Pamela Aall. Washington DC: United States Institute of Peace, 53-68.

Goldsmith, Arthur A. 2007. "Does Nation-Building Work? Reviewing the Record.” In Governance in Post-Conflict Societies: Rebuilding Fragile States, London: Routledge, 2544.

Goodhand, Jonathan. 2006. Aiding Peace: The Role of NGOs in Armed Conflict. Colorado: Lynne Rienner Publishers.

Grawert, Elke. 2013. "Introduction.” In Forging Two Nations: Insights on Sudan and South Sudan, ed. Elke Grawert. Addis Ababa: Organisation for Social Science Research in Eastern and Southern Africa, 15-51.

Grzymala-Busse, Anna. 2008. "Beyond Clientelism: Incumbent State Capture and State Formation." Comparative Political Studies 41(4/5): 638-73.

Grzymala-Busse, Anna, and Pauline Jones Luong. 2002. "Reconceptualizing the State: Lessons from Post-Communism." Politics \& Society 30(4): 529-54.

Gurowitz, Amy. 1999. "Mobilizing International Norms: Domestic Actors, Immigrants, and the Japanese State.” World Politics 51(3): 413-45. http://www.journals.cambridge.org/abstract_S0043887100009138.

Haddad, Simon. 2009. "Lebanon: From Consociationalism to Conciliation." Nationalism and Ethnic Politics 15(3-4): 398-416. http://www.tandfonline.com/doi/abs/10.1080/13537110903346684 (March 4, 2014).

Hajjar, Sami G. 2009. "The Convoluted and Diminished Lebanese Democracy.” Democracy and Security 5(3): 261-76. http://www.tandfonline.com/doi/abs/10.1080/17419160903304864 (March 10, 2014).

Hakim, Georges. 1966. "The Economic Basis of Lebanese Polity.” In Politics in Lebanon, ed. Leonard Binder. New York: John Wiley \& Sons, Inc, 57-69.

Haldén, Peter. 2010. "Systems-Building Before State-Building: On the Systemic Preconditions of State-Building." Conflict, Security \& Development 10(4): 519-45. http://www.tandfonline.com/doi/abs/10.1080/14678802.2010.500540.

Hameiri, Shahar. 2009. “Capacity and Its Fallacies: International State Building as State Transformation.” Millennium - Journal of International Studies 38(1): 55-81.

Hamzeh, A Nizar. 2000. “Lebanon's Islamists and Local Politics: A New Reality." Third World Quarterly 21(5): 739-59.

Harb, Boutros. 1998. “Le Relancement D’une Vie Politique.” In Parties et Forces Politiques Au Liban: Renouveau et Enagagement, ed. Antoine Messarra. Beirut: Fondation Konrad 
Adenauer, 53-56.

Harb, Mona, and Reinoud Leenders. 2005. 'Know Thy Enemy: Hizbullah, 'terrorism' and the Politics of Perception." Third World Quarterly 26(1): 173-97.

Harik, Judith. 1996. "Between Islam and the System: Sources and Implications of Popular Support for Lebanon's Hizballah.” Journal of Conflict Resolution 40(1): 41-67.

Hartzell, Caroline A. 2006. "Structuring the Peace: Negotiated Settlements and the Construction of Conflict Management Institutions." In Conflict Prevention and Peacebuilding in PostWar Societies: Sustaining the Peace, eds. T. David Mason and James D. Meernik. Oxon: Routledge, 31-52.

Hartzell, Caroline, Matthew Hoddie, and Donald Rothchild. 2001. "Stabilizing the Peace After Civil War: An Investigation of Some Key Variables.” International Organization 55(1): 183-208.

Hess, Steve. 2010. "Coming to Terms with Neopatrimonialism: Soviet and American NationBuilding Projects in Afghanistan." Central Asian Survey 29(2): 171-87.

Hottinger, Arnold. 1966. “Zu'ama' in Historical Perspective.” In Politics in Lebanon, ed. Leonard Binder. New York: John Wiley \& Sons, Inc, 85-106.

Hudson, Michael C. 1999. "Lebanon after Ta’if: Another Reform Opportunity Lost.” Arab Studies Quarterly 21(1): 27-40.

Hutchison, M. L., and K. Johnson. 2011. "Capacity to Trust? Institutional Capacity, Conflict, and Political Trust in Africa, 2000-2005." Journal of Peace Research 48(6): 737-52. http://jpr.sagepub.com/cgi/doi/10.1177/0022343311417981 (March 10, 2014).

Inbal, Aliza B., and Hanna Lerner. 2007. "Constitutional Design, Identity and Legitimacy in Post-Conflict Reconstruction." In Governance in Post-Conflict Societies: Rebuilding Fragile States, ed. Derick W. Brinkerhoff. London: Routledge, 45-63.

International Crisis Group. 2006. Israel/Hizbollah/Lebanon: Avoiding Renewed Conflict.

International Monetary Fund. 2006. Lebanon: Selected Issue. Washington DC. http://www.imf.org/external/pubs/ft/scr/2006/cr06200.pdf.

Iskandar, Adnan. 1964. Bureaucracy in Lebanon. Beirut: American University of Beirut. - 1996. Public Service Accountability in Lebanon. Beirut. http://ddc.aub.edu.lb/projects/pspa/PSAccount/PSAccount-0.html.

Jackman, Robert W. 1987. "Political Institutions and Voter Turnout in the Industrial Democracies." The American Political Science Review 81(2): 405-24. 
Jad, Sana Souaid. 2011. The Balance Sheet Approach and the Public Debt Stock Analysis: The Case of Lebanon. Beirut. http://www.bdl.gov.lb/.

Jawad, Rana. 2002. "A Profile of Social Welfare in Lebanon: Assessing the Implications for Social Development Policy." Global Social Policy 2(3): 319-42.

Jok, Madut Jok. 2011. Diversity, Unity, and Nation Building in South Sudan. Washington DC. http://www.usip.org/sites/default/files/Diversity\%2C Unity\%2C and Nation Building in South Sudan \%28Jok\%29.pdf.

Jong, Ferdinand De. 2005a. “A Joking Nation : Conflict Resolution in Senegal.” Canadian Journal of African Studies 39(2): 391-415.

_ 2005b. "Contested Casamance : Introduction." Canadian Journal of African Studies 39(2): 213-29.

Von Kaltenborn-Stachau, Henriette. 2008. The Missing Link - Fostering Positive Citizen-State Relations in Post-Conflict Environments. Washington DC. http://siteresources.worldbank.org/EXTGOVACC/Resources/CommGAPMissingLinkWeb. pdf.

Kameir, El Wathig. 2011. The Political Economy of South Sudan: A Scoping Analytical Study. Abidjan.

Kanaan, Nimat, and Randa Aboul-Hosn. 1998. "Mapping of Living Conditions in Lebanon." Mapping of Living Conditions in Lebanon (UNDP). http://www.undp.org.lb/programme/propoor/poverty/povertyinlebanon/molc/setting/A/1975.htm\# (November 2, 2015).

Kanol, Direnç. 2011. "Assessing the Legitimacy of the EU.” Interdisciplinary Political Studies 1(0): 49-59.

Kaplan, Seth. 2008. “The Remarkable Story of Somaliland.” Journal of Democracy 19(3): 14357.

Kaufmann, Daniel, Aart Kraay, and Massimo Mastruzzi. 2010. The Worldwide Governance Indicators Methodology and Analytical Issues. Washington DC.

Keefer, Philip E., Ambar Narayan, and Tara Vishwanath. 2006. "Decentralization in Pakistan: Are Local Governments Likely to Be More Accountable than Central Governments?" In Decentralization and Local Governance in Developing Countries: A Comparative Perspective, eds. Pranab Bardhan and Dilip Mookherjee. Cambridge: MIT Press, 285-304.

Kerr, Malcolm H. 1966. "Political Decision Making in a Confessional Democracy." In Politics in Lebanon, ed. Leonard Binder. New York: John Wiley \& Sons, Inc, 167-86. 
Khadiagala, Gilbert M. 1995. "State Collapse and Reconstruction in Uganda." In Collapsed States: The Disintegration and Reconstruction of Legitimate Authority, ed. I. William Zartman. Colorado: Lynne Rienner Publishers, 33-47.

Kingston, Paul, and Marie-Joëlle Zahar. 2004. "Rebuilding A House of Many Mansions: The Rise and Fall of Militia Cantons in Lebanon." In States Within States, eds. Paul Kingston and Ian S. Speaars. New York: Palgrave, 81-98.

Kisirwani, M., and W. M. Parle. 1987. "Assessing the Impact of the Post Civil War Period on the Lebanese Bureaucracy: A View from Inside." Journal of Asian and African Studies 22(12): 17-29. http://jas.sagepub.com/cgi/doi/10.1177/002190968702200102.

Kisirwani, Maroun. 1997a. "Accountability of Lebanese Civil Servants: An Overview of Disciplinary Mechanisms.” In Lebanon Beyond 2000, eds. Amin Saikal and Geoffrey Jukes. Canberra: Centre for Middle Eastern and Central Asian Studies.

_ 1997b. "The Rehabilitation and Reconstruction of Lebanon." In Remaking the Middle East, eds. Paul J White and William S Logan. Oxford: Berg, 87-104.

Kisirwani, Maroun, and William M. Parle. 1987. "Assessing the Impact of the Post Civil War Period on the Lebanese Bureaucracy: A View from Inside." Journal of Asian and African Studies 22(1-2): 17-29.

Kitschelt, Herbert, and Steven I. Wilkinson. 2007. "Citizen-Politician Linkages: An Introduction." In Patrons, Clients, and Policies: Patterns of Democratic Accountability and Political Competition, eds. Herbert Kitschelt and Steven I. Wilkinson. Cambridge: Cambridge University Press, 1-49.

Kon, Madut. 2015. "Institutional Development, Governance, and Ethnic Politics in South Sudan." Journal of Global Economics 3(2): 1-6.

http://www.esciencecentral.org/journals/institutional-development-governance-and-ethnicpolitics-in-south-sudan-2375-4389-1000147.php?aid=57097.

Larson, Greg, Peter Biar Ajak, and Lant Pritchett. 2013. South Sudan's Capability Trap: Building a State with Disruptive Innovation. Cambridge. https://www.hks.harvard.edu/content/download/69085/1249150/version/1/file/268_SudanPDIA.pdf.

Leenders, Reinoud. 2012. Spoils of Truth: Corruption and State-Building in Postwar Lebanon. Ithaca: Cornell University Press.

LeRiche, Matthew, and Matthew Arnold. 2012. South Sudan: From Revolution to Independence. London: C. Hurst \& Co (Publishers) Ltd.

Levi, Margaret, and Audrey Sacks. 2009. "Legitimating Beliefs: Sources and Indicators." 
Regulation \& Governance 3(4): 311-33.

Levi, Margaret, Audrey Sacks, and Tom Tyler. 2009. "Conceptualizing Legitimacy, Measuring Legitimating Beliefs.” American Behavioral Scientist 53(3): 354-75.

Lipset, Seymour Martin. 1983. Political Man: The Social Bases of Politics. London: Heinemann.

Lister, Sarah, and Andrew Wilder. 2005. "Strengthening Subnational Administration in Afghanistan: Technical Reform or State-Building?" Public Administration and Development 25(1): 39-48.

Loehlin, John C. 1998. Latent Variable Models: An Introduction to Factor, Path, and Structural Analysis. Third. New Jersey: Lawrence Erlbaum Associates.

Low-beer, Ann. 2001. Paradigm Politics, School Textbooks and Cultural Identity: The Struggle in Bosnia and Hercegovina.

Lyons, Terrence. 2005. Demilitarizing Politics: Elections on the Uncertain Road to Peace. Colorado: Lynne Rienner Publishers.

Mane, Bacary Domingo. 2014. "POLE DE DEVELOPPEMENT DE LA CASAMANCE." Sud Online. http://www.sudonline.sn/au-dela-des-questions-economique-etadministrative_a_17983.html.

March, James G., and Johan P. Olsen. 1989. Institutions: The Organizational Basis of Politics. New York: The Free Press.

Marquette, Heather, and Danielle Beswick. 2011. "State Building, Security and Development: State Building as a New Development Paradigm?” Third World Quarterly 32(10): 1703-14.

Marshall, Monty G, and Keith Jaggers. 2002. Political Regime Characteristics and Transitions, 1800-2002: Dataset User's Manual. Maryland.

Marut, Jean-Claude. 2010. Le Conflit de Casamance: Ce Qui Disent Les Armes. Paris: Édition Karthala.

Mason, David T., Mehmet Gurses, Patrick T. Brandt, and Jason Michael Quinn. 2011. "When Civil Wars Recur: Conditions for Durable Peace after Civil Wars." International Studies Perspectives 12(2): 171-89.

Maxwell, Daniel, Kirsten Gelsdorf, and Martina Santschi. 2012. Researching Livelihoods and Services Affected by Conflict Livelihoods, Basic Services and Social Protection in South Sudan. London. http://community.eldis.org/.5a0b0243/Livelihoods basic services and social protection in Sri Lanka.pdf.

Mayall, James. 2005. "The Legacy of Colonialism.” In Making States Work: State Failure and the Crisis of Governance, eds. Simon Chesterman, Michael Ignatieff, and Ramesh Thakur. 
New York: United Nations University Press, 36-58.

Mcloughlin, Claire. 2014. "When Does Service Delivery Improve the Legitimacy of a Fragile or Conflict-Affected State?” Governance: n/a-n/a. http://doi.wiley.com/10.1111/gove.12091 (May 2, 2014).

von der Mehden, Fred R., and Kim Quaile Hill. 1980. “Area Experts’ Images of African Nations." Comparative Political Studies 12(4): 497-510.

Meierhenrich, Jens. 2004. "Forming States After Failure." In When States Fail: Causes and Consequences, ed. Rot. Princeton: Princeton University Press, 153-68.

Mendy, Toumany. 2006. Politique et Puissance de L'argent Au Sénégal: Les Désarrois D’un Peuple Innocent. Paris: L'Harmattan.

Messarra, Antoine. 1998. “L'expérience Libanais Du Parti Dans Le Cadre Arabe." In Partis et Forces Politiques Au Liban: Renouveau et Engagement, ed. Antoine Messarra. Beirut: Fondation Konrad Adenauer, 15-40.

Migdal, Joel S. 2001. State in Society: Studying How States and Societies Transform and Constitute One Another. Cambridge: Cambridge University Press.

Miller, Benjamin. 2015. "Stateness, National Self-Determination and War and Peace in the Twenty-First Century." Ethnopolitics 14(5): 531-39. http://www.tandfonline.com/doi/full/10.1080/17449057.2015.1051818.

Ministry of Foreign Affairs Denmark. 2005. A Joint Evaluation: Humanitarian and Reconstruction Assistance to Afghanistan, 2001-05: From Denmark, Ireland, The Netherlands, Sweden and the United Kingdom.

Ministry of Social Affairs, and United Nations Development Programme. 2007. The effects of brief mindfulness intervention on acute pain experience: An examination of individual difference Development of Mapping of Living Conditions in Lebanon, 1995-2004: A Comparison with the Results of "Mapping of Living Conditions in Lebanon, 1998. " Beirut.

Mitchell, Timothy. 1991. "The Limits of the State: Beyond Statist Approaches and Their Critics." The American Political Science Review 85(1): 77-96.

Mukhopadhyay, Dipali. 2009. "Disguised Warlordism and Combatanthood in Balkh: The Persistence of Informal Power in the Formal Afghan State." Conflict, Security \& Development 9(4): 535-64.

Muller, Edward N., Thomas O. Jukam, and Mitchell A. Seligson. 1982. "Diffuse Political Support and Antisystem Political Behavior : A Comparative Analysis." American Journal of Political Science 26(2): 240-64. 
Najem, Tom Pierre. 2000. Lebanon's Renaissance: The Political Economy of Reconstruction. Reading: Ithaca Press.

Nassif, Georges. 1998. "Les Parties Libanaises En Crise: Comment Transforment-Elles Politiquement." In Parties et Forces Politiques Au Liban: Renouveau et Enagagement, ed. Antoine Messarra. Beirut: Fondation Konrad Adenauer, 123-29.

Ndegwa, Stephen N, and Brian Levy. 2003. The Politics of Decentralization in Africa: A Comparative Analysis. Washington DC.

http://www1.worldbank.org/publicsector/LearningProgram/Decentralization/Ndegwa.pdf.

Netemeyer, Richard G., William O. Bearden, and Subhash Sharma. 2003. Scaling Procedures: Issues and Applications. California: Sage Publications, Inc.

Nettl, J.P. 1968. “The State as a Conceptual Variable.” World Politics 20(4): 559-92.

News, BBC. 2009. "Senegal Apology for Christ â€ $€^{\mathrm{TM}}$ Slur '.” BBC News. http://news.bbc.co.uk/go/pr/fr/-/2/hi/africa/8435805.stm.

Norton, Augustus Richard. 2000. "Hizballah and the Israeli Withdrawal from Southern Lebanon." Journal of Palestine Studies 30(1): 22-35.

O Senegal. 2014. "Une Autoroute Maritime Se Développe Entre Dakar et La Casamance." $O$ Senegal. http://www.osenegal.com/news/transport/autoroute-maritime-se-developpe-dakarcasamance/.

OECD. 2010. The State's Legitimacy in Fragile Situations: Unpacking Complexity. http://www.oecd.org/dac/incaf/44794487.pdf.

Ottaway, Marina. 1995. "Democratization in Collapsed States." In Collapsed States: The Disintegration and Restoration of Legitimate Authority, ed. I. William Zartman. Colorado: Lynne Rienner Publishers, 235-50.

Oxhorn, Philip. 2004. "Unraveling the Puzzle of Decentralization.” In Decentralization, Democratic Governance and Civil Society in Comparative Perspectives, eds. Philip Oxhorn, Joseph S. Tulchin, and Andrew D. Selee. Washington DC: Woodrow Wilson Centre Press, 3-32.

Ozer, Daniel J. 1999. "Four Principles for Personality Assessment." In Handbook of Personality: Theory and Research, eds. Lawrence A. Pervin and Oliver P. John. New York: Guilford.

Paris, Roland. 2005. "Wilson's Ghost: The Faulty Assumptions of Postconflict Peacebuilding." In Turbulent Peace: The Challenges of Managing International Conflict, eds. Chester A. Crocker, Fen Osler Hampson, and Pamela Aall. Washington DC: United States Institute of Peace, $765-84$. 
—. 2006. "NATO’s Choice in Afghanistan: Go Big or Go Home." Policy Options: 35-43.

Picard, Elizabeth. 1993. The Lebanese Shi'a and Political Violence. Geneva.

Pierson, Paul. 2004. Politics in Time: History, Institutions, and Social Analysis. Princeton: Princeton University Press.

Posner, Daniel. 2004. "Civil Society and the Reconstruction of Failed States." In When States Fail: Causes and Consequences, ed. Robert Rotberg. Princeton: Princeton University Press, $237-55$.

Radon, Jenik, and Sarah Logan. 2014. "South Sudan: Governance Arrangements, War, and Peace." Journal of International Affairs 68(1): 149-67.

http://search.ebscohost.com/login.aspx?direct=true $\& \mathrm{db}=$ buh\&AN=100052751\&site=ehostlive.

Regan, Patrick M. 2002. "Third-Party Interventions and the Duration of Intrastate Conflicts." The Journal of Conflict Resolution 46(1): 55-73.

Riak, Maker M. 2013. "Reversing the Trend of Corruption in South Sudan: Is Rwanda a Suitable Model?" Journal of Developing Societies 29(4): 487-501. http://jds.sagepub.com/cgi/doi/10.1177/0169796X13504681.

Rotberg, Robert I. 2004. "When States Fail: Causes and Consequences." In When States Fail: Causes and Consequences, ed. Robert I. Rotberg. New Jersey: Princeton University Press, $1-49$.

Saidi, Nasser H. 1994. "The Economic Reconstruction of Lebanon: War, Peace, and Modernization.” In Peace for Lebanon? From War to Reconstruction, ed. Deirdre Collings. Boulder: Lynne Rienner Publishers, 195-212.

Salamy, Imad. 2014. The Government and Politics of Lebanon. Oxon: Routledge.

Saleh, Ali Salman, and Charles Harvie. 2005. "An Analysis of Public Sector Deficits and Debt in Lebanon: 1970-2000.” Middle East Review of International Affairs 9(4): 106-36.

Salem, Elie Adib. 1973. Modernization without Revolution: Lebanon's Experience. London: Indiana University Press.

Salloukh, Bassel F. 2006. "The Limits of Electoral Engineering in Divided Societies: Elections in Postwar Lebanon." Canadian Journal of Political Science 39(3): 635-55.

Salloukh, Bassel F., Rabie Barakat, and Jinan S. Al-Habbal. 2015. Politics of Sectarianism in Postwar Lebanon. London: Pluto Press.

Sambanis, Nicholas. 2001. "Do Ethnic and Nonethnic Civil Wars Have the Same Causes ?: A Theoretical and Empirical Inquiry (Part 1)." The Journal of Conflict Resolution 45(3): 259- 
82.

Saouli, Adham. 2003. "Lebanon's Hizbullah: The Quest for Survival.” World Affairs 166(2): 7180.

Al Sayegh, Daoud. 1998. “Organisations Sectaires et Les Forces Politiques: La Recherche Des Limites." In Parties et Forces Politiques Au Liban: Renouveau et Enagagement, ed. Antoine Messarra. Beirut: Fondation Konrad Adenauer, 167-72.

Schaffer, Frederic C. 2000. Democracy in Translation: Understanding Politics in an Unfamiliar Culture. Ithaca: Cornell University Press.

Scharpf, Fritz W. 2003. Problem Solving Effectiveness and Democratic Accountability in the EU.

Schenker, David. 2007. Lebanon Goes to Paris III: High Stakes in France and Beirut. Washington DC. http:/www.washingtoninstitute.org/policy-analysis/view/lebanon-goes-toparis-iii-high-stakes-in-france-and-beirut.

Sedgwick, Mark. 2010. "Measuring Egyptian Regime Legitimacy.” Middle East Critique 19(3): 251-67. http://www.tandfonline.com/doi/abs/10.1080/19436149.2010.514474 (March 10, 2014).

Selee, Andrew D., and Joseph S. Tulchin. 2004. "Decentralization and Democratic Governance: Lessons and Challenges." In Decentralization, Democratic Governance and Civil Society in Comparative Perspectives, eds. Philip Oxhorn, Joseph S. Tulchin, and Andrew D. Selee. London: Woodrow Wilson Centre Press, 295-320.

Shapiro, Ian. 2001. 'Problems, Methods, and Theories in the Study of Politics, or What's Wrong with Political Science and What to Do about It." Political Theory 30(4): 596-619.

Sharan, Timor. 2011. "The Dynamics of Elite Networks and Patron-Client Relations in Afghanistan.” Europe-Asia Studies 63(6): 1109-27.

Siegle, Joseph, and Patrick O’Mahony. 2010. "Decentralization and Internal Conflict." In Making Decentralization Work: Democracy, Development, and Security, eds. Ed Connerley, Kent Eaton, and Paul Smoke. Colorado: Lynne Rienner Publishers, 135-66.

De Simone, Sara. 2015. "Building a Fragmented State: Land Governance and Conflict in South Sudan." Journal of Peacebuilding and Development 10(3): 60-73. http://dx.doi.org/10.1080/15423166.2015.1085812.

Sisk, Timothy. 2013. Statebuilding: Consolidating Peace After Conflict. London: Polity Press.

Skocpol, Theda. 1979. States \& Social Revolutions: A Comparative Analysis of France, Russia, \& China. Cambridge: Cambridge University Press.

Sobek, David. 2010. "Masters of Their Domains: The Role of State Capacity in Civil Wars.” 
Journal of Peace Research 47(3): 267-71.

Le Soleil. 2012. "Benoit Sambou Annonce Un Projet de 350 Millions : Les Zones Post-Conflit Vont Relancer L'agriculture En Casamance.” Le Soleil.

http://www.lesoleil.sn/index.php?option=com_content\&view=article\&id=16706:benoitsambou-annonce-un-projet-de-350-millions-les-zones-post-conflit-vont-relancerlagriculture-en-casamance \&catid=78:a-la-une.

South Sudan Bureau for Community Security and Small Arms Control, South Sudan Peace and Reconciliation Commission, and United Nations Development Programme. 2012. Community Consultation Report: Warrap State, South Sudan. Juba. http://www.undp.org/content/dam/southsudan/library/Documents/CSAC Reports/UNDPSS-Warrap-consult-12.pdf.

South Sudan National Bureau of Statistics. 2011. South Sudan Statistical Yearbook 2011. Juba. http://static1.1.sqspcdn.com/static/f/750842/18935415/1349357346780/South+Sudan+Statis tical+Yearbook+2011+FINAL.pdf?token=xcrh+XTeo9vWw3HAwjYs5YtHA48=.

Starr, S. Frederick. 2006. "Sovereignty and Legitimacy in Afghan Nation-Building." In NationBuilding: Beyond Afghanistan and Iraq, ed. Francis Fukuyama. Baltimore: The Johns Hopkins University Press, 107-24.

Streeck, Wolfgang, and Kathleen Thelen. 2005. "Introduction: Institutional Change in Advanced Political Economies." In Beyond Continuity: Institutional Change in Advanced Economies, eds. Wolfgang Streeck and Kathleen Thelen. Oxford: Oxford University Press, 1-39.

Suchman, Mark C. 1995. "Managing Legitimacy: Strategic and Institutional Approaches." The Academy of Management Review 20(3): 571-610.

The World Bank. 2005. "Senegal Receives 20 Million for Emergency Recovery Project in Casamance." World Bank.

http://web.worldbank.org/external/default/main?pagePK=64027221\&piPK=64027220\&the SitePK=296303\&menuPK=296336\&Projectid=P069207.

Thies, Cameron G. 2010. "Of Rulers, Rebels, and Revenue: State Capacity, Civil War Onset, and Primary Commodities.” Journal of Peace Research 47(3): 321-32.

Traboulsi, Fawwaz. 2007. A History of Modern Lebanon. London: Pluto Press.

Treier, Shawn, and Simon Jackman. 2008. "Democracy as a Latent Variable.” American Journal of Political Science 52(1): 201-17.

Van der Vossen, Bas. 2012. "The Asymmetry of Legitimacy." Law and Philosophy 31(5): 56592.

de Waal, Alex. 2014. "When Kleptocracy Becomes Insolvent: Brute Causes of the Civil War in 
South Sudan." African Affairs 113(452): 347-69.

Walter, Barbara F. 2004. "Does Conflict Beget Conflict? Explaining Recurring Civil War." Journal of Peace Research 41(3): 371-88.

Washburne, Sarah Lykes. 2013. "Post-War Governance and the Impact of International Aid in South Sudan." In Forging Two Nations: Insights on Sudan and South Sudan, ed. Elke Grawert. Addis Ababa: Organisation for Social Science Research in Eastern and Southern Africa, 188-200.

Wassara, Samson S. 2015. "South Sudan: State Sovereignty Challenged at Infancy." Journal of Eastern African Studies 9(4): 634-39. http://www.tandfonline.com/doi/full/10.1080/17531055.2015.1105439.

Weil, Frederick D. 1989. "The Sources and Structures of Legitimation in Western Democracies: A Consolidated Model Tested with Time-Series Data in Six Countries since World War II." American Sociological Review 54(5): 682-706.

Widner, Jennifer A. 2004. "Building Effective Trust in the Aftermath of Severe Conflict." In When States Fail: Causes and Consequences, ed. Robert Rotberg. Princeton: Princeton University Press, 222-36.

Wood, Elisabeth Jean. 2008. "The Social Processes of Civil War: The Wartime Transformation of Social Networks.” Annual Review of Political Science 11(1): 539-61. http://www.annualreviews.org/doi/abs/10.1146/annurev.polisci.8.082103.104832.

Young, John. 2006. The South Sudan Defence Forces in the Wake of the Juba Declaration. Geneva. http://www.smallarmssurveysudan.org/fileadmin/docs/working-papers/HSBA-WP01-SSDF.pdf.

Zambakari, Christopher. 2013. "Post-Referendum South Sudan: Political Drivers of Violence and the Challenge of Democratic Nation-Building." In Forging Two Nations: Insights on Sudan and South Sudan, ed. Elke Grawert. Addis Ababa: Organisation for Social Science Research in Eastern and Southern Africa, 98-111.

Zanotti, L. 2008. "Imagining Democracy, Building Unsustainable Institutions: The UN Peacekeeping Operation in Haiti." Security Dialogue 39(5): 539-61.

El Zein, Fares. 2003. Dissertation Thesis "Politics of Administrative Reform in Post War Lebanon." University at Albany.

Zürcher, Christoph et al. 2013. Costly Democracy: Peacebuilding \& Democratization After War. Stanford, California: Stanford University Press.

Abla, Zeina, Amal Karaki, and Nada Dimachkieh Sweidan. 2014. Lebanon Millennium 
Development Goals Report 2013-2014. Beirut.

http://www.lb.undp.org/content/lebanon/en/home/library/mdg/lebanon-mdg-report-2013$2014 /$.

Afrique Jet. 2014. "Projet Pôle de Développement de La Casamance." Afrique Jet. $\mathrm{http}: / / \mathrm{www}$.afriquejet.com/afrique-ouest/3654-projet-pole-de-developpement-de-lacasamance.html.

Allen, Daniel. 2010. "New Directions in the Study of Nation-Building: Views through the Lens of Path Dependence." International Studies Review 12(3): 413-29.

Angeles, Leonora C., and Francisco A. Magno. 2004. "The Philippines: Decentralization, Local Governments, and Citizen Action.” In Decentralization, Democratic Governance and Civil Society in Comparative Perspectives, eds. Philip Oxhorn and Joseph S. Tulchin.

Washington DC: Woodrow Wilson Centre Press, 211-65.

Armstrong, Andrea, and Barnett Rubin. 2005. "The Great Lakes and South Central Asia." In Making States Work: State Failure and the Crisis of Governance, eds. Simon Chesterman, Michael Ignatieff, and Ramesh Thakur. New York: United Nations University Press, 79101.

Attipoe, Olympio, Biplove Choudhary, and Nicholas Jonga. 2014. An Analysis of Government Budgets in South Sudan from a Human Development Perspective. Juba. http://www.undp.org/content/dam/southsudan/library/Discussion Papers/SS-Discussion paper final.pdf.

Atzili, Boaz. 2010. "State Weakness and 'Vacuum of Power' in Lebanon." Studies in Conflict \& Terrorism 33(8): 757-82. http://www.tandfonline.com/doi/abs/10.1080/1057610X.2010.494172 (March 7, 2014).

Baaklini, Abdo I. 1976. Legislative and Political Development: Lebanon, 1842-1972. Durnham: Duke University Press.

Barbara, Julien. 2008. "Antipodean Statebuilding: The Regional Assistance Mission to Solomon Islands and Australian Intervention in the South Pacific." Journal of Intervention and Statebuilding 2(2): 123-49.

Bardhan, Pranab, and Dilip Mookherjee. 2006. "The Rise of Local Governments: An Overview." In Decentralization and Local Governance in Developing Countries: A Comparative Perspective, eds. Pranab Bardhan and Dilip Mookherjee. Cambridge: MIT Press, 1-52.

Baroudi, Sami E. 1998. "Economic Conflict in Postwar Lebanon: State-Labor Relations Between 1992 and 1997." Middle East Journal 52(4): 531-50.

Beck, Linda J. 2008. Brokering Democracy in Africa: The Rise of Clientelist Democracy in 
Senegal. New York: Palgrave.

Beetham, David, and Christopher Lord. 1998. Legitimacy and the EU. London: Addison-Wesley Longman.

Bellamy, Paul. 2007. "Introduction." In Civil Wars of the World: Major Conflicts Since World War II, eds. Karl Jr Derouen and Uk Heo. Santa Barbara, California: ABC-CLIO Inc., 1-26.

Bennett, Andrew, and Colin Elman. 2006. "Qualitative Research: Recent Developments in Case Study Methods." Annual Review of Political Science 9(1): 455-76.

http://www.annualreviews.org/doi/abs/10.1146/annurev.polisci.8.082103.104918 (February $21,2014)$.

Blair, Harry. 2007. "Rebuilding and Reforming Civil Services in Post-Conflict Societies." In Governance in Post-Conflict Societies: Rebuilding Fragile States, ed. Derick W.

Brinkerhoff. London: Routledge, 161-84.

Blomberg, S Brock, Gregory D Hess, and Siddharth Thacker. 2006. "On the Conflict Poverty Nexus." Economics and Politics 18(3): 237-67. http://www.blackwellsynergy.com/doi/abs/10.1111/j.1468-0343.2006.00170.x.

Bollen, Kenneth A. 1980. "Issues in the Comparative Measurement of Political Democracy." American Sociological Review 45(3): 370-90.

. 1986. "Political Rights and Political Liberties in Nations: An Evaluation of Human Rights Measures, 1950 to 1984." Human Rights Quarterly 8(4): 567-91. . 1990. "Political Democracy: Conceptual and Measurement Traps." Studies In Comparative International Development 25(1): 7-24.

—. 2011. "Evaluating Effect, Composite, and Casual Indicators in Structural Equation Models." MIS Quarterly 35(2): 359-72.

Bollen, Kenneth A, and Richard Lennox. 1991. "Conventional Wisdom on Measurement: A Structural Equation Perspective." Psychological Bulletin 110(2): 305-14.

Bollen, Kenneth A, and Pamela Paxton. 2000. "Subjective Measures of Liberal Democracy." Comparative Political Studies 33(1): 58-86.

Bollen, Kenneth A, and Kwok-fai Ting. 2000. "A Tetrad Test for Causal Indicators." Psychological Methods 5(1): 3-22.

Branch, Adam, and Zachariah Cherian Mampilly. 2005. "Winning the War, but Losing the Peace? The Dilemma of SPLM/A Civil Administration and the Tasks Ahead." The Journal of Modern African Studies 43(1): 1-20.

Brinkerhoff, Derick W. 2005. "Rebuilding Governance in Failed States and Post-Conflict 
Societies: Core Concepts and Cross-Cutting Themes." Public Administration and Development 25(1): 3-14.

_ 2007. "Introduction - Governance Challenges in Fragile States: Re-Establishing Legitimacy, Rebuilding Effectiveness, and Reconstituting Legitimacy." In Governance in Post-Conflict Societies: Rebuilding Fragile States, ed. Derick W. Brinkerhoff. London: Routledge, 1-21.

Brinkerhoff, Derick W., and Ronald W. Johnson. 2009. "Decentralized Local Governance in Fragile States: Learning from Iraq." International Review of Administrative Sciences 75(4): 585-607.

Brosché, Johan. 2016. "Crisis of Governance in South Sudan : Electoral Politics and Violence in the World's Newest Nation.” Journal of Modern African Studies 54(1): 67-90.

Busumtwi-Sam, James. 2004. "Development and Peacebuilding: Conceptual and Operational Deficits in International Assistance." In Durable Peace: Challenges for Peacebuilding in Africa, eds. Taiser M. Ali and Robert O. Matthews. Toronto: University of Toronto Press, $315-53$.

Cammett, Melanie. 2013. Democracy in Post-Invasion Iraq. http://watson.brown.edu/costsofwar/files/cow/imce/papers/2013/Democracy in PostInvasion Iraq.pdf.

- 2014. Compassionate Communalism: Welfare and Sectarianism in Lebanon. Ithaca: Cornell University Press.

Caplan, Richard. 2004. "Partner or Patron? International Civil Administration and Local Capacity-Building." International Peacekeeping 11(2): 229-47.

Chassay, Clancy. 2006. "Christian Leader Says Lebanese Opposition Ready for Power." The Guardian. http://www.theguardian.com/world/2006/dec/13/syria.lebanon.

Coburn, Noah. 2011. Bazaar Politics: Power \& Pottery in an Afghan Market Town. California: Stanford University Press.

Cole, Elizabeth A., and Judy Barsalou. 2006. Unite or Divide? The Challenges of Teaching History in Societies Emerging from Violent Conflict.

Collier, Paul. 2002. Aid, Policy and Growth in Post-Conflict Countries.

Collier, Paul, and Anke Hoeffler. 1998. "On the Causes of Civil War." Oxford Handbook of the Economics of Peace and Conflict 50: 563-73.

—. 2004. "Greed and Grievance in Civil War." Oxford Economic Papers 56(4): 563-95. Cook, Traci D. 2007. A Place To Call Their Own: Southern Sudanese Comment on the Hard 
Work Adn Struggles of Self-Governance. Washington DC.

Crow, Ralph E, and Adnan Iskandar. 1961. "Administrative Reform in Lebanon.” International Review of Administrative Sciences 27(3): 293-307.

Dahl, Robert. 1971. Polyarchy: Participation and Opposition. New Haven: Yale University Press.

Diallo, Boucounta. 2009. La Crise Casamançaise: Problématique et Voies de Solutions. Paris: L'Harmattan.

Diamond, Larry, and Marc F. Plattner. 2006. Electoral Systems and Democracy. Baltimore: The Johns Hopkins University Press.

Dibeh, Ghassan. 2005. 44 The Political Economy of Postwar Reconstruction in Lebanon. Helsinki.

Dinnen, Sinclair. 2007. "A Comment on State-Building in Solomon Islands." The Journal of Pacific History 42(2): 255-63.

- 2008. "The Solomon Islands Intervention and the Instabilities of the Post-Colonial State." Global Change, Peace \& Security 20(3): 339-55.

Dodge, Toby. 2013. "Intervention and Dreams of Exogenous Statebuilding: The Application of Liberal Peacebuilding in Afghanistan and Iraq." Review of International Studies 39(5): 1189-1212. http://journals.cambridge.org/article_S0260210513000272.

Dodge, Tony. 2011. "Domestic Politics and State-Building." In Afghanistan: To 2015 and beyond, eds. Toby Dodge and Nicholas Redman. International Institute for Strategic Studies, 69-96.

Doyle, Michael W., and Nicholas Sambanis. 2000. "International Peacebuilding: A Theoretical and Quantitative Analysis." American Political Science Review 94(4): 779-801. http://www.drworley.org/NSPcommon/Nation Building/2000,12 APSR Doyle Sambanis.pdf.

- 2006. Making War and Building Peace. New Jersey: Princeton University Press.

Ducci, María Elena. 2004. "Local Governance and Democracy: The View from the Chilean Border." In Decentralization, Democratic Governance and Civil Society in Comparative Perspectives, eds. Philip Oxhorn, Joseph S. Tulchin, and Andrew D. Selee. Washington DC: Woodrow Wilson Centre Press, 119-39.

Eaton, Kent, and Larry Schroeder. 2010. "Measuring Decentralization.” In Making Decentralization Work: Democracy, Development, and Security, eds. Ed Connerley, Kent Eaton, and Paul Smoke. Colorado: Lynne Rienner Publishers, 167-90. 
Von Einsiedel, Sebastian. 2005. "Policy Responses to State Failure." In Making States Work: State Failure and the Crisis of Governance, eds. Simon Chesterman, Michael Ignatieff, and Ramesh Thakur. New York: United Nations University Press, 13-35.

El-Khazen, Farid. 1998. "Les Alliances et Les Conflits Entre Les Parties Politiques Au Liban." In Parties et Forces Politiques Au Liban: Renouveau et Enagagement, ed. Antoine Messarra. Beirut: Fondation Konrad Adenauer, 133-42.

- 2000. The Breakdown of the State in Lebanon: 1967-1976. Cambridge: Harvard University Press.

El-Mufti, Karim. 2011. Public Policy Initiative The Management of Public Interest in Lebanon, a Broken Concept. Beirut. http://policylebanon.org/topmenu/policyareas/areas/Ressource.html?Id=79\#.

El-Solh, Raghid. 994. "Religious Identity and Citizenship: An Overview of Perspectives." In Peace for Lebanon? From War to Reconstruction 1, ed. Deidre Collings. Boulder: Lynne Rienner Publishers, 231-40.

El-Zein, Fares, and Holly Sims. 2004. "Reforming War's Administrative Rubble in Lebanon." Public Administration and Development 24: 279-88.

Englebert, Pierre. 2000. State Legitimacy and Development in Africa. Colorado: Lynne Rienner Publishers.

Eriksen, Erik O., and John E. Fossum. 2004. "Europe in Search of Legitimacy: Strategies of Legitimation Assessed.” International Political Science Review 25(4): 435-59.

Evans, Martin. 2005. "Insecurity or Isolation? Natural Resources and Livelihoods in Lower Casamance." Canadian Journal of African Studies 39(2): 284-314.

Evans, Peter B. 1989. "Predatory, Developmental, and Other Apparatuses : A Comparative Political Economy Perspective on the Third World State." Sociological Forum: Special Issue: Comparative National Development: Theory and Facts for the 1990s 4(4): 561-87.

Fall, Aissatou. 2010. Understanding The Casamance Conflict: A Background. Accra. http://www.kaiptc.org/publications/monographs/monographs/monograph-7-aissatou.aspx.

Fawaz, Mona, and Isabelle Peillen. 2003. The Case of Beirut, Lebanon. Beirut. http://www.ucl.ac.uk/dpu-projects/Global_Report/cities/beirut.htm.

Fearon, James D. 2004. “Why Do Some Civil Wars Last So Much Longer than Others?” Journal of Peace Research 41(3): 275-301.

Foucher, Vincent. 2005. "La Guerre Des Dieux ? Religions et Séparatisme En Basse Casamance." Canadian Journal of African Studies 39(2): 363-90. 
Frahm, Ole. 2015. "Making Borders and Identities in South Sudan." Journal of Contemporary African Studies 33(2): 251-67. http://www.tandfonline.com/doi/full/10.1080/02589001.2015.1070461.

François, Monika, and Inder Sud. 2006. "Promoting Stability and Development in Fragile and Failed States." Development Policy Review 24(2): 141-60.

Fraser, John. 1974. "Validating a Measure of National Political Legitimacy." American Journal of Political Science 18(1): 117-34.

Fukuyama, Francis. 2006. America at the Crossroads: Democracy, Power, and the Neoconservative Legacy. Connecticut: Yale University Press.

Gamble, David P. 1957. The Wolof of Senegambia. London: International African Institute.

Gaspard, Toufic K. 2004. A Political Economy of Lebanon, 1948-2002: The Limits of LaissezFaire. Leiden: Brill.

Geddes, Barbara. 1990. "How the Cases You Choose Affect the Answers You Get: Selection Bias in Comparative Politics." Political Analysis 2(1): 131-50.

Gehrold, Stefan, and Inga Neu. 2010. Caught Between Two Fronts: In Search of Lasting Peace in the Casamance Region. Berlin.

Gellar, Sheldon. 1995. Senegal: An Africam Nation between Islam and the West. Second edi. Boulder: Westview Press.

-2005. Democracy in Senegal: Tocquevillian Analytics in Africa. New York: Palgrave.

Gemayel, Amine. 1992. Rebuilding Lebanon. Lanham: University Press of America.

Gerry, John. 2007. Case Study Research: Principles and Practices. New York: Cambridge University Press.

Ghani, Ashraf, and Clare Lockhart. 2008. Fixing Failed States: A Framework for Rebuilding a Fractured World. New York: Oxford University Press.

Ghosn, Faten, and Amal Khoury. 2011. "Lebanon after the Civil War: Peace or the Illusion of Peace?” Middle East Journal 65(3): 381-97.

Ghossain, Antoine. 1988. "Confessional Communities, Space and Political Reform in Lebanon." Social Compass1 35(4): 563-83.

Gilley, Bruce. 2006a. "The Determinants of State Legitimacy: Results for 72 Countries." International Political Science Review 27(1): 47-71.

_. 2006b. "The Meaning and Measure of State Legitimacy: Results for 72 Countries." European Journal of Political Research 45(3): 499-525. 
— 2012. "State Legitimacy: An Updated Dataset for 52 Countries." European Journal of Political Research 51(5): 693-99. http://doi.wiley.com/10.1111/j.14756765.2012.02059.x\%5Cnhttps://sremote.pitt.edu/doi/10.1111/j.14756765.2012.02059.x/,DanaInfo=onlinelibrary.wiley.com+pdf (January 26, 2014).

Mac Ginty, Roger. 2010. "Warlords and the Liberal Peace: State-Building in Afghanistan." Conflict, Security \& Development 10(4): 577-98.

Gleditsch, Nils Petter. 1996. "Environmental Change, Security, and Conflict." In Turbulent Peace: The Challenges of Managing International Conflict1, eds. Chester A. Crocker, Osler Hampson, and Pamela Aall. Washington DC: United States Institute of Peace, 53-68.

Goldsmith, Arthur A. 2007. "Does Nation-Building Work? Reviewing the Record." In Governance in Post-Conflict Societies: Rebuilding Fragile States, London: Routledge, 2544.

Goodhand, Jonathan. 2006. Aiding Peace: The Role of NGOs in Armed Conflict. Colorado: Lynne Rienner Publishers.

Grawert, Elke. 2013. "Introduction.” In Forging Two Nations: Insights on Sudan and South Sudan, ed. Elke Grawert. Addis Ababa: Organisation for Social Science Research in Eastern and Southern Africa, 15-51.

Grzymala-Busse, Anna. 2008. "Beyond Clientelism: Incumbent State Capture and State Formation." Comparative Political Studies 41(4/5): 638-73.

Grzymala-Busse, Anna, and Pauline Jones Luong. 2002. "Reconceptualizing the State: Lessons from Post-Communism.” Politics \& Society 30(4): 529-54.

Gurowitz, Amy. 1999. "Mobilizing International Norms: Domestic Actors, Immigrants, and the Japanese State." World Politics 51(3): 413-45. http://www.journals.cambridge.org/abstract_S0043887100009138.

Haddad, Simon. 2009. "Lebanon: From Consociationalism to Conciliation." Nationalism and Ethnic Politics 15(3-4): 398-416. http://www.tandfonline.com/doi/abs/10.1080/13537110903346684 (March 4, 2014).

Hajjar, Sami G. 2009. "The Convoluted and Diminished Lebanese Democracy." Democracy and Security 5(3): 261-76. http://www.tandfonline.com/doi/abs/10.1080/17419160903304864 (March 10, 2014).

Hakim, Georges. 1966. "The Economic Basis of Lebanese Polity.” In Politics in Lebanon, ed. Leonard Binder. New York: John Wiley \& Sons, Inc, 57-69.

Haldén, Peter. 2010. "Systems-Building Before State-Building: On the Systemic Preconditions of State-Building." Conflict, Security \& Development 10(4): 519-45. 
http://www.tandfonline.com/doi/abs/10.1080/14678802.2010.500540.

Hameiri, Shahar. 2009. "Capacity and Its Fallacies: International State Building as State Transformation.” Millennium - Journal of International Studies 38(1): 55-81.

Hamzeh, A Nizar. 2000. "Lebanon's Islamists and Local Politics: A New Reality.” Third World Quarterly 21(5): 739-59.

Harb, Boutros. 1998. “Le Relancement D’une Vie Politique.” In Parties et Forces Politiques Au Liban: Renouveau et Enagagement, ed. Antoine Messarra. Beirut: Fondation Konrad Adenauer, 53-56.

Harb, Mona, and Reinoud Leenders. 2005. 'Know Thy Enemy: Hizbullah, 'terrorism' and the Politics of Perception.” Third World Quarterly 26(1): 173-97.

Harik, Judith. 1996. "Between Islam and the System: Sources and Implications of Popular Support for Lebanon's Hizballah." Journal of Conflict Resolution 40(1): 41-67.

Hartzell, Caroline A. 2006. "Structuring the Peace: Negotiated Settlements and the Construction of Conflict Management Institutions." In Conflict Prevention and Peacebuilding in PostWar Societies: Sustaining the Peace, eds. T. David Mason and James D. Meernik. Oxon: Routledge, 31-52.

Hartzell, Caroline, Matthew Hoddie, and Donald Rothchild. 2001. "Stabilizing the Peace After Civil War: An Investigation of Some Key Variables." International Organization 55(1): 183-208.

Hess, Steve. 2010. "Coming to Terms with Neopatrimonialism: Soviet and American NationBuilding Projects in Afghanistan." Central Asian Survey 29(2): 171-87.

Hottinger, Arnold. 1966. 'Zu'ama' in Historical Perspective.” In Politics in Lebanon, ed. Leonard Binder. New York: John Wiley \& Sons, Inc, 85-106.

Hudson, Michael C. 1999. "Lebanon after Ta'if: Another Reform Opportunity Lost." Arab Studies Quarterly 21(1): 27-40.

Hutchison, M. L., and K. Johnson. 2011. "Capacity to Trust? Institutional Capacity, Conflict, and Political Trust in Africa, 2000-2005." Journal of Peace Research 48(6): 737-52. http://jpr.sagepub.com/cgi/doi/10.1177/0022343311417981 (March 10, 2014).

Inbal, Aliza B., and Hanna Lerner. 2007. "Constitutional Design, Identity and Legitimacy in Post-Conflict Reconstruction." In Governance in Post-Conflict Societies: Rebuilding Fragile States, ed. Derick W. Brinkerhoff. London: Routledge, 45-63.

International Crisis Group. 2006. Israel/Hizbollah/Lebanon: Avoiding Renewed Conflict. International Monetary Fund. 2006. Lebanon: Selected Issue. Washington DC. 
http://www.imf.org/external/pubs/ft/scr/2006/cr06200.pdf.

Iskandar, Adnan. 1964. Bureaucracy in Lebanon. Beirut: American University of Beirut.

- 1996. Public Service Accountability in Lebanon. Beirut. http://ddc.aub.edu.lb/projects/pspa/PSAccount/PSAccount-0.html.

Jackman, Robert W. 1987. "Political Institutions and Voter Turnout in the Industrial Democracies." The American Political Science Review 81(2): 405-24.

Jad, Sana Souaid. 2011. The Balance Sheet Approach and the Public Debt Stock Analysis: The Case of Lebanon. Beirut. http://www.bdl.gov.lb/.

Jawad, Rana. 2002. "A Profile of Social Welfare in Lebanon: Assessing the Implications for Social Development Policy.” Global Social Policy 2(3): 319-42.

Jok, Madut Jok. 2011. Diversity, Unity, and Nation Building in South Sudan. Washington DC. http://www.usip.org/sites/default/files/Diversity\%2C Unity\%2C and Nation Building in South Sudan \%28Jok\%29.pdf.

Jong, Ferdinand De. 2005a. "A Joking Nation : Conflict Resolution in Senegal." Canadian Journal of African Studies 39(2): 391-415.

- 2005b. "Contested Casamance : Introduction." Canadian Journal of African Studies 39(2): 213-29.

Von Kaltenborn-Stachau, Henriette. 2008. The Missing Link - Fostering Positive Citizen-State Relations in Post-Conflict Environments. Washington DC.

http://siteresources.worldbank.org/EXTGOVACC/Resources/CommGAPMissingLinkWeb. pdf.

Kameir, El Wathig. 2011. The Political Economy of South Sudan: A Scoping Analytical Study. Abidjan.

Kanaan, Nimat, and Randa Aboul-Hosn. 1998. "Mapping of Living Conditions in Lebanon." Mapping of Living Conditions in Lebanon (UNDP).

$\mathrm{http}: / /$ www.undp.org.lb/programme/propoor/poverty/povertyinlebanon/molc/setting/A/1975.htm\# (November 2, 2015).

Kanol, Direnç. 2011. "Assessing the Legitimacy of the EU." Interdisciplinary Political Studies $1(0): 49-59$.

Kaplan, Seth. 2008. “The Remarkable Story of Somaliland.” Journal of Democracy 19(3): 14357.

Kaufmann, Daniel, Aart Kraay, and Massimo Mastruzzi. 2010. The Worldwide Governance Indicators Methodology and Analytical Issues. Washington DC. 
Keefer, Philip E., Ambar Narayan, and Tara Vishwanath. 2006. "Decentralization in Pakistan: Are Local Governments Likely to Be More Accountable than Central Governments?" In Decentralization and Local Governance in Developing Countries: A Comparative Perspective, eds. Pranab Bardhan and Dilip Mookherjee. Cambridge: MIT Press, 285-304.

Kerr, Malcolm H. 1966. "Political Decision Making in a Confessional Democracy." In Politics in Lebanon, ed. Leonard Binder. New York: John Wiley \& Sons, Inc, 167-86.

Khadiagala, Gilbert M. 1995. "State Collapse and Reconstruction in Uganda." In Collapsed States: The Disintegration and Reconstruction of Legitimate Authority, ed. I. William Zartman. Colorado: Lynne Rienner Publishers, 33-47.

Kingston, Paul, and Marie-Joëlle Zahar. 2004. "Rebuilding A House of Many Mansions: The Rise and Fall of Militia Cantons in Lebanon." In States Within States, eds. Paul Kingston and Ian S. Speaars. New York: Palgrave, 81-98.

Kisirwani, M., and W. M. Parle. 1987. "Assessing the Impact of the Post Civil War Period on the Lebanese Bureaucracy: A View from Inside." Journal of Asian and African Studies 22(12): 17-29. http://jas.sagepub.com/cgi/doi/10.1177/002190968702200102.

Kisirwani, Maroun. 1997a. "Accountability of Lebanese Civil Servants: An Overview of Disciplinary Mechanisms." In Lebanon Beyond 2000, eds. Amin Saikal and Geoffrey Jukes. Canberra: Centre for Middle Eastern and Central Asian Studies.

_ 1997b. "The Rehabilitation and Reconstruction of Lebanon." In Remaking the Middle East, eds. Paul J White and William S Logan. Oxford: Berg, 87-104.

Kisirwani, Maroun, and William M. Parle. 1987. "Assessing the Impact of the Post Civil War Period on the Lebanese Bureaucracy: A View from Inside." Journal of Asian and African Studies 22(1-2): 17-29.

Kitschelt, Herbert, and Steven I. Wilkinson. 2007. "Citizen-Politician Linkages: An Introduction." In Patrons, Clients, and Policies: Patterns of Democratic Accountability and Political Competition, eds. Herbert Kitschelt and Steven I. Wilkinson. Cambridge: Cambridge University Press, 1-49.

Kon, Madut. 2015. "Institutional Development, Governance, and Ethnic Politics in South Sudan." Journal of Global Economics 3(2): 1-6. http://www.esciencecentral.org/journals/institutional-development-governance-and-ethnicpolitics-in-south-sudan-2375-4389-1000147.php?aid=57097.

Larson, Greg, Peter Biar Ajak, and Lant Pritchett. 2013. South Sudan's Capability Trap: Building a State with Disruptive Innovation. Cambridge. https://www.hks.harvard.edu/content/download/69085/1249150/version/1/file/268_SudanPDIA.pdf. 
Leenders, Reinoud. 2012. Spoils of Truth: Corruption and State-Building in Postwar Lebanon. Ithaca: Cornell University Press.

LeRiche, Matthew, and Matthew Arnold. 2012. South Sudan: From Revolution to Independence. London: C. Hurst \& Co (Publishers) Ltd.

Levi, Margaret, and Audrey Sacks. 2009. "Legitimating Beliefs: Sources and Indicators." Regulation \& Governance 3(4): 311-33.

Levi, Margaret, Audrey Sacks, and Tom Tyler. 2009. "Conceptualizing Legitimacy, Measuring Legitimating Beliefs." American Behavioral Scientist 53(3): 354-75.

Lipset, Seymour Martin. 1983. Political Man: The Social Bases of Politics. London: Heinemann.

Lister, Sarah, and Andrew Wilder. 2005. "Strengthening Subnational Administration in Afghanistan: Technical Reform or State-Building?" Public Administration and Development 25(1): 39-48.

Loehlin, John C. 1998. Latent Variable Models: An Introduction to Factor, Path, and Structural Analysis. Third. New Jersey: Lawrence Erlbaum Associates.

Low-beer, Ann. 2001. Paradigm Politics, School Textbooks and Cultural Identity: The Struggle in Bosnia and Hercegovina.

Lyons, Terrence. 2005. Demilitarizing Politics: Elections on the Uncertain Road to Peace. Colorado: Lynne Rienner Publishers.

Mane, Bacary Domingo. 2014. "POLE DE DEVELOPPEMENT DE LA CASAMANCE." Sud Online. http://www.sudonline.sn/au-dela-des-questions-economique-etadministrative_a_17983.html.

March, James G., and Johan P. Olsen. 1989. Institutions: The Organizational Basis of Politics. New York: The Free Press.

Marquette, Heather, and Danielle Beswick. 2011. "State Building, Security and Development: State Building as a New Development Paradigm?” Third World Quarterly 32(10): 1703-14.

Marshall, Monty G, and Keith Jaggers. 2002. Political Regime Characteristics and Transitions, 1800-2002: Dataset User's Manual. Maryland.

Marut, Jean-Claude. 2010. Le Conflit de Casamance: Ce Qui Disent Les Armes. Paris: Édition Karthala.

Mason, David T., Mehmet Gurses, Patrick T. Brandt, and Jason Michael Quinn. 2011. "When Civil Wars Recur: Conditions for Durable Peace after Civil Wars." International Studies Perspectives 12(2): 171-89. 
Maxwell, Daniel, Kirsten Gelsdorf, and Martina Santschi. 2012. Researching Livelihoods and Services Affected by Conflict Livelihoods, Basic Services and Social Protection in South Sudan. London. http://community.eldis.org/.5a0b0243/Livelihoods basic services and social protection in Sri Lanka.pdf.

Mayall, James. 2005. “The Legacy of Colonialism.” In Making States Work: State Failure and the Crisis of Governance, eds. Simon Chesterman, Michael Ignatieff, and Ramesh Thakur. New York: United Nations University Press, 36-58.

Mcloughlin, Claire. 2014. "When Does Service Delivery Improve the Legitimacy of a Fragile or Conflict-Affected State?" Governance: n/a-n/a. http://doi.wiley.com/10.1111/gove.12091 (May 2, 2014).

von der Mehden, Fred R., and Kim Quaile Hill. 1980. “Area Experts' Images of African Nations." Comparative Political Studies 12(4): 497-510.

Meierhenrich, Jens. 2004. "Forming States After Failure." In When States Fail: Causes and Consequences, ed. Rot. Princeton: Princeton University Press, 153-68.

Mendy, Toumany. 2006. Politique et Puissance de L'argent Au Sénégal: Les Désarrois D’un Peuple Innocent. Paris: L'Harmattan.

Messarra, Antoine. 1998. “L’expérience Libanais Du Parti Dans Le Cadre Arabe.” In Partis et Forces Politiques Au Liban: Renouveau et Engagement, ed. Antoine Messarra. Beirut: Fondation Konrad Adenauer, 15-40.

Migdal, Joel S. 2001. State in Society: Studying How States and Societies Transform and Constitute One Another. Cambridge: Cambridge University Press.

Miller, Benjamin. 2015. "Stateness, National Self-Determination and War and Peace in the Twenty-First Century." Ethnopolitics 14(5): 531-39. http://www.tandfonline.com/doi/full/10.1080/17449057.2015.1051818.

Ministry of Foreign Affairs Denmark. 2005. A Joint Evaluation: Humanitarian and Reconstruction Assistance to Afghanistan, 2001-05: From Denmark, Ireland, The Netherlands, Sweden and the United Kingdom.

Ministry of Social Affairs, and United Nations Development Programme. 2007. The effects of brief mindfulness intervention on acute pain experience: An examination of individual difference Development of Mapping of Living Conditions in Lebanon, 1995-2004: A Comparison with the Results of "Mapping of Living Conditions in Lebanon, 1998." Beirut.

Mitchell, Timothy. 1991. "The Limits of the State: Beyond Statist Approaches and Their Critics." The American Political Science Review 85(1): 77-96.

Mukhopadhyay, Dipali. 2009. "Disguised Warlordism and Combatanthood in Balkh: The 
Persistence of Informal Power in the Formal Afghan State." Conflict, Security \& Development 9(4): 535-64.

Muller, Edward N., Thomas O. Jukam, and Mitchell A. Seligson. 1982. "Diffuse Political Support and Antisystem Political Behavior : A Comparative Analysis." American Journal of Political Science 26(2): 240-64.

Najem, Tom Pierre. 2000. Lebanon's Renaissance: The Political Economy of Reconstruction. Reading: Ithaca Press.

Nassif, Georges. 1998. "Les Parties Libanaises En Crise: Comment Transforment-Elles Politiquement." In Parties et Forces Politiques Au Liban: Renouveau et Enagagement, ed. Antoine Messarra. Beirut: Fondation Konrad Adenauer, 123-29.

Ndegwa, Stephen N, and Brian Levy. 2003. The Politics of Decentralization in Africa: A Comparative Analysis. Washington DC. http://www1.worldbank.org/publicsector/LearningProgram/Decentralization/Ndegwa.pdf.

Netemeyer, Richard G., William O. Bearden, and Subhash Sharma. 2003. Scaling Procedures: Issues and Applications. California: Sage Publications, Inc.

Nettl, J.P. 1968. “The State as a Conceptual Variable.” World Politics 20(4): 559-92.

News, BBC. 2009. "Senegal Apology for Christ â€ $€^{\mathrm{TM}}$ Slur '.” BBC News. http://news.bbc.co.uk/go/pr/fr/-/2/hi/africa/8435805.stm.

Norton, Augustus Richard. 2000. "Hizballah and the Israeli Withdrawal from Southern Lebanon." Journal of Palestine Studies 30(1): 22-35.

O Senegal. 2014. "Une Autoroute Maritime Se Développe Entre Dakar et La Casamance." $O$ Senegal. http://www.osenegal.com/news/transport/autoroute-maritime-se-developpe-dakarcasamance/.

OECD. 2010. The State's Legitimacy in Fragile Situations: Unpacking Complexity. http://www.oecd.org/dac/incaf/44794487.pdf.

Ottaway, Marina. 1995. "Democratization in Collapsed States." In Collapsed States: The Disintegration and Restoration of Legitimate Authority, ed. I. William Zartman. Colorado: Lynne Rienner Publishers, 235-50.

Oxhorn, Philip. 2004. "Unraveling the Puzzle of Decentralization." In Decentralization, Democratic Governance and Civil Society in Comparative Perspectives, eds. Philip Oxhorn, Joseph S. Tulchin, and Andrew D. Selee. Washington DC: Woodrow Wilson Centre Press, 3-32.

Ozer, Daniel J. 1999. “Four Principles for Personality Assessment.” In Handbook of Personality: 
Theory and Research, eds. Lawrence A. Pervin and Oliver P. John. New York: Guilford. Paris, Roland. 2005. "Wilson's Ghost: The Faulty Assumptions of Postconflict Peacebuilding." In Turbulent Peace: The Challenges of Managing International Conflict, eds. Chester A. Crocker, Fen Osler Hampson, and Pamela Aall. Washington DC: United States Institute of Peace, $765-84$.

—. 2006. "NATO's Choice in Afghanistan: Go Big or Go Home." Policy Options: 35-43.

Picard, Elizabeth. 1993. The Lebanese Shi'a and Political Violence. Geneva.

Pierson, Paul. 2004. Politics in Time: History, Institutions, and Social Analysis. Princeton: Princeton University Press.

Posner, Daniel. 2004. "Civil Society and the Reconstruction of Failed States." In When States Fail: Causes and Consequences, ed. Robert Rotberg. Princeton: Princeton University Press, $237-55$.

Radon, Jenik, and Sarah Logan. 2014. "South Sudan: Governance Arrangements, War, and Peace.” Journal of International Affairs 68(1): 149-67.

http://search.ebscohost.com/login.aspx?direct=true \&db=buh\&AN=100052751\&site=ehostlive.

Regan, Patrick M. 2002. "Third-Party Interventions and the Duration of Intrastate Conflicts." The Journal of Conflict Resolution 46(1): 55-73.

Riak, Maker M. 2013. "Reversing the Trend of Corruption in South Sudan: Is Rwanda a Suitable Model?” Journal of Developing Societies 29(4): 487-501. http://jds.sagepub.com/cgi/doi/10.1177/0169796X13504681.

Rotberg, Robert I. 2004. "When States Fail: Causes and Consequences." In When States Fail: Causes and Consequences, ed. Robert I. Rotberg. New Jersey: Princeton University Press, $1-49$.

Saidi, Nasser H. 1994. "The Economic Reconstruction of Lebanon: War, Peace, and Modernization." In Peace for Lebanon? From War to Reconstruction, ed. Deirdre Collings. Boulder: Lynne Rienner Publishers, 195-212.

Salamy, Imad. 2014. The Government and Politics of Lebanon. Oxon: Routledge.

Saleh, Ali Salman, and Charles Harvie. 2005. "An Analysis of Public Sector Deficits and Debt in Lebanon: 1970-2000." Middle East Review of International Affairs 9(4): 106-36.

Salem, Elie Adib. 1973. Modernization without Revolution: Lebanon's Experience. London: Indiana University Press.

Salloukh, Bassel F. 2006. "The Limits of Electoral Engineering in Divided Societies: Elections 
in Postwar Lebanon." Canadian Journal of Political Science 39(3): 635-55.

Salloukh, Bassel F., Rabie Barakat, and Jinan S. Al-Habbal. 2015. Politics of Sectarianism in Postwar Lebanon. London: Pluto Press.

Sambanis, Nicholas. 2001. "Do Ethnic and Nonethnic Civil Wars Have the Same Causes ?: A Theoretical and Empirical Inquiry (Part 1)." The Journal of Conflict Resolution 45(3): 25982.

Saouli, Adham. 2003. "Lebanon's Hizbullah: The Quest for Survival.” World Affairs 166(2): 7180.

Al Sayegh, Daoud. 1998. "Organisations Sectaires et Les Forces Politiques: La Recherche Des Limites." In Parties et Forces Politiques Au Liban: Renouveau et Enagagement, ed. Antoine Messarra. Beirut: Fondation Konrad Adenauer, 167-72.

Schaffer, Frederic C. 2000. Democracy in Translation: Understanding Politics in an Unfamiliar Culture. Ithaca: Cornell University Press.

Scharpf, Fritz W. 2003. Problem Solving Effectiveness and Democratic Accountability in the EU. Schenker, David. 2007. Lebanon Goes to Paris III: High Stakes in France and Beirut. Washington DC. http://www.washingtoninstitute.org/policy-analysis/view/lebanon-goes-toparis-iii-high-stakes-in-france-and-beirut.

Sedgwick, Mark. 2010. "Measuring Egyptian Regime Legitimacy.” Middle East Critique 19(3): 251-67. http://www.tandfonline.com/doi/abs/10.1080/19436149.2010.514474 (March 10, 2014).

Selee, Andrew D., and Joseph S. Tulchin. 2004. "Decentralization and Democratic Governance: Lessons and Challenges." In Decentralization, Democratic Governance and Civil Society in Comparative Perspectives, eds. Philip Oxhorn, Joseph S. Tulchin, and Andrew D. Selee. London: Woodrow Wilson Centre Press, 295-320.

Shapiro, Ian. 2001. "Problems, Methods, and Theories in the Study of Politics, or What's Wrong with Political Science and What to Do about It." Political Theory 30(4): 596-619.

Sharan, Timor. 2011. "The Dynamics of Elite Networks and Patron-Client Relations in Afghanistan.” Europe-Asia Studies 63(6): 1109-27.

Siegle, Joseph, and Patrick O’Mahony. 2010. "Decentralization and Internal Conflict.” In Making Decentralization Work: Democracy, Development, and Security, eds. Ed Connerley, Kent Eaton, and Paul Smoke. Colorado: Lynne Rienner Publishers, 135-66.

De Simone, Sara. 2015. "Building a Fragmented State: Land Governance and Conflict in South Sudan." Journal of Peacebuilding and Development 10(3): 60-73. 
http://dx.doi.org/10.1080/15423166.2015.1085812.

Sisk, Timothy. 2013. Statebuilding: Consolidating Peace After Conflict. London: Polity Press.

Skocpol, Theda. 1979. States \& Social Revolutions: A Comparative Analysis of France, Russia, \& China. Cambridge: Cambridge University Press.

Sobek, David. 2010. "Masters of Their Domains: The Role of State Capacity in Civil Wars." Journal of Peace Research 47(3): 267-71.

Le Soleil. 2012. "Benoit Sambou Annonce Un Projet de 350 Millions : Les Zones Post-Conflit Vont Relancer L'agriculture En Casamance.” Le Soleil.

http://www.lesoleil.sn/index.php?option=com_content\&view=article\&id=16706:benoitsambou-annonce-un-projet-de-350-millions-les-zones-post-conflit-vont-relancerlagriculture-en-casamance \&catid=78:a-la-une.

South Sudan Bureau for Community Security and Small Arms Control, South Sudan Peace and Reconciliation Commission, and United Nations Development Programme. 2012. Community Consultation Report: Warrap State, South Sudan. Juba. http://www.undp.org/content/dam/southsudan/library/Documents/CSAC Reports/UNDPSS-Warrap-consult-12.pdf.

South Sudan National Bureau of Statistics. 2011. South Sudan Statistical Yearbook 2011. Juba. http://static1.1.sqspedn.com/static/f/750842/18935415/1349357346780/South+Sudan+Statis tical+Yearbook+2011+FINAL.pdf?token=xcrh+XTeo9vWw3HAwjYs5YtHA48=.

Starr, S. Frederick. 2006. "Sovereignty and Legitimacy in Afghan Nation-Building." In NationBuilding: Beyond Afghanistan and Iraq, ed. Francis Fukuyama. Baltimore: The Johns Hopkins University Press, 107-24.

Streeck, Wolfgang, and Kathleen Thelen. 2005. "Introduction: Institutional Change in Advanced Political Economies." In Beyond Continuity: Institutional Change in Advanced Economies, eds. Wolfgang Streeck and Kathleen Thelen. Oxford: Oxford University Press, 1-39.

Suchman, Mark C. 1995. "Managing Legitimacy: Strategic and Institutional Approaches." The Academy of Management Review 20(3): 571-610.

The World Bank. 2005. "Senegal Receives 20 Million for Emergency Recovery Project in Casamance." World Bank. http://web.worldbank.org/external/default/main?pagePK=64027221\&piPK=64027220\&the SitePK=296303\&menuPK=296336\&Projectid=P069207.

Thies, Cameron G. 2010. "Of Rulers, Rebels, and Revenue: State Capacity, Civil War Onset, and Primary Commodities." Journal of Peace Research 47(3): 321-32.

Traboulsi, Fawwaz. 2007. A History of Modern Lebanon. London: Pluto Press. 
Treier, Shawn, and Simon Jackman. 2008. "Democracy as a Latent Variable." American Journal of Political Science 52(1): 201-17.

Van der Vossen, Bas. 2012. “The Asymmetry of Legitimacy.” Law and Philosophy 31(5): 56592.

de Waal, Alex. 2014. "When Kleptocracy Becomes Insolvent: Brute Causes of the Civil War in South Sudan." African Affairs 113(452): 347-69.

Walter, Barbara F. 2004. "Does Conflict Beget Conflict? Explaining Recurring Civil War." Journal of Peace Research 41(3): 371-88.

Washburne, Sarah Lykes. 2013. "Post-War Governance and the Impact of International Aid in South Sudan.” In Forging Two Nations: Insights on Sudan and South Sudan, ed. Elke Grawert. Addis Ababa: Organisation for Social Science Research in Eastern and Southern Africa, 188-200.

Wassara, Samson S. 2015. "South Sudan: State Sovereignty Challenged at Infancy." Journal of Eastern African Studies 9(4): 634-39.

http://www.tandfonline.com/doi/full/10.1080/17531055.2015.1105439.

Weil, Frederick D. 1989. "The Sources and Structures of Legitimation in Western Democracies: A Consolidated Model Tested with Time-Series Data in Six Countries since World War II." American Sociological Review 54(5): 682-706.

Widner, Jennifer A. 2004. "Building Effective Trust in the Aftermath of Severe Conflict." In When States Fail: Causes and Consequences, ed. Robert Rotberg. Princeton: Princeton University Press, 222-36.

Wood, Elisabeth Jean. 2008. "The Social Processes of Civil War: The Wartime Transformation of Social Networks.” Annual Review of Political Science 11(1): 539-61. http://www.annualreviews.org/doi/abs/10.1146/annurev.polisci.8.082103.104832.

Young, John. 2006. The South Sudan Defence Forces in the Wake of the Juba Declaration. Geneva. http://www.smallarmssurveysudan.org/fileadmin/docs/working-papers/HSBA-WP01-SSDF.pdf.

Zambakari, Christopher. 2013. "Post-Referendum South Sudan: Political Drivers of Violence and the Challenge of Democratic Nation-Building." In Forging Two Nations: Insights on Sudan and South Sudan, ed. Elke Grawert. Addis Ababa: Organisation for Social Science Research in Eastern and Southern Africa, 98-111.

Zanotti, L. 2008. "Imagining Democracy, Building Unsustainable Institutions: The UN Peacekeeping Operation in Haiti." Security Dialogue 39(5): 539-61.

El Zein, Fares. 2003. Dissertation Thesis "Politics of Administrative Reform in Post War 
Lebanon." University at Albany.

Zürcher, Christoph et al. 2013. Costly Democracy: Peacebuilding \& Democratization After War. Stanford, California: Stanford University Press.

Abla, Zeina, Amal Karaki, and Nada Dimachkieh Sweidan. 2014. Lebanon Millennium Development Goals Report 2013-2014. Beirut. http://www.lb.undp.org/content/lebanon/en/home/library/mdg/lebanon-mdg-report-2013$2014 /$.

Afrique Jet. 2014. "Projet Pôle de Développement de La Casamance.” Afrique Jet. http://www.afriquejet.com/afrique-ouest/3654-projet-pole-de-developpement-de-lacasamance.html.

Allen, Daniel. 2010. "New Directions in the Study of Nation-Building: Views through the Lens of Path Dependence." International Studies Review 12(3): 413-29.

Angeles, Leonora C., and Francisco A. Magno. 2004. "The Philippines: Decentralization, Local Governments, and Citizen Action.” In Decentralization, Democratic Governance and Civil Society in Comparative Perspectives, eds. Philip Oxhorn and Joseph S. Tulchin.

Washington DC: Woodrow Wilson Centre Press, 211-65.

Armstrong, Andrea, and Barnett Rubin. 2005. "The Great Lakes and South Central Asia." In Making States Work: State Failure and the Crisis of Governance, eds. Simon Chesterman, Michael Ignatieff, and Ramesh Thakur. New York: United Nations University Press, 79101.

Attipoe, Olympio, Biplove Choudhary, and Nicholas Jonga. 2014. An Analysis of Government Budgets in South Sudan from a Human Development Perspective. Juba. http://www.undp.org/content/dam/southsudan/library/Discussion Papers/SS-Discussion paper final.pdf.

Atzili, Boaz. 2010. "State Weakness and 'Vacuum of Power' in Lebanon." Studies in Conflict \& Terrorism 33(8): 757-82. http://www.tandfonline.com/doi/abs/10.1080/1057610X.2010.494172 (March 7, 2014).

Baaklini, Abdo I. 1976. Legislative and Political Development: Lebanon, 1842-1972. Durnham: Duke University Press.

Barbara, Julien. 2008. "Antipodean Statebuilding: The Regional Assistance Mission to Solomon Islands and Australian Intervention in the South Pacific." Journal of Intervention and Statebuilding 2(2): 123-49.

Bardhan, Pranab, and Dilip Mookherjee. 2006. "The Rise of Local Governments: An Overview." 
In Decentralization and Local Governance in Developing Countries: A Comparative Perspective, eds. Pranab Bardhan and Dilip Mookherjee. Cambridge: MIT Press, 1-52.

Baroudi, Sami E. 1998. "Economic Conflict in Postwar Lebanon: State-Labor Relations Between 1992 and 1997." Middle East Journal 52(4): 531-50.

Beck, Linda J. 2008. Brokering Democracy in Africa: The Rise of Clientelist Democracy in Senegal. New York: Palgrave.

Beetham, David, and Christopher Lord. 1998. Legitimacy and the EU. London: Addison-Wesley Longman.

Bellamy, Paul. 2007. "Introduction.” In Civil Wars of the World: Major Conflicts Since World War II, eds. Karl Jr Derouen and Uk Heo. Santa Barbara, California: ABC-CLIO Inc., 1-26.

Bennett, Andrew, and Colin Elman. 2006. "Qualitative Research: Recent Developments in Case Study Methods." Annual Review of Political Science 9(1): 455-76. http://www.annualreviews.org/doi/abs/10.1146/annurev.polisci.8.082103.104918 (February 21, 2014).

Blair, Harry. 2007. "Rebuilding and Reforming Civil Services in Post-Conflict Societies." In Governance in Post-Conflict Societies: Rebuilding Fragile States, ed. Derick W. Brinkerhoff. London: Routledge, 161-84.

Blomberg, S Brock, Gregory D Hess, and Siddharth Thacker. 2006. "On the Conflict Poverty Nexus." Economics and Politics 18(3): 237-67. http://www.blackwellsynergy.com/doi/abs/10.1111/j.1468-0343.2006.00170.x.

Bollen, Kenneth A. 1980. "Issues in the Comparative Measurement of Political Democracy." American Sociological Review 45(3): 370-90. . 1986. "Political Rights and Political Liberties in Nations: An Evaluation of Human Rights Measures, 1950 to 1984." Human Rights Quarterly 8(4): 567-91. - 1990. "Political Democracy: Conceptual and Measurement Traps." Studies In Comparative International Development 25(1): 7-24.

—. 2011. "Evaluating Effect, Composite, and Casual Indicators in Structural Equation Models." MIS Quarterly 35(2): 359-72.

Bollen, Kenneth A, and Richard Lennox. 1991. "Conventional Wisdom on Measurement: A Structural Equation Perspective." Psychological Bulletin 110(2): 305-14.

Bollen, Kenneth A, and Pamela Paxton. 2000. "Subjective Measures of Liberal Democracy." Comparative Political Studies 33(1): 58-86.

Bollen, Kenneth A, and Kwok-fai Ting. 2000. "A Tetrad Test for Causal Indicators.” 
Psychological Methods 5(1): 3-22.

Branch, Adam, and Zachariah Cherian Mampilly. 2005. "Winning the War, but Losing the Peace? The Dilemma of SPLM/A Civil Administration and the Tasks Ahead." The Journal of Modern African Studies 43(1): 1-20.

Brinkerhoff, Derick W. 2005. "Rebuilding Governance in Failed States and Post-Conflict Societies: Core Concepts and Cross-Cutting Themes." Public Administration and Development 25(1): 3-14.

_ 2007. "Introduction - Governance Challenges in Fragile States: Re-Establishing Legitimacy, Rebuilding Effectiveness, and Reconstituting Legitimacy." In Governance in Post-Conflict Societies: Rebuilding Fragile States, ed. Derick W. Brinkerhoff. London: Routledge, 1-21.

Brinkerhoff, Derick W., and Ronald W. Johnson. 2009. "Decentralized Local Governance in Fragile States: Learning from Iraq." International Review of Administrative Sciences 75(4): 585-607.

Brosché, Johan. 2016. "Crisis of Governance in South Sudan : Electoral Politics and Violence in the World's Newest Nation.” Journal of Modern African Studies 54(1): 67-90.

Busumtwi-Sam, James. 2004. "Development and Peacebuilding: Conceptual and Operational Deficits in International Assistance." In Durable Peace: Challenges for Peacebuilding in Africa, eds. Taiser M. Ali and Robert O. Matthews. Toronto: University of Toronto Press, $315-53$.

Cammett, Melanie. 2013. Democracy in Post-Invasion Iraq. http://watson.brown.edu/costsofwar/files/cow/imce/papers/2013/Democracy in PostInvasion Iraq.pdf.

- 2014. Compassionate Communalism: Welfare and Sectarianism in Lebanon. Ithaca: Cornell University Press.

Caplan, Richard. 2004. "Partner or Patron? International Civil Administration and Local Capacity-Building." International Peacekeeping 11(2): 229-47.

Chassay, Clancy. 2006. "Christian Leader Says Lebanese Opposition Ready for Power." The Guardian. http://www.theguardian.com/world/2006/dec/13/syria.lebanon.

Coburn, Noah. 2011. Bazaar Politics: Power \& Pottery in an Afghan Market Town. California: Stanford University Press.

Cole, Elizabeth A., and Judy Barsalou. 2006. Unite or Divide? The Challenges of Teaching History in Societies Emerging from Violent Conflict. 
Collier, Paul. 2002. Aid, Policy and Growth in Post-Conflict Countries.

Collier, Paul, and Anke Hoeffler. 1998. "On the Causes of Civil War." Oxford Handbook of the Economics of Peace and Conflict 50: 563-73.

—. 2004. "Greed and Grievance in Civil War." Oxford Economic Papers 56(4): 563-95.

Cook, Traci D. 2007. A Place To Call Their Own: Southern Sudanese Comment on the Hard Work Adn Struggles of Self-Governance. Washington DC.

Crow, Ralph E, and Adnan Iskandar. 1961. "Administrative Reform in Lebanon.” International Review of Administrative Sciences 27(3): 293-307.

Dahl, Robert. 1971. Polyarchy: Participation and Opposition. New Haven: Yale University Press.

Diallo, Boucounta. 2009. La Crise Casamançaise: Problématique et Voies de Solutions. Paris: L'Harmattan.

Diamond, Larry, and Marc F. Plattner. 2006. Electoral Systems and Democracy. Baltimore: The Johns Hopkins University Press.

Dibeh, Ghassan. 2005. 44 The Political Economy of Postwar Reconstruction in Lebanon. Helsinki.

Dinnen, Sinclair. 2007. "A Comment on State-Building in Solomon Islands." The Journal of Pacific History 42(2): 255-63.

- 2008. "The Solomon Islands Intervention and the Instabilities of the Post-Colonial State." Global Change, Peace \& Security 20(3): 339-55.

Dodge, Toby. 2013. "Intervention and Dreams of Exogenous Statebuilding: The Application of Liberal Peacebuilding in Afghanistan and Iraq." Review of International Studies 39(5): 1189-1212. http://journals.cambridge.org/article_S0260210513000272.

Dodge, Tony. 2011. "Domestic Politics and State-Building." In Afghanistan: To 2015 and beyond, eds. Toby Dodge and Nicholas Redman. International Institute for Strategic Studies, 69-96.

Doyle, Michael W., and Nicholas Sambanis. 2000. "International Peacebuilding: A Theoretical and Quantitative Analysis." American Political Science Review 94(4): 779-801. http://www.drworley.org/NSPcommon/Nation Building/2000,12 APSR Doyle Sambanis.pdf.

—. 2006. Making War and Building Peace. New Jersey: Princeton University Press.

Ducci, María Elena. 2004. "Local Governance and Democracy: The View from the Chilean 
Border." In Decentralization, Democratic Governance and Civil Society in Comparative Perspectives, eds. Philip Oxhorn, Joseph S. Tulchin, and Andrew D. Selee. Washington DC: Woodrow Wilson Centre Press, 119-39.

Eaton, Kent, and Larry Schroeder. 2010. "Measuring Decentralization.” In Making Decentralization Work: Democracy, Development, and Security, eds. Ed Connerley, Kent Eaton, and Paul Smoke. Colorado: Lynne Rienner Publishers, 167-90.

Von Einsiedel, Sebastian. 2005. "Policy Responses to State Failure." In Making States Work: State Failure and the Crisis of Governance, eds. Simon Chesterman, Michael Ignatieff, and Ramesh Thakur. New York: United Nations University Press, 13-35.

El-Khazen, Farid. 1998. "Les Alliances et Les Conflits Entre Les Parties Politiques Au Liban." In Parties et Forces Politiques Au Liban: Renouveau et Enagagement, ed. Antoine Messarra. Beirut: Fondation Konrad Adenauer, 133-42.

- 2000. The Breakdown of the State in Lebanon: 1967-1976. Cambridge: Harvard University Press.

El-Mufti, Karim. 2011. Public Policy Initiative The Management of Public Interest in Lebanon, a Broken Concept. Beirut. http://policylebanon.org/topmenu/policyareas/areas/Ressource.html?Id=79\#.

El-Solh, Raghid. 994. "Religious Identity and Citizenship: An Overview of Perspectives." In Peace for Lebanon? From War to Reconstruction 1, ed. Deidre Collings. Boulder: Lynne Rienner Publishers, 231-40.

El-Zein, Fares, and Holly Sims. 2004. "Reforming War's Administrative Rubble in Lebanon." Public Administration and Development 24: 279-88.

Englebert, Pierre. 2000. State Legitimacy and Development in Africa. Colorado: Lynne Rienner Publishers.

Eriksen, Erik O., and John E. Fossum. 2004. "Europe in Search of Legitimacy: Strategies of Legitimation Assessed." International Political Science Review 25(4): 435-59.

Evans, Martin. 2005. "Insecurity or Isolation? Natural Resources and Livelihoods in Lower Casamance." Canadian Journal of African Studies 39(2): 284-314.

Evans, Peter B. 1989. "Predatory, Developmental, and Other Apparatuses : A Comparative Political Economy Perspective on the Third World State." Sociological Forum: Special Issue: Comparative National Development: Theory and Facts for the 1990s 4(4): 561-87.

Fall, Aissatou. 2010. Understanding The Casamance Conflict: A Background. Accra. http://www.kaiptc.org/publications/monographs/monographs/monograph-7-aissatou.aspx. 
Fawaz, Mona, and Isabelle Peillen. 2003. The Case of Beirut, Lebanon. Beirut. http://www.ucl.ac.uk/dpu-projects/Global_Report/cities/beirut.htm.

Fearon, James D. 2004. “Why Do Some Civil Wars Last So Much Longer than Others?” Journal of Peace Research 41(3): 275-301.

Foucher, Vincent. 2005. "La Guerre Des Dieux ? Religions et Séparatisme En Basse Casamance.” Canadian Journal of African Studies 39(2): 363-90.

Frahm, Ole. 2015. "Making Borders and Identities in South Sudan." Journal of Contemporary African Studies 33(2): 251-67. http://www.tandfonline.com/doi/full/10.1080/02589001.2015.1070461.

François, Monika, and Inder Sud. 2006. "Promoting Stability and Development in Fragile and Failed States." Development Policy Review 24(2): 141-60.

Fraser, John. 1974. "Validating a Measure of National Political Legitimacy." American Journal of Political Science 18(1): 117-34.

Fukuyama, Francis. 2006. America at the Crossroads: Democracy, Power, and the Neoconservative Legacy. Connecticut: Yale University Press.

Gamble, David P. 1957. The Wolof of Senegambia. London: International African Institute.

Gaspard, Toufic K. 2004. A Political Economy of Lebanon, 1948-2002: The Limits of LaissezFaire. Leiden: Brill.

Geddes, Barbara. 1990. "How the Cases You Choose Affect the Answers You Get: Selection Bias in Comparative Politics." Political Analysis 2(1): 131-50.

Gehrold, Stefan, and Inga Neu. 2010. Caught Between Two Fronts: In Search of Lasting Peace in the Casamance Region. Berlin.

Gellar, Sheldon. 1995. Senegal: An Africam Nation between Islam and the West. Second edi. Boulder: Westview Press.

- 2005. Democracy in Senegal: Tocquevillian Analytics in Africa. New York: Palgrave.

Gemayel, Amine. 1992. Rebuilding Lebanon. Lanham: University Press of America.

Gerry, John. 2007. Case Study Research: Principles and Practices. New York: Cambridge University Press.

Ghani, Ashraf, and Clare Lockhart. 2008. Fixing Failed States: A Framework for Rebuilding a Fractured World. New York: Oxford University Press.

Ghosn, Faten, and Amal Khoury. 2011. "Lebanon after the Civil War: Peace or the Illusion of Peace?” Middle East Journal 65(3): 381-97. 
Ghossain, Antoine. 1988. "Confessional Communities, Space and Political Reform in Lebanon." Social Compass1 35(4): 563-83.

Gilley, Bruce. 2006a. "The Determinants of State Legitimacy: Results for 72 Countries." International Political Science Review 27(1): 47-71. - 2006b. "The Meaning and Measure of State Legitimacy: Results for 72 Countries." European Journal of Political Research 45(3): 499-525.

_ 2012. "State Legitimacy: An Updated Dataset for 52 Countries." European Journal of Political Research 51(5): 693-99. http://doi.wiley.com/10.1111/j.14756765.2012.02059.x\%5Cnhttps://sremote.pitt.edu/doi/10.1111/j.14756765.2012.02059.x/,DanaInfo=onlinelibrary.wiley.com+pdf (January 26, 2014).

Mac Ginty, Roger. 2010. "Warlords and the Liberal Peace: State-Building in Afghanistan." Conflict, Security \& Development 10(4): 577-98.

Gleditsch, Nils Petter. 1996. "Environmental Change, Security, and Conflict." In Turbulent Peace: The Challenges of Managing International Conflict1, eds. Chester A. Crocker, Osler Hampson, and Pamela Aall. Washington DC: United States Institute of Peace, 53-68.

Goldsmith, Arthur A. 2007. "Does Nation-Building Work? Reviewing the Record." In Governance in Post-Conflict Societies: Rebuilding Fragile States, London: Routledge, 2544.

Goodhand, Jonathan. 2006. Aiding Peace: The Role of NGOs in Armed Conflict. Colorado: Lynne Rienner Publishers.

Grawert, Elke. 2013. "Introduction.” In Forging Two Nations: Insights on Sudan and South Sudan, ed. Elke Grawert. Addis Ababa: Organisation for Social Science Research in Eastern and Southern Africa, 15-51.

Grzymala-Busse, Anna. 2008. "Beyond Clientelism: Incumbent State Capture and State Formation." Comparative Political Studies 41(4/5): 638-73.

Grzymala-Busse, Anna, and Pauline Jones Luong. 2002. "Reconceptualizing the State: Lessons from Post-Communism." Politics \& Society 30(4): 529-54.

Gurowitz, Amy. 1999. "Mobilizing International Norms: Domestic Actors, Immigrants, and the Japanese State." World Politics 51(3): 413-45. http://www.journals.cambridge.org/abstract_S0043887100009138.

Haddad, Simon. 2009. "Lebanon: From Consociationalism to Conciliation." Nationalism and Ethnic Politics 15(3-4): 398-416.

http://www.tandfonline.com/doi/abs/10.1080/13537110903346684 (March 4, 2014). 
Hajjar, Sami G. 2009. "The Convoluted and Diminished Lebanese Democracy." Democracy and Security 5(3): 261-76. http://www.tandfonline.com/doi/abs/10.1080/17419160903304864 (March 10, 2014).

Hakim, Georges. 1966. "The Economic Basis of Lebanese Polity.” In Politics in Lebanon, ed. Leonard Binder. New York: John Wiley \& Sons, Inc, 57-69.

Haldén, Peter. 2010. "Systems-Building Before State-Building: On the Systemic Preconditions of State-Building." Conflict, Security \& Development 10(4): 519-45. http://www.tandfonline.com/doi/abs/10.1080/14678802.2010.500540.

Hameiri, Shahar. 2009. "Capacity and Its Fallacies: International State Building as State Transformation.” Millennium - Journal of International Studies 38(1): 55-81.

Hamzeh, A Nizar. 2000. "Lebanon's Islamists and Local Politics: A New Reality.” Third World Quarterly 21(5): 739-59.

Harb, Boutros. 1998. “Le Relancement D’une Vie Politique.” In Parties et Forces Politiques Au Liban: Renouveau et Enagagement, ed. Antoine Messarra. Beirut: Fondation Konrad Adenauer, 53-56.

Harb, Mona, and Reinoud Leenders. 2005. 'Know Thy Enemy: Hizbullah, 'terrorism' and the Politics of Perception." Third World Quarterly 26(1): 173-97.

Harik, Judith. 1996. "Between Islam and the System: Sources and Implications of Popular Support for Lebanon's Hizballah.” Journal of Conflict Resolution 40(1): 41-67.

Hartzell, Caroline A. 2006. "Structuring the Peace: Negotiated Settlements and the Construction of Conflict Management Institutions." In Conflict Prevention and Peacebuilding in PostWar Societies: Sustaining the Peace, eds. T. David Mason and James D. Meernik. Oxon: Routledge, 31-52.

Hartzell, Caroline, Matthew Hoddie, and Donald Rothchild. 2001. "Stabilizing the Peace After Civil War: An Investigation of Some Key Variables.” International Organization 55(1): 183-208.

Hess, Steve. 2010. "Coming to Terms with Neopatrimonialism: Soviet and American NationBuilding Projects in Afghanistan." Central Asian Survey 29(2): 171-87.

Hottinger, Arnold. 1966. 'Zu'ama' in Historical Perspective." In Politics in Lebanon, ed. Leonard Binder. New York: John Wiley \& Sons, Inc, 85-106.

Hudson, Michael C. 1999. "Lebanon after Ta'if: Another Reform Opportunity Lost.” Arab Studies Quarterly 21(1): 27-40.

Hutchison, M. L., and K. Johnson. 2011. "Capacity to Trust? Institutional Capacity, Conflict, and 
Political Trust in Africa, 2000-2005." Journal of Peace Research 48(6): 737-52.

http://jpr.sagepub.com/cgi/doi/10.1177/0022343311417981 (March 10, 2014).

Inbal, Aliza B., and Hanna Lerner. 2007. "Constitutional Design, Identity and Legitimacy in Post-Conflict Reconstruction." In Governance in Post-Conflict Societies: Rebuilding Fragile States, ed. Derick W. Brinkerhoff. London: Routledge, 45-63.

International Crisis Group. 2006. Israel/Hizbollah/Lebanon: Avoiding Renewed Conflict.

International Monetary Fund. 2006. Lebanon: Selected Issue. Washington DC. http://www.imf.org/external/pubs/ft/scr/2006/cr06200.pdf.

Iskandar, Adnan. 1964. Bureaucracy in Lebanon. Beirut: American University of Beirut. 1996. Public Service Accountability in Lebanon. Beirut. http://ddc.aub.edu.lb/projects/pspa/PSAccount/PSAccount-0.html.

Jackman, Robert W. 1987. "Political Institutions and Voter Turnout in the Industrial Democracies." The American Political Science Review 81(2): 405-24.

Jad, Sana Souaid. 2011. The Balance Sheet Approach and the Public Debt Stock Analysis: The Case of Lebanon. Beirut. http://www.bdl.gov.lb/.

Jawad, Rana. 2002. "A Profile of Social Welfare in Lebanon: Assessing the Implications for Social Development Policy.” Global Social Policy 2(3): 319-42.

Jok, Madut Jok. 2011. Diversity, Unity, and Nation Building in South Sudan. Washington DC. http://www.usip.org/sites/default/files/Diversity\%2C Unity\%2C and Nation Building in South Sudan \%28Jok\%29.pdf.

Jong, Ferdinand De. 2005a. "A Joking Nation : Conflict Resolution in Senegal.” Canadian Journal of African Studies 39(2): 391-415.

. 2005b. "Contested Casamance : Introduction." Canadian Journal of African Studies 39(2): 213-29.

Von Kaltenborn-Stachau, Henriette. 2008. The Missing Link - Fostering Positive Citizen-State Relations in Post-Conflict Environments. Washington DC. http://siteresources.worldbank.org/EXTGOVACC/Resources/CommGAPMissingLinkWeb. pdf.

Kameir, El Wathig. 2011. The Political Economy of South Sudan: A Scoping Analytical Study. Abidjan.

Kanaan, Nimat, and Randa Aboul-Hosn. 1998. "Mapping of Living Conditions in Lebanon." Mapping of Living Conditions in Lebanon (UNDP).

http://www.undp.org.lb/programme/pro- 
poor/poverty/povertyinlebanon/molc/setting/A/1975.htm\# (November 2, 2015).

Kanol, Direnç. 2011. "Assessing the Legitimacy of the EU.” Interdisciplinary Political Studies 1(0): 49-59.

Kaplan, Seth. 2008. “The Remarkable Story of Somaliland.” Journal of Democracy 19(3): 14357.

Kaufmann, Daniel, Aart Kraay, and Massimo Mastruzzi. 2010. The Worldwide Governance Indicators Methodology and Analytical Issues. Washington DC.

Keefer, Philip E., Ambar Narayan, and Tara Vishwanath. 2006. "Decentralization in Pakistan: Are Local Governments Likely to Be More Accountable than Central Governments?" In Decentralization and Local Governance in Developing Countries: A Comparative Perspective, eds. Pranab Bardhan and Dilip Mookherjee. Cambridge: MIT Press, 285-304.

Kerr, Malcolm H. 1966. "Political Decision Making in a Confessional Democracy." In Politics in Lebanon, ed. Leonard Binder. New York: John Wiley \& Sons, Inc, 167-86.

Khadiagala, Gilbert M. 1995. "State Collapse and Reconstruction in Uganda." In Collapsed States: The Disintegration and Reconstruction of Legitimate Authority, ed. I. William Zartman. Colorado: Lynne Rienner Publishers, 33-47.

Kingston, Paul, and Marie-Joëlle Zahar. 2004. "Rebuilding A House of Many Mansions: The Rise and Fall of Militia Cantons in Lebanon." In States Within States, eds. Paul Kingston and Ian S. Speaars. New York: Palgrave, 81-98.

Kisirwani, M., and W. M. Parle. 1987. "Assessing the Impact of the Post Civil War Period on the Lebanese Bureaucracy: A View from Inside." Journal of Asian and African Studies 22(12): 17-29. http://jas.sagepub.com/cgi/doi/10.1177/002190968702200102.

Kisirwani, Maroun. 1997a. "Accountability of Lebanese Civil Servants: An Overview of Disciplinary Mechanisms." In Lebanon Beyond 2000, eds. Amin Saikal and Geoffrey Jukes. Canberra: Centre for Middle Eastern and Central Asian Studies.

- 1997b. "The Rehabilitation and Reconstruction of Lebanon." In Remaking the Middle East, eds. Paul J White and William S Logan. Oxford: Berg, 87-104.

Kisirwani, Maroun, and William M. Parle. 1987. "Assessing the Impact of the Post Civil War Period on the Lebanese Bureaucracy: A View from Inside." Journal of Asian and African Studies 22(1-2): 17-29.

Kitschelt, Herbert, and Steven I. Wilkinson. 2007. "Citizen-Politician Linkages: An Introduction." In Patrons, Clients, and Policies: Patterns of Democratic Accountability and Political Competition, eds. Herbert Kitschelt and Steven I. Wilkinson. Cambridge: Cambridge University Press, 1-49. 
Kon, Madut. 2015. "Institutional Development, Governance, and Ethnic Politics in South Sudan." Journal of Global Economics 3(2): 1-6.

http://www.esciencecentral.org/journals/institutional-development-governance-and-ethnicpolitics-in-south-sudan-2375-4389-1000147.php?aid=57097.

Larson, Greg, Peter Biar Ajak, and Lant Pritchett. 2013. South Sudan's Capability Trap:

Building a State with Disruptive Innovation. Cambridge. https://www.hks.harvard.edu/content/download/69085/1249150/version/1/file/268_SudanPDIA.pdf.

Leenders, Reinoud. 2012. Spoils of Truth: Corruption and State-Building in Postwar Lebanon. Ithaca: Cornell University Press.

LeRiche, Matthew, and Matthew Arnold. 2012. South Sudan: From Revolution to Independence. London: C. Hurst \& Co (Publishers) Ltd.

Levi, Margaret, and Audrey Sacks. 2009. "Legitimating Beliefs: Sources and Indicators.” Regulation \& Governance 3(4): 311-33.

Levi, Margaret, Audrey Sacks, and Tom Tyler. 2009. "Conceptualizing Legitimacy, Measuring Legitimating Beliefs." American Behavioral Scientist 53(3): 354-75.

Lipset, Seymour Martin. 1983. Political Man: The Social Bases of Politics. London: Heinemann.

Lister, Sarah, and Andrew Wilder. 2005. "Strengthening Subnational Administration in Afghanistan: Technical Reform or State-Building?" Public Administration and Development 25(1): 39-48.

Loehlin, John C. 1998. Latent Variable Models: An Introduction to Factor, Path, and Structural Analysis. Third. New Jersey: Lawrence Erlbaum Associates.

Low-beer, Ann. 2001. Paradigm Politics, School Textbooks and Cultural Identity: The Struggle in Bosnia and Hercegovina.

Lyons, Terrence. 2005. Demilitarizing Politics: Elections on the Uncertain Road to Peace. Colorado: Lynne Rienner Publishers.

Mane, Bacary Domingo. 2014. "POLE DE DEVELOPPEMENT DE LA CASAMANCE." Sud Online. http://www.sudonline.sn/au-dela-des-questions-economique-etadministrative_a_17983.html.

March, James G., and Johan P. Olsen. 1989. Institutions: The Organizational Basis of Politics. New York: The Free Press.

Marquette, Heather, and Danielle Beswick. 2011. "State Building, Security and Development: State Building as a New Development Paradigm?" Third World Quarterly 32(10): 1703-14. 
Marshall, Monty G, and Keith Jaggers. 2002. Political Regime Characteristics and Transitions, 1800-2002: Dataset User's Manual. Maryland.

Marut, Jean-Claude. 2010. Le Conflit de Casamance: Ce Qui Disent Les Armes. Paris: Édition Karthala.

Mason, David T., Mehmet Gurses, Patrick T. Brandt, and Jason Michael Quinn. 2011. "When Civil Wars Recur: Conditions for Durable Peace after Civil Wars." International Studies Perspectives 12(2): 171-89.

Maxwell, Daniel, Kirsten Gelsdorf, and Martina Santschi. 2012. Researching Livelihoods and Services Affected by Conflict Livelihoods, Basic Services and Social Protection in South Sudan. London. http://community.eldis.org/.5a0b0243/Livelihoods basic services and social protection in Sri Lanka.pdf.

Mayall, James. 2005. "The Legacy of Colonialism.” In Making States Work: State Failure and the Crisis of Governance, eds. Simon Chesterman, Michael Ignatieff, and Ramesh Thakur. New York: United Nations University Press, 36-58.

Mcloughlin, Claire. 2014. "When Does Service Delivery Improve the Legitimacy of a Fragile or Conflict-Affected State?" Governance: n/a-n/a. http://doi.wiley.com/10.1111/gove.12091 (May 2, 2014).

von der Mehden, Fred R., and Kim Quaile Hill. 1980. “Area Experts' Images of African Nations." Comparative Political Studies 12(4): 497-510.

Meierhenrich, Jens. 2004. "Forming States After Failure." In When States Fail: Causes and Consequences, ed. Rot. Princeton: Princeton University Press, 153-68.

Mendy, Toumany. 2006. Politique et Puissance de L'argent Au Sénégal: Les Désarrois D'un Peuple Innocent. Paris: L'Harmattan.

Messarra, Antoine. 1998. "L'expérience Libanais Du Parti Dans Le Cadre Arabe." In Partis et Forces Politiques Au Liban: Renouveau et Engagement, ed. Antoine Messarra. Beirut: Fondation Konrad Adenauer, 15-40.

Migdal, Joel S. 2001. State in Society: Studying How States and Societies Transform and Constitute One Another. Cambridge: Cambridge University Press.

Miller, Benjamin. 2015. "Stateness, National Self-Determination and War and Peace in the Twenty-First Century." Ethnopolitics 14(5): 531-39. http://www.tandfonline.com/doi/full/10.1080/17449057.2015.1051818.

Ministry of Foreign Affairs Denmark. 2005. A Joint Evaluation: Humanitarian and Reconstruction Assistance to Afghanistan, 2001-05: From Denmark, Ireland, The Netherlands, Sweden and the United Kingdom. 
Ministry of Social Affairs, and United Nations Development Programme. 2007. The effects of brief mindfulness intervention on acute pain experience: An examination of individual difference Development of Mapping of Living Conditions in Lebanon, 1995-2004: A Comparison with the Results of "Mapping of Living Conditions in Lebanon, 1998." Beirut.

Mitchell, Timothy. 1991. "The Limits of the State: Beyond Statist Approaches and Their Critics." The American Political Science Review 85(1): 77-96.

Mukhopadhyay, Dipali. 2009. "Disguised Warlordism and Combatanthood in Balkh: The Persistence of Informal Power in the Formal Afghan State." Conflict, Security \& Development 9(4): 535-64.

Muller, Edward N., Thomas O. Jukam, and Mitchell A. Seligson. 1982. "Diffuse Political Support and Antisystem Political Behavior : A Comparative Analysis." American Journal of Political Science 26(2): 240-64.

Najem, Tom Pierre. 2000. Lebanon's Renaissance: The Political Economy of Reconstruction. Reading: Ithaca Press.

Nassif, Georges. 1998. "Les Parties Libanaises En Crise: Comment Transforment-Elles Politiquement." In Parties et Forces Politiques Au Liban: Renouveau et Enagagement, ed. Antoine Messarra. Beirut: Fondation Konrad Adenauer, 123-29.

Ndegwa, Stephen N, and Brian Levy. 2003. The Politics of Decentralization in Africa: A Comparative Analysis. Washington DC. http://www1.worldbank.org/publicsector/LearningProgram/Decentralization/Ndegwa.pdf.

Netemeyer, Richard G., William O. Bearden, and Subhash Sharma. 2003. Scaling Procedures: Issues and Applications. California: Sage Publications, Inc.

Nettl, J.P. 1968. "The State as a Conceptual Variable.” World Politics 20(4): 559-92.

News, BBC. 2009. "Senegal Apology for Christ â€ $\mathrm{T}^{\mathrm{TM}}$ Slur '." BBC News. http://news.bbc.co.uk/go/pr/fr///2/hi/africa/8435805.stm.

Norton, Augustus Richard. 2000. "Hizballah and the Israeli Withdrawal from Southern Lebanon." Journal of Palestine Studies 30(1): 22-35.

O Senegal. 2014. "Une Autoroute Maritime Se Développe Entre Dakar et La Casamance.” $O$ Senegal. http://www.osenegal.com/news/transport/autoroute-maritime-se-developpe-dakarcasamance/.

OECD. 2010. The State's Legitimacy in Fragile Situations: Unpacking Complexity. http://www.oecd.org/dac/incaf/44794487.pdf.

Ottaway, Marina. 1995. "Democratization in Collapsed States." In Collapsed States: The 
Disintegration and Restoration of Legitimate Authority, ed. I. William Zartman. Colorado: Lynne Rienner Publishers, 235-50.

Oxhorn, Philip. 2004. "Unraveling the Puzzle of Decentralization." In Decentralization, Democratic Governance and Civil Society in Comparative Perspectives, eds. Philip Oxhorn, Joseph S. Tulchin, and Andrew D. Selee. Washington DC: Woodrow Wilson Centre Press, 3-32.

Ozer, Daniel J. 1999. "Four Principles for Personality Assessment." In Handbook of Personality: Theory and Research, eds. Lawrence A. Pervin and Oliver P. John. New York: Guilford.

Paris, Roland. 2005. "Wilson's Ghost: The Faulty Assumptions of Postconflict Peacebuilding." In Turbulent Peace: The Challenges of Managing International Conflict, eds. Chester A. Crocker, Fen Osler Hampson, and Pamela Aall. Washington DC: United States Institute of Peace, $765-84$.

—. 2006. "NATO's Choice in Afghanistan: Go Big or Go Home." Policy Options: 35-43.

Picard, Elizabeth. 1993. The Lebanese Shi'a and Political Violence. Geneva.

Pierson, Paul. 2004. Politics in Time: History, Institutions, and Social Analysis. Princeton: Princeton University Press.

Posner, Daniel. 2004. "Civil Society and the Reconstruction of Failed States." In When States Fail: Causes and Consequences, ed. Robert Rotberg. Princeton: Princeton University Press, $237-55$.

Radon, Jenik, and Sarah Logan. 2014. "South Sudan: Governance Arrangements, War, and Peace." Journal of International Affairs 68(1): 149-67.

http://search.ebscohost.com/login.aspx?direct=true \&db=buh\&AN=100052751\&site=ehostlive.

Regan, Patrick M. 2002. "Third-Party Interventions and the Duration of Intrastate Conflicts." The Journal of Conflict Resolution 46(1): 55-73.

Riak, Maker M. 2013. "Reversing the Trend of Corruption in South Sudan: Is Rwanda a Suitable Model?” Journal of Developing Societies 29(4): 487-501.

http://jds.sagepub.com/cgi/doi/10.1177/0169796X13504681.

Rotberg, Robert I. 2004. "When States Fail: Causes and Consequences." In When States Fail: Causes and Consequences, ed. Robert I. Rotberg. New Jersey: Princeton University Press, $1-49$.

Saidi, Nasser H. 1994. "The Economic Reconstruction of Lebanon: War, Peace, and Modernization." In Peace for Lebanon? From War to Reconstruction, ed. Deirdre Collings. Boulder: Lynne Rienner Publishers, 195-212. 
Salamy, Imad. 2014. The Government and Politics of Lebanon. Oxon: Routledge.

Saleh, Ali Salman, and Charles Harvie. 2005. "An Analysis of Public Sector Deficits and Debt in Lebanon: 1970-2000.” Middle East Review of International Affairs 9(4): 106-36.

Salem, Elie Adib. 1973. Modernization without Revolution: Lebanon's Experience. London: Indiana University Press.

Salloukh, Bassel F. 2006. "The Limits of Electoral Engineering in Divided Societies: Elections in Postwar Lebanon.” Canadian Journal of Political Science 39(3): 635-55.

Salloukh, Bassel F., Rabie Barakat, and Jinan S. Al-Habbal. 2015. Politics of Sectarianism in Postwar Lebanon. London: Pluto Press.

Sambanis, Nicholas. 2001. "Do Ethnic and Nonethnic Civil Wars Have the Same Causes ?: A Theoretical and Empirical Inquiry (Part 1)." The Journal of Conflict Resolution 45(3): 25982.

Saouli, Adham. 2003. "Lebanon's Hizbullah: The Quest for Survival." World Affairs 166(2): 7180.

Al Sayegh, Daoud. 1998. "Organisations Sectaires et Les Forces Politiques: La Recherche Des Limites." In Parties et Forces Politiques Au Liban: Renouveau et Enagagement, ed. Antoine Messarra. Beirut: Fondation Konrad Adenauer, 167-72.

Schaffer, Frederic C. 2000. Democracy in Translation: Understanding Politics in an Unfamiliar Culture. Ithaca: Cornell University Press.

Scharpf, Fritz W. 2003. Problem Solving Effectiveness and Democratic Accountability in the EU.

Schenker, David. 2007. Lebanon Goes to Paris III: High Stakes in France and Beirut. Washington DC. http://www.washingtoninstitute.org/policy-analysis/view/lebanon-goes-toparis-iii-high-stakes-in-france-and-beirut.

Sedgwick, Mark. 2010. "Measuring Egyptian Regime Legitimacy." Middle East Critique 19(3): 251-67. http://www.tandfonline.com/doi/abs/10.1080/19436149.2010.514474 (March 10, 2014).

Selee, Andrew D., and Joseph S. Tulchin. 2004. "Decentralization and Democratic Governance: Lessons and Challenges." In Decentralization, Democratic Governance and Civil Society in Comparative Perspectives, eds. Philip Oxhorn, Joseph S. Tulchin, and Andrew D. Selee. London: Woodrow Wilson Centre Press, 295-320.

Shapiro, Ian. 2001. "Problems, Methods, and Theories in the Study of Politics, or What's Wrong with Political Science and What to Do about It." Political Theory 30(4): 596-619.

Sharan, Timor. 2011. "The Dynamics of Elite Networks and Patron-Client Relations in 
Afghanistan.” Europe-Asia Studies 63(6): 1109-27.

Siegle, Joseph, and Patrick O’Mahony. 2010. "Decentralization and Internal Conflict." In Making Decentralization Work: Democracy, Development, and Security, eds. Ed Connerley, Kent Eaton, and Paul Smoke. Colorado: Lynne Rienner Publishers, 135-66.

De Simone, Sara. 2015. "Building a Fragmented State: Land Governance and Conflict in South Sudan." Journal of Peacebuilding and Development 10(3): 60-73. http://dx.doi.org/10.1080/15423166.2015.1085812.

Sisk, Timothy. 2013. Statebuilding: Consolidating Peace After Conflict. London: Polity Press.

Skocpol, Theda. 1979. States \& Social Revolutions: A Comparative Analysis of France, Russia, $\&$ China. Cambridge: Cambridge University Press.

Sobek, David. 2010. "Masters of Their Domains: The Role of State Capacity in Civil Wars." Journal of Peace Research 47(3): 267-71.

Le Soleil. 2012. "Benoit Sambou Annonce Un Projet de 350 Millions : Les Zones Post-Conflit Vont Relancer L'agriculture En Casamance.” Le Soleil.

http://www.lesoleil.sn/index.php?option=com_content\&view=article\&id=16706:benoitsambou-annonce-un-projet-de-350-millions-les-zones-post-conflit-vont-relancerlagriculture-en-casamance\&catid=78:a-la-une.

South Sudan Bureau for Community Security and Small Arms Control, South Sudan Peace and Reconciliation Commission, and United Nations Development Programme. 2012. Community Consultation Report: Warrap State, South Sudan. Juba. http://www.undp.org/content/dam/southsudan/library/Documents/CSAC Reports/UNDPSS-Warrap-consult-12.pdf.

South Sudan National Bureau of Statistics. 2011. South Sudan Statistical Yearbook 2011. Juba. http://static1.1.sqspcdn.com/static/f/750842/18935415/1349357346780/South+Sudan+Statis tical+Yearbook+2011+FINAL.pdf?token=xcrh+XTeo9vWw3HAwjYs5YtHA48=.

Starr, S. Frederick. 2006. "Sovereignty and Legitimacy in Afghan Nation-Building." In NationBuilding: Beyond Afghanistan and Iraq, ed. Francis Fukuyama. Baltimore: The Johns Hopkins University Press, 107-24.

Streeck, Wolfgang, and Kathleen Thelen. 2005. "Introduction: Institutional Change in Advanced Political Economies." In Beyond Continuity: Institutional Change in Advanced Economies, eds. Wolfgang Streeck and Kathleen Thelen. Oxford: Oxford University Press, 1-39.

Suchman, Mark C. 1995. "Managing Legitimacy: Strategic and Institutional Approaches." The Academy of Management Review 20(3): 571-610.

The World Bank. 2005. "Senegal Receives 20 Million for Emergency Recovery Project in 


\section{Casamance." World Bank.}

http://web.worldbank.org/external/default/main?pagePK=64027221\&piPK=64027220\&the SitePK=296303\&menuPK=296336\&Projectid=P069207.

Thies, Cameron G. 2010. "Of Rulers, Rebels, and Revenue: State Capacity, Civil War Onset, and Primary Commodities." Journal of Peace Research 47(3): 321-32.

Traboulsi, Fawwaz. 2007. A History of Modern Lebanon. London: Pluto Press.

Treier, Shawn, and Simon Jackman. 2008. "Democracy as a Latent Variable." American Journal of Political Science 52(1): 201-17.

Van der Vossen, Bas. 2012. "The Asymmetry of Legitimacy." Law and Philosophy 31(5): 56592.

de Waal, Alex. 2014. "When Kleptocracy Becomes Insolvent: Brute Causes of the Civil War in South Sudan.” African Affairs 113(452): 347-69.

Walter, Barbara F. 2004. "Does Conflict Beget Conflict? Explaining Recurring Civil War." Journal of Peace Research 41(3): 371-88.

Washburne, Sarah Lykes. 2013. "Post-War Governance and the Impact of International Aid in South Sudan.” In Forging Two Nations: Insights on Sudan and South Sudan, ed. Elke Grawert. Addis Ababa: Organisation for Social Science Research in Eastern and Southern Africa, 188-200.

Wassara, Samson S. 2015. "South Sudan: State Sovereignty Challenged at Infancy." Journal of Eastern African Studies 9(4): 634-39. http://www.tandfonline.com/doi/full/10.1080/17531055.2015.1105439.

Weil, Frederick D. 1989. "The Sources and Structures of Legitimation in Western Democracies: A Consolidated Model Tested with Time-Series Data in Six Countries since World War II." American Sociological Review 54(5): 682-706.

Widner, Jennifer A. 2004. "Building Effective Trust in the Aftermath of Severe Conflict." In When States Fail: Causes and Consequences, ed. Robert Rotberg. Princeton: Princeton University Press, 222-36.

Wood, Elisabeth Jean. 2008. "The Social Processes of Civil War: The Wartime Transformation of Social Networks.” Annual Review of Political Science 11(1): 539-61. http://www.annualreviews.org/doi/abs/10.1146/annurev.polisci.8.082103.104832.

Young, John. 2006. The South Sudan Defence Forces in the Wake of the Juba Declaration. Geneva. http://www.smallarmssurveysudan.org/fileadmin/docs/working-papers/HSBA-WP01-SSDF.pdf. 
Zambakari, Christopher. 2013. "Post-Referendum South Sudan: Political Drivers of Violence and the Challenge of Democratic Nation-Building." In Forging Two Nations: Insights on Sudan and South Sudan, ed. Elke Grawert. Addis Ababa: Organisation for Social Science Research in Eastern and Southern Africa, 98-111.

Zanotti, L. 2008. "Imagining Democracy, Building Unsustainable Institutions: The UN Peacekeeping Operation in Haiti." Security Dialogue 39(5): 539-61.

El Zein, Fares. 2003. Dissertation Thesis "Politics of Administrative Reform in Post War Lebanon." University at Albany.

Zürcher, Christoph et al. 2013. Costly Democracy: Peacebuilding \& Democratization After War. Stanford, California: Stanford University Press.

Abla, Zeina, Amal Karaki, and Nada Dimachkieh Sweidan. 2014. Lebanon Millennium Development Goals Report 2013-2014. Beirut. http://www.lb.undp.org/content/lebanon/en/home/library/mdg/lebanon-mdg-report-2013$2014 /$.

Afrique Jet. 2014. "Projet Pôle de Développement de La Casamance." Afrique Jet. http://www.afriquejet.com/afrique-ouest/3654-projet-pole-de-developpement-de-lacasamance.html.

Allen, Daniel. 2010. "New Directions in the Study of Nation-Building: Views through the Lens of Path Dependence." International Studies Review 12(3): 413-29.

Angeles, Leonora C., and Francisco A. Magno. 2004. "The Philippines: Decentralization, Local Governments, and Citizen Action." In Decentralization, Democratic Governance and Civil Society in Comparative Perspectives, eds. Philip Oxhorn and Joseph S. Tulchin. Washington DC: Woodrow Wilson Centre Press, 211-65.

Armstrong, Andrea, and Barnett Rubin. 2005. "The Great Lakes and South Central Asia." In Making States Work: State Failure and the Crisis of Governance, eds. Simon Chesterman, Michael Ignatieff, and Ramesh Thakur. New York: United Nations University Press, 79101.

Attipoe, Olympio, Biplove Choudhary, and Nicholas Jonga. 2014. An Analysis of Government Budgets in South Sudan from a Human Development Perspective. Juba. http://www.undp.org/content/dam/southsudan/library/Discussion Papers/SS-Discussion paper final.pdf.

Atzili, Boaz. 2010. "State Weakness and 'Vacuum of Power' in Lebanon." Studies in Conflict \& Terrorism 33(8): 757-82. http://www.tandfonline.com/doi/abs/10.1080/1057610X.2010.494172 (March 7, 2014).

Baaklini, Abdo I. 1976. Legislative and Political Development: Lebanon, 1842-1972. Durnham: Duke University Press.

Barbara, Julien. 2008. "Antipodean Statebuilding: The Regional Assistance Mission to Solomon Islands and Australian Intervention in the South Pacific." Journal of Intervention and 
Statebuilding 2(2): 123-49.

Bardhan, Pranab, and Dilip Mookherjee. 2006. "The Rise of Local Governments: An Overview." In Decentralization and Local Governance in Developing Countries: A Comparative Perspective, eds. Pranab Bardhan and Dilip Mookherjee. Cambridge: MIT Press, 1-52.

Baroudi, Sami E. 1998. "Economic Conflict in Postwar Lebanon: State-Labor Relations Between 1992 and 1997." Middle East Journal 52(4): 531-50.

Beck, Linda J. 2008. Brokering Democracy in Africa: The Rise of Clientelist Democracy in Senegal. New York: Palgrave.

Beetham, David, and Christopher Lord. 1998. Legitimacy and the EU. London: Addison-Wesley Longman.

Bellamy, Paul. 2007. "Introduction." In Civil Wars of the World: Major Conflicts Since World War II, eds. Karl Jr Derouen and Uk Heo. Santa Barbara, California: ABC-CLIO Inc., 1-26.

Bennett, Andrew, and Colin Elman. 2006. "Qualitative Research: Recent Developments in Case Study Methods." Annual Review of Political Science 9(1): 455-76. http://www.annualreviews.org/doi/abs/10.1146/annurev.polisci.8.082103.104918 (February 21, 2014).

Blair, Harry. 2007. "Rebuilding and Reforming Civil Services in Post-Conflict Societies." In Governance in Post-Conflict Societies: Rebuilding Fragile States, ed. Derick W. Brinkerhoff. London: Routledge, 161-84.

Blomberg, S Brock, Gregory D Hess, and Siddharth Thacker. 2006. "On the Conflict Poverty Nexus." Economics and Politics 18(3): 237-67. http://www.blackwellsynergy.com/doi/abs/10.1111/j.1468-0343.2006.00170.x.

Bollen, Kenneth A. 1980. "Issues in the Comparative Measurement of Political Democracy." American Sociological Review 45(3): 370-90. . 1986. "Political Rights and Political Liberties in Nations: An Evaluation of Human Rights Measures, 1950 to 1984." Human Rights Quarterly 8(4): 567-91.

. 1990. "Political Democracy: Conceptual and Measurement Traps." Studies In Comparative International Development 25(1): 7-24.

—. 2011. "Evaluating Effect, Composite, and Casual Indicators in Structural Equation Models." MIS Quarterly 35(2): 359-72.

Bollen, Kenneth A, and Richard Lennox. 1991. "Conventional Wisdom on Measurement: A Structural Equation Perspective." Psychological Bulletin 110(2): 305-14.

Bollen, Kenneth A, and Pamela Paxton. 2000. "Subjective Measures of Liberal Democracy." Comparative Political Studies 33(1): 58-86.

Bollen, Kenneth A, and Kwok-fai Ting. 2000. "A Tetrad Test for Causal Indicators." Psychological Methods 5(1): 3-22.

Branch, Adam, and Zachariah Cherian Mampilly. 2005. "Winning the War, but Losing the 
Peace? The Dilemma of SPLM/A Civil Administration and the Tasks Ahead." The Journal of Modern African Studies 43(1): 1-20.

Brinkerhoff, Derick W. 2005. "Rebuilding Governance in Failed States and Post-Conflict Societies: Core Concepts and Cross-Cutting Themes." Public Administration and Development 25(1): 3-14.

. 2007. "Introduction - Governance Challenges in Fragile States: Re-Establishing Legitimacy, Rebuilding Effectiveness, and Reconstituting Legitimacy." In Governance in Post-Conflict Societies: Rebuilding Fragile States, ed. Derick W. Brinkerhoff. London: Routledge, 1-21.

Brinkerhoff, Derick W., and Ronald W. Johnson. 2009. "Decentralized Local Governance in Fragile States: Learning from Iraq." International Review of Administrative Sciences 75(4): 585-607.

Brosché, Johan. 2016. "Crisis of Governance in South Sudan : Electoral Politics and Violence in the World's Newest Nation.” Journal of Modern African Studies 54(1): 67-90.

Busumtwi-Sam, James. 2004. "Development and Peacebuilding: Conceptual and Operational Deficits in International Assistance." In Durable Peace: Challenges for Peacebuilding in Africa, eds. Taiser M. Ali and Robert O. Matthews. Toronto: University of Toronto Press, 315-53.

Cammett, Melanie. 2013. Democracy in Post-Invasion Iraq. http://watson.brown.edu/costsofwar/files/cow/imce/papers/2013/Democracy in PostInvasion Iraq.pdf.

- 2014. Compassionate Communalism: Welfare and Sectarianism in Lebanon. Ithaca: Cornell University Press.

Caplan, Richard. 2004. "Partner or Patron? International Civil Administration and Local Capacity-Building." International Peacekeeping 11(2): 229-47.

Chassay, Clancy. 2006. “Christian Leader Says Lebanese Opposition Ready for Power.” The Guardian. http://www.theguardian.com/world/2006/dec/13/syria.lebanon.

Coburn, Noah. 2011. Bazaar Politics: Power \& Pottery in an Afghan Market Town. California: Stanford University Press.

Cole, Elizabeth A., and Judy Barsalou. 2006. Unite or Divide? The Challenges of Teaching History in Societies Emerging from Violent Conflict.

Collier, Paul. 2002. Aid, Policy and Growth in Post-Conflict Countries.

Collier, Paul, and Anke Hoeffler. 1998. "On the Causes of Civil War." Oxford Handbook of the Economics of Peace and Conflict 50: 563-73.

—. 2004. "Greed and Grievance in Civil War." Oxford Economic Papers 56(4): 563-95.

Cook, Traci D. 2007. A Place To Call Their Own: Southern Sudanese Comment on the Hard Work Adn Struggles of Self-Governance. Washington DC. 
Crow, Ralph E, and Adnan Iskandar. 1961. “Administrative Reform in Lebanon.” International Review of Administrative Sciences 27(3): 293-307.

Dahl, Robert. 1971. Polyarchy: Participation and Opposition. New Haven: Yale University Press.

Diallo, Boucounta. 2009. La Crise Casamançaise: Problématique et Voies de Solutions. Paris: L'Harmattan.

Diamond, Larry, and Marc F. Plattner. 2006. Electoral Systems and Democracy. Baltimore: The Johns Hopkins University Press.

Dibeh, Ghassan. 2005. 44 The Political Economy of Postwar Reconstruction in Lebanon. Helsinki.

Dinnen, Sinclair. 2007. "A Comment on State-Building in Solomon Islands." The Journal of Pacific History 42(2): 255-63.

. 2008. "The Solomon Islands Intervention and the Instabilities of the Post-Colonial State." Global Change, Peace \& Security 20(3): 339-55.

Dodge, Toby. 2013. "Intervention and Dreams of Exogenous Statebuilding: The Application of Liberal Peacebuilding in Afghanistan and Iraq." Review of International Studies 39(5): 1189-1212. http://journals.cambridge.org/article_S0260210513000272.

Dodge, Tony. 2011. “Domestic Politics and State-Building.” In Afghanistan: To 2015 and beyond, eds. Toby Dodge and Nicholas Redman. International Institute for Strategic Studies, 69-96.

Doyle, Michael W., and Nicholas Sambanis. 2000. "International Peacebuilding: A Theoretical and Quantitative Analysis." American Political Science Review 94(4): 779-801. http://www.drworley.org/NSPcommon/Nation Building/2000,12 APSR Doyle Sambanis.pdf. . 2006. Making War and Building Peace. New Jersey: Princeton University Press.

Ducci, María Elena. 2004. "Local Governance and Democracy: The View from the Chilean Border." In Decentralization, Democratic Governance and Civil Society in Comparative Perspectives, eds. Philip Oxhorn, Joseph S. Tulchin, and Andrew D. Selee. Washington DC: Woodrow Wilson Centre Press, 119-39.

Eaton, Kent, and Larry Schroeder. 2010. "Measuring Decentralization.” In Making Decentralization Work: Democracy, Development, and Security, eds. Ed Connerley, Kent Eaton, and Paul Smoke. Colorado: Lynne Rienner Publishers, 167-90.

Von Einsiedel, Sebastian. 2005. "Policy Responses to State Failure." In Making States Work: State Failure and the Crisis of Governance, eds. Simon Chesterman, Michael Ignatieff, and Ramesh Thakur. New York: United Nations University Press, 13-35.

El-Khazen, Farid. 1998. "Les Alliances et Les Conflits Entre Les Parties Politiques Au Liban." In Parties et Forces Politiques Au Liban: Renouveau et Enagagement, ed. Antoine Messarra. Beirut: Fondation Konrad Adenauer, 133-42. 
. 2000. The Breakdown of the State in Lebanon: 1967-1976. Cambridge: Harvard University Press.

El-Mufti, Karim. 2011. Public Policy Initiative The Management of Public Interest in Lebanon, a Broken Concept. Beirut. http://policylebanon.org/topmenu/policyareas/areas/Ressource.html?Id=79\#.

El-Solh, Raghid. 994. "Religious Identity and Citizenship: An Overview of Perspectives." In Peace for Lebanon? From War to Reconstruction 1, ed. Deidre Collings. Boulder: Lynne Rienner Publishers, 231-40.

El-Zein, Fares, and Holly Sims. 2004. "Reforming War's Administrative Rubble in Lebanon." Public Administration and Development 24: 279-88.

Englebert, Pierre. 2000. State Legitimacy and Development in Africa. Colorado: Lynne Rienner Publishers.

Eriksen, Erik O., and John E. Fossum. 2004. "Europe in Search of Legitimacy: Strategies of Legitimation Assessed." International Political Science Review 25(4): 435-59.

Evans, Martin. 2005. "Insecurity or Isolation? Natural Resources and Livelihoods in Lower Casamance." Canadian Journal of African Studies 39(2): 284-314.

Evans, Peter B. 1989. "Predatory, Developmental, and Other Apparatuses : A Comparative Political Economy Perspective on the Third World State." Sociological Forum: Special Issue: Comparative National Development: Theory and Facts for the 1990s 4(4): 561-87.

Fall, Aissatou. 2010. Understanding The Casamance Conflict: A Background. Accra. http://www.kaiptc.org/publications/monographs/monographs/monograph-7-aissatou.aspx.

Fawaz, Mona, and Isabelle Peillen. 2003. The Case of Beirut, Lebanon. Beirut. http://www.ucl.ac.uk/dpu-projects/Global_Report/cities/beirut.htm.

Fearon, James D. 2004. “Why Do Some Civil Wars Last So Much Longer than Others?” Journal of Peace Research 41(3): 275-301.

Foucher, Vincent. 2005. "La Guerre Des Dieux ? Religions et Séparatisme En Basse Casamance." Canadian Journal of African Studies 39(2): 363-90.

Frahm, Ole. 2015. "Making Borders and Identities in South Sudan." Journal of Contemporary African Studies 33(2): 251-67. http://www.tandfonline.com/doi/full/10.1080/02589001.2015.1070461.

François, Monika, and Inder Sud. 2006. "Promoting Stability and Development in Fragile and Failed States.” Development Policy Review 24(2): 141-60.

Fraser, John. 1974. "Validating a Measure of National Political Legitimacy." American Journal of Political Science 18(1): 117-34.

Fukuyama, Francis. 2006. America at the Crossroads: Democracy, Power, and the Neoconservative Legacy. Connecticut: Yale University Press.

Gamble, David P. 1957. The Wolof of Senegambia. London: International African Institute. 
Gaspard, Toufic K. 2004. A Political Economy of Lebanon, 1948-2002: The Limits of LaissezFaire. Leiden: Brill.

Geddes, Barbara. 1990. "How the Cases You Choose Affect the Answers You Get: Selection Bias in Comparative Politics." Political Analysis 2(1): 131-50.

Gehrold, Stefan, and Inga Neu. 2010. Caught Between Two Fronts: In Search of Lasting Peace in the Casamance Region. Berlin.

Gellar, Sheldon. 1995. Senegal: An Africam Nation between Islam and the West. Second edi. Boulder: Westview Press.

-2005. Democracy in Senegal: Tocquevillian Analytics in Africa. New York: Palgrave.

Gemayel, Amine. 1992. Rebuilding Lebanon. Lanham: University Press of America.

Gerry, John. 2007. Case Study Research: Principles and Practices. New York: Cambridge University Press.

Ghani, Ashraf, and Clare Lockhart. 2008. Fixing Failed States: A Framework for Rebuilding a Fractured World. New York: Oxford University Press.

Ghosn, Faten, and Amal Khoury. 2011. "Lebanon after the Civil War: Peace or the Illusion of Peace?" Middle East Journal 65(3): 381-97.

Ghossain, Antoine. 1988. "Confessional Communities, Space and Political Reform in Lebanon." Social Compass 1 35(4): 563-83.

Gilley, Bruce. 2006a. "The Determinants of State Legitimacy: Results for 72 Countries." International Political Science Review 27(1): 47-71.

_. 2006b. "The Meaning and Measure of State Legitimacy: Results for 72 Countries." European Journal of Political Research 45(3): 499-525.

_ 2012. "State Legitimacy: An Updated Dataset for 52 Countries." European Journal of Political Research 51(5): 693-99. http://doi.wiley.com/10.1111/j.14756765.2012.02059.x\%5Cnhttps://sremote.pitt.edu/doi/10.1111/j.14756765.2012.02059.x/,DanaInfo=onlinelibrary.wiley.com+pdf (January 26, 2014).

Mac Ginty, Roger. 2010. "Warlords and the Liberal Peace: State-Building in Afghanistan." Conflict, Security \& Development 10(4): 577-98.

Gleditsch, Nils Petter. 1996. "Environmental Change, Security, and Conflict." In Turbulent Peace: The Challenges of Managing International Conflictl, eds. Chester A. Crocker, Osler Hampson, and Pamela Aall. Washington DC: United States Institute of Peace, 53-68.

Goldsmith, Arthur A. 2007. "Does Nation-Building Work? Reviewing the Record." In Governance in Post-Conflict Societies: Rebuilding Fragile States, London: Routledge, 2544.

Goodhand, Jonathan. 2006. Aiding Peace: The Role of NGOs in Armed Conflict. Colorado: Lynne Rienner Publishers.

Grawert, Elke. 2013. "Introduction.” In Forging Two Nations: Insights on Sudan and South 
Sudan, ed. Elke Grawert. Addis Ababa: Organisation for Social Science Research in Eastern and Southern Africa, 15-51.

Grzymala-Busse, Anna. 2008. "Beyond Clientelism: Incumbent State Capture and State Formation." Comparative Political Studies 41(4/5): 638-73.

Grzymala-Busse, Anna, and Pauline Jones Luong. 2002. "Reconceptualizing the State: Lessons from Post-Communism." Politics \& Society 30(4): 529-54.

Gurowitz, Amy. 1999. "Mobilizing International Norms: Domestic Actors, Immigrants, and the Japanese State." World Politics 51(3): 413-45.

http://www.journals.cambridge.org/abstract_S0043887100009138.

Haddad, Simon. 2009. "Lebanon: From Consociationalism to Conciliation." Nationalism and Ethnic Politics 15(3-4): 398-416. http://www.tandfonline.com/doi/abs/10.1080/13537110903346684 (March 4, 2014).

Hajjar, Sami G. 2009. "The Convoluted and Diminished Lebanese Democracy." Democracy and Security 5(3): 261-76. http://www.tandfonline.com/doi/abs/10.1080/17419160903304864 (March 10, 2014).

Hakim, Georges. 1966. "The Economic Basis of Lebanese Polity." In Politics in Lebanon, ed. Leonard Binder. New York: John Wiley \& Sons, Inc, 57-69.

Haldén, Peter. 2010. "Systems-Building Before State-Building: On the Systemic Preconditions of State-Building." Conflict, Security \& Development 10(4): 519-45. http://www.tandfonline.com/doi/abs/10.1080/14678802.2010.500540.

Hameiri, Shahar. 2009. "Capacity and Its Fallacies: International State Building as State Transformation." Millennium - Journal of International Studies 38(1): 55-81.

Hamzeh, A Nizar. 2000. "Lebanon's Islamists and Local Politics: A New Reality.” Third World Quarterly 21(5): 739-59.

Harb, Boutros. 1998. “Le Relancement D’une Vie Politique.” In Parties et Forces Politiques Au Liban: Renouveau et Enagagement, ed. Antoine Messarra. Beirut: Fondation Konrad Adenauer, 53-56.

Harb, Mona, and Reinoud Leenders. 2005. 'Know Thy Enemy: Hizbullah, 'terrorism' and the Politics of Perception." Third World Quarterly 26(1): 173-97.

Harik, Judith. 1996. "Between Islam and the System: Sources and Implications of Popular Support for Lebanon's Hizballah." Journal of Conflict Resolution 40(1): 41-67.

Hartzell, Caroline A. 2006. "Structuring the Peace: Negotiated Settlements and the Construction of Conflict Management Institutions." In Conflict Prevention and Peacebuilding in PostWar Societies: Sustaining the Peace, eds. T. David Mason and James D. Meernik. Oxon: Routledge, 31-52.

Hartzell, Caroline, Matthew Hoddie, and Donald Rothchild. 2001. "Stabilizing the Peace After Civil War: An Investigation of Some Key Variables." International Organization 55(1): 183-208. 
Hess, Steve. 2010. "Coming to Terms with Neopatrimonialism: Soviet and American NationBuilding Projects in Afghanistan.” Central Asian Survey 29(2): 171-87.

Hottinger, Arnold. 1966. “Zu'ama' in Historical Perspective.” In Politics in Lebanon, ed. Leonard Binder. New York: John Wiley \& Sons, Inc, 85-106.

Hudson, Michael C. 1999. "Lebanon after Ta'if: Another Reform Opportunity Lost." Arab Studies Quarterly 21(1): 27-40.

Hutchison, M. L., and K. Johnson. 2011. "Capacity to Trust? Institutional Capacity, Conflict, and Political Trust in Africa, 2000-2005." Journal of Peace Research 48(6): 737-52. http://jpr.sagepub.com/cgi/doi/10.1177/0022343311417981 (March 10, 2014).

Inbal, Aliza B., and Hanna Lerner. 2007. "Constitutional Design, Identity and Legitimacy in Post-Conflict Reconstruction." In Governance in Post-Conflict Societies: Rebuilding Fragile States, ed. Derick W. Brinkerhoff. London: Routledge, 45-63.

International Crisis Group. 2006. Israel/Hizbollah/Lebanon: Avoiding Renewed Conflict.

International Monetary Fund. 2006. Lebanon: Selected Issue. Washington DC. http://www.imf.org/external/pubs/ft/scr/2006/cr06200.pdf.

Iskandar, Adnan. 1964. Bureaucracy in Lebanon. Beirut: American University of Beirut. . 1996. Public Service Accountability in Lebanon. Beirut. http://ddc.aub.edu.lb/projects/pspa/PSAccount/PSAccount-0.html.

Jackman, Robert W. 1987. "Political Institutions and Voter Turnout in the Industrial Democracies." The American Political Science Review 81(2): 405-24.

Jad, Sana Souaid. 2011. The Balance Sheet Approach and the Public Debt Stock Analysis: The Case of Lebanon. Beirut. http://www.bdl.gov.lb/.

Jawad, Rana. 2002. "A Profile of Social Welfare in Lebanon: Assessing the Implications for Social Development Policy." Global Social Policy 2(3): 319-42.

Jok, Madut Jok. 2011. Diversity, Unity, and Nation Building in South Sudan. Washington DC. http://www.usip.org/sites/default/files/Diversity\%2C Unity $\% 2 \mathrm{C}$ and Nation Building in South Sudan \%28Jok\%29.pdf.

Jong, Ferdinand De. 2005a. “A Joking Nation : Conflict Resolution in Senegal.” Canadian Journal of African Studies 39(2): 391-415.

_. 2005b. "Contested Casamance : Introduction." Canadian Journal of African Studies 39(2): 213-29.

Von Kaltenborn-Stachau, Henriette. 2008. The Missing Link-Fostering Positive Citizen-State Relations in Post-Conflict Environments. Washington DC. http://siteresources.worldbank.org/EXTGOVACC/Resources/CommGAPMissingLinkWeb. pdf.

Kameir, El Wathig. 2011. The Political Economy of South Sudan: A Scoping Analytical Study. Abidjan. 
Kanaan, Nimat, and Randa Aboul-Hosn. 1998. "Mapping of Living Conditions in Lebanon." Mapping of Living Conditions in Lebanon (UNDP). http://www.undp.org.lb/programme/propoor/poverty/povertyinlebanon/molc/setting/A/1975.htm\# (November 2, 2015).

Kanol, Direnç. 2011. "Assessing the Legitimacy of the EU." Interdisciplinary Political Studies 1(0): 49-59.

Kaplan, Seth. 2008. "The Remarkable Story of Somaliland.” Journal of Democracy 19(3): 14357.

Kaufmann, Daniel, Aart Kraay, and Massimo Mastruzzi. 2010. The Worldwide Governance Indicators Methodology and Analytical Issues. Washington DC.

Keefer, Philip E., Ambar Narayan, and Tara Vishwanath. 2006. "Decentralization in Pakistan: Are Local Governments Likely to Be More Accountable than Central Governments?" In Decentralization and Local Governance in Developing Countries: A Comparative Perspective, eds. Pranab Bardhan and Dilip Mookherjee. Cambridge: MIT Press, 285-304.

Kerr, Malcolm H. 1966. "Political Decision Making in a Confessional Democracy." In Politics in Lebanon, ed. Leonard Binder. New York: John Wiley \& Sons, Inc, 167-86.

Khadiagala, Gilbert M. 1995. "State Collapse and Reconstruction in Uganda." In Collapsed States: The Disintegration and Reconstruction of Legitimate Authority, ed. I. William Zartman. Colorado: Lynne Rienner Publishers, 33-47.

Kingston, Paul, and Marie-Joëlle Zahar. 2004. "Rebuilding A House of Many Mansions: The Rise and Fall of Militia Cantons in Lebanon." In States Within States, eds. Paul Kingston and Ian S. Speaars. New York: Palgrave, 81-98.

Kisirwani, M., and W. M. Parle. 1987. "Assessing the Impact of the Post Civil War Period on the Lebanese Bureaucracy: A View from Inside." Journal of Asian and African Studies 22(12): 17-29. http://jas.sagepub.com/cgi/doi/10.1177/002190968702200102.

Kisirwani, Maroun. 1997a. "Accountability of Lebanese Civil Servants: An Overview of Disciplinary Mechanisms." In Lebanon Beyond 2000, eds. Amin Saikal and Geoffrey Jukes. Canberra: Centre for Middle Eastern and Central Asian Studies.

- 1997b. "The Rehabilitation and Reconstruction of Lebanon." In Remaking the Middle East, eds. Paul J White and William S Logan. Oxford: Berg, 87-104.

Kisirwani, Maroun, and William M. Parle. 1987. "Assessing the Impact of the Post Civil War Period on the Lebanese Bureaucracy: A View from Inside." Journal of Asian and African Studies 22(1-2): 17-29.

Kitschelt, Herbert, and Steven I. Wilkinson. 2007. "Citizen-Politician Linkages: An Introduction.” In Patrons, Clients, and Policies: Patterns of Democratic Accountability and Political Competition, eds. Herbert Kitschelt and Steven I. Wilkinson. Cambridge: Cambridge University Press, 1-49.

Kon, Madut. 2015. "Institutional Development, Governance, and Ethnic Politics in South Sudan." Journal of Global Economics 3(2): 1-6. 
http://www.esciencecentral.org/journals/institutional-development-governance-and-ethnicpolitics-in-south-sudan-2375-4389-1000147.php?aid=57097.

Larson, Greg, Peter Biar Ajak, and Lant Pritchett. 2013. South Sudan's Capability Trap: Building a State with Disruptive Innovation. Cambridge. https://www.hks.harvard.edu/content/download/69085/1249150/version/1/file/268_SudanPDIA.pdf.

Leenders, Reinoud. 2012. Spoils of Truth: Corruption and State-Building in Postwar Lebanon. Ithaca: Cornell University Press.

LeRiche, Matthew, and Matthew Arnold. 2012. South Sudan: From Revolution to Independence. London: C. Hurst \& Co (Publishers) Ltd.

Levi, Margaret, and Audrey Sacks. 2009. "Legitimating Beliefs: Sources and Indicators." Regulation \& Governance 3(4): 311-33.

Levi, Margaret, Audrey Sacks, and Tom Tyler. 2009. "Conceptualizing Legitimacy, Measuring Legitimating Beliefs.” American Behavioral Scientist 53(3): 354-75.

Lipset, Seymour Martin. 1983. Political Man: The Social Bases of Politics. London: Heinemann.

Lister, Sarah, and Andrew Wilder. 2005. "Strengthening Subnational Administration in Afghanistan: Technical Reform or State-Building?" Public Administration and Development 25(1): 39-48.

Loehlin, John C. 1998. Latent Variable Models: An Introduction to Factor, Path, and Structural Analysis. Third. New Jersey: Lawrence Erlbaum Associates.

Low-beer, Ann. 2001. Paradigm Politics, School Textbooks and Cultural Identity: The Struggle in Bosnia and Hercegovina.

Lyons, Terrence. 2005. Demilitarizing Politics: Elections on the Uncertain Road to Peace. Colorado: Lynne Rienner Publishers.

Mane, Bacary Domingo. 2014. "POLE DE DEVELOPPEMENT DE LA CASAMANCE." Sud Online. http://www.sudonline.sn/au-dela-des-questions-economique-etadministrative_a_17983.html.

March, James G., and Johan P. Olsen. 1989. Institutions: The Organizational Basis of Politics. New York: The Free Press.

Marquette, Heather, and Danielle Beswick. 2011. "State Building, Security and Development: State Building as a New Development Paradigm?” Third World Quarterly 32(10): 1703-14.

Marshall, Monty G, and Keith Jaggers. 2002. Political Regime Characteristics and Transitions, 1800-2002: Dataset User's Manual. Maryland.

Marut, Jean-Claude. 2010. Le Conflit de Casamance: Ce Qui Disent Les Armes. Paris: Édition Karthala.

Mason, David T., Mehmet Gurses, Patrick T. Brandt, and Jason Michael Quinn. 2011. "When Civil Wars Recur: Conditions for Durable Peace after Civil Wars." International Studies 
Perspectives 12(2): 171-89.

Maxwell, Daniel, Kirsten Gelsdorf, and Martina Santschi. 2012. Researching Livelihoods and Services Affected by Conflict Livelihoods, Basic Services and Social Protection in South Sudan. London. http://community.eldis.org/.5a0b0243/Livelihoods basic services and social protection in Sri Lanka.pdf.

Mayall, James. 2005. "The Legacy of Colonialism.” In Making States Work: State Failure and the Crisis of Governance, eds. Simon Chesterman, Michael Ignatieff, and Ramesh Thakur. New York: United Nations University Press, 36-58.

Mcloughlin, Claire. 2014. "When Does Service Delivery Improve the Legitimacy of a Fragile or Conflict-Affected State?" Governance: n/a-n/a. http://doi.wiley.com/10.1111/gove.12091 (May 2, 2014).

von der Mehden, Fred R., and Kim Quaile Hill. 1980. “Area Experts' Images of African Nations." Comparative Political Studies 12(4): 497-510.

Meierhenrich, Jens. 2004. “Forming States After Failure.” In When States Fail: Causes and Consequences, ed. Rot. Princeton: Princeton University Press, 153-68.

Mendy, Toumany. 2006. Politique et Puissance de L'argent Au Sénégal: Les Désarrois D'un Peuple Innocent. Paris: L'Harmattan.

Messarra, Antoine. 1998. “L'expérience Libanais Du Parti Dans Le Cadre Arabe.” In Partis et Forces Politiques Au Liban: Renouveau et Engagement, ed. Antoine Messarra. Beirut: Fondation Konrad Adenauer, 15-40.

Migdal, Joel S. 2001. State in Society: Studying How States and Societies Transform and Constitute One Another. Cambridge: Cambridge University Press.

Miller, Benjamin. 2015. "Stateness, National Self-Determination and War and Peace in the Twenty-First Century." Ethnopolitics 14(5): 531-39. http://www.tandfonline.com/doi/full/10.1080/17449057.2015.1051818.

Ministry of Foreign Affairs Denmark. 2005. A Joint Evaluation: Humanitarian and Reconstruction Assistance to Afghanistan, 2001-05: From Denmark, Ireland, The Netherlands, Sweden and the United Kingdom.

Ministry of Social Affairs, and United Nations Development Programme. 2007. The effects of brief mindfulness intervention on acute pain experience: An examination of individual difference Development of Mapping of Living Conditions in Lebanon, 1995-2004: A Comparison with the Results of "Mapping of Living Conditions in Lebanon, 1998." Beirut.

Mitchell, Timothy. 1991. "The Limits of the State: Beyond Statist Approaches and Their Critics." The American Political Science Review 85(1): 77-96.

Mukhopadhyay, Dipali. 2009. "Disguised Warlordism and Combatanthood in Balkh: The Persistence of Informal Power in the Formal Afghan State." Conflict, Security \& Development 9(4): 535-64.

Muller, Edward N., Thomas O. Jukam, and Mitchell A. Seligson. 1982. "Diffuse Political 
Support and Antisystem Political Behavior : A Comparative Analysis." American Journal of Political Science 26(2): 240-64.

Najem, Tom Pierre. 2000. Lebanon's Renaissance: The Political Economy of Reconstruction. Reading: Ithaca Press.

Nassif, Georges. 1998. "Les Parties Libanaises En Crise: Comment Transforment-Elles Politiquement." In Parties et Forces Politiques Au Liban: Renouveau et Enagagement, ed. Antoine Messarra. Beirut: Fondation Konrad Adenauer, 123-29.

Ndegwa, Stephen N, and Brian Levy. 2003. The Politics of Decentralization in Africa: A Comparative Analysis. Washington DC.

http://www1.worldbank.org/publicsector/LearningProgram/Decentralization/Ndegwa.pdf.

Netemeyer, Richard G., William O. Bearden, and Subhash Sharma. 2003. Scaling Procedures: Issues and Applications. California: Sage Publications, Inc.

News, BBC. 2009. "Senegal Apology for Christ â€ $€^{\mathrm{TM}}$ Slur'.” BBC News. http://news.bbc.co.uk/go/pr/fr/-/2/hi/africa/8435805.stm.

Norton, Augustus Richard. 2000. "Hizballah and the Israeli Withdrawal from Southern Lebanon." Journal of Palestine Studies 30(1): 22-35.

O Senegal. 2014. "Une Autoroute Maritime Se Développe Entre Dakar et La Casamance." $O$ Senegal. http://www.osenegal.com/news/transport/autoroute-maritime-se-developpe-dakarcasamance/.

OECD. 2010. The State's Legitimacy in Fragile Situations: Unpacking Complexity. http://www.oecd.org/dac/incaf/44794487.pdf.

Ottaway, Marina. 1995. "Democratization in Collapsed States.” In Collapsed States: The Disintegration and Restoration of Legitimate Authority, ed. I. William Zartman. Colorado: Lynne Rienner Publishers, 235-50.

Oxhorn, Philip. 2004. "Unraveling the Puzzle of Decentralization.” In Decentralization, Democratic Governance and Civil Society in Comparative Perspectives, eds. Philip Oxhorn, Joseph S. Tulchin, and Andrew D. Selee. Washington DC: Woodrow Wilson Centre Press, 3-32.

Ozer, Daniel J. 1999. "Four Principles for Personality Assessment." In Handbook of Personality: Theory and Research, eds. Lawrence A. Pervin and Oliver P. John. New York: Guilford.

Paris, Roland. 2005. "Wilson's Ghost: The Faulty Assumptions of Postconflict Peacebuilding." In Turbulent Peace: The Challenges of Managing International Conflict, eds. Chester A. Crocker, Fen Osler Hampson, and Pamela Aall. Washington DC: United States Institute of Peace, $765-84$.

—. 2006. “NATO’s Choice in Afghanistan: Go Big or Go Home." Policy Options: 35-43.

Picard, Elizabeth. 1993. The Lebanese Shi'a and Political Violence. Geneva.

Pierson, Paul. 2004. Politics in Time: History, Institutions, and Social Analysis. Princeton:

Princeton University Press. 
Posner, Daniel. 2004. "Civil Society and the Reconstruction of Failed States." In When States Fail: Causes and Consequences, ed. Robert Rotberg. Princeton: Princeton University Press, 237-55.

Radon, Jenik, and Sarah Logan. 2014. "South Sudan: Governance Arrangements, War, and Peace." Journal of International Affairs 68(1): 149-67.

http://search.ebscohost.com/login.aspx?direct=true \&db=buh\&AN=100052751\&site=ehostlive.

Regan, Patrick M. 2002. "Third-Party Interventions and the Duration of Intrastate Conflicts." The Journal of Conflict Resolution 46(1): 55-73.

Riak, Maker M. 2013. "Reversing the Trend of Corruption in South Sudan: Is Rwanda a Suitable Model?" Journal of Developing Societies 29(4): 487-501. http://jds.sagepub.com/cgi/doi/10.1177/0169796X13504681.

Rotberg, Robert I. 2004. "When States Fail: Causes and Consequences." In When States Fail: Causes and Consequences, ed. Robert I. Rotberg. New Jersey: Princeton University Press, $1-49$.

Saidi, Nasser H. 1994. “The Economic Reconstruction of Lebanon: War, Peace, and Modernization." In Peace for Lebanon? From War to Reconstruction, ed. Deirdre Collings. Boulder: Lynne Rienner Publishers, 195-212.

Salamy, Imad. 2014. The Government and Politics of Lebanon. Oxon: Routledge.

Saleh, Ali Salman, and Charles Harvie. 2005. “An Analysis of Public Sector Deficits and Debt in Lebanon: 1970-2000.” Middle East Review of International Affairs 9(4): 106-36.

Salem, Elie Adib. 1973. Modernization without Revolution: Lebanon's Experience. London: Indiana University Press.

Salloukh, Bassel F. 2006. "The Limits of Electoral Engineering in Divided Societies: Elections in Postwar Lebanon.” Canadian Journal of Political Science 39(3): 635-55.

Salloukh, Bassel F., Rabie Barakat, and Jinan S. Al-Habbal. 2015. Politics of Sectarianism in Postwar Lebanon. London: Pluto Press.

Sambanis, Nicholas. 2001. "Do Ethnic and Nonethnic Civil Wars Have the Same Causes ?: A Theoretical and Empirical Inquiry (Part 1)." The Journal of Conflict Resolution 45(3): 25982.

Saouli, Adham. 2003. “Lebanon's Hizbullah: The Quest for Survival.” World Affairs 166(2): 7180.

Al Sayegh, Daoud. 1998. “Organisations Sectaires et Les Forces Politiques: La Recherche Des Limites." In Parties et Forces Politiques Au Liban: Renouveau et Enagagement, ed. Antoine Messarra. Beirut: Fondation Konrad Adenauer, 167-72.

Schaffer, Frederic C. 2000. Democracy in Translation: Understanding Politics in an Unfamiliar Culture. Ithaca: Cornell University Press.

Scharpf, Fritz W. 2003. Problem Solving Effectiveness and Democratic Accountability in the EU. 
Schenker, David. 2007. Lebanon Goes to Paris III: High Stakes in France and Beirut.

Washington DC. http://www.washingtoninstitute.org/policy-analysis/view/lebanon-goes-toparis-iii-high-stakes-in-france-and-beirut.

Sedgwick, Mark. 2010. "Measuring Egyptian Regime Legitimacy.” Middle East Critique 19(3): 251-67. http://www.tandfonline.com/doi/abs/10.1080/19436149.2010.514474 (March 10, 2014).

Selee, Andrew D., and Joseph S. Tulchin. 2004. "Decentralization and Democratic Governance: Lessons and Challenges." In Decentralization, Democratic Governance and Civil Society in Comparative Perspectives, eds. Philip Oxhorn, Joseph S. Tulchin, and Andrew D. Selee. London: Woodrow Wilson Centre Press, 295-320.

Shapiro, Ian. 2001. "Problems, Methods, and Theories in the Study of Politics, or What's Wrong with Political Science and What to Do about It." Political Theory 30(4): 596-619.

Sharan, Timor. 2011. "The Dynamics of Elite Networks and Patron-Client Relations in Afghanistan.” Europe-Asia Studies 63(6): 1109-27.

Siegle, Joseph, and Patrick O’Mahony. 2010. "Decentralization and Internal Conflict.” In Making Decentralization Work: Democracy, Development, and Security, eds. Ed Connerley, Kent Eaton, and Paul Smoke. Colorado: Lynne Rienner Publishers, 135-66.

De Simone, Sara. 2015. "Building a Fragmented State: Land Governance and Conflict in South Sudan.” Journal of Peacebuilding and Development 10(3): 60-73. http://dx.doi.org/10.1080/15423166.2015.1085812.

Sisk, Timothy. 2013. Statebuilding: Consolidating Peace After Conflict. London: Polity Press.

Skocpol, Theda. 1979. States \& Social Revolutions: A Comparative Analysis of France, Russia, \& China. Cambridge: Cambridge University Press.

Sobek, David. 2010. "Masters of Their Domains: The Role of State Capacity in Civil Wars." Journal of Peace Research 47(3): 267-71.

Le Soleil. 2012. "Benoit Sambou Annonce Un Projet de 350 Millions : Les Zones Post-Conflit Vont Relancer L’agriculture En Casamance.” Le Soleil.

http://www.lesoleil.sn/index.php?option=com_content\&view=article\&id=16706:benoitsambou-annonce-un-projet-de-350-millions-les-zones-post-conflit-vont-relancerlagriculture-en-casamance \& catid=78:a-la-une.

South Sudan Bureau for Community Security and Small Arms Control, South Sudan Peace and Reconciliation Commission, and United Nations Development Programme. 2012. Community Consultation Report: Warrap State, South Sudan. Juba. http://www.undp.org/content/dam/southsudan/library/Documents/CSAC Reports/UNDPSS-Warrap-consult-12.pdf.

South Sudan National Bureau of Statistics. 2011. South Sudan Statistical Yearbook 2011. Juba. http://static1.1.sqspcdn.com/static/f/750842/18935415/1349357346780/South+Sudan+Statis tical+Yearbook+2011+FINAL.pdf?token=xcrh + XTeo9vWw3HAwjYs5YtHA48=.

Starr, S. Frederick. 2006. "Sovereignty and Legitimacy in Afghan Nation-Building." In Nation- 
Building: Beyond Afghanistan and Iraq, ed. Francis Fukuyama. Baltimore: The Johns Hopkins University Press, 107-24.

Streeck, Wolfgang, and Kathleen Thelen. 2005. "Introduction: Institutional Change in Advanced Political Economies." In Beyond Continuity: Institutional Change in Advanced Economies, eds. Wolfgang Streeck and Kathleen Thelen. Oxford: Oxford University Press, 1-39.

Suchman, Mark C. 1995. "Managing Legitimacy: Strategic and Institutional Approaches." The Academy of Management Review 20(3): 571-610.

The World Bank. 2005. "Senegal Receives 20 Million for Emergency Recovery Project in Casamance." World Bank. http://web.worldbank.org/external/default/main?pagePK=64027221\&piPK=64027220\&the SitePK=296303\&menuPK=296336\&Projectid=P069207.

Thies, Cameron G. 2010. "Of Rulers, Rebels, and Revenue: State Capacity, Civil War Onset, and Primary Commodities.” Journal of Peace Research 47(3): 321-32.

Traboulsi, Fawwaz. 2007. A History of Modern Lebanon. London: Pluto Press.

Treier, Shawn, and Simon Jackman. 2008. "Democracy as a Latent Variable.” American Journal of Political Science 52(1): 201-17.

Van der Vossen, Bas. 2012. "The Asymmetry of Legitimacy.” Law and Philosophy 31(5): 56592.

de Waal, Alex. 2014. "When Kleptocracy Becomes Insolvent: Brute Causes of the Civil War in South Sudan." African Affairs 113(452): 347-69.

Walter, Barbara F. 2004. "Does Conflict Beget Conflict? Explaining Recurring Civil War." Journal of Peace Research 41(3): 371-88.

Washburne, Sarah Lykes. 2013. "Post-War Governance and the Impact of International Aid in South Sudan." In Forging Two Nations: Insights on Sudan and South Sudan, ed. Elke Grawert. Addis Ababa: Organisation for Social Science Research in Eastern and Southern Africa, 188-200.

Wassara, Samson S. 2015. "South Sudan: State Sovereignty Challenged at Infancy." Journal of Eastern African Studies 9(4): 634-39. http://www.tandfonline.com/doi/full/10.1080/17531055.2015.1105439.

Weil, Frederick D. 1989. "The Sources and Structures of Legitimation in Western Democracies: A Consolidated Model Tested with Time-Series Data in Six Countries since World War II." American Sociological Review 54(5): 682-706.

Widner, Jennifer A. 2004. "Building Effective Trust in the Aftermath of Severe Conflict." In When States Fail: Causes and Consequences, ed. Robert Rotberg. Princeton: Princeton University Press, 222-36.

Wood, Elisabeth Jean. 2008. "The Social Processes of Civil War: The Wartime Transformation of Social Networks." Annual Review of Political Science 11(1): 539-61. http://www.annualreviews.org/doi/abs/10.1146/annurev.polisci.8.082103.104832. 
Young, John. 2006. The South Sudan Defence Forces in the Wake of the Juba Declaration. Geneva. http://www.smallarmssurveysudan.org/fileadmin/docs/working-papers/HSBA-WP01-SSDF.pdf.

Zambakari, Christopher. 2013. "Post-Referendum South Sudan: Political Drivers of Violence and the Challenge of Democratic Nation-Building." In Forging Two Nations: Insights on Sudan and South Sudan, ed. Elke Grawert. Addis Ababa: Organisation for Social Science Research in Eastern and Southern Africa, 98-111.

Zanotti, L. 2008. "Imagining Democracy, Building Unsustainable Institutions: The UN Peacekeeping Operation in Haiti.” Security Dialogue 39(5): 539-61.

El Zein, Fares. 2003. Dissertation Thesis "Politics of Administrative Reform in Post War Lebanon." University at Albany.

Zürcher, Christoph et al. 2013. Costly Democracy: Peacebuilding \& Democratization After War. Stanford, California: Stanford University Press. 